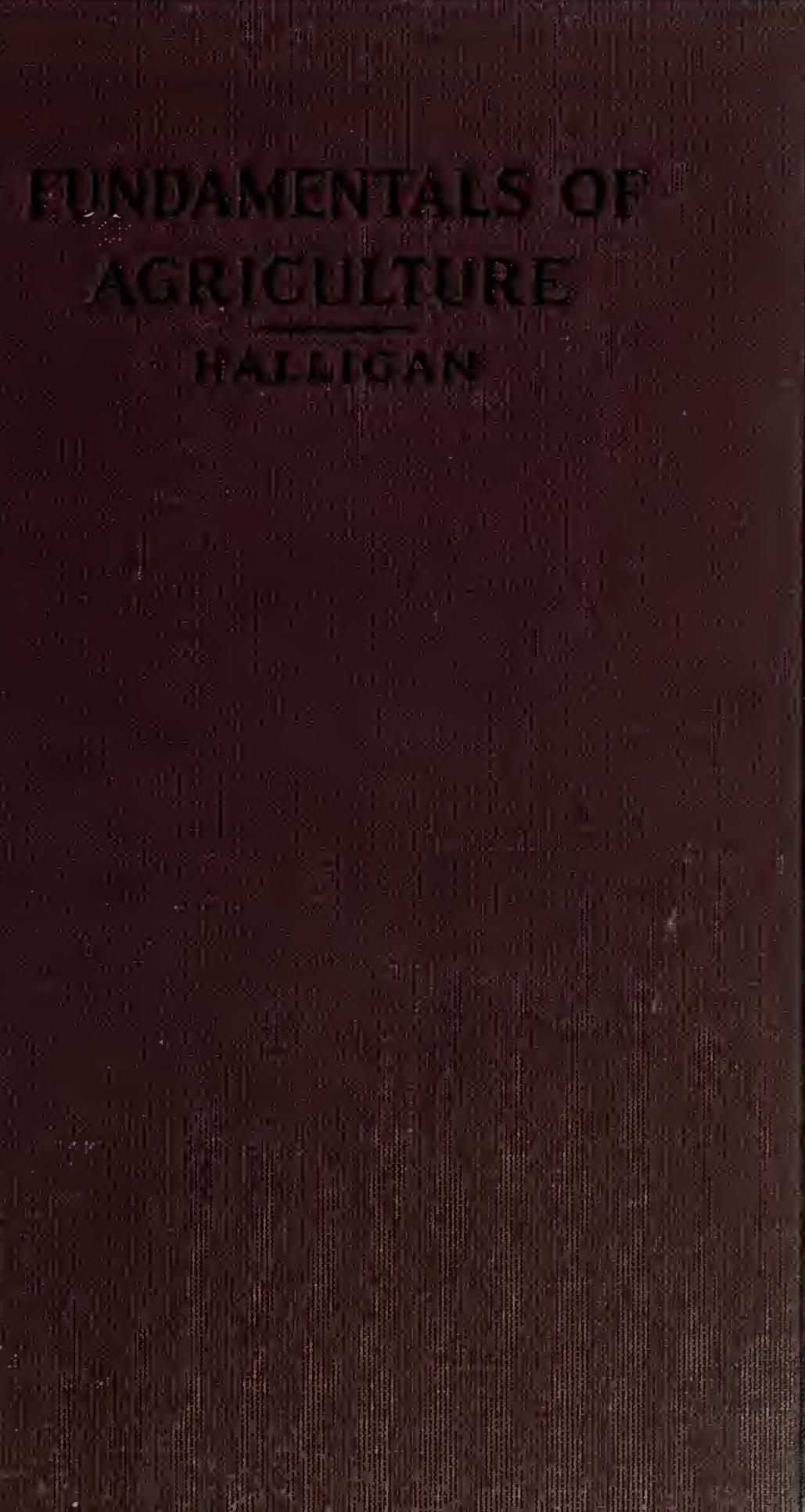




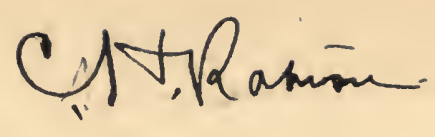

\section{UNIVERSITY OF CALIFORNIA LOS ANGELES}
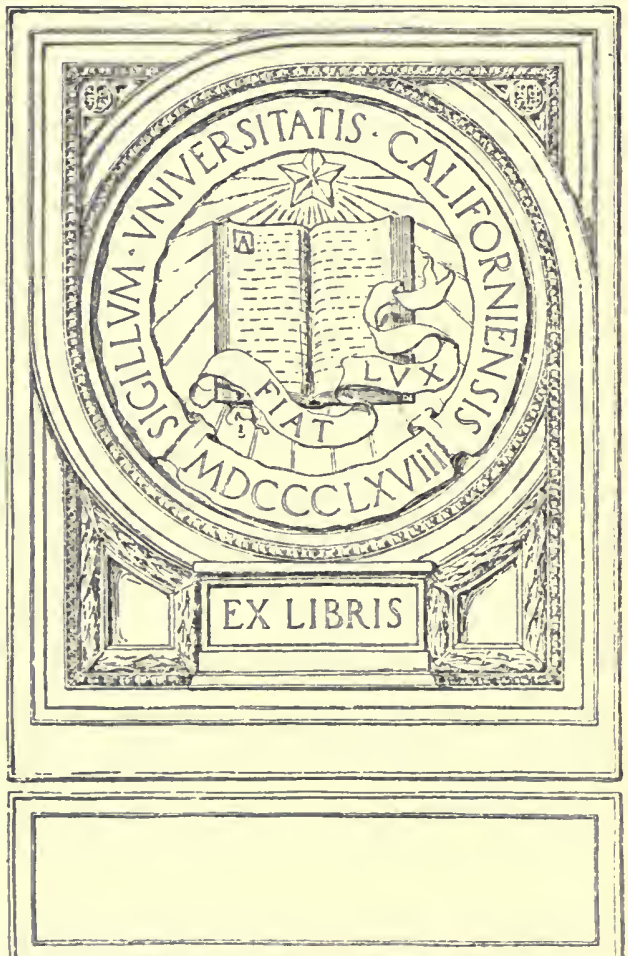

Digitized by the Internet Archive in 2007 with funding from Microsoft Corporation 


\title{
FUNDAMENTALS OF AGRICULTURE
}

\author{
EDITED BY \\ JAMES EDWARD HALLIGAN \\ Chemist in Charge, Louisiana State Experiment Station
}

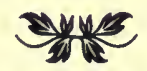

D C. HEATH AND COMPANY BOSTON NEW YORK CHICAGO 
Copyright, 1911, BY

D. C. HEATH AND COMPANY

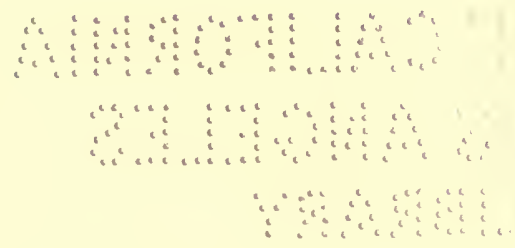




\section{3}

\section{PREFACE.}

The world lives on the products of agriculture, and consequently some knowledge of this subject should be of importance to every one independent of his vocation in life. It is the object of this book, therefore, to present the fundamentals of this important subject, so as to answer questions and conditions which prevail in everybody's life.

Every subject in this book is written by an expert in his line. This idea was carried out in order to furnish the student with the best information that could be obtained. The editor thought it would be better to have authorities treat of the various topics rather than write the book alone, as there are very few men who are competent enough to warrant their writing the best text-book on agriculture.

A list of bulletins and reference books is appended at the end of each chapter. The teacher should send for the bulletins (which can be had free of charge) some time before the particular subject is assigned, in order that fuller information may be offered to the students than is included in the text.

The teacher should endeavor to present the subjects in season, and not necessarily in the order they are given, so that field trips may be taken to impress the topic or topics on the student's mind and to excite interest. In propounding questions to the class originality should predominate. At the end of most sections a few questions are asked to give the teacher an idea of what is required. Field experiments should be conducted, and the text should be followed only to furnish the student with the principles or working knowledge. In a work of this kind it is impossible to treat of 


\section{CHAPTER III.-MANURES AND FERTILIZING MATERIALS.}

By J. E. Halligan, Chemist in Charge, Louisiana State Experiment Station.

PAGE

Section XI.-FArm Manures . . . . . . . 58

Section XII.-Commercial Fertilizers . . . . . 62

Section XIII.-Valuation of Fertilizers . . . . 67

Section XIV.-Mixing Fertilizers . . . . . . . . 69

Section XV.-Application of Fertilizers . . . . 72

CHAPTER IV.-FARM CROPS.

Section XVI.-Diversification and Rotation of Crops . $\quad 75$

By Prof. Lyman Carrier, Department of Agronomy, Virginia

Polytechnic Institute.

Section XVII.-CoRn

By Prof. A. D. Shamel, Bureau of Plant Industry, U. S. Department of Agriculture.

Section XVIII.-Methods of Culture of Corn . . . 93

Section XIX.-Cotton • • . • • • • • . . 104

By Prof. W. R. Dodson, Dean of the College of Agricuiture, Louisiana State University, and Director Louisiana Experiment Stations.

Section XX.-The Culture of Cotton . . . . . ili

Section XXI.-RICE . . . . . . . . . . II8

By Prof. W. R. Dodson, Dean of the College of Agriculture,

Louisiana State University, and Director Louisiana Experiment Stations.

Section XXII.-Wheat, Oats, Rye, and Barley . 125

By Prof. O. D. Center, Department of Crop Production, University of Illinois.

Section XXIII.-Sugar Cane 150

By Prof. H. P. Agee, Asst. Directcr in Charge, Louisiana Sugar Experiment Station. 
By Dr. E. H. Jenkins, Director Connecticut Agricultural Experiment Station.

Section XXV (a).-Root Crops, Mangels, Irish Potatoes, Sugar Beets, Etc. . . . . . . . . 164

By J. E. Halligan, Chemist in Charge, Louisiana State Experiment Station.

(b).-Sweet Potatoes, Peanuts, and WaterMELONS . . . . . . . I80

By Prof. S. E. McClendon, Asst. Director Louisiana State Experiment Station.

Section XXVI.-Forage Crops

By Prof. C. V. Piper, Bureau' of Plant Industry, U. S. Department of Agriculture.

Section XXVII.-Some Important Forage Plants . . . 190

Section XXVIII.-WeEd . . . . . . . . . 197

By Prof. Lyman Carrier, Department of Agronomy, Virginia Polytechnic Institute.

CHAPTER V.-TREES AND THE GARDEN.

Section XXiX.-The Planting and Care of the Orchard 204

By Prof. C. P. Halligan, Department of Horticulture, Michigan State Agricultural College.

Section XXX.-Pomology . . . . . . . . . 209

By Prof. C. P. Halligan, Department of Horticulture, Michigan State Ágricultural College.

Section XXXI.-Forestry

By Prof. Lyman Carrier, Department of Agronomy, Virginia Polytechnic Institute.

Section XXXII.-The Injury of Gas and Electricity to

TrEes

By Dr. G. E. Stone, Department of Botany, Massachusetts Agricultural College.

Section XXXIII.-Ornamental Trees and Sirubs 226

By Prof. Charles A. Keffer, Department of Horticulture and Forestry, University of Tennessee. 


\section{CHAPTER III.-MANURES AND FERTILIZING MATERIALS.}

By J. E. Halligan, Chemist in Charge, Louisiana State Experiment Station.

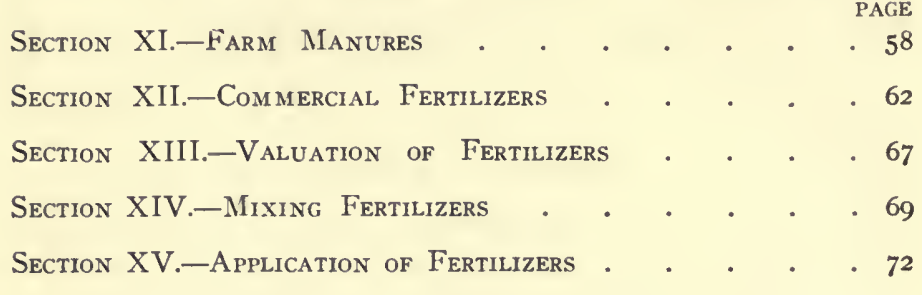

\section{CHAPTER IV.-FARM CROPS.}

Section XVI.-Diversification and Rotation of Crops . $\quad 75$

By Prof. Lyman Carrier, Department of Agronomy, Virginia Polytechnic Institute.

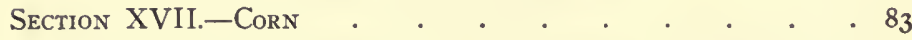

By Prof. A. D. Shamel, Bureau of Plant Industry, U. S. Department of Agriculture.

Section XVIII.-Methods of Culture of Corn . . 93

Section XIX.-CotTon . . . . . . . . . 104

By Prof. W. R. Dodson, Dean of the College of Agricuiture, Louisiana State University, and Director Louisiana Experiment Stations.

Section XX.-The Culture of Cotton . . . . . III

Section XXI.-Rice . . . . . . . . . 118

By Prof. W. R. Dodson, Dean of the College of Agriculture, Louisiana State University, and Director Louisiana Experiment Stations.

Section XXiI.-Wheat, Oats, Rye, and Barley 125

By Prof. O. D. Center, Department of Crop Production, University of Illinois.

Section XXIII.-Sugar Cane 150

By Prof. H. P. Agee, Asst. Director in Charge, Louisiana Sugar Experiment Station. 
By Dr. E. H. Jenkins, Director Connecticut Agricultural Experiment Station.

Section XXV (a).-Root Crops, Mangels, Irish Potatoes,

Sugar Beets, Etc. . . . . . . . . 164

By J. E. Halligan, Chemist in Charge, Louisiana State Experiment Station.

(b).-Sweet Potatoes, Peanuts, and WaterMELONS . . . . . . . 180

By Prof. S. E. McClendon, Asst. Director Louisiana State Experiment Station.

Section XXVI.-Forage Crops

By Prof. C. V. Piper, Bureau' of Plant Industry, U. S. Department of Agriculture.

Section XXVII.-Some Important Forage Plants .

By Prof. Lyman Carrier, Department of Agronomy, Virginia Polytechnic Institute.

CHAPTER V.-TREES AND THE GARDEN.

Section XXIX.-The Planting and Care of the Orchard 204

By Prof. C. P. Halligan, Department of Horticulture, Michigan State Agricultural College.

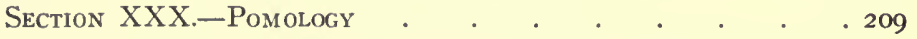

By Prof. C. P. Halligan, Department of Horticulture, Michigan State Ágricultural College.

Section XXXI.-Forestry

By Prof. Lyman Carrier, Department of Agronomy, Virginia Polytechnic Institute.

Section XXXII.-The Injury of Gas and Electricity to

Trees

By Dr. G. E. Stone, Department of Botany, Massachusetts Agricultural College.

Section XXXIII.-Ornamental Trees and Shrubs .226

By Prof. Charles A. Keffer, Department of Horticulture and Forestry, University of Tennessee. 
SEcTION XXXIV. THE GARDEN

By Prof. Charles A. Keffer, Department of Horticulture and Forestry, University of Tennessee.

\section{CHAPTER VI.-PLANT DISEASES.}

By Prof. H. R. Fulton, Department of Botany, Pennsylvania State College.

Section XXXV.-Causes of Plant Diseases . . . . 240

Section XXXVI.-Control of Fungus Diseases . . . . 243

Section XXXVII.-Fruit Crop Diseases . . . . . . 248

Section XXXViII.-Garden CROP Diseases . . . . $25^{2}$

Section XXXIX.-Field Crop Diseases . . • . . 255

CHAPTER VII.-INSECTS AND BIRDS.

Section XL.-What an Insect Is . . . . . . 26 I

By Prof. Glenn W. Herrick, Department of Entomology, Cornell University.

Section XLI.-Insect Friends of the Farmer . . . 267

Section XLII.-Insect Enemies of the Farmer . . . 271

Section XliII.-The Boll Weevil . . . . . . 274

By Prof. Wilmon Newell, Texas State Entomologist.

Section XliV.-The Cattle Tick . . . . . . . 283

By Prof. Wilmon Newell, . Texas State Entomologist.

Section XLV.-The Cotton Worm, or Cotton Caterpillar . 285

By Prof. Wilmon Newell, Texas State Entomologist.

Section XLVI.-Orchard And Garden Insects • . . 288

By Prof. A. L. Quaintance, U. S. Department of Agriculture, Bureau of Entomology.

Section XlViI.-House Flies and Mosquitoes

By Dr. A. W. Morrill, U. S. Department of Agriculture, Bureau of Entoinology. 
PAGE

Section XLVIII.-BeE Keeping . . . . . . . 30I

By Prof. Wilmon Newell, Texas State Entomologist.

Section XLIX.-Wild Birds.

. 304

By Prof. E. H. Forbush, State Ornithologist of Massachusetts.

Section L.-Birds of Orchard and Woodland . . . . 308

Section LI.-Birds of the Field and Garden . . . . 3iI

Section LiI.-Other Birds . . . . . . . . 314

CHAPTER VIII.-LIVE-STOCK AND DAIRYING.

Section LiII.-Principles of Animal Breeding and Grading 318

By Prof. E. S. Good, Department of Animal Husbandry, Kentucky State University.

Section 'LIV.-Types and Breeds of Horses $\cdot 320$

By Prof. E. S. Good, Department of Animal Husbandry, Kentucky State University.

Section LV.-Types and Breeds of Cattle $\cdot 333$

By Prof. E. S. Good, Department of Animal Husbandry, Kentucky State University.

Section LVI.-Types and Breeds of Sheep 345

By Prof. Joseph E. Wing, Staff Correspondent Breeder's Gazette.

Section LVII.-Types and Breeds of Swine $35^{2}$

By Prof. C. S. Plumb, Department of Animal Husbandry, Ohio State University.

Section LVIII (a).-Poultry

By Prof. D. J. Lambert, Department of Poultry Husbandry. Rhode Island State College.

(b).-Poultry Houses and Care of Poultry - 365

By J. E. Halligan, Chemist in Charge, Louisiana State Experiment Station.

Section LIX.-Dairying $\cdot 374$

By Dr. F. W. Woll, Department of Agricultural Chemistry, University of Wisconsin. 


\section{CHAPTER IX.-FEEDS AND FEEDING.}

By J. E. Halligan, Chemist in Charge, Louisiana State Experiment Station.

Section LX.-The Composition of Plants . . . 387

Section LXI.-The Composition of Farm Animals and the

Nutritive Elements . • . • . . . . 389

Section LXII.-Physiology of Digestion and Food Economics 393

By Dr. W. H. Dalrymple, Department of Veterinary Science, Louisiana State University.

Section LXiII.-Natural and Commercial Stock Feeds .396

By J. E. Halligan, Chemist in Charge, Louisiana State Experiment Station.

Section LXIV.-Vegetable Oil, Alcoholic and Breakfast

Food By-Products . . . . . . . . $40 \mathrm{I}$

Section LXV.-Other By-Products . . . . . . 404

Section LXVI.-Composition, Digestibility, and Nutritive

RAtio . . . . . . . . . . . 407

Section LXVII.-Feeding Standards . . . . . . 4II

Section LXVIII.-Rations . . . . . . . . . 4I5

Section LXiX.-Terms of a Nutritive Ratio . . . . 4I8

Section LXX.-How to Improve a Ration . . . . . 420

Section LXXi.-How to Reduce the Cost of a Ration . . 422

Section LXXII.-Feeds for Farm Animals . • . 425

Section LXXili.-A Few Remarks About Feed Stuffs • 430

\section{CHAPTER X.-MISCELLANEOUS.}

Section LXXIV.-Farm Management

434

By Prof. Fred W. Card, Late of the Department of Horticulture, Rhode Island College of Agriculture and Mechanic Arts.

Section LXXV.-Farm Machinery $43^{8}$

By Prof. L. W. Chase, Department of Farm Mechanics, University of Nebraska. 
Section LXXVI.-The Disposal of Sewage on the Farm

PAGE

By Prof. J. B. Davidson, Department of Agricultural Engineering, Iowa State College.

Section LXXVII.-Earth Roads .455

By Prof. J. B. Davidson, Department of Agricultural Engineering, Iowa State College.

Section LXXVIII.-The Country Home . . . . . 460

By J. E. Halligan, Chemist in Charge, Louisiana State Experiment Station.

Section LXXIX.-Truck Gardening

.464

By Prof. G. L. Tiebout, Department of Horticulture, Louisiana State University.

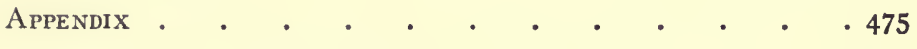

$\operatorname{INDEX} \quad \cdot \quad \cdot \quad \cdot \quad \cdot \quad \cdot \quad \cdot \quad \cdot \quad \cdot 485$ 



\section{N T R O D U C T I O N.}

Section I.-Means of Promoting Agricultural LiFE IN AMERICA.

By Kenyon L. Butterfield,

President of the Massachusetts Agricultural College and member of Ex-President Roosevelt's Country Life Commission.

Farming a Subject of Study.-In our study of the means of promoting agriculture and country life in America, we are first of all obliged to take into account the wonderful progress which agricultural science has made during recent years. The United States Department of Agriculture and the State Experiment Stations are constantly placing at our. disposal new truths which can be successfully worked over into the actual practice of the farm. A new generation of young farmers is being trained for successful agricultural practice in ways far different from those which their fathers used, and in a much more thorough manner. Farming is no longer a matter of experience onlyit has become a subject of study.

A Farmer Must Be an Educated Man.-The very fact that there is so much that is new to learn about agriculture, and that farm practice must be worked over in the light of this new knowledge, makes it important that everything possible be done to give a wide distribution to what we already know about the science of agriculture. As in every other industrial occupation in modern life, the farmer must make a profit. It is not fair to say that in thus encouraging farmers to make more money, we are devoting ourselves simply to greater material gain, although there is a possible danger that this may be the result. As a matter of fact, the education of a good farmer under 
modern conditions means a real education of the man himself. A modern farmer must have a wide range of knowledge, appreciate the reign of law, and adapt himself to the rapidly changing conditions of the market. He must be a broadly educated man. Thus there has developed a great need for agricultural schools and colleges, experiment stations, farmers' institutes, farmers' organizations for social and business ends,-all the machinery that is now working to give increased prosperity to the farming industry. We cannot put too much energy, and thought, and money, into the running of this social machinery, because it is vital to the development of the greatest business in America.

How the Profits Should Be Used.-But at the same time that a man is being educated in order to make a better success of the business of farming, he is also learning that when he has made this greater profit, he has not really reached the end of the road. He has not yet reached his goal. The next step is to learn how to use this profit in a way that shall build him up as a man, develop the right sort of family life, and contribute to the welfare of the neighborhood. One of the serious difficulties in our agricultural development arises from the fact that a good many farmers when they have attained business success on a farm, leave it for village or city life. They seem to have no interest in the rural community, after they have reached a certain degree of wealth.

A Higher Life.-All these considerations lead to the thought that in our attempts to improve farm conditions, we must keep in sight the great human problems, as well as the great questions of better crops, and of better methods of selling these crops at a profit. We must develop the right sort of home life. We must have in the country those facilities for enjoyment and culture that will keep people alive to all of those things that make for a higher manhood and nobler womanhood。 


\section{H A P T E R I.}

\section{THE SOIL.}

By Prof. A. R. Whitson,

Department of Soils, University of Wisconsin.

\section{Section II.-Relation of the Soil to Plant} GROWTH.

As agriculture depends on the soil, a full knowledge of the soil and its management is necessary to scientific farming. The soil is an extremely complex mixture with complex physical, chemical, and biological properties, all of which it would be interesting to study, but from the standpoint of practical agriculture we are interested only in those properties of the soil which influence the growth of crops. We must, therefore, look at the soil through the plant.

Absorption of $W$ ater. - The first effect of the soil on the plant is its relation to the germination of seed. This process begins with the absorption of water, and the rate at which absorption takes place is influenced by several factors. Firming the soil brings the seed in closer contact and so hastens the absorption of water. Warm water is absorbed more quickly than cold, and for this reason especially, seed germinate more quickly in warm than in cold soils.*

Oxygen.-Besides moisture, germinating seed require oxygen, so that while the soil must have sufficient moisture and be in sufficiently close contact with the

* This influence of temperature can readily be shown by placing equal weights of dry peas or beans in two vessels of water, one of which is warm and the other cold, allowing them to stand half an hour and then drying the surface with a cloth and weighing. 
seed to allow the latter to absorb this moisture, it must not be water-logged nor so closely packed a round the seed as to exclude air, otherwise the seed will rot and fail to germinate. It is true that seeds can germinate entirely soaked in water, but this happens in case of water which has had an opportunity to absorb oxygen from the air, while water that remains stagnant in the soil for some time is robbed of its oxygen and is unfit for the germination of seed.

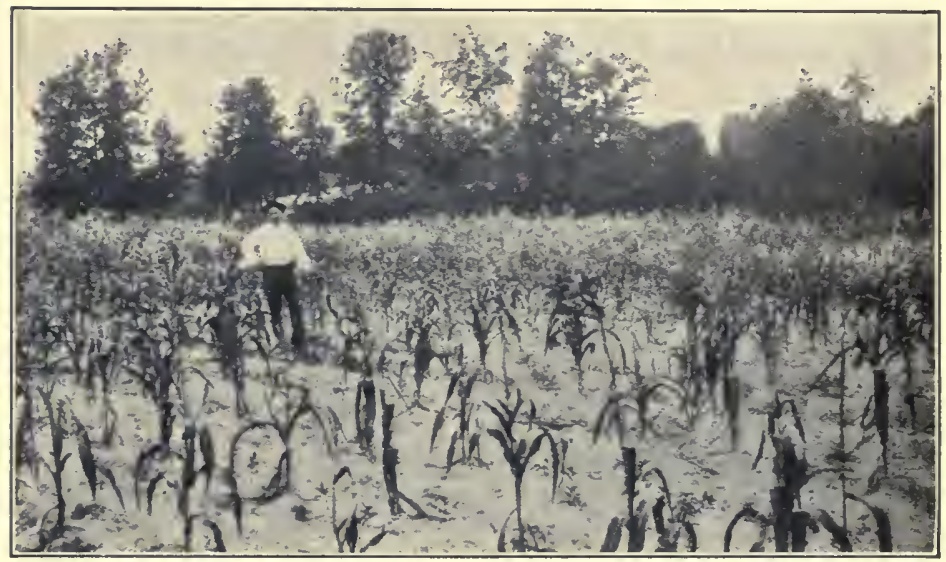

A POOR CROP, DUE TO LACK OF THE ESSENTIAL ELEMENTS.

The Essential Elements.-Under proper conditions of moisture and temperature seed will germinate and continue to grow for some time. Sooner or later, however, growth will cease unless certain chemical elements, usually spoken of as the essential elements, are available. These are nitrogen, phosphorus, sulphur, potassium, calcium, magnesium, and iron, and in addition hydrogen and oxygen of the water. These elements are absorbed by the plant from the soil in the form of salts which are soluble in the water. The salts are formed in the soil as the result of chemical processes which we will refer to later. Of these ele- 
ments, phosphorus, nitrogen, hydrogen, and oxygen are largely built up into the organic compounds which compose the tissue of the plant, while the remaining elements are chiefly used in the plant as carriers of the other elements and do not constitute a component of the plant on maturity but remain in the cell sap. In the case of plants which dry up as they approach maturity the concentration of salts in this way forces a considerable part of these elements out of the plant and they are returned to the soil.

Amounts of Elements Removed by Crops.-In order to study the influence of the removal of crops from the soil we must determine the amount of these essential elements which are removed by mature crops. The following table from Bulletin 47 of the Minnesota Experiment Station gives the amounts of these essential elements removed by average crops.

TABLE SHOWING THE PLANT FOOD MATERIAL REMOVED BY THE CROPS IN POUNDS PER ACRE.

\begin{tabular}{|c|c|c|c|c|c|}
\hline Crop & $\begin{array}{l}\text { Gross } \\
\text { Weight }\end{array}$ & $\begin{array}{l}\text { Nitro- } \\
\text { gen }\end{array}$ & $\begin{array}{l}\text { Phos- } \\
\text { phoric } \\
\text { Acid }\end{array}$ & Potash & Lime \\
\hline Wheat, 20 bu. . . . & 1200 & 25 & 12.5 & 7 & 1 \\
\hline Straw........... & 2000 & IO & $7 \cdot 5$ & 28 & 7 \\
\hline Total....... & $\ldots$ & 35 & 20 & 35 & 8 \\
\hline Barley, 40 bu. .... & 1920 & 28 & I5 & 8 & I \\
\hline 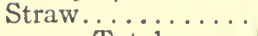 & 3000 & 12 & 5 & 30 & 8 \\
\hline Total...... & & 40 & 20 & $3^{8}$ & 9 \\
\hline Oats, 50 bu....... & 1600 & 35 & I 2 & 10 & I. 5 \\
\hline Straw........... & 3000 & I5 & 6 & 35 & $9 \cdot 5$ \\
\hline Total...... & $\ldots$ & 50 & I 8 & 45 & II \\
\hline Corn, 65 bu...... & 2200 & 40 & I 8 & 15 & $\mathrm{I}$ \\
\hline Stalks.......... & 6000 & 45 & 14 & 80 & 20 \\
\hline Total...... & $\ldots$ & 85 & 32 & .95 & 21 \\
\hline Peas, 30 bu...... & I 800 & . & I 8 & 22 & 4 \\
\hline Straw.......... & 3500 & $\cdots$ & 7 & $3^{8}$ & 71 \\
\hline Total...... & $\ldots$ & .. & 25 & 60 & 75 \\
\hline Flax, r 5 bu. ..... & 900 & 39 & I5 & 8 & 3 \\
\hline Straw ........... & 1800 & 15 & 3 & 19 & I 3 \\
\hline Total...... & $\ldots$ & 54 & 18 & 27 & I 6 \\
\hline Meadow hay...... & 2000 & - 30 & 20 & 45 & 12 \\
\hline Red Clover hay. . . & 4000 & 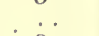 & 28 & 66 & 75 \\
\hline Potatoes, 300 bu. . & 18000 & 80 & 40 & $15^{\circ}$ & 50 \\
\hline Mangels, io tons. . & 20000 & 75 & 35 & 150 & 30 \\
\hline
\end{tabular}


Uses of Water to the Plant and Amount Required. -Besides these elements the plant throughout its growth requires water. This water is used by the plant in carrying into and through it the necessary salts; in keeping the cell walls of the leaf tissue moist, so as to allow them to absorb carbon dioxide from the atmosphere, and in regulating the temperature of the plant by evaporation of water from the leaf, just as the temperature of the animal body is regulated by the evaporation of the perspiration. The amount of water used by crops varies greatly with the kind of crop and with the climatic conditions, but is always large. For instance in the growth of one pound of dry matter of corn about 250 to 300 pounds of water are used; for potatoes, 350 to 400 ; for clover, 500 to 600.

EXERCISE.-What is organic matter? What is inorganic matter? What does a seedling live upon before roots are developed to take food from the soil? Using the results in the Table, calculate the amount of nitrogen, phosphoric acid and potash removed by forty acres of potatoes yielding 250 bushels per acre. Compare the amount in the previous question with that removed by 40 acres of corn yielding 30 bushels per acre. Which of these two crops (corn or potatoes) is the more exhausting on the soil? How many acre inches of water will be necessary to produce 3 tons of clover hay?

\section{Section III.-Soil Fertility.}

The Fertility of the Soil depends in part on the rate at which the essential elements for plant growth become available as a result of the chemical decomposition of the rock particles and residue of former plants of which the soil is composed. It also depends on the amount and availability of moisture, and on the tilth or physical condition of the soil with reference to the readiness with which it can be penetrated by the roots of growing crops. The decomposition of the rock particles is, of course; very slow, and is largely the result of the action of carbon dioxide in the soil moisture, just as is the case in the forming of the soil 
from the original rock. This carbon dioxide is set free by the decomposition of vegetable matter, so that the presence of considerable decomposing vegetable matter is essential to the fertility of most soils. Moreover the vegetable matter itself contains more or less of the same chemical elements which had been used in the growth of plants from which it was formed. These soluble salts accumulating in the soil constitute the immediately available plant food.

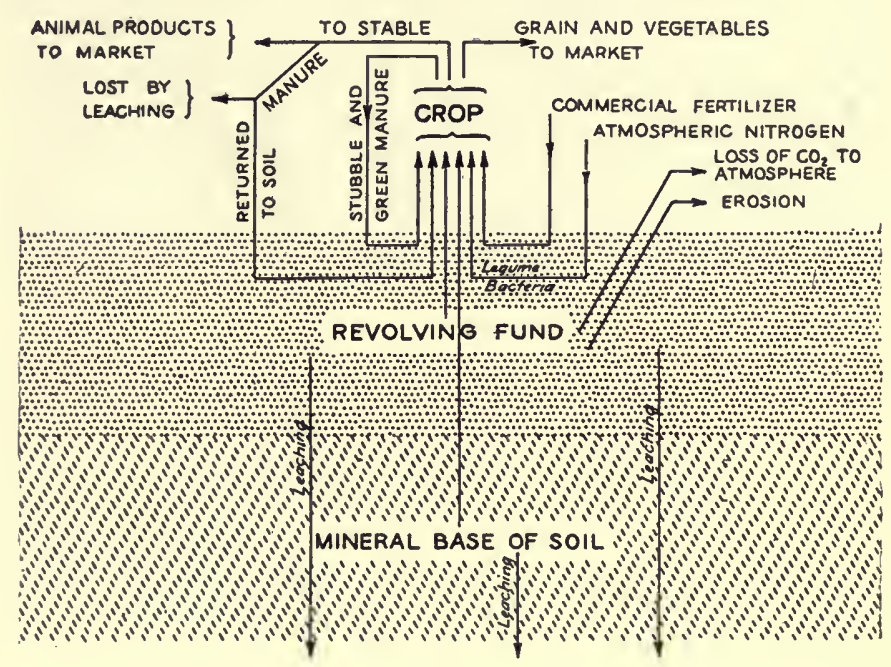

FIG. 2.

The Revolving Fund of Soil Fertility.-Figure 2 is constructed to show the various factors which are concerned in soil fertility. As illustrated in this figure a considerable quantity of material accumulates in the soil from the decomposition of the mineral bases, from the residue of roots and other portions of vegetation growing on the ground, and from manure and other fertilizers added. All of these together constitute the revolving fund of soil fertility. From this the crop largely derives its supply of the essential elements 


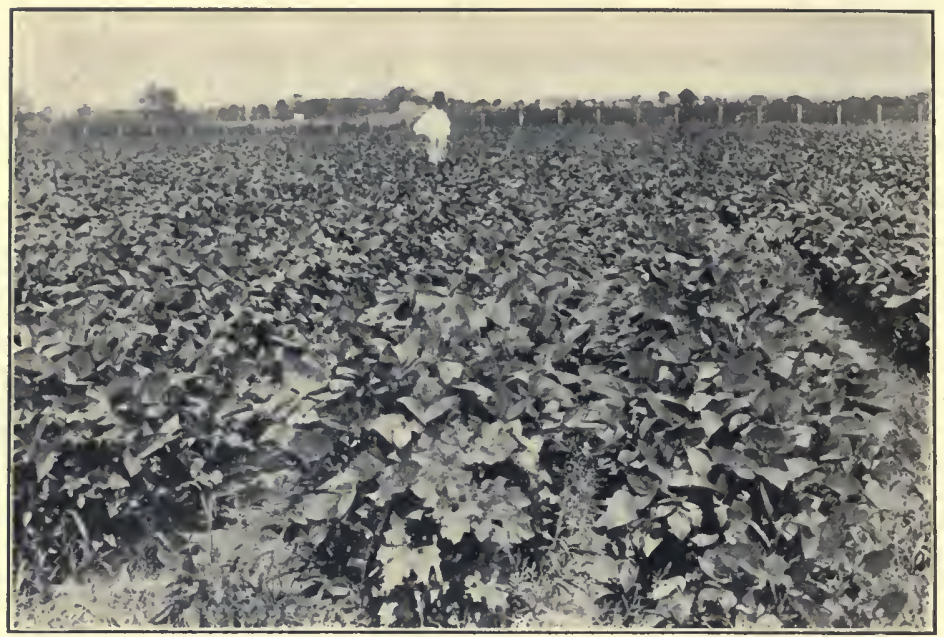

COW PEAS IN ROWS: A GOOD METHOD OF MAINTAINING SOIL FERTILITY.

during any single season of growth, but a small amount is absorbed directly from the mineral base of the soil and added to the revolving fund after going through the crop. The diagram also illustrates the ways in which this revolving fund is lost by erosion, by decomposition of the organic matter, the carbon dioxide passing off into the atmosphere; by the loss of material in grain and vegetables sold on the one hand and of animal products on the other. It also indicates the loss of fertility by the leaching of manure. Another source of gain is from the atmospheric nitrogen, which is absorbed by certain bacteria forming nodules on members of the legume or pea family of plants. A study of this diagram will show the great complexity of the problem of maintaining the fertility of the soil. It is possible to estimate the losses in some of the ways indicated, as, for instance, in the products sold from the farm and to a certain extent from the manure, but the losses by leaching and by erosion as well as by decomposition of organic matter, it is almost impossible 
to estimate with any accuracy, although we know that they are frequently large, even greater than the losses in ways which we can estimate.

Limiting Factors in Soil Fertility.-As previously stated, there are a number of factors which go to determine the fertility of the soil, such as moisture-holding capacity, aeration, tilth or penetrability of the roots, and supply of essential elements. A lack in any one of these requirements will limit.the power of any particular soil to produce good crops. If, for instance, the supply of nitrogen, potash, or of water be inadequate the amount of this substance that is present becomes the limiting factor in crop production. This principle is illustrated in the accompanying diagram, Fig. 3, which was devised by Dr. Dobenec, of Germany. The amount of water which the barrel can hold is determined by the height of the lowest

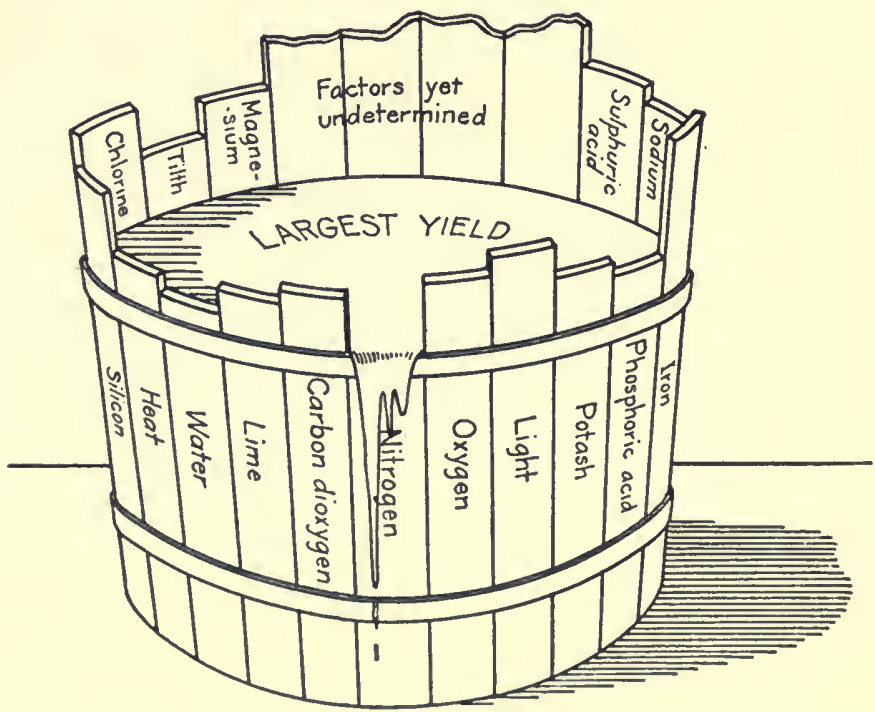

FIG. 3 . 
stave. If the length of this stave is increased then the next shortest stave will determine the capacity of the barrel, and so on until all are of equal length. The same relation holds among the factors determining the fertility of the soil.

Humus.-We must now consider some of these important factors. One of the most important is known as humus. This is a black waxy or tar-like substance formed by the partial decomposition of vegetable matter in the soil and constituting a coating around soil grains. Humus is important in binding the sands together, so as to give them greater coherence and in part prevent their being blown by the wind as would otherwise be the case. It also greatly increases the moisture-holding capacity of the soil, since this substance can hold two or three times its weight of moisture. On heavy clay soils it has the effect of lessening the tenacity with which the grains of soil are held together in lumps and so improves the tilth. Moreover this humus contains a great deal of nitrogen which by going through a chemical process caused by the bacteria in the soil is changed into the form of a salt of nitrogen or nitrate, which can be absorbed by the plant. It is, therefore, of the utmost importance that the supply of humus in the soil be maintained.

Sources of Humus.-Now humus is chiefly formed from the fine roots of grasses and exists in large amounts on prairie soils where these grasses have been growing for thousands of years. In the soil kept cultivated it is being continually burned out, and the best method by which it can be handled or even maintained is by rotation of crops including the growing of grasses a part of the time either for pasture or hay. Green manuring crops add somewhat to this as does stable manure, but to a very much less extent than the fine roots of grasses.

Chemical Reaction of Soils.-Another important matter with reference to the condition of soils is what is known as their chemical reaction, that is, as to 
whether they are acid, neutral, or alkaline in character. It is found that blue litmus paper, used for testing substances to determine whether they are acid or not, when applied to many soils will turn pink or red, indicating acidity.

Acidity and Liming.-This acidity is not in itself injurious to most plants, but it is unfavorable to the maintenance of fertility. This is especially true with reference to the availability of phosphorus and accumulation of nitrogen by legumes. It is, therefore, usually desirable to correct this acidity by adding either fresh slaked lime or simple ground limestone or marl. The use of fresh lime or of simply water-slaked lime is somewhat dangerous, since it is apt to hasten the burning out of the organic matter or humus. It is usually better, therefore, to use old thoroughly slaked lime or finely ground limestone or marl.

Maintaining Fertility with Legumes.-The accumulation of nitrogen by legumes, which has been referred to above, is a matter of the utmost importance

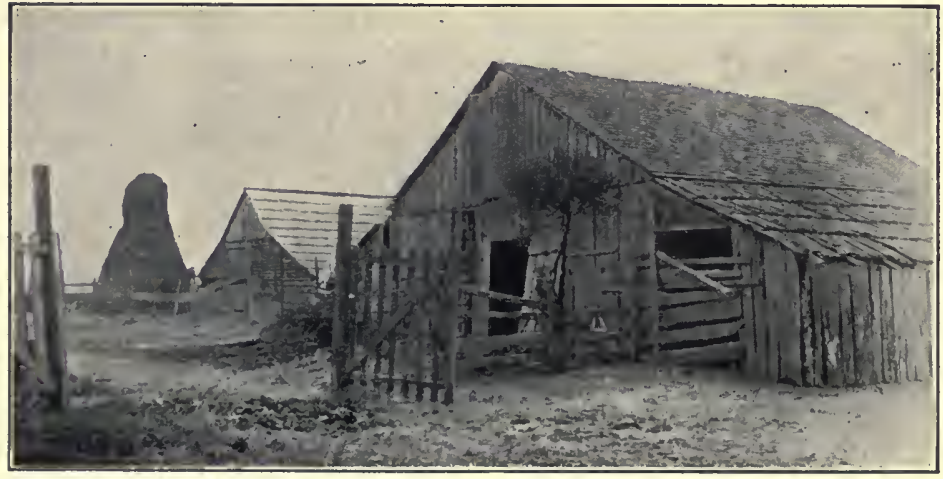

A FARM WHERE THE MANURE IS NOT PRESERVED AND THE SOIL IS ALLOWED TO RUN DOWN.

in maintaining the fertility of the soil. Nitrogen constitutes four-fifths of the atmosphere and, of course, exists in large amounts in the air all through the soil. 
Certain bacteria living in the soil penetrate the root hairs of plants belonging to the legume or pea family, causing the development of small nodules or tubercles within which they develop in great abundance, and from which they derive a part of their nourishment. The nitrogen which they need, however, to produce protoplasm is absorbed from the air of the soil, and then the plant absorbing the material set free in the decomposition of these bacteria in the tubercles secure their supply of nitrogen and build it up into their tissue. It is, therefore, possible for plants of this family, when these bacteria are present to grow well on soil not supplied with organic matter, provided, of course, they have the necessary supply of potash, phosphate, lime, magnesia, and other essential elements.

Roots of Legumes Leave Nitrogen in the Soil.Moreover these plants not only secure the nitrogen in this way which is left in their seed of the aerial part of the plant, but a good deal secured in this way is left in the roots of the plants and so when this sod of clover, cow peas, or soy beans or other such crop is plowed, and later planted to cotton, corn, or other crop, not able to secure its nitrogen in this way, it is supplied with nitrogen coming from the decomposition of the roots of the legume plants. The growing of a good crop of cow peas or soy beans will in this way usually leave enough nitrogen in the soil for a good crop of cotton or corn, and therefore the rotation of a legume plant with other crops is one of the most important methods to be used by the farmer in maintaining fertility.

Legumes do not Interfere with the Growing of Other Crops.-It is often possible to sow some legume, such as crimson clover, cow peas, or soy beans between the rows of cultivated plants at the time of their last cultivation, which by growing during the fall and following spring, add greatly to the nitrogen of the soil without the necessity of giving up the ground an entire year for this purpose. 
Use Legumes for Feed and Return the Manure to the Soil.-However, legume plants are always richest in protein, the most important food element, so that they should be grown and used for feed on the farm as far as possible. By so doing a large part of the nitrogen in the seed and hay of this crop is returned to the soil through the manure.

Phosphorus.-Of the other essential elements phosphorus is the chief one to which the farmer must give thought. It always exists in small amounts in the soil, usually from .03 to .2 of a per cent., and since

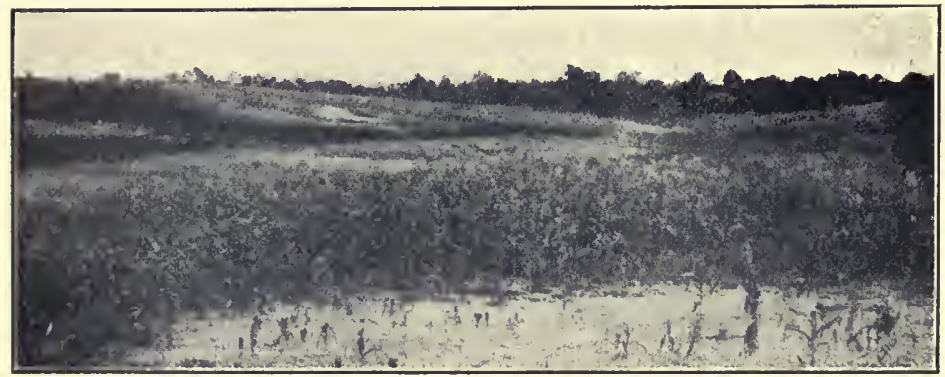

AVERAGE PRODUCTION REDUCED BY INFERTILE SPOTS.

it is required by all crops and goes chiefly to the seed the supply in the soil is very likely to be exhausted. This supply can be maintained only by lessening the sale of seed or crops containing this element or adding the phosphorus directly in the form of fertilizer. In the case of the cotton crop, for instance, if the seed is brought back to the farm, and used as feed for animals kept on the farm there is little loss of phosphorus. In dairy states where cream or butter is the chief thing sold there is positively little loss of phosphorus except by leaching.

Supplying Phosphorus to the Soil.-Untreated or raw rock phosphate (native deposits-see chapter on fertilizers), becomes available to plants only very slowly, but is of course much cheaper, and has twice 
as much phosphoric acid in it as in acid phosphate (raw rock phosphate treated with sulphuric acid), and when used with considerable amounts of organic matter, such as stable or green manure, becomes available rapidly enough to supply crops with this element when the first application is in quantities of a half to threequarters of a ton per acre. This acid phosphate, however, is more immediately available, and can be used to advantage when organic matter is not available.

Potash usually exists in the soil in large enough amounts so that when the soil is kept properly supplied with organic matter by the decomposition of which carbon dioxide is set free so as to react on the mineral part of the soil containing the potash, this element becomes available. But certain soils, especially sandy soils, are often deficient in this element in which case it must be supplied as a fertilizer. From 50 to I 00 pounds of potash is a good application.

ExERCISE.-Does a soil in good physical condition or one in poor physical condition have the greater percentage of pore space? Why? What causes humus to be black in color? What effect will this have upon soil temperature? May green manuring ever be detrimental? Make a list of the leguminous plants in your vicinity. From the results in Delaware Bulletin No.60, calculate the amount of nitrogen left in the soil when 3 tons of cowpea hay were removed. Calculate the number of acres in your county. What per cent. is subject to erosion? Name the states drained by the Mississippi River and tributaries. How many square miles in the above area? The Mississippi River deposits 3,702,758,400 cu. ft. of solid material in the Gulf of Mexico annually. If the weight of a cubic foot of soil averages 80 pounds, how many tons does the Mississippi River deposit annually? The area of the surface of an acre is $43,560 \mathrm{sq}$. ft. How many acres of soil one foot deep will be formed at the mouths of the Mississippi River every year?

\section{Section IV.-Soll Physics.}

In addition to the influence which the soil has on the growth of plants on account of the chemical elements which it furnishes, it greatly affects the growth of plants through physical factors. Among these are included the water supply of the plant, conditions with 
reference to root development, temperature, and aeration. Moreover, since cultivation of the soil is necessary for several purposes, such as the covering of weeds, the maintenance of tilth, conservation of moisture, etc., the readiness with which this cultivation can be carried on is an important factor in the value of the soil.

Classes of Soil Particles.-When any soil is examined in the field it is noticed at once that it is composed of lumps or granules of various size which in turn are made up of the individual grains varying all the way from a coarse sand to the finest dust. These ultimate grains of which the soil is composed are usually classified into four groups : first, gravel; second, sand; third, silt; and the finest of all is called clay. When a lump of soil is placed in a bottle of water and shaken until all the particles are loosened from each other, and then mixed through a larger volume of water and allowed to settle, it will be found that the gravel and sand will settle almost immediately, while the silt will remain in suspension from a few minutes to several hours; and the largest part of the clay will remain in suspension for several hours, and the finest even for days. Now all soils are composed of varying amounts of these different classes of soil particles. Sandy soils have a large percentage of sand, but also a small percentage of silt and clay. Clay soils have a large percentage of clay and smaller amounts of sand. Relative amounts of these various sized grains in any given soil are spoken of as the mechanical composition of this soil. The sandy soils are those in which the sands predominate, silt those in which the silt size of grains predominates, and clay soils those in which the clay size predominates. In the system adopted by the Bureau of Soils, U. S. Dept. of Agriculture, the following size of soil grains are used: Fine gravel 2-I m.m. Coarse sand $\mathrm{I}-.5 \mathrm{~m} . \mathrm{m}$. Medium sand $.5-.25$ m.m. Fine sand .25-. IO m.m. Very fine sand . I O-.05 m.m. Silt .05-.005 m.m. Clay .005-o m.m. 


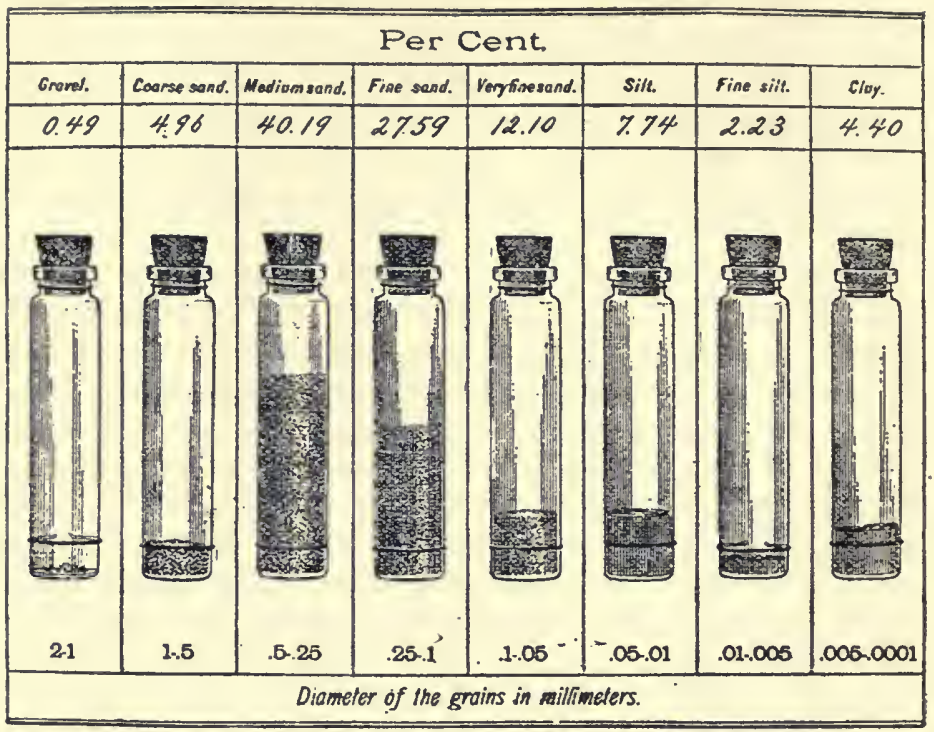

MECHANICAL ANALYSIS OF A SANDY SOIL.

Mechanical Composition and Texture.-The mechanical composition of soils is of great importance because it determines many of their physical properties. The granulation of the soil or clustering due to the aggregation of these soil grains is largely caused by films of water surrounding several grains and holding them together in small aggregates or clusters. These in turn are held togetherwhere they come in contact with each other by the same films so that the aggregation of these clusters into lumps is the result of the surface tension of the films of water surrounding the soil grains. Now if we compare equal volumes of coarse and fine soils, we will see at once that there is a much larger area of surface in the fine soil than in the coarse soil. There is, therefore, a much greater tendency of the fine soils to adhere as a result of this surface tension of the soil films. We can understand, therefore, why it is that the clay soils have a much more marked ten- 
dency to gather into large clusters or lumps than in the case of the sandy soils. The action of the surface tension of the water, however, is not the only thing which produces this effect. Some salts in solution in this water have the effect of acting as a cement between the soil grains, so that as the water dries out the soil grains a re held firmly together often in very hard lumps.

Cause of Shrinkage of Soils.-The tendency to shrink possessed by the soils as they dry out is because the films of water are at first quite thick, but become thinner as moisture is lost by evaporation and as contraction results a tension is produced which is finally relieved by cracking at the weakest point causing the development of checks and cracks running all through the soil. If a tin can with sharp edges is forced down into the soil and then carefully dug up and turned into an upright position and examined by filling carefully with water, it will be found that from a third to a half of the can was occupied by air alone, indicating that the soil only occupies from one-third to two-thirds of the space. This tendency to form soil aggregates or crumbs is illustrated in Fig. 6.

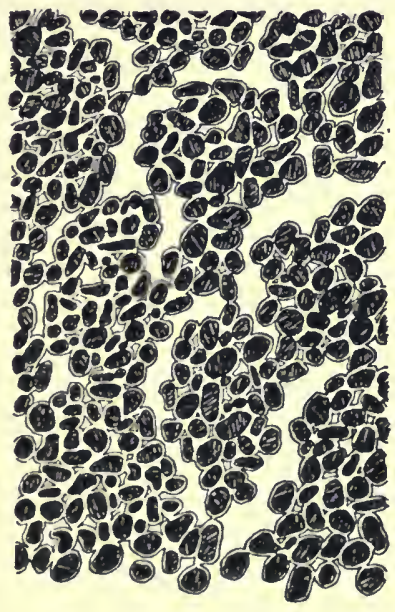

FIG. 6 .

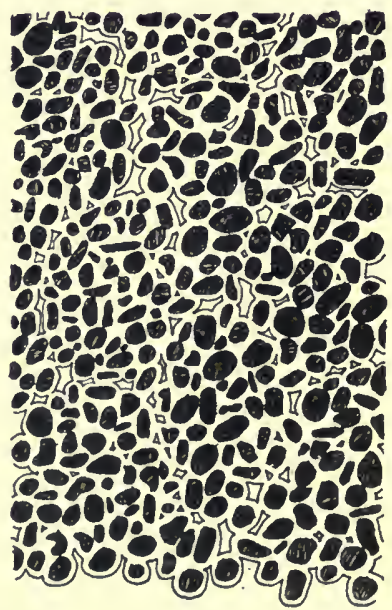


Puddling of Soil and Its Cause.-When soils a re in a very moist condition their particles are free to move over each other quite readily, and if they are worked when in that condition the soil grains do move about until they are packed as closely as possible, the soil clusters being broken up. The soil is then said to be puddled. If the soil is allowed to dry after being worked when wet in this way, it contracts into a dense mass which, in the case of clay, will be very hard. This process when carried to the extreme is that used

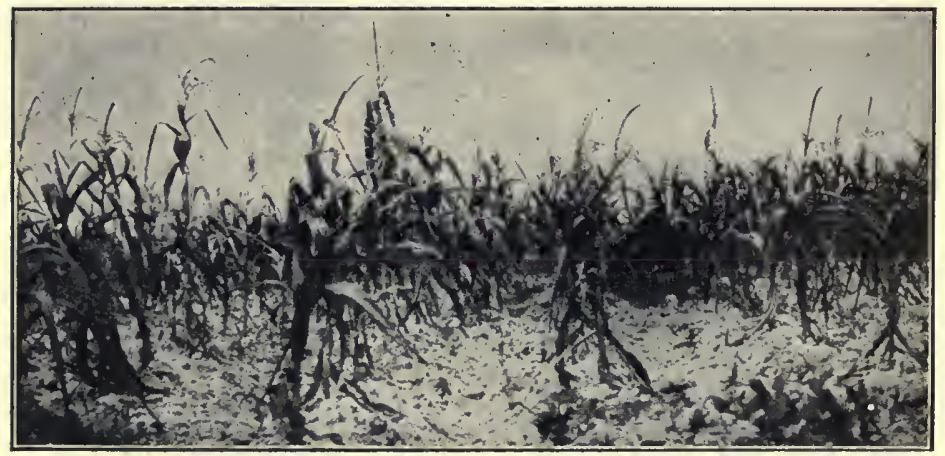

INJURIOUS RESULTS FROM CULTIVATION GIVEN AFTER GROUND HAD BECOME TOO DRY.

in brick making. It is extremely important, therefore, for the farmer to be careful when working with clay soils that they are not worked when so wet as to cause any of this puddling, because the dense chunks resulting will frequently leave the soil in poor tilth for several years afterward. On the other hand, if the soil is allowed to dry somewhat before being worked the clusters fall apart readily and good tilth can be developed.

Tilth of Soil.-As previously mentioned, humus also influences the mechanical condition of the soil in that it tends to cement the grains of sand more closely than would the films of water around such coarse grains, 
while coming between the fine grains of clay it has the opposite tendency by lessening the tenacity with which they are held together so as to decrease the tendency to puddle. Salts which are developed in arid regions are apt to cause this to cement so firmly as to produce hard pan. Moreover hard pan is often produced at the depth at which the plowing runs if the ordinary mold board plow is used on the heavy clay soils always plowing to the same depth. The plowing of such soils rather deeply in the fall, leaving them to be acted on by the frosts of the winter tends to produce the crumb-like condition of good tilth. This effect of freezing and thawing is, of course, more marked in the north than in the south, and the northern soils usually have a better tilth than do those of the south. Careful attention to the tilth of the soil along these lines greatly increases the readiness with which the soil can be penetrated by the roots. This is an important factor in the growth of crops, because unless the roots are able to penetrate the soil thoroughly in all directions they are unable to obtain sufficient moisture or the supply of the various chemical substances so necessary for their growth.

EXERCISE.-Make a physical analysis of your soil by putting some in a bottle partially filled with water, shaking thoroughly; then let the soil settle. By the different sizes calculate the percentage of clay, silt, sand and gravel. Name your soil. Compare the pore space in sand with that in clay. Which will hold the more water and why? Compare a puddled soil with one in good condition, in regard to its water-holding capacity.

\section{Section V.-Water Requirements of Crops.}

Forms of Water in Soil.-We must now examine the soil from the standpoint of the water requirements of the crop. If the neck of a funnel be stoppered, the funnel filled with soil in a granular condition, and then water poured on until the funnel is full, we will have the soil in a saturated condition. The soil allowed to 
remain in such a condition is said to be water-logged. If now the stopper be removed a portion of the water will be drawn off by the force of gravi-

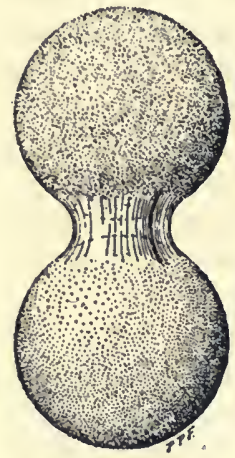

DEVICE TO ILLUSTRATE ACTION OF CAPILLARY WATER. tation, and it is often spoken of as the gravitational water or drained water. If the funnel is again stoppered and allowed to stand with the surface exposed a large part of the moisture retained by the grains in clusters will move up through the soil to replace the loss by evaporation from the surface. This upward movement of water is produced by the surface tension of the moisture films which becomes greater as some of the water is lost by evaporation. This movement is of a capillary nature, and the water held and moved by surface tension is therefore spoken of as the capillary moisture of the soil. If this funnel of soil be allowed to stand exposed in this way for several days or weeks, protected from rain, the soil will apparently become dry. It is air dry. However, if the soil be now weighed and placed in an oven and kept above the boiling point of water for a few hours and again weighed it will be found to have lost more moisture. Again if this oven-dry soil is exposed to the air of the room for a few hours and re-weighed, it will be found to have taken up some moisture. This moisture taken up in this way is spoken of as hygroscopic moisture.

Drainage.-The removal of gravitational water by natural or artificial underdrainage is necessary since if it remains in the soil the latter becomes water-logged. The oxygen is absorbed by chemical combination of substances in the soil and roots of crops are unable to develop in it. Fresh water falling as rain absorbs considerable oxygen from the air so that if there is a more or less constant movement downward of rain 


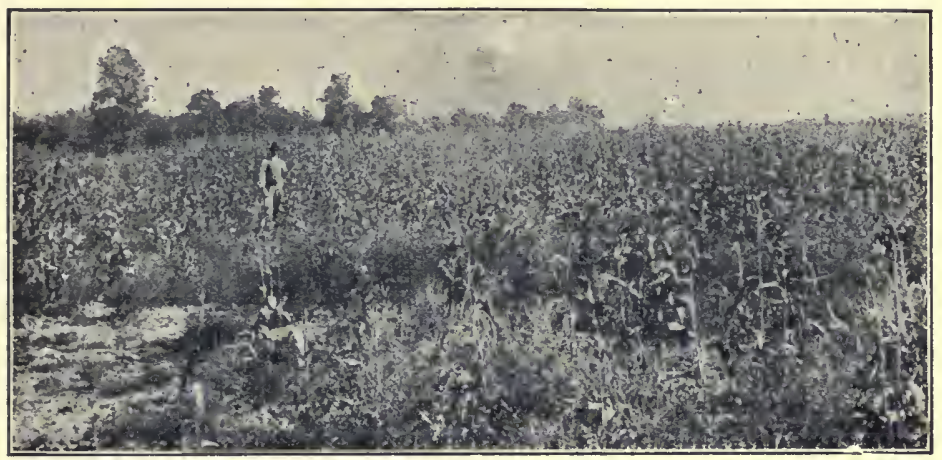

PRODUCTION REDUCED BY UNDRAINED SPOTS.

water through the soil the roots of plants may develop readily in it though the soil is thoroughly saturated. It is the water-logged condition which is unfavorable to crops.

Water Holding Capacity of Soils.-From this it will be seen that crops must largely rely on the capillary moisture of the soil for their water supply. The amount of capillary water which soils are able to hold and the protection of this water from loss by evapo-

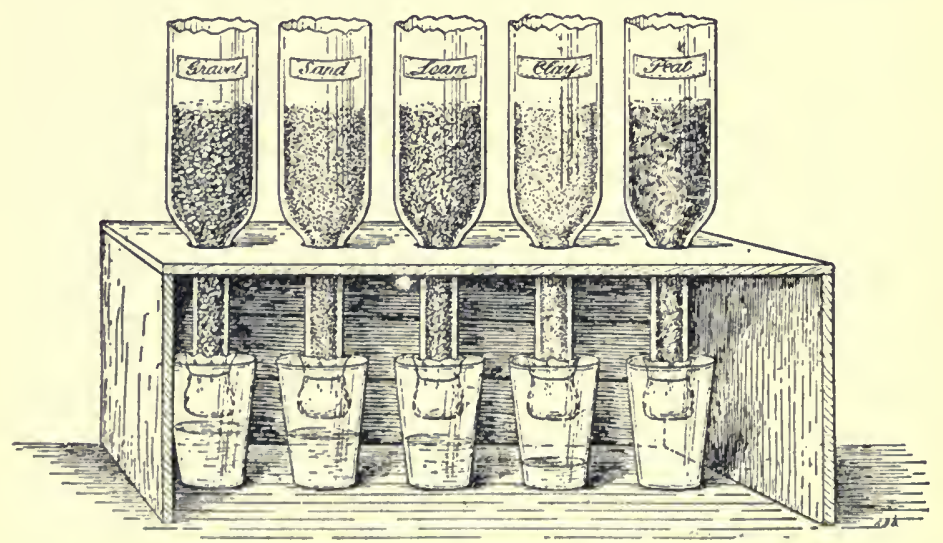

APPARATUS TO TEST THE CAPACITY OF SOILS TO HOLD WATER. 
ration at the surface of the ground are therefore questions of the utmost importance.. The amount of capillary water which the soil can hold is influenced by the mechanical composition of the soil, its condition of granulation, and the height of the surface above the ground water table, or saturated portion of the subsoil. Coarse sands are able to hold only a small amount of capillary water so that coarse sandy soils often shortly after rains will be found to have gained only from five to ten per cent. by weight of water. Finer soils, such as sandy loams and silt loams will retain from fifteen to twenty-five per cent., while heavier clay soils retain from thirty to forty or even fifty per cent. of water, expressed in per cent. of the weight of water to that of dry soil. Since, as previously stated, humus has a large water-holding capacity, soils in which this substance is abundant retain much more water than those in which it is small in amount. A large part of the advantage which clay loam soils have over the sandy soils is on account of their larger water-holding capacity. This is especially true with reference to the growing of crops, such as grasses for pasture or hay purposes. The grass growing throughout the season requires a soil with a large water-holding capacity to enable it to continue growing during the absence of rain for a period of a few weeks. The grasses have developed an extremely fine root system which enables them to penetrate clay soils and so take advantage of their large water-holding capacity. Such heavy clay soils are, therefore, often spoken of as grass soils.

Produce Soil Mulch by Frequent Shallow Cultivation.- Since a great deal of the capillary water is lost by soils on account of its being drawn up to the surface and evaporated, it is important if possible to prevent this evaporation. This may be done by producing a soil mulch. It is a simple experiment to get a small stream of water falling on a board to follow the path made for it by drawing a wet finger over it and making a moistened surface in a zigzag path. The water 


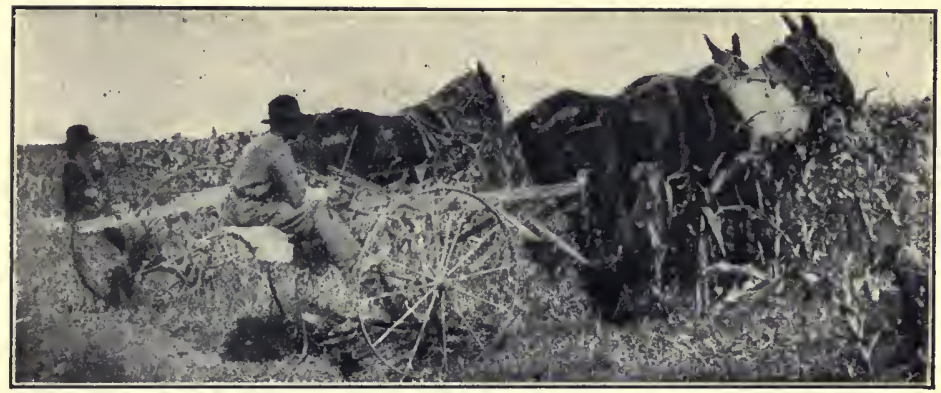

SURFACE CULTIVATOR AND DISK CULTIVATOR USED TO PRODUCE SOIL MULCH.

will continue to move along this wetted path for some time. The fact is that it is much easier for the water to move over the wetted surface than over the dry surface. This principle is made use of in developing the soil mulch. If the surface two or three inches of the soil is stirred thoroughly on a dry windy day it will become thoroughly dry and then offer a great deal of resistance to the upward movement of the moisture from below, and so greatly lessen the loss by evaporation. This treatment is of great importance in managing land in cultivated crops, such as cotton and corn

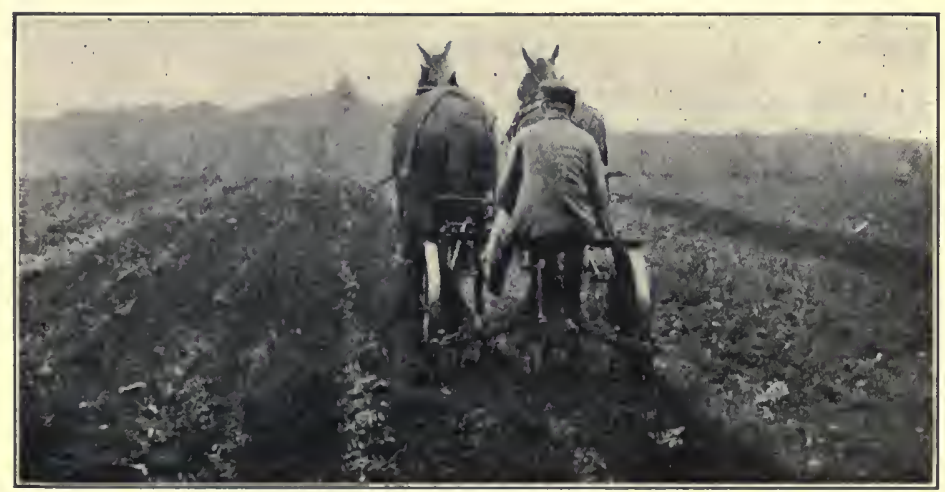

NARROW SHOVELS AND FENDERS FOR EARLY CULTIVATION. 
whenever a dry period comes on. It is of greatest importance, of course, in those sections of the country where the rainfall is light and the so-called dry farming is based largely on a thorough use of this system of mulching. It is, of course, necessary that the cultivation be not deep enough to injure the fine roots of crops which often come comparatively near the surface, especially during a wet season. Cultivation should, therefore, be sufficiently shallow to escape this danger.

How to Influence Upward Movement of Capillary Moisture.-Not only is it possible in this way to prevent the loss of moisture, but it is also possible to influence the upward movement of capillary moisture so that in a dry season when the seed is placed in the soil, moisture can be drawn up to the seed. This can be accomplished by rolling the ground, since this firming of the soil increases the upward movement of the moisture. Following the rolling it is necessary again to use the drag to produce the soil mulch so as to prevent the loss of water altogether.

EXERCISE.-What kind of soil water can plants use? Which is better : level or ridged cultivation? Why?

REFERENCES FOR COLLATERAL READING.

The SoIL.

Yearbooks of the U. S. Dept. of Agriculture:

I895-Reasons for cultivating the soil.

I895-Origin, value and reclamation of alkali lands.

1897-Some interesting soil problems.

1899-Soil investigations in the United States.

1902-The movement and retention of water in soils.

1908-Soil mulches for checking evaporation.

Farmers' Bulletins, Nos. :

I87-Drainage of farm lands.

I92-Barnyard manure.

262 and $329-$ Dry farming.

266-Management of soil to conserve moisture.

278-Leguminous crops for green manuring.

$320-$ Reclamation of salt marshes.

326 - Building up a rundown cotton plantation.

$371-D r a i n a g e$ of irrigated lands. 
Experiment Station Bulletins, Nos.:

$60-$ Delaware-Cover crops as green manure.

68-Illinois-Methods of maintaining the productive capacity of Illinois soils.

I25-Illinois-Thirty years of crop rotation on the common prairie soil of Illinois.

I84-Ohio-The maintenance of soil fertility.

Books :

Soils-Burkett-Orange Judd Co., New York City.

The Soil-King-The Macmillan Co., New York City.

Soils-Fletcher-Doubleday, Page \& Co., New York City.

The Fertility of the Land-Roberts-The Macmillan Co., New York City.

Bacteriology in Relation to Country Life-Lipman-The Macmillan Co., New York City.

Soils and Fertilizers-Snyder-The Macmillan Co., New York City.

Soils-Lyon \& Fippin-The Macmillan Co., New York City. 


\section{H A P T E R II.}

\section{PLANT LIFE.}

By Dr. Ernst A. Bessey,

Department of Botany, Michigan State Agricultural College.

\section{Section VI.-How Plants Live.}

Protoplasm.-All living things possess certain characteristics in common. If one studies plants and animals he finds that the living substances of both are practically alike. This living substance is called protoplasm. It is more or less sticky or slimy and of about the consistency of the white of an egg. It is this that grows, that builds the framework, and performs all the functions of life.

Cells.-Protoplasm is found in all the familiar animals and plants, not in one large mass, but in thousands of little parts, microscopically small, called cells. Each one of these has a thinner or thicker outer layer to separate it from its neighbors and to give it strength. In most animals some cells have thick walls and make up the skeleton, while the rest of the cells are soft walled and are to a large extent motile. In plants, most of the cells have fairly firm walls, so that there is no such chance for motility as in animals.

Activities of Protoplasm.-As long as the protoplasm is alive it is at work. One function that is peculiar to protoplasm is the ability to manufacture new protoplasm out of various substances which are not of themselves alive. This new protoplasm is alive and like that which produced it. Other activities of protoplasm are the taking in and transformation of food substances, manufacture of food in some cases, secre- 
tion of cell walls, production of various secretions, respiration, formation of new cells, etc.

Plants Require Energy.-All activities of plants require energy. Protoplasm obtains the energy to do its work by the oxidation (i. e., combustion) of food. The food is in many cases digested and carried to the different cells in solution, and there is oxidized by the oxygen taken in from the air. Carbon dioxide, a gas which will not support life, is produced and is given

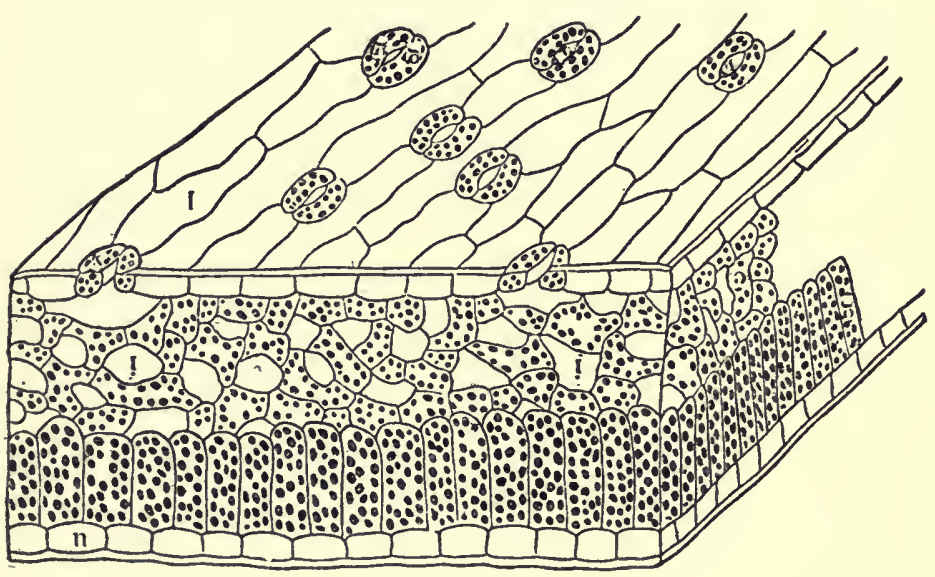

SECTION OF LEAF.

off. These processes are the same in the cells of animals and plants. The differences lie mainly in the way the food and oxygen reach the cells. In animals we find regular digestive and respiratory systems while these are practically lacking in plants, where there is no general blood system to carry food and oxygen to the cells and carbon dioxide away from them.

Plants Manufacture their Food.-Common plants differ further from animals in the fact that they manufacture their own food. All the common animals have to take in their food from outside, but all green plants manufacture their food in their green parts. 
This food then diffuses slowly to all the living cells of the plant, there to be used up as described above, or to be made use of in making new protoplasm, or

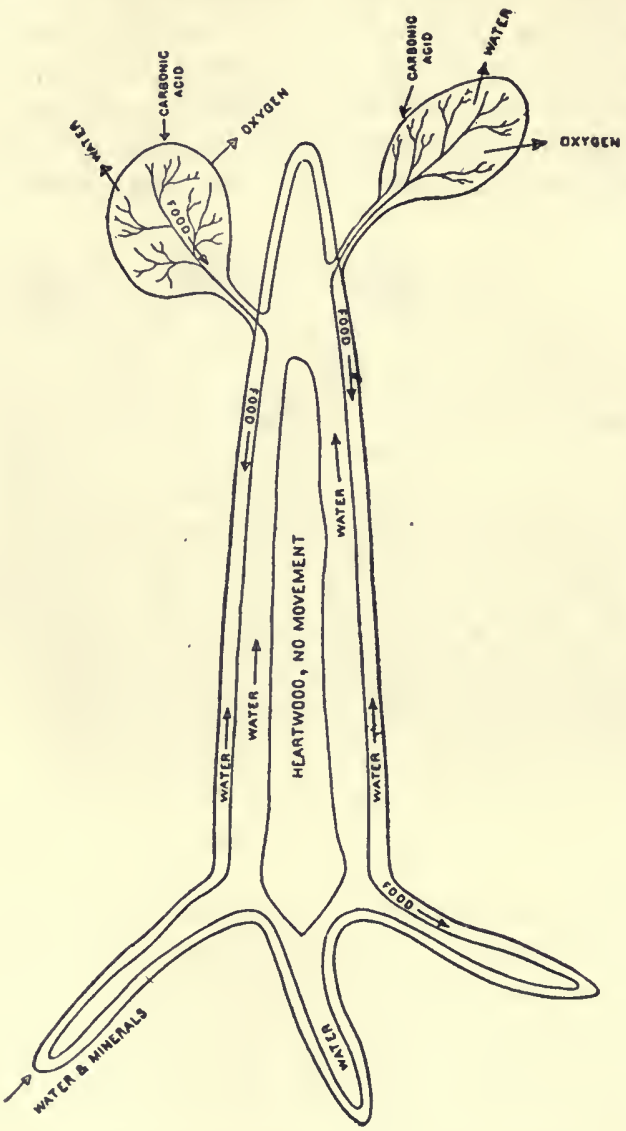

PATHWAYS OF WATER AND FOOD MATERIALS.

in building the cell walls. This manufacturing of food takes place only in the light. The substances out of which it is made are water, which the plants get from the ground if they are not water plants, and 
carbon dioxide, of which a small amount is always present in the air and in water.

Plants Require Power.-In the plant when its cells begin to manufacture food out of the raw materials, water and carbon dioxide, we look for the source of the power and find it in the sunlight. Keep a plant in the dark and it will grow as long as the stored-up food lasts, but then dies, because it cannot manufacture any food in the absence of light. Ordinarily a plant manufactures enough food by day to last it over night, with some to spare. Trees that shed their leaves produce enough food during the summer to keep them alive all winter, and furnish the material out of which all the new leaves and twigs are made, until the new leaves are able to manufacture food for themselves.

Plants Require Light.-Thus it is clear why many plants do poorly in the shade; they do not get enough light to enable them to keep up their food supply. Trees lighted only on one side grow out in that direction, while the branches on the shaded side remain small, hence the trees become unsymmetrical. The so-called "smothering out" of some weeds, by a rapidly growing crop, is in part due to shading them so that they get insufficient light, and are so weakened that they cannot secure all the water and mineral matter they need from the soil.

Plant Requirements.-A green plant, then, if it has plenty of light, oxygen, and a sufficient supply of water and carbon dioxide, has no need of any food from the outside.

Plants Require Mineral Substances.-In addition to these, however, a plant needs certain other substances. There are certain mineral substances needed to take part in the building of new protoplasm and new cell walls, and for certain other purposes. These minerals are found in the soil, in solution, in the soil water, and are absorbed with the latter by the plant. Most of these necessary mineral substances are present 
in sufficient quantity in ordinary soils, but certain ones are usually rather limited in amount, so that several large crops in succession exhaust the available supply. So it becomes necessary to add these to the soil, or in other words, we have to apply fertilizers. The sub-

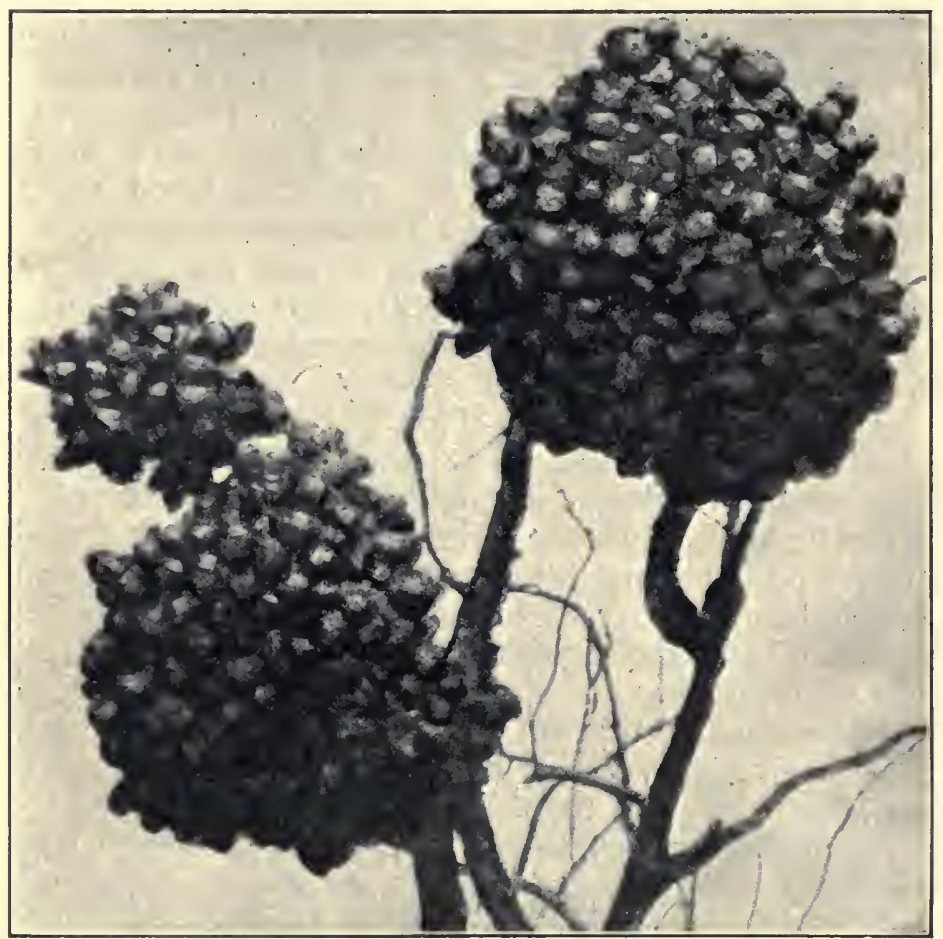

TUBERCLES OF VELVET BEAN PRODUCED BY INOCULATION.

stances most generally applied are potash, phosphoric acid, nitrogen (i. e., ammonia), and, for many soils, lime.

Some Plants Gather Nitrogen from the Air.-Although almost four-fifths of the air is composed of nitrogen, most plants cannot make use of this supply, and would die for want of it unless compounds con- 


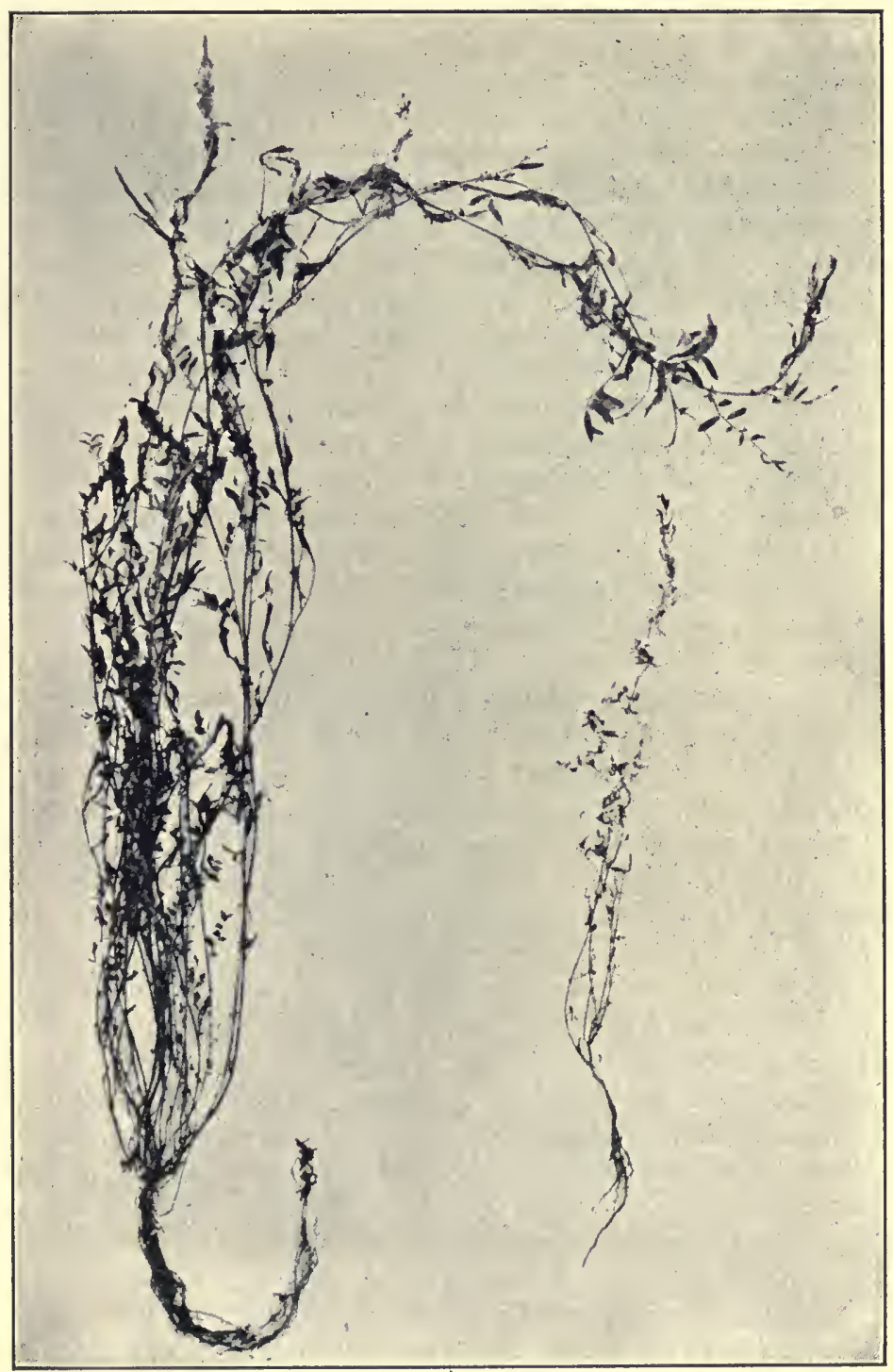

COMPARISON OF VETCH PLANTS GROWN UPON INOCULATED AND UNINOCULATED SOIL. 
taining it were present in the soil. Certain plants (mainly bacteria), have the power of making use of this atmospheric nitrogen. When these plants die their decay adds this nitrogen to the soil's supply. Of greatest benefit to the agriculturist in this connection are the bacteria which form tubercles on the roots of plants of the bean family (legumes), such as bean, pea, clover, alfalfa, cowpea, velvet bean, beggarweed, soy-bean, lespedeza, etc. These bacteria use the nitrogen of the air and then when they die, the plant in which they live uses them to get nitrogen from. Thus plants of this sort instead of reducing the nitrogen supply actually increase it.

Inoculation of the Soil Sometimes Is Necessary.The particular bacterium attaches itself only to the kind of legume to which it is suited. Bacteria accustomed to forming tubercles on cowpea roots will not grow on clover roots. If it is wished to grow cowpeas on soil where there are no suitable bacteria present, it is necessary to inoculate the soil, either by sowing soil from a field that has produced good cowpeas, or, if such cowpea soil cannot be found, by inoculating the seed before sowing with a pure culture of the proper bacteria which have been isolated from cowpea tubercles. Such cultures may be obtained from the U. S. Dept. of Agriculture as well as from various dealers. If the soil is used for inoculating the field, extreme care must be taken that it comes from a field free from any diseases of the crops to be grown subsequently. It is easy to convey various fungus diseases and insect and other pests (e. g., root knot, nematodes, etc.) if soil is taken from fields where such troubles are present. The same conditions as herein mentioned apply to many of the other. legumes.

Plants Use a Large Amount of Water.-Far more water is taken up by the roots than the plant really needs for the manufacture of food. Large quantities, however, are lost by evaporation from the leaves 
and this accounts for the excess absorbed by the roots. During the course of a season, a field of wheat or corn will evaporate from its leaves a great many tons of water, equal to many inches of rainfall.

Roots Absorb Soil Water.-To obtain the necessary supply of water and mineral matter the root system must be rather widely spreading and have a large absorbing surface. If the finer rootlets are carefully removed from the soil and the excess of soil washed off, they will be found to have a short distance back from their tips, bands of fine whitish hairs, one-eighth of an inch, to many times that in length. These socalled root hairs penetrate between, and wind a round, the soil particles, lying in the film of water which surrounds them and absorb the water. Practically all the absorption of water is accomplished by these hairs.

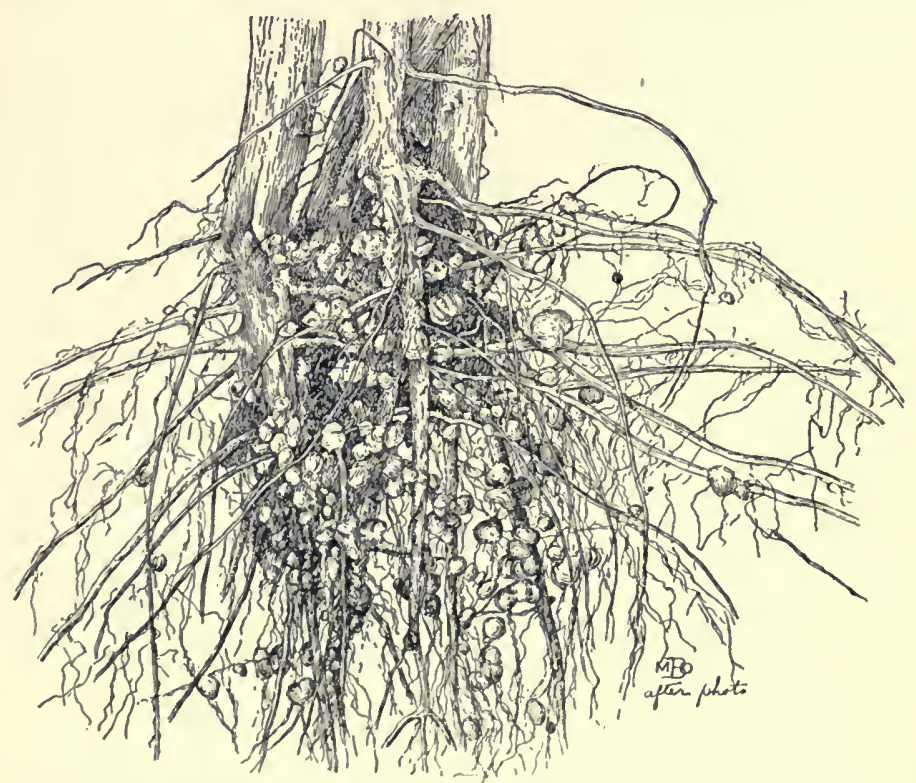

ROOTS OF YELLOW SOY BEAN GROWN ON LAND INOCULATED WITH TUBERCLE-FORMING BACTERIA. 
Roots Should Not Be Disturbed.-If the roots are disturbed these delicate hairs are pulled off or broken so that almost no water can be absorbed until the root has formed new hairs, which may take several hours. So in transplanting plants it is necessary to avoid disturbing the roots more than can be helped, and to remove some of the leaves to check the evaporation surface; otherwise so much water will be lost from the

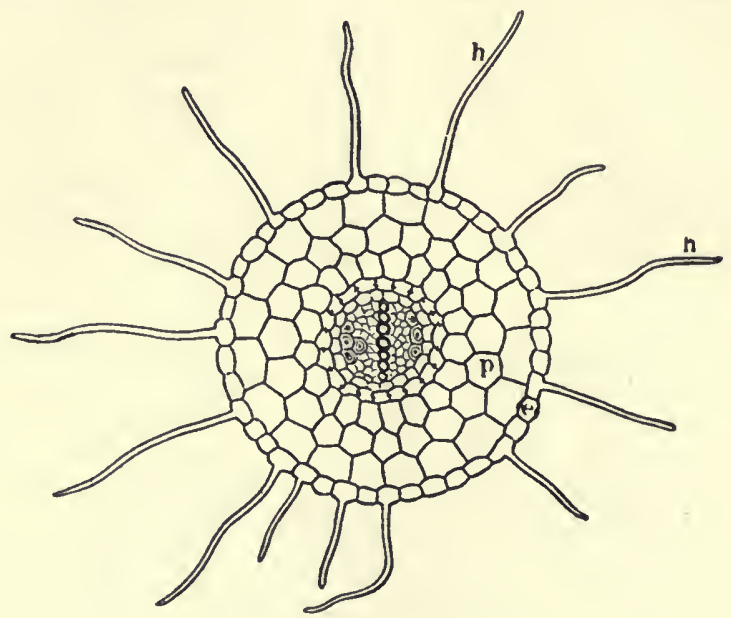

CROSS-SECTION OF ROOT.

leaves by evaporation, before the roots are able to absorb any, that the plant will die.

Roots Search Deep for Food.-In some plants the distance to which the roots will go in search for water and mineral food is marvelous. Alfalfa roots will penetrate many feet downward while the lateral roots of some trees extend a hundred feet or more from the base of the trunk.

Roots Require Oxygen.-Since roots contain many living cells they, too, require air so as to obtain the oxygen necessary for the oxidation of the food. This is obtained from the air present in the soil. If, how- 
ever, the soil instead of being merely good and moist becomes water-logged, so that all the spaces between the soil particles are filled with water, in place of containing some air, the roots begin to suffer because they cannot obtain enough oxygen. The result is that plants not native to such soils die if this condition persists longer than a few days.

How Some Plants Get Air to the Roots.-Certain plants have other contrivances for getting air to the roots and thus can live with their roots in water, or in water-soaked soil. The stems may be hollow and filled with air; the cavities extending down into the roots, or certain roots may grow up into the air as air-absorbing organs, like the cypress knees for example, and the aerating roots of some of the mangroves. It is noteworthy that the cypress does not form knees unless the soil is very wet.

Parasites and Saprophytes.-There are some plants which, like animals, do not manufacture their own food, but have to take what has been prepared by other organisms. Such plants are called parasites if they feed upon living animals or plants, and saprophytes if they live on dead animal or vegetable substances. They are not green and do not need light, although light is not harmful to some of them. If they have any leaves, they are mostly very small and like little scales. Many of these parasites are the cause of great injury to crops and have great economic importance. We need but mention a few of the more common ones: rust of grain; smut of oats, wheat and corn; black heart or wilt of cotton and other crops; leaf blights and spots on the fruits of most of our common fruits; brown rot of peaches; decay of timber; dodder or love vine of clover and alfalfa; etc. These as well as the methods of combating them are discussed more fully in the section on Plant Diseases.

Exercise.-How do plants and animals differ? Why is shade injurious to some plants? Why are trees at the border of a field undesirable? 


\section{Section VII.-Kinds of Plants.}

Number of Plants.-Perhaps between 200,00o and 250,000 different species of plants are already known, and it has been estimated that possibly as many more really exist but are as yet unknown. Of the known plants, about one-half are called seed plants, while the remainder comprise the ferns, mosses, algae, fungi, and bacteria.

Bacteria are perhaps the simplest plants known. They consist usually of but one cell each, or a few
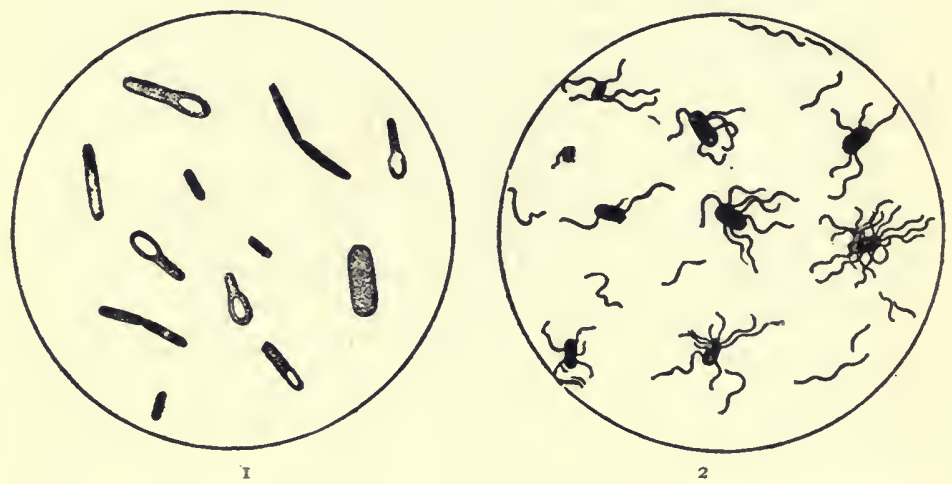

I. Typical rod-shaped bacteria. 2. Bacteria with hair-like appendages which enable them to swim in milk or water.

such loosely connected. They are all microscopic in size, rarely exceeding one five-thousandth of an inch in length and sometimes not one-tenth as large. They are visible to the naked eye only when they occur in immense numbers, as slimy masses. They do not (with few exceptions) make their own food, but are either parasites or saprophytes. They multiply rapidly by. simply growing in length and dividing in the middle. Under favorable conditions, this may occur every twenty minutes, so that in ten hours, if nothing hinders their multiplication, one germ would give rise 
to over one billion germs. Being exceedingly small as well as numerous, they are found almost everywhere; in the soil, water, milk, food, dust and even floating around in the air. While most are harmless yet some cause serious diseases of man and animals, as for example: tuberculosis, typhoid fever, diphtheria, plague, anthrax (charbon), glanders, foul brood of hens and many other troubles. Pear blight, black rot of cabbage and cauliflower, one of the wilt diseases of melons, crown gall and many other plant diseases are alse due to bacteria. Souring of milk is also due to these omnipresent plants. On the other hand, some are of great value to the farmer, in that they add to the nitrogen supply of the soil, or change the substances in the soil into forms more available for the use of crops. Mention has already been made of the bacteria which make the tubercles on the roots of plants of the bean family.

Algae are also low plants but they are higher than bacteria. Like them some algae have but one cell and are microscopic in size, but others have many cells and may attain a length of many feet. They all live in water or in wet places. They contain green coloring matter and are therefore able to manufacture their own food and cannot exist without light. Besides the green color, many have red or brown colors, and are very beautiful. There are many kinds of algae, but few are of much economic importance. Some of the red seaweeds (erroneously called sea-mosses) are edible. The kelps and rockweeds are often thrown upon the beach in immense quantities and are used for fertilizers. The green slimy masses in brooks, ponds, watering troughs, etc., are also algae. While they are harmless, yet they are useless.

Fungi.-To the farmer probably the fungi are of more importance than the algae. They are plants with no leaves, no true stems and no roots. They consist of many microscopic cells festered together in fine white threads which penetrate the substance on which 


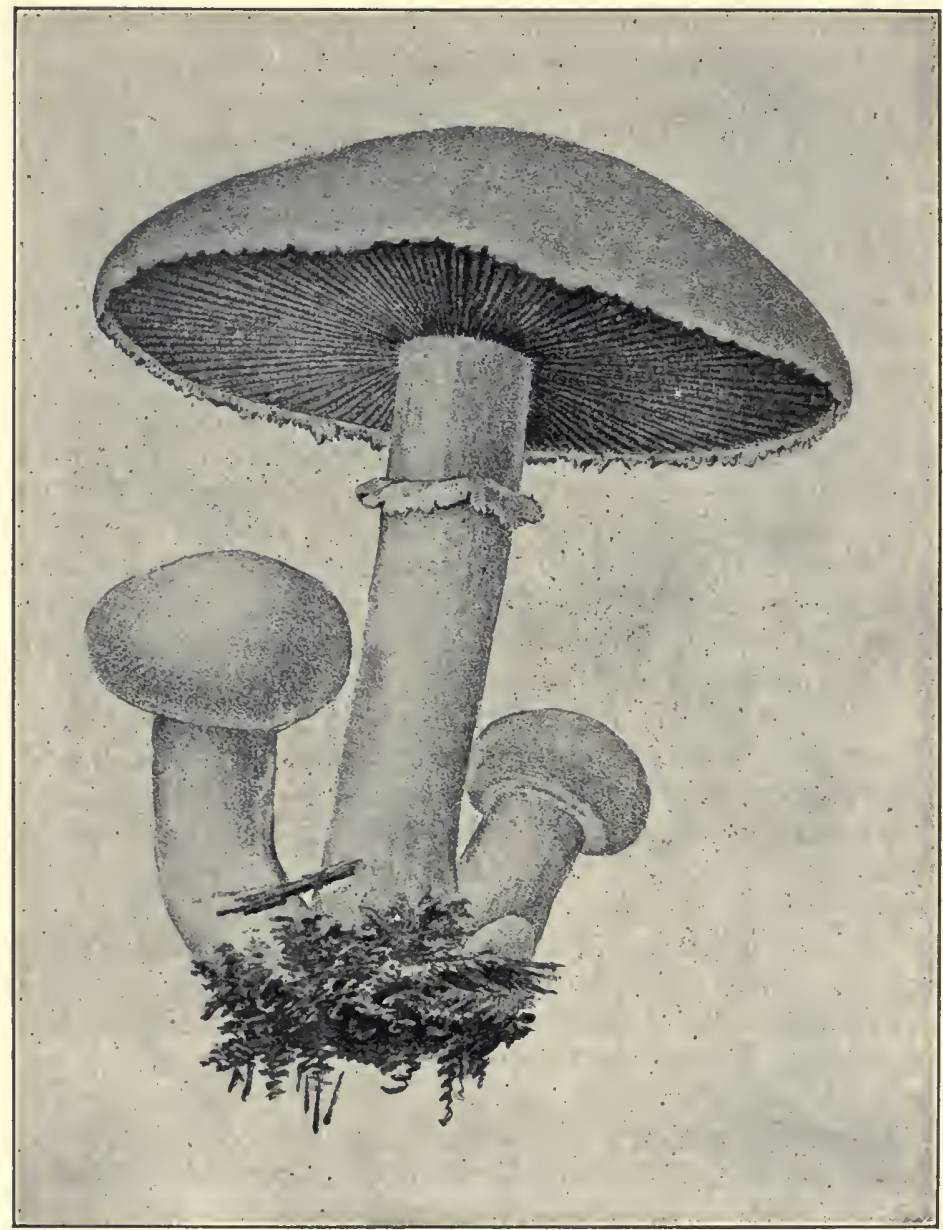

COMMON FIELD MUSHROOM.

they feed, absorbing nourishment from them. They are saprophytes or parasites, i. e., do not make their own food and have no need of light. The plant diseases that cause the most injury to the farmer are due to fungi. The things we call puff balls, toadstools, 
bracket fungi, etc., are the fruiting bodies of some fungi. A few fungi, mainly toadstools and puff balls, are edible and one or two toadstools, e. g., the common mushroom, are cultivated. Let it be noted here that the popular belief that "toadstools are poisonous, mushrooms edible" is erroneous, since a mushroom is a toadstool. Some toadstools are edible, some are poisonous and none should be eaten unless one is absolutely certain that he has one of the edible kinds.

Mosses and Ferns, are green plants and therefore make their own food. They are of little economic interest aside from their ornamental value. They are mostly small, but in the tropics some ferns attain the dimensions of trees.

Spores.-In all the foregoing plants no real seeds are formed. In most of them the new plants arise from the growth of small bodies consisting of but a single cell and called spores.

Seeds.-In the seed plants we find a great advance in that true seeds are formed. A seed instead of consisting of a microscopically small spore, is visible without magnification, and is made up of a great many cells. It is, in fact, a small plant which after attaining a certain size has stopped growing and become surrounded by a protection layer, the seed coat. This little plant remains in this condition of suspended growth until placed in a favorable location when it absorbs water and starts its growth anew.

Seed Plants.-With the exception of mushrooms, which are fungi, and ferns, all of the plants commonly cultivated for profit or ornament are seed plants. This is also true of the plants of the forests and jungles which furnish us with their valuable products. In view, therefore, of their so great importance the remainder of this chapter is confined to a discussion of seed plants.

ExERCISE.-Find and bring to the class specimens of as many different kinds of plants as you can and which are not seed plants. 
Section VIII.-Parts and Structure of Seed Plants.

Parts of Seed Plants.-The main parts of such a plant in the vegetative condition are root, stem and leaves. The seeds come from the flowers which do not appear until the plant has reached a certain stage of development.

Function of the Root.-The root has two main func-

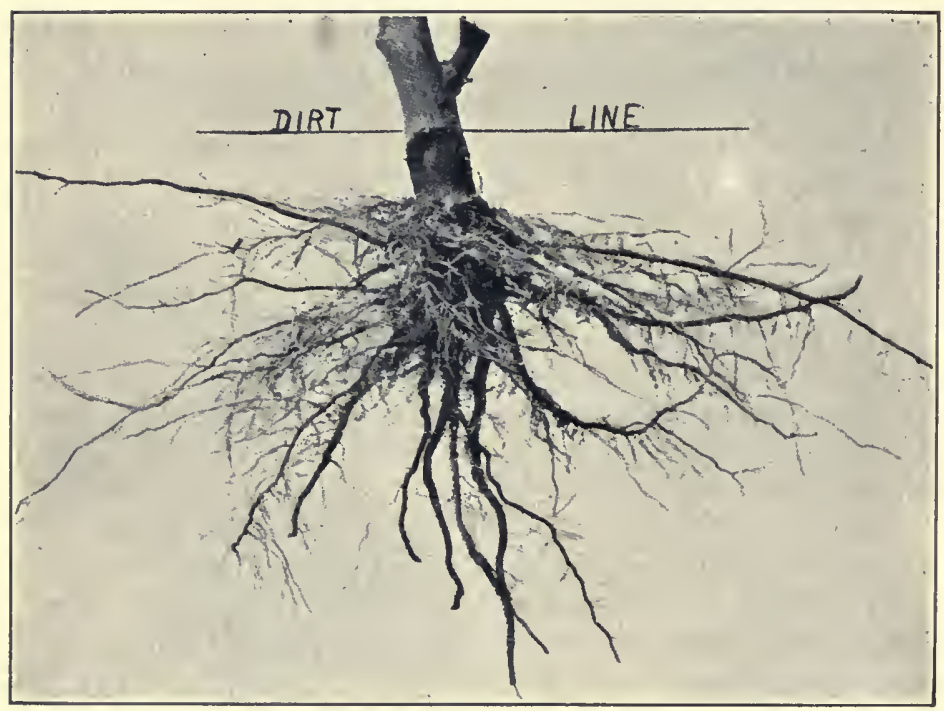

ROOT SYSTEM OF A TOBACCO PLANT.

tions, to hold the plant firmly in place and to absorb the necessary water and dissolved mineral matters from the soil. Some roots perform only one or the other function, but in most plants they perform both. In addition some roots like those at the base of corn and some other plants come out at some distance above the ground and act as braces. In many plants the first root of the seedling continues to grow and is the largest and most important root, namely the tap root. 
On the other hand in many plants lateral roots become of more importance than the tap root, and this dies early. Plants of the latter kind are perhaps usually less deeply rooted and therefore more easily transplanted than those with a tap root. In addition to the functions mentioned above many roots serve as special organs for storing food. Examples are sweet potatoes, cassava (tapioca or manioc plant), carrot, beet, etc.

The Leaves are the factories for the production of the plant's food. In some plants, as for example most cacti, there are no leaves and their function is assumed by the green stem which may be flattened to resemble a leaf somewhat. Some plants hold their leaves only during the growing season and are called deciduous, while others retain them

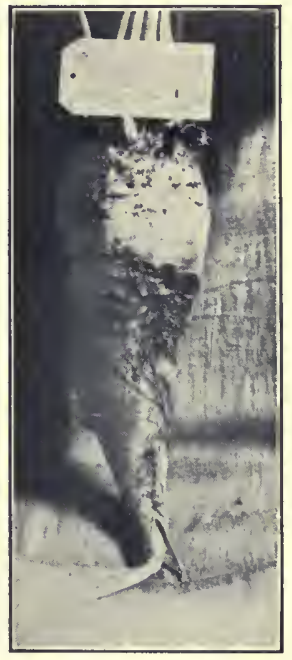

BEET ROOT. at least until the next season's leaves have appeared, often for several years, and are called evergreen. In the temperate zones it is mostly the needle-leaved trees (pines, spruces, cedars, etc.), that are evergreen, while most of the broad-leaved trees, except a few like holly and live oak, are deciduous.

Parts of the Leaf.-Leaves consist usually of a flattened blade strengthened by the so-called nerves or veins which also carry water to all parts of the leaf, and of a stalk, called the petiole. Often there are two little more or less leaf-like bodies attached at the base of the petiole, called stipules. A complete leaf is therefore said to consist of blade, petiole and stipules, but many leaves may lack one or both of the last two. The blade may be in one piece or may be lobed or divided into several parts called leaflets, as for example the three leaflets of a clover or oxalic leaf, or the 
many leaflets of the leaf of locust, walnut, chinaberry, etc.

The Bud.-In many plants we find the leaves coming out of buds when they start out in the spring. A bud contains the young leaves, tightly wrapped and folded, and may be surrounded for protection by thick or thin scales, which are themselves only modified leaves.

Kinds of Stems.-The stem may be short, as in those plants whose leaves form a cluster at the surface of the ground or may be much elongated, as in the big trees of California attaining a height of about 400 feet. Although the usual habit of a stem appears to be upright growth, yet there are many exceptions. They may twine around other objects for support, as in the hop or morning glory, or trail on the ground. Some plants, like the strawberry, may send out stems along the surface of the ground which take root here and there, forming clusters of leaves at those points; these eventually becoming new plants. Such stems are called runners. In some plants stems are produced in a similar way but entirely underground, coming to the surface at intervals and producing new plants. Such stolons are produced by Bermuda and Johnson grass, Solomon's seal, golden rod and many other plants. When an underground stem becomes enlarged to store up food it is called a tuber. The most familiar example is the Irish potato. Tubers can be distinguished from enlarged roots by the presence of buds (or eyes) and leaves (usually reduced to small scales, or entirely lacking). Both of these are lacking on true roots.

Structure of Stems.-On cutting a stem across it is found usually to have the following structure. At the outside is a thicker or thinner layer, the bark or cortex, the outer part of which may be alive or may be made up of a thick layer of dead cork cells. Inside the bark is the woody portion and in the center is the pith. Between the wood and the bark is a thin layer 
of cells called cambium. It is this that is broken when the bark is lifted in budding. The cambium is lacking in palms and those other plants where there is no distinction of cortex and woody portion. Sometimes the wood is represented only by a few fibrous strands arranged in a circle in the outer part of the pith next to the cortex. These strands serve two purposes;

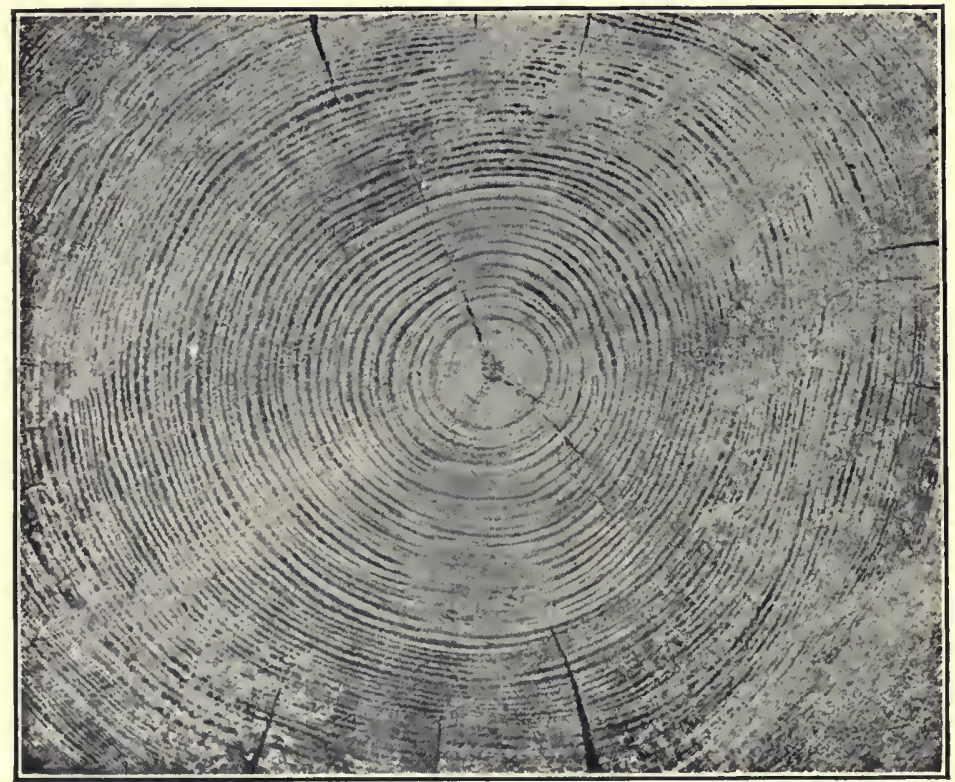

SHOWING GROWTH OF TREES.

they act as a skeleton to support the plant and as a water conducting system, for it is through them that the water ascends from the roots. In those plants that live several years, such as trees and shrubs, these fibrous strands increase in number and size, and the spaces between become filled with wood fibers so that all the space within the bark is a solid mass of wood. This grows in thickness, by the layer of cambium next to it turning to wood, while the cambium layer next 
to the bark adds to the bark on the inside. Each period of growth of wood is marked as a ring, so that in the temperate climates where the growth periods are annual, the age of a tree can be quite accurately determined by counting the rings in the cross section of the trunk near the ground.

Parts of Stcms.-A stem may be unbranched, as in most palms, but usually is branched. At the end of each branch is the growing point. This produces as it grows, little projections on its sides which become the leaves. At the point where a leaf joins the stem, a bud is usually produced. It is by the growth of such buds that branching of the stem occurs. Often they do not grow unless the terminal bud is injured, in which case they push out.

ExERCISE.-Bring in seed plants showing different kinds of roots. Find as many different kinds of stems as possible. Bring in specimens of leaves that are complete and that have certain parts lacking.

\section{Section IX.-Reproduction of Plants.}

Flozvers. - When the plant has reached the proper stage of development it prepares for seed production. With the exception of the plants classed as Gymnosperms, which will be mentioned further on, this takes place in special organs called flowers.

Stamens and Pistils.-The essential parts of flowers are two; stamens and pistils. In the stamen is produced the pollen, a dust like usually yellowish powder (more rarely a sticky mass of fine grain). This must be brought in some way to the top of the pistil, where each grain of pollen grows out into a microscopic tube which bores its way down inside of the pistil, until it reaches the minute bodies called ovules that are to become the seeds. Entering one of these, the contents of the pollen tube unite with its contents, and as a result of the union a new plant begins to grow. This attains a certain size and then stops its growth, be- 
comes filled with or surrounded by food, is provided with a protection coat and is called a seed. In probably the majority of cases several stamens, and one or sometimes more pistils, occur in the same flower, yet it often happens that they occur in separate flowers

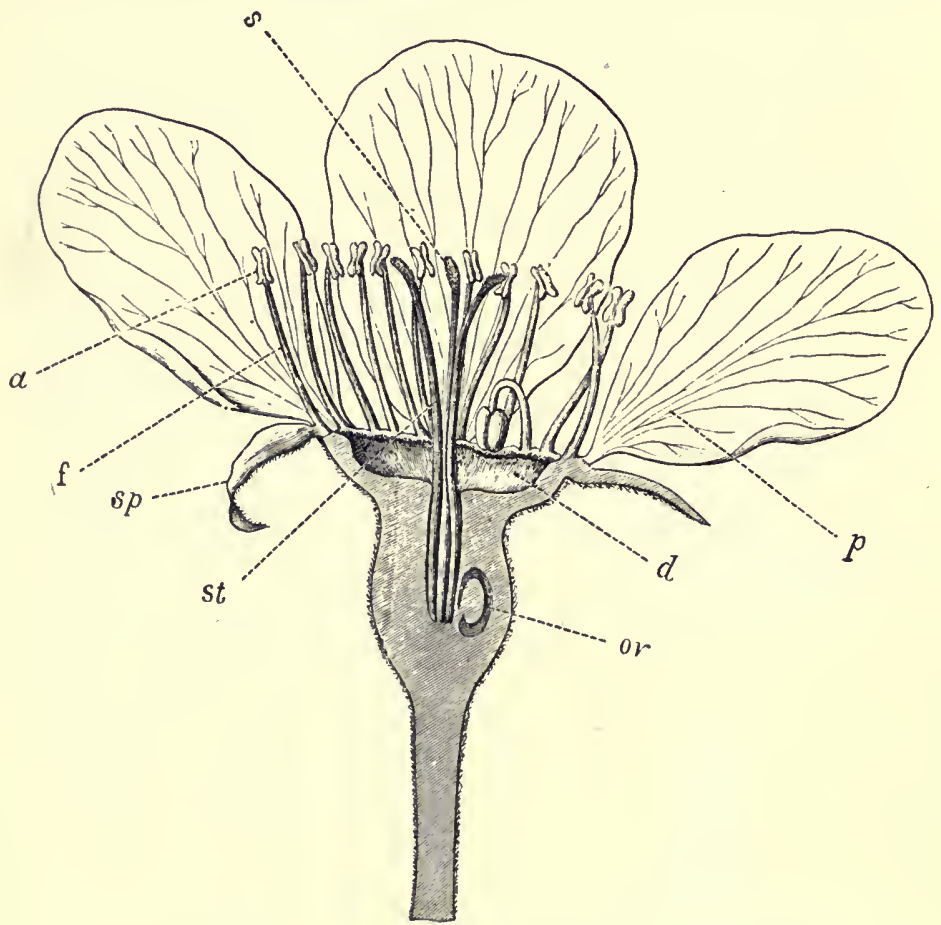

ENLARGED SECTION OF A BARTLETT PEAR FLOWER.

st, style; $s p$, sepal; $f$, filament; $a$, anther; $s$, stigma; $p$, petal; $d$, dish; ov, ovule.

on the same plant as in corn, or even on separate plants, as in hops, willow, date palms, Canada thistle, etc.

Parts of the Pistil.-The pistil consists of a basal, enlarged portion, called the ovary, within which the seeds are developed, and a receptive portion called the 
stigma, which the pollen must reach in order to fertilize the bodies (called ovules), which become seeds. There may be or not, depending upon the plant, a longer or shorter piece called the style between the stigma and ovary. In the young ear of corn the young grain is the ovary, the silk being the style out to the feathery part which is the stigma.

Parts of the Stamen.-The stamens consist of two (or four) little elongated-usually yellow-bags or boxes, in which the pollen is produced, and of a stalk supporting them. These parts are called respectively anthers and filament.

Petals and Sepals.-In addition to stamens and pistils most flowers have one or two sets of somewhat leaflike organs, those next to the stamens usually being colored, the petals, while the outside set is mostly green, the sepals. The petals considered together are called the corolla and the sepals together the calyx. The whole flower is borne on a longer or shorter stalk, or this may be wanting.

$V$ ariation in Arrangement.-This general scheme of the flower, i. e., beginning at the outside, sepals,

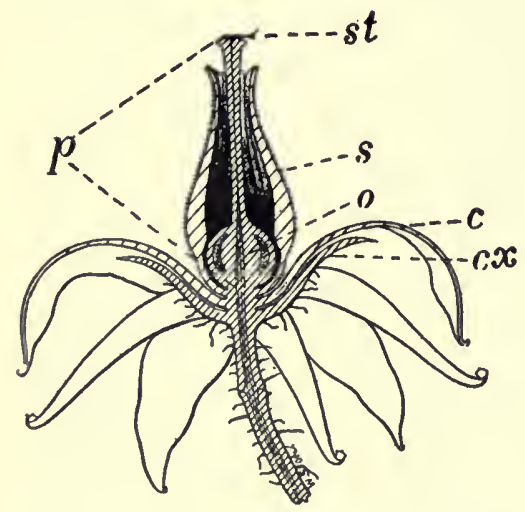

SECTION OF A TOMATO FLOWER.

$c x$, calyx; $c$, corolla; s, stamens; $p$, pistil; o, ovary; st, stigma. petals, stamens and pistil, exhibits endless variation. The sepals, petals and stamens may become united to each other, each in its own series, or the stamens may be united to the petals and appear to arise from them. The axis of the flower may be widened where the calyx, corolla and stamens join it, leaving the pistil sitting as it were in the middle of 
a disk at whose edges are the stamens, petals and sepals. This widened disk-like portion may turn up and surround the pistil so that the other organs are borne above the ovary instead of below it. The flower instead of being symmetrical may be one sided. The members of each part are also subject to modification and any of the parts may be lacking, although of course stamens and pistils are not both absent in the same flower.

Fertilization.-Many flowers secrete nectar, a sugary liquid, which is eagerly sought by insects. Many of the modifications suggested above are to attract insects (or humming birds) to the flowers and to cause them to come in contact with the stamens and pistils in their attempts to obtain the nectar. In this way pollen is carried from one flower to another and fertilization is made more certain. As a general rule, which has, however, many exceptions, we can safely say that showy flowers, as well as inconspicuous

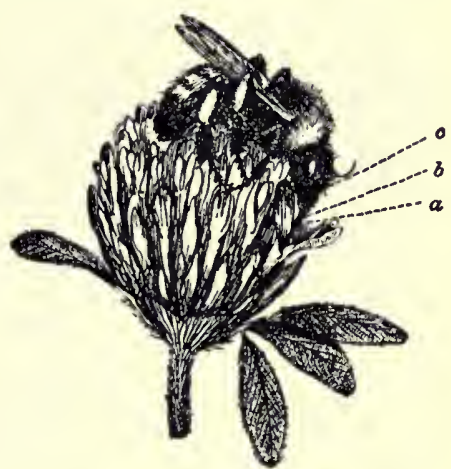

BUMBLE-BEE POLLINATING RED CLOVER.

$a$, stamens; $b$, proboscis of bee; $c$, where bee receives pollen. ones, which produce an abundance of perfume or honey, are usually pollinated by the aid of insects or birds, while those that are not so, are wind pollinated, i. e., the pollen is fine and produced in great abundance and floats in the air, some of it eventually, by chance, falling on the stigma of flowers of the same kind. Most grasses (e. g., corn), many of the trees such as oaks, willows, pines, etc., are wind pollinated.

Close Fertilization.-In a number of cases the pollen is set free from the stamen before the flower opens 
and the pistil is thus fertilized by pollen from the same flower, i. e., is close-fertilized or self-pollinated. This is generally the case with wheat, oats, peas and many other plants. Mostly, however, the pollen is not set free till the flower opens. Frequently, perhaps, in the majority of cases the stigma is not ready to receive pollen at the same time that the pollen in that flower is being shed, so that self-pollination is avoided.

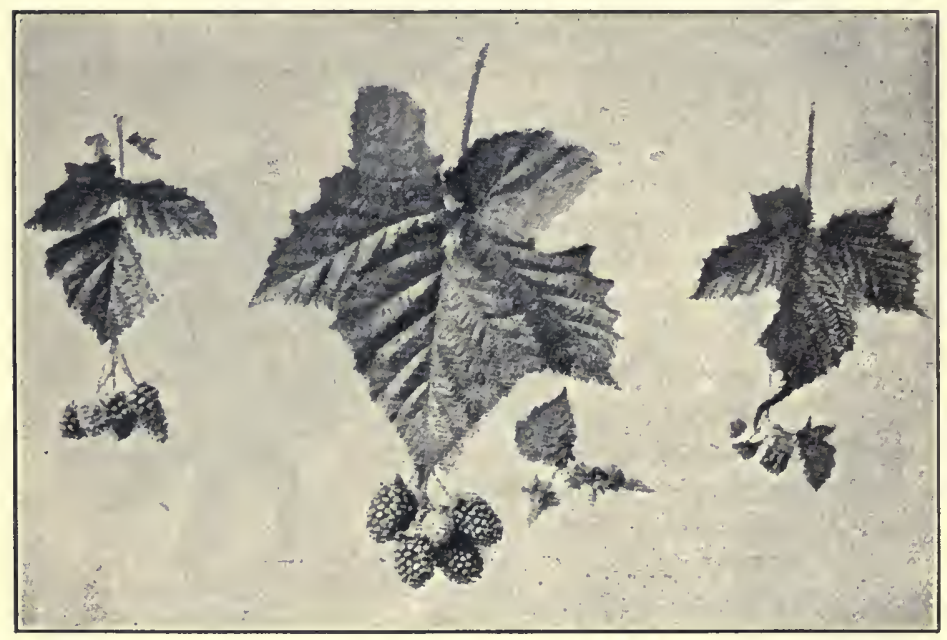

RASPBERRY-BLACKBERRY HYBRID “PRIMUS" AND PARENTS.

California dewberry; female parent; Siberian raspberry, male parent.

Some plants, indeed, are sterile to their own pollen and require pollen from a different plant of the same kind. Such plants of course are especially dependent upon insects. Some varieties of pears and other fruits which are propagated by budding or grafting, are sterile to pollen from the same variety, so that plants of other varieties of the same fruit have to be set among them to insure fruitfulness.

Hybridization.-Ordinarily, in the natural course of events, it is only when pollen of the same species of plant reaches the stigmas that seed formation oc- 
curs. However, it is known that often pollen of a closely related kind of plant is able to cause fertilization and produce seeds capable of germination. This is called hybridization. The plants growing from these seeds usually show more or less of a blending of the character of the two parents, or some characters of the one and some of the other. Many such hybrids occur in nature, but more are known as the result of human effort.

Fruit and Seed Distribution.-After pollination, when the seeds begin to grow there begins the formation of what is termed, botanically, a fruit. Used in this sense a fruit is any structure, whether edible or inedible, fleshly or dry, that is produced to accompany or enclose the seeds. Usually the corolla falls off and often the calyx as well. In the simplest fruits the ovary simply enlarges and forms a sort of pod which becomes dry as the seeds ripen and splits open to let them escape. Examples are the bolls of cotton, pods of beans, peas, mustard, etc. In other cases the outer part of the ovary becomes fleshy and edible with the result that it is sought after by animals for food, the seeds being carried thus to various distances. Cherries, plums, etc., a re good examples of this class. The calyx, too, may become fleshy or the flower stalk or the flower axis. The latter is the case in the strawberry. The ovary, or the parts outside of it, may develop hooks to catch in animals' hair to aid in distribution, or the calyx may have a downy structure for wind conveyance as in the thistle or dandelion. The seeds often have various devices to aid in distribution by wind, water or animals. A few fruits explode throwing the seeds out to a great distance.

Kinds of Seed Plants.-There are two great subdivisions of seed plants; the flowering plants with real flowers, with the seed produced inside of the ovary and the Gymnosperms where no true flowers occur, with the seed produced on open scales. Usually these scales are bunched together into a dry or fleshy cone. 
The pollen is produced in stamens also arranged in a cone. Examples are pine; spruce, cedar, cypress, juniper, etc. The needle-leaved trees and some others belong to this group.

Kinds of Flowering Plants.-The true flowering plants are again divided, the one class possessing seeds with but one seed leaf and with the parts of the flowers mostly in threes, the other with two seed leaves and the parts of the flowers mostly in fives. The first class has its leaves with the veins mostly all parallel, while in the second class the veins are mostly net-like or diverging. In the trees belonging to the first group the trunk does not regularly increase in thickness as it gets older, while in the second class the wood increases in thickness each year by the so-called annual rings. All the grasses, palms, lilies, orchids, etc., belong to the first group, while to the second belong most of the remaining cultivated plants; e. g., fruits such as apple, pear, peach, orange, persimmon; most of the vegetables, as beet, potato (sweet and Irish), turnip, cabbage, artichoke, carrot, etc., the various nuts, and practically all timber trees except the needle-leaved ones.

Stages of Plant Development.-In the development of a plant from the seed we can distinguish several stages. Usually three are considered, viz., germination, growth and maturity. In reality the one grades into the other, by such gradual degrees, that the distinctions are mostly somewhat artificial. Growth may occur in all three stages, and is always present in the first two. As was pointed out a seed is simply a young plant, with development arrested, surrounded by or containing sufficient food to give it a start, until it is far enough developed to manufacture enough food to supply its own needs.

Parts of a Seed.- In a ripe seed we can distinguish within the seed coat the young plant, of ten called the embryo, it being often surrounded by a layer of cells serving to feed it when it grows, the endosperm. In 
the embryo itself we can usually distinguish one or two seed leaves, the beginnings of the next leaves (plumule), and the radicle (the part that forms the stem below the seed leaves and the roots).

Germination.- When the seed is placed where the conditions of warmth and moisture are favorable it absorbs water, swells and often bursts its coat. The radicle emerges and turns downward. The seed-leaves may either remain underground in the old seed coat while the

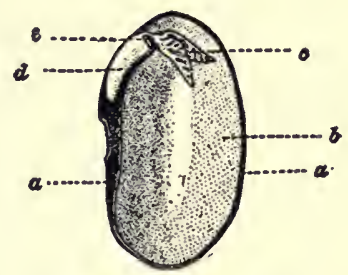

SEED OF BEAN.

$a$, seed coat; $b$, cotyledon; $c$, plumule; $d$, radicle; $e$, scar left by removal of cotyledon. plumule pulls out and pushes up to the air as in the pea, or the whole seed may emerge from the ground, the seed-leaves opening out and turning green and beginning to manufacture food as in the bean, cucumber, cotton, etc. The first few leaves after the seed-leaves are in nearly all cases less complex than the latter ones. Thus the clover leaf that follows the seed-leaves has but one leaflet instead of three.

Length of Life.-After a certain length of time we find that the production of flowers begins. For many plants this terminates the period of growth, death ensuing after the seeds are ripened, but for many others the plant continues to grow, producing flowers and seeds at yearly intervals. From germination of seed until death of the mature plant, may be only six weeks for some desert plants, while many trees do not begin to flower until many years old and live hundreds of years.

Reproduction of Plants.-As a rule most plants are not solely dependent upon seed production for their reproduction, or at least other methods of multiplication can be applied even when they do not occur naturally. Thus some plants give rise to new ones at various points on their roots as in the suckers of plums, others have root-stalks (underground stems), which 
emerge at various distances from the parent plant and produce new plants. Tubers are swollen, food-stuffed underground stems for reproduction purposes. Some plants take root at the ends of long recurring stems, as in black raspberries. Bulbs are formed by many plants both below and above ground, as in the onion. But in addition to their natural means, many plants will take root and grow when their stems are placed in moist soil or in water. These are called cuttings. Others take root when the stem is laid down and covered at one point with earth, layering, as it is called. A few plants like some begonias, form new plants if a single leaf is placed on wet sand. Some roots can be treated as cuttings, e. g., horseradish, while in other plants the crown of the plant with attached roots can be separated into many parts, each capable of becoming a new plant, as in the violet.

Grafting is the process of inserting a portion of a stem (with at least one bud) of one plant, into the stem or root of another plant, in such a way that the parts unite completely, and growth of the inserted portion ensues. The part inserted is called the cion, the other the stock.

Budding is simply a form of grafting in which the cion consists of a small piece of the bark containing one bud. This is slipped into a slit in the bark of the stock, in such a way that the bark laps over the bark of the cion, leaving only the bud and a small piece of bark exposed. The growth resulting from any of the buds of a cion is like the tree from which the cion came. Then it is possible to propagate a good sort of fruit, and be sure that the trees obtained will be of the kind desired. The same is true of cuttings, layerings and other methods of propagation mentioned above.

Stocks Used for Grafting.-In grafting, as a general rule, seedlings of the same species of plant are used for stocks. Sometimes closely related species are used, as quince stocks for pear cions to produce dwarf 
ing of the latter, American grape stocks for the European grape to avoid the ravages of the insect called Phylloxera, which kills the roots of the latter but injures those of the former only a little. Grafting is not successful except when cion and stock come from closely related plants.

EXERCISE.-Examine flowers of wild rose, bean, mustard, Irish potato, sunflower, or aster, lily, corn and canna and find the different parts, noting their number and arrangement. How many kinds of fruits (speaking botanically) can you find?

\section{Section X.-Plant Breeding.}

In the various forms of grafting and other methods of propagation mentioned the operator makes use of sorts of plants already existent. But it is possible to make use of methods by which improved sorts a re produced. These can then be perpetuated by grafting or other means. This production of new sorts is called Plant Breeding.

Seed Selection.-The simplest form of this is seed selection. It is based upon the fact that plants rarely come absolutely "true to seed." In other words all plants grown from seeds vary some from each other and from the parent plant. In the case of the ordinary fruits this is very noticeable, while in some plants that are ordinarily grown from seed the variation is slight, but even there it exists. Seed selection consists simply in saving the seed of those few plants out of hundreds or thousands grown which seem to show the most desirable characteristics.

Methods of Seed Selection.-For the farmer the production of new sorts is perhaps out of the question, but he can use this method to improve the yield and quality of his main crops with but a few hours extra work each year. Shortly before the seed is ripe he goes over his field and picks out a number of plants that seem to him to come nearest to his ideal of what 
that plant should be, paying attention to vigor, shape, productiveness, earliness, etc., of the plant as well as the special features of the parts for which the plant is grown (e. g., grain, fiber, fruit, etc.). These plants are marked and when the seed is ready for gathering they are taken by themselves and the seed saved for next year's planting. Enough may be taken in some crops to plant all of the next crop, but with some only enough can be selected in this way to plant in a plot by itself, all the seed from this plot being used the following year. If possible the seed of each selected plant should be kept by itself and a certain number

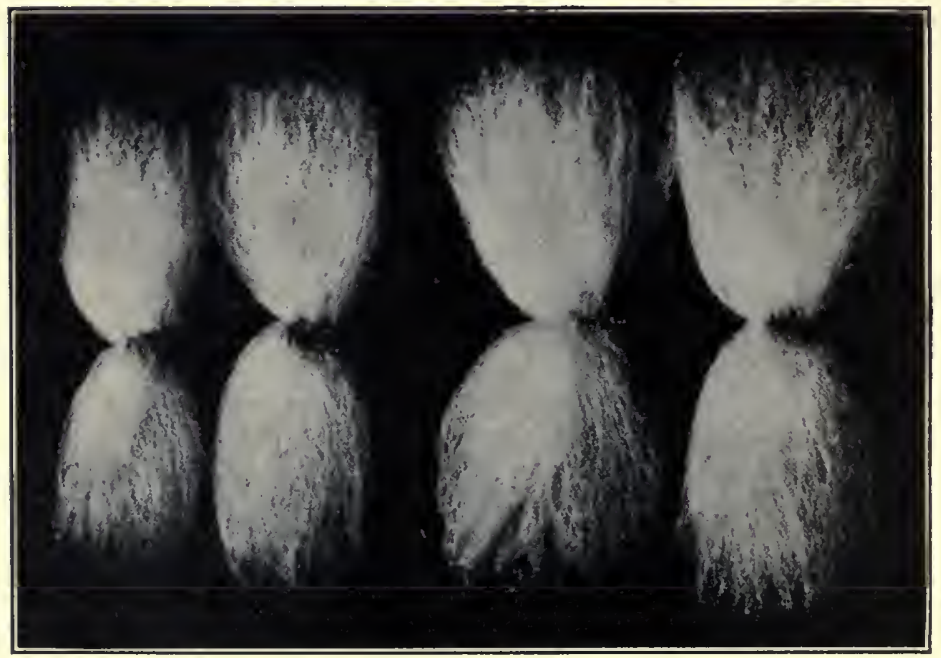

COTTON, SHOWING IMPROVEMENT PRODUCED IN LENGTH AND QUANTITY OF FIBER BY THREE YEARS OF SELECTION.

from each lot tested as to its power of germination. That lot or those lots only should be saved that show a high rate of germination. The lighter seeds should be discarded as the best plants are produced by the heavier seeds. One step further in advance consists in roguing the fields. This means to go over the 
field just before the flowers are opening and remove all plants that are very poor, or that deviate too far from the ideal, so that their pollen may not reach the pistils of the remaining plants and cause their bad

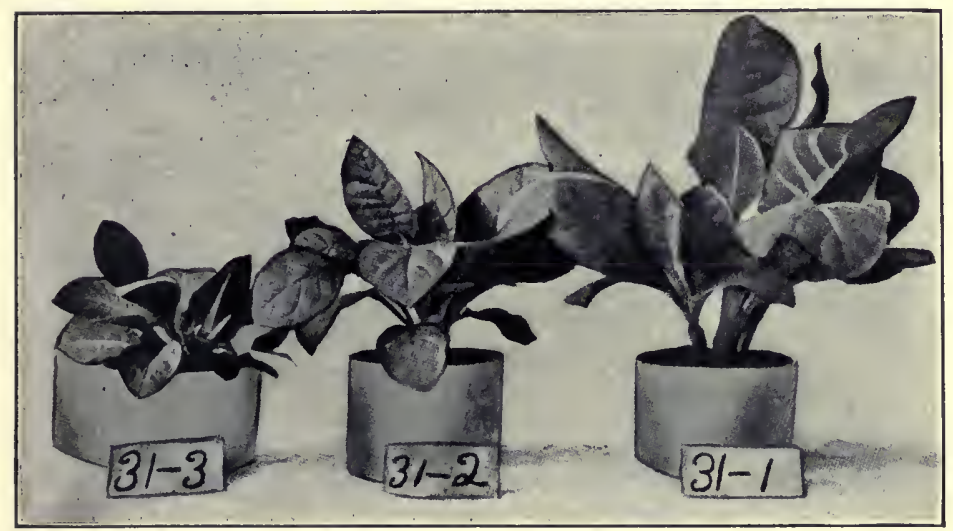

TOBACCO SEEDLINGS FROM Light (3I-3), MEDIUM (3I-2), AND HEAVY (3I-I) GRADES OF SEED.

character to be given to the next generation. Of course this is unnecessary in those plants when the flowers are self-pollinated.

Improvement by Artificial Cross-Pollination.-By seed selection only those characters can be chosen that happen to appear as natural variations among the plants grown. We possess the power, however, by artificial cross-pollination, of combining the desirable characters of different plants. Of course this method is limited by the fact already mentioned that only very closely related plants can be crossed successfully, but it is readily applicable to different varieties of the same species of plant, as for example various sorts of cotton, wheat, corn, etc.

Examples of Artificial Cross-Pollination.-A few examples will show what can be accomplished. The common sweet orange is killed by cold only a few de- 


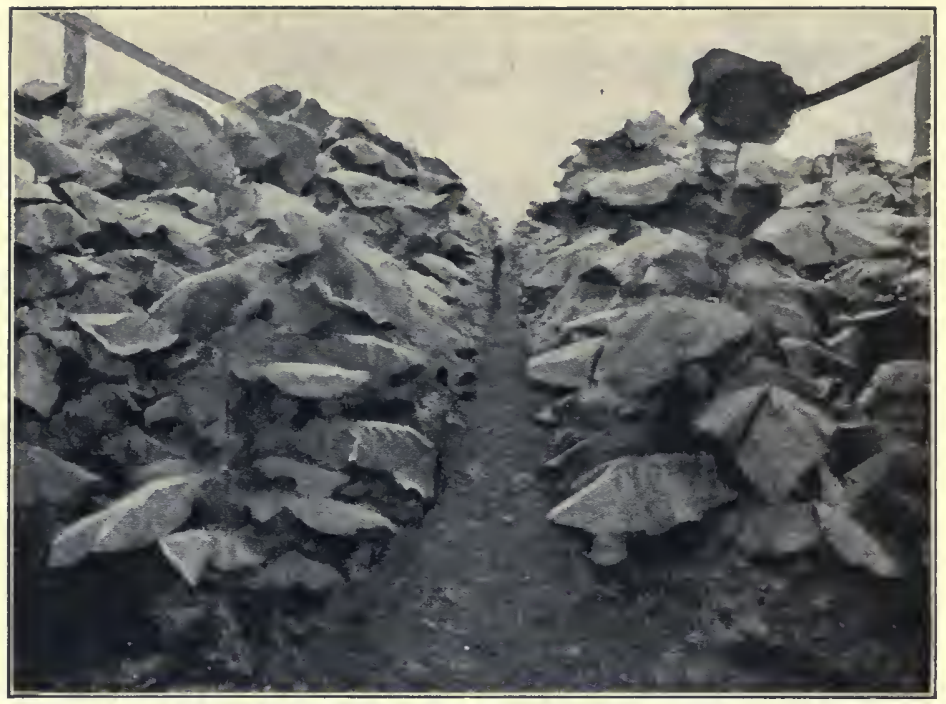

TOBACCO, SHOWING UNIFORMITY OF TYPE SECURED BY SEED SELECTION.

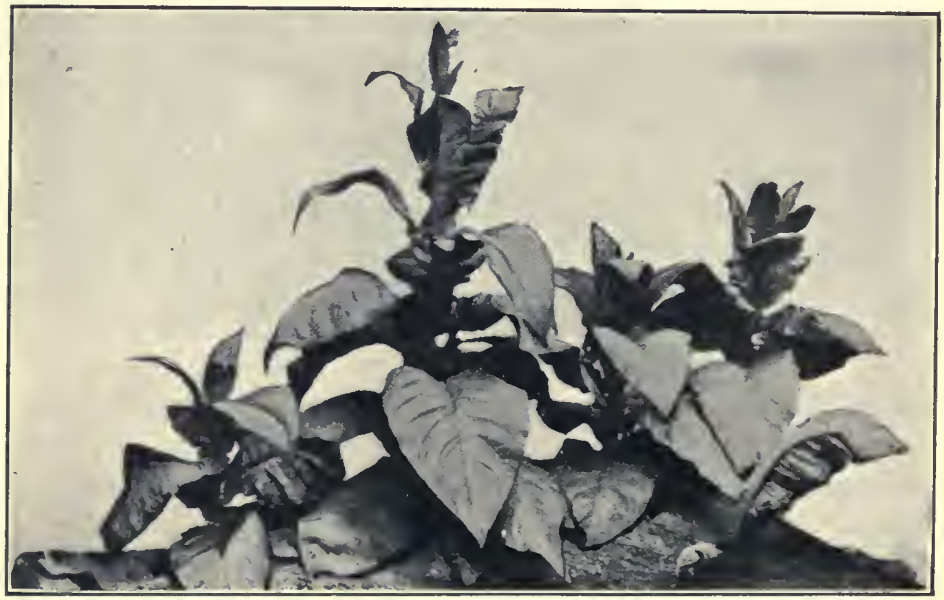

PLANTS SHOWING LACK OF UNIFORMITY OF TYPE FROM NEGLECT OF SEED SELECTION. 
grees below freezing, while the trifoliate orange endures a temperature down to zero or colder. The fruit of the latter is, however, practically inedible. The U. S. Dept. of Agriculture succeeded in crossing the trifoliate and the sweet orange, obtaining a number of seeds. Of the plants obtained from these seeds many were'worthless but some bore edible fruits, not so good as the sweet orange it is true, but far superior to the fruit of the trifoliate orange. Furthermore, they are capable of enduring considerable cold, thus enabling farmers to grow a kind of orange far north of the orange belt. The watermelon is subject to a disease which spreads through the soil and entering the roots causes the plant to die by choking up the water-conveying vessels, whence the name "wilt" is applied to the disease. The inedible stock melon or citron is not subject to the disease. By crossing the latter on a choice variety of watermelon, and selecting and inbreeding for several generations those of the progeny that possessed the right color, shape, vigor, abundance of melon and resistance to the disease have been produced. By crossing the slow-growing black walnut with the Japanese walnut, Luther Burbank of California has produced a variety of walnut very rapid in its growth, and yet possessing wood of an excellent quality.

Methods of Hybridization.-The methods used are essentially as follows: For the two parents are chosen closely related species, or plants of different varieties of the same species, each possessing certain characteristics which it is desired to combine in the new variety sought. One is chosen to bear the seed and one to furnish the pollen. Some flowers of the former are selected shortly before they are ready to open, and the petals are removed with scissors or pried apart and the yet unopened stamens removed, disturbing the flower as little as possible. This is to prevent any chance of self-pollination. These flowers are then enclosed in paper bags so as to prevent the access of 
insects which might bring pollen. When the stigma has become receptive, the bag is removed and pollen applied from ripe stamens taken from the plant chosen
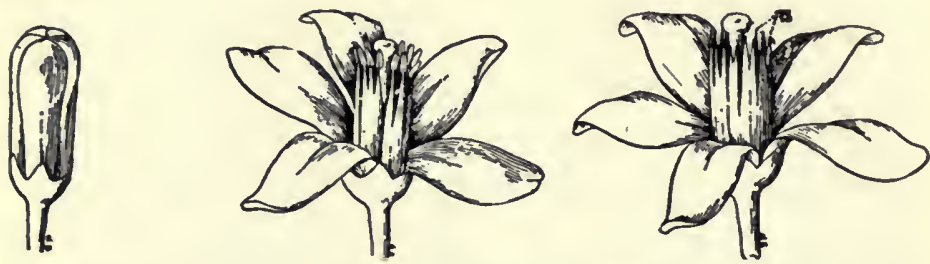

ORANGE FLOWER BUD; MATURE ORANGE FLOWER; AN EMASCULATED ORANGE FLOWER.

$a-$ shows where anthers were detached.

to be the other parent. The bag is again replaced until development has proceeded so far that the stigma is no longer receptive. If the two parents are closely enough related seeds will be formed. The plants arising from these may resemble either parent or may be intermediate. If they possess the characteristics sought for and are capable of being propagated by grafting or cuttings, etc., this can be done and the work is accomplished. However, if they are of a sort propagated by seed they are allowed to flower and produce seed, of course excluding accidental pollination from outside.

$V$ ariation in the Second Generation.-The plants of the second generation are usually very variable, showing all sorts of combinations of the various characters of the parents, or they may resemble one or the other of them. Those which show the desired combination of characters are self-pollinated and their seed sown again. Usually in the course of a few generations, the race becomes fixed and the characters permanent so long as pollination by some other variety is prevented.

EXERCISE.-How would you improve the yield of corn on your farm? How would you test the germinating power of seeds? 


\section{REFERENCES FOR COLLATERAL READING.}

\section{Plant Life.}

Yearbooks of the U. S. Dept. of Agriculture:

1896 -The superior value of large heavy seed.

$1897-$ Hybrids and their utilization in plant breeding.

1898-Pollination of pomaceous fruits.

I898-Improvement of plants by selection.

1899-Progress of plant breeding in the United States.

Bureau of Plant Industry, U. S. Dept. of Agriculture, Bulletin Nos.:

58-The vitality and germination of seeds.

78 -Improving the quality of wheat.

96-Tobacco breeding.

Division of Vegetable Physiology and Pathology, U. S. Dept. of Agriculture, Bulletin No.:

29-Plant breeding.

Farmers' Bulletin, No.:

I57-The propagation of plants.

Experiment Station Bulletin, No.:

251-Cornell-Plant breeding for farmers.

Books :

Plant Breeding-Bailey-Macmillan Co., New York City.

The Essentials of Botany-Bessey-Henry Holt \& Co., New York City. 


\section{H A P T E R I I I.}

\section{MANURES AND FERTILIZING MATERIALS.}

By Prof. J. E. Halligan,

Chemist in Charge, Louisiana State Experiment Station.

\section{Section XI.-Farm Manures.}

There are two kinds of manures, natural manures and artificial manures or commercial fertilizers.

Natural Manures.-Under this head come those fertilizing materials which are not manufactured, but occur naturally. Farm manure, marl, wood ashes, muck, and gypsum are natural manures.

Farm Manure.-This fertilizer is of a variable composition, the texture or the coarseness of which depends upon the kind and amount of bedding used. Farm manure is of two kinds: stable manure and barnyard manure. Manure which is collected or accumulated in stables and which contains all the excrements is called stable manure. This manure is protected from the rain and the sun, and is free from losses of fertilizer ingredients. Sufficient bedding is supplied to absorb all the liquid portion of such a manure. Manure which is allowed to be exposed to the action of the rain and the sun is called barnyard manure. This manure collects around barnyards and may consist of pure excrements, or excrements and bedding in varying proportions.

Conditions Affecting the Value of Farm Manure.The method of handling and preserving manure, the kind and amount of bedding used, the kind of animals and their age, and the kind of food furnished the animal all affect the value of farm manure. 
Stable manure is better than barnyard manure because it contains all the solid and liquid portions. All manure should be kept under a shed or other suitable cover to protect it from the rain and the sun and sufficient bedding should be employed to absorb all the liquid portion. The urine contains a great deal of the nitrogen, which, if not absorbed, is lost; so that when this portion is allowed to go to waste, the value of the manure is greatly diminished. The manure of young

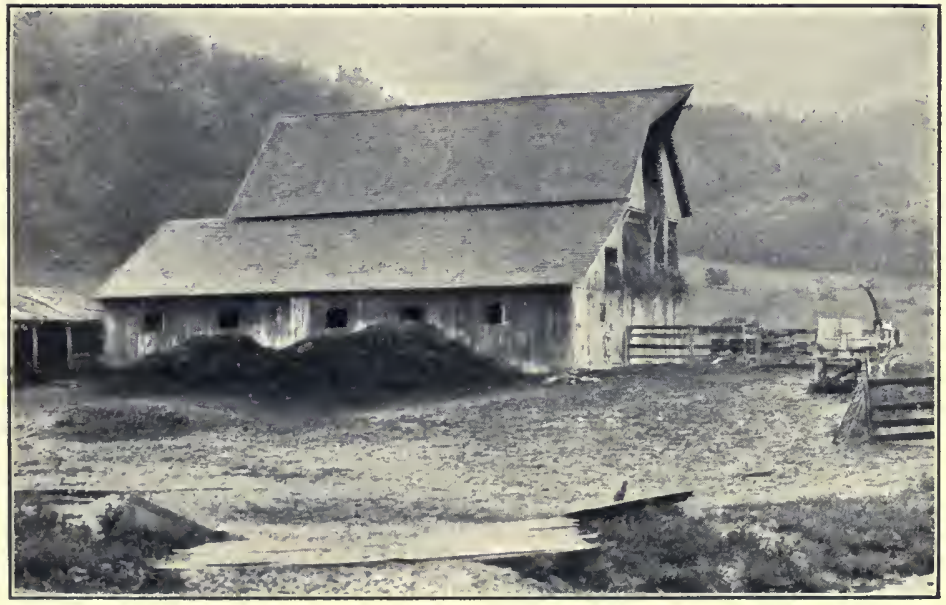

MANURE IMPROPERLY KEPT.

animals is not as rich as that from mature animals. The manure from sheep and poultry is richer than the manure from horses, cows and swine. Animals fed highly nitrogenous feeds, such as cotton-seed meal and linseed meal, produce a more valuable manure than animals fed coarser feeds.

Effects of Manure.-Farm manure improves the texture and condition of the soil and makes the plant food that is stored in the soil available. When manure is put upon the land it decomposes rapidly on account of its already partially decayed condition; fer- 
mentation sets in and acids are formed which act upon the unavailable plant food and renders it available. During the process of decay humus is formed which has a tendency of making heavy soils (like clay soils) loose, and light sandy soils more binding. It increases soil warmth and renders the moisture conditions of the soil more satisfactory.

Lasting Qualities of Farm Manure.-Manure is one of the most efficient fertilizers for the farmer to use. It has wonderful lasting qualities; one good application will last for several years. The Rotham-

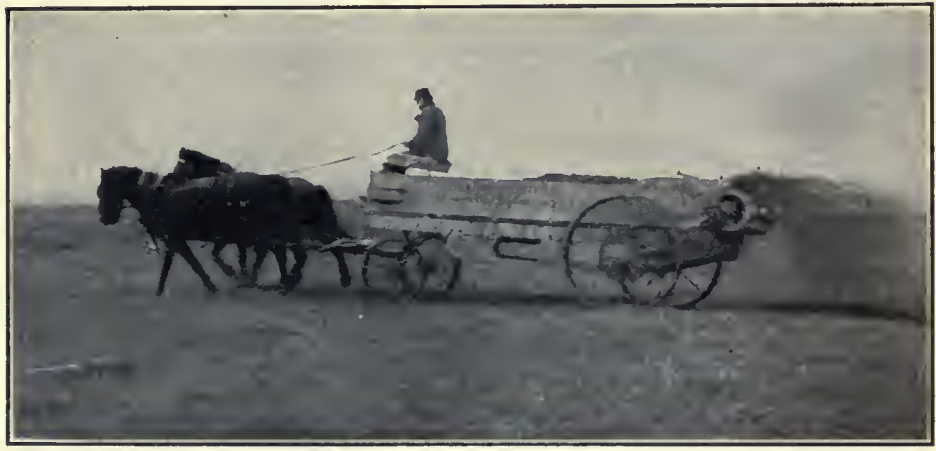

A MANURE SPREADER.

stead Experiment Station of England has made valuable experiments with manure as a fertilizer on barley to show its almost permanent effect. The experiment is as follows: The first plot received an application of 14 tons of farm manure per acre for 20 years ( $1852-7 \mathrm{I}$ ), and since that time has been left unmanured. Another plot has been left unmanured during the entire period since I 852 . The yield on the first plot for 20 years after the application of manure was discontinued, was 30 bushels per acre, while the unmanured plot where nothing was applied gave an average yield of I 3 bushels per acre.

Marl.-This material is an earth. It is sometimes 


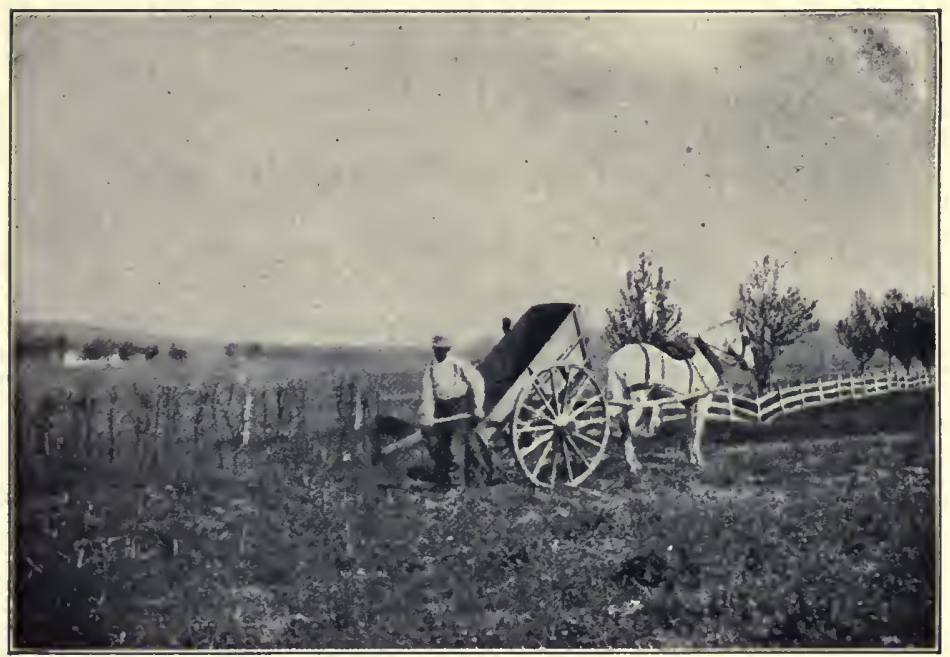

ONE WAY OF HANDLING MANURE.

used to furnish plant food and to improve the physical condition of sandy soils. While it is variable in composition it generally contains phosphoric acid, potash and lime.

Wood Ashes.-In some sections this material is used for fertilizer. Hard wood ashes are more valuable than soft wood ashes. Wood ashes average about 30 per cent. lime, 5 per cent. potash and $\mathrm{I} .5$ per cent. phosphoric acid. In the North it is sometimes used on tobacco lands.

Muck.-This is heavy dark earth found in swampy places. It is rich in organic matter and can be used on sandy soils.

Gypsum.-This substance is sold as land plaster and is used for its lime content.

Composts.-A compost is usually made up of layers of manure and vegetable matter. Sometimes lime, acid phosphate, cotton seed, and similar fertilizing materials are added to it. A compost can be made in the following manner: First select a shady place and pro- 
vide a good drainage. Then make a foundation with a layer of earth. On top of this place a layer of leaves and manure, then a layer of earth, another layer of leaves and manure, a layer of earth, etc. The top of the compost should be covered with earth and shaped to shed water. Keep the compost pile moist so as not to lose nitrogen which will escape as ammonia. The manure, leaves and any other fertilizing material that may be used, will decay due to the action of bacteria. The same changes will take place in a compost as in the soil, when the compost is kept thoroughly moist. Before applying any of the compost to the land mix it well. The earth is used in layers to absorb the ammonia that is set free in the process of decay of the organic materials. The amount of fertilizing material obtained from a compost will be equal to the amount of fertilizing material added to it, provided there is no loss; but the availability of the fertilizing material will be greater.

Exercise.-Have the pupils bring some sand, clay and farm manure to the classroom. Also four tomato cans. Mix some sand and farm manure together and also mix some clay and farm manure. Punch holes in the bottom of the tomato cans. Fill each can threequarters full of the following: I. Sand. 2. Mixed sand and farm manure. 3. Mixed clay and farm manure. 4. Clay. Pour an equal quantity of water in the four cans. Which soil holds the water the longest? In which can does the water pass through the quickest? How does the mixture of farm manure with the sand and the clay help these soils? Record the time it takes for the water to begin to pass through each can.

\section{Section XII.-Commercial Fertilizers.}

Commercial fertilizers, sometimes called artificial manures, are those which are manufactured and sold on our markets to furnish food for the plant.

The Essential Elements. - The chief function of fertilizers is to supply those elements which the crops have taken away from the land and which are necessary for producing profitable crops : namely, nitrogen, 
phosphoric acid and potash. These three elements are called "the essential elements" for two reasons: First, because they are the elements which are removed in greatest amounts by the harvesting of crops, and secondly, they are present in smaller amounts in the soil than the other elements. The other elements which are needed for the growing crops are usually present in sufficient quantities in the air and the soil but sometimes it is necessary to add lime to the soil.

Nitrogenous Fertilizers.-This is a name applied to the fertilizers which are rich in nitrogen. Cottonseed meal, nitrate of soda, sulphate of ammonia, fish scrap and tankage are the principal nitrogenous fertilizers sold.

I. Cotton-seed Meal. This is the by-product from the manufacture of cotton-seed oil. It consists of the ground kernel or meat of the cotton seed, from which most of the hulls are removed and the oil extracted. It has a bright yellow color and is somewhat coarser than flour. It is variable in composition, depending on the amount of hulls present containing from 5 to 7 per cent. of nitrogen. It is a good fertilizer for crops having a long growing season and is especially adapted for the general southern crops.

2. Nitrate of Soda. This substance is obtained from the west coast of Chili. It is sometimes called "Chili Saltpetre." It is a salt, but it is coarser and of: a yellower color than table salt and contains about I 5 per cent. to I 6 per cent. nitrogen, or about twice as much as cotton-seed meal. In the North it is used a great deal for fertilizing cereals (wheat, oats, rye and barley). It is also used to a great extent by market gardeners all over the country to force their crops for early market. It is soluble in water and for this reason it should be applied a little at a time. It has the tendency to produce quick growth.

3. Sulphate of Ammonia. This is a by-product obtained in the manufacture of illuminating gas. It looks much like table salt and contains about 20 per 
cent. nitrogen. For crops it has about the same value and effect as nitrate of soda.

4. Fish Scraps. This is the dried refuse from fish canneries and from the manufacture of glue. Fish scrap and fish make good fertilizers, for they act quickly because of their rapid decay.

5. Tankage. This is the refuse from slaughter

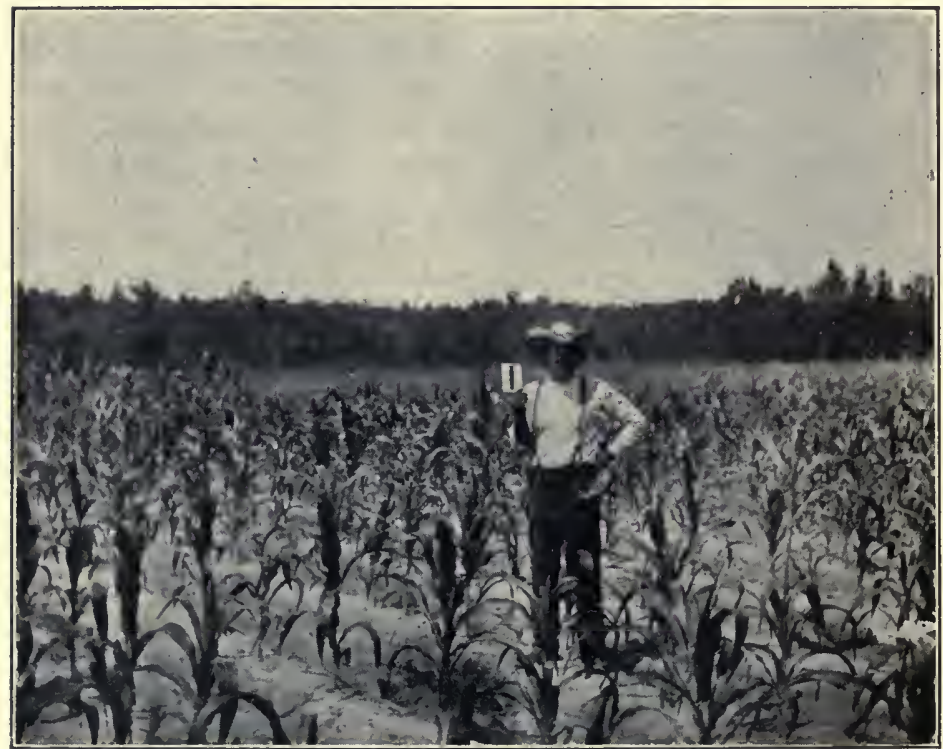

CORN GROWN WITHOUT FERTILIZER.

houses and consists of meat, bone, etc. (from which the fat has been extracted), and dried blood. Like cotton-seed meal, it is suited for crops having a long growing season. It is a brown powdery substance and possesses a strong odor. It is variable in composition and generally contains from 6 per cent. to ro per cent. nitrogen.

Fertilizing Materials Containing Phosphoric Acid. - The phosphoric acid fertilizers are derived princi- 
MANURES AND FERTILIZING MATERIALS.

pally from phosphate rocks and bones. The phosphate rocks are classed as river rock and land rock. The river rock is dredged from the bottom of rivers and the land rock is mined. Phosphate rock is found in Tennessee, Florida, North Carolina and South Carolina. When phosphate rock is ground it is called ground phosphate rock, or floats.

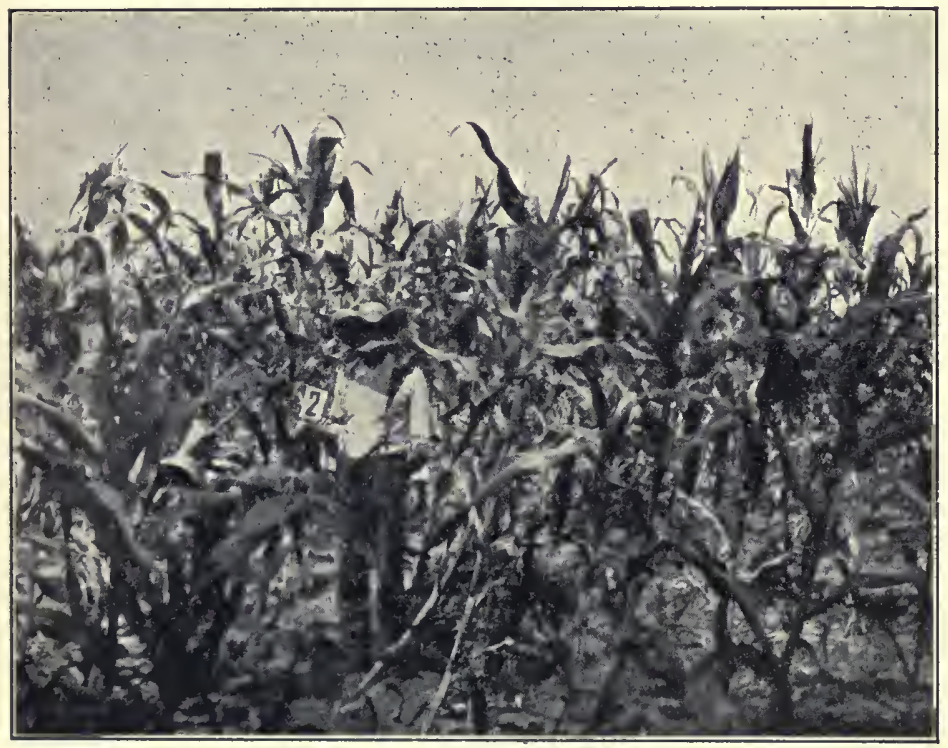

CORN GROWN WITH FERTILIZER.

The phosphoric acid in phosphate rock is in a form that the plants cannot use readily. In order to make this phosphoric acid available as a plant food, sulphuric acid is added to the ground phosphate rock. This acid changes the phosphoric acid into a form which the plant can readily take up. When sulphuric acid is added to the ground phosphate rock, the resultant product is called acid phosphate. The phosphoric acid in acid phosphate exists in three forms: 
I. That which is immediately available to plants and is soluble in water, namely, soluble phosphoric acid. 2. That which is soluble to the roots of the plants but is insoluble in water, namely, reverted phosphoric acid. 3. That which is insoluble to the roots of plants but is soluble in strong acids. The phosphoric acid in phosphate rock is in the insoluble form. The sum of the soluble and the reverted phosphoric acids is called available phosphoric acid, because the plant can easily use it for food. The sum of the available and the insoluble phosphoric acids is called total phosphoric acid.

Bones.-All bones contain phosphoric acid. The phosphoric acid is mostly in the insoluble form. On this account the phosphoric acid in bones is slowly available for plant food. Sometimes bones are treated with sulphuric acid to render the phosphoric acid available. The product is then called dissolved bone.

Potash.-Most of the potash used for fertilizer is derived from mines in Germany. Kainit, muriate of potash and sulphate of potash are the names of these salts. Kainit is the crude product of the mines. It contains about $\mathrm{I} 2$ per cent. potash. Muriate of potash and sulphate of potash are manufactured from the crude salts found in these German mines. They contain about 5o per cent. potash. All these potash salts are soluble in water and great care should be exercised in their application to the land.

EXERCISE.-Write in your note-book the names of the fertilizers you have seen. Describe them. Under which class do they belong? Try to procure samples of the different fertilizers mentioned in this section. If they cannot be obtained in your town, write to the nearest fertilizer factory and you can easily get them. Have the pupils examine them and require the pupils to become proficient in naming them. 


\section{Section XiII.-Valuation of Fertilizers.}

Meaning of the Guarantee.-Nitrate of soda, kainit, cotton-seed meal, acid phosphate, etc., are sold either unmixed or mixed. When any two fertilizers are mixed they are called mixed or manufactured fertilizers. In order to protect the purchasers, most states have passed laws which require that the manufacturer shall state the amounts of phosphoric acid, nitrogen and potash which his fertilizers contain. This statement is called the guarantee. The guarantee is printed either on the sack or on tags which are

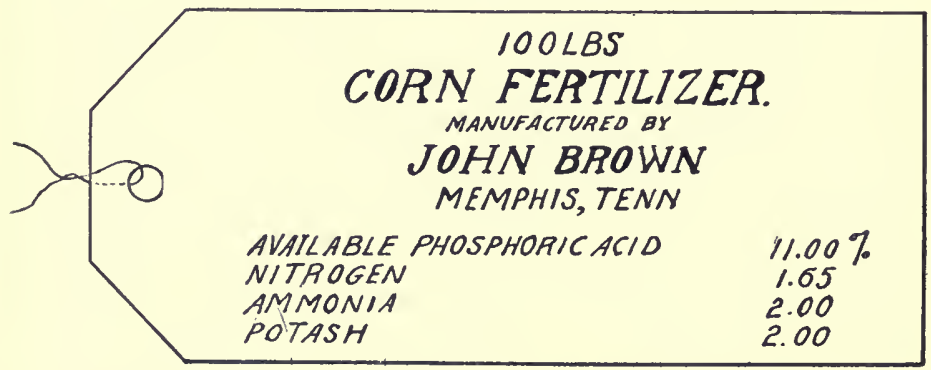

A TAG WITH THE GUARANTEE OR SAMPLE OF COMMERCIAL FERTILIZER TAG.

attached to the sacks. The weight of the contents of each sack is required by many states. Supposing a fertilizer is guaranteed 8 per cent. available phosphoric acid, I.65 per cent. nitrogen and 2 per cent. potash; it means that in every Ioo lbs. of this fertilizer there are at least $8 \mathrm{lbs}$. of available phosphoric acid, I.65 lbs. of nitrogen and 2 lbs. of potash.

$V$ aluation of Fertilizers.-The commercial value of a fertilizer depends upon the market prices of the ingredients nitrogen, phosphoric acid and potash. In most of the states the chemist charged with the enforcement of fertilizer laws, ascertains the average market values of the materials which furnish nitrogen, 
phosphoric acid and potash. From these market prices he makes out a schedule of values to cover the average cost of nitrogen, phosphoric acid and potash. Suppose, for instance, the chemist fixes the following as the values-Nitrogen 16 cents a pound, available phosphoric acid 5 cents a pound and potash 5 cents a pound. Then a fertilizer guaranteed Io per cent. available phosphoric acid, 2 per cent. nitrogen and 2 per cent. potash, is worth, \$I8.40 a ton, since,

Ingredients, per ton lbs. Price,

Available phosphoric acid. $10 \%$ of $2000=200 \mathrm{lbs} .200 \times \$ .05=\$ 10.00$ Nitrogen............. $2 \%$ of $2000=40$ lbs. $40 \mathrm{x} .16=6.40$ Potash............... $2 \%$ of $2000=40$ lbs. $40 \mathrm{x} .05=2.00$

Commercial value per ton.

$=\overline{\$ 18.40}$

The values adopted by the chemists generally represent the wholesale cost of fertilizer materials. The values are given so as to enable the purchaser to arrive at some conclusion concerning the commercial value of fertilizers. These values do not take into account the freight, business losses, cost of manufacture, and manufacturer's profit. Hence the selling prices of fertilizers are somewhat higher than would be estimated from the chemist's values.

Agricultural Value of Fertilizers.-The commercial value of a fertilizer should not be taken as its agricultural value in all cases. The commercial value gives the cost of a fertilizer, while the agricultural value shows the worth of a fertilizer for producing crops. To determine the agricultural value of a fertilizer, the farmer must experiment in the field.

Exercise.-Is there a fertilizer law in your state? If there is such a law and your parents haven't any fertilizer at home, go to the store where fertilizers are sold and copy in your note-book the printed guarantee on the sacks or tags. Name some mixed and unmixed fertilizers used in your section. What is the commercial valuation of a fertilizer guaranteed 8 per cent. available phosphoric acid, 3 per cent. nitrogen and 4.5 per cent potash? Require the pupils to work several problems of the above nature, to familiarize themselves thoroughly with this subject. 


\section{Section XIV.-Mixing Fertilizers.}

Home Mixing.-When a farmer buys fertilizing materials and mixes them at home it is called home mixing. The materials containing the ingredients nitrogen, phosphoric acid and potash, are regular commodities, and can be purchased in most large towns and cities. Often the cost of a home mixed fertilizer is much less than the manufactured article furnishing the same amounts of fertilizer ingredients and the farmer can mix his fertilizer to suit the needs of his crops. In making home mixtures the farmer should find out just what ingredients and their amounts his crops need and purchase the unmixed fertilizers accordingly.

Composition of Fertilizers.

\begin{tabular}{|c|c|c|c|}
\hline Name of Fertilizer & $\begin{array}{l}\text { Available phos- } \\
\text { phoric acid in } \\
\text { per cent. }\end{array}$ & $\begin{array}{l}\text { Nitrogen } \\
\text { in } \\
\text { per cent. }\end{array}$ & $\begin{array}{l}\text { Potash } \\
\text { in } \\
\text { per cent. }\end{array}$ \\
\hline 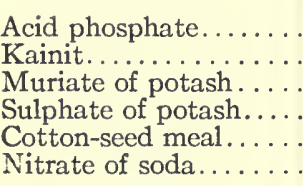 & $\begin{array}{c}14.0 \\
\ldots \ldots \\
\ldots \\
\ldots \\
2.5 \\
\ldots\end{array}$ & $\begin{array}{c}\ldots \ldots \\
\ldots \ldots \\
\ldots \\
\ldots \\
6.2 \\
15.5\end{array}$ & $\begin{array}{r}\ldots \ldots \\
12.0 \\
50.0 \\
50.0 \\
1.5 \\
\ldots .\end{array}$ \\
\hline
\end{tabular}

Mixing Fertilizers.-Suppose a farmer wishes to make a quickly available fertilizer containing 8 per cent. available phosphoric acid, 1.65 per cent. nitrogen and 2 per cent. potash. What materials should he purchase and how much of each to make a ton of fertilizer of the above composition? In the above table, acid phosphate can be selected for the available phosphoric acid. Nitrate of soda would be preferable to cotton-seed meal for the supply of nitrogen, because a quickly available fertilizer is wanted. Kainit or muriate of potash can be chosen for the potash. In 
this example we will select muriate of potash. The above table gives the composition of acid phosphate as 14 per cent. available phosphoric acid, the nitrate of soda as 15.5 per cent. nitrogen and the muriate of potash as 50 per cent. potash. Since 8 per cent. available phosphoric acid (the amount desired in the finished product) is equal to $8 \mathrm{lbs}$. of available phosphoric acid to every I oo lbs. of fertilizer, in $2,000 \mathrm{lbs}$. there will be needed $8 \times 20$ or 160 lbs. of available phosphoric acid. In the same way we find that we must have $33 \mathrm{lbs}$. of nitrogen and $40 \mathrm{lbs}$. of potash. The following statement represents this more clearly:

\begin{tabular}{|c|c|c|}
\hline & $\begin{array}{l}\text { Amount wanted } \\
\text { per hundred. }\end{array}$ & $\begin{array}{l}\text { Amount required } \\
\text { per ton. }\end{array}$ \\
\hline osnhoric & 8 lbs. X 20 & $=\quad 160 \mathrm{lbs}$ \\
\hline 11 s & I. 65 lbs. $\times 20$ & $33 \mathrm{lbs}$. \\
\hline Pota & 2 lbs. $\times 20$ & 40 bs. \\
\hline
\end{tabular}

The next step is to find out the number of pounds of acid phosphate required to furnish $\mathrm{I} 6 \mathrm{o}$ lbs. of available phosphoric acid. The table of composition states that Ioo lbs. of acid phosphate contains $\mathrm{r}_{4} \mathrm{lbs}$. of available phosphoric acid. Then $14:$ roo as $160: x$ (number of pounds of acid phosphate required). Or $\mathrm{I} 4 \mathrm{x}=\mathrm{r} 6,000 \mathrm{x}=\mathrm{r}, \mathrm{I} 43$ lbs. The pounds of nitrate of soda and muriate of potash are figured in a similar way.

I4 : $100=160:$ number of pounds of acid phosphate required.

15.5: $100=33:$ number of pounds of nitrate of soda required.

$50: 100=40:$ number of pounds of muriate of potash required.

In other words, the quantities of fertilizers as stated below will be needed to make one ton of fertilizer of the desired composition.

I 43 lbs. of acid phosphate containing $14 \%$ available phosphoric acid. $213 \mathrm{lbs}$. of nitrate of soda containing $15.5 \%$ nitrogen.

$80 \mathrm{lbs}$. of muriate of potash containing $50 \%$ potash.

I 436 lbs. Total. 
'The total pounds of fertilizers required are only I, $436 \mathrm{lbs}$. In order to satisfy the formula namely, 8 per cent. available phosphoric acid, r.65 per cent nitrogen and 2 per cent. potash, some material has to be added to make the total weight 2,000 lbs. The calculations were figured on a ton basis, and if we do not add material to make 2,ooo lbs. the fertilizer will contain more than 8 per cent. available phosphoric acid, 1.65 per cent. nitrogen and 2 per cent. potash. The farmer can add soil or sand to make the total weight 2,000 lbs. In this case $2,000-\mathrm{I}, 436=564$ lbs. the amount of soil necessary to add to make 2,000 lbs.

Fillers.-When the manufacturer of fertilizers makes a fertilizer of the above composition, out of the same materials, he is forced to add some make weight substance such as sand or cinders, to make the total weight 2,000 lbs. This make-weight substance is called the filler. In the general meaning of the term, a filler is spoken of as something added to a fertilizer to make weight.

Cost of the Fertilizer.-Let us find out the cost of the above fertilizer when acid phosphate sells for \$I 4 per ton, nitrate of soda for $\$ 50$ per ton and muriate of potash for $\$ 40$ per ton.

Acid phosphate at $\$ \mathrm{I} 4$ per ton costs $\$ .007$ per $1 \mathrm{~b}$.

Nitrate of soda at $\$ 50$ per ton costs $\$ .025$ per lb.

Muriate of potash at $\$ 40$ per ton costs $\$ .020$ per lb. Then :-

II 43 (the number of lbs. of acid phosphate required) $\mathrm{x} \$ .007=\$ 8.00 \mathrm{I}$

213 (the number of lbs. of nitrate of soda required) $x .025=5.325$

80 (number of $\mathrm{lbs}$. of muriate of potash required) $x .020=1.600$

1436 lbs. total.

Cost

$\$ 14.926$

If the manufacturer's price for a fertilizer of this composition, namely, 8 per cent. available phosphoric acid, 1.65 per cent. nitrogen and 2 per cent. potash, is $\$ 20$ per ton, it would be a paying proposition to buy the raw materials and mix them at home. 
Exercise. - I. How much filler would it be necessary to add to a fertilizer made up of cotton-seed meal, kainit and acid phosphate, of the following composition -8 per cent. available phosphoric acid, 1.65 per cent. nitrogen and 2 per cent. potash-provided the acid phosphate contains I4.5 per cent. of available phosphoric acid? 2. In the above mixture how much available phosphoric acid and potash does the cotton-seed meal furnish? 3. If kainit sells for $\$ 10$ a ton and muriate of potash for $\$ 40$ a ton, which is the cheaper source of potash? Which is the more economical to buy, cotton-seed meal containing 6.5 per cent nitrogen at $\$ 25$ a ton, or cotton-seed meal carrying 6 per cent. nitrogen at $\$ 24$ a ton?

\section{Section XV.-Application of Fertilizers.}

Why Fertilizers are Added.-In the harvesting of crops a great deal of plant food-namely, nitrogen, phosphoric acid and potash-is taken away from the soil. In order to furnish the new crops with these necessary ingredients, fertilizers are applied which contain them.

Amounts of Fertilizer per Acre.-The amount of fertilizer used per acre varies a great deal. The condition of the soil and the nature of the crop regulate to a certain extent the amount of fertilizer to use. As a general rale the truck crops (lettuce, radish, cabbage, tomato, etc.) receive a great deal more fertilizer than the general crops. Sometimes I, 00o lbs. of fertilizer are applied per acre for truck crops. The quantities of fertilizer applied for cotton, corn, tobacco and other general crops are $200-600$ lbs. per acre.

Kinds of Fertilizers for the Crop.-Some crops require different fertilizer ingredients from others. Tobacco requires more potash than phosphoric acid. Leguminous crops, such as cowpeas, alfalfa, soya bean, etc., take nitrogen from the air and so it is unnecessary to apply fertilizers containing nitrogen for these crops. Wheat requires more nitrogen than any other ingredient for its production.

Kinds of Fertilizers for the Soil.--Soils are variable in composition. Some soils contain enough potash for 
ordinary crops. Soils which are dark or black in color usually contain considerable organic matter and do not need much nitrogen. Some soils are deficient in lime and are sour or acid. To make a sour soil sweet, requires the addition of lime.

Effects of Fertilizer Ingredients.-The ingredient nitrogen tends to produce growth. If plants give a

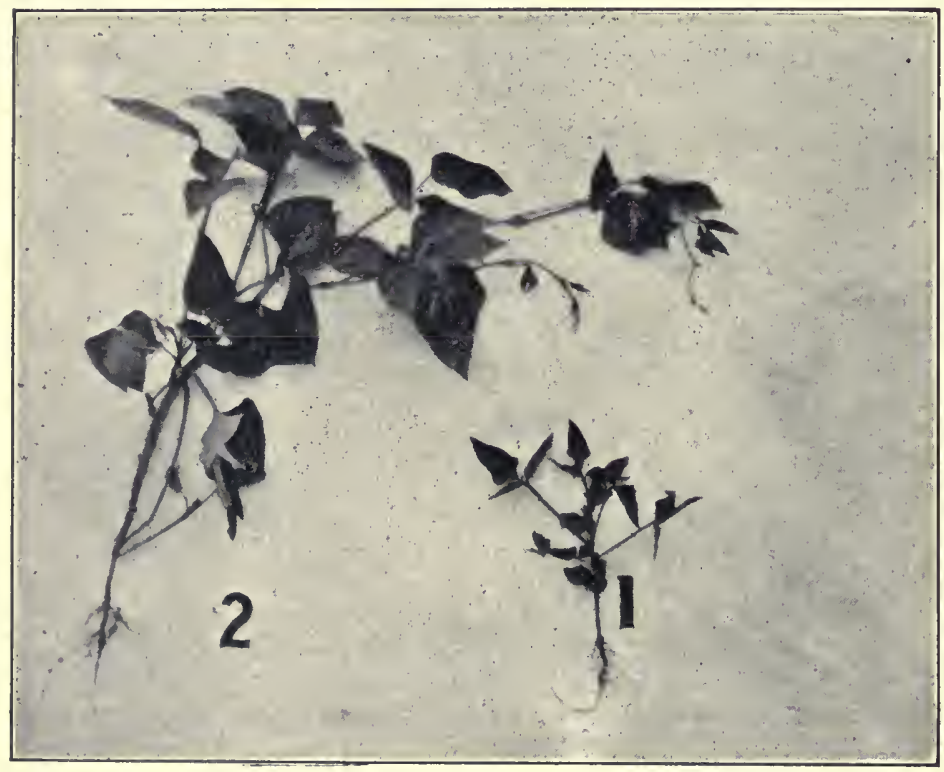

COWPEAS.

1, without fertilizer; 2, with fertilizer.

rank growth it is generally due to an excess of nitrogen. Too little growth indicates a lack of nitrogen. Phosphoric acid helps to form the grain of plants. A deficiency of phosphoric acid results in light weight grains, with such crops as corn, oats, wheat, barley and rice. Phosphoric acid also tends to hasten maturity in plants. Potash has a tendency to give firmness to fruit and it enables the truck farmer to raise 
vegetables and fruits that will stand shipping, as potash is present in the stems and leaves of plants.

Fertilizers for the Crop and the Soil.-Every farmer should set aside plats of ground and run experiments and determine for himself the requirements of his land for the crops he wishes to raise. To secure the best results it is necessary that the soil be kept in good physical condition. The soil should be kept well drained and open; apply the proper fertilizers at the right time; purchase fertilizers as set forth by the guarantee, and buy those fertilizers which furnish the greatest amount of plant food for the least money.

EXERCISE-How much fertilizer do your folks use? What kinds of fertilizers do they apply and for what crops? Do they ever add nitrate of soda or sulphate of ammonia, in the early spring? For what crops?

\section{REFERENCES FOR COLLATERAL READING.}

\section{Manures and Fertilizing Materials.}

Yearbooks of the U. S. Dept. of Agriculture:

I895-Soil ferments importance in agriculture.

I895-Humus in its relation to soil fertility.

1896-Potash and its function in agriculture.

1902-Fertilizers for special crops.

Farmers' Bulletins, Nos. :

44-Commercial fertilizers.

I92-Barnyard manure.

222-225-Home mixing of fertilizers.

245 - Renovation of wornout soils.

278 -Leguminous crops for green manuring.

327 -Conservation of natural resources.

342 -Conservation of soil resources.

Experiment Station Bulletins, Nos.

9.-New York, Geneva-Composition and use of fertilizers.

I 3-Louisiana, I23-Texas, I33-Indiana, Commercial fertilizers.

123-Illinois-Fertility in Illinois soils.

I20-Illinois-Circular-The use of commercial fertilizers.

I 40 -Kentucky-Fertilizers.

I82-I83-Ohio-The maintenance of fertility.

Books :

49-Georgia State Board of Agriculture-Fertilizers.

Fertilizers-Voorhees-The Macmillan Co., New York City.

Soils and Fertilizers-Snyder-The Macmillan Co., New York City.

The Fertility of the Land-Roberts-The Macmillan Co., New York City.

Soils-Fletcher-Doubleday, Page \& Co., New York City. 


\section{HA P TER IV.}

\section{FARM CROPS.}

Section XVI.-Diversification and Rotation OF CROPS.

By Prof. Lyman Carrier,

Department of Agronomy, Virginia Polytechnic Institute.

One-Crop Farming Ruins Farms.-One-crop farming has ruined more farms in America than any other cause. The evil results from this practice are not confined to any one locality or section. Continuous cropping, year after year, with tobacco in Virginia, North Carolina and Kentucky; with corn in Indiana, Illinois, and Iowa; with wheat in Minnesota and the Dakotas; and with cotton in the Gulf states, has in each instance had the same effect, and that is soil depletion. The instances just given are the ones most noticeable because the crops, with the partial exception of corn, are all sold off the farm where they are grown. Usually nothing is put back on the land to make up for the fertility that is removed. This is practiced as long as a crop can be grown at a profit. Then the farm is either abandoned or the use of commercial fertilizers begun.

Fertility Must Be Restored to the Soil.-Most of the cultivated land in America was originally extremely fertile, but at the present time run-down, worn-out farms are altogether too common. There is no real reason for the fertility of a soil to become exhausted. There are farms in Denmark and Italy that have been in cultivation for five or six hundred years at least, 
that produce more abundantly now than they did a generation ago. A mistaken idea is quite prevalent that land needs resting, that is, to lie idle for a year or two every five or six years that it is cropped. This is not necessary in order to keep up its producing power. The best farmers in this country are the ones that work their land to its fullest capacity. There

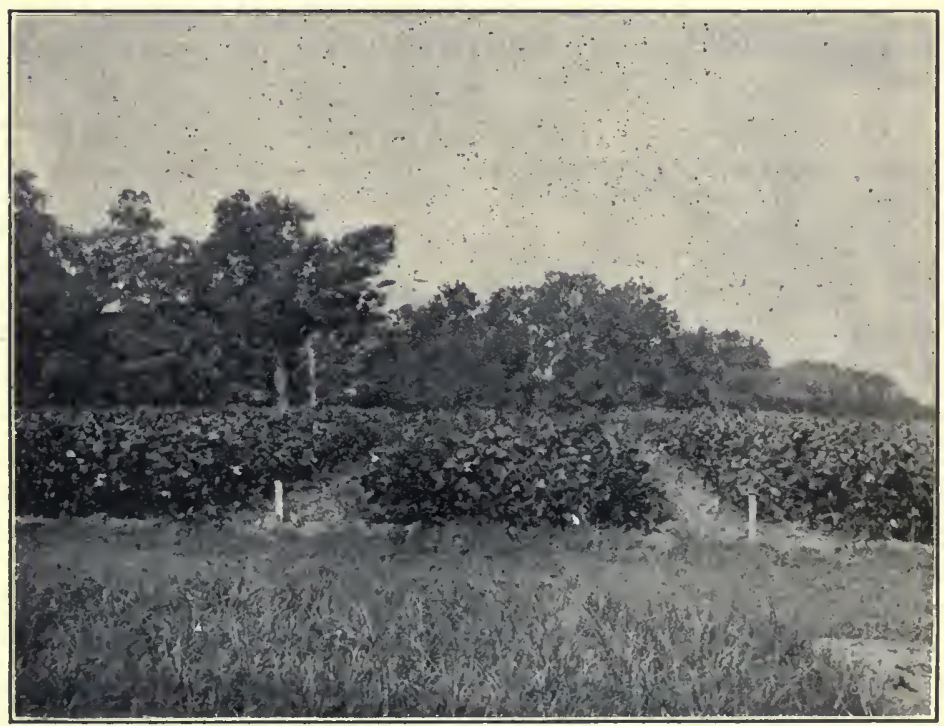

SOY BEANS. A SOIL-IMPROVING CROP.

must be, however, provision made for returning to the soil part of the fertility removed in the crops.

Use Soil-Improving Plants.-By diversifying the crops grown, a farmer may use soil-improving plants, such as peas, soy beans, and the clovers in his cropping system. These often yield a good profit above the expense of raising and harvesting, and they also provide forage for all classes of live-stock. If so desired a quick growing legume may be grown for plowing under as a green manure. The chief advantages 
from diversification are discussed under the subject of rotation of crops.

Rotation of Crops.-A rotation of crops, as the name implies, is the growing of a certain number of crops following each other in regular order on each field. When a regular rotation is practiced, each field produces a series of crops, as cotton, followed by corn, winter oats, and cowpeas in the order named, and is then planted again to the first crop in the series, which, in this case, would be cotton. All of the crops of the rotation are grown on the farm each year, so any one crop may be considered as the beginning of the series.

A rotation differs from diversification only in the fact that in the former the crops are grown in a definite system, while in the latter this regularity may be lacking.

Rotations are usually designated by the length of time it takes to complete them, as a four-year rotation or a three-year rotation. The word "course" is sometimes substituted for the word "year," but its use is not recommended because its meaning is not so evident.

Arrangement of Fields for a Rotation.-It is highly important that there be approximately the same number of acres devoted to each crop in the rotation every year. This enables the farmer to plan his work to better advantage, to keep a definite number of livestock and to estimate his income. In order to accomplish this, there should be the same number of fields of equal area, as it takes years to complete the rotation. For example, if it is a four-year rotation, the farm should be divided into four fields.

Advantages from a Rotation.-The chief reasons for practicing a rotation of crops rather than haphazard planting or single crop farming may be given as follows:

I. It distributes the labor on the farm more evenly throughout the year and allows the farmer to plan his work more systematically. 
2. All plants do not require the same amounts of the different elements of plant food. Potatoes and tobacco use large quantities of potash, while grain crops draw heavily on the supply of nitrogen and phosphoric acid. As these elements become available slowly and are likely to be washed out of the soil by rains, a series of crops tends to utilize them more completely without loss.

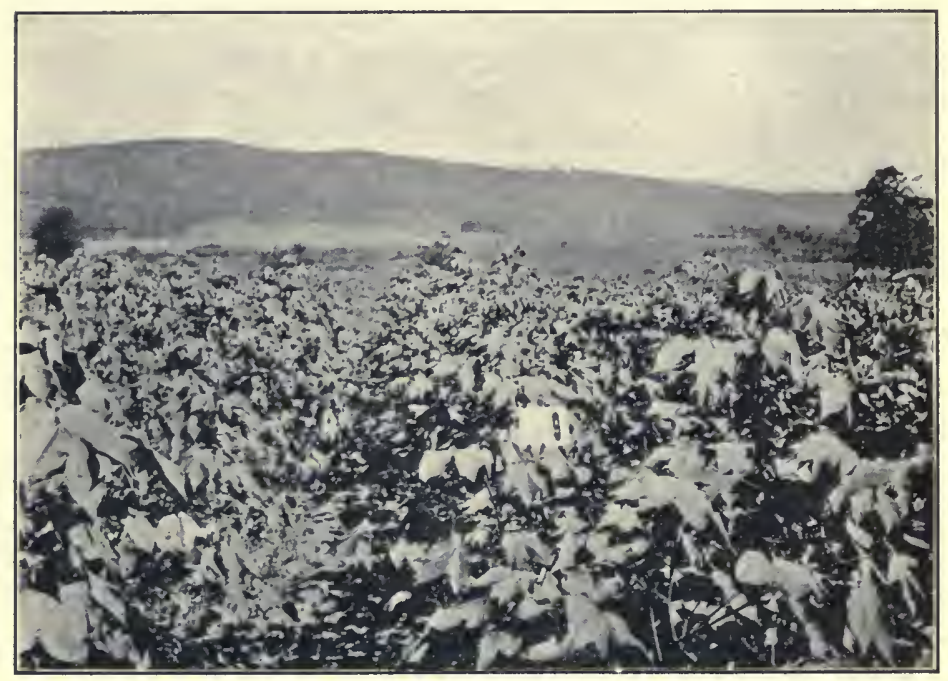

COTTON GROWN IN ROTATION.

3. Some plants feed deeply in the soil while others feed near the surface. Oats and rye are shallow rooted plants while the roots of corn and alfalfa penetrate to considerable depths. By alternating these crops the reserve supply of plant food in the subsoil may be utilized. The openings left by the decay of roots in the subsoil aid also in draining and aerating the soil.

4. A cultivated crop every three or four years tends to keep down weeds. Corn, potatoes, tobacco and 
cotton, properly tended, are known as "cleaning crops." If the land is kept continually in hay or grain, which is not cultivated, it becomes foul with weeds.

5. By the use of legumes, nitrogen from the air may be stored up in the soil for the use of other crops. It is estimated that a crop of red clover one year old will

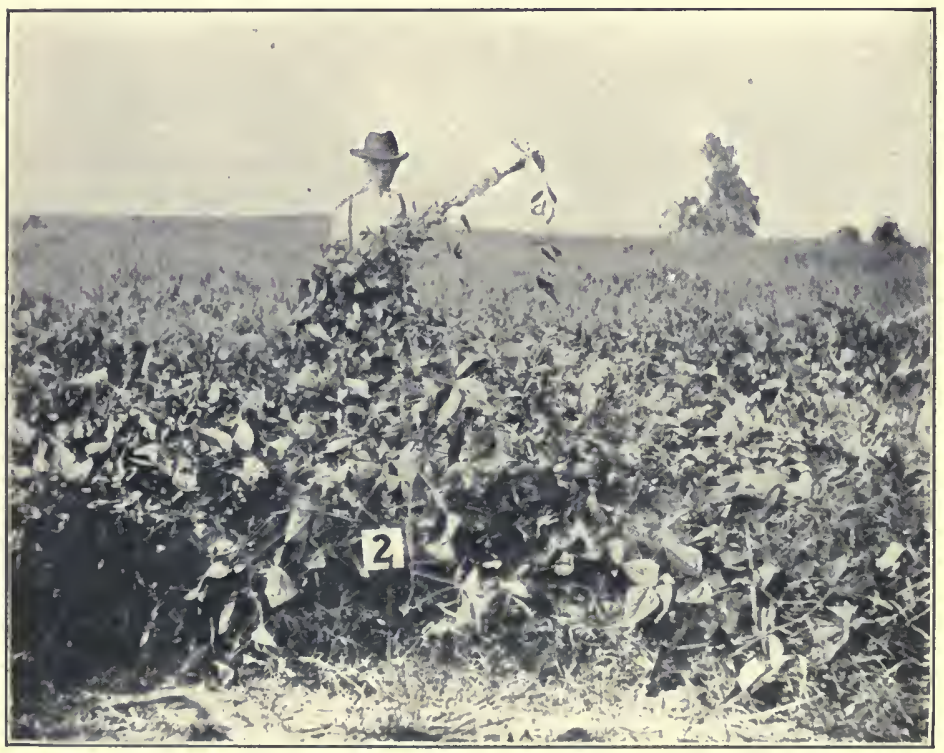

COWPEAS GROWN WITH FERTILIZER.

have twenty to thirty pounds of nitrogen stored in the roots alone. This is worth from four to six dollars. A crop of crimson clover seeded in corn at the last working, at a cost for seed of about one dollar per acre, will catch about fifteen dollars' worth of nitrogen on that a rea.

6. It keeps the ground covered with crops most of the year and prevents leaching. Bare fields should be avoided as much as possible. 
7. It furnishes a more regular income during the year. In single crop farming sales come but once, hence single crop farmers often do business on credit during the greater part of the year.

8. It furnishes a variety of forage which is essential to live-stock farming. diseases.

9. It lessens the danger from insect pests and plant

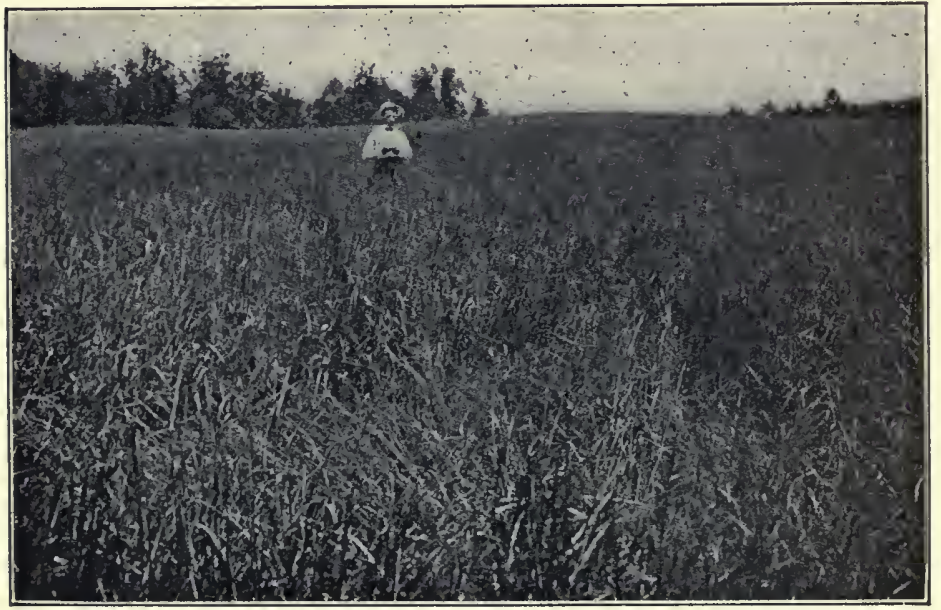

FIELD OF GRASS SUCCEEDING WHEAT WHICH FOLLOWED TOBACCO.

Principles to be Observed in Planning a Rotation of Crops.-Each farmer should select the rotation for his own farm from the great number of combinations of crops that may be grown. It is impossible to say what the best rotation may be for any particular farm without a careful study of the soil, climatic conditions, insect pests, plant diseases and market demands of the section where the farm is located. The following principles may aid in planning a cropping system, but success in farming can never be attained by following a series of set rules.

The crops grown in a rotation should all be adapted 
to the locality and to the type of farming to be followed.

Such crops should be chosen as will keep the ground occupied as much of the time as possible. There should be no long vacant periods between the harvesting of one crop and the seeding of the next on the same field. There should be a leguminous crop, such as clover, peas, vetch, etc., grown every three or four

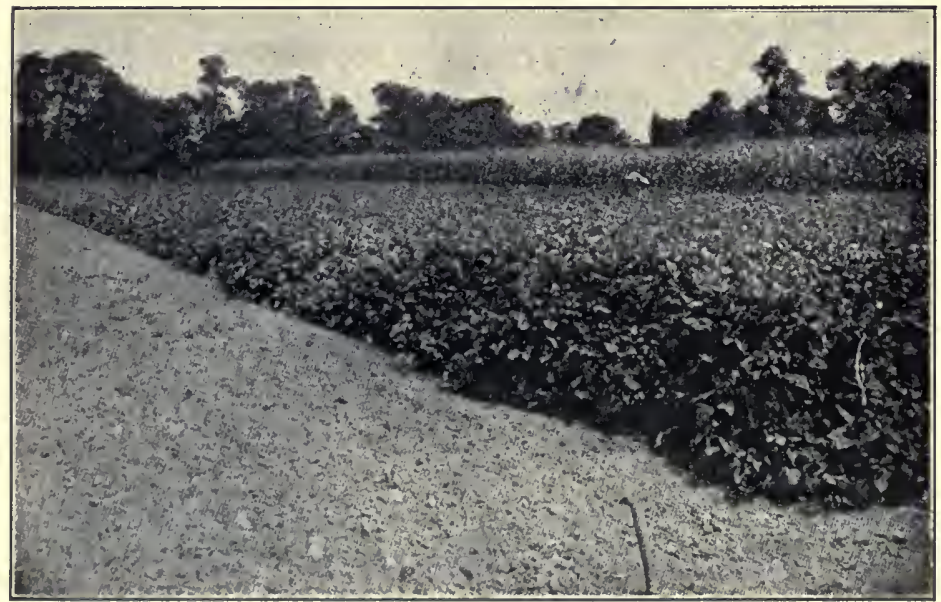

CROP ROTATION PLOTS ON A MODEL FARM.

years at least to make use of the free nitrogen of the air.

Crop Rotations.-The following are a few examples, out of a great many that might be given, of crop rotations :

I. A four-year rotation for general farming.

Ist year. Corn seeded to wheat in the fall, with clover and timothy sown at the same time as the wheat or the following spring.

and year. Wheat.

3 rd year. Hay.

$4^{\text {th }}$ year. Either hay or pasture. 
In this rotation a crop of oats seeded in the spring is often substituted for the wheat; the clover and grass being seeded at the same time as the oats. Many farmers are beginning to sow their clover and grass seed after the small grain is harvested, using a diskharrow to prepare the seed bed.

2. A three-year rotation commonly practiced in the tobacco growing districts.

Ist year. Tobacco.

2nd year. Wheat.

3 rd year. Clover, either cut for hay or plowed under.

3. A three-year rotation for the Cotton-belt.

Ist year. Cotton.

2nd year. Corn with cowpeas between the rows.

3rd year. Small grain, usually oats, followed with cowpeas.

4. A five-year rotation recommended for livestock farms.

Ist year. Corn, seeded at the last working to crimson clover.

2nd year. Crimson clover, cut for hay or plowed under, followed with cowpeas to be cut for hay and the land seeded to some small grain.

3rd year. Small grain, wheat, oats or rye, stubble to be disked and seeded to a mixture of clover and grass.

4th year. Hay.

$5^{\text {th }}$ year. Hay or pasture.

EXERCISE.-Are any of the crop rotations cited in the foregoing section used in your community? Name the crop rotations followed at your home town. How can they be improved? Name the leguminous plants grown in the neighborhood. 


\section{Section XVII.-CoRn.}

By Prof. A. D. Shamel,

Bureau of Plant Industry, U. S. Dept. of Agriculture.

Present Distribution of the Corn Crop.-The production of corn in the corn-producing countries of the world, I902-1906, as given in the agricultural statistics, I 907 Yearbook, U. S. Dept. of Agriculture, is as follows :

\begin{tabular}{|c|c|c|c|c|c|}
\hline COUNTRY & $\begin{array}{c}1902 \\
\text { Bushels }\end{array}$ & $\begin{array}{c}1903 \\
\text { Bushels }\end{array}$ & $\begin{array}{c}\text { I904 } \\
\text { Bushels }\end{array}$ & $\begin{array}{l}\text { I905 } \\
\text { Bushels }\end{array}$ & $\begin{array}{l}\text { I } 906 \\
\text { Bushels }\end{array}$ \\
\hline $\begin{array}{l}\text { North America } \\
\text { United States....... } \\
\text { Canada (Ontario)... } \\
\text { Mexico............ }\end{array}$ & $\begin{array}{r}2,523,648,000 \\
21,159,000 \\
78,099,000 \\
\end{array}$ & $\begin{array}{r}2,244,177,000 \\
30,211,000 \\
90,879,000 \\
\end{array}$ & $\begin{array}{r}2,467,481,000 \\
20,880,000 \\
88,131,000 \\
\end{array}$ & $\begin{array}{r}2,707,994,000 \\
21,582,000 \\
85,000,000 \\
\end{array}$ & $\begin{array}{r}2,927,416,000 \\
24,745,000 \\
70,000,000 \\
\end{array}$ \\
\hline $\begin{array}{l}\text { Total North } \\
\text { America.... }\end{array}$ & $2,622,906,000$ & $2,365,267,000$ & $2,576,492,000$ & $2,814,576,000$ & $3,022,161,000$ \\
\hline $\begin{array}{l}\text { South America } \\
\text { Argentina.......... } \\
\text { Chile............. } \\
\text { Uruguay......... }\end{array}$ & $\begin{array}{r}84,018,000 \\
866,000 \\
5,060,000 \\
\end{array}$ & $\begin{array}{r}148,948,000 \\
1,118,000 \\
5,289,000 \\
\end{array}$ & $\begin{array}{r}175,189,000 \\
1,477,000 \\
3,035,000 \\
\end{array}$ & $\begin{array}{r}140,708,000 \\
1,244,000 \\
4,417,000 \\
\end{array}$ & $\begin{array}{r}194,912,000 \\
846,000 \\
3,226,000 \\
\end{array}$ \\
\hline $\begin{array}{c}\begin{array}{c}\text { Total South } \\
\text { America..... }\end{array} \\
\end{array}$ & $89,944,000$ & I $55,355,000$ & $179,701,000$ & $146.369,000$ & $198,984,000$ \\
\hline $\begin{array}{l}\text { Europe } \\
\text { Austria ............. } \\
\text { Hungary (proper)... } \\
\text { Croatia-Slavonia ... } \\
\text { Bosnia-Herzegovina }\end{array}$ & $\begin{array}{r}13,462,000 \\
104,546,000 \\
15,255,000 \\
5,863,000 \\
\end{array}$ & $\begin{array}{r}16,056,000 \\
135,751,000 \\
23,766,000 \\
8,411,000 \\
\end{array}$ & $\begin{array}{r}\mathrm{I} 2,529,000 \\
59,400,000 \\
\mathrm{I} \mathbf{1}, 364,000 \\
6,464,000 \\
\end{array}$ & $\begin{array}{r}17,293,000 \\
94,045,000 \\
18,385,000 \\
9,584,000 \\
\end{array}$ & $\begin{array}{r}18,177,000 \\
162,923,000 \\
25,600,000 \\
8,936,000 \\
\end{array}$ \\
\hline $\begin{array}{c}\text { Total Austria- } \\
\text { Hungary.... } \\
\end{array}$ & 139, I 26,000 & I $83,994,000$ & $89,757,000$ & $139,307,000$ & $215,636,000$ \\
\hline 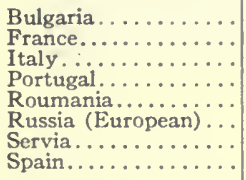 & $\begin{array}{l}18,100,000 \\
24,928,000 \\
71,028,000 \\
16,000,000 \\
68,447,000 \\
48,419,000 \\
18,396,000 \\
25,272,000 \\
\end{array}$ & $\begin{array}{l}22,836,000 \\
25,360,000 \\
88,990,000 \\
14,000,000 \\
80,272,000 \\
50,464,000 \\
19,479,000 \\
18,759,000\end{array}$ & $\begin{array}{r}12,758,000 \\
19,482,000 \\
90,545,000 \\
15,000,000 \\
19,598,000 \\
25,920,000 \\
9,498,000 \\
21,300,000\end{array}$ & $\begin{array}{l}19,649,000 \\
24,030,000 \\
97,265,000 \\
16,000,000 \\
59,275,000 \\
33,331,000 \\
21,431,000 \\
31,880,000\end{array}$ & $\begin{array}{r}20,000,000 \\
14,581,000 \\
93,007,000 \\
16,000,000 \\
130,546,000 \\
70,501,000 \\
27,786,000 \\
30,000,000 \\
\end{array}$ \\
\hline Total Europe. & $429,716,000$ & $504,154,000$ & $303,858,000$ & $442,168,000$ & $618,057,000$ \\
\hline 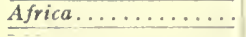 & $36,899,000$ & 36, I 18,000 & $38,862,000$ & $37,655,000$ & $37.700,000$ \\
\hline Australasia......... & $\begin{array}{r}7,846,000 \\
\end{array}$ & 5.614 .000 & 10.519 .000 & 8.880 .000 & $9.261,000$ \\
\hline Grand Total... & $3,187,3 1 \longdiv { 1 , 0 0 0 }$ & $3,066,508,000$ & $3,109,432,000$ & $3,449,648,000$ & $3,886,163.000$ \\
\hline
\end{tabular}

Discussion of Corn Production.-This table shows that the great bulk of the corn crop of the world is produced in North America, particularly the United States. Europe is second so far as amount of pro- 
duction is concerned, while the amount of corn produced by all the other countries of the world is comparatively small. Roumania and the Argentine Republic are two corn-growing countries where the increase in the production of corn has been remarkable during the past decade. The great undeveloped areas in Argentine, suitable for corn culture, make it possible

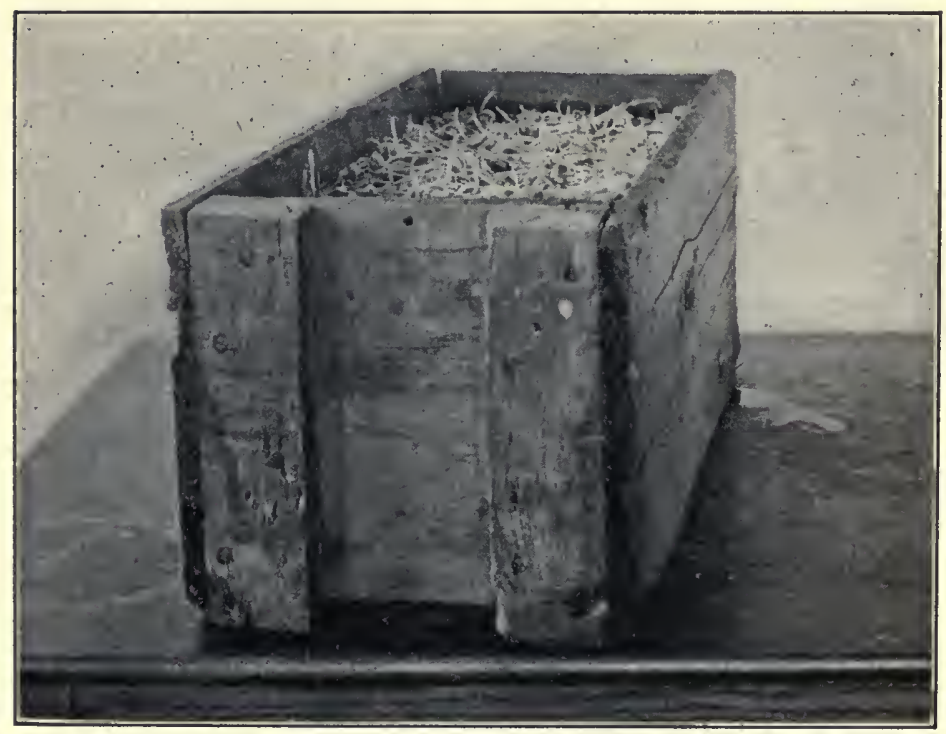

GERMINATING BOX FOR CORN.

that this country may soon become one of the leading corn-producing countries in the world. As a result of extensive experiments by the English Government in South Africa, in the culture of corn in the Transvaal, Rhodesia, Cape Colony, and other colonies, it is predicted that this region may become an extensive corn producing area. In the United States nearly all of the land suitable for corn culture has been occupied, so that it is improbable that there will be any great increase in production in this country due to increase 
of the area now producing corn. A marked increase in total production in the United States is being effected, however, by the use of higher yielding varieties of corn by corn growers.

The Production in the Corn Belt.-The production of corn in the different states in the United States commonly known as the Corn Belt of the United States, and mostly lying in the Mississippi Valley, is shown in the following interesting table. The figures show the average acres cultivated in the respective states, and the average yields per acre for ten years, viz., I 898 to I 907 , inclusive. The total yields can easily be determined from these figures.

ACREAGE AND YIELD PER ACRE OF LEADING CORNGROWING STATES IN THE UNITED STATES-I898 TO 1907, INCLUSIVE.

\begin{tabular}{|c|c|c|}
\hline State & Acreage & Bushels per acre \\
\hline 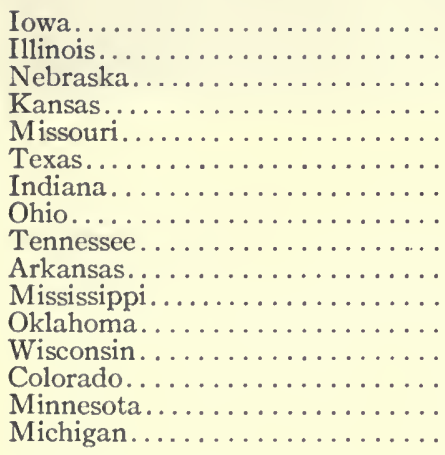 & $\begin{array}{l}8,652,208 \\
8,593,229 \\
7,664,271 \\
7,495,991 \\
6,493,259 \\
5,672,266 \\
4,308,329 \\
3,043,702 \\
3,097,349 \\
2,326,209 \\
2,220,778 \\
1,759,307 \\
1,380,000 \\
1,305,000 \\
1,331,543 \\
1,298,973\end{array}$ & $\begin{array}{l}32.54 \\
34.37 \\
22.11 \\
22.49 \\
28.48 \\
19.28 \\
35.07 \\
35.12 \\
22.93 \\
18.90 \\
15.47 \\
23.57 \\
33.54 \\
20.31 \\
29.54 \\
31.91\end{array}$ \\
\hline
\end{tabular}

From this table it will be seen that the great cornproducing states in the United States are Iowa, Illinois, Nebraska, Kansas, Missouri, Texas, Indiana and Ohio.

The production of corn in the United States has increased enormously in the past quarter of a century, 


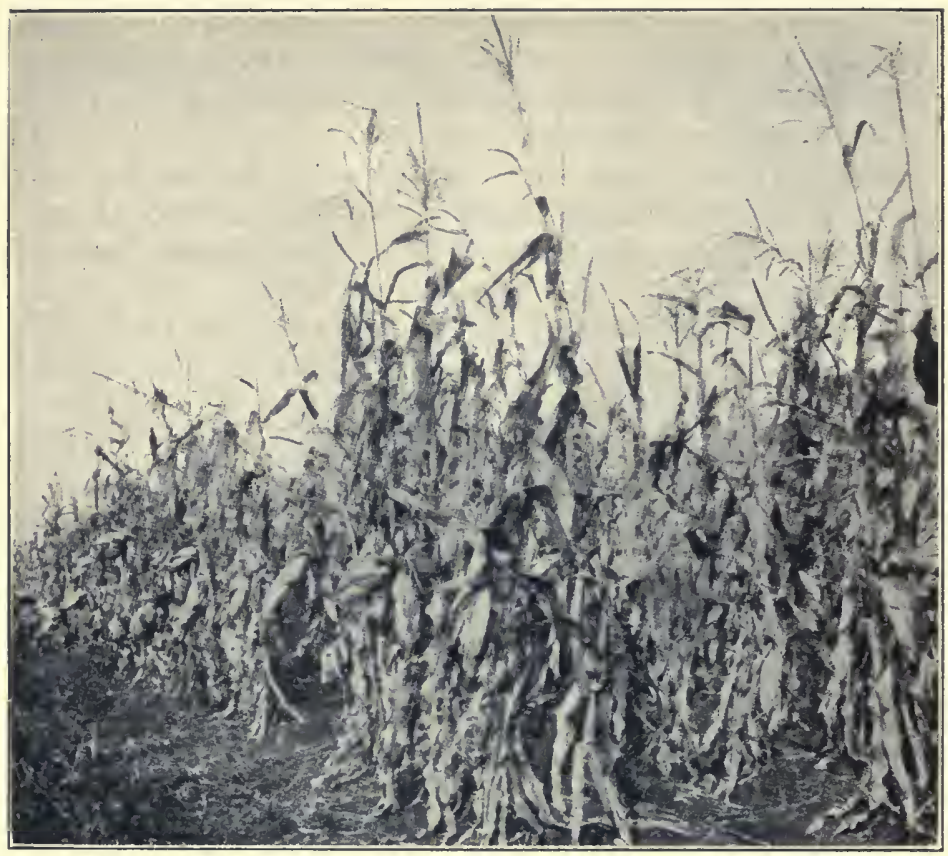

A GOOD FIELD OF CORN.

as is shown in the following table, showing the comparative increase in production of corn and in the population of the United States.

POPULATION AND PRODUCTION OF CORN IN THE UNITED STATES-I850 TO 1900.

\begin{tabular}{c|c|c|c}
\hline Year & Population & $\begin{array}{c}\text { Total Production of Corn in } \\
\text { Bushels for. United States }\end{array}$ & $\begin{array}{c}\text { Bushels per } \\
\text { Capita }\end{array}$ \\
\hline & & $592,071,104$ & \\
1850 & $23,191,876$ & $838,792,742$ & 25.5 \\
1860 & $31,443,321$ & $760,944,549$ & 26.6 \\
1870 & $38,558,471$ & $1,754,591,676$ & 19.7 \\
1880 & $50,155,783$ & $2,122,327,547$ & 34.9 \\
1890 & $62,622,190$ & $2,666,440,279$ & 33.8 \\
1900 & $75,997,873$ & & 35.0 \\
\hline
\end{tabular}


Classification.-Zea Mays, commonly known as Indian corn, is divided into six species-groups by Dr. E. S. Sturtevant, ${ }^{*}$ as follows :

I. Zea Indentata.-The Dent Corns. The hard flinty part of the kernel called corneous endosperm is at the sides of the kernel in dent corn. The soft white mealy part of the kernel called starchy endosperm is contained in the kernel between the hard flinty portions, and reaches from the tip to the top of the kernels. In the process of drying out or maturing of the kernels, the summit or top of the kernel is drawn in, due to the shrinkage of the starchy endosperm, and in this manner the tops of the kernels become indented in various ways and shapes. The kernels are usually long, angular, and generally fit closely together on the cob. The ears are large, bear a comparatively large number of rows of kernels, and a large number of kernels in the row. The heart or germ surrounded by fatty food substances is comparatively large, indicating rich feeding value and early vigorous growth of the sprouting kernels when planted in the soil or other-

* Dr. Sturtevant, the celebrated authority in the classification of Zea Mays, published an interesting bulletin on the subject, No. 57, of the U. S. Dept. of Agriculture.

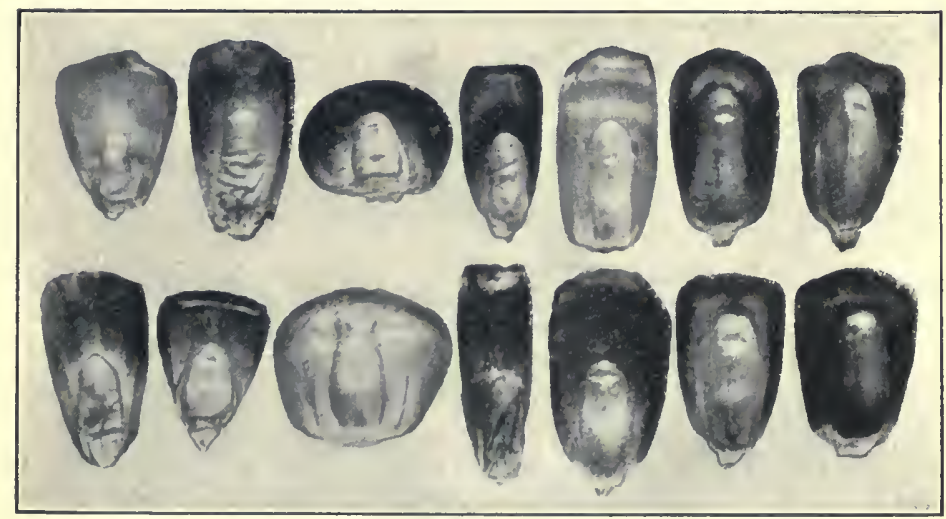

TYPES OF CORN KERNELS. 


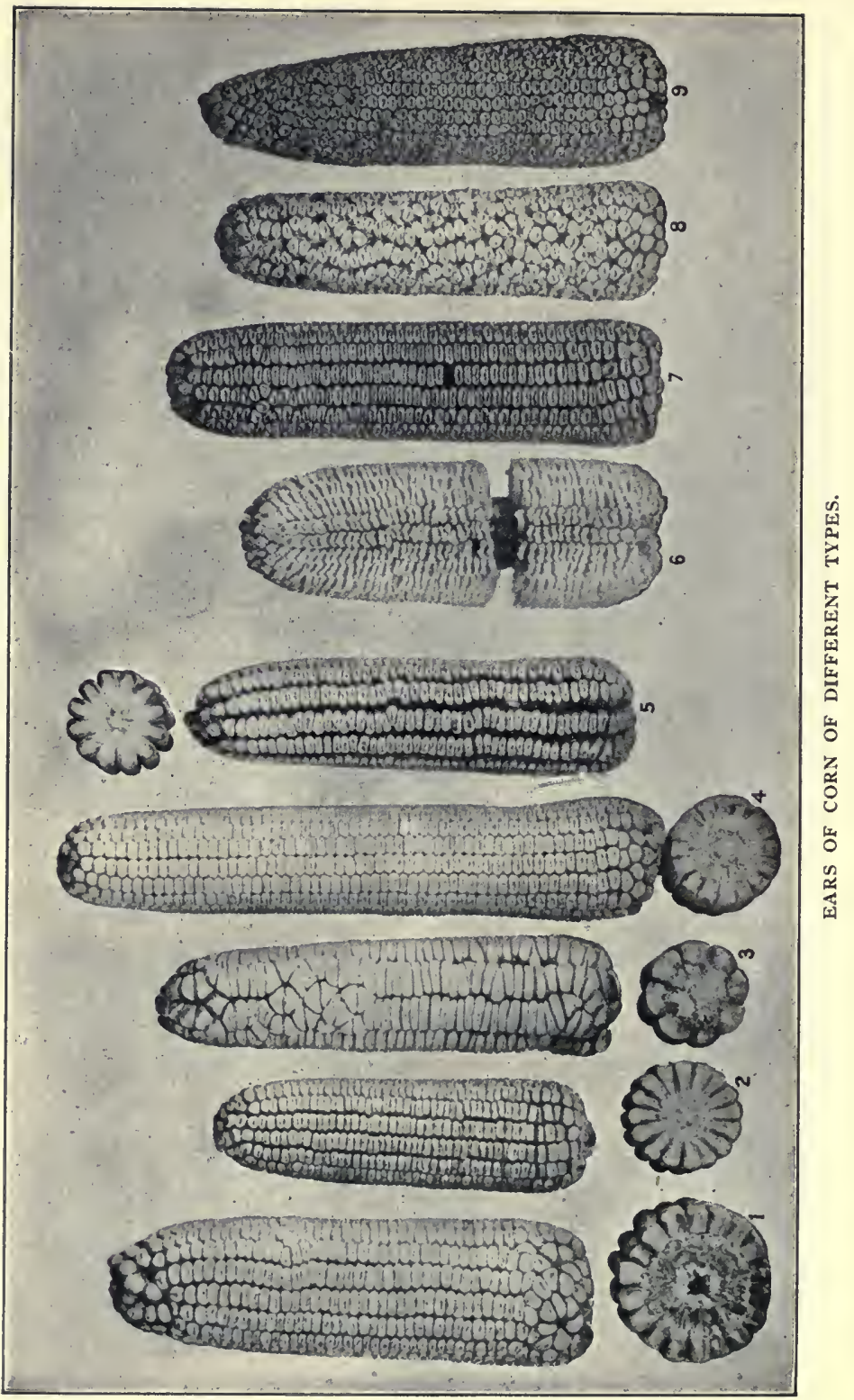


wise. The dents are the principal corns grown in the United States for food purposes, manufacture of alcohol and glucose, and various valuable by-products, and are the corns of most importance grown in foreign corn-growing countries.

2. Zea Amylacea.-The Soft Corns. This speciesgroup is distinguished by the absence of the hard flinty corneous endosperm, and through the uniform shrinkage of the soft starchy endosperm there is little or no indentation of the kernels. The soft corns are grown principally in Central and South America and other countries of southern latitude.

3. Zea Indurota.-The Flint Corns. In the flint corns the hard flinty corneous endosperm of the kernels enclose the soft starchy endosperm. There is comparatively little soft starchy endosperm, so that the kernels are smooth, hard and have a flinty appearance as a whole, hence the name flint corn. There are generally from eight to twelve rows of kernels on the cob, the kernels being shallow, and the plants are usually early in maturing. The flint corns have been grown in northern regions, as New England, Canada and similar regions having short growing seasons, but are being rapidly displaced in these regions by the heavier yielding and richer dent corns.

4. Zea Saccharata.-The Sweet Corns. The kernels of the sweet corns are translucent, and very wrinkled and shriveled in appearance when dry. It is principally grown for roasting ears for table use in the northern sections of the United States, and for canning purposes. The sweet corns are very high in sugar content, and the texture of the kernels in the milk stage is very tender. The sweet corns are probably of American origin, having been discovered by the settlers in the colonies, in cultivation by the Indians in what is now Massachusetts and other regions.

5. Zea Everata.-The Pop Corns. The pop corn kernels have a large proportion of the corneous endosperm, and when dried and heated under proper con- 


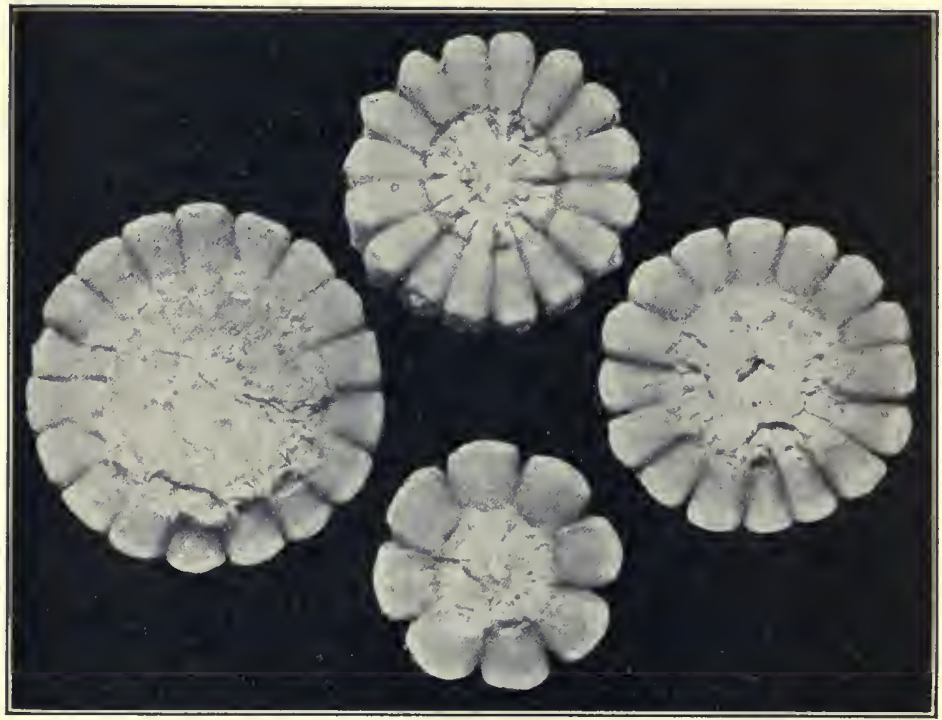

TYPES OF COBS.

At left, ear has too large cob and kernels are too shallow; at right, well-formed ear with medium size cob, kernels are deep and wedge-shape; at top, kernels not of shape to fill well space between grain rows; at bottom, cob too small and kernels too shallow and round.

ditions turn inside out, probably through the explosion of the moisture retained in the kernels. The ears, kernels, and plants are usually of small size, and are cultivated in the United States for popping purposes only, but in some countries, as Austria, these corns are grown for the main crop for animal food as well as for human use. The plants and seeds are hardy, being resistant to unfavorable conditions such as dry weather and low temperatures.

6. Zea Tunicata.-The Pod Corns. The kernels of this species-group are enclosed in pods or husks, and the ears as a whole are frequently enclosed in general husks as is the case with the ears of the other species-groups. In the extensive cultivation of dent and sweet corns, ears of pod corn frequently or occasionally appear, which come fairly true to seed when 
planted. The kernels are usually small, hard and flinty, and the ears and kernels vary greatly in their physical characteristics. The pod corn is not a corn of commerce but is grown to a limited extent in southern countries where it is claimed to be immune or resistant to the attack of certain insects, such as the corn weevils. It is claimed that the husks fitting closely about the individual kernels protect the kernels.

Description of the Corn Plant.-The staminate flowers (the tassel) and the pistillate flowers (the cob and silks, commonly called the shoot) are borne on the same plant, but at different places. The tassel is arranged in the form of a panicle, this terminal inflorescence, or collection of flowers, being called the tassel. The pistillate flowers are borne on a hardened spike or cob, springing from a node on the stem or stalk. In the tassel there are two single flowers in each spikelet, and each flower bears three stamens, which are borne upon slender thread-like filaments. The filaments lengthen during the development of the flower, and push out the pollen-bearing anthers. The anthers are two-celled and at maturity split just above and along one side, allowing the pollen grains to fall

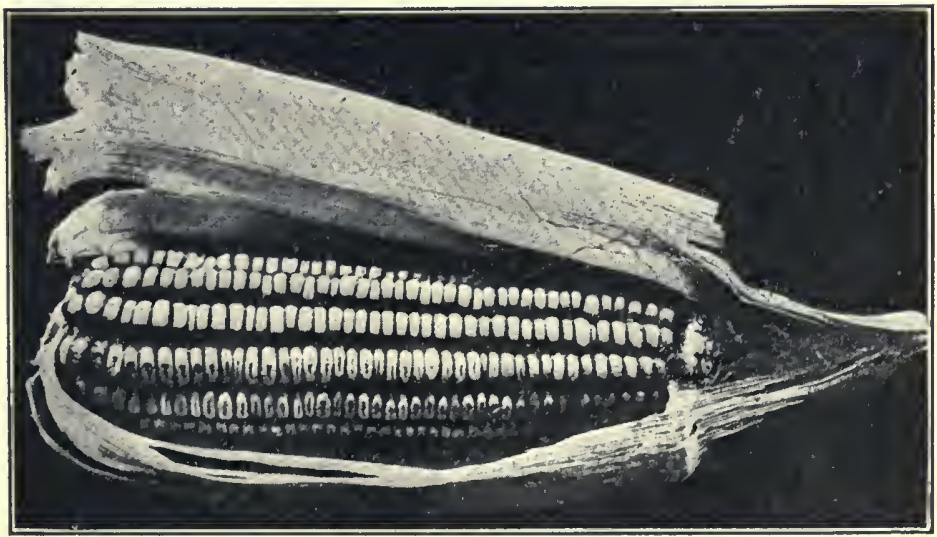

TWO-YEAR-OLD CORN SHOWING PROTECTION FROM WEEVILS DUE TO A TIGHT-FITTING HUSK. 
out or be shaken out by the wind, by which means they are frequently wafted long distances. It has been estimated by the writer that each anther produces about 2,500 pollen grains, and that a single tassel bears about 10,000 anthers, so that the plant produces about $25,000,000$ pollen grains. The pistillate flowers are protected by husks or modified leaves, which open at the proper time to permit the projection of the stigmatic portion of the silk or pistil. This stigma, in a receptive condition, is moist with a sticky substance, and covered with fine hairs. Pollen grains falling on the

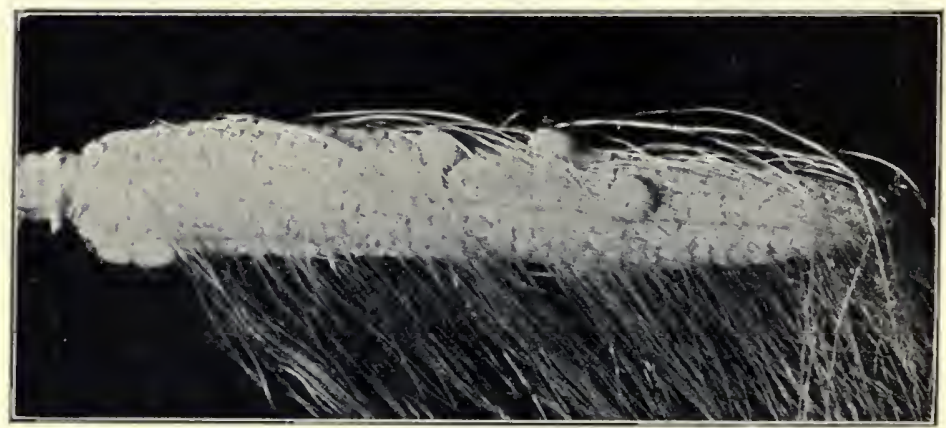

EAR OF CORN BORNE BY ISOLATED STALK, SHOWING LACK OF SELF FERTILIZATION.

receptive stigma are caught by these hairs, and under the influence of the moisture of the stigma and heat of the atmosphere germinate.

The germinating pollen grain sends a pollen tube through the hollow silk to the top of the ovule, where the nuclei of the pollen grain unites with the egg cell within the ovule, and fertilization takes place. The fertilized egg cell begins growth, and together with the surrounding ovary develops into the kernel of corn. As a rule there are from 500 to $\mathrm{I}, 200$ ovaries borne by each cob, with a silk for each ovary.

So it can be seen from the above description that every silk must be pollinated by at least one pollen grain in order for the production of mature corn 
which we use for so many purposes. The corn plant in the United States is an annual, the weight of seed about equals the weight of the stalk with leaves and husks attached, and it requires from 50 to I 40 days of growth to mature the plant.

EXERCISE-What is the average rainfall and temperature for the growing season in your section? What is the average yield of corn in your locality? How does this yield compare with the average for the United States? Bring some corns of different types to the classroom and make a study of the kernels as described in this article. Examine the corneous endosperm and starchy endosperm of kernels of different types.

SeCtion XVIII.MeThods OF CULTURE OF CORN.

Germination of the Seed. - The conditions for germination are: (I) vitality, (2) heat, (3) mo is ture, (4) oxygen or air. Without vitality seed corn will not grow. It is injured by cold weather, extreme wet weather,

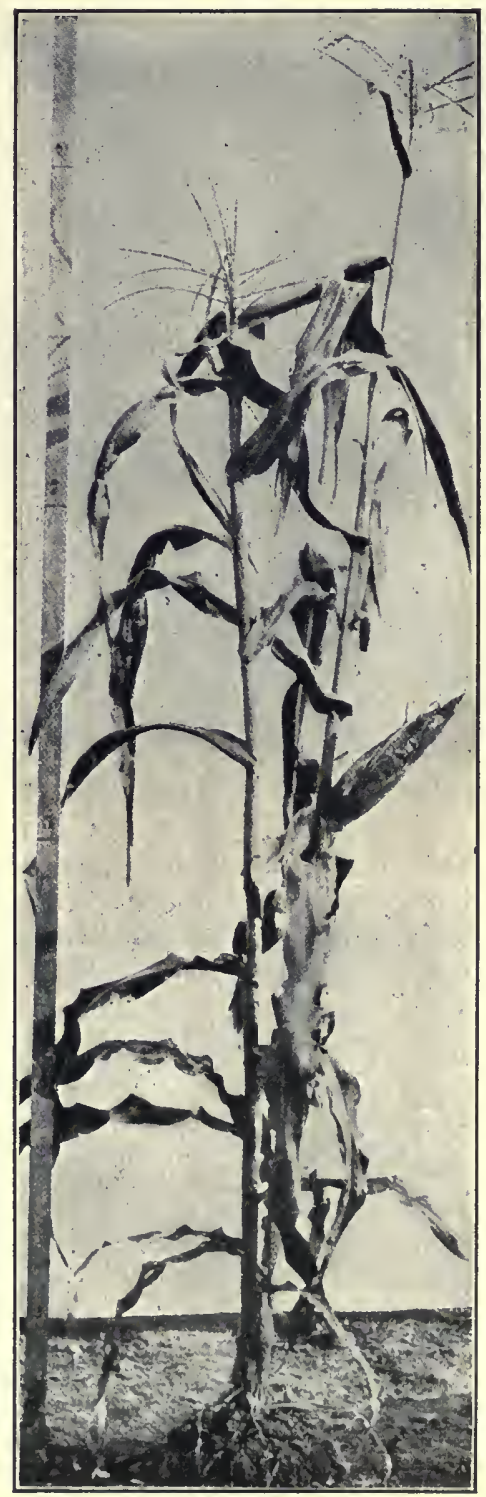

BARREN AND PRODUCTIVE CORN STALKS. 


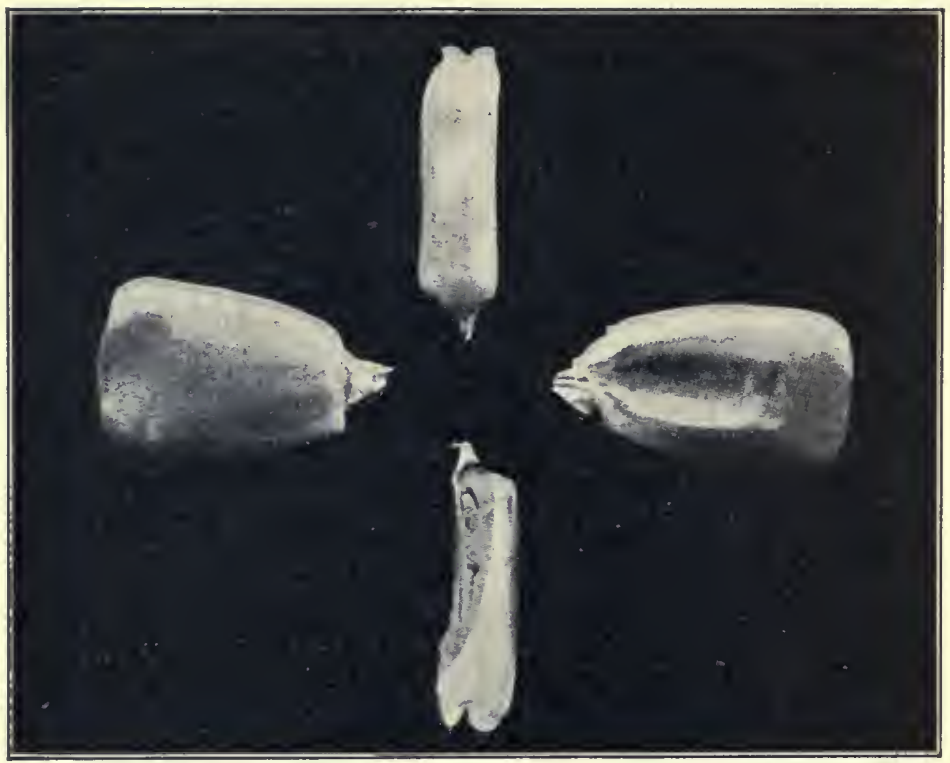

WELL-SHAPED KERNELS.

extreme heat and other causes. If the kernel matures properly on the stalk, is dried out carefully by a free circulation of dry air after husking, the vitality is conserved in good condition under all ordinary circumstances of weather. A certain temperature, usually 70 degrees to 80 degrees Fahrenheit, is most favorable to germination of the seed. Too low or too high temperatures injure the germination of the seed. A certain degree of moisture, such as contained in moist friable soil, is necessary to the best germination. Without moisture germination will not take place. A certain amount of oxygen is necessary for the sprouting seed. The process of germination requires the oxygen to make available the plant food stored up in the seed. Without all of these conditions germination will not take place, and it is the business of the corn.grower to supply these conditions for the 
sprouting of the seed, in the most favorable amounts for perfect germination. The preparation of the seed bed is the means the farmer uses to modify and supply these conditions for the planted seed.

Preparation of the Seed Bed.-As stated above, the object of the preparation of the soil is to provide the most favorable conditions for the sprouting of the seed and further the growth of the living plant. The kind of plowing, the depth of plowing, the time of plowing, etc., must necessarily depend largely upon the nature of the soil, the climate, the lay of the land, and numerous other factors. However, this general principle can be kept in mind under all conditions, viz., the corn plants need a deeply prepared seed bed soil, in fine tilth, so as to supply and conserve moisture, admit heat and air, and provide abundance of space for the innumerable small spreading roots and root hairs. The functions of the roots are to hold the plants in place, support them in an upright position, and supply plant food which is carried to the leaves, elaborated, by the chemical process of the fluids in the cells of the plant in the presence of air and sunshine, into materials that build up the various parts of the plant

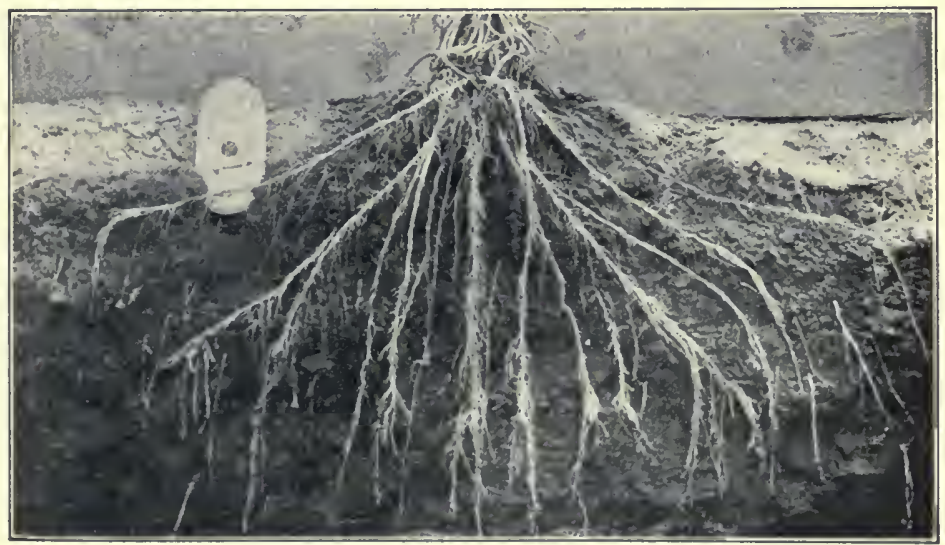

ROOT DISTRIBUTION AT SILKING TIME. 
during the growing period. During this period there is an immense quantity of water transpired by the plant, given off through the leaves, and it is necessary to till the soil so as to supply an abundance of soil water for the use of the plants. Without the necessary water, the plants become stunted, wilt and die. Most good corn soils, when properly handled and rotated, can be plowed from 6 to Io inches deep. The plowed land should be disked and harrowed to bring it to a fine mellow condition before the seed is planted.

Planting.-There are two general methods of planting corn, in drills and hills. When drilled the seeds a re usually dropped singly in rows from 3 to 4
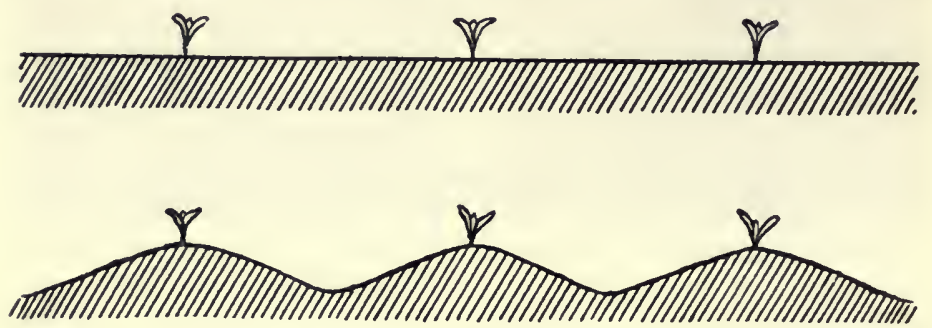

TWO METHODS OF PLANTING CORN.

feet apart, from Io to 16 inches apart in the rows. When planted in hills, i. e., " checked," from two to four kernels are planted in rows from 3 to 4 feet apart, the hills being planted from 3 to 4 feet apart.

The advantage of checking lies in the fact that this method permits of cross cultivation, which is an important factor in the cultivation of the crop. Wherever possible the writer believes in checking seed corn.

Cultivation.-The objects of cultivation are: ( 1 ) to conserve soil moisture, (2) remove weeds, (3) preserve a fine tilth, (4) aerate the soil. Extensive experiments have shown that, under normal conditions, it is best to use small shovel cultivators, or "surface" cultivators, and go over the field from six to eight 


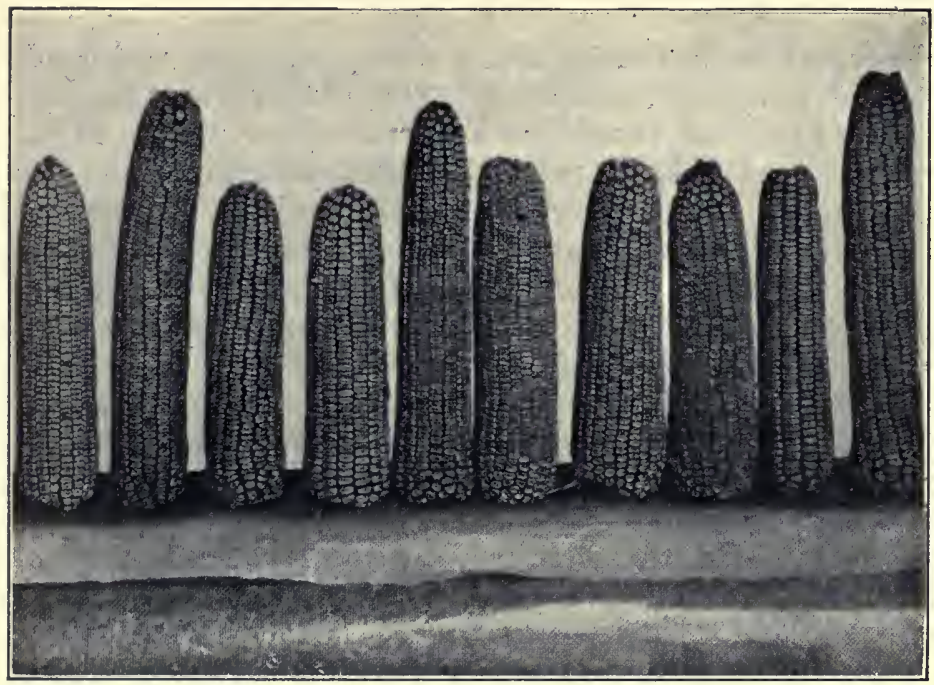

TEN EARS OF BOONE COUNTY WHITE CORN SHOWING VARIABILITY IN TYPE RESULTING FROM FAILURE TO SELECT SEED.

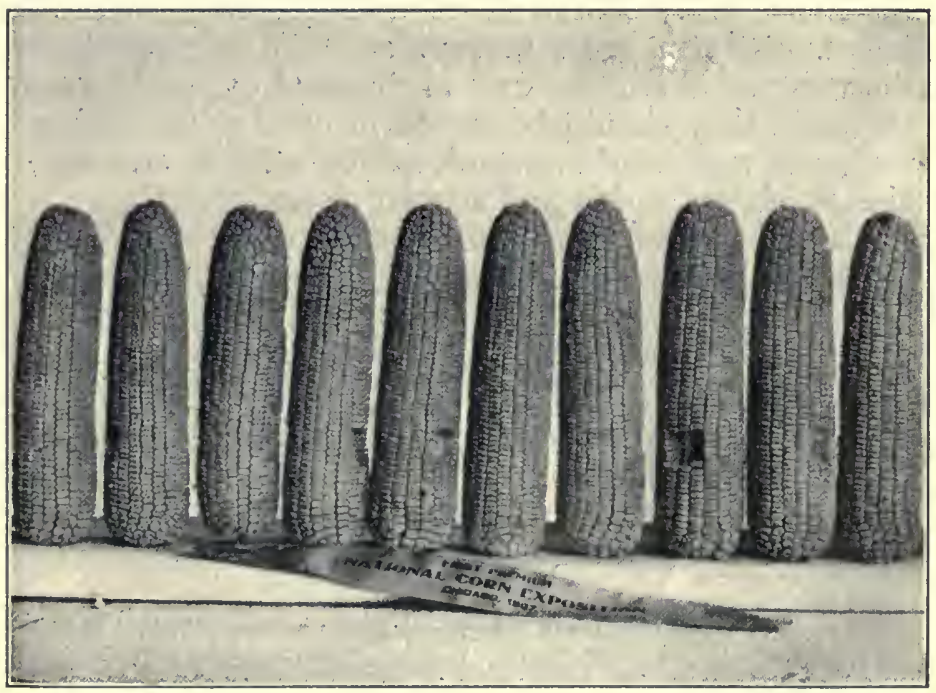

TEN EARS OF SAME VARIETY SHOWING RESULTS OF THIRTY-TWO YEARS OF SEED SELECTION. 
times at least during the growing season. On level fields two row cultivators are preferable. In all events the soil should be kept free from weeds at all times, and a loose mellow mulch maintained on the surface. After the corn reaches waist high, or too high for the one or two row cultivators, it pays especially in dry seasons to hitch one horse on to a small harrow or other shallow-toothed instrument and keep the surface soil frequently stirred.

Harvesting. - The method of harvesting depends on the purpose for which the corn is grown. In general the writer believes that if possible all of the crop on the ordinary farm should be fed to live-stock, after which the manure should be carefully composted and returned to the land. Silos are ideal means of preparing the corn plant for food. Shredders and other means of tearing up the stalks and husks are desirable implements wherever practicable. Feeding the fodder from the shock is wasteful, but better than not feeding at all. If fed in this manner, hogs ought to follow cattle in order to save as much as possible of the waste. When the ears are husked or jerked from the stalk they should be stored in open cribs, covered well, and protected from mice, rats, weevils and other agents of destruction and waste.

$V$ arieties.-Some of the leading varieties of corn may be classified according to corn regions as follows :*

* A history of the production of some of these varieties was published by the writer some years ago in a Bulletin from the Illinois Exp. Station, Urbana, Ill., entitled, "Some Standard Seed Corn Varieties."

Dent CoRns :

Northern Varieties:

Brewers' Yellow Dent, Minnesota No. I3.

Central Varieties:

Reids' Yellow Dent, Leaming, Boone County White, Johnston County White, Pride of the North, Silver Mine, Bloody Butcher and Strawberry.

Southern Varieties:

Whelchel White Dent, West's White Dent, Hickory King, 
Selection of Seed.-If a corn grower is not satisfied with his corn, if it is low yielding or undesirable for other reasons, it should be his business to investigate the possibility of securing other varieties of higher yielding power, and of more profitable production. This can be done in several ways: (I) study yield tests in Experiment Station Reports of Home State Agricultural Experiment Station; (2) through the Agricultural Press; (3) personal visits to planters using other varieties; and (4) by correspondence with corn breeders' organizations.

After securing a satisfactory variety it should be improved by intelligent and continuous selection of seed. In order to make the best selection it is desirable to study the plants as early as possible, observe them frequently all season, and save seed ears from the type of plant bearing the kind of ears desired. When the crop is husked a sharp lookout should be kept for fine ears, and the desirable ones for seed thrown in a separate receptacle for future more careful inspection. The best ears are frequently found unexpectedly developed in nature's laboratory by means we do not fully understand.

Corn Judging. The first corn judging school, so far as the writer knows, was held at the University of Illinois in the fall of r 898 . A short corn judging course of two weeks for farmers, the same winter, at-

Boone County White, Marlborough Prolific, Shaw's ImSWEet Corns : proved, Calhoun Red Cob.

Crosby, Country Gentleman, Molakhof, Evergreen, and numerous local strains.

POP CORNS :

White Transparent, Rice, and numerous local and other varieties.

Flint CoRns:

Canada Eight-Rowed, Longfellow, Wilson Hybrid, Yellow Creole, and numerous local varieties.

Fod Corns and Soft Corns:

No special varieties known to the writer other than a new variety of pod corn not named: widely advertised by H. J. Sconce, a corn breeder of Illinois. 
tended by sixty-five Illinois corn growers, was given at the same place. The first score card for students' use was written about 1891 . So it can be seen that systematic corn judging is a matter of recent history.

The object of corn judging is to compare seed ears of given varieties as to their value for seed purposes. Scales of points, standards of perfection, etc., have been prepared for the important varieties. It is impossible to quote these score cards here, but the important points will be briefly mentioned. It should be kept in mind that the score cards, etc., are of assistance in the study of ears of corn, but the experienced judge does not, and the writer believes cannot, solely use them in picking out seed for breeding purposes. The important points are:-

I. Maturity. Unless a corn matures it is useless in the region where grown. The ears should be sound, firm, dry, and not show signs of weathering.

2. Vitality. Unless a corn will grow it is useless for seed purposes. The germ should be large, plump, bright and show indications of perfect preservation of vitality.

3. Yield. Unless a corn produces a profitable yield it is not worth planting under normal conditions. The higher the yield of shelled corn the better the corn. As a rule high yield is associated with large,

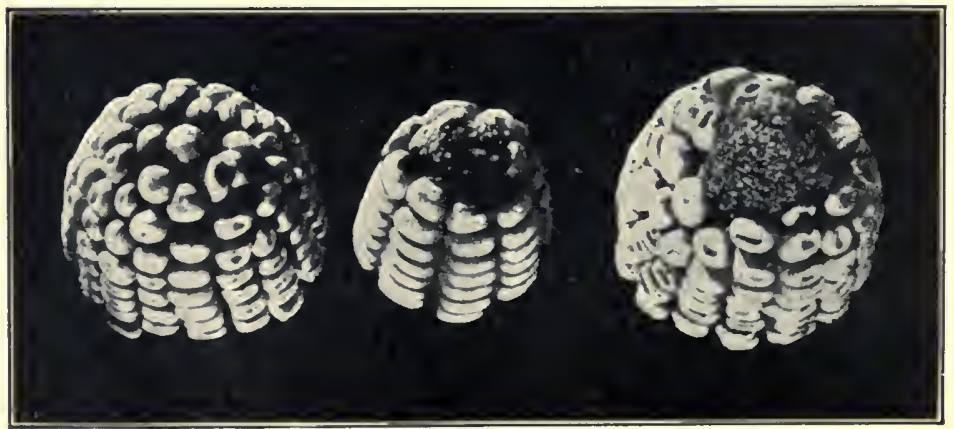

WELL AND POORLY DEVELOPED CORN AT TIPS. 


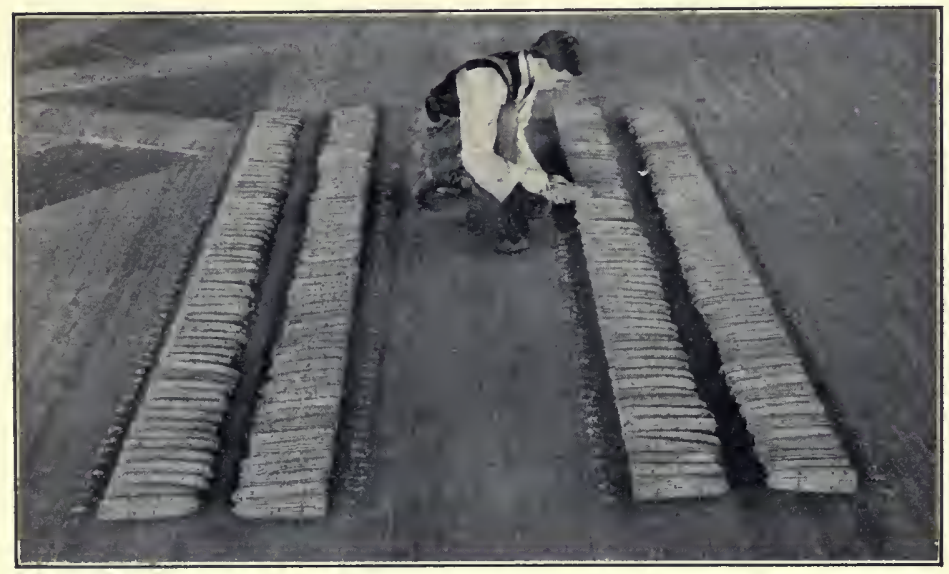

REMOVING KERNELS FOR GERMINATING TEST.

heavy, mature ears, bearing deep wedge-shaped kernels, having large germs and a large proportion of the hard flinty endosperm. The rows of kernels are usually straight in well-bred varieties, the color pure, white kernels, white cob, yellow or other color of kernels, red cob, although there are exceptions to this rule. In all events the heaviest mature dry ears are usually the best. The ears should conform to variety characteristics.

Seed Corn Testing.-Although the general condition of the seed corn can be judged from the condition of the kernels, it is wise to test every seed ear planted. This can be done as follows: Secure a box at least 2 feet $\times 3$ feet and 6 inches deep. Fill half full of moist sawdust. Mark a white piece of cloth the size of the box off into checker-board squares with a lead pencil. The square should be about 2 inches $\mathrm{x} 2$ inches. Lay this cloth, marked side up, on top of the sawdust, and tack to sides of box. Number each square. Take a sample of six kernels, from different parts of the ear, from every ear. Be sure each ear is labeled. Lay the sample kernels from ear No. I 
in square No. I, and so on. Cover the samples with a cloth and pack the remainder of the box full of wet sawdust. Cover with boards and set away in a warm

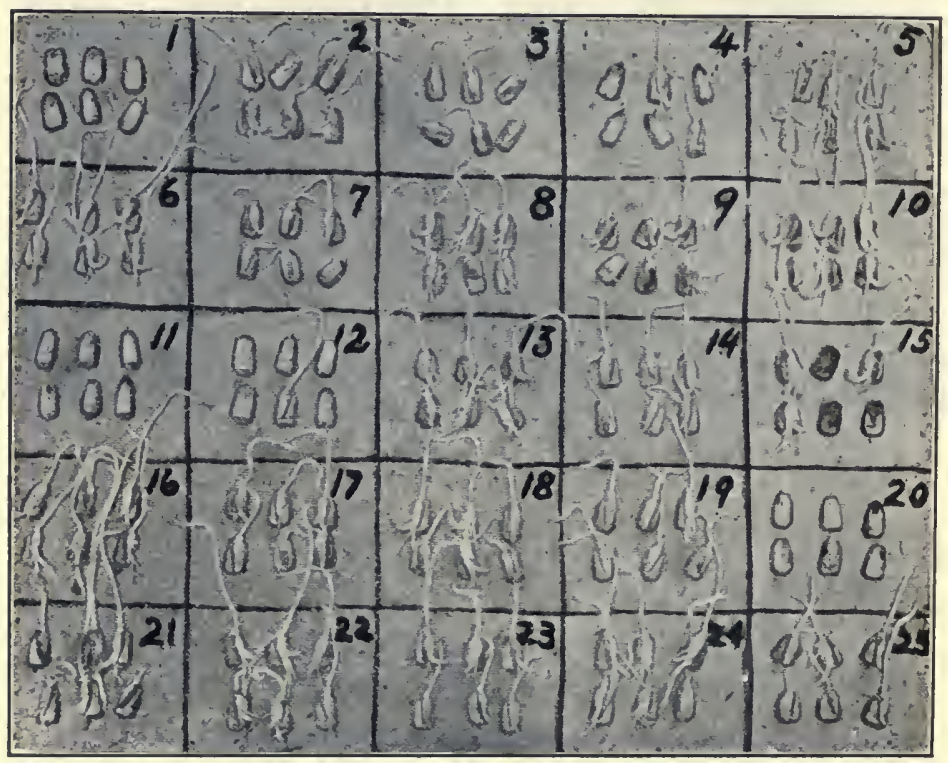

SEED IN GERMINATING BOX.

safe place. At the end of seven days carefully roll off the top cloth. Study the samples. If a sample, say No. 5, has germinated poorly, discard ear No. 5 . Save for planting only the ears, the samples from which show healthy vigorous normal sprouts. This practice will help insure a perfect stand, which is essential to a high yield.

Corn Breeding.- The term corn breeding is here used to mean the improvement in yielding power of corn by seed selection. The writer uses the following plan. The best ears, in the entire crop, are planted in a separate patch of not less than one acre. In order to study the yielding power by individual ears, 
ten are selected and a row roo hills long planted from each. During the summer the tassels from all of the poor or barren stalks are pulled out before the pollen falls. In the fall the ten rows are husked and weighed separately, and from these figures the best type of ear determined upon for future use and guide for selecting of seed ears. The best ears of the patch are all saved for future close inspection and used if needed. This plan is kept up under all circumstances. The seed is stored on racks, one ear deep. . Warm dry air is passed through the seed room. An open attic is an admirable place. When dry, the seed is in good condition for passing the winter.

The Rolation of Corn with Other Crops.-All experience points to the fact that the soil becomes corn

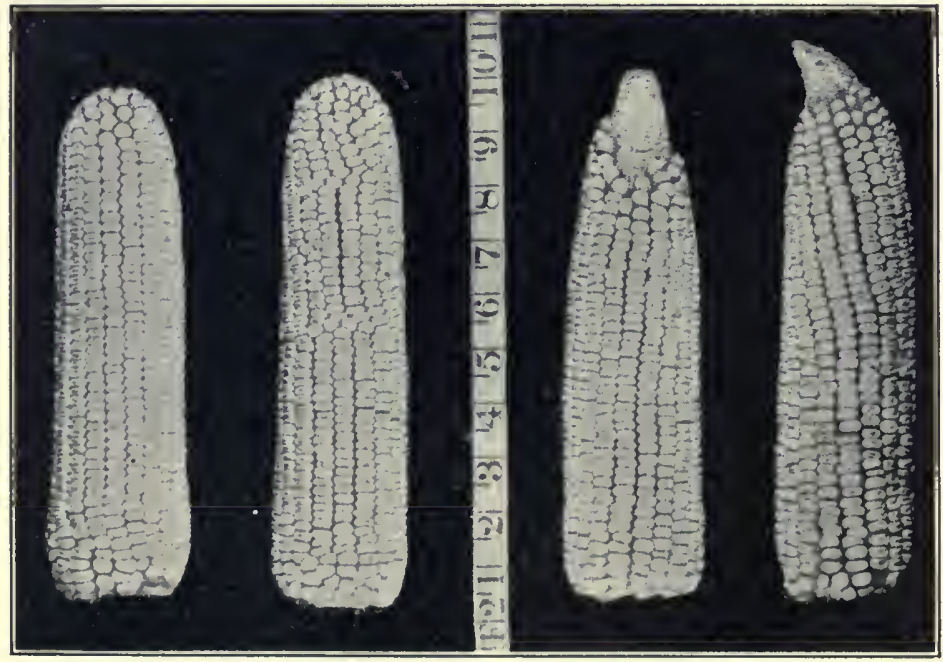

IMPROVEMENT OF CORN BY SELECTION.

sick if this crop is grown too long on the same land continuously. Therefore it is considered to be wise to rotate this crop with others. The crops to be used for rotation depend largely on the region where the 
crop is grown. If possible the rotation should always include a legume. In the corn belt, corn, oats or wheat and clover is a good rotation. In the south, corn, cowpeas, or soy beans or other legumes with or without a cereal ought to be considered. If the legume can be fed on the land so much the better.

ExERCISE--State the popular method of planting corn among your people and state why this method is used. Bring a cornplant in tassel to school and make a study of its roots, stalk, leaves, tassel, etc. Do all stalks of corn produce ears? How many ears of corn generally grow per stalk? If the rows of corn are planted $5 \mathrm{ft}$. apart, the distance between the plants is $2 \mathrm{ft}$., and 115 ears shell a bushel, what would be the yield if every stalk produced an car? Name the varieties of corn of your section. Bring ten ears of corn to school and learn how to pick out the best ear. How would you improve the yield of corn? State what corn is used for at your home.

\section{Section XIX.-Cotton.}

By Prof. W. R. Dodson,

Dean of the College of Agriculture, La. State University and Director of the La. Experiment Stations.

Importance of the Crop.-Cotton is the most important farm crop grown in the United States south of the thirty-seventh parallel of latitude. No other vegetable fiber is used throughout the world so extensively or for such a diversity of purposes. The southern states produce from ten to thirteen million bales of 500 pounds each, which is about three-fourths of the world's supply of cotton, and the value approximates three-quarters of a billion dollars annually. Nearly two-thirds of the crop is exported and is our greatest article of export. The value of the cotton and cottonseed products exported from the United States is greater than twice the value of the exported packing house products. It is greater than twice the value of all the grain and grain products exported. It is more than one-third of all the agricultural exports of the United States including forest products.

History.-It is not known when and where cotton was first used by mankind. Probably it is native to 
the tropics of both hemispheres. Very early writers refer to it as tree wool. It is probable that it was carried from Asia to Egypt, and from there to Europe in early times. Its rapid growth in favor to the position of the most important fiber crop of the world covers a period of but little more than a century. The invention of the cotton-gin in 1793 , for separating the

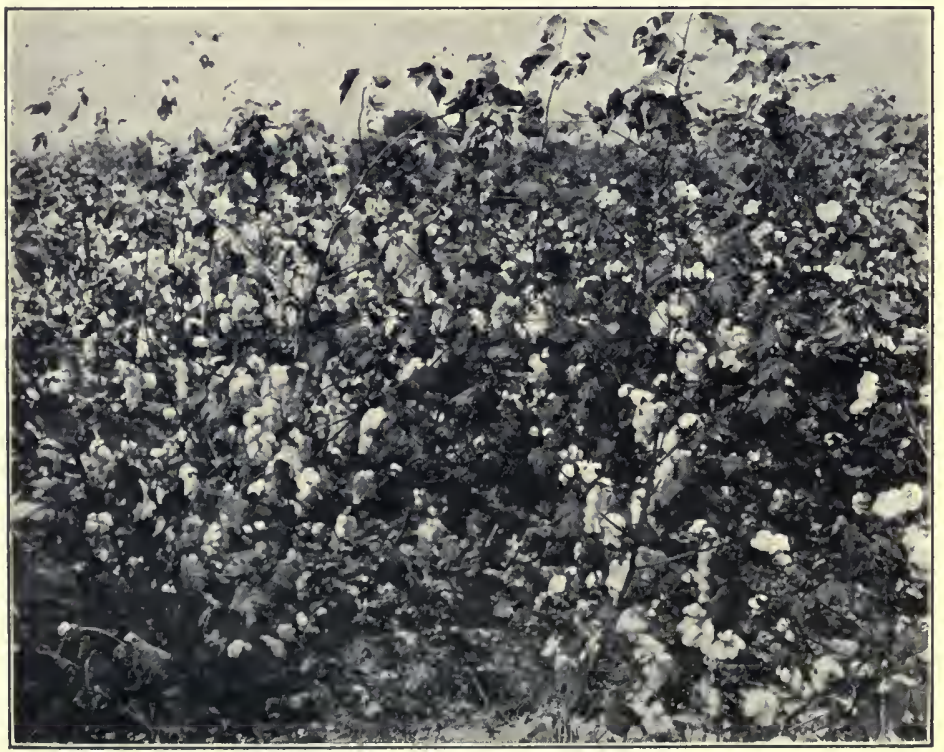

A FIELD OF COTTON.

lint from the seed, caused a sudden expansion of the cotton-growing industry.

Region of Cultivation.-Cotton can be grown more or less successfully in any latitude where the period of exemption from frost is five and half to six months, and where favorable soil and moisture conditions are to be had. It thrives best in well drained mixed soils. The territory of the United States south of the thirtyseventh parallel and east of El Paso, Texas, offers the 


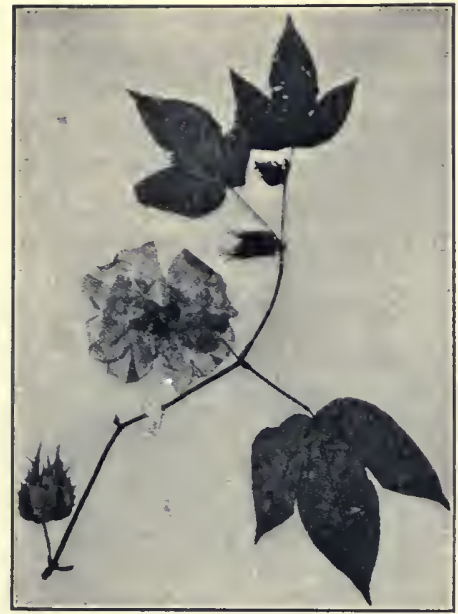

SEA ISLAND COTTON.

most favorable conditions for extensive cotton production.

Botanical Characters and Habit of Growth.The cotton plant belongs to the Mallow family, and the generic name, Gossipium, means silky, referring to the character of the lint. All cultivated species are perennial in climates free from freezing temperatures, and become more or less tree-like. In sub-tropical countries they are regarded as annuals, the seed being planted for each crop. The stalk is always more or less woody. 'The habit of branching varies with the varieties. Some develop a strong central stalk with short laterals, like Jackson limbless, and others have lateral branches, almost as long as the central stalk. The distance between the joints is regarded as important in the production of early cotton. The fruit is borne at the joints of the side limbs, and in the territory where early fruiting is desired, either because of short summer or the ravages of the boll weevil, improvement to this end is made by selecting seed from stalks that branch

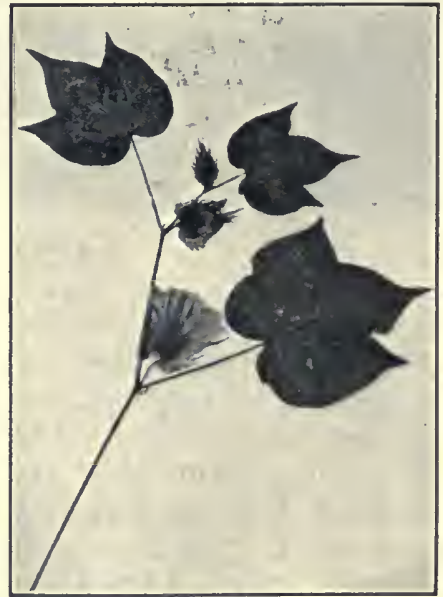

AMERICAN UPLAND COTTON. 
near the ground, have the joints close together, both in main stem and side branches, and with fruit branches at the greatest number of joints. As the seed of a single stalk reproduces fairly true to parent stock, the seed of an improved strain can be multiplied rather rapidly. The flower bud with adherent leaf bracts is called a "square." The flowers are white or cream-colored when they first open, but gradually turn pink and close at night. The second day they are deep pink, almost red, and at the close of the second day they wither and in a day or two drop off. Sea Island cotton has yellow blooms.

Rains falling in the early part of the day when cotton is blooming rapidly cause considerable damage by preventing fertilization of the flower, preventing the formation of a boll.

Selecting and Breeding.-The stigma of the flower stands above the stamens, and cross breeding may be accomplished without great difficulty. About three weeks are required for development from a small flower bud to a splendid bloom. It will be from forty to fifty days from the time the bloom opens until the boll is mature. A period of seventy to ninety days after planting, with gradually increasing temperature, warm nights and well-distributed rainfall, produces the best stalk; and if this kind of season is followed by hot, moderately dry weather until late in the season, a maximum crop will be produced.

The division of the stigma indicates the number of cells the boll will have at maturity. Five cells are generally preferred, not only on account of convenience in picking the mature crop, but because the best returns are generally secured. The mature seed with the adhering lint in one cell of the boll is called a "lock." A lock generally contains six to eight seeds. The mature bolls burst open through the middle of the cells, and the locks are exposed. When the divisions of the boll separate widely the cotton is most easily picked, but is liable to be blown to the ground 
and damaged by storms. By selection strains have been developed under the name of "stormproof " that do not open widely, but such strains are generally

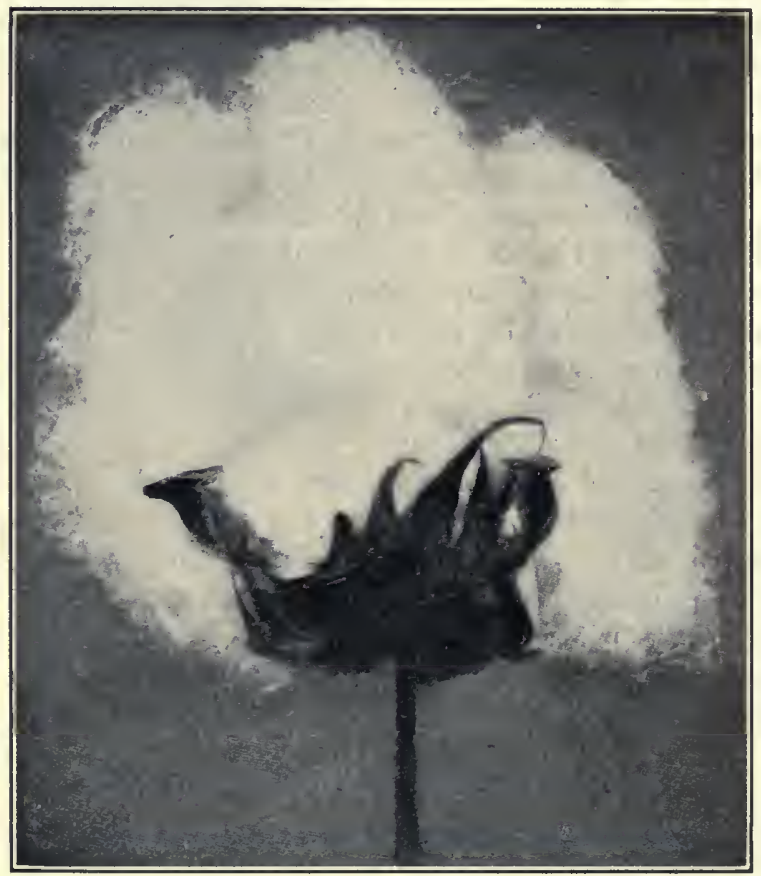

NATURAL OPEN COTTON BOLL.

rather difficult to pick. Most of the early varieties have small bolls and short fiber. From 70 to 100 bolls of these varieties are required to yield a pound of seed cotton. Large boll varieties are also being established for early maturity, and of these 55 to 70 bolls make a pound of seed cotton. Satisfactory results have not been secured in attempts to grow an early variety with long lint.

Select Seed from Best Plants.- - The average farmer gives little if any attention to selecting his cotton seed 
from the best plants. A little intelligent work in this line will greatly improve the crop, because he can modify almost any of the characteristics of the plant by selecting seed from the stalks showing the desired characters most strongly developed. It is generally best to take advantage of what others have accomplished in these lines and start with seed that are known to be good, and continue the improvement for adaptation to local conditions. The seed from each selected stalk should be planted in a row by itself and if it shows strongly the desired characters the crop can be saved for a larger planting. A nursery plot where the selections of fifty or more stalks can be per-

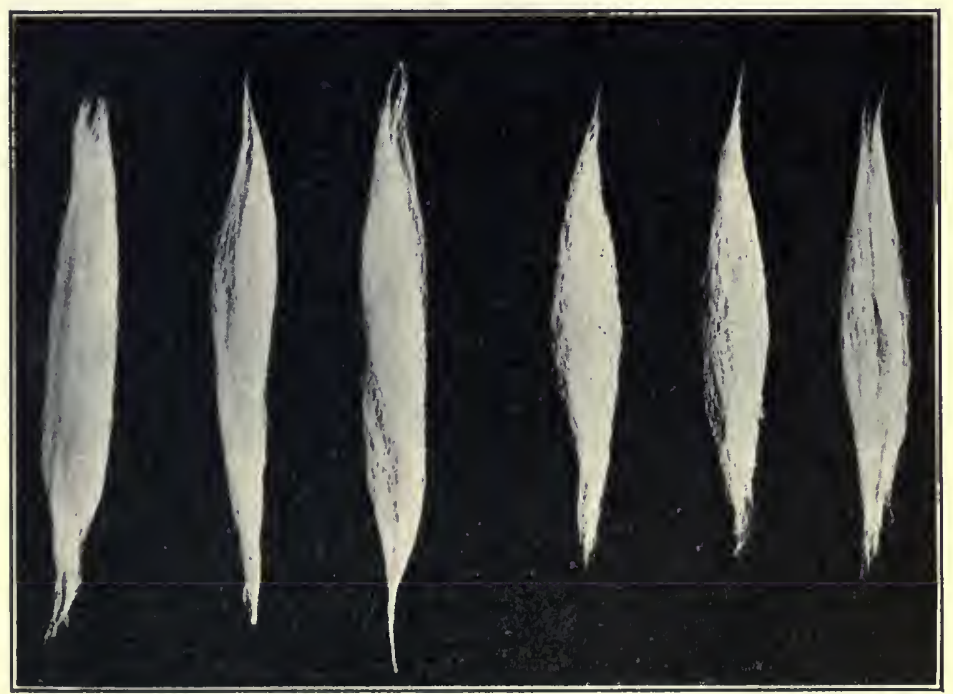

COTTON IMPROVED BY SELECTION OF SEED.

petuated in this way each year will lead to great improvement in the field crop.

Nature of Fiber.- The fibers or hairs develop from the surface of the seed. In the Sea Island cotton, and in some seeds of many upland cottons, the hairs be- 
come separated from the seed at maturity, leaving the surface of the seed perfectly smooth, except a little area at the small end. When we view a fiber under the microscope we find it to be a collapsed tube approximately I/I 500 of an inch in diameter, and somewhat spirally twisted. These characters give it spinning qualities. The value of the lint depends primarily upon its length, fineness and strength. The Sea Island fiber is one and a half inches or more in length and

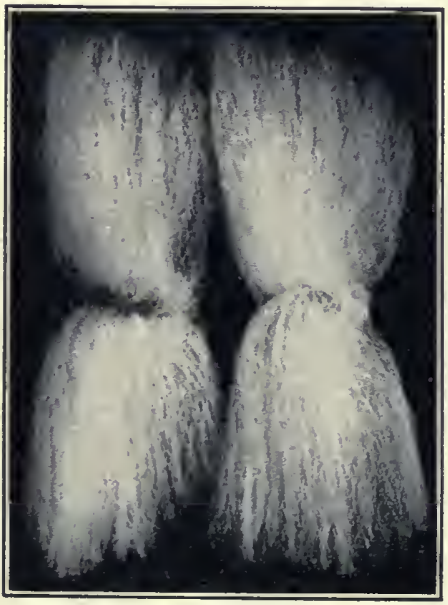

SEEDS WITH FIBER ATTACHED; LONG STAPLE COTTON.

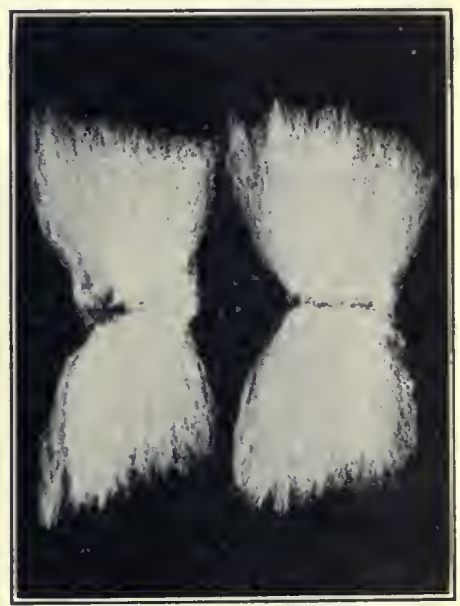

SEEDS WITH FIBER ATTACHED; SHORT STAPLE COTTON.

forms a class by itself. It sells for about three times as much as middling short staple. It is grown on the coast line and outlying islands of South Carolina and Georgia and cannot be successfuly grown in the interior.

Long Staple Upland Cotton has lint from one and a quarter inches to one and five-eighth inches in length and constitutes a second class. The Black Rattler, the Bender, Allen's Long Staple, Flora Dora and Griffin are among the best varieties. These are cultivated mostly in the rich alluvial lands. Allen's Long Staple 
is the most popular for uplands. The boll weevil greatly curtails the long staple crop, as all long staple varieties mature later than short staple varieties, and the boll weevils become very numerous in late summer, destroying all squares and young bolls.

Short Staple.-Fibers of less length than given above are classed as "short staple." The bulk of the cotton crop is of this kind. Market quotations are based on "middlings," "short staple" as a standard. Coarse cloth is made of short lint, the finer grades of longer staple. Where the boll weevil is to be contended with, the King, Simpkin's, Toole's and Cook's Improved are among the best small boll early varieties. The Triumph and Rowden are large boll early varieties suited to some soils.

EXERCISE.-Give the names of the varieties of cotton of your section. What types are they? Classify them as having large and small bolls; large and small seed; as branching high and close to the ground; as early and late maturing. Do you know of any planters selecting and improving cotton? Secure leaves anid stalks of as many varieties as possible and make notes of their differences.

\section{Section XX.-The Culture of Cotton.}

Preparation of Soil for Planting. - Where flat cultivation is practiced, or where grain has been the preceding crop, the land is generally plowed broadcast and harrowed in preparation for the planting of cotton. Where cotton follows a previous crop of cotton and cultivation is in ridges, the preparation generally consists of listing two or four furrows on the old middles and subsequently breaking out the old row. This may be accomplished with a double mold board plow or other implement. The newly formed ridge is harrowed with an A harrow. In most soils it is advantageous to prepare the land as far in advance of the planting as practicable. Running a double mold board plow down the old middle before listing gives better preparation than can be secured without 
it. Broadcast plowing will generally give the best preparation of the soil. After harrowing, the ridges can be sufficiently reformed by the disk cultivator at one passing of the implement.

Rows vary in width from $3 / 2$ feet in poor lands to $5 \mathrm{I} / 2$ feet in the rich alluvial lands.

Planting is generally done with a planter, though it may be done by hand, a small shovel plow being used

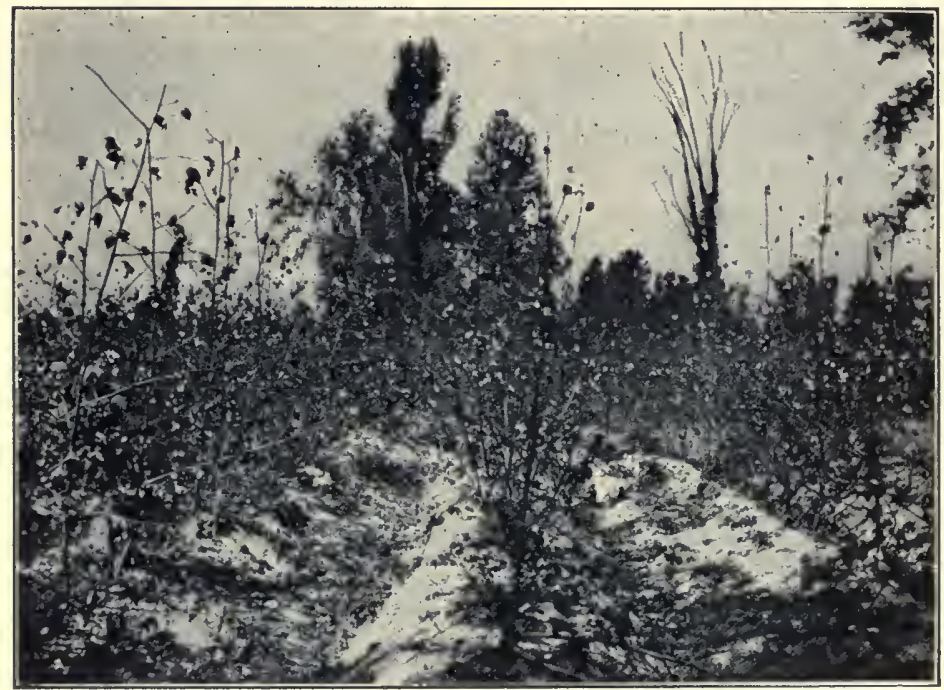

FIELD OF IMPROVED COTTON, SHOWING METHOD OF RIDGE CULTURE.

to open the furrow for the seeds. The seeds are then covered by a drag or harrow or small plow. About one bushel of thirty pounds of seed is required to plant an acre. The seeds are put in much thicker than required for a stand. Planting is begun as soon as the danger of frost is thought to have passed. About the I $5^{\text {th }}$ of March would be early planting for southern latitudes and May i 5 th would be late planting for northern latitudes. The planting period is approximately thirty days for a given locality. 
Thinning to a Stand is accomplished by "chopping out" with a hoe the excess of young plants, leaving three or four stalks in hills 12 inches apart in poor land, and as much as 20 to 24 inches apart in rich bottom land. A little later these hills are thinned to one stalk. No machine has been invented that will accomplish this work satisfactorily, but off-barring close to the row so as to leave a narrow ridge with abrupt sides greatly facilitates the process, and lessens the amount of hoeing for cleaning the land.

Fertilizers may be applied before the seeds are planted or at the time of returning soil to the plants after chopping out, or as a top dressing during the cultivating season. When the fertilizer is sown in the middle and the row bedded on it the best results in early maturity will be secured except in sandy lands, where fertilizers should be applied during cultivation. Chemical fertilizers that are readily soluble, like nitrate of soda, are applied as top dressing, and application should not be made very far in advance of the period when their effect is desired. Nitrogen stimulates the vigor of growth in stem and leaf. Phosphorus stimulates the production of fruit, and potassium frequently prevents shedding of leaves prematurely. Potassium is of little or no value in many soils. On average soils 300 to 400 pounds of fertilizer made of equal parts of cotton-seed meal and highgrade acid phosphate gives good results. Where a. crop of cowpeas precedes cotton, or where large stalks are produced, phosphate only should be used. It has been estimated that 500 pounds of lint would contain only $\mathrm{I} .7$ pounds of nitrogen, .5 pounds phosphoric acid and 2.3 pounds potassium; but that the accompanying thousand pounds of seed would contain $3 \mathrm{I}$ pounds nitrogen, I 3 pounds phosphoric acid and I 2 pounds of potassium. It will thus be seen that the loss of fertility is mainly in the seed, and the nitrogen will not be fully restored by the fertilizer given above. No consideration is here given to the loss in the stalks 


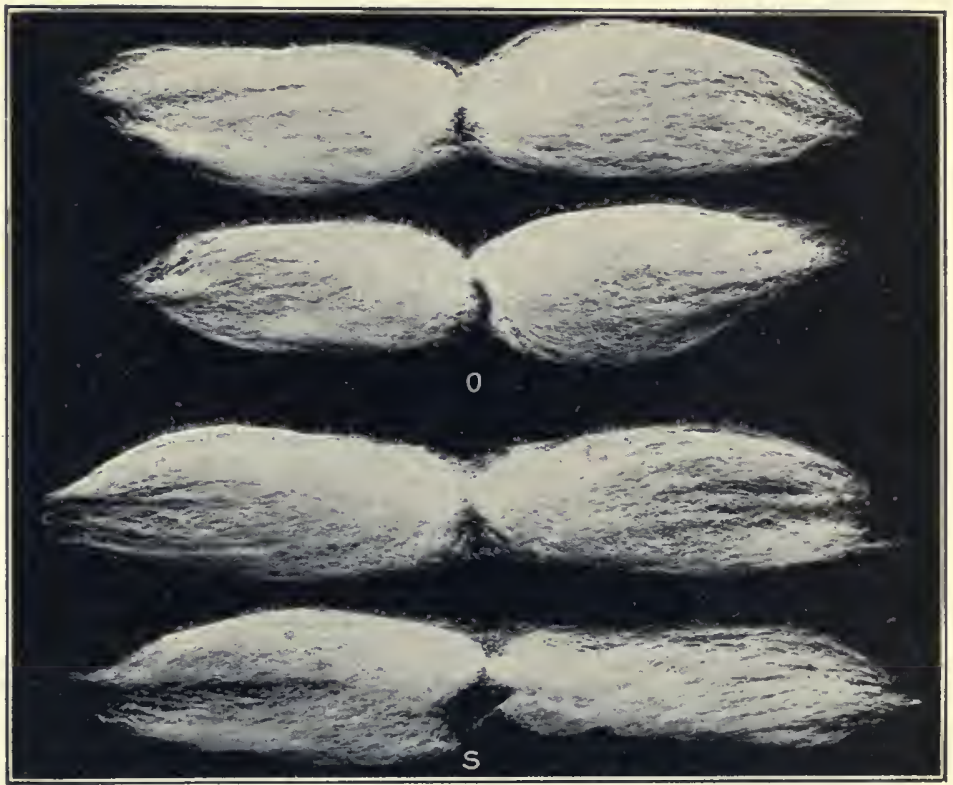

IMPROVEMENT OF SEA ISLAND COTTON BY SELECTION.

$\mathrm{O}$, ordinary cotton; $\mathrm{S}$, selected cotton.

and leaves. When these are burned the nitrogen in them is lost. A portion of the other food elements remains in the ashes. Where it is possible to do so, the stalks should be cut with a stalk cutter and plowed under.

Cultivating.-The method of cultivating the crop varies greatly in different sections. In the light soils sweeps are used almost entirely. On stiffer soils plows and cultivators are used more extensively. The destruction of grass and weeds and the conservation of moisture may be most effectively and economically accomplished with modern cultivators, and their use is increasing. The soils should be cultivated as soon as possible after each rain, or in dry weather as often as may be necessary to maintain a mulch of loose soil. 
A man with a double team can cultivate about six acres in one day. If the middles are also to receive additional cultivation, the same area in the same time can be gone over with a single team with a sweep or middle cultivator. The lateness to which cultivation can be carried profitably will vary greatly in different sections.

Harvesting.-Cotton is harvested by hand labor. A moderately good hand can pick 200 pounds of seed cotton in a day. Picking is contracted for by the hundred pounds, the price ranging from 50 to 75 cents. Several machines for picking cotton have been patented, but none of them have come into general use.

Ginning.-After the seed cotton leaves the farm it is handled entirely by machinery. It is ginned, carded and woven by steam power. A suction fan lifts it from the wagon to the gin, where revolving saws take off the lint, leaving the clean seed. I,500 pounds of short staple or 1,700 pounds of long staple

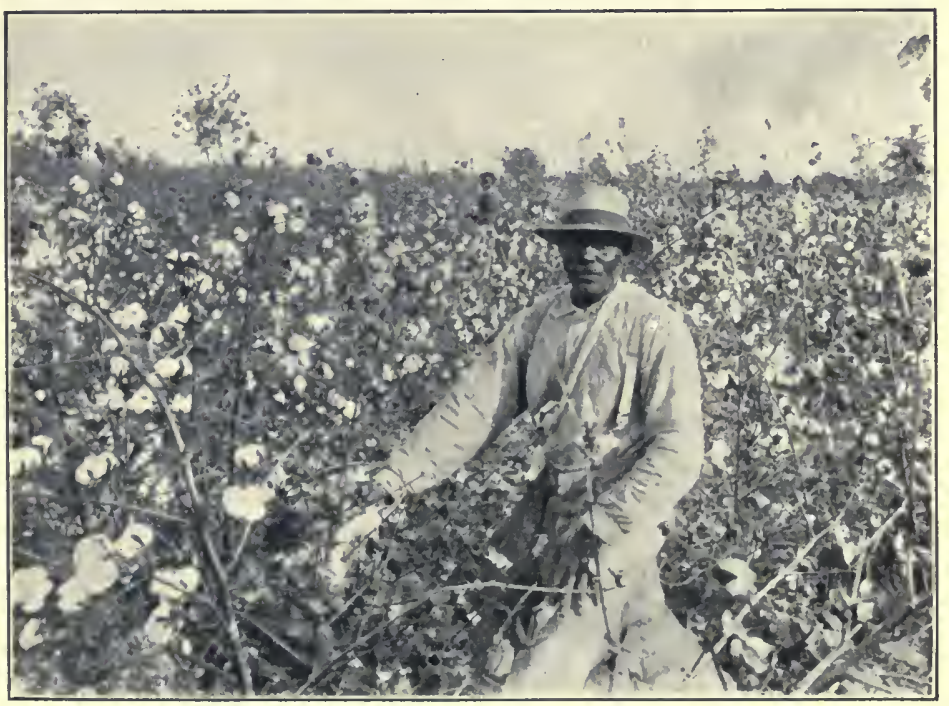

PICKING COTTON. 
will give a bale of 500 pounds of lint. The pressed bales are covered with jute bagging and bound with six steel bands. It takes about seven yards of bagging to cover a bale. Ginning is done at a stipulated price per hundred pounds, or per bale. The gin saws injure the fiber of long staple, and Sea Island is ginned on roller gins. Long staple upland cotton is ginned on saw gins run at a slow speed.

Cotton Seeds are delivered to the oil mills. A ton of seed will give about 40 gallons of oil, 800 pounds of meal and about the same amount of hulls. From 40 to 60 pounds of short lint called "linters" can be removed from a ton of seed before they are put in the hullers. There will be from 40 to 80 pounds of dirt and trash. The real value of the seed is determined by the quality of oil it will produce. If the seeds have been kept dry and are well matured they will produce fine oil, which is worth sometimes twice as much as the lower grades secured from damaged seed. The time will soon come when seed will be graded by the quality of oil that can be secured from them, and the farmer will be repaid for taking the best possible care of his seed.

Cotton-seed meal should contain 4I per cent. protein, 24 to 27 per cent. carbohydrates, 7 to 10 per cent. fat, thus giving one of our most highly concentrated feed stuffs.

As a fertilizer it should contain 6.58 per cent. nitrogen, 2.8 per cent. phosphoric acid and 1.5 per cent. potash.

From these figures one can readily estimate what should be the relative price of seed and meal.

General Statement.-A considerable portion of the cotton crop is produced by negro tenants, who work a single small mule or pony, using only a small turn plow, a harrow and a sweep as implements. The land is poorly prepared and poorly cultivated. No other crop would give returns under the same treatment sufficient to supply a people with food and clothing. 
Probably four-fifths or more of the crop is produced on the credit or advancing system. The farmer purchases on credit from the merchant his implements and provisions, and pledges his crop for payment. The merchant in turn pledges the crop to the commission merchant or banks to secure money on merchandise to advance the farmer. At the gathering time the crop

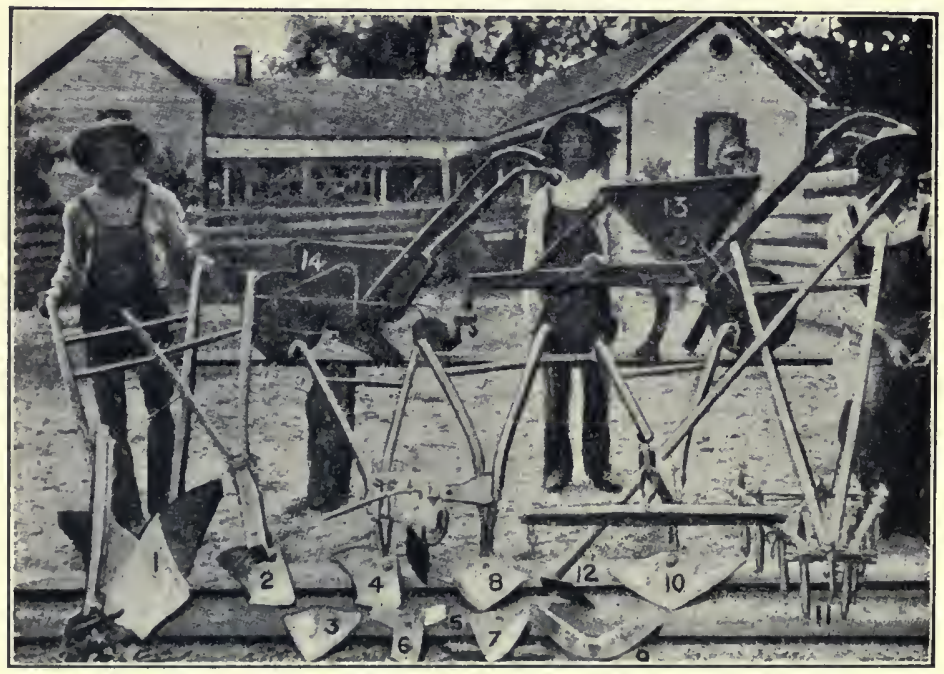

TOOLS USED IN THE CULTIVATION OF COTTON AND CORN.

I. Middle buster or middle splitter; 2, stock with half shovel or turning plow; 3, small solid sweep; 4 , Georgia stock with half shovel with fender attached to use in barring off; 5,10 -inch heel sweep; 6 , diamond scooter; 7 , duck-bill plow; 8 , solid sweep with 18 -inch heel sweep attached to Georgia stock; 9, 18-inch heel sweep; 10, 18-inch solid sweep attached to Georgia stock; I I, harrow; 12 , hoe-typical form of those used in chopping cotton; 13 , fertilizer distributer; 14 , cotton planter.

is rushed into the market in a few months, and the accounts are settled if the crop brings enough to pay the debts. If not the old debts are carried over to the new year with the hope that better yields and better prices will be secured the coming season.

EXERCISE.-What is the average production of lint cotton per acre at your home? What price does cotton bring? Does the price vary? What price did your neighbors receive for their cot- 
ton seed this past year? What is the best way to plant cotton in your section? State the width of the rows and the distance between the plants after thinning. Also state the composition of the fertilizers employed. What month is cotton planted at your home? Visit a gin and an oil mill and be prepared to recite on the manufacturing processes employed in preparing cotton and its products for market.

\section{Section XXI.-Rice.}

By Prof. W. R. Dodson,

Dean of College of Agriculture, Louisiana State University, and Director Louisiana Experiment Stations.

Importance of the Rice Crop.-For many centuries rice has probably been the most important grain crop grown for human consumption, if measured by the number of pounds produced. Statistics indicate that the annual crop of rice at the present time is a little less than one hundred and eleven billion pounds. Only recently has this quantity been surpassed by the production of corn and wheat. The United States, exclusive of Hawaii and the Philippine Islands, produces annually over five million pounds of rice, Louisiana, Texas, South Carolina and Arkansas raising nearly all of this amount. Rice culture is being extended quite rapidly into new territory in Louisiana and Arkansas, and no doubt large areas of the Delta lands on streams tributary to the Mississippi River can be devoted to this crop, if cotton production in the presence of the boll weevil cannot be made remunerative. The consumption of rice in America is increasing, and the crop will be of increasing importance in agriculture.

Types.-The rice plant is an annual grass. It stools freely, grows to a height of two to six feet, bears from I 00 to 200 or more grains per head, which mature from four to six weeks from time of planting, some varieties being earlier, some later than these extremes. There are a very large number of varieties. Two general types of rice are recognized, Honduras 


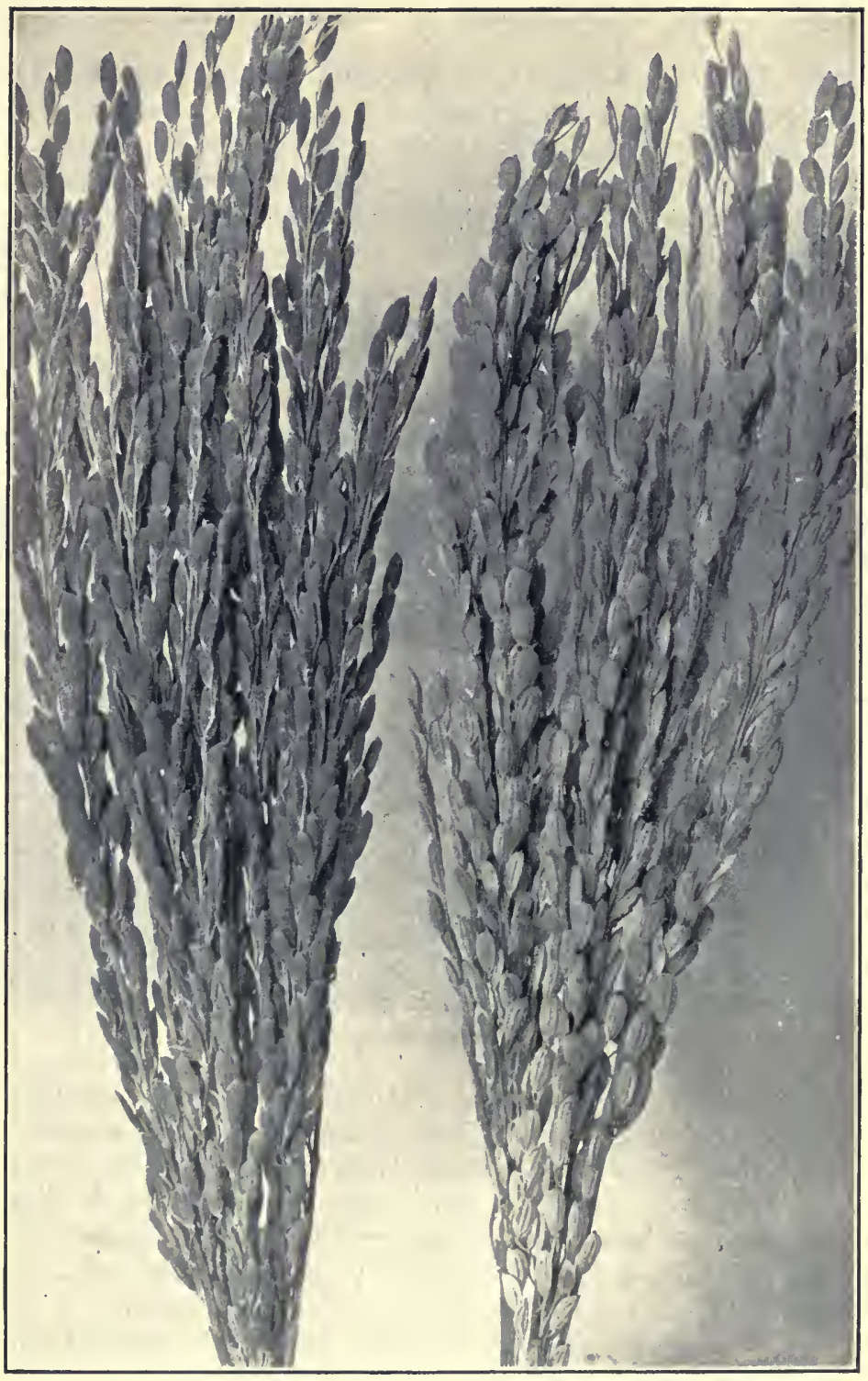

TYPES OF RICE.

Honduras.

Japan. 
and Japan. The Honduras type has a long grain, grows taller, thrives in cooler weather, and is planted earlier than the Japan type. The Japan type has a short, round grain, generally requires hotter weather for rapid growth and is planted as late as the first of June in South Louisiana.

Planting.-In seeding the average planter uses from sixty to seventy pounds of seed per acre.

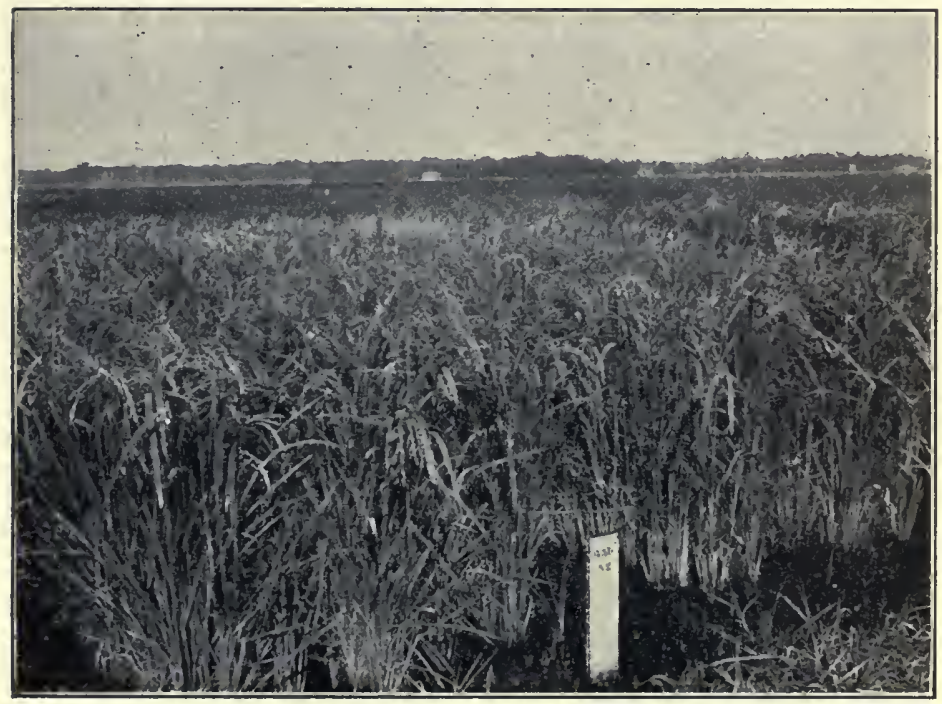

A FIELD OF RICE.

On fresh lands a smaller quantity and on old lands a larger quantity is required. Seed are sown on wellprepared land by a grain drill, or broadcasted and harrowed in. A grain drill costs about eighty dollars and should last eight or ten years. One machine will sow ten acres or more per day, covering the seed as sown.

Flnoding.-When plants are about six inches high flooding begins, and the land is submerged for about ninety days to a depth of not less than four inches. 
Embankments, or levees, are built with plow and shovel on contour lines of the topography of the land, so as to hold the water at the desired depth. The greatest depth is seldom more than ten to twelve inches, so the levees are built on six or eight inch contour lines.

Cultivation not General.--In the United States rice is not cultivated with implements, except in small areas. Flooding to destroy weeds and soften the soil is more profitable.

Stretch Water Flooding.-In Carolina water is turned on as soon as the rice is tall enough to permit flooding without submerging the young plants, this flooding being designated as " stretch water" flooding, because the early irrigation is supposed to cause the blades to elongate. After a period the water is withdrawn, the crop hoed and allowed to stand dry for some time; then the crop is flooded again and the water is kept on it continuously until the approach of the harvest season. Along the Atlantic Coast the tide water is used for irrigation. In other sections water is pumped from streams or wells.

Conveying Water by Gravity and the Syphon.-In the alluvial lands the areas nearest the streams are higher than those more remote, and when the water is raised to the top of the bank it is readily conveyed to any portion of the field desired by gravity. Where protection levees are constructed along streams the water is pumped into a pond on the river side of the levee and then carried across the levee by a syphon. Frequently the annual high water comes at the season irrigation is desired, and the water is high enough on the levee to enable the planter to operate the syphon without the aid of a pump. The cost of irrigation is then at its minimum.

Canals.-In the prairies of Texas, Louisiana and Arkansas large canals are constructed above ground for conveying the water across the country for many miles, and very large pumping plants are installed to 
lift water from the streams into these canals, and thousands of acres are irrigated from one canal. Enterprises of this kind are operated by corporations which charge fees or a per cent. of the crop as rental for water furnished the rice grower. One-fifth of the crop is a standard charge.

Wells.-It costs from two to six dollars per acre to supply water from a well. Where well water is used the wells are bored to a depth of 200 to 325 feet, and are generally ten or twelve inches in diameter. One well should furnish enough water for 200 acres or more. It costs from three to four dollars a foot to put down such wells. A pump costs six or seven hundred dollars. Steam or gasoline power is used to drive the pump. A horse-power of thirty-five is considered desirable for this work. The cost of the power ranges from a thousand to fifteen hundred dollars. About thirteen thousand five hundred gallons of water are required daily for an acre of rice.

Harvesting. - The water is withdrawn as the grain begins to turn yellow, which is usually ten days to two weeks in advance of the harvest. Harvest begins in early August, and continues until the middle of October. Where the soil is firm, and the levees not too close together, the crop is harvested with the grain harvester, which will cut about eight acres a day with first-class team power. The grain is tied in bundles by the machine with a hemp string, and the bundles dropped in groups ready for shocking. Harvesting costs about one dollar per acre. The harvesting machine costs \$I 75 and should last five or six years when properly cared for. The bundles are assembled in shocks of sixteen to twenty or more, the bundles standing on end, and are capped with two bundles, the straw of which is broken in the middle sufficiently to cause both ends to droop when the bundle is supported in the middle. These serve as a cover to shed water and protect the grain from sunshine and birds. Two men can shock the grain as fast as one machine can 
cut it. The rice remains in the shock until cured, and may then be stacked or hauled directly to the factory. If stacked and allowed to go through the "sweat," the quality of the grain is improved. Where harvesting machines cannot be used the rice is cut with a sickle, spread on the stubble to cure, and is then tied by hand in bundles, and shocked as above described. The material used here for tying is a bunch of rice straws. Harvesting in this way costs from four to seven.dollars per acre.

Threshing and Yields.-Threshing is done by the

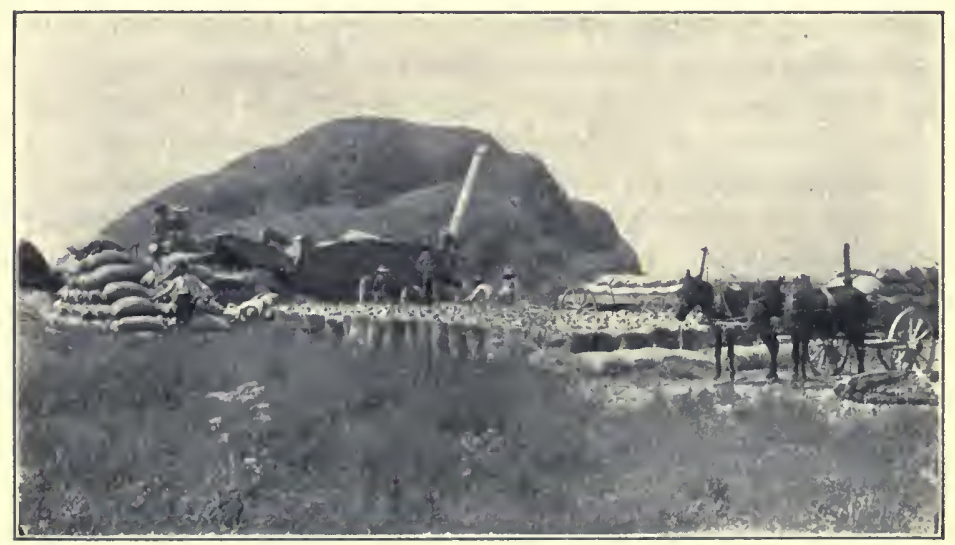

THRESHING RICE.

same machines made for wheat, except that they are built for heavier work, and the screens are slightly modified. A threshing machine, including self-feeder, straw stacker and grain sacker, costs about a thousand dollars, without the power to run it. A traction engine of twenty to twenty-five horse-power is generally used in the prairie section. Stationary engines are usually employed in the alluvial lands. A good machine will thresh from three to four hundred sacks per day. The threshed rice is put in four bushel sacks, and the crop yield is estimated 
by the farmer in sacks. A sack will weigh from one hundred and fifty to one hundred and ninety pounds, though a bushel is supposed to be fortyfour pounds. An acre of rice in the prairie section will produce from six to fifteen sacks. Ten sacks is a good average. The alluvial lands produce from 30 to 40 per cent. more. Much larger yields are sometimes secured. It costs from ten to twelve cents a sack to thresh rice exclusive of the cost of the bag. The grain coming from the threshing machine is designated as rough rice, sometimes called "paddy." In this form it goes to the miller. It is sold by the barrel of $\mathrm{I}_{62}$ pounds. For the milling products of rough rice consult the chapter on Feeds and Feeding.

Fertilizers are not extensively used in rice growing. Their influence in production in yield and quality of grain has not been well worked out. In Louisiana and Texas the addition of phosphorus to the soil generally increases the yield perceptibly. A small amount of nitrogen is beneficial on old lands, but should be used cautiously, as it may cause the rice to lodge (fall down). Potash is thought by some of the best planters to harden the grain and improve the milling quality. It is presumed that nitrification is retarded or suspended during the period of irrigation, and where organic fertilizers are to be applied, they should be used as far in advance of planting as circumstances will permit.

Rotation of Crops in rice culture is essential. Red rice (a weed) and water weeds accumulate in succession rice so as to make the crop unprofitable. On the alluvial lands after two or three crops of rice the fields lie idle for a year or may be devoted to cotton or corn. In the prairie section no effort is made to cultivate the rice fields with any other crop.

Rice $W$ eeds are a serious menace to the crop everywhere, except in the newest lands. Much can be done to diminish the trouble by a small expenditure in efforts to prevent seeds from maturing after the rice crop is 
harvested. The damage to the crop is not limited to the influence on yields, but decreases the price when seeds are sent to market with the grain.

Diseases.-The only serious disease of the rice is "blast" or "rotten neck." This disease is sometimes serious on the Atlantic Coast. The U. S. Department of Agriculture has demonstrated that the disease can be almost exterminated by the use of lime on the soil. Two smuts destroy occasional grains on the Gulf Coast, but neither is yet a serious disease.

Insect Enemies of the rice crop are not abundant. The rice weevil causes some damage to stored grain, but this can be largely prevented by fumigation. The corn-root worm and the rice maggot cause some destruction of the young crop in early spring, but by proper manipulation of the water damage from these insects can be greatly minimized. Some damage is occasioned by bugs stinging the grain when it is in the milk or dough stage. No remedy for this trouble has yet been discovered.

EXERCISE.-If rice is grown in your locality, name the popular type. Why is this type given preference? Do any of the planters import seed from foreign countries? Why? Are weeds ever introduced in this way? What effect has the rice crop on the fertility of the land? If fertilizers are used find out the percentages of available phosphoric acid, nitrogen and potash contained in the most popular brands. How much fertilizer is used per acre and when is it applied?

The threshing of rice should be explained to the class by a visit to a rice plantation during the harvest season.

\section{Section XXiI.-Oats, Wheat, Rye, Barley.}

\section{By Prof. O. D. Center,}

Department of Crop Production, University of Illinois.

General Description.-The great family of true grasses (Gramineæ) has four very important members represented by the cereals-oats, wheat, rye and barley. These grasses are all characterized by their hollow stems, closed joints, leaves on alternate sides of the stem, and with the leaf sheath which envelops the 
stem split on the side opposite the leaf blade. Wheat, rye and barley all belong to the same tribe of the grass family, but oats belong to a different tribe.

There are a number of well-known pasture and meadow grasses as well as several troublesome weeds which belong to the same tribe as wheat, rye and barley. The tribe, Aveneæ, however, has scarcely another member of any great importance except oats,

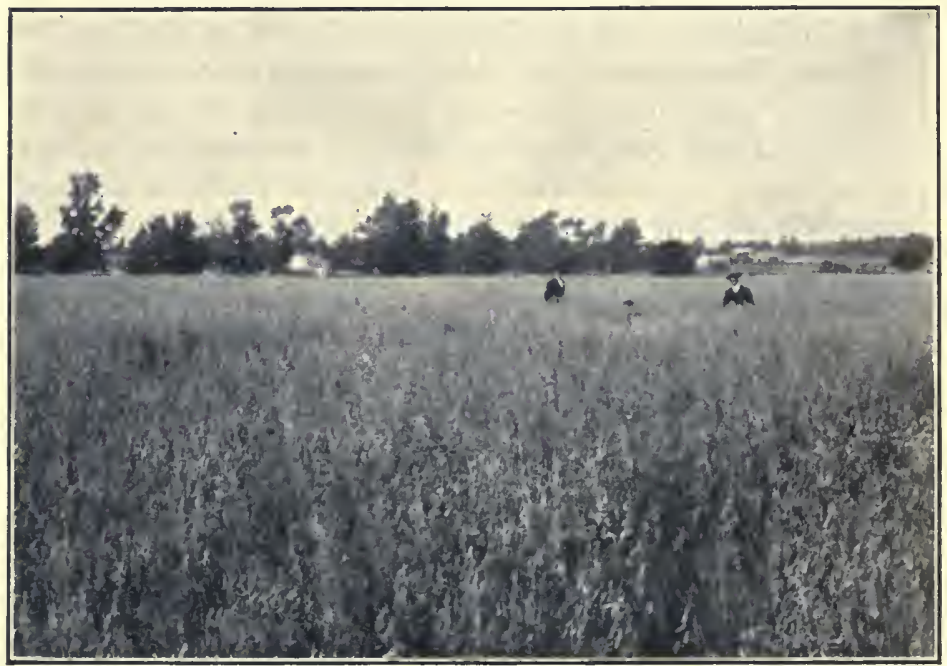

A GOOD STAND OF OATS.

although it contains one member that is a serious pest known as Avena fatua, or wild oats.

Wheat, rye and barley all resemble each other in the general shape and formation of the seed head. They all produce their flowers on unbranched stemless spikelets, on alternate sides of the main stalk, thus forming a compact head which is known as a spike. Oats on the other hand show no resemblance to the sort of seed head produced by wheat, rye or barley, and indeed, show considerable variation within the tribe. 
The seed head of oats bears its flowers on alternate sides of the main stem as does wheat, rye or barley, but these flowers are borne upon branches which vary in length and position. This arrangement forms a head which is called a panicle; this may be open or closed, one-sided or symmetrical, since each spikelet is borne at the end of a limber stem, and these stems are of variable length.

Oats-The Plant.-The oat plant is, generally speaking, more quickly influenced by a fertile soil and a favorable season of growth than the other members of the grass family. Hunt* states that the height of the oat plant probably averages three and one-half feet. The Kansas Station $\rightarrow$ shows that as an average of three years, and with thirteen varieties the height of the plant was 40 inches. Differences in height are found, however, even among different individuals of the same variety.

Upon germination the oat plant pushes what appears to be a single, tightly rolled pale green leaf through the soil to the surface. This leaf is soon supplemented with a second leaf, and within a comparatively short time with several more. For a considerable length of time this appearance of the plant indicates nothing but leaves, which are spreading rather than upright in their character of growth. As soon, however, as the oat plant begins to "shoot," which means a lengthening of the internodes of the stem, and a pushing up of the seed head, the whole appearance of the plant changes. The leaves which were formerly bunched together close to the ground are now scattered along the stalk, and the whole plant appears somewhat sparsely leaved and naked. This appearance is intensified as maturity approaches, since the lower leaves lose their activity and color, and become shriveled and dry. The head and upper stem remain green the longest, although this condition is less marked with oats than with wheat, rye or barley.

* Cereals in America.

+ Bulletin No. 166. 


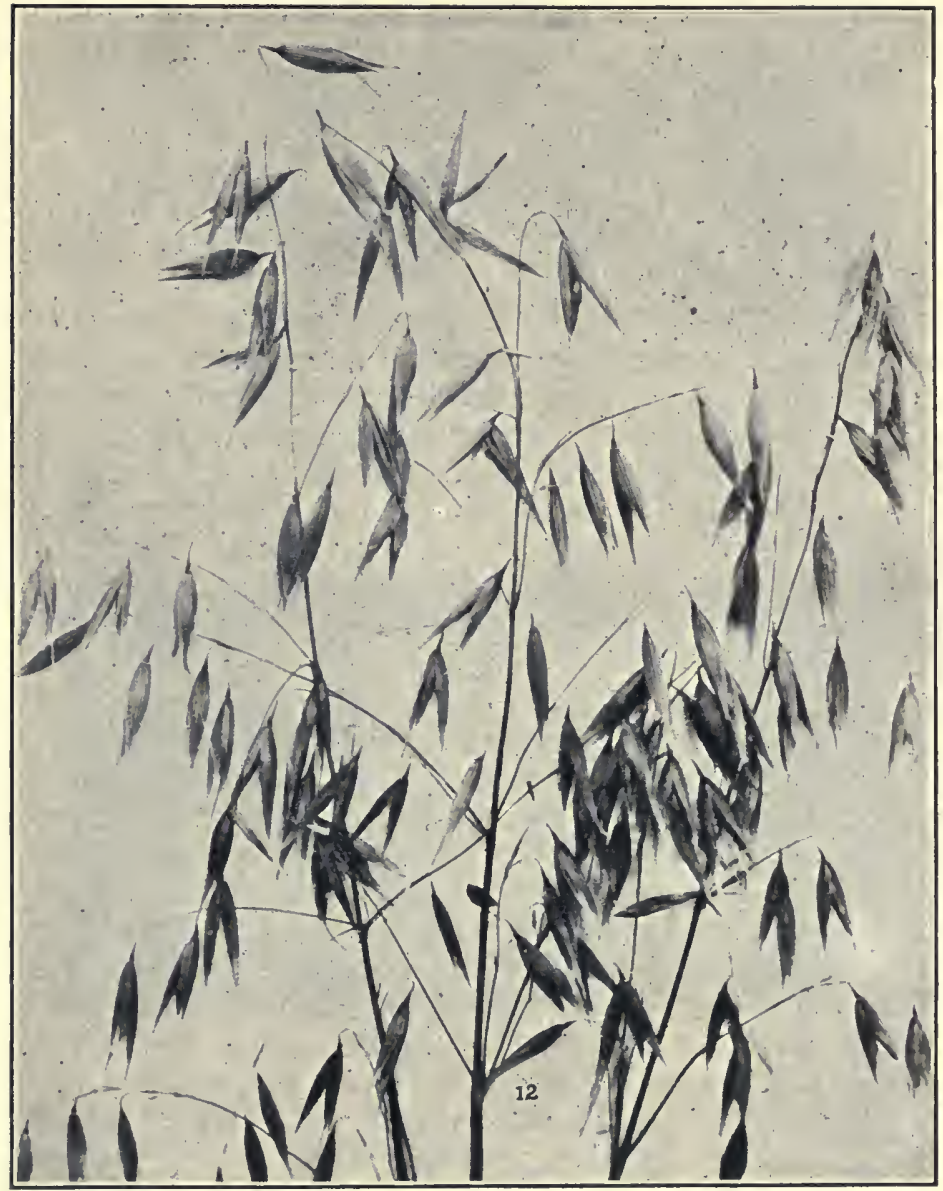

A TYPICAL OAT PANICLE-SPREADING TYPE.

The Roots.-When a grain of oats germinates there is a circle (whorl) of three temporary or seminal roots thrown out from the point where the radicle breaks through the seed oats. These seminal roots are soon replaced by the coronal, or permanent ones, which are thrown out from the nodes. The space 
between the seminal and coronal roots will depend almost wholly on the depth of planting the seed oats.

Usually, when moisture conditions are normal, the permanent roots start out about one inch below the surface, but any node below the soil or even above the surface, but very near to it, may throw out a whorl of roots. The permanent roots soon occupy all the available surface soil, since they grow rapidly; branching and rebranching so abundantly that the whole soil area is soon filled with a mass of roots. As soon as this condition is reached the roots descend at a rather sharp angle. The Minnesota* and Dakota Stations have found that these roots are numerous to a depth of four feet, and that occasionally they may be found to a depth of six or seven feet. It is supposed that the purpose of these deep-growing roots is to secure water.

The Stalk (culm).-The stalk of oats, wheat, rye and barley is similar in all respects except in height. The stalk of oats is usually a little larger in circumference and less harsh or tough in texture than the stalk of the other grains mentioned. In height, rye is the tallest of these four cereals, wheat and barley are practically the same height, although barley is more often the shorter of the two, while oats is the shortest in height of straw of any of the four. The conditions of soil and climate have a greater influence on the culm of oats than on wheat, rye or barley. The length of the culm exerts a considerable influence on the liability to lodge, and also on the ease or difficulty in harvesting. The height and vigor of the culm determines to a considerable extent the proportion of grain to straw secured. Generally speaking a height and vigor that is common, although not at all invariable, yields one pound of grain to two pounds of straw.

The Leaves.-The leaf of the oat plant is made up of four parts: ( I) The blade which is the free end * Minnesota Bulletin, No. 62. 
of the leaf and which varies in length, width, shape, hairiness, and shape and prominence of veins; $(2)$ the sheath which in all plants of the grass family encloses the stem tightly and is split down the side of the stem opposite the leaf blade; upon removing the sheath from any internode of the culm while the plant is green and growing, the culm underneath will be found white and tender; (3) the ligule, a thin tissue-like guard or band which forms the connecting line between the blade and the sheath and which clasps the stalk tightly; this together with the (4) auricles, other thin projections of leaf tissue which are at the junction of the leaf and sheath, and which are at either side of the upper end of the sheath act as a rain and dust guard, thus preventing these from getting in between the sheath and the internode which it envelops.

The Head (panicle).-A typical oat head usually contains from three to five whorls of small branches, each in turn bearing from three to five florets or spikelets. Each floret is at the end of a limber pedicel which is of such variable length as to form a head which may appear very compact or one that may be equally open. Each floret is composed of two or more flowers, but it is seldom that more than two flowers mature.

Of these two flowers that normally mature the lower invariably forms the larger grain. This large grain usually bears an awn, although the length and persistence of this awn varies greatly with the different varieties of oats. When but a single flower matures the oats are known as "single" oats, but when, as is usual, two flowers mature, the oats are known as "twin" oats. The entire panicle varies in length, but will usually average about ten inches.

The general shape and structure of the oat grain is similar to that of wheat, rye and barley, except that it is more elongated, has a hairy pericarp, and remains enclosed in its hull (flowering glume and palea). The per cent. of hull on oats depends on conditions of 
environment and on variety, since it varies from twenty to sometimes fifty per cent. The average amount of hull in American grown oats is about thirty per cent. When oats are used for oatmeal, or rolled oats, the manufacturer desires a plump, heavy grain with a thin hull.

Position of Oats as a Crop.-Oats stand second among the cereals of the United States as regards number of bushels produced. They are excelled only by corn. In total acreage or in money value of the grain they take third place among the cereals. As oats do not do well in warm climates, we find that more than three-fourths of all those grown in the United States are produced north of the thirty-eighth parallel. The North Central states lying both east and west of the Mississippi River are the states producing the great bulk of all the oats grown.

Classification of $\mathrm{O}$ ats.-O Oats are classified as spring and fall varieties. The fall varieties are grown principally south of 38 degrees North latitude, although within the past few years there have been developed hardier varieties of this class, until occasionally we now find fall sown oats as far north as Central Ohio or Illinois. Where fall sown oats, usually called "winter oats," can be successfully grown they are preferable to spring sown oats. They make an early and vigorous growth, head from a week to ten days earlier than the spring sown grain, ripen earlier and more uniformly and produce grain of better quality and of heavier yield. The Ohio Station* has found that a two years' trial with winter oats showed them to outyield the spring sown sorts by 3.6 bushels of grain, which in turn averaged six pounds heavier per bushel than did the spring oats.

Oats are farther classified as spreading and side oats. This classification is based wholly on the type of seed head produced. Spreading oats are those with an open panicle, much branched, and with the * Circular No. 88. 
branches arranged symmetrically about the central stem. Side oats on the other hand have the branch-

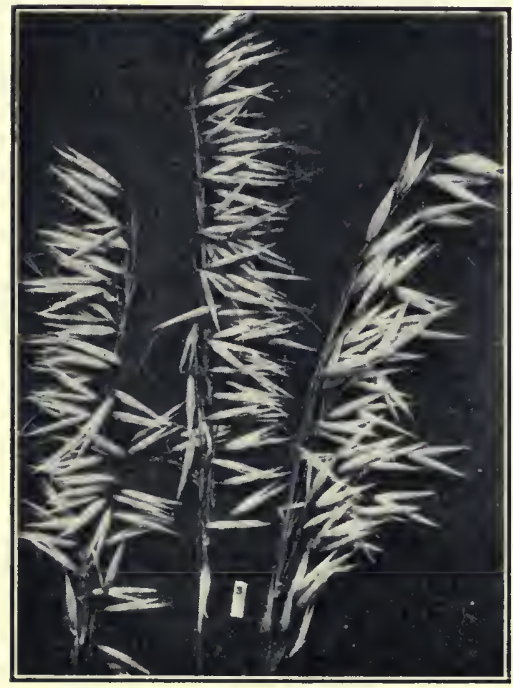

A TYPICAL OAT PANICLE-CLOSED, OR SIDE TYPE. ing of the panicle greatly restricted, and all the branches hang from one side of the main stem. In extensive variety tests carried on by several stations it is found that less than one-tenth of the total number of varieties tested belonged to the type "side oats."

Th e classification of oats as given by the United States Department of Agriculture appears the most comprehensive and reasonable of any classification yet suggested. This division is based on characteristic features of the types and varieties represented, so that the name applied to any class indicates its distinguishing feature.

This classification includes five groups:

r. Northern oats.

2. Early oats.

3. Red oats.

4. Winter oats.

5. Hulless oats.

Northern oats are such as are most commonly grown north of the fortieth parallel. They include a large number of varieties and types of grain, but are generally characterized by requiring from 100 to 125 days to mature fully. Early oats are also largely grown throughout the same area as the Northern 
class, but these are characterized by their early maturity, about ninety days, their comparatively short, fine, stiff straw and their long, slender grains. These two sorts comprise more than two-thirds of all the oats produced in the United States. Red oats are varieties of a brown or red color, developed into and especially adapted to the warmer states. The grain is usually large and plump with a heavy hull and often with a stiff short awn or beard, which is persistent on the back of the large grain of the twin oats in a spikelet. This class together with the winter oats are the most common sorts of the Southern States.

Hulless oats are an unimportant class, and may be found in limited quantities in almost any oat producing section. They derive their name from the fact that the outer hull, which commonly clings to oats belonging to the other classes, is in this class removed in threshing.

Improvement of Oats.-Much less has been done toward the improvement of oats than with wheat or barley. All of the classes mentioned can be considerably improved. Selection of varieties of the different classes which are earlier, more hardy, possess stiffer straw, and that are more resistant to drought, heat, and disease will do much toward the rapid improvement of oats. Considerable gain can be made by giving greater attention to the character and fertility of the soil, to the selection of better seed, and to the preparation of the seed bed upon which the oats are sown. The careful and complete preparation of the seed bed, the use of only large plump seed, and sowing oats with the drill rather than broadcast have been repeatedly shown to result in rapid improvement and in increased yields. The rate of seeding per acre can be greatly lessened when there is a better preparation of the seed bed, and when the grain drill is used in seeding. The Experiment Stations of Minnesota, Ohio, Kansas and of Ontario have each reported improvement of yield and quality when only the large 


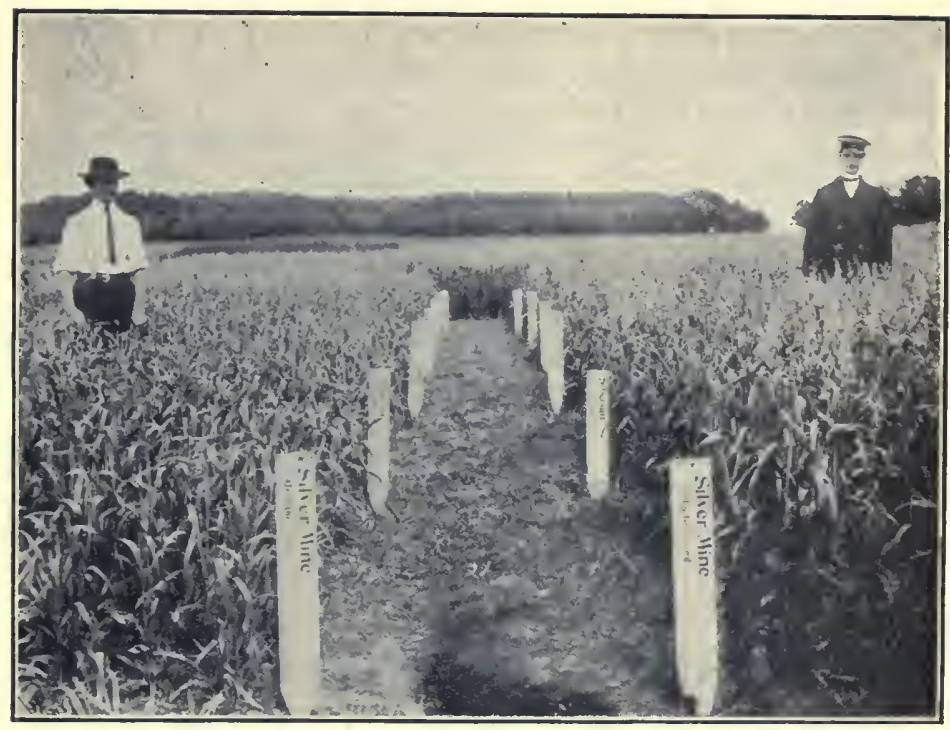

OAT FIELD SHOWING INCREASED VIGOR OF GROWTH DUE TO SEED SELECTION AND GRADING.

plump, heavy seed was sown in comparison to the small, light weight seed. The Stations of Illinois, Kansas, Iowa and Ontario also report increased yields of $5,5 \cdot 3,9.6$, and 4 bushels more grain per acre, respectively, when oats were drilled instead of broadcasted.

Seeding of Oats.-The time of oats seeding differs naturally with the latitude of the section in which they are grown. In the Southern States where winter varieties are sown, the best results are secured when the grain is sown between October io and November Io. The spring sown sorts are produced to the best advantage when seeded during February. The Northern States vary in seeding time from March first to May first, depending almost wholly upon the latitude. Kansas is the state north of parallel 38 degrees to begin oats seeding earliest in the spring, closely followed by Missouri, Southern Illinois, Indiana, Ohio 
and Pennsylvania; then by Nebraska, Northern Illinois, Iowa, Minnesota and Wisconsin, and finally during the last of April and the first week of May by the Canadian provinces.

The rate of seeding will also vary both with the latitude and with the method of seeding practised. Generally speaking, it has been shown advisable to seed oats at the rate of from 6 to Io pecks per acre, the rate depending largely on the type of soil on which they are sown, the method of seeding practised, and the use to which the crop is put. 'The Ohio Station in a series of tests covering eleven years found that with all varieties of all types tested, a seeding of eleven pecks per acre was advisable. Where clover is seeded with oats as a nurse crop, as is often done, a lighter seeding is desirable than would otherwise be given were the oats sown alone.

Yield of Oats.- The yield per acre of oats steadily increases from the South toward the North. In the

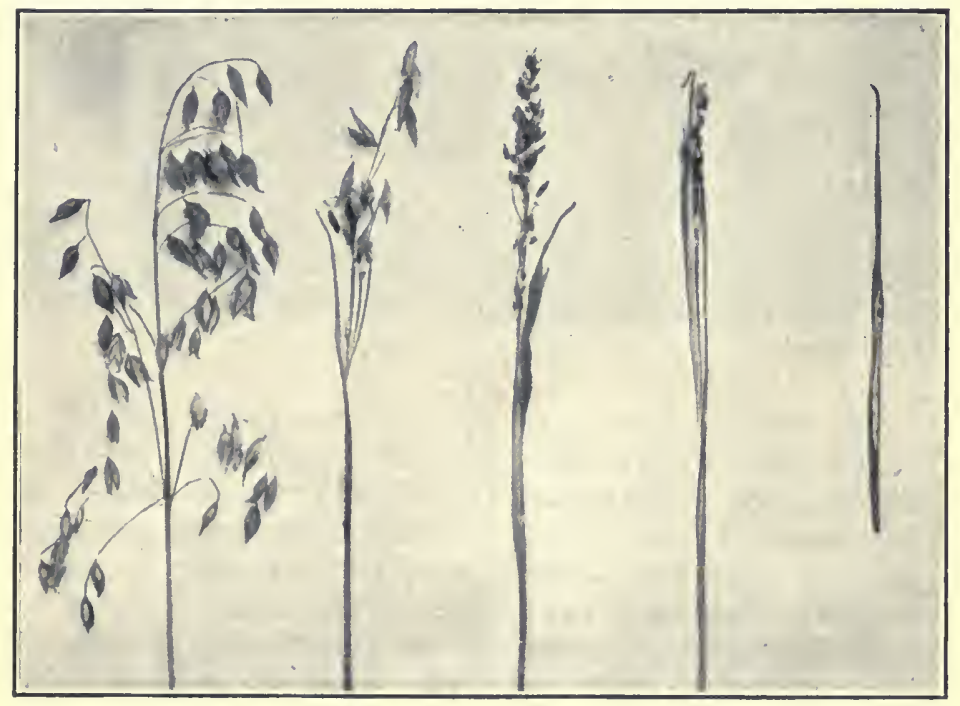

DIFFERENT STAGES OF SMUT DEVELOPMENT IN THE OAT HEAD. 
Southern States the yield per acre has averaged less than eighteen bushels during the past forty years. In the Central portion of the United States, which includes Virginia, the southern portion of Ohio, Indiana, Missouri, etc., the yield gradually increases until an average of nearly twenty-five bushels per acre is secured. The northern half of Ohio, Indiana, and Illinois, together with Iowa, Wisconsin, Nebraska, Michigan, and South Dakota, show an average yield of nearly thirty-five bushels per acre, while yields of 60 to 75 bushels with an occasional 100 bushels are not uncommon with the men who give their soil, seed, and sowing the greatest amount of attention. In Canada the yield per acre is considerably higher than in the United States, since fifty bushels may safely be taken as an average, and a roo-bushel yield is often secured.

Enemies of Oats.-Oats have practically the same enemies to contend with in the way of weeds and insects as do wheat, barley and rye. The weeds most often injurious to the crop are the smart weeds, the milk weeds, and the wild mustards. The insects most commonly found doing damage are the chinch bug, army worm, and sometimes the grasshopper. The fungus diseases most commonly attacking oats are two species of rust and two forms of smut. For the rusts there is no known remedy, but for the smuts, the treatment of the seed grain with formalin solution, is not only an inexpensive but an effective means of prevention.

\section{WhEAT.}

The Plant.-In general, the description of the wheat plant differs but little from that of oats. In particular, it is usually of a different shade of green in color, of a hardier character, of slightly taller growth, and of a decidedly harsher or stiffer straw. Its general character of growth from germination until the heading period differs but little from that of oats, except that some of the varieties of most of the species 
of wheat are of a more prolonged period of growth than is generally required for oats.

In height, the wheat plant is from two to five feet, the shorter wheat being found among the sub-species known as "club" wheat, and the taller found among the late maturing varieties of the sub-species known as "bread" wheat.

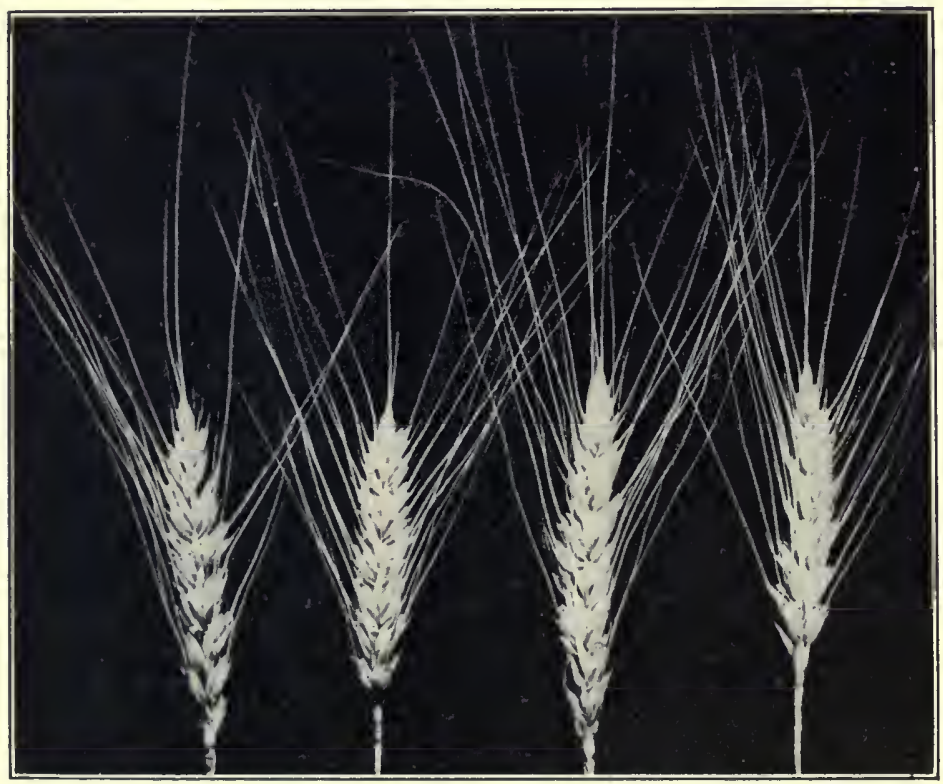

TYPICAL HEADS OF BEARDED WHEAT.

Among the varieties of wheat commonly sown there is found much greater diversity of forms and character of plants before they begin to develop a stalk and a seed head than is common among oats. These differences are shown by the width, length, and number of leaves as well as by the tendency of the plants to grow somewhat erect, or to remain recumbent. As soon as the plant begins to joint (that is, to put forth a seed stalk), the resemblance to oats becomes more 
marked, until the putting forth of the head. The general appearance, however, makes it comparatively easy to distinguish between wheat and oat plants at almost any stage of their growth, except at a time when the plants are quite young.

The Roots.-Wheat, upon germination, puts forth a circle of three temporary roots at the point where the radicle breaks through the seed coats in exactly the same manner as oats. The permanent roots soon follow, issuing from the nodes. Any node below the surface of the soil, or even near the soil above the surface, may throw out a whorl of roots. Upon continued growth these roots extend on all sides of the plant, gradually going deeper until a depth of from ten to eighteen inches is reached, depending largely on the character of the soil. From this depth the roots descend almost vertically, following almost invariably. the line of the least resistance. Thus we find the deep roots occupying an abandoned passage made by a worm or an old crawfish hole, or the space occupied by the deep tap root of a preceding clover plant, or even a crack formed sometime previously during some excessively dry spell. These passages naturally fill up easily and quickly during rains with the sediment from the surface, and the soil within them is therefore less firm and compact. It also probably contains a higher percentage of available moisture and plant food.

The Stalk (culm).- As with oats, the culm of wheat is a slender, elongated cylinder divided into unequal sections by joints or nodes. Unlike oats, however, the culm of wheat is more often more or less filled with pith, and is also more variable in thickness of walls and in color.

The length of culm varies greatly with different varieties, and although there is no definite relation between height and yield it is commonly thought, other things being equal, that the longer the culm the higher the yield of grain. Certain it is that the production of a tall culm will more quickly deplete the fertility of 
the soil, if the straw is not returned to the land, than the production of a short-stalked sort under the same conditions.

The Leaves.-The leaves of the wheat plant require no more detailed description as to their structure, than has already been given to oats. This same general description applies also to the structure of the leaves of both rye and barley. Aside from their difference in shade of color, their greater width, and a common production of more hair on their upper surfaces, the leaves of the wheat plant are not at all unlike those of the oat plant.

The Head (spike).-Although the resemblance between the oat and the wheat plant may be considerable

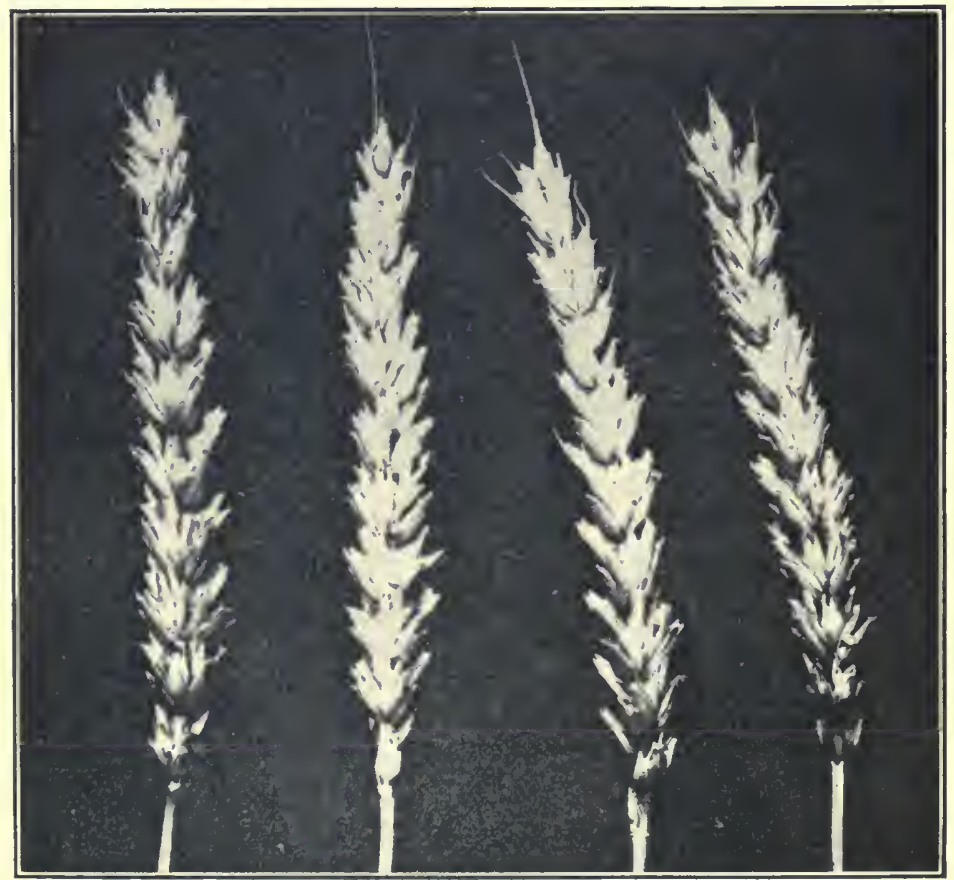

TYPICAL HEADS OF BEARDLESS WHEAT. 
when the roots, culms and leaves only are considered, the resemblance ceases when the seed head is examined. Instead of a loosely constructed branched panicle we find a more or less compact, unbranched head, called a spike. The spikelets that form the wheat head are arranged alternately at the joints of the stem, and the joints are short and very closely set. The portion of the stem which bears the head is bent or

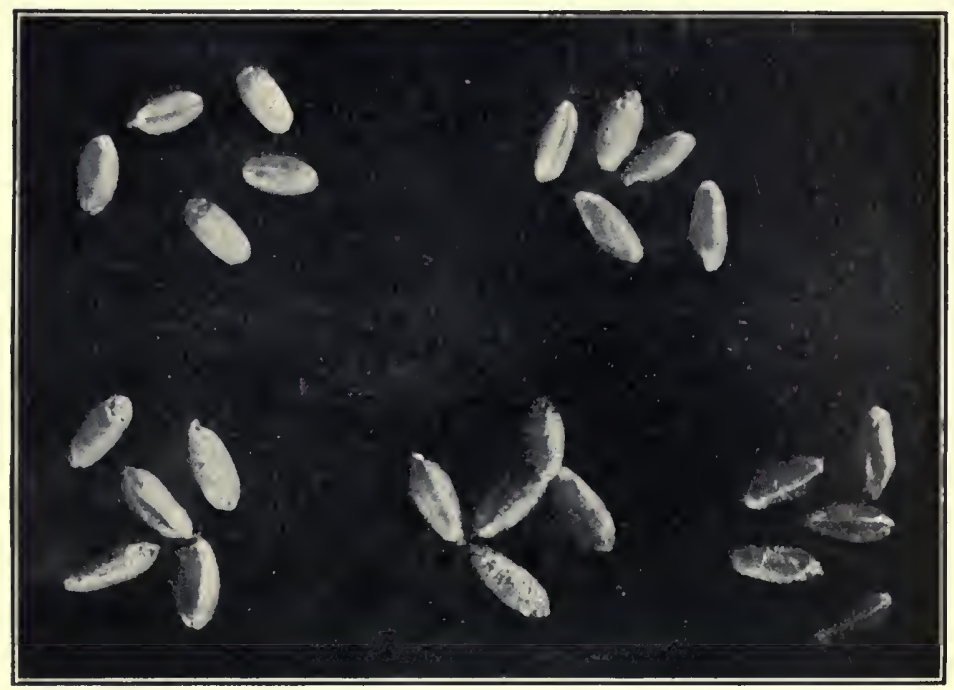

TYPICAL WHEAT GRAINS.

hollowed out on the side next to the spikelet until we have a zigzag effect. This portion of the stem is known as the rachis. There is but a single spikelet at each joint of the rachis, and these spikelets may be closely set or somewhat apart from each other. This gives quite a variation between varieties, since some are remarkably compact, while others are very loosely constructed. It is by no means the varieties with compact spikes that always give the heavier yields of grain, for there is a wide variation even between varieties 
having the same type of head. Generally speaking, the spike of American grown wheat will average about three and one-half inches in length and contain an average of forty kernels.

The Grain.-A wheat grain is a one-called, dry fruit with a thin ripened ovary growing together with the seed, so that the seed and pod form a single body. The fruit of wheat is called a caryopsis. In shape the wheat kernel is about twice as long as broad, slightly flattened in its longest dimension, and with a crease or furrow extending laterally on the side opposite the embryo. The grain contains a relatively small embryo, and a very large development of endosperm.

Bessey * gives the structure of a wheat grain as consisting of the (I) ovary wall or pericarp, the (2) outer and (3) inner integument, the (4) nucellus, which portions are usually grouped together under the common name of bran, the (5) aleurone cells also called the gluten cells, and the (6) starch cells.

The United States Department of Agriculture gives as the average analysis of wheat:

Water ................. $10.5 \%$

Crude Fiber ............. $1.8 \%$

Ash
Fat $\ldots \ldots \ldots \ldots \ldots \ldots, 2.1 \%$

Protein …................ Nitrogen Free Extract...7r.9\%

Unlike oats, wheat when ground has a property, common only with rye, of forming a sticky dough when mixed with water. This is due to the gluten contained in the grain, which gives to wheat when mixed with yeast its value for making light bread.

Wheat-Position.-Wheat stands third of the great cereals in the United States in number of bushels produced. In value of crop, however, it stands second. In I 909 the total yield of wheat in the United States as given by the Bureau of Statistics of the United States Department of Agriculture, was 737,r 89,000 bushels, which was slightly more than twenty per cent. of the total crop of the world. The average

* Bulletin No. 32, Nebraska Experiment Station. 
price received made the wheat crop for the United States of greater value than the oat crop by more than $\$ 324$, o0o, ooo, al. though the oat crop exceeded the wheat crop by more than $270,000,000$ bushels. IV heat-Classification. Wheat has been classified by different writers in several ways. Hackel * divided the genus into two sections, Aegilops and Sitopyros, and placed all the cultivated species under the last section. Under this section he then places: ( I) Einkorn, (2) Spelt, (3) Emmer, (4) Common or Bread Wheat, (5) Club, (6) Poulard, (7) Polish and (8) Durum wheat, each as a separate type.

T h e classification of wheat as made by Carleton $\rightarrow$ is on a wholly different

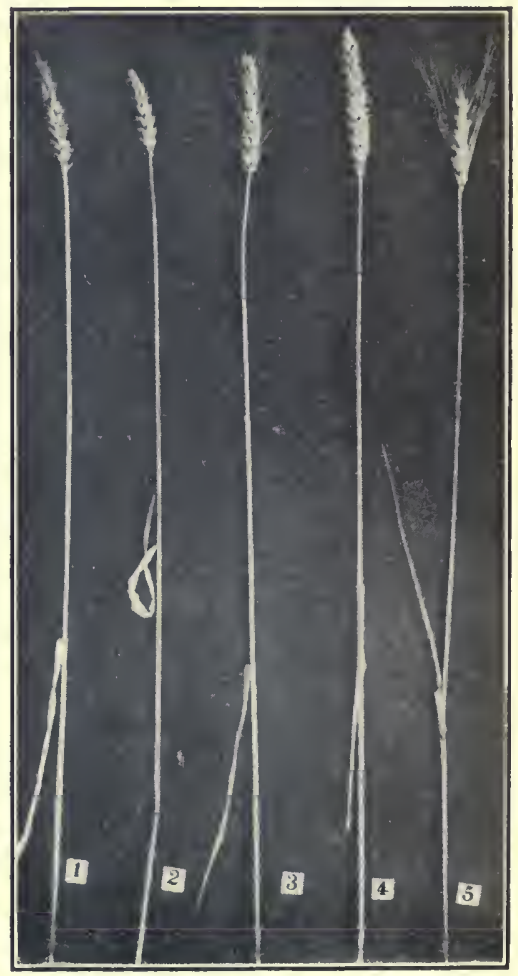

TYPICAL HEADS OF FIVE COMMON VARIETIES OF BREAD WHEAT.

I, Wheedling; 2, Dawson golden chaff; 3, Rudy 4, K. B. No. 2; 5, Turkey red. basis than that of Hackel, and is based almost wholly on the character of the grain produced. This classification includes: (I) Soft, (2) Semi-hard, (3) Southern,

* The True Grasses, Edward Hackel.

$\dagger$ Bulletin No. 24, United States Department Agriculture, Division $P \& P$. 
(4) Hard spring, (5) Hard winter, (6) Durum, (7) Irrigated and (8) White wheat.

Wheat is also often

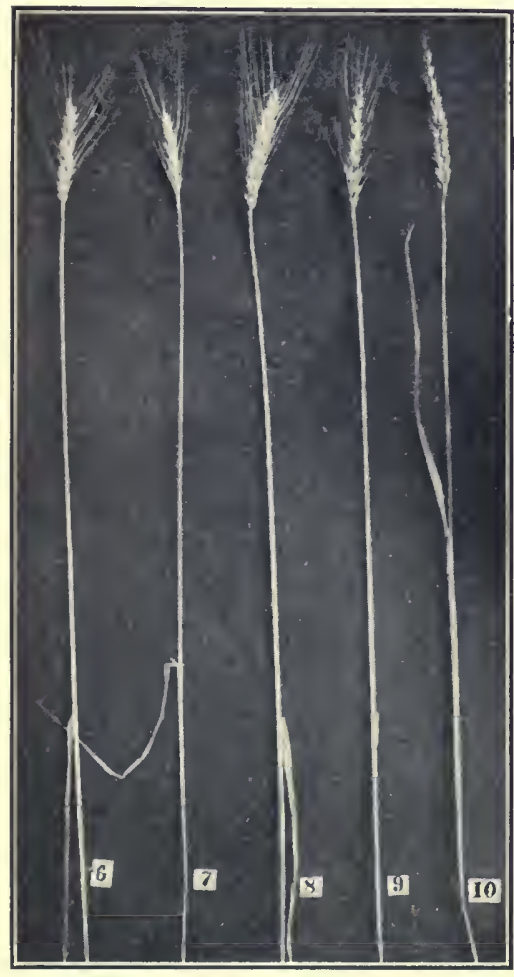

TYPICAL HFADS OF FIVE COMMON VARIETIES OF BREAD WHEAT.

6. Malakoff; 7, Pesterboden; 8, Indiana Swamp; 9. Fulcaster; 10, Harvest King. classified as spring or winter, depending upon the time the seed is sown. Spring sown wheat can be transformed into a winter sort or winter wheat into a spring sown sort by slowly addpting each to climatic differences.

Wheat Improvement. - Considerable work has already been done towards the development of wheat. This has taken place through three avenues of work: (I) By selection of variation found in established varieties, (2) by introduction of foreign varieties, (3) by crossing two or more varieties and eliminating all but the desirable hybrids through subsequent selection.

Wheat Seeding.-Wheat seeding differs but little from that of oats. The use of the grain drill is more common, and in general the seed bed is more carefully prepared, but aside from this there is practically no difference. The time of seeding will depend more largely on climatic conditions, on the fertility of the 
soil, and on the liability of insect injury than is true of oats. It has often been said, and quite truly, that the earlier and better the seed bed is prepared the later the seeding may be delayed.

In the winter wheat belt it is usual to seed anywhere from September 20 to October I 5 , depending largely on the factors already stated. In the spring wheat areas the seeding is done as early as possible, since results secured from grain so seeded are superior to those of later sowing. The rate of seeding will vary as greatly as does the type of wheat sown. A seeding of from four to eight pecks per acre, with a strong tendency toward the smaller amount, is a very common practice.

Wheat Harvesting.- The harvesting of wheat is in no way different from that of oats, with the exception that in the western part of the United States machines called the "Combines" are used in harvesting. A "Combine" is simply a combination of a harvester and a thresher, so that both operations are performed at one and the same time.

Wheat-Yield.-The average yield per acre of wheat is far less than that of oats. The general average in the United States for the past ten years is I4 bushels per acre, while England has averaged 32 bushels and Germany 28 bushels per acre during the same period. That the yield per acre can be greatly increased by a better preparation of the seed-bed, a more careful selection of varieties and a systematic grading of the seed grain has been demonstrated by a number of experiment stations. At the University of Illinois as an average of the past six years, and with eleven varieties of wheat, the average yield per acre has been 35 bushels. This yield has been surpassed by a number of farmers throughout the state, some of whom have exceeded 50 bushels per acre.

Wheat-Enemies.-Wheat has a greater number of enemies than oats. Of the weeds, cheat (Bromus secalinus) and cockle (Agrostemma githago) are 
probably the most common and troublesome. Among the insect enemies are the Hessian Fly and the Chinch Bug. Among the diseases are Rust (Puccinia graminis), Scab (Fusarium roseum) and the SmutsStinking (Tilletia foetens), Loose (Ustilago tritici).

\section{RYE.}

$R y e$ is one of the cereals which differs considerably from those already described. It is considerably taller, more slender and tougher than either oats, wheat or barley. It is said also that rye is a perennial plant which has lost this character under cultivation. It is a plant more closely related to wheat than either oats or barley, yet differs considerably from either. This is a plant better adapted to poor soils than oats or wheat. It is often called the grain of poverty, because of its ability to produce a fair crop on land illy adapted for the other cereals. It responds readily to good soil and treatment, however, and is doubtless able to overcome adverse conditions because of its different rooting habits.

Rye-The Roots.-Rye, in germinating, throws out a whorl of four temporary roots instead of three, as with the plantlet of wheat, oats or barley. Rye is enabled therefore to stand greater extremes of temperature and unfavorable conditions than the other crops. It is commonly considered the most hardy of this group of cereals, and its greater root development shows at least one reason why this is so. The permanent roots differ but little from those of the other grains, except that they usually ramify the soil to greater distances and to greater depths.

Rye-The Culm.-The rye culm is decidedly more slender in comparison to its length than the other cereals under discussion. It is too, longer, and with a tougher, harsher straw. The leaves show scarcely any difference from those of wheat with the exception of being narrower and of greater length. When the 
plant is young, too, the leaves more commonly are closely recumbent than with wheat.

Rye-The Head.-A head of rye is of the same general structure as that of wheat. It is also known as a spike. A rye spike is considerably longer than a wheat spike, generally averaging not less than 5 inches. The spikelets are joined to the rachis in a more open formation than the usual wheat spike shows, and in number vary from 25 to 35 in a single head. The grain is longer and more slender than a wheat grain, the transverse crease is less clearly marked, the grain is more pointed, and the surface is commonly quite wrinkled. In structure, however, the rye and wheat grain are very similar.

Rye-Position.-Rye occupies a position fifth in importance among the cereals of the United States. The United States, however, produces but a small percentage of the total crop of the world. Rye is the principal grain of Russia where over fifty per cent. of the total yield of the world is produced. Rye is classified only as spring and winter varieties, the winter sort being the one usually sown. So far as we are able to learn there is no systematic attempt at improvement of rye either through selection or crossing. Rye seeding and harvesting differ in no essential particular from that of wheat. The yield secured throughout the United States during the past ten years has averaged i 6 bushels per acre. This is far too small since given a fertile soil and careful seed-bed preparation, yields of 30 to 35 bushels are not uncommon. Rye is almost wholly free from insect enemies, except such as will attack any of the cereals. The only enemy or disease peculiar to this crop is known as ergot. This is an enlarged and peculiar development of the grains. It is readily recognized, and when found, the grain should not be fed to animals or eaten by persons. 


\section{BARLEY.}

The barley plant has much the same appearance and habit of growth as wheat. The head or spike differs, however, and the general height of the plant is less. It is the most shallow rooted of any of the four cereals discussed, and although the roots usually grow with remarkable rapidity they are neither vigorous nor long lived. The barley spike varies more than the spike of wheat or rye. At each joint of the rachis there may be one, two or three spikelets depending upon the type of barley produced; with one spikelet at each joint the barley would be known as two-rowed; if two spikelets are present it becomes four-rowed, and if three are found, it is six-rowed barley. We have therefore barley with a thin flattened spike or with a spike that is rather square and compact.

Barley is further characterized by being almost universally bearded. By this is meant that the flowering glume is prolonged into a stiff awn, which often reaches a length of six or more inches. This characteristic renders barley a disagreeable crop to handle, since these beards readily break off, and because of their sharp points and barbed edges work through the clothing, greatly to the annoyance of those handling the crop. Because of this undesirable feature, there has been considerable attention given to the production of a barley free from these annoying beards. Until recently there has seemingly been nothing of sufficient merit yet developed to claim any great attention. The United States Department of Agriculture has, however, recently succeeded in producing a true beardless barley that promises to supersede the awned sorts. The Agronomist in charge of Barley Investigations reports: "This office has succeeded in produsing a winter barley without awns which is entirely distinct from the beardless barley now cultivated. This new variety is a selection from a large 
number of hybrids. The beardless varieties now cultivated bear a trifurcate appendage, the central portion of which is hooded. The new variety is entirely free from any form of appendage."

Barley, in addition to being classified as two, four and six-rowed is farther classed as winter and spring.

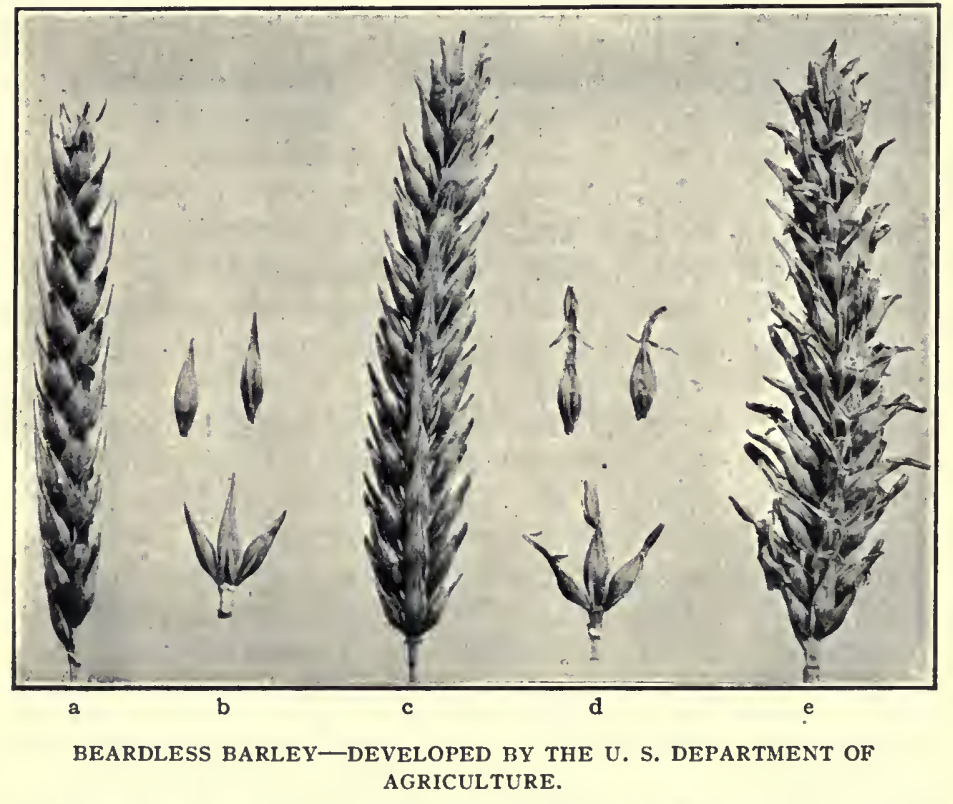

a, Side view of head of new awnless body; b, separate grains and a spikelet of the same; $c$, front view of the head of same barley; d, separate grains and spikelet of hooded barley; e, head of hooded barley.

As with wheat, spring barley may be converted into winter or winter barley into spring. The barley grain, like that of the oats, remains enclosed in the hull (flowering glume and palea) after threshing. When this hull is removed the kernel resembles that of wheat. Barley is a cereal that has been given attention with a view to improvement, second only to 
wheat. The ends sought for are stiff straw, vigorous growth, and productive varieties.

In seeding barley, the first requisite is a thoroughly prepared seed-bed. The root system of this cereal being comparatively feeble, every advantage obtained through good preparation is desirable. In spring sown barley early seeding is a requisite to heavy yield. The rate of seeding in general is eight pecks per acre, although barley will permit of thicker seeding than oats or wheat, since it tillers less freely than these grains. Harvesting of barley differs in no particular from that of oats or wheat. Since a large part of the barley crop is used for malting, greater care should be exercised in handling the cut grain.

Barley ranks fourth among the cereals in number of bushels of grain produced in the United States. The grain, however, is of less value than wheat or oats. In yield barley has averaged a trifle above twenty-five bushels per acre for the past ten years. This yield is far too low, as is true with all the cereals produced. Where weather conditions are favorable and where the soil conditions are made as agreeable as possible, yields of from 35 to 45 bushels per acre are not infrequent.

The insect enemies of barley are those commonly affecting wheat. However, the chinch bug is more often found destructive with this crop than with wheat and the Hessian fly less destructive. The diseases prevalent with barley are no different than those attacking wheat or oats. 


\section{Section XXIII.-Sugar Cane.}

By Prof. H. P. Agee,

Asst. Director in Charge, Louisiana Sugar Experiment Station.

The sugar cane is one of the grasses. The roots of the cane, like those of all grasses, are fibrous and extend laterally from the root stock, which is nothing more than the close jointed, woody underground portion of the stalk itself. These roots are fibrous and delicate, and the root stock is not of sufficient length to give material support to the stalk which, with its heavy weight, is often uprooted by winds. The depth to which the roots penetrate is dependent largely upon the texture of the soil and the level of the ground water. Instances are reported of roots descending to the depth of five to ten feet, but this is unusual.

The Stalk of the cane has a general cylindrical form and varies in length with conditions of growth and variety from three to four feet to fifteen or eighteen. It is sometimes erect, but more often crooked on account of bending from its own weight, or being prostrated by wind. The diameter of the stalk varies from one to three inches and is practically uniform throughout the entire length, though in some of the varieties there is a slight taper from the base upward. The stalk consists of nodes and internodes. These internodes or sections are from one to two inches in length to six or eight inches, and occur in an average cane to the number of about fifteen to twenty, though when short and crowded together there are often as many as sixty to eighty. The rind has a polished appearance, is tough and thick, and according to variety is colored in various shades and mixtures of red, purple, green and yellow, or it may be striped or splotched in a combination of these colors. The color is materially affected by a wax-like covering called "cerosin," which occurs on the mature joints. This may be either white or black. 
The leaves of the cane are alternate, that is, they grow from every other node of the stalk at opposite sides of the cane. They are long and narrow, being about three feet in length and their degree of erectness is dependent upon the varieties, as is the intensity of their green color. The midrib is whitish in most varieties, reddish or purplish in others. It is well developed and has a channel-like depression on the upper

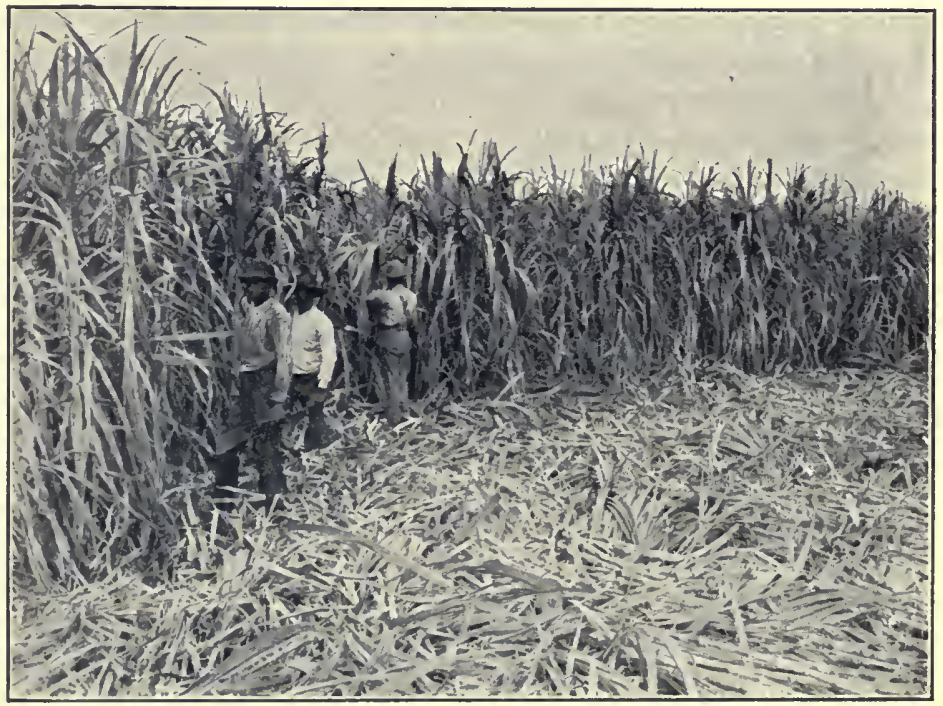

HARVESTING SUGAR CANE.

side. When the plant is immature the leaves clasp the stalk tightly and recede gradually during the growth, and finally wither and drop as the joint to which they are attached matures.

Bud or Eye and Seed.-At each node under the base of the leaf is the bud or eye of the cane. It is about a quarter of an inch each way and is, according to variety, protruding or inconspicuous, and round, oval or triangular in shape. It is covered with layers of tough protective tissue. Each eye is a new cane in 
embryo, and it serves in planting for the propagation of the new crop. It was long thought that the eye was the true seed of the plant, but it was proved a number of years ago that the tassels or arrows that the canes bear do not consist entirely of sterile flowers, as had been generally believed. Though it is possible to germinate a small percentage of these seeds, it is only with great difficulty, and it is impractical to grow cane commercially from the seed of the tassel. They serve a most important purpose, however, in being the means of propagating new varieties.

The translucent dots around the stalk at the eye are embryotic rootlets, which sprout simultaneously with the eye when the cane is planted and serve to furnish nourishment to the young cane prior to the development of its own root system.

In tropical countries at the approach of maturity a certain percentage of some varieties send up arrows or tassels bearing flowers. When an individual floret is examined with a lens it is found to have three stamens inserted upon the ovary, surmounted by two elongated styles with terminal feathery stigmas. The fact that most of the resulting seeds are infertile is no doubt due to the fact that cane has for so long a time been reproduced from the bud or eye.

The maximum sucrose content is generally attained at two to three months after flowering, after which a deterioration sets in.

The general matrix is composed of pith and cells and appears hexagonal as seen in cross section. The greater portion of the inner part of the stalk is composed of these cells, and in them occur the sugar and other products which are needed for the future use of the plant. At the nodes the pith almost entirely disappears, and the whole tissue is made up of bundles and modified pith that fills the space between. Distributed through the pith of the stalk are bundles or tubes of a fibrous consistency. These run parallel and distinct from each other throughout the internode, but 
unite at the node. They serve the function of conveying the water from the root to the leaf carrying food material from the soil. They contain no sugar. The elaborated food material coming from the leaf to be distributed through the plant is conveyed downward through other tubes. The remaining tissues that surround these tubes or bundles are mostly of a modified fiber and serve the general purpose of strengthening the stalk.

Sugar Cane Territory of the United States.-The sugar cane is indigenous to tropical environment and thrives most luxuriantly where summer heat is to be had throughout the year. In the United States, therefore, cane culture is maintained upon a somewhat different status than elsewhere. Nearly all of it is grown in Louisiana; Texas produces a small quantity, and a limited amount can be found in other states adjacent to the Gulf. Louisiana, though lying without the tropics, ranks fourth among the cane-growing localities of the world, producing annually from 300,000 to 350,000 tons of sugar.

With other conditions practically ideal, the temperatures of the Louisiana winters are too low to be withstood by the cane. Hence the crop is a forced one and the growing period is cut short by the necessity of harvesting when the plant is yet immature. The prevailing methods of agriculture have been especially designed to meet this contingency, and are therefore unique compared with the rest of the cane-producing countries favored with a twelve-month growing period.

That area of Louisiana devoted to cane lies principally along the banks of the Mississippi and smaller rivers and bayous.

The Soil is the rich alluvial formation that has been deposited by these streams. At the time of high water in former years when the surrounding country was inundated, the deposit was greater near the natural channels of the streams, and as a result the cane lands of to-day, though nearly flat, have a gradual slope 
from the river or bayous back toward the swamps. These narrow strips of land are protected from overflow by levees on the banks of the streams, and often by additional embankments at the edge of the swamps. These levees at the back of the fields have from time to time been built further back into the marsh and swamp lands, and much reclamation has been effected in this manner. The soil may be classified as varying from sandy and silty loams to loamy and stiff clays. The following chemical analysis may be considered as fairly representative of the general run of soils of the sugar belt :

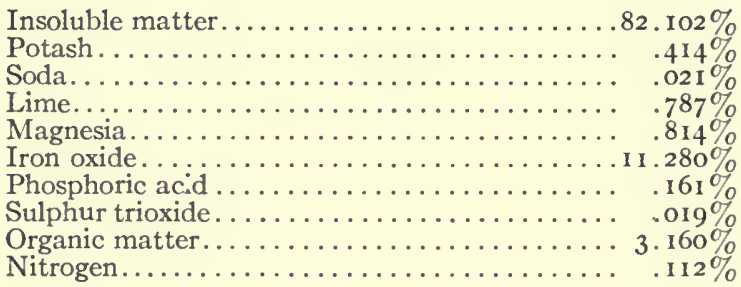

Drainage.-The annual rainfall is about sixty inches and irrigation is unnecessary, though it would prove beneficial in certain periods of drought that occasionally occur. A greater problem with which the planters must contend is that of removing the excess of water. The whole method of cultivation is based upon establishing proper drainage. The cane is planted on ridged rows from nine to eighteen inches in height. Large drainage ditches occur at intervals of fifteen to twenty rows, and in addition there are quarter drains running at right angles to the rows. The water is carried by the ditches into large canals, and most plantations are provided with extensive pumping plants to remove the water from the canals.

Cultivation.-It is perhaps in the agricultural practices that the greatest advance has been effected. The following is the method of cultivation employed. The ground is thoroughly prepared by deep breaking 
with plows of the disk or moldboard type. Rows from five to seven feet wide are laid off and thrown up into high ridges. These ridges are opened by a double moldboard plow, and into this opened furrow the cane stalks are placed in continuous lines and covered three to four inches by means of the plow. (The entire stalk is used for planting instead of the green top as is the general practice elsewhere.) The cane is thus protected from frosts, and in early spring the earth is thrown from each side of the cane by plows, a process termed "off-barring," and hoes are employed to remove all but a slight covering of earth from the stalks. Being thus left on a narrow, welldrained ridge, the eyes germinate earlier than they otherwise would. After the cane has come up well, the fertilizer is applied and the earth returned to the cane. The cultivation from that time on is carried out by means of the disk cultivator, and an implement to loosen the earth in the middles between the rows. This treatment is carried on until the cane has reached a sufficient growth to render the continuance of the work with these implements no longer advisable. Hand hoeing is resorted to in removing weeds and grass from between the stools of cane.

Harvesting and Planting.-There are as yet no harvesting implements in commercial use, though several have been patented, and work is under way to bring them to the degree of perfection which is necessary for their adoption. At present the cane is cut by hand knives and it is a laborious process. It consists of cutting off the green portion at the top, stripping the leaves from the stalk, and severing it at the base.

Many of the plantations are now using mechanical loaders to place the cane in the wagons for transportation to the factory. Hoists, derricks, and devices of various types are employed to transfer the cane from the wagons to railroad cars, and also for loading it upon the carrier at the factory, and hand labor is 
practically eliminated at this point. In the event of a killing frost during the harvest period, the cane is cut without the removal of the leaves and tops, preserved by placing in windrows, and removed as the needs of the factory demand. In most instances an effort is made to do as much of the planting as is possible before the grinding season. After the harvesting begins labor is no longer available for planting cane, and that cane desired for further planting is preserved in windrows covered with earth for early spring planting. It is the usual practice to grow two crops of cane: that is, plant cane (from planted stalks), and first year stubble (growth from the live underground joints of the preceding year's crop), and then to produce an intervening crop of corn, with cowpeas sown between the corn rows, before replanting cane. This crop of corn and cowpeas serves as a soil renovator, and at the same time furnishes necessary feed for the plantation mules.

Fertilizers are applied to both plant and stubble cane. Those most commonly used are cotton-seed meal combined with acid phosphate and tankage alone. Application of 500 pounds to $75^{\circ}$ pounds to the acre is practiced.

Manufacture of Syrup, Sugar and Molasses.-In no industry is the manufacture more closely allied to agriculture than in sugar making. The raw material being of too perishable and too bulky a nature to permit of its distant transportation, the plantation maintains its own factory or else sells its production of cane to a nearby central factory. The cane is ground between massive rollers which bring out the juice. The juice is treated with sulphur and afterwards with lime, and is then heated. It is then separated from its precipitated impurities by decantation and filtration, after which it is concentrated by boiling in vacuum apparatus of special construction until it is a mass of sugar and molasses. This molasses is separated from the sugar crystals by purging in high speed 
centrifugal machines and is sold as such, or is reworked for low grade sugars. Syrup is the juice of the cane which has been concentrated without the removal of sugar. Some of the smaller places are entirely devoted to the manufacture of syrup for table use.

The modern sugar factory is an extensive installation of machinery and requires expert technical supervision to be operated to best advantage. Some of

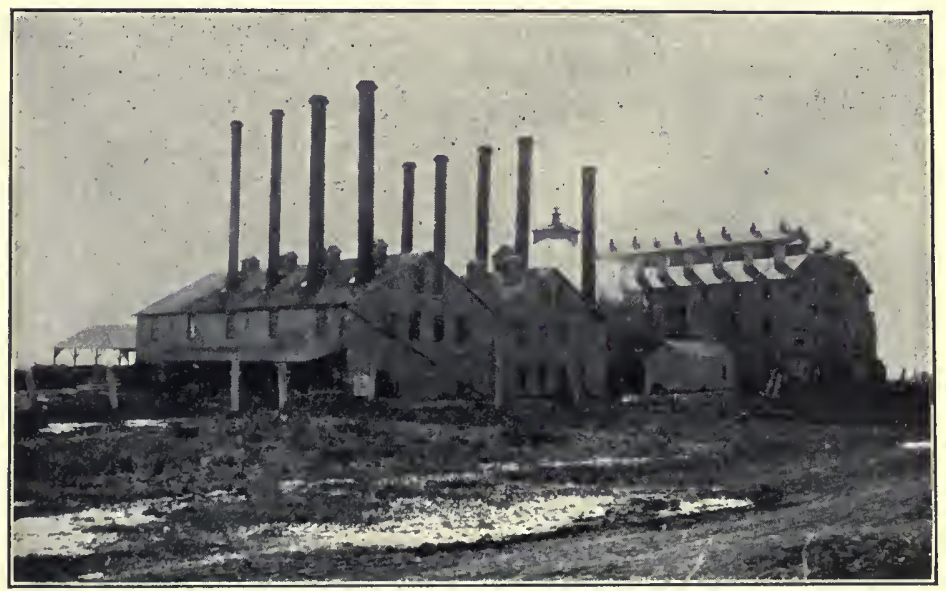

A MODERN SUGAR FACTORY.

these plants have a capacity of handling over a thousand tons of cane per twenty-four hours.

The average yield of cane in Louisiana is about twenty-two to twenty-six tons to the acre. A ton of cane gives an average of about one hundred and sixty pounds of sugar.

Other Sugar-cane Producing Countries. - The leading cane-producing countries are Cuba, Java and the Territory of Hawaii. East India also has an enormous production which, however, is consumed locally. Mexico, the various islands of the Orient and of the West Indies, and many of the countries of South and 
Central America, and one or two localities in Africa also contribute to the 7,000,000 of tons of cane sugar that is furnished annually to the markets of the world.

As would be expected, widely varying systems of agriculture and manufacture prevail in the production of this sugar. For instance, in some sections drainage is the all-important consideration, while in others irrigation is necessary. In many localities the methods are crude, almost primitive in character, while in other places, though far distant from the centers of civilization, progressiveness is evidenced by steam plows and the latest implements for cultivation, together with labor-saving devices, and the most modern installations for converting the raw material into marketable products.

EXERCISE-If sugar cane is grown in the section, bring stalks of as many varieties as can be obtained to the classroom and examine them as described in this article.

If sugar or syrup is manufactured in the neighborhood, the teacher should take the class out to such a place and require the pupils to take notes of harvesting, planting, fertilization, and manufacturing. For information on sugar cane write to the Louisiana Experiment Station, Baton Rouge, La.

\section{Section XXIV.-Toвacco.}

By DR. E. H. Jenkins,

Director Connecticut Agricultural Experiment Station.

Tobacco belongs to the night-shade family of plants, which includes potatoes, tomatoes and egg plants, and also the medicinal or poisonous plants, henbane, and jimson weed or stramonium.

Tobacco Plant an Annual.-The tobacco plant grows from five to nine feet high, and has from twenty to thirty large leaves and white or pink flowers borne at the top of the plant and on a few side shoots. It grows from the seed and matures in one season, being killed by frost. The leaves only are used in commerce. 
Importance of Tobacco.-It is a crop like tea and coffee, which supplies neither food nor clothing, but is used all over the world as a luxury and for its semimedicinal effects. It was introduced to the world from this continent. Its cultivation and export were leading industries of the Virginia settlers, and for a time it was used among them as money, even the sala-

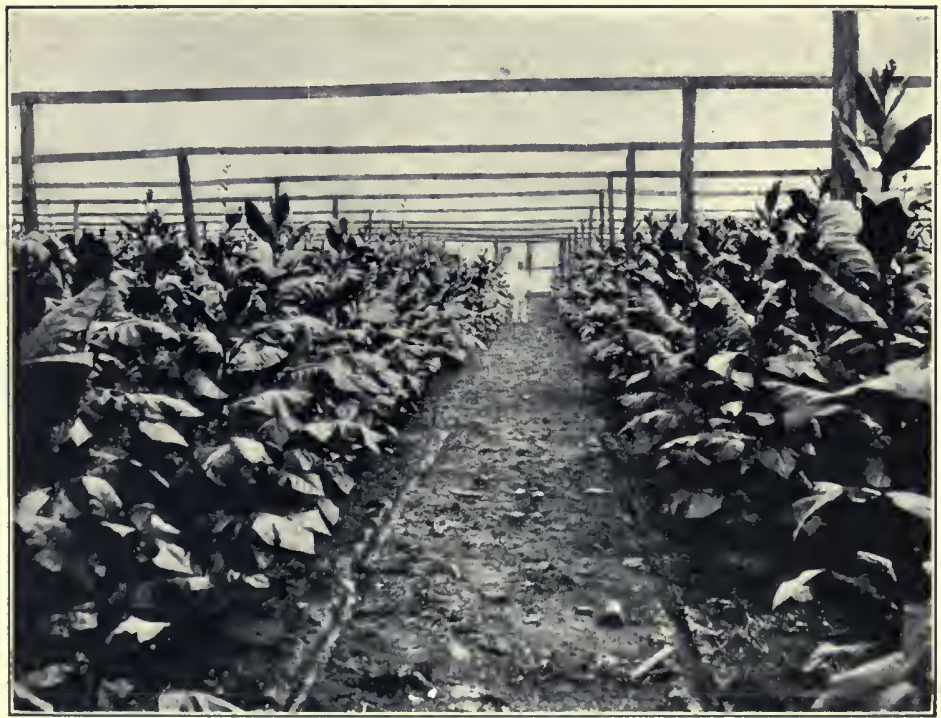

SELECTED TOBACCO PLANTS.

ries of clergymen and fines for violation of law being fixed at so many pounds of tobacco. In Maryland it was made a legal tender by statute.

To-day the tobacco crop of the United States is valued at not far from sixty million dollars, and Kentucky and Virginia produce the larger part of it.

The tobacco plant will mature in almost any part of the United States, but it can be grown profitably only in certain sections where climate and soil are both suitable. 
Types.-There are six quite distinct types of tobacco grown in this country:

I. Cigar tobacco, both wrappers and fillers. A cigar is made up of a filler, which gives the flavor and furnishes the main part of it; a binder, which is rolled over the filler and holds it together, and the wrapper, which is rolled tightly over the whole and gives it its finished appearance. Cigar wrappers are raised

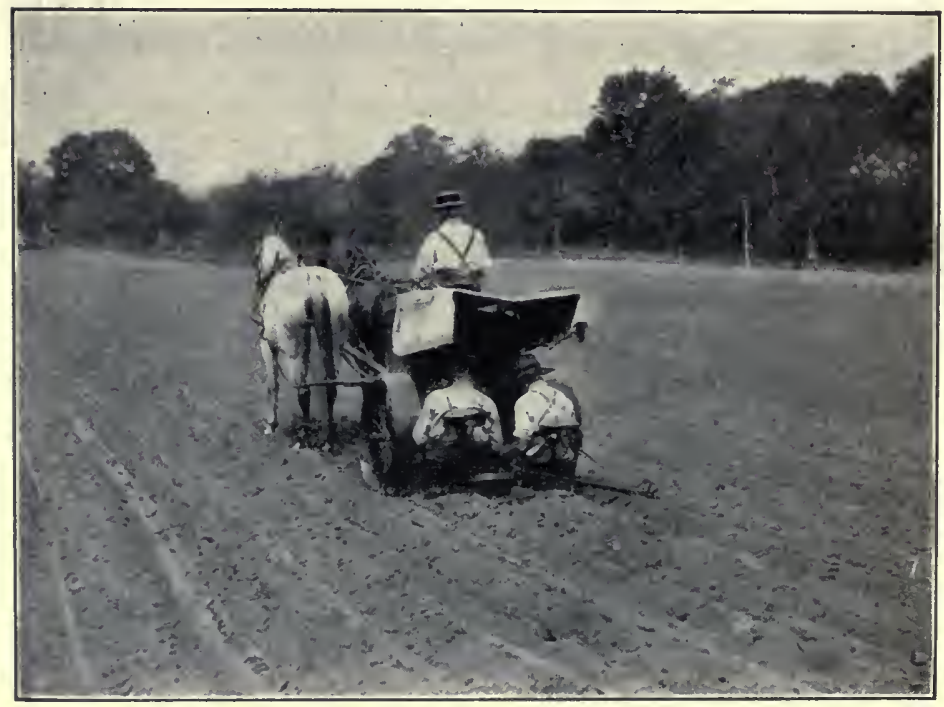

SETTING OUT TOBACCO PLANTS BY MACHINERY.

chiefly in New England, Pennsylvania, New York and Wisconsin; also in Florida, southern Georgia and Texas, and fillers in Pennsylvania, New York, Ohio, and the extreme Southern States.

2. White Burley tobacco, raised in Kentucky, the leading tobacco growing state.

3. Export or heavy tobacco, grown mostly in the Middle West.

4. Bright yellow tobacco, peculiar to Virginia and the Carolinas. 
5. Suncured tobacco, raised in a small way in Virginia.

6. Perique, grown only in a single parish of Louisiana.

Planting and Growing.-The methods of planting and growing the different types are much alike, but the method of curing is different for each. The seed is sown in beds, which are protected from the spring frost by glass or cotton cloth covers, and which have to be carefully watered, weeded and aired.

When the danger of frosts is past and the land is warm, the young plants, a few inches high, are carefully pulled from the bed and transplanted by hand or machine into the field, which has been thoroughly prepared by plowing and harrowing, and often by liberal dressing with manure or fertilizers. The plants are set in rows from three to four feet apart, and they stand from twelve to twenty-four inches apart in the row.

The land is cultivated very thoroughly and often, and the crop protected from worms of various kinds which prey upon it.

The plants are not allowed to blossom and produce seed, for this would take the strength from the leaves, which are the only valuable part of the plant. So the flower bud is broken off from the tip of every plant in the field soon after it appears, and also the suckers or side branches, which begin to grow as soon as the flower buds are taken off.

Harvesting. - When the best leaves on the plant are ripe, the crop is harvested. Sometimes the whole plant is cut down at the surface of the ground and afterwards strung on a lath which is thrust through the split stalk, five or six plants being strung on a lath, and these are hung, tops down, on poles fastened in the tobacco barn at the proper distance apart. Another way of harvesting, commonly practiced with the cigar wrapper leaf, is to pick the leaves from the plants standing in the field as they ripen, beginning at the 


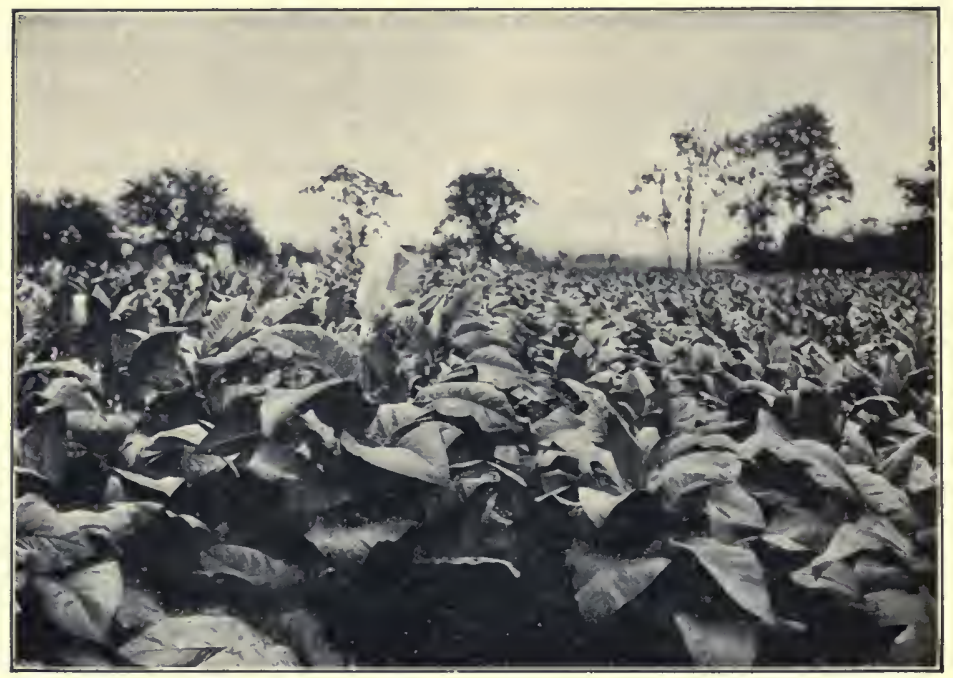

AN EXCELLENT TOBACCO CROP.

bottom. Three or four pickings are thus made at intervals of a week or ten days. The leaves, carefully laid in baskets, are taken to the barn and there strung on strings attached to laths, each lath carrying about forty leaves, and hung up in the barn as above described.

Curing.-When the barn is filled with tobacco in this way, the process of curing begins. This requires more care and skill than anything else connected with the crop.

The object is to dry out the leaf gradually, so that it will "come to color;" that is, will get the characteristic colors (yellow or brown) which cured tobacco of the particular kind grown should have, and not to let the fermentation which causes this change go too far, making the leaf too dark. If the barn is too dry, the leaf dries too rapidly to get the right color and remains green. If it is too damp, the leaf will "pole burn," become discolored and rot. Often fires are 
put on the earth floor of the barn, or furnaces outside the barn, with flues running through it, are used to dry the leaf when the air outside is so damp as to threaten injury. This process of curing takes from three to six weeks in the case of cigar wrapper tobacco. Each of the types of leaf is cured differently, but the general purpose and result are as just described.

Sorting and Grading.-When the leaf has been properly cured it is very brittle if dry, and cannot be handled until it becomes damp in time of fog or rain. Then the leaves which have become soft and pliable are broken off from the stalks, or the strings of leaves are cut from the laths which held them and are bundled together for further treatment. All kinds of to-

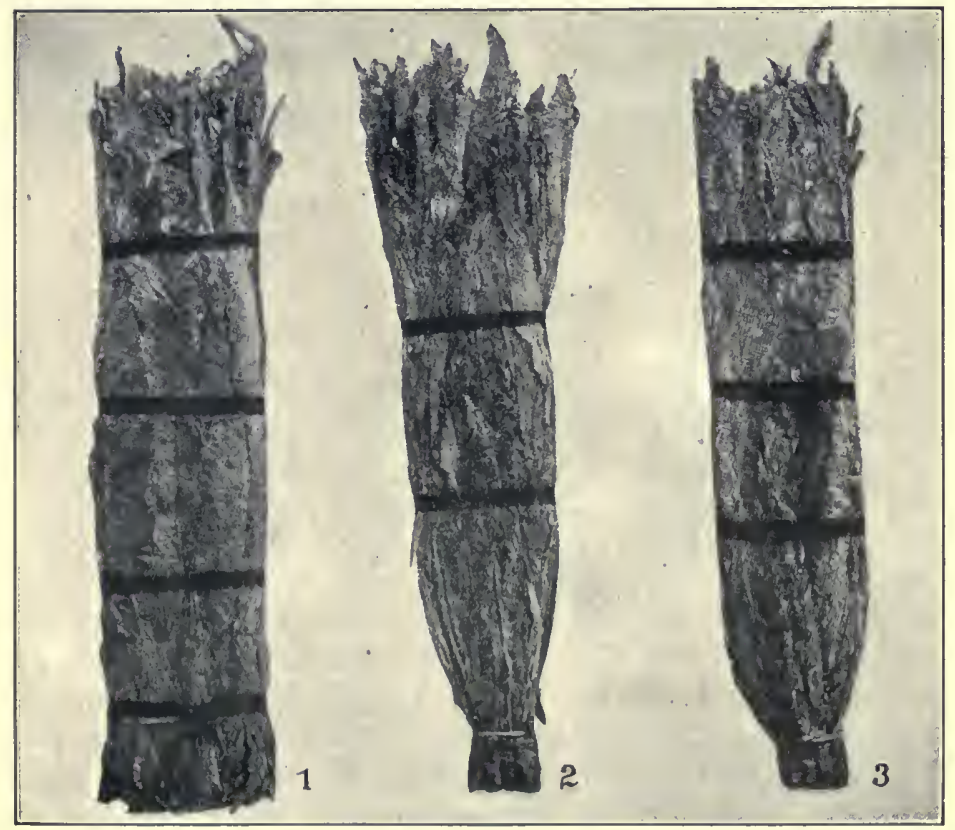

EXPORT TOBACCO.

I, English olive-green strips; 2, olive-green leaf; 3, Austrian. 
bacco have to be sorted, to put by themselves the different grades and to remove damaged and inferior leaves, and in addition most types of tobacco have to be fermented or "sweated," either by the farmer or the dealer, before they are ready to be manufactured. The price which is paid for the leaf when ready for manufacture into cigars, cigarettes, pipe or smoking tobacco, chewing tobacco, or snuff ranges from a few cents to three or four dollars per pound, depending on the uses to which it can be put and the quality of the crop. Much depends on the skill with which the crop is grown, cured and fermented.

Note for the TeAcher.-If tobacco is not grown in your locality, ask the pupils if they have ever seen this crop growing. If any of them are familiar with tobacco, have one of them explain the process of planting, cultivating, harvesting and curing. If tobacco is grown in the neighborhood the class should be taken to a prosperous farm and the crop studied.

\section{Section XXV.-Root CRops.}

\section{(A) Mangels, Irish Potatoes, Sugar Beets, Etc. \\ By J. E. Halligan,}

Chemist in Charge, Louisiana State Experiment Station.

Root crops generally include those plants that store up their food in a thickened stem and root. The food is stored in the stem entirely in the kohlrabi, and in the cabbage the food is found in the leaves. Most of this class of plants are biennials with the exception of rape, which is an annual.

These crops are not grown as extensively in America as in Europe. In Canada they are more popular than in the United States. They should be grown more extensively in this country because they furnish excellent feed for live-stock, especially for dairy cattle and sheep. They are succulent and seem to give results much above what their chemical composition would indicate. They have a tonic and laxative effect. 


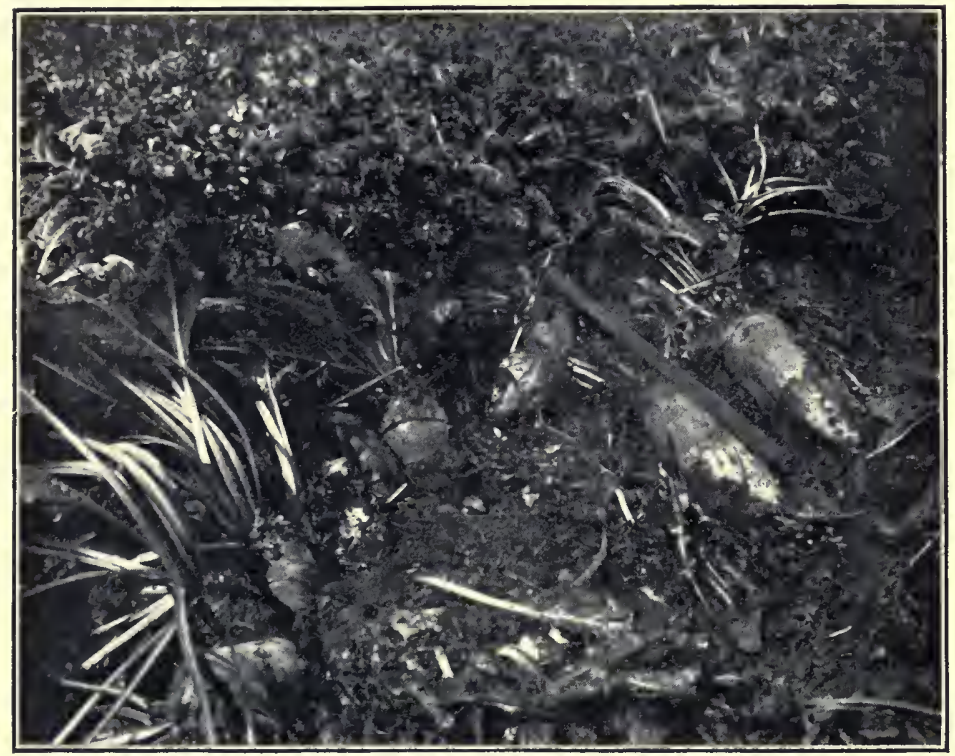

STOCK BEETS.

According to Bulletin 243 of the Cornell Experiment Station: "The reason why the production of roots is of special interest in the North Atlantic States is that these states raise a comparatively large amount of roughage and a small amount of concentrates, while the North Central States raise a large amount of cereals or concentrates in proportion to hay and forage, as shown in the following table which gives the ratio of concentrates to roughage in the North Atlantic and North Central States according to the census of I 900 :

North North

All cereals, except wheat, million tons.

All hay and foragc, million tons............... $15.6 \quad 49.0$

Per cent. of cereals, except wheat........... $22.0 \quad 58.5$

Tons cereals, except wheat, per animal unit....... $0.55 \quad$ I.55

Tons hay and forage, per animal unit......... I.95 I.IO

Total tons of food per animal (of about $\mathrm{I}, \mathrm{000}$ lbs. live weight $) \ldots \ldots \ldots \ldots \ldots \ldots \ldots \ldots, 2.50 \quad 2.65$ 
Roots Contain Much Water.- "One of the objections to roots as a food product lies in the fact of their high water content. This limits the amount which may be fed and becomes of special importance when they are fed in connection with silage. On account of this high water content it is not practicable to feed a sufficient amount entirely to take the place of the cereals, even should this be desirable for other reasons. The trend of experimental evidence is that the feeding value of the different types and varieties of root crops depends more largely on the percentage of dry matter than on any other factor; for example, the percentage of dry matter apparently modifies their feeding value more largely than the percentage of sugar.

Yield of Root Crops.- "The following table shows the minimum, average and maximum number of pounds of dry matter per acre which was obtained at the Cornell Experiment Station in 1904, I905 and r 906 from sowings made during May:

\begin{tabular}{|c|c|c|c|}
\hline & Minimum & Average & Maximum \\
\hline Mangels.............. & 2,168 & 5, I 55 & 8,453 \\
\hline Half-sugar mangels..... & 5,480 & 5,880 & 6,440 \\
\hline Sugar beets.......... & 6,014 & 7,090 & 8,090 \\
\hline Rutabagas........... & 3,537 & 4,331 & 5,079 \\
\hline Hybrid turnips........ & 2,584 & 3,694 & 5, I I I \\
\hline Common turnips....... & 1,710 & 2,680 & 3,500 \\
\hline Kohlrabi.............. & 3,570 & 4,070 & 4,540 \\
\hline Cabbages............. & 4,076 & 4,662 & 5,588 \\
\hline Carrots............. & 1,878 & 3,134 & 4,379 \\
\hline Parsnips............. & 2,080 & 3,130 & 3,680 \\
\hline
\end{tabular}

"The estimated yield of grain from flint corn, the same seasons, at this station was approximately 2,000 pounds; while the yield of dry matter in silage from dent corn was about four thousand pounds. It is probable that the season of 1904 was relatively favorable to the production of roots as compared to Indian corn, but this was not true of 1905 and 1906 . In the latter years the average yields from roots were better than in I904, although the land used was conceded by all interested to be less favorable than that used in 1904 . 
Roots Versus Cereals.- " The present high price of cereals is a factor in favor of the production of root crops. If corn meal continues to be worth twenty dollars a ton or more, economy in the production of roots would be indicated, while, if the price should fall to ten dollars a ton, corn meal would probably be the cheaper source of concentrates. The serious handicap to the raising of root crops is the fact that, with present cultural methods, a large amount of hand labor is required. The point of view that it is desired here to emphasize is that while roots may not be economically raised as a substitute for silage or other coarse fodders, it may be economical to raise them as a partial substitute for concentrates, particularly the cereal grains."

Mangel Wurzels, often called mangels, is one of the most popular of the root crops, because of the large yields obtained and its feeding value. Experiments show that mangels give better returns with dairy cows than turnips, carrots or sugar beets.

$V$ arieties.-Some of the principal varieties of mangel wurzels are the Mammoth Long Red, Golden Tankard, Red Globe and Yellow Globe. There are several varieties of mangel wurzels which are the result of crossing with the sugar beet, and are called halfsugar mangel wurzels. According to Bulletin 244 Cornell Experiment Station: "Two half-sugar mangels, Vilmorin Half-sugar Rosy and Carter Halfsugar are recommended as suitable stock to use for breeding American strains. Sugar beets, although rich in dry matter, are generally so much more expensive to harvest that the writers are not prepared to advocate their extensive use for stock feeding."

Climate and Soil.- The mangel is adapted to a cool climate and a moist soil. The North Atlantic States are especially adapted for the growing of mangels, as the season is short and the corn crop is uncertain because of the early frost. Root crops may be grown in the South in the late fall or winter when the land is 
ordinarily idle. Mangels stand drought better than the other root crops.

A loose, deep, rich, well-drained soil is necessary for the production of large yields. The seed bed should be free from lumps as the young seedlings are tender and weak and cannot well penetrate such soil. It is generally advisable to plow very deeply in preparing the seed bed for this crop, as such practice tends to encourage the root to grow under the surface and permits of a deeper feeding area.

Fertilizers.-Most root crops are gross feeders and require considerable plant food in available forms. On soils deficient in organic matter, farm manure at the rate of seven to ten tons per acre should be applied in the fall and supplemented in the spring at planting time with three hundred to five hundred pounds of a fertilizer containing 8 to ro per cent. of available phosphoric acid, 2.5 to 4.5 per cent. of nitrogen, and 4 to 6 per cent. of potash in the form of sulphate. The nitrogen should be supplied from nitrate of soda, and some quickly available organic form as dried blood. Green manures, such as some leguminous crop plowed under, may be substituted for the farm manure, and in such substitution the nitrogen content in the fertilizer may be cut down somewhat. On rich soils, or those containing plenty of organic matter, the fertilizer as given above should be used at planting time.

Seeding and Planting.-From six to eight pounds of seed per acre is recommended for mangels. The seed should be planted in rows thirty to forty inches apart, in May in the North and in September or early October in the far South. If narrower rows are used, it is necessary to cultivate by hand labor, which increases the expense of production. The plants should be thinned to a distance of six to ten inches, depending on the variety, as soon as possible.

Cultivation.-The mangel, as well as some of the other root crops, germinates slowly, and for such crops it is sometimes advisable to sow a small amount of 
some crop that germinates quickly to mark the rows and allow of early cultivation. Buckwheat may be used for this purpose, and it can be chopped out when the plants are thinned. Root crops should be cultivated often enough to keep the land free from weeds and prevent the loss of moisture by evaporation.

Yields.-Average soils should produce twenty to forty tons of mangels per acre. The following table, the work of the New Jersey Experiment Station,* shows the comparative tonnage and nutrient yields of mangels and corn forage:

\begin{tabular}{|c|c|c|c|c|}
\hline Containing pounds of & Mangels & $\begin{array}{l}\text { Corn } \\
\text { Forage }\end{array}$ & $\begin{array}{l}\text { Mangels } \\
\text { increase }\end{array}$ & $\begin{array}{c}\text { Corn Forage } \\
\text { increase }\end{array}$ \\
\hline Weight of green crop... & 56,600 & 20,000 & 36,000 & \\
\hline Dry matter............... & 4,684 & 6,130 & $\ldots \ldots$ & $\mathrm{I}, 446$ \\
\hline Crude fat... & 33.9 & I 52.2 & & I I 8.3 \\
\hline Crude fiber..... & 379.2 & I, $484 \cdot 7$ & $\ldots \ldots$ & I, I05.5 \\
\hline de protein. .... & 684.9 & 468.9 & 216.0 & $\ldots \ldots$ \\
\hline Crude ash........... & 503.7 & 243.8 & $259 \cdot 9$ & \\
\hline Carbohydrates........ & 3, I I 2.6 & $3,780.2$ & $\ldots \ldots$ & 667.6 \\
\hline
\end{tabular}

It is shown in the above table that although mangels produced almost three times as much tonnage yield as the corn forage, they only produced 75 per cent. as much dry matter.

Harvesting.- Root crops should be harvested before the heavy frosts set in. They should be dried and stored in cool cellars where the temperature is such that they will not freeze or become too warm. Sometimes they are placed in pits in the field and covered with earth or other material to prevent their freezing. The cellars and pits should be dry, well aired, and drained. In the far South root crops may be pulled from day to day as needed.

Sugar Beet.-This crop is grown quite extensively for the production of sugar in this country. It does best in a zone of varying width in the center of which passes the isothermal line of 70 degrees Fahrenheit 
for the months of June, July and August.* For the year I $909,4,081,382$ tons of sugar beets were worked which produced 5 12,469 tons of sugar. The average yield per acre of beets in Germany is a little over thirteen tons, while in the United States it is almost ten tons. The normal width between the rows is 18 inches and the distance between the plants is 8 inches. The ideal weight of the beet is two pounds. These figures will give a yield of 43.3 tons per acre with a perfect stand. There is a difference of 33.3 tons be-

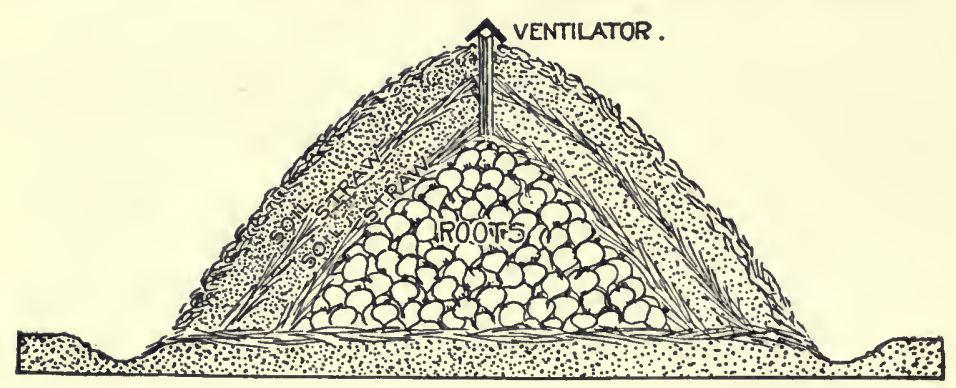

A CROSS SECTION OF AN EASILY CONSTRUCTED PIT FOR ROOTS.

Place the roots upon a layer of straw on a well-drained location and cover with straw, then soil, then a second layer of straw and a second layer of soil. Then place a thick layer of straw or coarse horse manure on the outside. Dig a drain around the pit to prevent the ground becoming water-logged.

tween our production and the ideal, so there is a great chance for improvement in the growing of this crop.†

Requirements.-This crop requires water, sunlight and a rich soil. The preparation of the soil is about the same as for the mangel. Like the mangel it gets started slowly and a mixture of equal parts of nitrate of soda and acid phosphate applied at the rate of 100 to $\mathrm{I} 5 \mathrm{O}$ pounds to the acre is very helpful in giving the sugar beet a start. About sixteen to twenty pounds of seed per acre are required for a good stand. The seed should be planted from $3 / 4$ of an inch to I $3 / 4$

* Farmers' Bul. 52-Revised.

i Report No. 92, U. S. Dept. of Agriculture. 


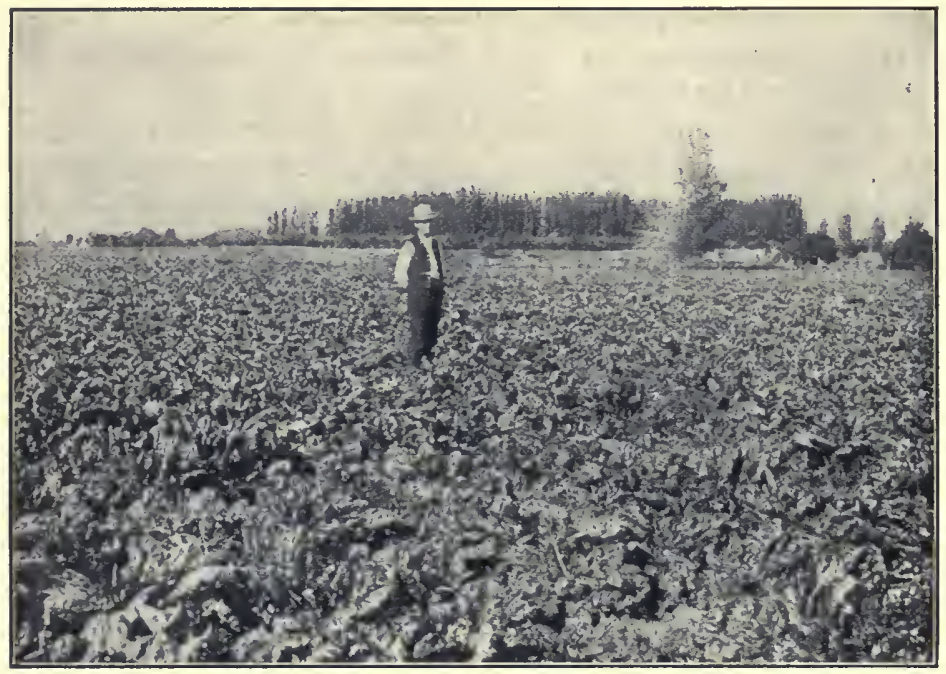

A FIELD OF SUGAR BEETS GROWN UNDER IRRIGATION IN OREGON.

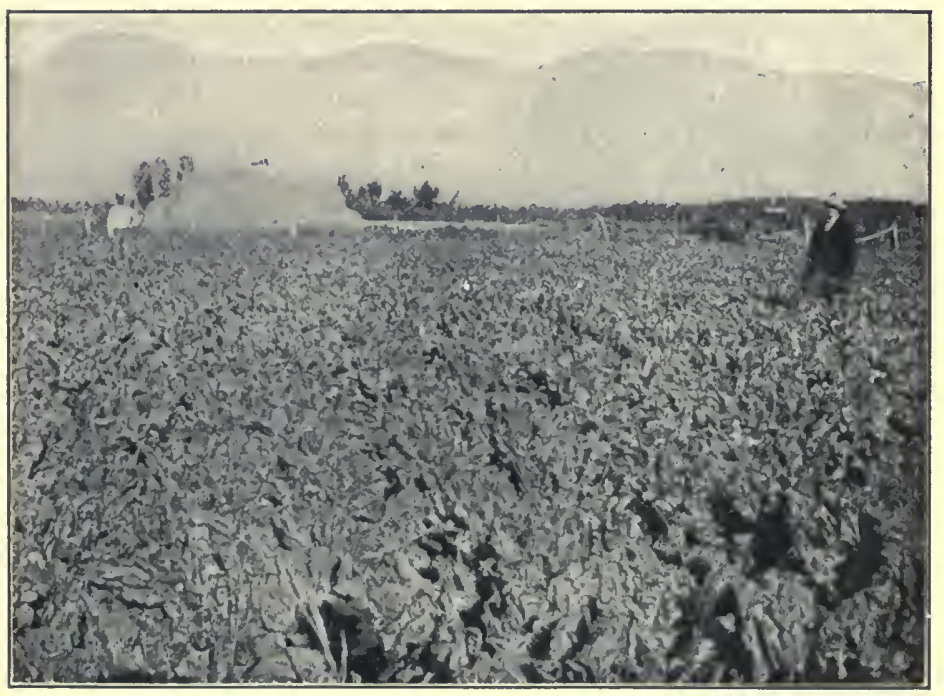

FIELD OF SUGAR BEETS IN UTAH. 
inches deep; the depth depending upon the soil moisture. Shallow planting is preferable when there is plenty of moisture.

Time to Plant.-In the Eastern States and through the Mississippi Valley the sugar beet is planted from April to early June; in Utah, Idaho, Colorado and Montana about two to three weeks earlier; in California from November I 5 th to June Ist.

$V$ arieties.-For sugar the Kleinwauzlebener and the Vilmorin Improved are popular, and for stock beets the Lane's Improved Imperial, Danish Improved, Queen of Denmark, White Green Top and White Rose Top are grown.

Irrigation.-As the sugar beet is often grown in regions of light rainfall, it is often necessary to supply water by artificial means to insure a profitable crop.

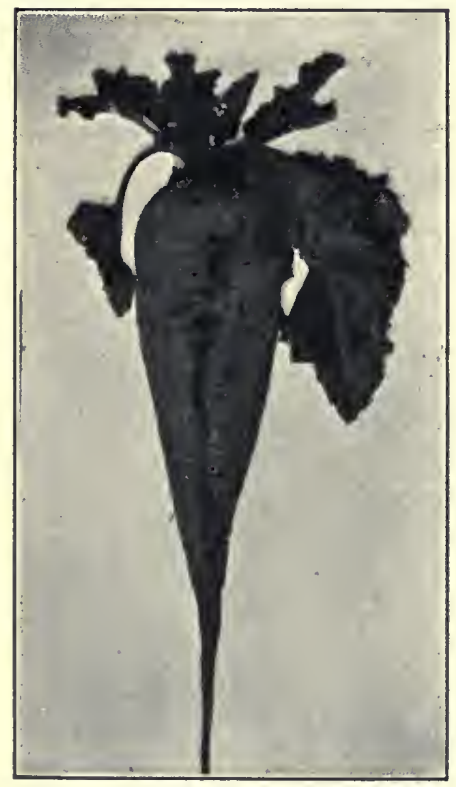

A WELl-SHAPED SUGAR BEET.
Water should never be applied to this crop unless it absolutely needs it. During dry spells the sugar beet sends down its tap roots to the lower soil in search for water, but if it is irrigated it will not do this and will possibly suffer should a long dry spell occur. If beets do not appear wilted in the early morning, they should not be supplied with water.

The water is usually applied in the rows and at such times as necessary. Water should never be applied late in the season, as it tends to produce growth and decreases the sugar content. 
Harvesting.-The time of harvesting varies a great deal, depending upon the time of planting. Beets planted from April to June are ready by early October, and those planted in November and December should be harvested in June and early July. The harvest period is indicated by the appearance of the leaves, which droop, turn yellow and many of them wither and die.

The beets are harvested by loosening with a turn plow, the share of which cuts off the beets at the proper depth and throws them over the moldboard. Sometimes a digger is used which consists of two prongs that run deep enough to cut the beet below the middle part. This machine is only suitable when the rows are straight and the beets uniform in size. The beets are pulled out and the leaves removed by means of a sharp knife with hand labor.*

Turnips and Rutabagas (Swedes, or Swedish turnips).-These crops are valuable to follow some early harvested crop as potatoes or tomatoes. In this way they may be used as a catch crop. They are sown either in the drill, 30 to 36 inches apart, or broadcast. When sown in the drill, 3 to 4 pounds of seed per acre will suffice, and the plants should be thinned to 6 inches and well cultivated. For broadcasting 4 to 6 pounds of seed are necessary. Seeds should be sown about one-half to one inch deep, depending on the amount of soil moisture. Turnips grow more quickly than rutabagas, but do not yield or keep so well. To combine the quick growing of the turnip and the superior keeping and yielding qualities of the rutabagas crosses have been made which are called hybrid turnips. These crops will not stand drought as well as mangels and are not able to secure plant food so readily, especially phosphoric acid. Turnips should yield about five to twenty tons per acre and rutabagas ten to thirty tons. The principal varieties of turnips grown for feeding are the Mammoth Purple Top and Improved Green Globe; hybrid turnips, 
Yellow Aberdeen and Pioneer; rutabagas, Kangaroo and Holborn Elephant. The fertilizer recommended for mangels is satisfactory for these crops, although the phosphoric acid may be increased to advantage.

Carrots are valuable to supply appetizing food for horses. They will grow on poorer soils and under more varying climatic conditions than turnips and mangels. They require a soil well prepared. On account of their slow germination they should be fertilized to stimulate early growth. Rotted manure is more desirable than fresh manure. The seed is usually planted at the rate of 6 to 8 pounds per acre, in rows 18 to 30 inches apart, and thinned from 3 to 6 inches. They yield from 10 to 30 tons per acre. The principal varieties are: for human consumption, Vilmorin Coreless Long Red, Intermediate and Lane's Scarlet Intermediate; for stock feed, Long White, Long Orange, Orange Giant and Yellow Belgian.

Kohlrabi.-This is not strictly a root, but the food is stored in a thickened stem. It is grown for stock feeding and does well wherever rutabagas thrive. It should be cultivated similarly to rutabagas. In sections, as in the Middle West, this crop is a good substitute for rutabagas as the latter tend to produce poor roots and large necks. The advantages of kohlrabi over rutabagas are that it may be grown on a heavier soil; it is easily pastured because its thickened stem grows above ground; it stands drought, warm climate and frost better; it is not so subject to diseases; it is not so apt to taint milk. Good seed is hard to obtain and is more expensive than rutabaga seed. Some of the principal varieties are Short Top White, Carter Model and Purple and White Vienna.

Cabbage is not grown for stock feeding so much in this country as in Europe. It is often advisable for the farmer to grow cabbage, as it generally brings a good market price, and if it does not, it may be fed to live stock. It is not as good as other root crops for feeding because it is more difficult to keep, it re- 
quires more plant food to grow, and it furnishes less dry matter. The cabbage is adapted to cool moist climates, although it will grow under a variety of climatic conditions. The Northern States and Canada are adapted for its growth.

Soil and Fertilizer.-The cabbage may be raised on all types of soil that are abundantly supplied with available plant food and water. The soil should be plowed deeply and thoroughly harrowed to insure a loose fine seed bed. Farm manure at the rate of io to I 5 tons per acre should be applied before fall plowing. In the spring this may be supplemented with an application of $I, 000$ to $I, 500$ pounds of quicklime and 600 pounds of a fertilizer analyzing 4 to 5 per cent. of nitrogen, 7 to 9 per cent. of available phosphoric acid, and 8 to 9 per cent. of potash, derived from nitrate of soda, superphosphate and potash salts or wood ashes.

Seeding.- Seed may be sown in the field in 3 feet rows, during early May, and afterwards thinned from 2 to $2 \frac{1}{2}$ feet when they have reached a height of 3 to 4 inches. About $1 / 2$ to $3 / 4$ of a pound of seed per acre is sufficient in this method of planting. The commercial growers like this method of growing cabbage.

Resetting.-Many of the smaller growers prefer to grow their plants in a greenhouse or hotbed and transplant the young plants to the field. If transplanting is favored, the plants should be in the field by the last of May or the first of June.

Cultivating and Storing.-The land should be thoroughly cultivated, and when the young plants are backward an application of 50 to 75 pounds of nitrate of soda per acre will help to produce vigorous growth. If the market price is unsatisfactory, cabbages may be stored by placing them with their stems and roots on, head down, in some protected spot and covered with straw. A storage house is of course preferable. Surehead and Autumn King are varieties that have given good results. 
Rape is being widely grown in Canada and the northern part of the United States. It is grown in these sections for a soiling crop and for pasture. It is. an excellent nutritious and succulent feed. It requires a rich, deep and warm sandy or loam soil for best development. It is best adapted to cool, moist climates, but it also does well in the semi-arid regions of this country when irrigated. It stands drought as well as general farm crops and can endure frost better than turnips, rutabagas and cabbage. It is ready to use eight to ten weeks after seeding and may be pastured or cut for feed. With cattle and sheep care should be taken not to allow them too much when they are fed it first as it may cause bloating. It does not seem to cause swine to bloat. It is an easy matter to accustom cattle and sheep to rape by allowing them to pasture it a little each day, gradually increasing the length of time. The Dwarf Essex and Giant are popular varieties.

Soil and Seeding.-The land should be plowed deeply in the fall and again in the spring when necessary. In the spring the soil should be harrowed and the land put in a fine mellow condition. It may be fertilized similar to cabbage. Seeding should take place in the Northern States from May $25^{\text {th }}$ to July 2oth, and in the Southern States during September and early October. The seed may be planted in drills at the rate of 2 to 5 pounds per acre. The rows should be 24 to 30 inches apart. Sometimes it is broadcasted. Rape makes a good cover crop, as it may follow early maturing crops and so may be used to advantage in rotations.

\section{Irish Potatoes.}

Importance.-The potato crop for 1909 was $367,-$ 0oo, 00o bushels, which was worth $\$ 2$ I $2,000,000$. To fully appreciate the value of this crop we may say that 
the potato crop for I 909 was worth half as much as the oat crop, over double that of the tobacco crop, almost as much as the entire sugar, barley and flaxseed crops taken together, and nearly five times as much as the rice and rye crops combined.*

The potato is grown in every state and territory in the United States. The following table shows the acreage in some of the principal potato growing states:

\section{State}

Maine.............. I30,000

New York........... 438,00o

Pennsylvania.......... 305,000

Ohio............... I 82,000

Illinois............ I64,000

Michigan............ 348,000

Wisconsin........... 262,000

Minnesota............. I60,000

Iowa.............. I 45,000

Nebraska............. I05,000
Average Yield Farm Value Per Acre

Bus.

225

I 20

78

93

9 I

105

102

I 5

89

78
Per Acre

Dec. I, I909

$\$ 105 \cdot 75$

60.00

50.70

52.08

$55 \cdot 5 \mathrm{I}$

36.75

38.76

40.25

48.95

46.80

Soil.-Although the potato is grown on all kinds of soils and in widely varying climates, it requires for * Ig09 Yearbook, U. S. Dept. of Agriculture.

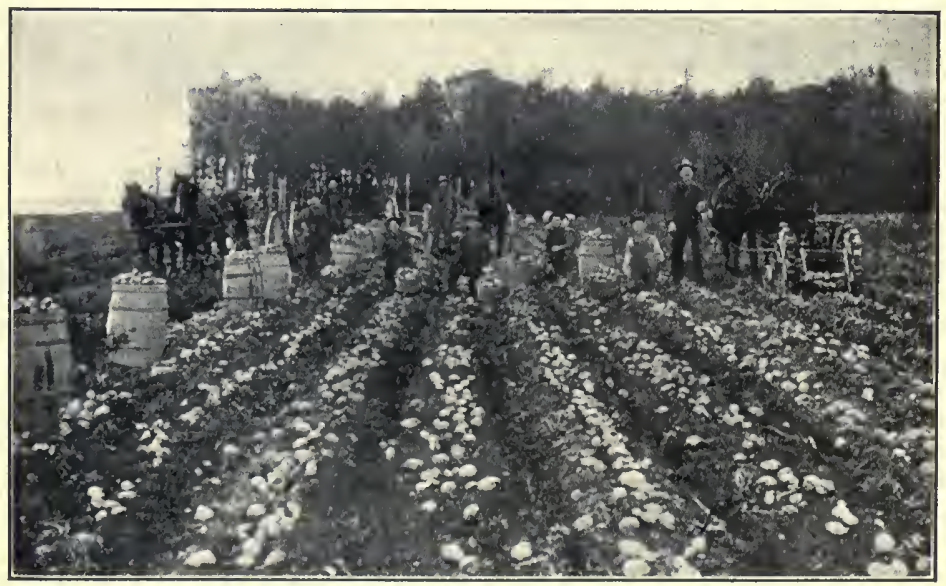

POTATO-DIGGING SCENE IN MAINE. 
best development a light well-drained soil that will permit free spreading of the growing tubers. A moist though not wet soil well supplied with decayed organic matter and an excess of available plant food, so that the plant will always have what it needs, is desirable and essential for best results. Heavy soils are not as suitable as light friable soils, but may be improved by the addition of organic matter. The best results are

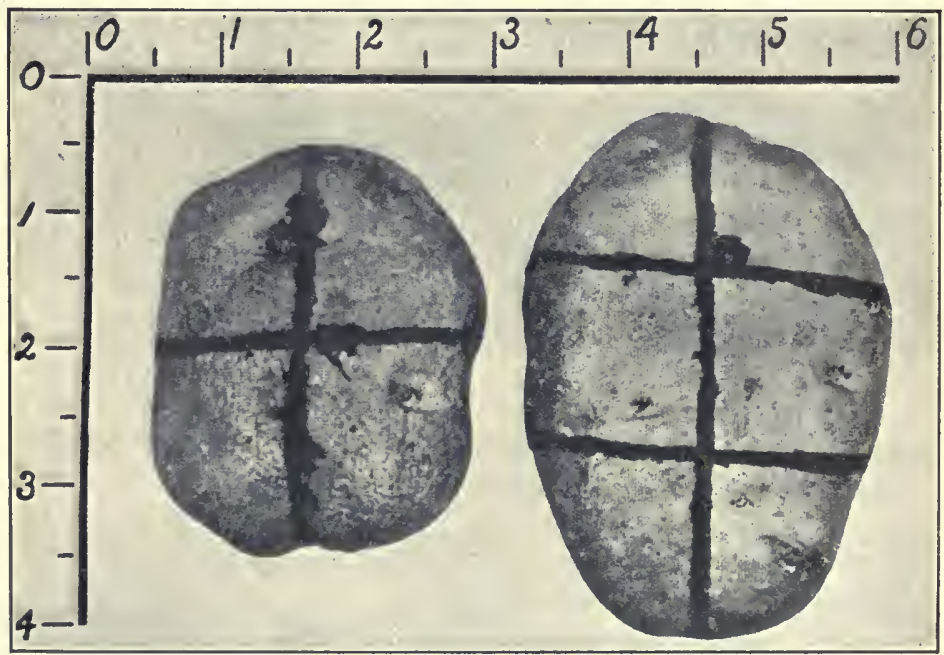

THE BLACK LINES SHOW WHERE TO CUT WHEN TUBERS ARE OF THIS SIZE AND SHAPE.

obtained when the crop is grown in rotation. In Maine, where the production per acre is highest, the following rotation is popular:

Ist year, potatoes.

2nd year, grain, sowed to clover.

3 rd year, clover, which is plowed under in the fall and followed by potatoes the next spring.

Whenever sod is plowed under or farm manure applied, care should be exercised that the organic matter is thoroughly rotted before planting time, as 
fresh manure or sod diminish the moisture supply and are apt to favor the production of scabby potatoes. Potatues may follow corn which has been heavily fertilized with green or farm manure.

Fertilizers.-Irish potatoes are an exhaustive crop from the fertilizer standpoint, but from the money value viewpoint they are less exhaustive than the small grains. They are grown as an early and a late crop in the North, and in the South they are generally most profitable when harvested in early spring. The early crops are forced with heavy fertilization, while the late crops are allowed to grow slowly and with less fertilizer. Potash as sulphate seems to be best, as it produces more uniform potatoes which stand storage better than when fertilized with potash in the form of chloride. For early potatoes 800 to 2,000 pounds per acre of a fertilizer containing plant food in available forms, carrying 3 to 4 per cent. of nitrogen, 6 to 8 per cent. of available phosphoric acid, and 8 to ro per cent. of potash as sulphate is recommended. For late potatoes 600 to $\mathrm{I}, 200$ pounds of a fertilizer containing 2.5 to 3 per cent. of nitrogen, 6 to 8 per cent. of available phosphoric acid, and 8 per cent. of potash as sulphate is desirable. It should be understood that these fertilizers supplement barnyard manure or leguminous green manure. The fertilizers should be applied before the crop is planted, and covered with sufficient earth to prevent injuring the tubers.

Planting.-Experiments show that vigorous pota. toes that weigh 4 ounces when cut in half are the best. Scabby and shriveled potatoes should not be used. The tubers should be planted in rows 3 feet apart and $x_{5}$ inches should be the distance between the plants. The planting may be accomplished with any of the modern potato planters. In level culture the seed pieces may be planted at a depth of 3 to 4 inches, while in ridge culture $I$ to 2 inches is deep enough.

Cultivation.-Potatoes require a large amount of water for successful growth and frequent shallow 
cultivation is therefore necessary to conserve the moisture and keep the land free from weeds. In ridge culture a horse hoe is used, and in level culture a shallow-toothed cultivator; hence level culture is preferable for conserving the moisture content of the soil and protecting the roots.

Harvesting and Storing.-When the vines wilt and die the potatoes are ready to dig. For early potatoes the size of the tubers regulates the time of digging, as an early market makes a great difference in the farmers' profits. On small farms hand digging with a tined fork is resorted to, while on large areas a machine called the potato digger is used with good success. In harvesting potatoes great care should be taken not to injure them. Early potatoes in particular have tender skins which are easily bruised by careless handling and such injury lowers their market price. The potatoes should not be exposed any more than is necessary to the light. In storing potatoes a low temperature should be maintained. Potatoes will stand a temperature of 33 degrees Fahrenheit. Too high a temperature is injurious, as it causes the potatoes to sprout.

\section{(b) Sweet Potatoes, Peanuts and Water- MELONS.}

By Prof. S. E. McClendon,

Asst. Director Louisiana State Experiment Station.

I. Sweet Potatoes are well adapted, and produce smoother roots of medium size when grown on welldrained, loose, sandy soils. If the lands are heavy and very rich, with an abundance of moisture, the potatoes may grow excessively large and be of inferior quality.

Preparation of the Land.-The land should be well prepared before planting. After the slips or vines 
are set out the crop should be well worked to keep down all weeds. The vines grow rapidly and should not be moved more than is necessary in hoeing or cultivating.

Poor land should receive an application of organic matter supplemented with fertilizer. A fertilizer furnishing 2.5 per cent. of nitrogen, 7 per cent. of available phosphoric acid and 8 per cent. of potash, in available forms, is desirable.

How to Plant.-The potatoes are placed in a bed made up of good soil and manure, and after they have sprouted the slips are pulled and transferred to the field. For early potatoes bedding should be started as soon as all danger of heavy frost has passed. The slips should be set in four feet rows about eighteen inches apart. The vines grow rapidly, and in a few weeks may be trimmed and the cuttings so obtained planted out. The season in which potatoes may be planted, especially in the South, is quite long, as a good crop may be produced in 90 to I oo days.

Harvesting.- In digging potatoes place them in small heaps in the field. These heaps should be scattered along the rows to insure thorough drying before storing them. Potatoes should be handled very carefully, so as not to bruise and rub the skin off. Bruised potatoes admit the germs which cause rotting.

Storing and Preservation.--Potatoes may be kept in banks of earth or pits; but perhaps potato houses are more satisfactory. When banked, a well-drained spot is desirable. Some straw or hay should be placed upon the ground, and the potatoes should be piled in heaps. After the heaps are built to the desired size, a thin layer of straw, hay, or corn stalks is placed over the potatoes. Then this is partly covered with earth, leaving the tip of the heap exposed for ventilation. Before freezing weather this tip should also be covered. Potatoes keep well this way until spring, when they begin to sprout.

Storage House.-If a large acreage is planted, a 
house should be built for storing the crop. A convenient structure may be built the desired size, with double walls which are filled in with sawdust. This house should be provided with ventilators that may be opened and closed according to weather conditions.

$V$ arieties.-The Dooley Yam and the Sugar Yam are popular varieties for Southern table use. These potatoes are soft and sweet when cooked. The Northern market demands a firm, mealy potato. The Southern Queen and similar varieties are desirable for stock.

2. Peanuts.-A light sandy loam soil, well drained, with an abundance of lime, is best adapted for growing peanuts commercially.

A Rotation Crop.- When grown in a well-planned rotation and following a crop where clean culture has been practiced, the peanut becomes an important and profitable crop. The peanut should be placed in rotation so as to occupy the land between a spring maturing crop and one that is to be planted early in the fall. This crop is well adapted to a system in which intensive farming is practiced.

Preparation of the Land.- The land should be well prepared. On poorly drained land the rows should be slightly ridged to keep the plant above water. If fertilizer is necessary a mixture containing phosphoric acid and potash is desirable. The peanut being a legume obtains all the nitrogen it needs from the air.

How to Plant.-Peanuts germinate earlier and better if shelled before planting. The inferior kernels can be discarded when the nuts are shelled, thus insuring a better stand. If the whole nuts are planted, germination is hastened by soaking them in water for twenty-four hours before planting. The quantity of seed required to plant an acre will depend somewhat upon the variety, distance of rows and the distance the nuts are dropped in the drill. Usually $I / 2$ to $I$ bushel of shelled and 2 bushels of unshelled nuts are planted per acre. 


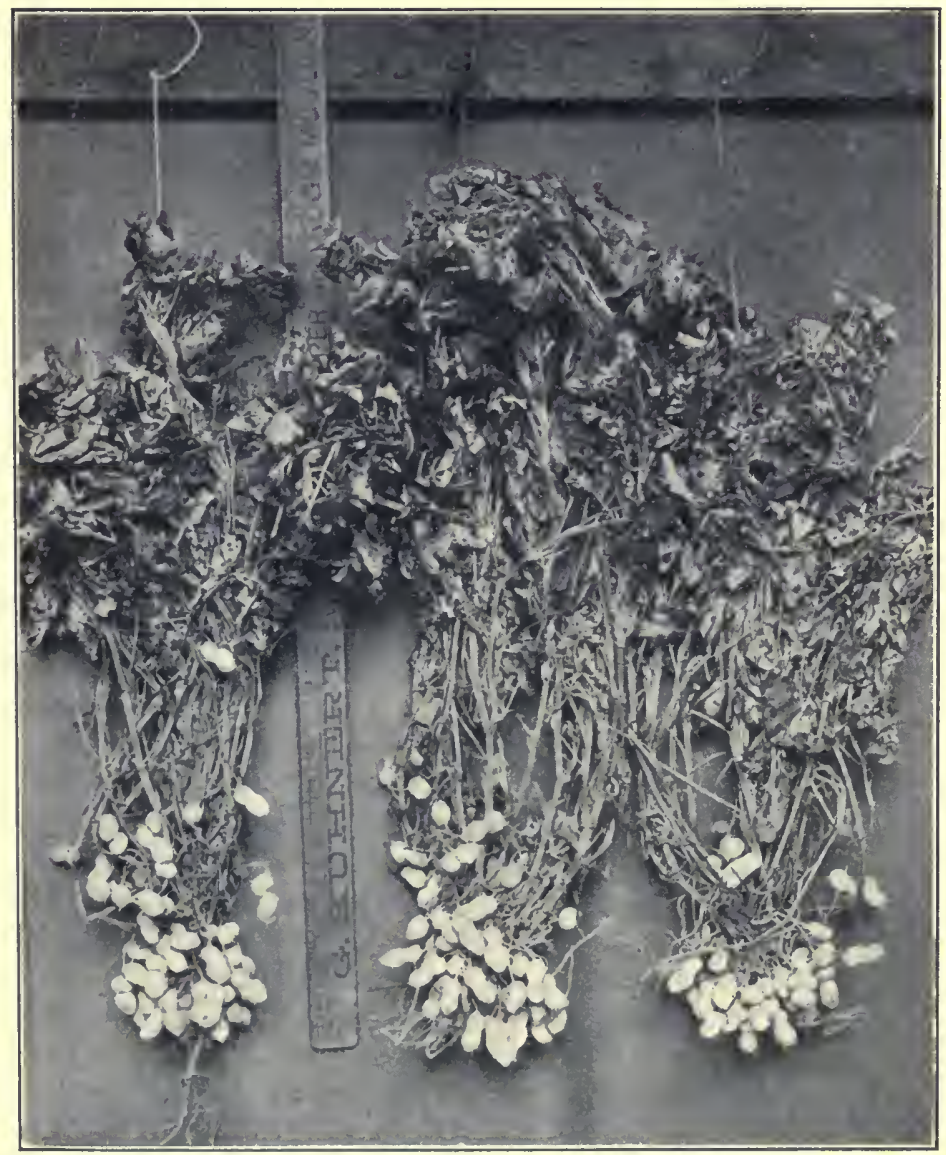

PEANUTS.

Cultivation and Harvesting. - The cultivators used for cotton and corn may be utilized in cultivating this crop. Frequent shallow cultivation is recommended. As soon as the nuts have ripened, the peanuts should be put in shocks and thoroughly cured. A yield of 50 to 70 bushels is good. The Spanish variety is the easiest to harvest, as the nuts cling to the vine when pulled. 
As a Pasture Crop.-Peanuts are also used as a pasture crop for hogs, allowing the hogs to gather the crop.

The peanut is an important commercial crop in North Carolina, Virginia, Tennessee, and North Louisiana.

3. Watermelons do best on sandy well-drained soils. The hilly lands of the Southern States, when made very rich, are well adapted to the growing of melons.

Preparation of the Land.-The land should be put in good condition. If stable manure is used, it should be distributed some time before planting and allowed to rot. Two shovelfuls of a compost, made of stable manure, cotton-seed meal and acid phosphate, applied under each hill and thoroughly mixed with the soil, will prove beneficial. If this is not available, a mixture of 500 to 600 pounds of equal parts of cotton-seed meal and acid phosphate applied broadcast is sufficient per acre. The rows should be marked off ro feet wide.

Cultivation.-Shallow and frequent cultivation is best, being careful not to disturb the vines. When cultivating the last time cowpeas may be planted between the rows, which will improve the soil and prevent the vine from sunburning. On account of diseases melons should not be planted on the same land two years in succession.

How to Grow Large Melons.-Very large melons may be grown by selecting two or three of the best from each hill, keeping the others cut off. Melons weighing 60 pounds will readily sell for 40 or 50 cents, when 20-pound melons will be hard to sell at ro cents each.

Watermelons are an important commercial crop in many sections; thousands of carloads are shipped to the markets during the season. Watermelons for the market must have a strong firm rind.

Exercise.-Name some of the root crops grown in your locality. Give the tonnage per acre. State the methods used for storing them. Bring an Irish and a sweet potato to the classroom and note the 
difference in their structure. Which is a true root and why? What varieties of sweet potatoes are grown in your section and what is the average yield? Why does the Spanish peanut cling to the plant so well when pulled? Is the Spanish a running variety? Which way do the most successful peanut growers plant their nuts, shelled or unshelled? Bring nuts of as many varieties as possible to school and note their difference. Are there any nodules on the roots of peanuts? Which varieties of watermelons are the best eating, home varieties or market varieties? Why?

\section{Section XXVI.-Forage Crops.}

By Prof. C. V. PIPER,

Bureau of Plant Industry, U. S. Dept. of Agriculture.

Forage crops include all plants cultivated to produce food for farm animals, especially where the whole plant is thus used. They may be utilized in various ways, namely, as soiling crops, ensilage, pasturage and hay or fodder. Some forage crops are used in only one way, others in two or more.

Soiling Crops.-A soiling crop is any forage plant that is cut and fed green to animals. Some forage crops, like kale and Japanese sugar cane, are fed wholly or mainly in this manner, but practically any forage crop can be thus utilized. It is possible, especially in portions of the country where the winters are mild, to provide a series of such crops so that cows can have green feed the year around. Such a system of feeding is rarely practiced, however, owing to the large amount of labor necessitated. An exceedingly desirable characteristic in a soiling crop is its ability to grow again from the root after being cut. For this purpose such plants as teosinte, pearl millet and Guinea grass are particularly useful in the South.

Ensilage.-For a description of this consult the chapter on Feeds and Feeding.

Pasturage.-Any forage crop that is harvested by the animals feeding on it in the field is said to be pastured. The term pasture is, however, usually applied to fields of more or less permanent character where 
cattle are allowed to graze. Such fields are usually planted in perennial grasses and legumes, so that they are productive for at least two or three years. Good pastures are a very useful adjunct to the farm, because animals can be fed much more cheaply in this way than in any other.

Hay is any forage crop after it is cut and cured or dried for feed. When the plant dried is very coarse, for example, corn, the hay is commonly called fodder. Grasses are more frequently used for hay than any other plants, because they cure or dry readily. More

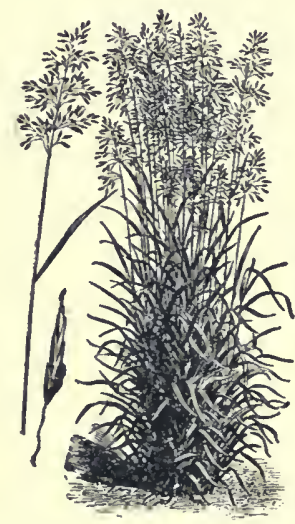

HUNGARIAN, OR AWNLESS BROME GRASS.
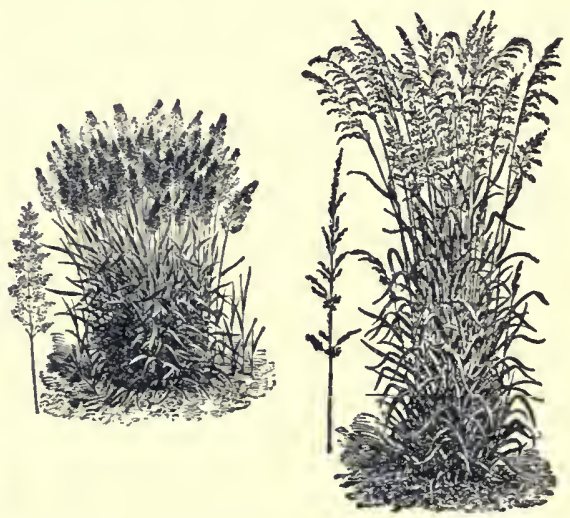

RED TOP, OR HERD'S GRASS.
TALL MEADOW OAT GRASS.

succulent plants, like cowpeas, are also grown for hay, but they are difficult to cure unless the weather is very favorable. Where perennial grasses are grown for hay, the field is often retained for two or more years. Such fields are termed meadows. It is not an uncommon practice to utilize the same field both as a meadow for hay and after the hay crop is removed to use it as a pasture.

Classes of Forage Crops.-About fifty different kinds of plants are cultivated in the United States primarily for forage purposes. Most of these belong 
to the grass family, which also contains our principal cereals. Next in importance to the grasses are the legumes, plants like clovers, alfalfa, cowpeas, peanuts, soy beans and velvet beans, all of which are able to use the nitrogen of the air, which most plants cannot obtain. Outside of these two plant families there are few important forage crops, perhaps the most valuable being rape and kale of the cabbage family and mangels of the beet family.

Characteristics of Forage Plants.-In both grasses and legumes, as well as other forage crops, there are parennials, living for several or many years, as well as annuals, which live for only one year or season. Some annuals are adapted for growing only in the summer, others for growing in the winter. Perennial forage crops are especially used in permanent meadows and pastures. The most valuable for this purpose are not only palatable and nutritious but able to occupy the ground against weeds, and in the case of pasture grasses to withstand continual trampling and close cropping. Some indeed occupy the ground so tenaciously that they become more or less troublesome as weeds, such as Johnson grass and Bermuda grass. A few annual forage plants reseed themselves readily, such as crab grass, lespedeza and bur clover.

Perennial Grasses.-The more important perennial forage grasses are timothy, Kentucky blue grass, Bermuda, orchard grass, redtop, tall meadow oat grass, Johnson grass, brome grass, meadow fescue, carpet grass and Para grass.

Annual Grasses.-Among the annual grasses used for hay, besides such small grains as oats, wheat, barley and rye, are the millets, rescue grass, crab grass and cheat. Here also might be included the coarser grasses, such as the sorghums, pearl millet and teosinte.

Perennial Legumes.-Practically the only perennial legumes grown on American farms are alfalfa and the clovers, red, white and alsike. 
Annual Legumes constitute a much more important crop in the Southern States than elsewhere. Among the important ones for summer crops are cowpeas, soy beans, velvet beans and lespedeza; for winter crops crimson clover, vetches and bur clover. In the North and West, Canada peas are by far the most important crop of this group.

Origin of Our Forage Crops.-It is an interesting fact that most of the forage crops grown in the United States are native to the Old World. This is the case almost without exception of plants which are broadcasted thickly, as in meadows and pastures where the plants have to occupy the ground to the exclusion of other plants. Most American grasses lack sufficient aggressiveness to be thus utilized. On the other hand some of the most important of American crops are natives of America, but these, without exception, need to be cultivated so as to protect them against weeds. Among such crops are corn, tobacco, cotton, potatoes, sweet potatoes, beans and others. While the aggressiveness of many Old World plants makes them invaluable for forage, it also makes others very troublesome as weeds, nearly all of our worst weeds having come to us from the Old World.

Meadow Mixtures.-Mixtures of forage crops in permanent meadows often give much better results than pure cultures.

I. In the Northern States the most commonly grown hay mixture consists of timothy and red clover. 2. South of the Ohio and Potomac Rivers timothy and clover do not as a rule give satisfaction. Here a mixture of $\mathrm{I} 2$ pounds of orchard grass, $\mathrm{I} 2$ pounds of tall meadow oat grass and 6 pounds of alsike clover is much more satisfactory. 3. It is frequently desirable to plant low-lying, poorly drained lands into a permanent meadow or pasture. In general, the best combination for this purpose is redtop and alsike clover.

Pasture Mixtures.-Mixtures of forage plants for pastures are desirable not only to keep down weeds, 


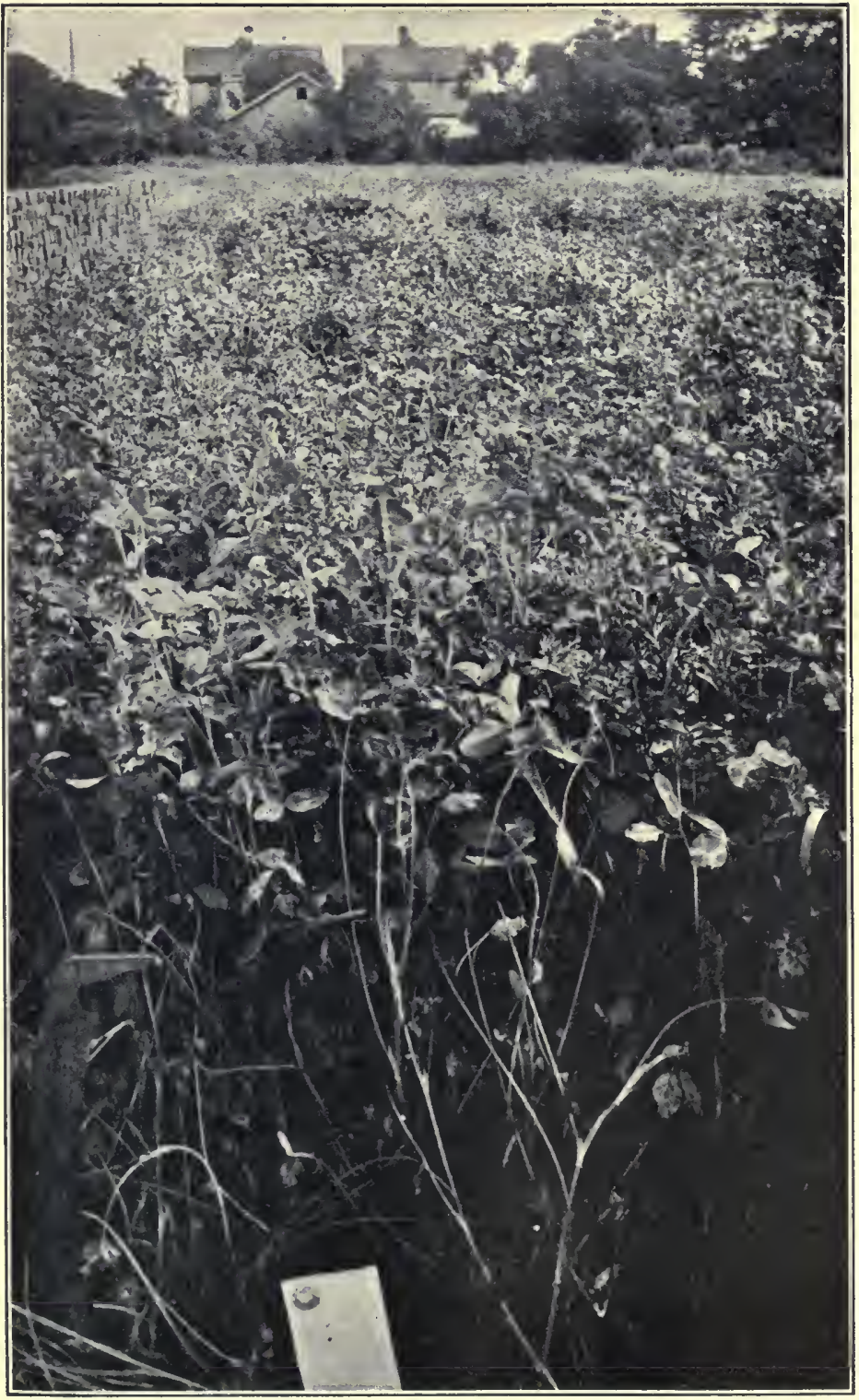

REI CLOVER. 
but also because the different plants in the mixture grow best at different times of the year, some growing best in early spring and fall, others in midsummer.

I. In the North the best pastures consist largely of Kentucky blue grass and white clover. 2. In the South several different combinations of plants 'go to make up permanent pastures; Bermuda grass, bur and white clovers; redtop, white clover and Kentucky blue grass as winter pasturage; the summer plants often include lespedeza, paspalum and Bermuda. In the extreme South, where carpet grass is abundant, lespedeza frequently grows with it.

EXERCISE.- $I_{11}$ what ways are the forage crops of your region utilized? Make a list of the soiling crops grown in your neighborhood. How often are your pastures planted? Which are the more common at your home, pastures or meadows? Why? What grasses and legumes make the best pastures and meadows for your section? Make a list of the annulal and perennial grasses and legumes that are common in your section of the country.

\section{Section XXVII - Some Important Forage Plants.}

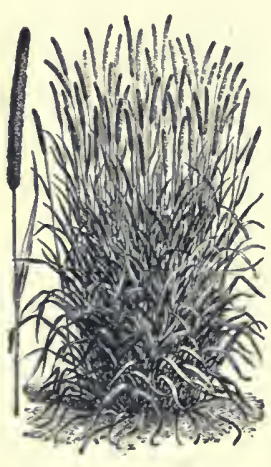

TIMOTHY.

Timothy is a native of Europe, but it first became important as a cultivated grass in the United States. In this country it is the most important of all the hay grasses, the bulk of the hay sold in the city markets being composed of this grass, either pure or mixed with red clover. The popularity of timothy depends not only on its high value as horse feed, but also on the cheapness of the seed and the ease with which it is grown. Fifteen pounds is sown per acre in combination with red clover.

Red Clover.-Scarcely less important than timothy is red clover, which also is a native of Europe. It is 
grown almost entirely in combination with timothy. The plant is a short-lived perennial, rarely living more than two years. Eight pounds of seed when grown with timothy is used per acre.

Alfalfa.-This is the great forage crop of the West, especially on irrigated lands, though in late years it has been grown in a constantly increasing area on nonirrigated lands. Alfalfa is a native of Asia and

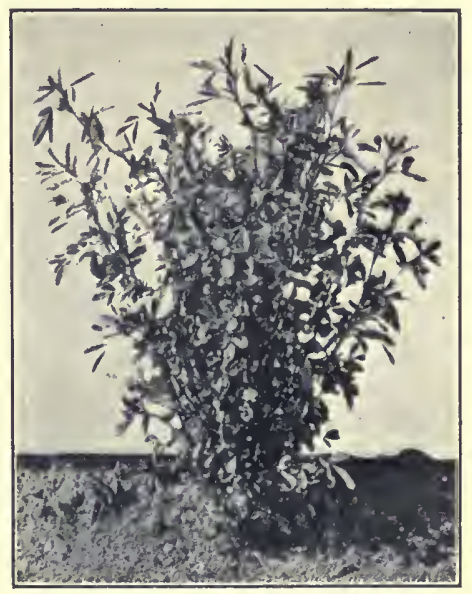

AN AIFALFA PLANT.

was first introduced into New York about I 79 I and into California about I $85 \mathrm{I}$. At the northernmost limit of its growth two or three cuttings a year can be obtained, while in the extreme southern part of California eight or nine cuttings may be secured. Alfalfa

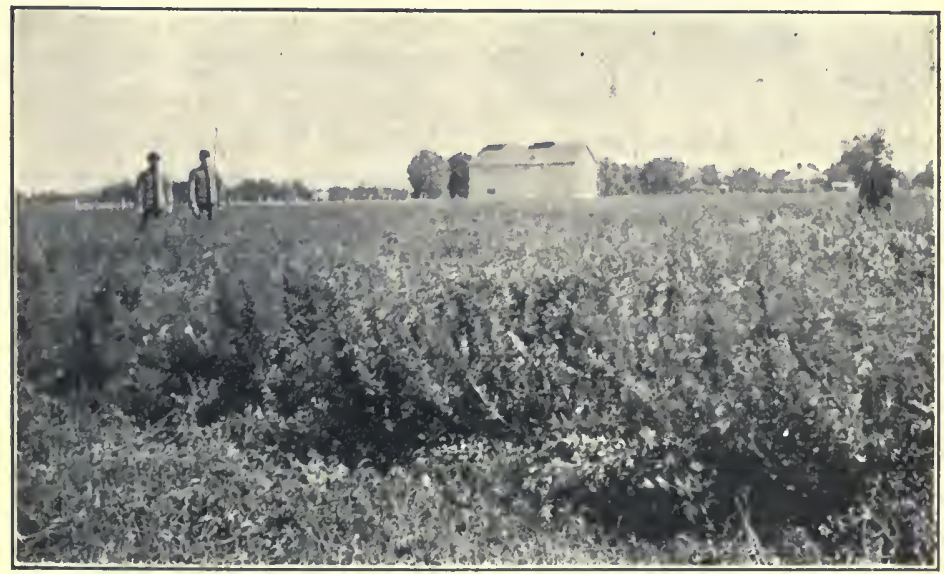

A FIELd OF ALFALFA. 
is primarily adapted to a region where the air is dry, and under such conditions, as in our West, thrives like a weed. In the more humid sections of the East and South, however, alfalfa thrives well only when the soil

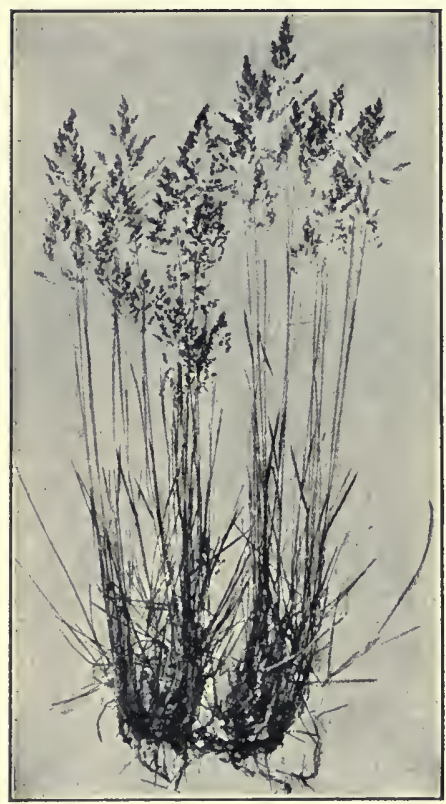

KENTUCKY BLUE GRASS. is deep, well drained and contains a sufficient quantity of lime. On this account it has become important mainly on soils of limestone origin. On such soils it will far outyield any other perennial forage crop.

Kentucky Blue Grass in its commonly cultivated form is a native of Europe; various forms of it are native in America, but these did not occur originally in the region where blue grass is now important. Blue grass is adapted to almost identically the same area as timothy, though as a lawn grass it is grown much farther south. It thrives especially on limestone soils, and it is such soils as these that constitute the famous blue grass region of Kentucky. Blue grass pasture is exceedingly palatable and live-stock prefer it to nearly all other grasses.

Bermuda Grass is a native of India, and is supposed to have been introduced into this country in I 8 I 2 . It now occurs throughout the Southern States and thrives fairly well as far north as Washington, D. C., and Central Kansas. It requires hot summer weather, and grows then with great rapidity on good soil, reaching a height of 18 inches. It makes a dense mass so that 
the yield of hay per acre is heavy and two or more cuttings can be made during a single season. It requires a dry climate to seed abundantly. Bermuda is objectionable as a lawn grass because it turns brownish in the autumn.

Johnson Grass is perhaps more feared in the South as a weed than any other plant, yet in many sections it is an important grass for hay, and large quantities of it are cut for this purpose. If Johnson grass is cut persistently for hay or heavily pastured, the new root-stocks become thin, short and near the surface of the ground. After such treatment Johnson grass is much more easily destroyed.

$V$ etches.-There are two vetches commonly grown in the United States, the common vetch and the hairy vetch. Common vetch is extensively grown on the Pacific Coast, and to a considerable extent in the South. In these regions it is grown as a winter crop. To a very limited extent it has been grown northward as a summer crop. On account of the weak stems of vetch it is usually sown with wheat, oats or rye, the stiff stems of which serve to hold the vetch stems upright.

Hairy vetch is much more hardy than common vetch, withstanding the winters as far north as Connecticut. It doés not grow much during the winter, but with the first warm weather of spring it grows very rapidly. When fully grown the fine stems are frequently six feet high and double that length when straightened out. In the South there is an increasing tendency to plant mixtures of hairy vetch with common vetch, as the latter is apt to freeze out in exceptionally cold winters.

Cowpeas.-The cowpea is a native of India and one of the oldest cultivated plants. Before the discovery of America it was commonly grown through Southern Europe as a food, but at the present time is more important in the United States than in any other part of the world. There are over one hundred different varieties of cowpeas. The multiplicity of varieties is 
due in part to the fact that in some portions of the world the varieties cross readily, thus giving rise to new varieties. When cowpeas are grown alone, the most common practice is to broadcast them on wheat or oat stubble. Another common practice is to plant them in corn at the time of the last cultivation. Where corn is grown for ensilage, many farmers also grow cowpeas in the corn, as the mixture makes a better ensilage than corn alone. Cowpea varieties are

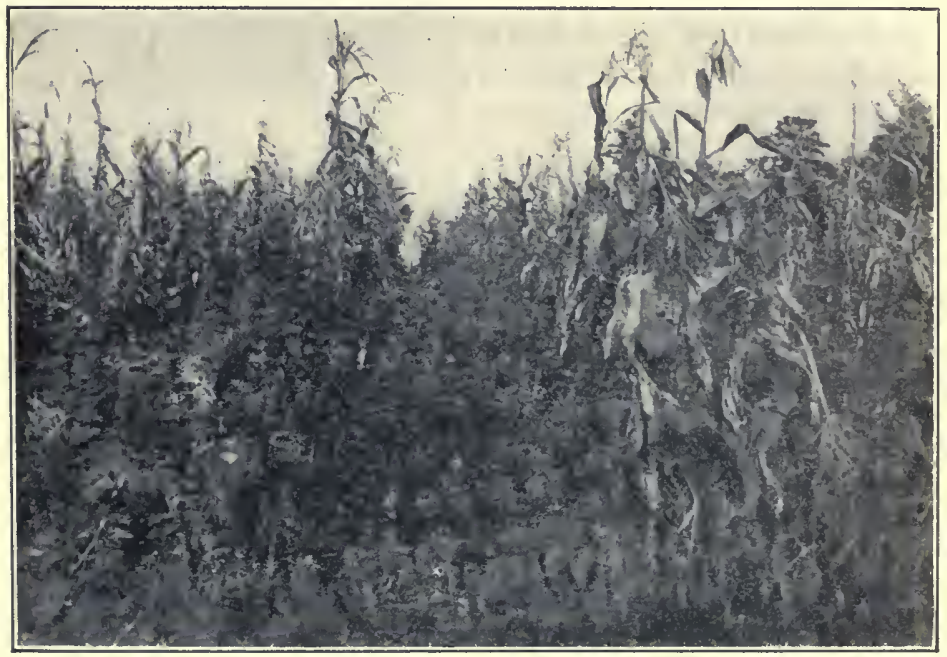

CORN AND COWPEAS.

distinguished in part by the color of the seeds, which may be white, buff, pink, red, black, marbled or speckled. Various combinations of these colors also occur. Cowpeas are usually planted from the middle of May to the first of June. When planted earlier or'on very rich land, the tendency is to go largely to vine. When planted late on poor soil, they go more largely to seed.

Soy Bean.-This plant is a native of Asia, and is largely grown by the Chinese and Japanese for food. In the United States it is being grown more and more 
extensively as a forage crop, especially in the Southern States. Soy beans are usually planted in rows, but sometimes they are broadcasted and sometimes planted in between corn rows after the manner of cowpeas. The Mammoth variety is more frequently grown in the South.

Lespedeza or Japan clover was introduced from Japan about i 830 , and now grows naturally throughout the Southern States. It is remarkable for its ability to grow on the poorest of soils. In such situations, however, it grows only to a

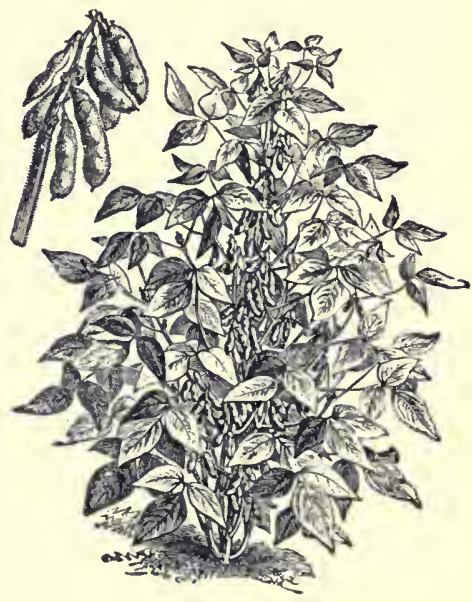

SOY BEAN. height of from 4 to 6 inches; on richer soils it will grow I 2 to 18 inches high, and so thickly as to furnish large crops of hay per acre.

Crimson Clover is an annual, native to Southern Eu-

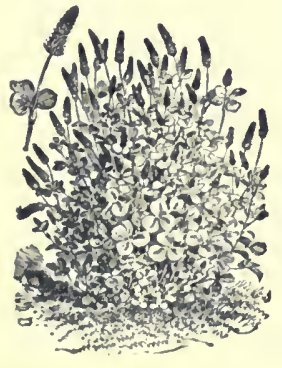

CRIMSON CLOVER. rope, and now extensively used as a winter crop along the Atlantic Coast from Central New Jersey to Georgia, it being most important in New Jersey, Delaware, Maryland, Virginia and North Carolina. Crimson clover is commonly sown in corn at the time it is laid by. Unless weather conditions are favorable, the farmer frequently fails to get a good stand. Its culture is extending southward, and in time it may be grown over most of the cotton belt.

Velvet Bean.-The velvet bean was introduced into Florida about fifty years ago from some unknown 
source, though, in all probability, it is a native of Southern Asia. It was first cultivated as an ornamental plant, but is now extensively grown as a soil improver and for forage. The usual method of harvesting the crop is to turn cattle into the field in late fall to pasture it.

Canada Pea.- The Canada pea, which is botanically the same species as the garden pea or English pea, is in some portions of the country an important forage crop. It is grown extensively for this purpose in many of the Northern and Western States. Very commonly it is sown with oats, the crop being harvested for hay. In Colorado, in recent years, it has been extensively grown and pastured to sheep.

Crab Grass is an annual grass native to India, and was introduced at an early day in the United States. It is commonly looked upon as a weed, as it springs up in great abundance in cornfields, on oat stubble, and often in cotton fields after cultivation has ceased. Large quantities of it are, however, cut for hay, the quality of which is fair. It is never necessary to sow the seed, as it volunteers on cultivated land as soon as the crop has been removed.

Rescue Grass is a native of Argentina, but now growing wild throughout the South. It is a valuable grass for winter pasturage on rich lands.

Cheat is a common weed in grain fields, but is sometimes grown for hay in Georgia and Alabama. Wheat and oats furnish a similar and better hay.

Millets-Of the millets there are many varieties, the most common that are grown for hay being German millet and Hungarian millet or Hungarian grass. The millets are particularly valuable in that they can be sown at almost any time during the summer, and produce a crop of hay within a short period.

Italian Rye Grass is a native of Europe and commonly used as a part of a mixture for lawn grasses, as it grows quickly and vigorously, especially during cool weather. It has been extensively used on the $\mathrm{Pa}$ - 
cific Coast, and is more and more becoming important in the sandy soil along the Atlantic Coast, as it grows rapidly on relatively poor soils. It is highly relished by live-stock both as pasture and as hay.

\section{AMOUNT OF SEED PER ACRE FOR SOME OF OUR FORAGE CROPS}

Alfalfa (broadcast)...20-30 lbs. Alfalfa (drilled)......15-20 lbs. Alsike Clover....... 5 5 lbs. Bermuda............ 3-5 lbs. Cowpea (drilled).... 1/3 bu. Crimson Clover.......15-20 lbs. Italian Rye Grass. . . 20-30 lbs. Johnson .......... I-I $1 / 2$ bu. Kentucky Blue ..... 3-4 bu. Lespedeza ......... I0-I5 lbs. Meadow Fescue . . . . 20-25 lbs.

Millet ............ 1/2 bu. Orchard .......... 1/5 bu. Red Clover........... Io-I5 lbs. Red Top (recleaned)...12-I5 lbs. Rescue............ 30 lbs. Tall Meadow Oat Grass.30-5o 1bs. Teosinte......... 4 4 -5 lbs. Timothy.............. Velvet Bean (drilled)... 2 pks. Velvet Bean (broadcast) I bu. Vetch (common) I bu. + I bu.cereal

EXERCISE.-How do legumes enrich the soil? Do the crops that follow legumes generally give higher yields? Ask your parents for the names of the varieties of cowpeas. Bring seeds of all the varieties of cowpeas you can secure to the classroom and describe them. Do your folks always receive clean seed? Bring specimens of grasses and legumes to school and make a thorough examination of their roots and general structure. Examine the roots of the legumes for the nodules.

The teacher should take the class to the fields and identify the grasses and legumes prevalent in the section. This subject can be made very interesting by such outdoor study.

\section{Section XXVIII.-Weeds.}

By Prof. Lyman Carrier,

Department of Agronomy, Virginia Polytechnic Institute.

A Weed is a Plant Out of Place.-There is no set line of demarkation between weeds and our most valuable farm crops, and many useful plants were once considered troublesome pests. Plants that are considered weeds in one part of the country may be staple farm crops in another. Artichokes are looked upon with disfavor by a great many farmers, because they are inclined to grow wild and persist in the land for a number of years. If pastured with hogs, however, 
artichokes furnish excellent winter forage, and the danger of beconing pests is greatly reduced. Johnson grass, the enemy of the cotton grower, has been widely recommended by agricultural writers because of its value for hay and pasture. As civilization advances uses will be found for plants that are now considered worthless, and as our knowledge and skill in plant breeding increases many plants of little value at the

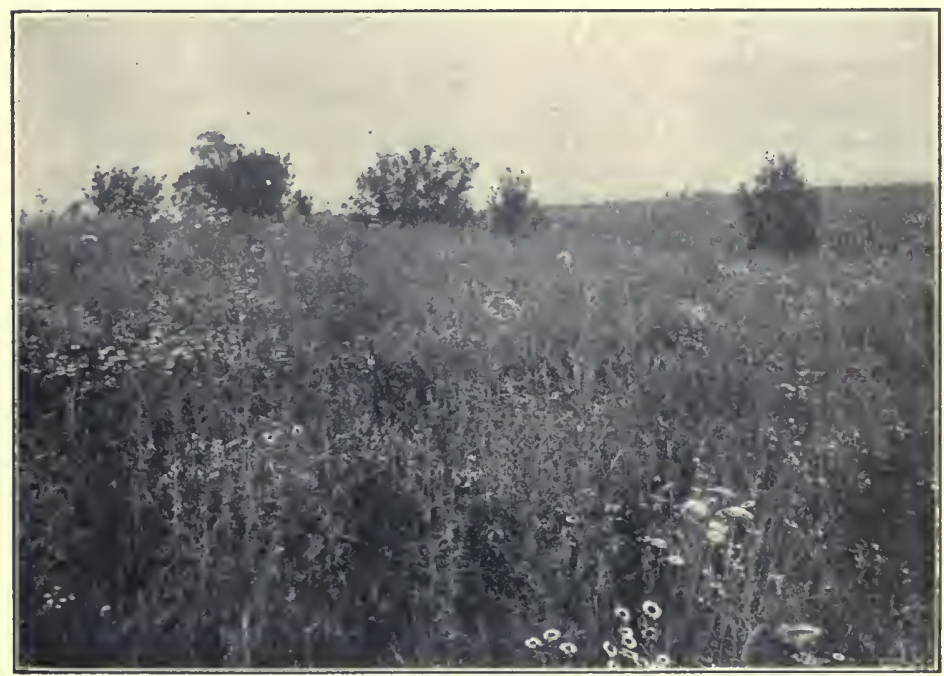

A WEED-INFESTED Field.

present time will be so improved that their cultivation will yield a profit.

Loss from Weeds.-Weeds lower the yield of the crop in which they grow in four ways. I. They utilize the available plant food in the soil that would otherwise be used by the crop. 2. They use enormous amounts of water in their growth, and often so exhaust the supply of moisture in the soil that the more valuable plants are unable to withstand periods of drought. 3. Sometimes the weeds get such a start ahead of the other plants that they deprive them of 
the sunlight necessary for their development. 4. A few plants, as the dodders for instance, are parasites, and derive their nourishment directly from the juices of the plants on which they grow.

Eradication of Weeds.- The chief interest a farmer has in weeds is to get rid of them. This is accomplished in various ways. Thorough cultivation which prevents the development of leaves will in time kill any weed. Plants, such as Johnson grass and Canadian thistle, which have a reserve supply of food stored in their roots, will take much longer to kill by this process than others lacking this advantage. No new material can be produced, however, without the aid of chlorophyll, the green substance of plants, so sooner or later the plants must die if the leaves are not allowed to grow. This same result is accomplished on small patches of bad weeds by covering them over with straw, boards, or pieces of building paper held in place by a few shovelfuls of dirt.

Chemicals as Weed Destroyers.-In the last four or five years much attention has been paid to the use of chemicals as weed destroyers. Spraying wheatfields infested with wild mustard with a 20 per cent. solution of sulphate of iron has been successful in destroying the mustard without injury to the wheat. Heavy applications of common table salt will kill all kinds of weeds, but unfortunately it makes no distinction between weeds and other plants in this respect.

Proper Cultivation Keeps Down Weeds.-Improving the fertility of land tends to lessen the trouble with weeds. On rich soils the cultivated crops are able to make sufficient growth to keep the weeds in checkthe reverse happens on soils lacking plant food. Usually the poorer a farm is in fertility the more liberally is it stocked with weeds.

Preventive Measures.-Preventive measures will do much to keep a farm from getting infested with weeds. All weeds along fences and other uncultivated places should be cut before they form seed. These waste 
places if allowed to grow up to weeds often harbor insects and plant diseases, as well as furnishing a supply of seed for the fields adjoining. A great deal of care should be exercised in regard to the quality of the seed sown. Often our worst weeds are scattered from one part of the country to another in grain and other farm seeds. All seed should be examined for purity before being sown.

EXERCISE-Name some weeds common to your locality. Name those weeds which are easy to get rid of. Set aside a small plot of ground which has some weeds growing on it and apply a saturated solution of common salt. Have the pupils note the effect of the salt on the weeds. If there is any wild mustard growing in your neighborhood apply a 20 per cent. solution of iron sulphate to a plot six feet square. The iron sulphate can be obtained at any drug store.

\section{REFERENCES FOR COLLATERAL READING.}

Rotation of CRops:

\section{FARM Crops.}

Yearbooks of the U. S. Dept. of Agriculture:

1902 - Practices in crop rotation.

1908-Intensive methods and systematic rotation of crops in tobacco culture

Farmers' Bulletins, Nos. :

144-Rotation of crops.

337-Cropping systems for New England dairy farms.

Experiment Station Bulletin, No.: CORN :

60-Delaware-Cover crops as green manure.

Farmers' Bulletins, Nos.:

81 -Corn culture in the South.

199-Corn growing.

229-The production of good seed corn.

253-The germination of seed corn.

292-The cost of filling silos.

303-Corn-harvesting machinery.

313-Harvesting and storing corn.

317-Shrinkage of corn in cribs.

$366-$ Corn breeding.

Experiment Station Bulletins, Nos.:

204-North Carolina-Some factors involved in successful corn growing.

Bulletins of the Middle West Experiment Stations.

\section{COTTON :}

Farmers' Bulletins, Nos. :

36-Cotton seed and its products.

48 - The manuring of cotton. 
217-Essential steps in securing early cotton.

285-The advantage of planting heavy cotton seed.

302-Sea Island cotton.

3r4-A method of breeding early cotton to escape boll weevil damage.

326-Building up a run-down cotton plantation.

364-A profitable cotton farm.

Office of Experiment Stations, U. S. Dept. of Agriculture, Bulletin, No.:

33-The cotton plant.

Experiment Station Bulletin, No.:

Io7-Alabama-Cotton.

RICE :

Farmers' Bulletins, Nos. :

I $10-305-$ Rice.

Experiment Station Bulletin, No.:

77-Louisiana-Rice.

Cereal Crops :

Farmers' Bulletins, Nos. :

I 22-2 10-237-262-273-Wheat.

222-Replacement of grain with silage.

276-Oat culture in the South.

Experiment Station Bulletins, Nos.:

2-Kansas-Circular-Preparing land for winter wheat.

Io-Washington-Wheat, barley, oats, peas and forage crops.

32-Nebraska-Wheat and some of its products.

62-Minnesota-Wheat varieties, breeding and cultivation.

70-Minnesota-Influence of wheat farming on soil fertility.

89-Nebraska-Winter wheat.

I 44-Kansas-Small grain crops.

8 -North Carolina Dept. of Agriculture-Culture of wheat and oats.

Sugar Cane:

Experiment Station Bulletins, Nos.:

5-Louisiana-Sugar making on a small scale.

75-Louisiana-Preservation of cane syrups.

78-Louisiana-Experiments with seedling canes.

9I-Louisiana-Chemistry of sugar cane and its products.

ToBacco :

Farmers' Bulletins, Nos.:

60 -Methods of curing.

82 -The culture of tobacco.

83 - Tobacco soils.

343-The cultivation of tobacco in Kentucky and Tennessee.

Bureau of Plant Industry, Bulletins, Nos. :

I38-The production of cigar wrapper tobacco under shade in the Connecticut Valley.

I43-Principles and practical methods of curing tobacco.

Root CROPS :

Farmers' Bulletins, Nos. :

35-I 49-244-Potatoes (Irish).

52-79-92-Sugar beet. 
I 29-273-324-Sweet potatoes.

295-Potatoes and other root crops.

309 -Root crops; culture and varieties.

385 -Potato growing in Northern sections.

386 - Potato culture on irrigated farms of the West.

Experiment Station Bulletins, Nos.:

243-New York-Cornell-Root crops for stock feeding.

$244-\mathrm{New}$ York-Cornell-Culture and varieties of roots for stock-feeding.

267-New York-Cornell-Fertilizer and seeding experiments with root crops.

Forage Crops and Grasses:

Yearbooks of the U. S. Dept. of Agriculture:

I895-Canadian field peas.

I902-Bacteria and the nitrogen problem.

Farmers' Bulletins, No. :

I6-Leguminous plants.

58-309-372-The soy bean.

66-Meadows and pastures.

69-IOI-I68-Millet.

72 -Cattle ranges of the Southwest.

I02-Southern forage plants.

I2I-Beans, peas and other legumes as food.

I35-246-288-Sorghum.

I47-Winter forage crops for the South.

237-Use of lime for clover sickness.

$260-$ Seed of red clover and its impurities.

267-356-Peanuts.

278-Leguminous crops for green manuring.

288-Non-saccharine sorghums-Kaffir corn.

300-Some important grasses and forage plants for the Gulf

Coast region.

309-318-Cowpeas.

3I 2-A successful Southern hay farm.

323-Clover farming on the sandy Jack-Pine lands.

339-Alfalfa.

$36 \mathrm{I}$-Meadow fescue; its culture and uses.

Experiment Station Bulletins, Nos. :

I 55-Kansas-Alfalfa.

I60-Kansas-Cowpeas.

Division of Agrostology, U. S. Dept. of Agriculture, Bulletin, No.:

I4-Economic grasses.

WEEDS :

Yearbooks of the U. S. Dept. of Agriculture:

I 896 -Migration of weeds.

I898-Weeds in cities and towns.

Farmers' Bulletins, Nos. :

28-Weeds and how to kill them.

279-A method of eradicating Johnson grass.

334 -Vitality of weed seeds in manure.

368 - The eradication of bindweed. 
Experiment Station Bulletins, Nos.:
If-Idaho-Twelve of Idaho's worst weeds.
$76-$ Wisconsin-Noxious weeds of Wisconsin.
8o-North Dakota-Weeds and methods of eradication.
I84-Virginia-Impurities in grass and clover seed sold in Virginia.

-Books :

Cereals in America-Hunt-Orange Judd Co., New York City.

Forage and Fiber Crops in America-Hunt-Orange Judd Co., New York City.

Farm Grasses in the United States-Spillman-Orange Judd Co., New York City.

Cotton-Burkett \& Poe-Doubleday, Page \& Co., New York City.

The Potato-Fraser-Orange Judd Co., New York City.

Corn Plants-Sargent-Houghton, Mifflin \& Co., New York City. Sugar Cane-Stubbs \& Purse-D. G. Purse, Savannah, Ga. Manual of Corn Judging-Shamel-Orange Judd Co., New York City.

Corn-Bowman \& Crossley-Ames, Iowa. 


\section{H A P TER V.}

\section{TREES AND THE GARDEN.}

Section XXIX.-The Planting and Care of the ORCHARD.

By Prof. C. P. Halligan,

Department of Horticulture, Michigan State Agricultural College.

Every Farmer should have an Orchard.-Fruits are grown with success in nearly all parts of the United States. Although there are certain districts which, because of certain favorable conditions of soil and climate, a re better adapted for fruit growing than others, there is no reason why every farmer should not possess an orchard of sufficient size at least to supply the home. As food fruits are both pleasant and healthful, and as a farm crop they are one of the most widespread. Aithough oftentimes they apparently succeed in quite adverse conditions, larger crops of better fruits will be produced if they are given the proper care and attention.

Selection of a Site.-One of the first considerations in the growing of fruits is the selection of a proper site. Fruits cannot thrive with "wet feet." In the low wet places, for instance, apple trees grow with twisted trunks: This simply shows that these trees are sick with "wet feet" and that the soil needs drainage. In considering the drainage, the air drainage of the site needs attention. Cold air being heavier than warm air settles in the low spots first. Fruits planted in such places are not only more subject to the late frosts in the spring while they are in blossom but, owing to the poor circulation of air here, they 
are more subject to fungus diseases. Therefore, in selecting a site, one must be chosen with a gentle slope sufficient to insure good soil and air drainage. Such a site, with a soil of sufficient fertility and a good texture, constitutes the ideal site for a fruit garden.

Age to Plant Trees.-Trees are planted at different ages, depending upon the kind. Peaches and cherries, for example, are better at one year old, while apples, pears and plums are generally planted at the age of two or three years.

Roots should be Cut Clean.-As these trees are dug from the nursery many of the roots are wounded, while others are entirely cut away. At the time of planting, therefore, the roots of all of the trees should be carefully examined, using a sharp knife to make a clean cut wherever the roots have been left with rough jagged ends. A clean cut on all roots and branches heals most readily.

How to Plant a Tree.-In planting the tree the holes should be made a little larger than the natural spread of the roots, and the trees set about two inches deeper than they were in the nursery. The most important point in planting the trees is to see that the soil is packed firmly all around and under the roots. This is done to drive out all of the air spaces, and bring the soil particles into closest contact with the roots, as it must be remembered that the roots take their moisture by osmosis. The last two or three inches of soil should be left loose to act as a soil mulch.

Distance between Trees.-The distance apart that the trees are planted will depend largely upon the kind and variety. Thus, peaches are generally planted 20 to 25 feet apart, while apples are usually set from $3^{\circ}$ to 40 feet. Whatever the kind of fruit may be, the distance apart that the trees are set should be sufficient to insure plenty of room and sunlight for the tops, and a large feeding surface for the roots.

Trees should be Pruned when Planted.-After the trees are set, the top should be pruned, cutting out all 
of the weak branches and pruning the others well back. As much of the root surface was lost in digging the trees, this pruning tends to restore the natural balance

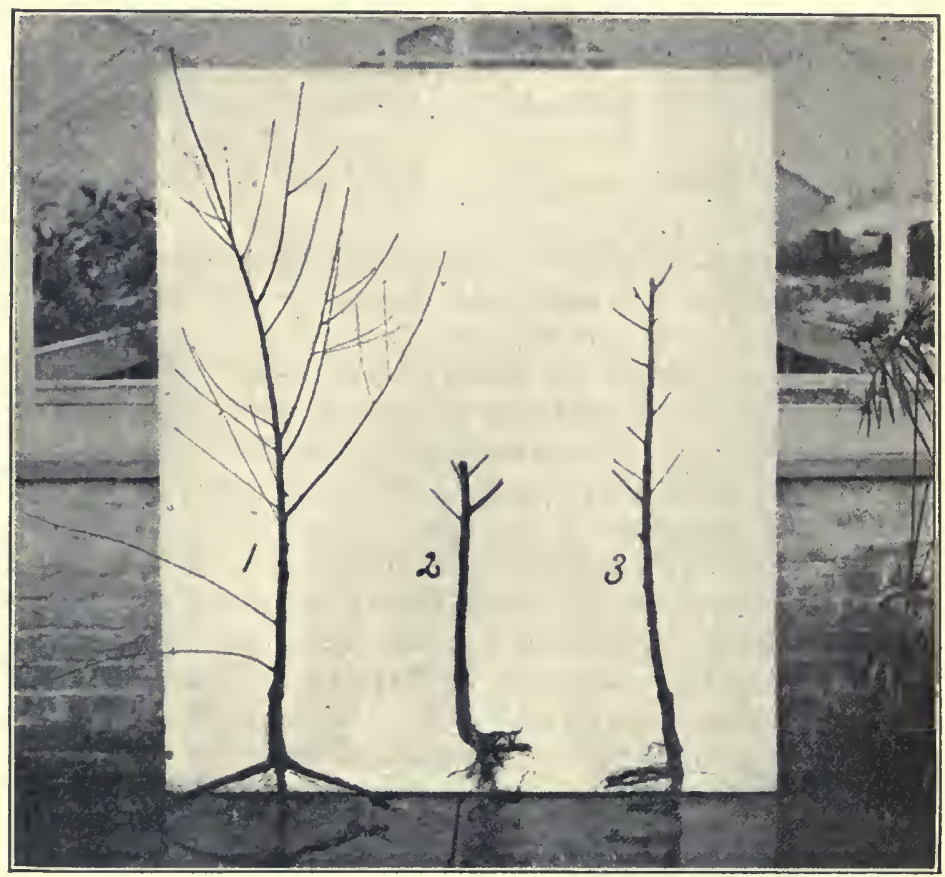

ILLUSTRATING PRUNING OF THE LARGER GRADES OF PEACH TREES. No. 2 is properly pruned, while No. 3 is headed too high.

which should exist between the tops and the roots. At this time, training the tree into an ideal form should be begun and the branches should be kept well spread along the trunk to prevent their splitting and breaking when they become heavily burdened with fruit.

Cultivation is Necessary. - The opinion is prevalent that fruit trees need little attention after planting. The best fruit growers, however, keepp their orchard tilled during the first half of the season as carefully as the average farmer tills his corn. After every rain 
the orchard should be carefully cultivated to form a soil mulch, as plenty of moisture is of first importance in the production of good fruits. Grasses, grains or other uncultivated crops should not be planted in the orchard at this time, as they absorb great quantities of moisture from the soil when the trees need it the most.

Cover Crops.-About midsummer, however, rye, oats, clover or other leguminous crops are generally sown. This is known as a cover crop. It absorbs the moisture and the available plant food from the soil, causing the growth of the tree to cease and the buds to mature. It protects the soil and roots in winter from freezing and thawing, and also from washing. Early in the spring this crop is plowed under, adding more humus and plant food to the soil. In this way

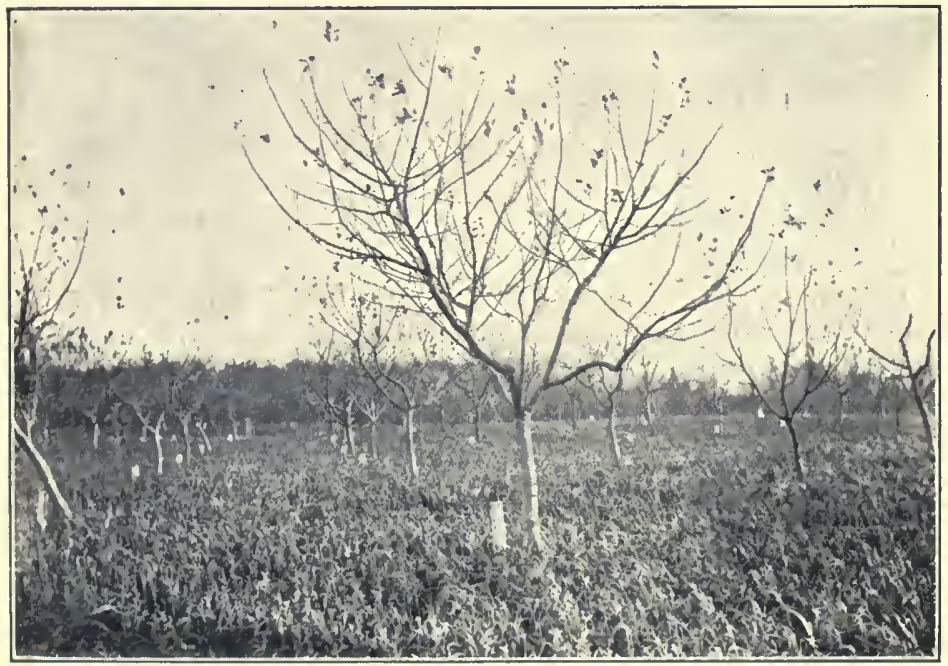

OATS AS A COVER CROP IN AN APPLE ORCHARD.

the fruit grower often maintains the fertility of his orchard with little or no additional fertilizer.

Spraying protects the trees from harmful insects and fungus diseases. Although most of our orchards are 


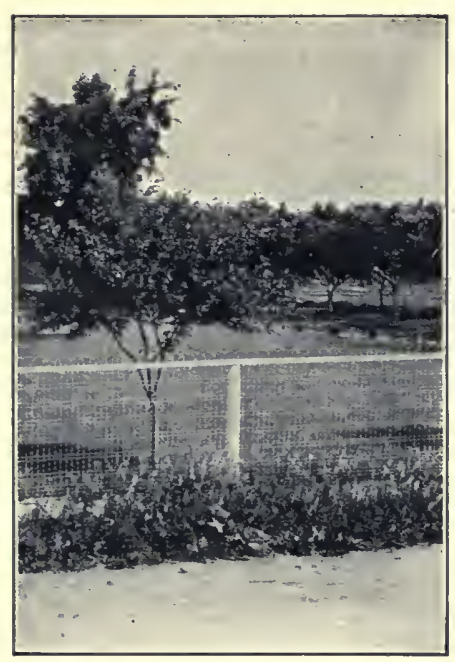

A WELL-TILIED ORCHARD.

still unsprayed, spraying is practiced regularly by the best fruit growers. It consists in spraying the trees with a liquid that destroys the harmful insects and fungi without injury to the tree and fruits. The particular liquid used and the time that it is applied vary with the different regions and different fruits. For most fungus diseases the mixture used consists of 4 pounds of copper sulphate, 5 pounds of lime and 50 gallons of water. Paris green is the poison generally applied for chewing insects, although other forms of arsenic are often preferable. This poison is generally applied with the former mixture, taking 6 to 8 ounces for the above amount.

EXERCISE-Select a site in your locality that you believe would be an ideal one for an orchard. Explain your reasons for this selection. Is there an orchard in your locality that you think is poorly situated? Why? Explain the proper method of planting a tree. How far apart are the apple trees planted on your farm or in an orchard in your locality? Do you think that this distance is the most desirable? Why is it necessary to prune the branches on the tree after it has been transplanted? How many farmers in your locality till their orchards? How many do not? Which are the more successful in producing good crops of fruit? Why is a cover crop advisable? Describe some harmful insects or diseases that you have seen on the apple. How could these have been prevented? 


\section{Section XXX.-Pomology.}

By Prof. C. P. Halligan,

Department of Horticulture, Michigan State Agricultural College.

Fruit growing and pomology as commonly known are synonymous terms. It comprises the art of growing all kinds of fruit. Covering such a broad field, it may be well, for proper consideration of the subject, to designate its several branches as follows: Tree fruits, as typified by the apple; vine fruits, as typified by the grape; and small fruits, as typified by the strawberry and raspberry.

I. Tree Fruits.-Tree fruits may be divided into three classes, namely, pome, stone and citrous fruits. Pome.—"Apple like" fruits are called pomes. Hence the apple, pear and quince comprise the pomes. Apples.-The apple is the most important commercial American fruit. It was early introduced into this country, and has been planted to such an extent that today North America stands as the leading apple growing country of the world. The apple thrives almost everywhere in the United States, and is grown on a great variety of soils. Being such a cosmopolitan fruit it is commonly neglected. The best results in apple growing, however, are to be expected only when the trees are given good care and attention. Thorough tillage, judicious fertilizing, regular pruning and spraying are all essential in producing the best crops of apples.

$V$ arietics.-In the selection of the varieties there is no best variety for all sections. Whereas the Baldwin may be the best commercial variety for New England, we find the Yellow Newton the best for Virginia, the Spitzenberg for Oregon, and the Ben Davis for Missouri. It is a safe rule in planting, therefore, to select the standard varieties that are best adapted to the particular section.

Pears.-Pears thrive particularly well in certain 
parts of the country, but in many places cannot be grown with success on a commercial scale. In many sections the trees are susceptible to fire blight, which is mentioned under plant diseases. The pear thrives best on a heavy strong clay, while on a sandy soil the tree tends to be short lived. Like the apple the pear also demands good care to produce the best crops. The tree suffers more from neglect than the apple, and the fruit needs to be picked before fully ripe, and stored in a moderately cool dry place to ripen to obtain its best flavor.

Varieties.-The Bartlett is the most popular standard variety, while the Anjou is one of the best for quality. The Keiffer, because of its vigorousness, hardiness and productiveness is an important commercial variety. Although poor in quality, it is a profitable and desirable sort for canning.

Quince.-The quince is a slow-growing tree, seldom exceeding fifteen feet in height. Being grown mostly for jelly or preserves, the demand for this fruit is generally limited, hence it has increased very little in commercial importance in this country. It requires a rich, well-drained moist soil to produce the best crops. As the tree is very shallow rooted, deep plowing should be avoided. Thorough tillage should be given to the trees. Cover crops are essential to protect the shallow roots of the trees from frost injury. The Orange, Champion and Rheo are the leading standard varieties.

Stone Fruits.-The peach, plum, cherry and apricot are called stone fruits.

The Peach.-The cultivation of this fruit is generally attended with great risk. In the North the buds are subject to freezing during the severe cold spells, while in the South they are likely to be killed by sudden freezes following a prolonged warm spell. The trees blossom early in the spring, and in many sections, especially on low land, the blossoms are apt to be killed by late frosts. Another danger which attends 
the growing of peaches is the disease "peach yellows." No cure is known for this disease, and if the infected trees are not dug up and burned, the disease will spread and destroy the whole orchard.

Peaches grow to perfection on a rich, sandy loam, often giving profitable crops in four or five years after planting. The trees demand careful cultivation, pruning and spraying to produce the best crops. The fruit should also be thinned so that no two peaches stand

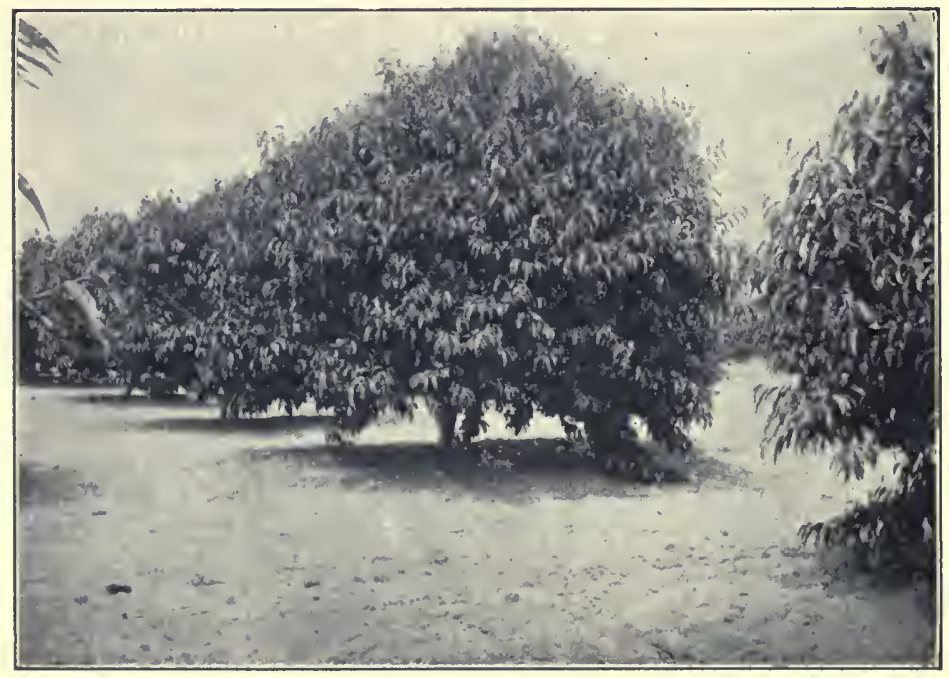

A PEACH ORCHARD.

closer on the same branch than 5 or 6 inches. This thinning results in larger and better fruit, and also induces annual bearing.

The Elberta is one of the most hardy, productive and cosmopolitan varieties, and is planted more than any other one variety.

Plums.-The plums cultivated in this country consist of three different classes: European, Japanese and American. These classes vary greatly as to their adaptability to the various climatic regions. In the 
Northeastern States the European type is most extensively grown, while in many parts of the South the Japanese and American seem to thrive the best. As a rule the trees grow best on a rather moist, clay loam, although certain varieties often seem to thrive on lighter soils. Often the plum is budded upon peach stock when it is necessary to plant the trees upon light soil. The trees bear annually after the fifth year, and will continue to produce profitable crops under proper care for about ten years. In most sections the trees should be carefully sprayed and the fruit thinned so that no two plums touch each other. Some of the most profitable varieties are Lombard, Green Gage, Abundance, Burbank, Wild Goose and Damson.

Cherries.-There are two principal types of cherries, sweet and sour. The trees of the sweet cherries are of a tall, erect growth, while the sour cherries consist of a low spreading growth. Although the sweet cherries may be grown with success in only comparatively few regions, because of the susceptibility of the fruit to rot, the sour cherries produce good crops in many sections of the country.

The Early Richmond and Montmorency are the leading sour varieties, while the Black Tartarian and Windsor and Dikeman seem to be the best sweet varieties.

Citrus Fruits.

Orange.-The orange is one of our oldest cultivated fruits. The principal orange sections of this country are Florida, the states bordering on the Gulf Coast (principally the Mississippi Delta region), parts of Texas and Arizona and California.

The orange will grow on almost any kind of soil. The rich alluvial lands produce the larger yields, but the poor sandy soils the better and higher priced fruit. On the sterile sandy soils fertilizers are used with good success, as the requirements of the crop are easily controlled on these soils of practically no fertility. Orange trees cannot stand a temperature as low as 26 
degrees Fahrenheit for more than a few hours, so that it is necessary to grow this fruit in warm localities. The trees are propagated by budding, and after remaining in the nursery for about two years they are ready to set out. Usually these trees are planted from 20 to 25 feet apart, depending upon the variety. The trees begin to bear in about five years, and may continue to bear fruit for many years when given the proper care and attention.

$V$ arieties.-There are a great many varieties of

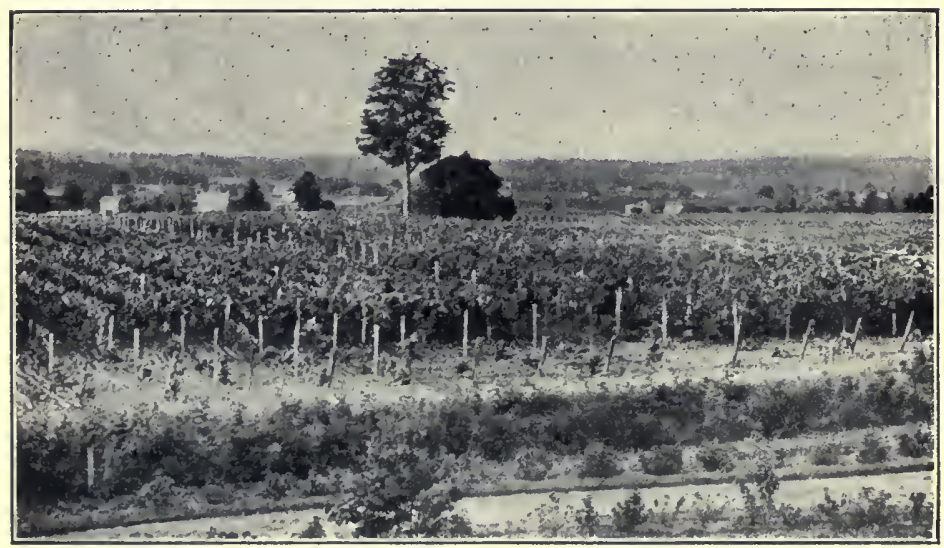

A TYPICAL EASTERN VINEYARD.

oranges. These may all be classed as sweet and bitter. The Washington Navel orange, sometimes called "Bahia" because it was imported from Bahia, Brazil, is a seedless orange especially adapted to California conditions. This variety does not thrive in Florida.

2. Vine Fruits.

Grapes.-Of all the fruits, the grape is probably the oldest one under domestication. Long before America had been discovered, the grape was extensively grown in the Old World for the production of wine. After many futile attempts by the early colo- 


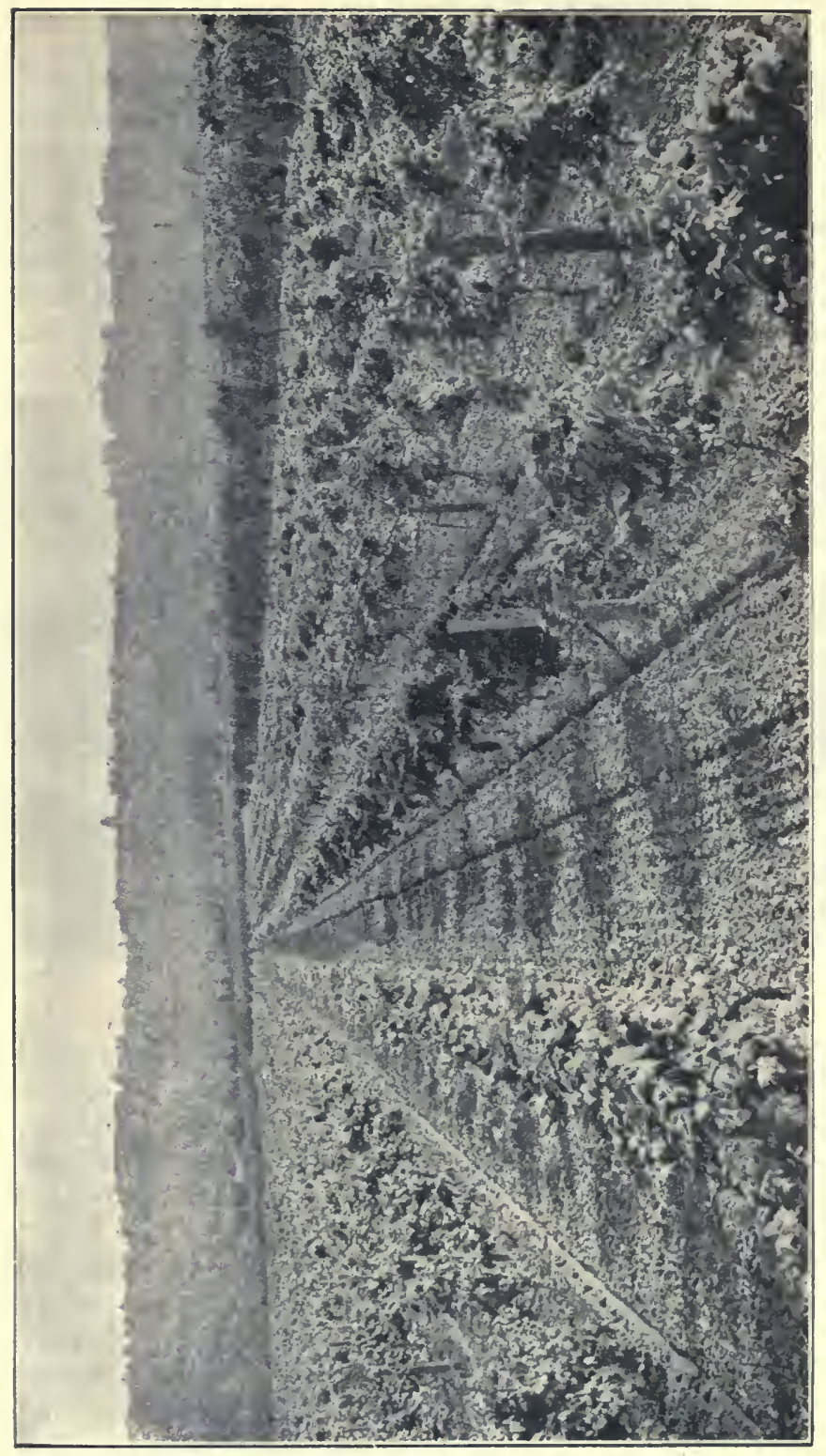

总 
nists to grow this Old World grape in their new land, it was finally given up, and to-day most of our successful commercial varieties are of our own native species. On the Pacific Slope, however, the Old World grape is successfully and extensively grown, but because of the unfavorable climate and its susceptibility to mildew and phylloxera, or rot louse, it cannot be grown with success in most other sections of the United States.

Grapes are grown in nearly all parts of this country, although only in a few sections has it developed into a commercial industry. These sections are generally bordering large bodies of water whose moderating influence favors the industry. The site for the vineyard should possess good soil and air drainage, and the soil should be only moderately rich. Too much nitrogen in the soil stimulates an excessive wood growth.

Pruning and Spraying. - The grape is naturally a rampant grower. Therefore severe annual pruning should be practiced to keep the vine within bounds and to reduce the amount of wood, thus limiting the amount of fruit produced. This pruning is usually performed in late winter or early spring, and the twigs are often made into hard-wood cuttings for the propagation of more vines. Spraying is practiced regularly by the best growers to control the mildew which attacks the foliage, and also to control the grape rot of the fruit.

Varieties.-The Concord is the leading standard variety of the American grape. The Worden, Brighton, Delaware, Niagara and Moore's Early are other leading varieties.

3. Small Fruits.-The small fruits are special favorites in the American fruit garden, as they give quick returns and are easily grown and occupy less space than the tree fruits.

Strawberry.-This fruit is grown with marked success in every section of the Union. It thrives on a 


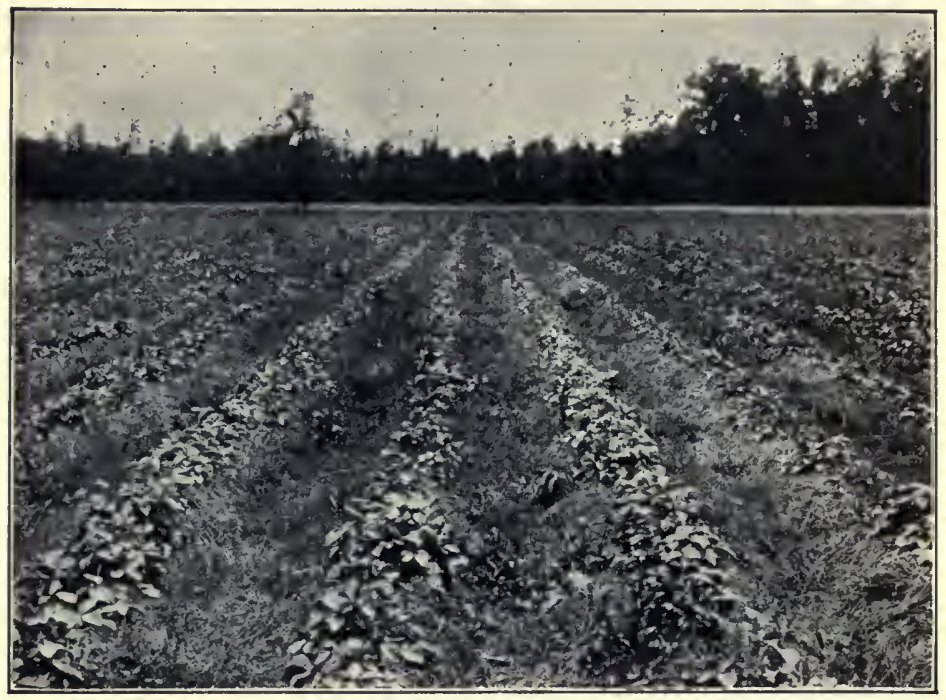

A FIELD OF COMMERCIAL STRAWBERRIES.

greater variety of soils than any other fruits, is comparatively free from insects and diseases, and produces an abundant crop under ordinary care. These favorable points of the strawberry have placed it as a commercial fruit second only to the apple.

How Planted.-In starting a bed of strawberries only young plants should be selected. These should be planted in the Northern States, early in the spring, but in the Southern States fall planting is most advisable, as it gives the plants time to become established before the hot, dry season overtakes them. The plants are generally set 18 inches apart in a row, and the rows a distance of 3 or 4 feet apart. This allows plenty of room for the plants to spread, and also for cultivation. In the home garden they may be planted closer. During the growing season they should be frequently cultivated, being careful, however, not to cultivate very deep as the plants are quite shallow rooted. In most of the Northern States and in many 
parts of the South strawberries are mulched or covered for the winter. After the ground is frozen in the fall, a covering of manure or clean straw is applied, thus protecting the plants from severe freezing, and also from the alternate freezing and thawing in the spring.

$V$ arieties.-In selecting varieties it must be remembered that some are pistillate, that is, they have no stamens, called imperfect, and others have both stamens and pistils, and are called perfect. Imperfect varieties, having no stamens, will not be fruitful unless interplanted with perfect varieties. Most plants seem to thrive with success only in certain localities, therefore it is wise in selecting the most desirable to plant those that thrive best in a particular section. Some of the most cosmopolitan kinds are the Michel and Bubach for early, Glen Mary, Dunlap, Sample and Brandywine for mid-season, and the Gandy for late.

Raspberries, Blackberries and Dewberries.—Good profits are made by the fruit grower from these favorite American fruits. Ripening as they do before most of the other fruits can be harvested, they fill an important place on the fruit farm. On farms located with good shipping facilities to a good market, they prove a good annual source of income. They are easily grown, and although they prefer a moist, cool soil, well filled with humus, they thrive well on any good, well-drained garden soil. In New York State large fields of raspberries are grown and the fruit dried. In this dry condition they are shipped to Alaska and other distant points.

The bushes should be pruned in the spring, cutting out all the weak and diseased canes, and then cutting the laterals about one-third back. After fruiting, all the old canes are removed, and only the new ones are allowed to remain. Some of the standard varieties of each are as follows:

Blackberries-Early Harvest, Agawam and Lucretia. 
Red Raspberry-Cuthbert, Shaffer and Turner.

Black Raspberry-Cumberland, Gregg and Kansas.

Currants and Gooseberries.-The reliability of these fruits entitles them to a place in every fruit garden. They do best in a soil that is cool, moist and well-filled with humus, hence they do not thrive in a hot, dry climate. Fall planting is preferable with these fruits, as they become well-established during the cool, moist days of early spring before the hot dry summer. The plants are shallow-rooted, and should be frequently cultivated to prevent the roots from drying out. From five to sixteen quarts of fruit should be produced annually upon every bush. In pruning the oldest canes are removed in early spring and new ones allowed to replace them. Large profits are often made on these crops, as there is a great demand for them in the city for making jelly, and also from the canning factories. In many localities, however, the demand is quite limited. On the fruit farm they are planted in the orchard between the trees, as they do well in a more or less shady situation. In the home fruit garden a spot on the north side of a building furnishes an admirable place for them.

The London Market is the leading variety of currant, while the Downing is one of the best varieties of gooseberries.

ExerCISE.-What is pomology? What branch of pomology is practiced the most in your locality? What are the factors that make the apple the most important American fruit? What varieties of apples are grown the most in your section? Explain the factors that make your locality a favorable or unfavorable one for the growing of pears. Name some of the uses of the quince. Why is the growing of peaches attended with great risk? Can you name any variety of plums that you think would thrive in your locality? How may one tell the difference between sour and sweet cherry trees? How do you account for the poor soils producing the highest priced oranges? Why are not oranges grown over a greater area? Where are navel oranges most successful? Can you name the best variety of grapes to grow in your locality? Is it an American or Old World grape? Explain how to start a strawberry bed. What is meant by "perfect" and "imperfect" flowers? Name the small fruits that can be most successfully grown in your locality. 


\section{Section XXXI.-Forestry.}

By Prof. Lyman Carrier,

Department of Agronomy, Virginia Polytechnic Institute.

The American people have been wasteful of their forests. A century ago forests were looked upon as a nuisance, as it required a large expenditure of labor to clear the land for the cultivation of other crops.

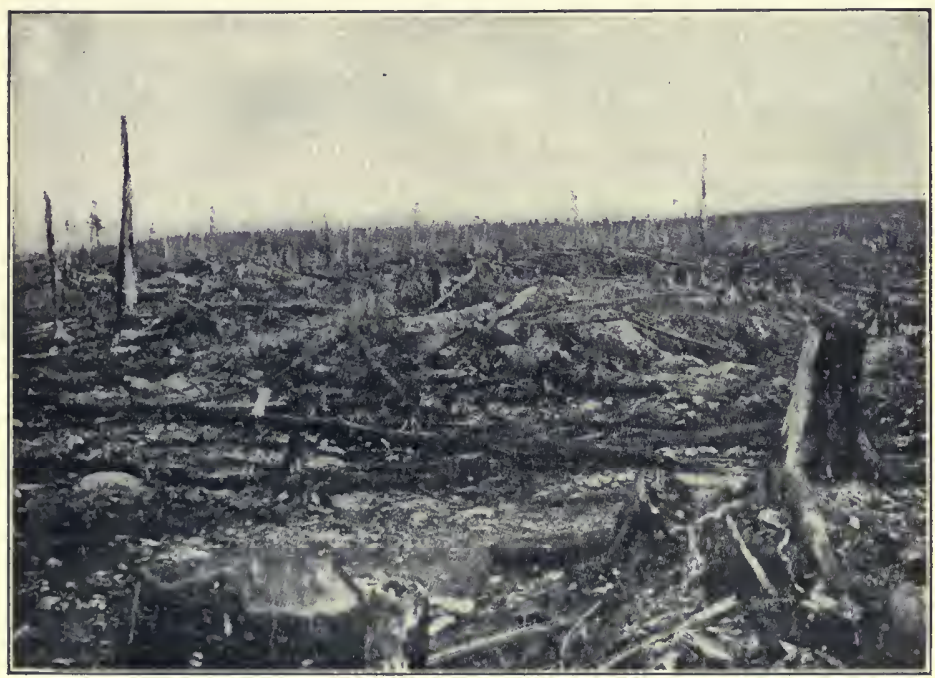

THE EFFECTS OF FIRE AFTER LUMBERING.

The timber did not pay for marketing-in many localities there was no demand for it at all. For this reason forests that would be worth untold fortunes at the present time were cut down and burned. As the demand for timber increased, its value rose until lumbering became a profitable business. Prospectors searched the continent over for the best tracts of timber. But no effort was made to conserve this valuable resource. The best trees were cut and the tops, brush, and other rubbish left where they fell. As a result, a 
forest fire almost always followed the lumberman and completed the work of destruction which he had only partly accomplished. Vast areas of white pine, one of the most useful of all woods, were cut over in Maine, Michigan and Wisconsin in about twenty-five years.

Pine Barrens. - The soil on which this timber grew was, as a rule, worthless for farming purposes, so the term "pine barrens" is now applied to thousands of acres of land that once supported the most magnificent and valuable forests in the world.

The South is the Present Destructive Section.-As the timber in the Northern States became scarce, the lumbermen transferred their operations to the Southern States and, in many cases, are practicing the same destructive methods that so quickly ruined the forests in the North.

Government Control and Study of Forestry.-Since about I 890 there has been a steadily increasing interest taken in the subject of Forestry, that is, the proper methods of preserving and utilizing our forests in order that we may have a permanent supply of timber. The Forest Service of the U. S. Department of Agriculture was created, and Departments of Forestry were started in a number of colleges and universities. Large tracts of timber land owned by the Government were withdrawn from the market, and put under the care of the Forest Service. Many lumber companies are beginning to realize the folly of past methods, and are endeavoring to save the young growth of timber when the larger trees are cut.

How a Forest should be Managed.-The timber crop needs just the same chance for growth that any farm crop does. It sprouts from seed, grows, matures and decays. In a properly conducted forest only the mature trees are cut for lumber, the young growth being allowed to develop. Loose brush should be piled and burned where it can do no damage. Crooked, ill-shaped trees should be cut out, as they 


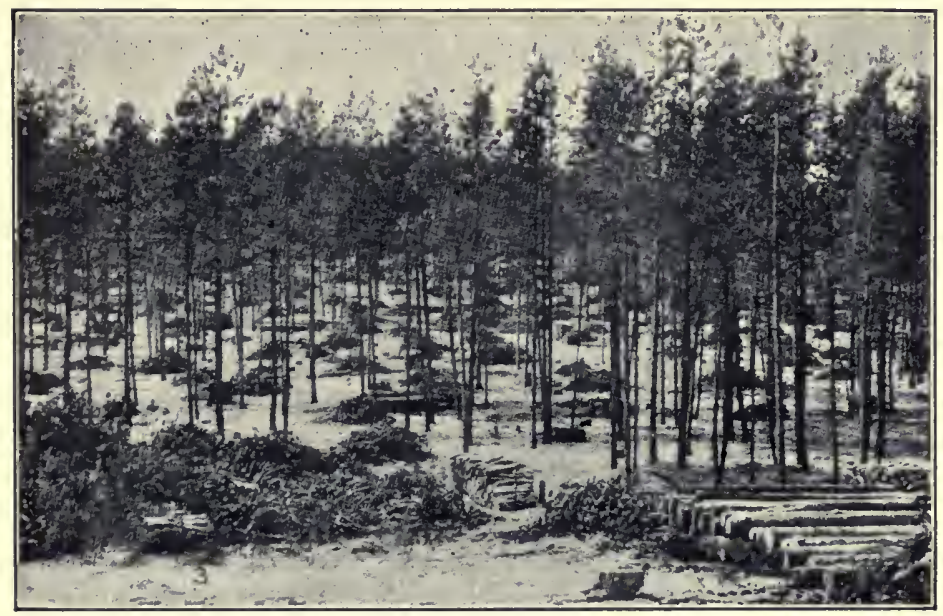

A WELl-MaNAGEd FOREST. BRUSH PILED TO PREVENT FIRE.

hinder the growth of the better specimens near them. No attempt to make a pasture out of a farm wood lot should ever be made. It is impossible to raise a crop of trees successfully and pasture a herd of animals at the same time on the same land. When thus managed, the owner of a forest derives a steady, regular income which will go on indefinitely.

How Trees are Injured.-Injury to trees happens in a great many ways. Fire is the principal source of damage, although wind, lightning, animals, fungus growths and extremes of heat and cold often do a great deal of harm. Insects often cause a great amount of trouble, especially in small pieces of woods and shade trees in towns and cities.

EXERCISE-Bring as many leaves of forest trees as possible to the classroom and see if you cannot identify them. How do the methods that are sometimes practiced in obtaining turpentine and maple sap injure the trees? What was the extent of damage of the last forest fire in your section? Has your State a Forest Commission? The class should take a trip to a forest or woodland, and name the different trees, criticize the method of lumbering, and point out trees that should be cut out to improve the growth of the forest. What trees of your locality are used for lumber? 
Section XXXII.-The Injury of Gas and Elec-
tricity to Trees.

By Dr. G. E. Stone,

Department of Botany, Massachusetts Agricultural College.

Causes of Gas Leakage.-The greatly increased death rate of trees from the effects of escaping illuminating gas in the soil may be accounted for in part by the larger amount of gas now used, and in part by the different methods of laying and calking the joints, the different types of connections, larger pipes, etc. Of course the heavy traffic on highways, the continual excavation of gas conduits and the effects of frost are also more or less responsible for leakage.

Gas Leakage Injures Trees-While the leakage of gas may be very slight from some gas mains, possibly only a few cubic feet a day, even this small amount will surely cause injury sooner or later, as the soil becomes charged with the gas. Such leakage may not cause the immediate death of the tree, but will shorten its life and often results in a condition which from ignorance of the true cause is sometimes called "general debility," a most convenient term.

Affected Trees Die.- There is absolutely no hope of recovery for a tree which has been affected with gas from a large leak. There appears to be little difference in the susceptibility of different species to gas poisoning, but trees with a large spread of roots are more likely to be affected than those with a limited spread.

Symptoms.-The symptoms of gas poisoning are distinct to one familiar with them; one of the first effects being a yellowing of the foliage, followed by a rapid defoliation of the tree if the poisoning is severe. The trunk assumes a dark color in some cases; the sapwood is often found to be discolored and it has peculiar, characteristic odors which assist in diagnosis; but when the tree is injured in late summer, when the flow 


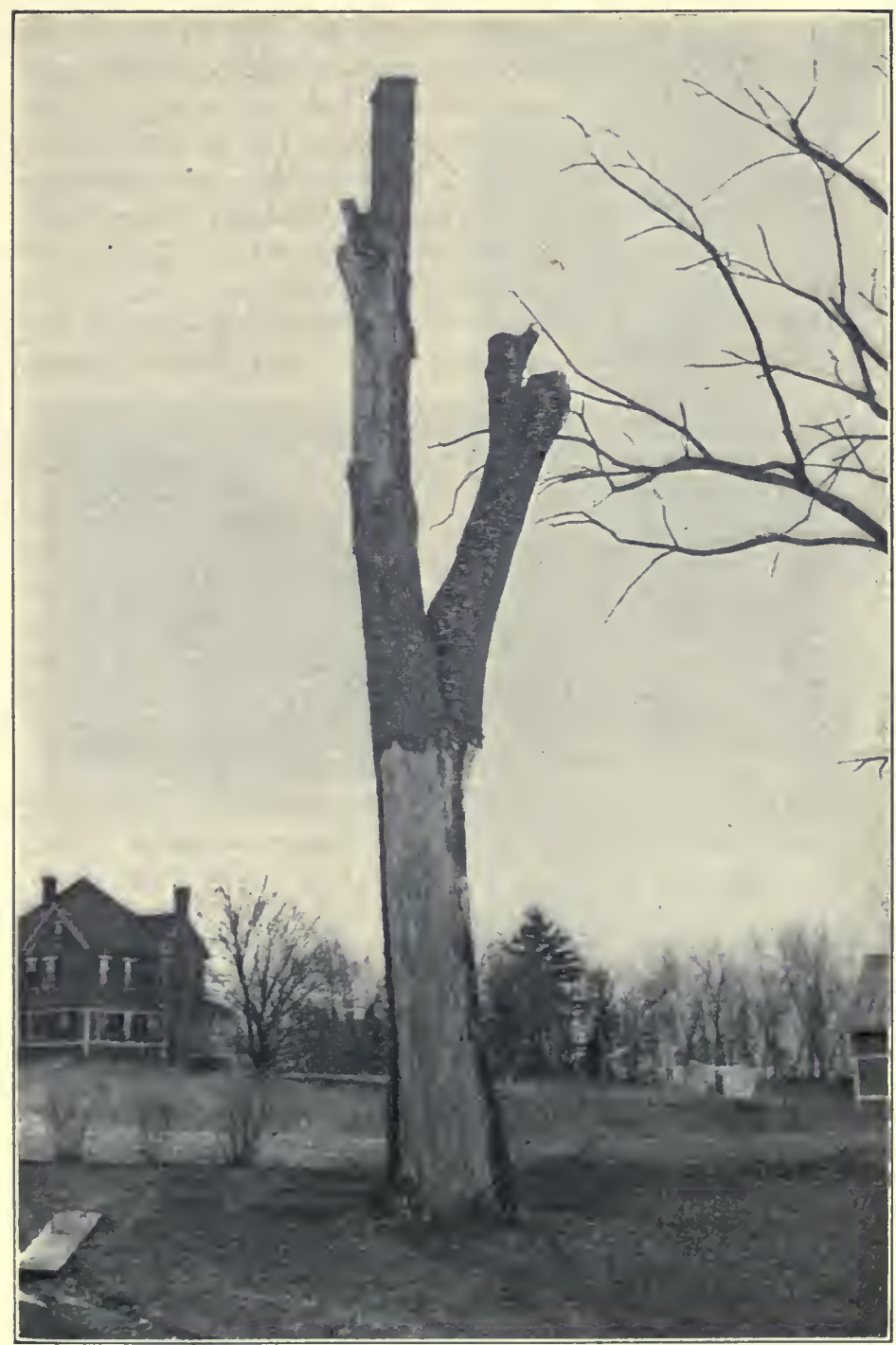

EFFECTS OF GAS ON ELM TREE ONE AND A HALF YEARS AFTER LEAKAGE OCCURRED. 
of sap is not so active, the odors are not as a rule so marked. If only one root becomes affected with gas, that part of the tree nearest it will show the effect first, and if the poisoning has not extended to the tree trunk, amputation of the affected root is the best remedy. Such fungi as Schizophyllum, Polystictus and others often appear on trees soon after they are affected, and their presence is sometimes significant.

Detection of Leakage.-Certain devices may be employed at no great expense when installing a system

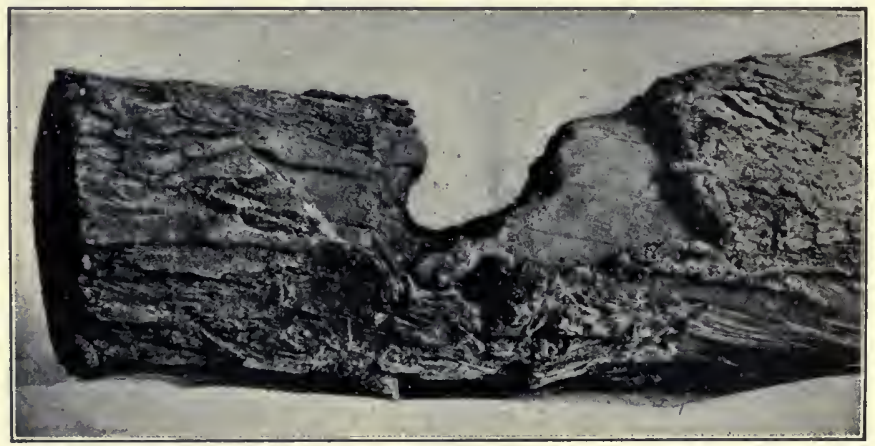

ONE EFFECT OF ALTERNATING CURRENT ON TREES.

of lines which will quickly detect a source of leakage and prevent gas from escaping into the soil, but little can be done for a tree when the soil near it has once become saturated with gas.

Electrical Injuries occur from three causes: alternating currents, direct currents and lightning. Alternating currents seldom completely kill a tree, causing only local burning at the point of contact with the wires. It is true that a large limb or even the top of a tree may be killed by the branches being burned off, but it would require an exceptionally high potential to affect a tree as a whole.

Do Not Attach Wires to a Tree.-Sometimes a tree may be injured a few feet below the point of contact with the wire, but that is all. There is always danger 
in allowing any alternating current wires to be attached to a tree.

Direct Currents are probably the more dangerous of the two, as a direct current seems to have a characteristic physiological effect upon protoplasm and causes disintegration of the cells. It is believed that a direct current can kill a tree even if its strength is not sufficient to cause burning, although it sometimes does cause local burning, as with the alternating current. These injuries usually occur from the direct currents from trolley lines, and instances have been known where the trunk of the tree has been girdled to the distance of ten feet or more from the base by leakage from trolley lines, and trees have died from electrocution.

Effect of Lightning.It is a well-known fact that lightning affects trees in different ways, and it is surmised that some trees are more susceptible than others, but little is known about this. Feeble lightning

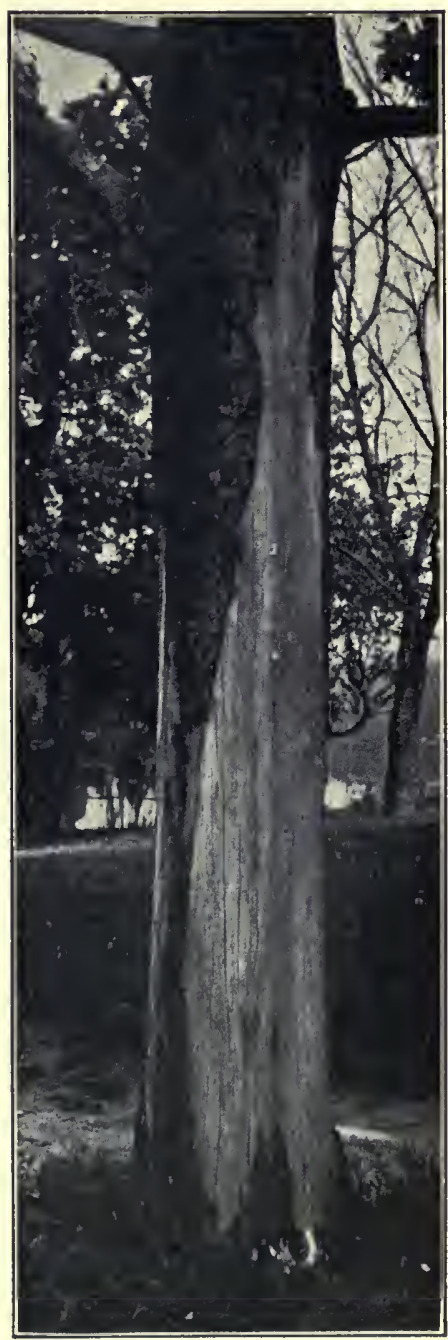

MAPLE TREE, KILLED BX DIRECT CURRENT. strokes often cause ridges on trees, and in such cases the discharge affects only a small part of the vital layer. 
Less common are earth discharges, which occur when the electrical conditions of the clouds and the earth change their potential from negative to positive, the lightning stroke passing from the ground up through the trunk of the tree and its limbs, discharging at the apices of the leaves.

ExERCISE-Try to find some trees that have been injured by gas or electricity. Do these trees appear as described in this text? Make a list of the trees on one of your principal streets that have telephone or telegraph wires attached or running through their branches. How would you remedy this condition?

\section{Section XXXIII.-Ornamental Trees and SHRUBS.}

\section{By Prof. Charles A. Keffer,}

Department of Horticulture and Forestry, University of Tennessee.

Adaptability is Important.-In every section of the country one may find trees and shrubs especially adapted to the soil and climate, and these have always the beauty of health and vigor. The amateur gardener, in his desire for variety and rarity, is apt to search the catalogues for foreign plants, without regard to the locality whence they come. People of the plains, seeing beautiful pictures of rhododendron and leucothoe (low evergreen shrub), determine to buy them for their gardens. Their home is in the mountains where the air is cool and fogs are frequent, and when transplanted to the plains they become sickly and seldom make vigorous plants. So it is unwise to transfer natives of swamps and wet soils generally to dry locations, or in any way to change seriously the natural conditions of soil and climate to which a plant is accustomed.

Select Local Hardy Forms.-Fortunately, the more common trees and shrubs used in ornamental planting succeed under a wide range of conditions. They have become common largely through their hardiness and 
vigor. The beginner in gardening will do well to confine his selections to hardy forms, such as grow in his locality, or in regions which he knows to be similar to his own. As a rule one may more safely transfer plants from the North to the South than from the South to the North, but this is not the universal rule. The long summers of the South are as trying to some

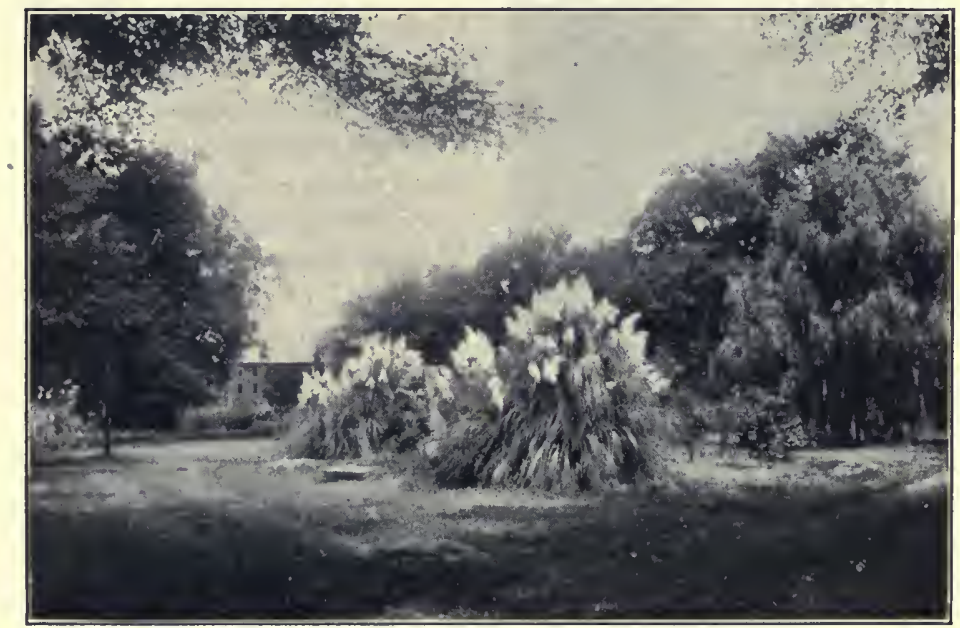

PAMPAS GRASS AS AN ORNAMENT FOR GROUNDS.

Northern plant forms as are the cold winters to Southern.

Individuality Must Be Considered.-Every tree has its own individuality, which fits it for certain uses and locations. The lombardy poplar grows slender and tall, and the willow oak is a spreading tree. The magnolia and the holly are both evergreen and are broadleaved, but how different their appearance! So, too, the flowering shrubs vary greatly in form and foliage as well as in flowering habit. Some are compact and shapely, like the Thunberg barberry, others are of graceful drooping habit, like the Van Houtei Spiræa, while the thick upright prickly stems of the Aralia have 
a totally different form. Not only the adaptability and the color of the flowers and foliage, but the form of the woody plants, must be carefully studied if they are to be used to advantage.

Changes in Appearance of Plants.-There is, furthermore, the changing appearance of each plant with

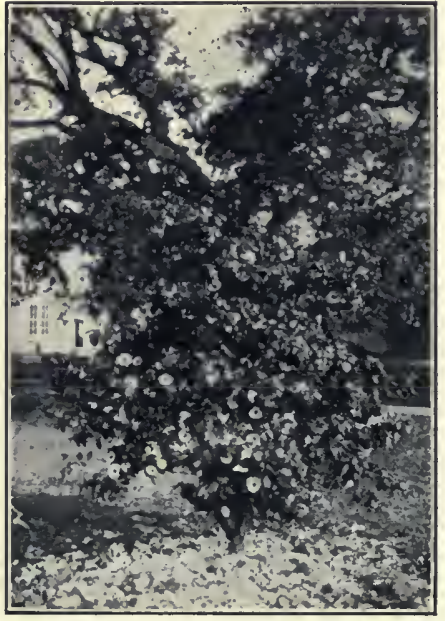

JAPONICA, AN ORNAMENTAL SHRUB. the change of the season to be considered. During midsummer, when every plant is in full leaf, one takes little note of the evergreens as a class, but in winter, when most of the flowering trees and shrubs have dropped their foliage, every evergreen in the grounds becomes conspicuous. They then show their usefulness, especially if planted to screen unsightly objects from view. In spring, when a host of shrubs are in full bloom, one does not notice the inconspicuous flowers of callicarpa (species of shrubs or trees), but in November its purple berried sprays are among the most attractive features of the garden. It is not until winter that one can admire the red twigs of the ozier dogwood, and the many bright-fruited plants that brighten the shrubbery border throughout the dull season.

Autumn Color, too, is easily provided in every garden if the gardener will study the foliage of trees and shrubs. In the North and in the limestone regions of the middle South, the hard maples are gorgeous in their autumn dress. Sweet gum and black gum, sour wood and sumac give rich reds and bronzes before their leaves fall, while every tree and shrub welcomes 
the rest season by some change from the green of its summer dress.

Beauties in Every Season.-Even in winter beauties appear that are not suspected in the full leafage of summer. The oak, the walnut and the beech spread their naked branches against the winter sky, each with its own distinctive form and winter color. So we find, at every season, something of interest in the trees and shrubs.

Lists of Woody Plants.-The following are a few lists of woody plants; it is not a complete list, for there is hardly a tree or shrub in all the world that may not find its proper place in somebody's garden. These lists are only suggestive; every studert can make additions or changes to adapt the list to his own neighborhood.

Tall Trees, More or Less Slender:

Deciduous:

Lombardy Poplar.

Carolina Poplar.

Black Gum.

European Larch.

Evergreen :

Lawson's Cypress.

Arbor Vitæ.

Tall Round-Headed Trees:

Deciduous :

Hard Maple.

Red Maple.

Silver Maple.

White Oak.

Red Oak.

Evergreen :

The Pines.

Tall Spreading Trees:

White Elm.

The Birches.

Black Walnut.

Catalpa.

Spiral Shaped Trees:

Deciduous :

Ginkgo.

Evergreen :

Hemlock.

The Spruces.
American Larch.

Bald Cypress.

Horse Chestnut.

Linden.

Red Cedar (eastern form).

Pin Oak.

Poplar (Tulip).

Beech.

White Ash.

Cucumber.

Magnolia.

Paulownia.

Chestnut.

Sycamore.

The Firs. 
Small Flowering Trees:
Dogwood.
Wild Plum.
Red Bud.
Crab Apple.
Hawthorn.
Fringe Tree.
Juneberry.
Choke-cherry.

Tall Flowering Trees:

$\begin{array}{ll}\text { Horse Chestnut. } & \text { Black Locust. } \\ \text { Catalpa. } & \text { Tulip Poplar. } \\ \text { Paulownia. } & \text { Magnolia. }\end{array}$

Black Wild Cherry.

Nut-Bearing Trees:
Black Walnut.
Shell-Bark Hickory.
Pecan.
Butternut.

Chestnut.

Evergreen Shrubs and Small Trees:

Broad-Leaved :

Holly.

Buddlea.

Box.

Euonymus-Spindle Tree, Burning Bush, Strawberry Bush.

Kalmia.

Rhododendron. Mahonia.

Needle- or Spine-Leaved :

Chinese Arbor Vitæ. Dwarf Junipers (several species).

Yew.

Dwarf Pine.

Retinisporas (several species)-a genus of conifers.

Deciduous Flowering Shrubs (named in order of blooming):

Yellow:

Jasminum Nudiflorum.

Forsythia.

Scotch Broom.

Pink and Red, all shades:

Flowering Almonds.

Pinxter Flower-Azalea.

Red Bud.

Tartarian Honeysuckle.

Flowering Quince.

Double-Flowering Peach.

Weigelia (in variety).

Althea-Rose of Sharon.

Flowering Currant.

Kerria.

Witch Hazel.

Spiræa A. Waterer, ) సี

Spiræa Douglasi,

Spiræa Billardii,

Tamarisk.

Roses (in variety).

Double-Flowering Thorn.

Wild Crab Apple.

Lilac and Blue Shades:

Lilac (in variety).

Amorpha (Indigo Shrub).

White:

Caryopteris (Blue Spiraea).

Dwarf Juneberry.

Flowering Dogwood.

White Flowering Almond

IVhite Fringe.

Pearl Bush.

Silver Bell.

White Lilac.

Spiraea Thunbergii, Spiraea Van Houtei,

Spiraa Van Houtei,

Spira Reevesiana
fl. pl. 
Dentzia Gracilis, Dentzia Crenata, Double Mock Orange.

Mock Orange.

Hydrangea.

Spiraea Sorbifolia-Bridal Wreath.

Brown :

Calycanthus (Sweet Shrub).

Pawpaw.

Small Trees and Shrubs Bearing Ornamental Fruits:

Lonicera Morrowi (red)
Lonicera Tartarica (yellow and red) $\}$ Honeysuckle.

Rhus Cotinus (Smoke Bush).

Rosa Rugosa (red)-Hedge Rose.

Berberis-in variety-(red)-Barberry.

Callicarpa (purple).

Flowering Dogwood (red).

Rhus Typhina (red)-Staghorn Sumach.

Symphoricarpus Racemosus (white)-Snowberry; Waxberry.

Holly (red).

Small Trees and Shrubs with Unusual Foliage:

Rhus Laciniata (cut-leaved Sumac).

Aralia Spinosa (very large decompound leaves)-Devil's Walking Stick.

Japanese Maples (cut-leaved and red-leaved).

Elægnus Augustifolia (whitish-green leaves)-Oleaster.

Golden Elder (yellow-leaved-green toward fall).

Golden Mock Orange (yellow-leaved-green toward fall).

Golden Spiraa (yellow-leaved).

Populus Alba (under side of leaf, white)-White Poplar.

Prunus Pessardi (purple-leaved plum).

Fagus Sylvatica Riversii (purple-leaved beech).

Cut-leaved Maple.

Cut-leaved Birch.

Small Trees and Shrubs with Bright-Colored Bark:

White Birch.

Golden Willow.

Cornus Sibirica-Red-twigged Dogwood.

EXERCISE.-Make a plan of a beautiful laid-out home grounds of your town, naming the trces and shrubs as far as possible. Make a list of the principal ornamental trees and shrubs common to your neighborhood.

The teacher should select some home that is unattractive because of the lack or improper arrangement of ornamental trees and shrubs, and have the students write their ideas on how to improve such a place. 


\section{Section XXXIV.-The Garden.}

\section{By Prof. Charles A. Keffer,}

Department of Horticulture and Forestry, University of Tennessee.

Garden is a word of larger meaning than is generally given it; for most people have in mind a place to grow vegetables when they speak of the garden. In its larger meaning it includes not only vegetables, fruits and flowers, but the lawn as well. Such a garden is best made in the country, where there is plenty of room, but even a small city lot may grow grass, flowers and vegetables, and in every small town there should be room in every yard for all the things that belong in a good garden.

$A$ Garden should Serve Its Purpose.-Every wellplanned garden should serve fully the purposes for which it was made. The vegetable section must yield an abundance of the best products, in great variety, and throughout the year. In the South there must be no season when the garden does not provide food for the gardener. In the North the garden must perforce be idle through the winter months, and so, in the growing season, the Northern gardener must cultivate root crops and vegetables for canning, besides those to be used from day to day.

Fruit Garden.-In the fruit garden care must be taken to select only those varieties that succeed in the locality, and for this reason the fruit gardens in different sections of the country differ greatly. Everywhere there may be strawberries, but in many parts of the South currants will not grow, while in the Dakotas it is difficult to grow blackberries and grapes.

Flower Garden.--Everywhere the flower garden may be made to yield great crops of bloom, but as with fruits the gardener must be careful to choose varieties adapted to his soil and climate. And every garden may contain a lawn, even though it be but a few square feet in extent, and the lawn will be beautiful and sat- 
isfying in exact proportion to the taste displayed in planning it and the perfection of its care. So we find in the garden a subject for careful study and a place for good work.

How to Plan a Garden.-In planning a garden all its possible uses and the work necessary to their fulfillment must be kept in mind. The vegetable and fruit departments should be convenient both to the kitchen and the barn. As far as possible the rows should be long and far enough apart to allow the use of horse cultivators. A wagon gate should permit of passage from barnyard to garden, so that manure and the larger implements of tillage can be most economically used. The permanent plants, such as grapes, blackberries, raspberries, asparagus, rhubarb, horse radish and Globe artichoke should be planted in contiguous rows, and next to these should be placed strawberries, and then such vegetables as sweet corn, celery, potatoes, beans and peas, which are to be cultivated with the horse hoe. The root and salad vegetables, such as lettuce, onions, beets, carrots, etc., will thus be brought together, since they require hand or wheel hoes. By this arrangement the vegetable land can be plowed without disturbing the fruits. The unit of distance between rows should be 15 inches or its multiple. The wheel hoe can be run easily between rows planted I 5 inches apart; the horse hoe can be used between rows 30 inches apart. Lima beans and large varieties of corn need more room, and may be planted in rows 45 inches apart. Celery, to be blanched with earth, needs 75 inches, the brambles should have at least 90 inches, and the grapes will need 150 inches.

The Vegetable Garden should be far more useful than it is. Most gardeners make a single sowing of each vegetable they grow, while even in the coldest regions the season of every vegetable can be prolonged by repeated sowings. In Tennessee one may have tomatoes from late June to October. Instead of one crop a year the same plat may be made to produce 
from two to four crops. This is particularly true of the South, where the hardiest vegetables, such as cabbage, can be grown during the winter months. Of course there is a limit to the season of every vegetable, but very few gardeners even approach this limit.

A Screen should Separate the Gardens.-The flower garden should be near the vegetables, for convenience in working. But the flower garden is for ornament, and the vegetable garden is not supposed to be beautiful, so one should make a screen between them. A grape arbor would make a fine screen in summer, but the vines are bare in winter, and the ornamental garden should be as beautiful as it can be made throughout the year. The screen should be evergreens, or, if the garden is very elaborate, the food-plants should be separated from the lawn by a stone wall against which a pergola may be built. In the South the evergreen screen may be of broad-leaved trees and shrubs, such as holly, euonymus, mahonia and wild olive, and where the air is moist enough rhododendrons and kalmia can be used. But in the North only conifers as the hardy pines, hemlock, spruces and arbor vitæs should be used. No large growing trees should find place in this screen planting, for they shade the gardens too much.

A Background for the Flowers.-A clipped hedge, or one of mixed planting, will make a good background for the flowers, which are to be set in regular beds of simple shape on the lawn side of the screen.

Location of Flower Garden and Lawn.-The flower garden should be at one side of the lawn, and the lawn should be as large as possible, carpeted with perfect grass and adorned with trees and flowering shrubs. The lawn should surround the dwelling, but by all means the largest and most beautiful part of it should be at one side or to the rear of the house, and thus make this part so secluded from street or highway that it will be like a great out-of-door living room. The Lawn.-Good grass is the foundation of every 
lawn. It is the floor, and the trees and shrubs and flowers and seats are the furniture. In the far South Bermuda is the best grass for lawns, but wherever it can be made to grow, Kentucky blue grass is preferable. The land should be made smooth, and enriched with lime and well-rotted manure or other fertilizer. If the space is small it may be sodded, but if large it will be cheaper to use seed. Blue grass seed is light, and

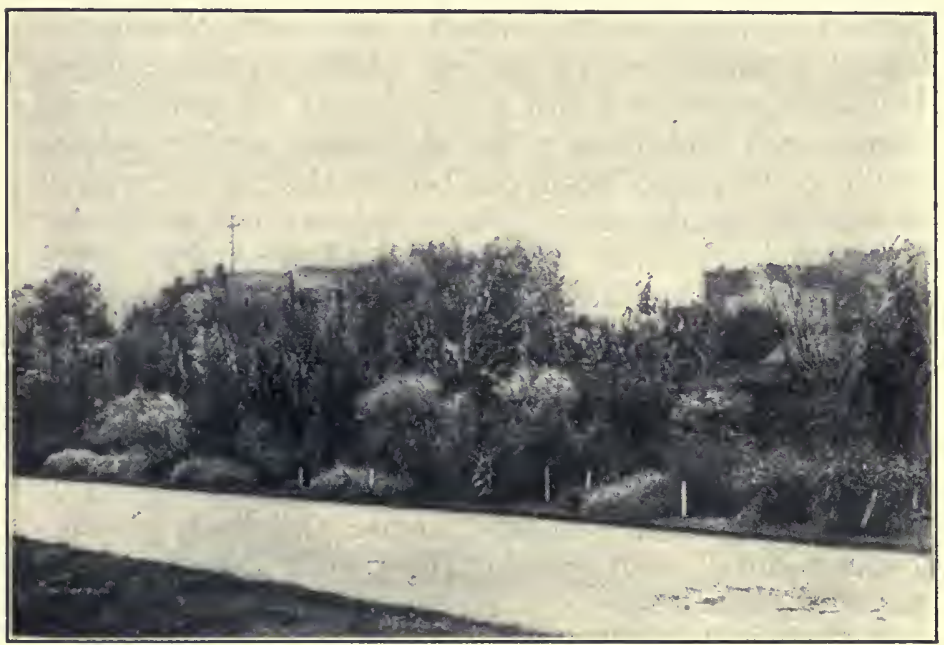

SCREEN OF GRASSES FOR A GARDEN.

it should be sown thick. Sow lengthwise, crosswise and on both diagonals in order to get an even stand, and from four to six bushels per acre can be used to advantage. The seed should be sown in winter, but the land is best prepared in the fall. If Bermuda is used quickest results can be had by setting the plants in rows or small blocks about a foot apart.

Selection and Site of Trees to Provide Shade.Most of the planting of the lawn should be near its borders, and the greatest care is necessary in the choice and placing of trees. Since the lawn is most enjoyed 
in the afternoon, whenever possible let the larger area be on the east side of the house. When this cannot be done, the greater part of the trees should be near the west side, to provide shade.

The Privacy of the lawn is best secured by massing shrubbery near its boundaries, especially on the street sides. This shrubbery border, like the flower garden, may be so planted as to have something in bloom throughout the year, from the yellow jasmines of earliest spring to the witch hazel of November. Lilac, snowball, mock orange, hybiscus, hydrangea, deutzia, the spiræas, and a long list of other flowering shrubs, may find place in the shrubbery border, adding to its variety and beauty. But it should be remembered that shrubs are in bloom only a little while, but they are in leaf for months, so particular attention should be paid to foliage effects. The shape and tinting of the leaves is of even more importance than the flowers.

The Shrubbery Border must vary in width and in height. Wherever an unsightly object appears it should be screened from view from the lawn by making the planting wide, and using dense and high growing forms. Small trees like dogwood, wild plum and holly may find place here.

$A$ Garden should be Simple.-Few things are more displeasing than a room crowded with many kinds of furniture and ornaments. A home loses its charm when it becomes a museum, however great the quality and number of the curios. So with a garden. It should suggest simplicity and coziness. It should be a place of sunshine and of pleasant shade. There should be broad stretches of grass where the shadows of its trees may have full play. To be too full of trees and shrubs is quite as grave a fault as to be bare.

House and Garden Make the Home.-And every garden, like every dwelling, should reflect the taste and individuality of its owner. House and garden together constitute the home, and they are entitled 
equally to the care of the home makers. Let the garden be well supplied with fruits and vegetables, but let it be equally well furnished as to beauty; give it a good lawn and flowers, and thus make this part of the home complete.

EXERCISE.-What vegetables, flowers, fruits and berries are raised in the gardens of your locality? State the time and methods of planting the various vegetables and flowers. What tools and implements are necessary for working the garden? Do any people use sprayers in their gardens? What grass is most used in your section for lawns? State how successful gardeners keep their lawns in good condition. Make a plan of a garden such as you would enjoy having. Make a list of your favorite flowering plants and state when they bloom and the color of their flowers.

The teacher should take the class to some garden in the section and require the pupils to make notes of the various features of suc. cessful gardening as described in this article. Send for some garden magazines and plantsmen's catalogues in which will be listed and pictured hosts of vegetables, flowers, trees and shrubs.

\section{REFERENCES FOR COLLATERAL READING.}

Trees and the Garden.

FRUIT TREES :

Yearbooks of the U. S. Dept. of Agriculture:

I 895-Principles of pruning and care of wounds in woody plants.

I896-Improvement of our native fruits.

I902-Top working of orchard trees.

I908-Promising new fruits.

Farmers' Bulletins, Nos. :

38-80-208-276-Peach.

I I3-I 53-I6I-208-233-243-247-283-Apples.

II3-The apple and how to grow it.

I4I-Apple culture in Vermont.

I8I-Pruning.

238-Citrus fruit growing in the Gulf States.

Experiment Station Bulletins, Nos. :

59--Illinois-Orchard management.

77-Georgia-The fig in Georgia.

98-99-IOO-IOI-Virginia-Orchard technique.

I39-Colorado-Pruning native fruit trees.

219 -New Jersey-The first season with the peach orchard.

262-New York-Cornell-Apple survey of Niagara County.

Nut Trees :

Farmers' Bulletins, Nos. :

I14-Chestnuts; cultivation and food value.

I24-Pecan culture.

$332-$ Nuts and their uses as food. 
Experiment Station Bulletins, Nos. :

69-Louisiana-Pecans.

85-Florida-Second report on pecan culture.

Forest TREes :

Yearbooks of the U. S. Dept. of Agriculture:

I 895-The relation of forests to farms.

I895-Tree planting in Western plains.

1896 - The uses of wood.

Farmers' Bulletins, Nos. :

67 -Forestry for farms.

I34-Tree planting in rural school grounds.

I73-358-Primer of forestry.

276-Suggestions for the management of the farm wood-lot.

Bureau of Forestry Publications, Nos. :

97-The timber supply of the United States.

II7-Preservation treatment of fence posts.

I30-Forestry in public schools.

I45-Forest planting on the Northern prairies.

Ornamental and Shade Trees:

Farmers' Bulletins, Nos. :

I34-Tree planting in rural school grounds.

2I0-Injuries to shade trees.

$360-$ Street trees.

367-Lightning and lightning conductors.

Experiment Station Bulletins, Nos.:

I7-Missouri-Circular-The planting and care of shade trees.

I05-Texas-Notes on forest and ornamental trees.

I25-Massachusetts-Shade trees.

256-New York-Cornell-Street trees; their care and preservation.

The Garden :

Yearbook of the U. S. Dept. of Agriculture:

I902-Plants as a factor in home adornment.

Farmers' Bulletins, Nos. :

35-I 49-244-365-Potato.

6I-84-233-259-Asparagus.

Io5-289-Beans.

I33-169-282-Celery.

I34-Tree planting on rural school grounds.

I 49-Arrangement of the farmers' vegetable garden.

I76-I 78-22 I-Cranberries.

I8I-Pruning.

I85-Beautifying the home grounds.

I86-220-225-296-Tomatoes.

198-210-Strawberries.

203-Canned fruits, preserves and jellies.

204-The cultivation of mushrooms.

208-Varieties of fruits recommended for planting.

2 I0-Effect of shading vegetables.

218-The school garden.

23I-Spraying for cucumber and melon diseases.

232-Okra; its culture and uses. 
233-354-Onion culture.

248-The lawn.

254-Cucumbers.

255-The home vegetable garden.

256-Preparation of vegetables for the table.

295-Potatoes and other root crops.

324-Sweet potatoes.

Books :

359 -Canning vegetables at home.

The Principles of Fruit Growing-Bailey-The Macmillan Co., New York City.

The Pruning Book-Bailey-The Macmillan Co., New York City.

The American Apple Orchard-Waugh-Orange Judd Co., New York City.

The Pecan and Its Culture-Hume-The American Fruit and Nut Journal-Petersburg, Va.

North American Trees-Britton-Henry Holt \& Co., New York City.

Art Out of Doors-Van Rensselaer-C. Scribner's Sons, New York City.

How to Plant the Home Grounds-Parsons-Doubleday, Page $\&$ Co., New York City.

Landscape Gardening-Waugh-Orange Judd Co., New York City.

Principles of Vegetable Gardening-Bailey-The Macmillan Co., New York City.

Garden Making-Bailey-Grosset \& Dunlap, New York City.

How To Make a Vegetable Garden-Fullerton-Doubleday, Page \& Co., New York City. 


\section{HAPTER VI.}

\section{PLANT DISEASES.}

\section{Section XXXV.-Causes of Plant Diseases.}

By Prof.,H. R. Fulton,

Department of Botany, Pennsylvania State College.

Plants suffer from diseases arising from many causes. Sometimes there is a natural tendency to weak or abnormal development; often the life or usefulness of a plant is threatened by unfavorable surroundings, such as starvation, heat, cold, drought and excessive moisture. In many cases the injury results from the attacks of living animals or plants.

Fungi.-A plant or an animal that gets its food directly from the tissues of another living animal or plant is a parasite; and the animal or plant upon which it feeds is the host. Parasitic plants belong for the most part to the group of fungi; these are plants of low order, which differ from the better known higher plants in size, form, and general life habits. The largest fungi are the toadstools and puffballs, the smallest are the bacteria, and between these extremes are the various molds, mildews, rusts, etc. While many of these can be detected with the unaided eye, the compound microscope is needed for the accurate observation of all but the largest forms.

Structure of Fungi.-Fungi have no roots, stems or leaves. Their bodies usually consist of fine, branching, whitish threads that often increase in length with great rapidity. A mass of these threads is termed the mycelium. The bacteria have bodies consisting of single short cells, or a row of only a few cellis, and are 


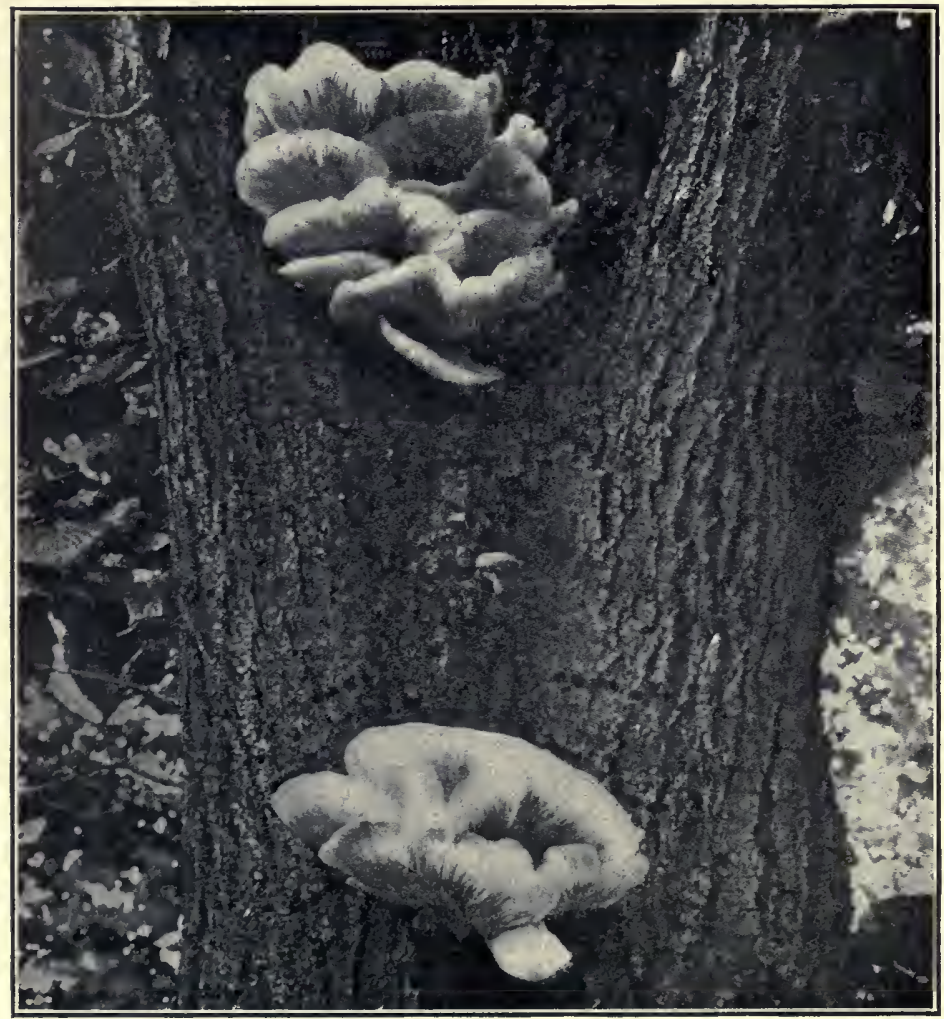

FUNGUS ON A LINDEN.

not usually thread-like. The conspicuous caps of such forms as toadstools are made up of many twisted and interwoven threads, something like the fibers of a rope.

Food of Fungi.-Fungi have no green chlorophyll, which is characteristic of higher plants, and so it is impossible for them to manufacture their food from simple substances; they must depend, as do animals, upon the elaborated food found in the bodies of animals or higher plants. While parasitic forms obtain their 
food from living hosts, a majority of fungi, known as saprophytes, live upon decaying vegetable or animal matter. Infection of a host takes place when the parasite begins to secure its food from it.

Reproduction of Fungi.-Fungi are reproduced by spores which under favorable conditions develop into new plants similar to the ones producing them, just as seeds of higher plants do. While fungus spores have the same office as seeds, they differ very much from seeds in size, structure and method of formation. Spores are exceedingly small, dust-like particles, and are simple in structure, consisting virtually of a single cell. They are formed in large numbers, sometimes

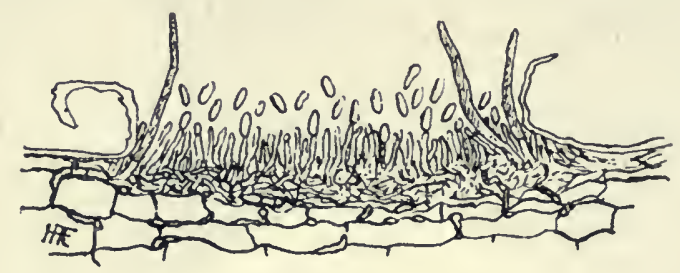

SECTION OF POD SHOWING POD SPOT FUNGI.

on special branches of the mycelium which extend freely in the air; sometimes in minute sunken cavities. Because of their lightness they are readily scattered by the air currents; and insects and water often play a part in their distribution.

Kinds of Spores.-Many fungi produce two kinds of spores at different times and for different purposes. During the period of vigorous growth there are produced, in large numbers, spores that germinate quickly, but that cannot withstand unfavorable conditions; these disseminate the fungus rapidly and extensively during the growing season, and may be called summer spores. As the fungus begins to decline there are formed in smaller numbers spores that will survive exposure to extreme cold or dryness; these carry the fungus over unfavorable periods, particularly the win- 
ter season, and may be called winter spores. The mycelium is ready to form a crop of summer spores within a few days, or at most a few weeks from the beginning of its growth, and usually spores are produced more or less continuously by the fungus plant during its life. Seasonal and weather conditions influence the germination of spores and the growth of fungi, more even than they influence the growth of higher plants. These, along with other conditions, cause diseases due to fungi to be more prevalent in some seasons and in some localities than in others.

ExERCISE.-Are seeds and spores similar? If not, state the difference in their structure. Bring some toadstools, puffballs and molds to school and examine their structure. Do they correspond to the description given of them in this article?

Section XXXVI.-Control of Fungus Diseases.

A diseased plant can seldom be cured; but in most cases it is possible to prevent the spread of the disease to sound parts of the affected plant or to other plants. The fungus must be given the least possible chance for its spread and growth; and at the same time the crop must be given the best chance for strong and vigorous growth.

Means of Control.-The exact means of control will vary with the crop and the disease, and are best considered in the accounts of diseases which follow. Here may be mentioned proper cultural methods that will produce a vigorous crop, resistant to contagious as well as functional diseases; rotation of crops that will lessen or eradicate diseases by eliminating their host plants, except at intervals; the cleaning up and destroying of all crop remains at the end of the season, thus lessening the chances for the fungus to survive the winter; destruction of volunteer plants and weeds along fences and roads, to control those diseases common to those and to crop plants, as well as other diseases 
that persist and develop in moist weedy places; careful selection of varieties to get those that are most resistant to disease and otherwise satisfactory; careful

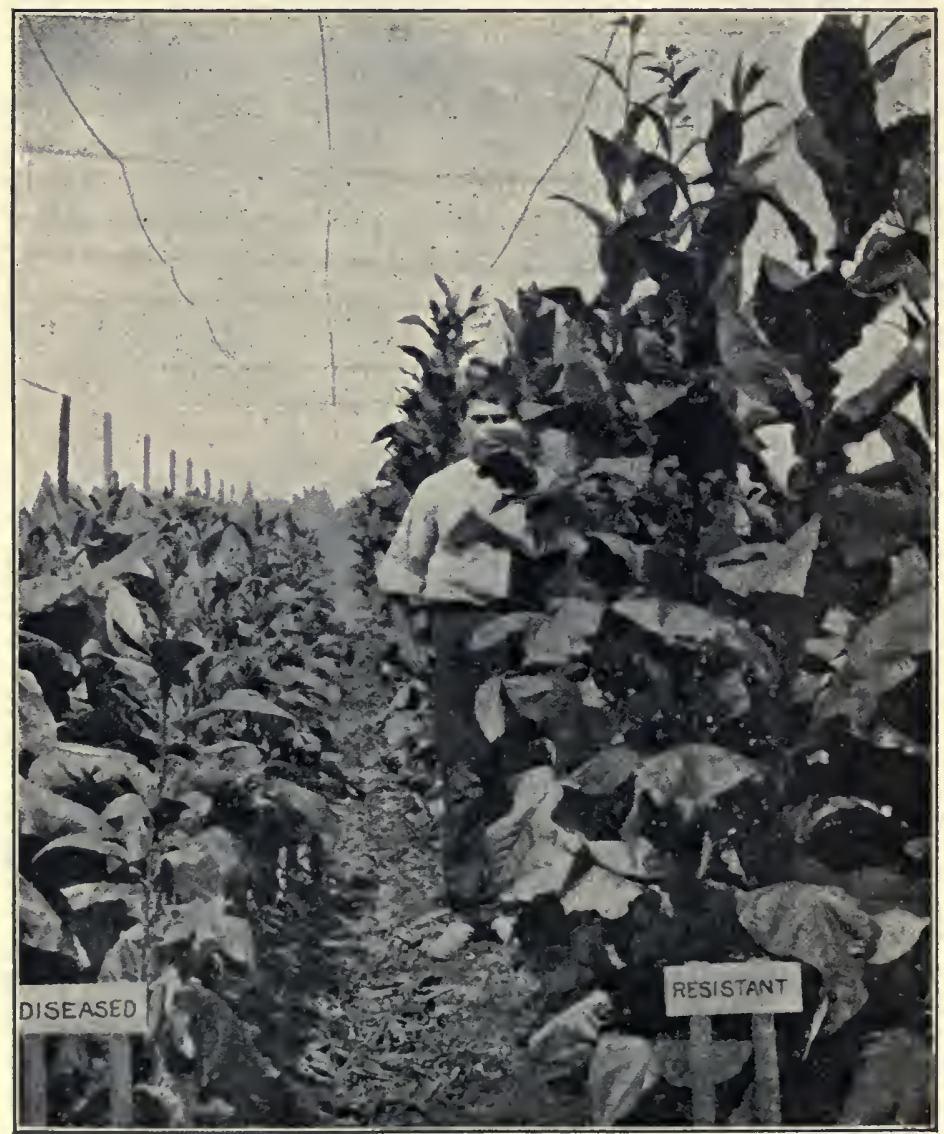

TOBACCO PLANTS FROM DISEASED AND RESISTANT STRAINS OF SEED.

attention to seed and nursery stock to be sure that certain diseases are not transmitted through them; prevention of insect injury and other wounds which open a way for infection by fungi. 


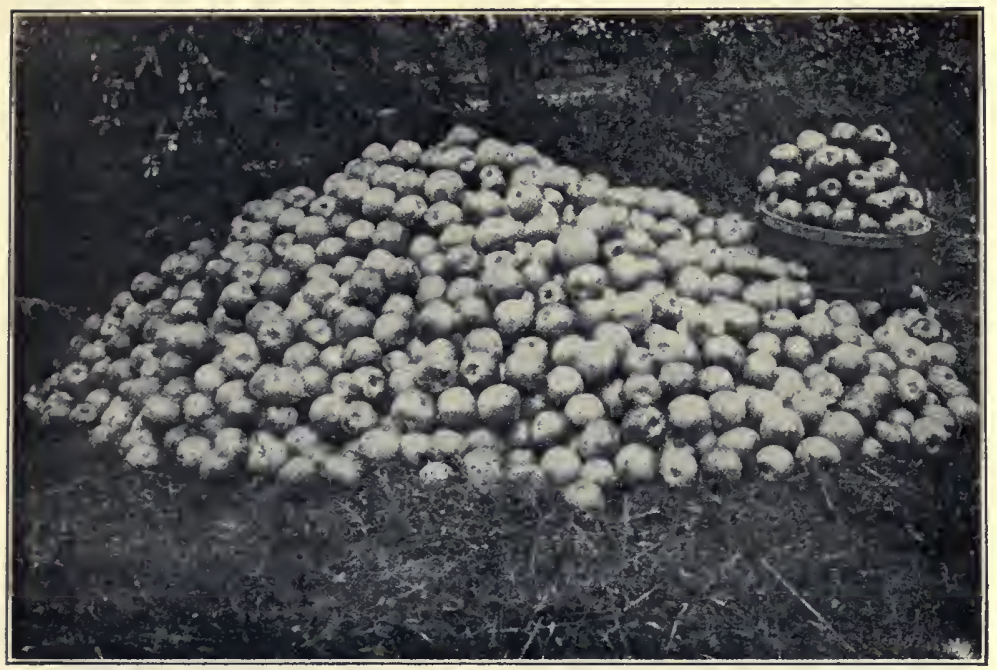

CROP FROM ONE TREE OF BEN DAVIS VARIETY, SPRAYED SIX TIMES. SOUND FRUIT IN PILE, WORMY FRUIT IN BASKET.

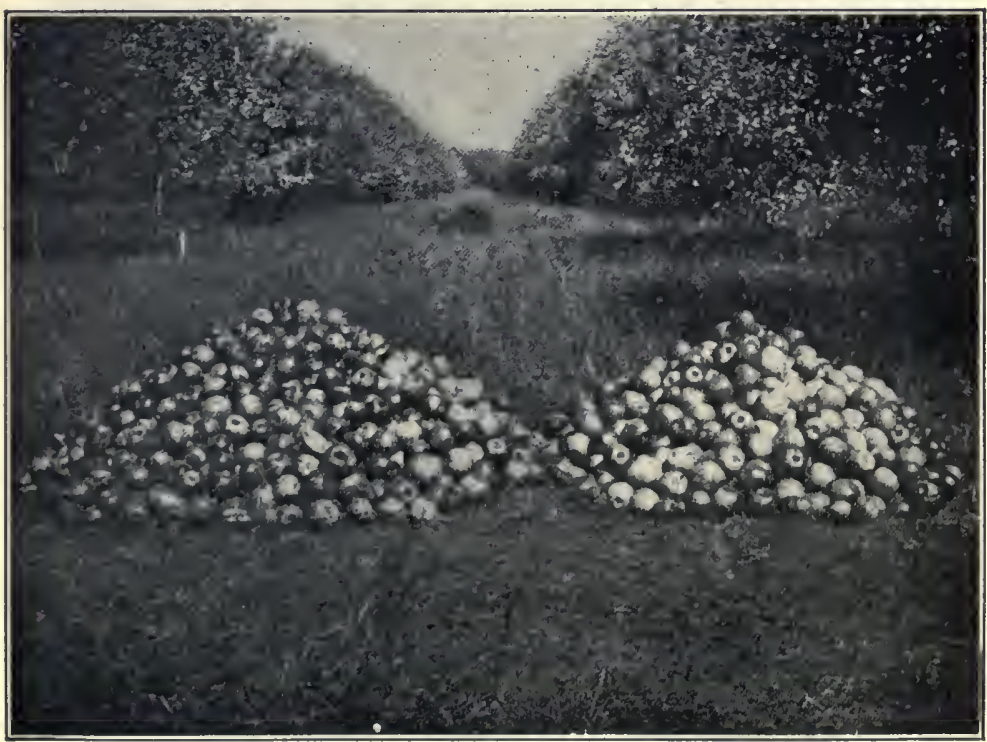

CROP FROM ADJACENT TREE, UNSPRAYED. SOUND FRUIT AT RIGHT, WORMY FRUIT AT LEFT. 
Fungicides are chemical substances which destroy the spores or mycelium of fungi. To be efficient the fungicide must destroy the fungus effectively, but must not injure the host plant; it must be reasonably cheap and easy to prepare and apply. To kill a fungus the fungicide must come in contact with it. Most parasitic fungi are buried within the bodies of their hosts and cannot be reached by an external application, and

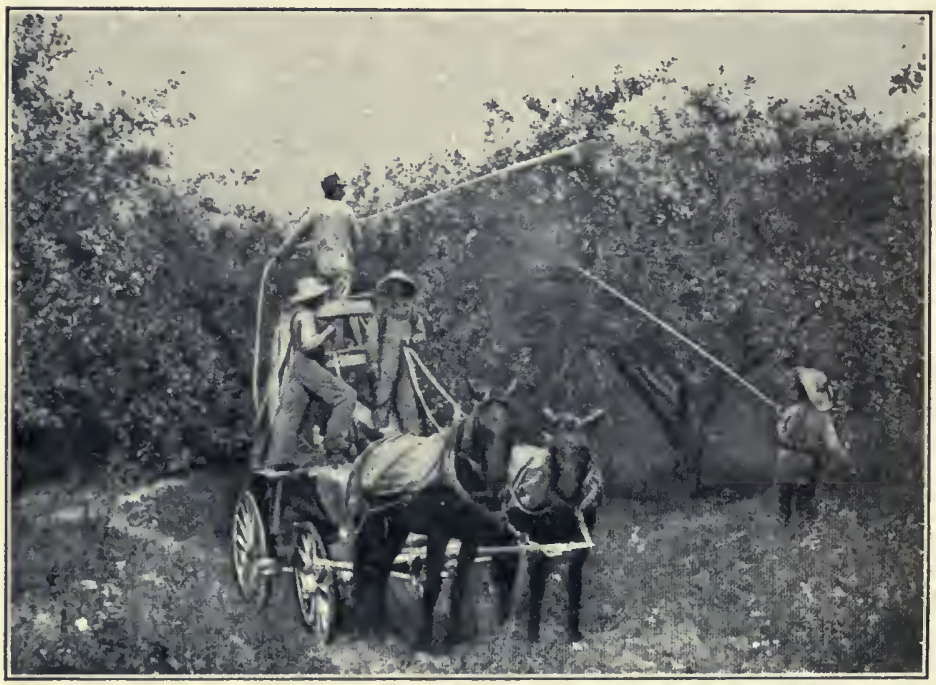

HAND-POWER TANK, USED IN SPRAYING.

hence it is seldom that fungicides can be used to effect a cure by direct destruction of the entire fungus. The usual use of fungicides is to form a protective coating over a plant to prevent spores from germinating upon its surface, and mycelium from penetrating to its interior. To be effective this covering, like a coat of armor, must be complete and constantly maintained during the period of exposure.

Spraying.-In spraying, as in all other procedures for the control of fungus diseases, success depends 
upon the timeliness and the thoroughness with which the work is done. Spraying is most profitable and successful for the diseases that infest their hosts at particular periods.

Preparation of Fungicides.-The chemical substances most often used as fungicides are copper sulphate or bluestone, sulphur, corrosive sublimate and formalin. The most generally useful fungicide is Bordeaux mixture. To prepare 50 gallons of usual strength, 5 pounds of bluestone and 5 pounds of freshly slaked stone lime are dissolved separately, each in 25 gallons of water. The two solutions are poured together while they are stirred thoroughly. The lime neutralizes the caustic action of the copper sulphate, which has a tendency to injure leaves and fruit.

Sulphur Mixtures.-Two sulphur mixtures are important. One is the boiled lime-sulphur wash, generally used against San José scale, but equally effective in destroying fungus spores. This wash is too strong to be used on any but dormant plants. Fifteen pounds of sulphur and 20 pounds of lime are required to make 50 gallons, and the mixture is boiled for an hour. Quite different in composition and use is the self-boiled lime-sulphur mixture. It requires 8 pounds of sulphur and 8 pounds of lime for 50 gallons, and it does not require boiling. The lime is slaked with cold water, and the sulphur added as the slaking begins; the heat thus developed causes as much of the sulphur as is needful to go into solution. This mixture is even safer to use on foliage and fruit than the Bordeaux mixture.

Corrosive sublimate and formalin are merely diluted with water before using. Their most important use is for disinfecting seed, soil, wounds or implements.

EXERCISE.-If any of the members of the class have ever seen fungicides made and applied, be prepared to tell the rest of the class the process and the crop or crops which were sprayed. 
Section XXXVII.-Fruit Crop Diseases.

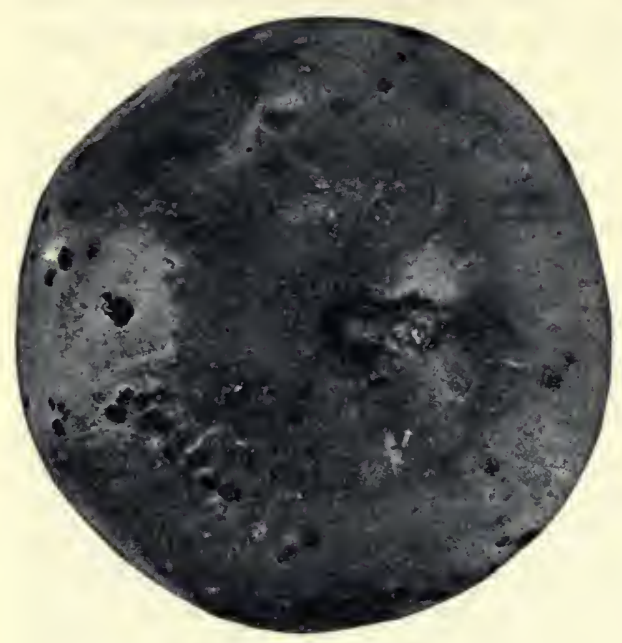

APPLE SCAB.

Apple Scab.The fungus that causes scab grows in the skin of the apple, causing the waxy portion to scurf off, and giv. ing rise finally to circular spots a quarter of an inch or more in diameter. These spots have rough, brown centers, a n d a resurrounded by a margin which is olive green. in

color, and consists of the growing fungus threads and the spores. This fungus does not rot the fruit, but it furnishes ready gateways for the entrance of other fungi which do cause rot; for this reason scabby fruit is poor in keeping quality. The scab fungus also grows, but less conspicuously, on the leaves and twigs of an infected tree; and in these, especially on fallen leaves on the ground, it remains alive over winter. Spores are carried to the young

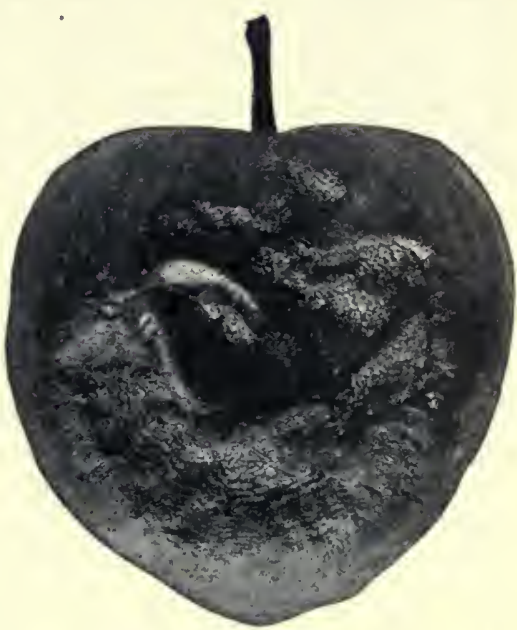

BITTER ROT OF APPLE, CAUSED BY A FUNGUS. 
leaves when the buds burst, and so finally to the forming fruit. Scab can be prevented if the young leaves and fruit are protected with a coating of a good fungicide, such as Bordeaux mixture, or commercial limesulphur wash diluted I in 30 . The first spraying should be made just before the blossoms open; the second, just as the petals fall; and the third, ten days or two weeks later.

Pear $S$ cab.-This disease is caused by a fungus much like the one causing apple scab. The spots on the pear have the appearance of sooty blotches; and when badly infected the fruit cracks. The fungus lives over winter on infected leaves or twigs. It can be controlled by three sprayings with Bordeaux mixture, just as for the apple scab.

Pear Blight.- The name fire blight is often used because of the scorched appearance of affected twigs. On these the leaves blacken and die early in the season, but do not fall. The disease is caused by bacteria. These live over from season to season in the affected larger limbs, between the bark and wood. In spring, as the sap rises, drops of milky, sticky fluid containing myriads of bacteria ooze out from cracks at the boundary between dead and sound bark. Insects readily carry these bacteria on their bodies, and so spread infection. Bacteria carried in this way to pear blossoms multiply very rapidly in the nectar, and work down through the flower stalk and fruit spur to the limb. In time they may girdle a large limb, killing it by destroying the growing tissue between the bark and wood. All affected twigs and small limbs should be cut away and destroyed; cankers on larger limbs should be cut out; large wounds should be disinfected with corrosive sublimate solution, one part in $\mathrm{I}, \mathrm{OOO}$ parts of water, and afterwards painted. Culture that induces rapid, succulent growth should be avoided. Fruit spurs should be confined to the smaller limbs, which can be removed, in case of infection, with least loss to the tree. Because of the protected position of the bacteria spraying is of little value. 
Potato Blights.-Under this term are included several different leaf troubles. Two of these are early blight and late blight. Besides these, there may be the shot-hole injury to leaves caused by flea-beetles. Spraying will protect from the blight fungi, if begun in time and thoroughly done. For early blight, it should begin when the plants are six or eight inches high, two applications of Bordeaux being given two weeks apart; these should be followed by three or four applications of Bordeaux at like intervals. A fourth trouble, more properly termed leaf-burn, is the drying out of leaflets from the tips and margins caused by lack of water. Deep plowing, addition of humus, and frequent shallow cultivation will tend to correct the conditions that induce this trouble.

Peach Leaf Curl.-Affected leaves are swollen and puckered in an irregular and characteristic way; their color becomes yellowish-green or dull red. They fall early in the season, and when a tree is severely attacked it may be practically defoliated by mid-season. Trees affected with leaf curl do not properly mature fruit during the current season; or make vigorous wood growth; or develop a full number of good fruit buds for the next season. The fungus causing this disease infects the young leaves when the buds break. It can be readily controlled by a single application of a good fungicide made in early spring just before the buds begin to swell. Either Bordeaux mixture or the lime-sulphur wash used commonly for scale insects is satisfactory.

Brown Rot.-This is the common rot which affects peaches, plums and cherries at the time of ripening, and most seriously in warm, wet weather. It is caused by a fungus, the threads of which grow rapidly inside the tissues of the fruit, and produce here and there over the surface small ash-colored tufts of spore bearing branches. The rotted fruit often remains hanging on the trees as dry shriveled mummies during the winter. The fungus threads in the dry flesh remain alive, and during the following spring may renew their growth and produce spores that infect the new crop. 
Control of Brown Rot.-Remove as far as possible the source of infection by knocking mummied fruit from the trees; by clearing the ground of rotted fruit; by spraying the trees with a good fungicide in early spring before the buds swell; and by picking decayed fruit as soon as it appears. Lessen the chances of in-

fection taking place by planting non-susceptible varieties; by pruning so as to let in light and air to all fruit-bearing branches; by thinning the young fruit; by keeping in check the curculio and other insects; and perhaps by spraying the fruit.

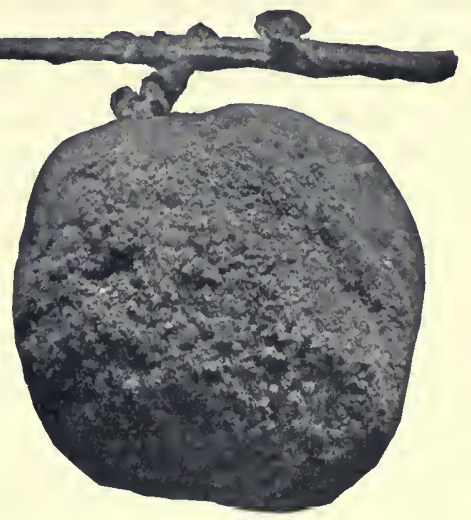

BROWN FOT OF PEACH.

Most fungicides are unsafe to use on peach and Japanese plum in foliage; but the self-boiled limesulphur wash seems to be a safe one for this purpose, and gives promise of being especially useful in the control of brown rot.

Grape Black Rot.-Affected grape berries show at first brown decayed spots; finally the berries become

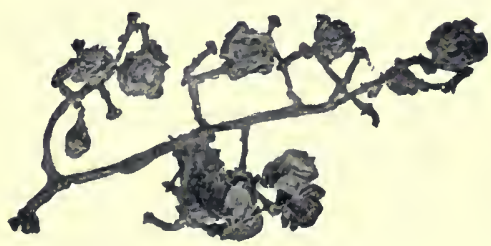

GRAPE BLACK ROT. dark and shriveled and rough with minute spore-producing pimples. The fungus also attacks leaves, tendrils, and even the canes of the grape; and these as well as the shriveled berries are sources of new infection. Lessen sources of infection for the next season by plowing under old leaves and berries. 
Keep down weeds, and trim and train the vines so as to secure the best ventilation. Spray thoroughly with Bordeaux mixture, beginning when the second or third leaf shows; apply again before the blossoms open, and a third time soon after the blossoms have fallen; two more applications at intervals of ten days or two weeks will be enough in ordinary seasons. Watch the weather closely and try to make each application a day or two before a period of rainy weather, since infection takes place at such a time.

EXERCISE.-Bring specimens of unhealthy or diseased fruits to the classroom and identify the diseases they are affected with.

\section{Section XXXVIII.-Garden Crop Diseases.}

Bean Pod Spot or Anthracnose.-The fungus produces on the pods of kidney beans spots of variable size, with reddish borders and dark brown, sunken centers. On close examination minute pinkish masses of spores may be distinguished scattered over some of

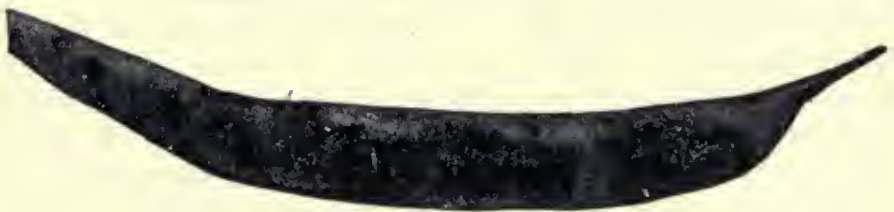

BEAN POD SPOT.

the larger spots. Seeds from badly infected pods are apt to contain mycelium, which remains dormant in the seeds and renews its growth as they germinate. It produces brown spots and spores on the seed and on leaves of plants grown from such infected seeds; these spores in turn affect the young leaves, causing their veins to become brown. In this way large numbers of spores are produced by the time the pods begin to form. When seed absolutely free from infection can be used for planting, pod spot is not likely to occur; such seed may be had from pods perfectly free from spot. Satisfactory disinfection of seed seems to be impracticable. Spraying with Bordeaux mixture helps 
in the control of the disease, especially if the first application is made when the seedlings emerge from the ground; the second when the first true leaves have expanded; and the third when the pods begin to form.

Cabbage Club Root.- This disease affects cabbage, cauliflower and turnip, as well as a number of other plants belonging to the mustard family. It is caused by the growth within the roots of a low type of fungus. The roots, large as well as small, become swollen and distorted in the peculiar way that suggests such common names as "finger and toe" and "big root" for the disease. Affected plants may wilt and die during a period of drought, because of the insufficiency of their root systems, and in any case the heads will be stunted. The organism causing the disease lives over for several years in the soil. The most important means of control is to grow only, non-susceptible crops on infected soil for about four years. A heavy dressing of lime thoroughly worked into the soil the preceding fall sometimes satisfactorily controls the disease. Extreme care must be taken not to infect clean soil by setting out plants that have become infected in the seed bed, or by transferring infected soil from any source on tools or on the roots of transplants.

Potato Scab.-This disease is caused by a threadlike fungus which grows in the skin of the potato tuber, producing irregular, rough, corky areas. The fungus lives over from year to year in the soil, and infected soil should not be planted to potatoes oftener than once in three or four years. The fungus flourishes in soil that is somewhat alkaline, and for this reason lime, wood ashes and stable manure favor the development of but do not directly cause scab. Most commercial fertilizers and green crops when plowed under reduce scab. Clean soils become contaminated by planting infected seed potatoes; these should be disinfected by soaking the uncut tubers for 2 hours in a solution of formalin, I pint in 30 gallons of water; or of corrosive sublimate, 4 ounces in 30 gallons of water. The only way to secure freedom from scab 
is to plant clean seed in clean ground; if either ground or seed is infected, the crop will be scabby; and the amount of scab will depend on the amount of original

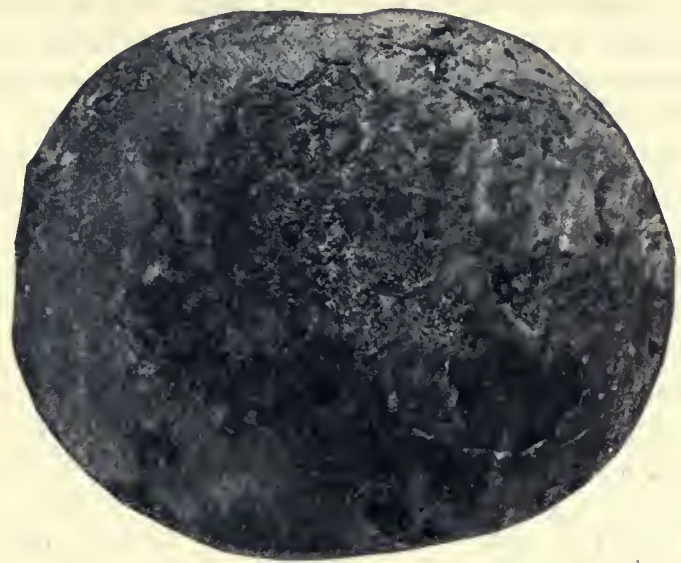

POTATO SCAB.

fungus infection and the favoring or retarding influence of the surroundings.

Bacterial Wilt of Cucumber, Melon and Squash.The first indication of this disease is the drooping of a single leaf during the day, at night it recovers, but is more wilted the next day, and is soon beyond recovery, while other leaves near by a re similarly affected. Finally the whole branch dies. This disease is caused by the growth and spread of bacteria in the sap tubes of the plant; these reduce the supply of water for parts beyond, and cause the wilting. If stem or leaf-stalk of an infected portion is cut across and pressed between the fingers, a milky, somewhat sticky fluid, containing bacteria, will exude from the sap tubes, instead of the clear watery sap. These bacteria are transferred readily from diseased to healthy leaves on the mouth parts of insects. Since they are well protected in the tissues of the plant, sprays have little or no direct effect in checking the disease, but a coating of Bor- 
deaux mixture makes the plants distasteful to the cucumber beetle and other carriers of the disease, and for this reason has a good effect in controlling its spread. Affected portions of vines should be promptly removed and destroyed.

Exercise.-If possible find some garden vegetables that do not look healthy and try to identify the disease they are troubled with. What would you do to previent these diseases?

\section{Section XXXiX.-Field Crop Diseases.}

Grain Smuts.-According to the mode of infection, smut diseases of grain crops fall into three classes, of which loose smut of oats, loose smut of wheat and corn smut are common examples.

Loose Smut of Oats is conspicuous because the grains are converted into masses of dark, dust-like spores of the fungus. These are shed as the grain ripens, or during harvesting and thrashing; so that seed oats become well dusted with them. When seed with smut spores adhering are planted, the spores germinate as the seeds sprout and the fungus enters the tissues of the tiny seedling oat plant before it appears above ground. Infection does not take place at any later time; but the fungus already in the plant grows upward with it, always hidden, until the plant heads out, and conditions are suitable for spore formation.

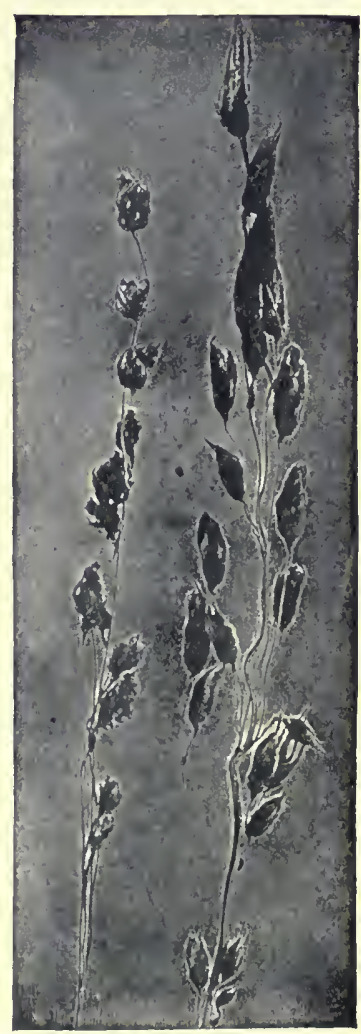

SMUT OF GRAIN. 
Loose Smut of Wheat affects the heads in the same way as the loose smut of oats. Its spores are shed earlier, however, and at harvest time only the stems of smutted heads remain. Some of the spores are carried by the wind to the later opening flowers, and the fungus enters the forming grains. These grains ripen normally, the mycelium becoming dormant. When they sprout, the mycelium begins to grow with the seedling wheat, and follows upward in the growing tip without giving evidence of its presence until spores are formed in the head.

The Corn Smut differs from the loose smut of oats and of wheat in being able to infect any soft tissue of its host, in never spreading far from the point of infection, and in maturing its spores a few days after infection. These spores may germinate at once, and spread infection through the field; or they may remain alive over winter, and start new infection the next season. The swollen spore masses occur on all aboveground parts of corn.

How to Control Smuts.-When infection takes place only in the seedling stage from spores adhering to the grains, smut can readily be controlled by disinfecting the seed. Formalin is most frequently used in a strength of one pint to forty gallons of water. The seed may be sprinkled in a pile if shoveled over so that every grain becomes thoroughly wet. The pile must be covered with wet cloths for two hours to prevent evaporation of the formalin. Besides loose smut of oats, stinking smut of wheat or bunt, covered smut of bárley, and grain smut of sorghum can be successfully controlled by seed treatment.

'How to' Avoid Smut.-When infection takes place at the time of flowering, and the mycelium is dormant inside the seed, disinfection is unsatisfactory. To reach effectively and destroy the mycelium severe treatment is required, and the grain is injured for seeding purposes. The only way of avoiding smut in such cases is to secure seed from a smut-free locality, or 
from a special seed plot, away from the general crop, from _which smutted heads are carefully removed as soon as they appear. Such a seed plot would also be useful for improving the quality of grain by selection. Loose smut of wheat and loose smut of barley can be controlled in this way.

Corn Smut stands alone in its class. Its continued spread during the season can be controlled by the prompt removal and destruction of the first smut masses before the spores are shed. Heavy dressings of barnyard manure on corn land tend to increase the amount of smut.

Grain Rusts.-The rust fungi attack leaves and stems of cereals. Orange-colored summer spores are quickly formed in elongated granular pustules. They spread the disease rapidly from plant to plant. Later dark brown winter spores are produced; these may carry the fungus over winter; but often the rusts live through the winter as mycelium in the leaves of fall planted grain crops or of protected wild grasses. While the rusts cause enormous loss each year, no satisfactory method of control is known. It is hoped that the problem will be solved by breeding varieties resistant to rust. Such are the so-called rust-proof varieties of oats planted in the South; but unfortunately these varieties are not satisfactory in the North. Since rust becomes worse from week to week as the crop matures, the amount of loss can be reduced by hastening maturity. Low, moist situations should be avoided, as well as rank growth, such as results from too much nitrogenous manure.

Cotton Wilt, Black Rot or Black.Heart.-The leaves of affected plants, sometimes of a single branch, wilt or turn yellow and fall off while nearby plants remain normal. The effects are most marked after the cotton is in bloom. The disease is due to a fungus which lives in the soil and enters the roots of cotton, growing upward in the water vessels of the wood of root and stem, clogging them and producing a charac- 


\section{$25^{8}$ FUNDAMENTALS OF AGRICULTURE.}

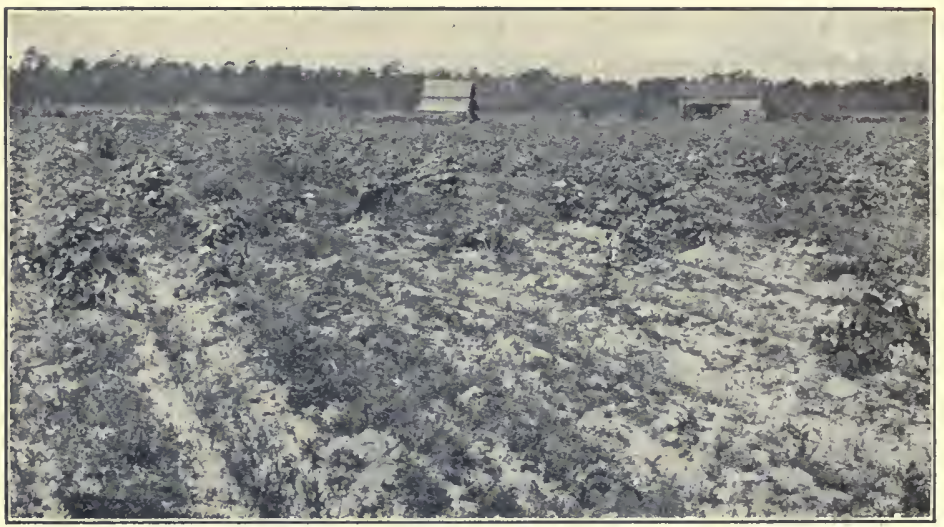

A FIELD OF COTTON DESTROYED BY WILT.

teristic brown discoloration. The disease is more prevalent in sandy or sandy loam soils, and spreads from year to year as long as cotton is grown. The cotton wilt fungus attacks only cotton and okra; and the similar wilt of cowpeas, of watermelons, of tomatoes, and of some other plants is due in each case to a different fungus. On land infested with cotton wilt a long rotation which brings in cotton once in four or

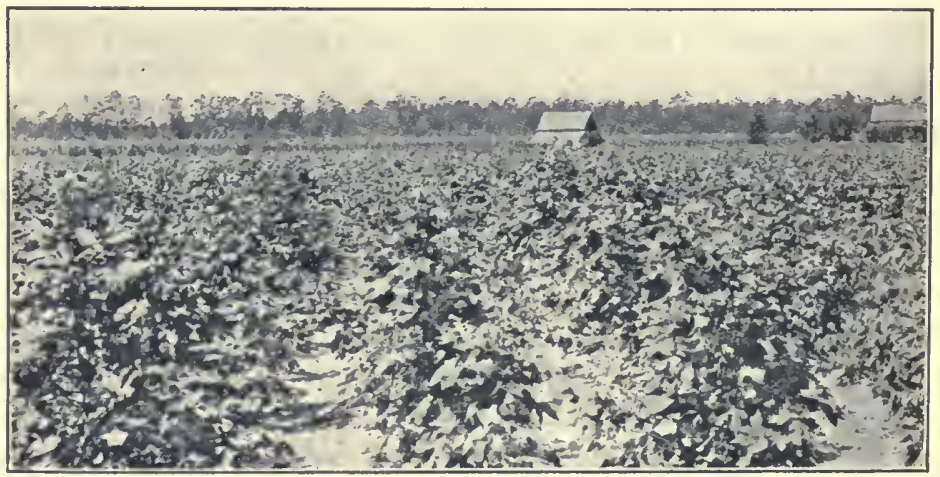

THE SAME FIELD PI.ANTED WITH A DILLON VARIETY, BRED BY THE U. S. DEPARTMENT OF AGRICULTURE TO RESIST THE WILT. 
five years will greatly reduce the trouble. Old stalks should be removed from the field at the end of the season. Varieties of cotton show a marked difference in natural susceptibility to the disease, and by selection the resistance can be increased. A satisfactory degree of resistance has thus been developed in several varieties.

Cotton Black Rust.-This disease is caused primarily by unfavorable soil conditions and not by any parasitic fungus. Affected plants have a yellowish appearance, the leaves drop off, the later formed bolls open poorly, and the lint yield is inferior in quantity and quality. All plants in a particular area show these effects. Rust occurs on thin soils from which the humus has been exhausted by continued cultivation of cotton, in soils that are deficient in potash, and in soils that lack drainage either because of their low situation, or because of their poor physical condition. The remedy for black rust is soil improvement. Humus can be restored and its physical condition improved by fertilizing with stable manure, or by adopting a rotation that will bring in a leguminous crop that may be plowed under. Drainage of low places will be necessary. A deficiency in potash can be met by applying a proper commercial fertilizer.

Shedding of Cotton Bolls and Squares.-Shedding is a physiological disease which occurs generally when there is a sudden check after a period of rapid growth, as when a season of showery weather is followed by dry, hot days. It is an adjustment to the new, less favorable conditions. The plant is not able to develop all of the fruitage begun under the more favorable conditions; and it eliminates the excess of bolls by shedding, giving the remaining ones a better chance to mature perfectly. Since the shedding depends so largely on weather conditions, little can be done to prevent it except to adopt such cultural practices as will tend to make the growth of the crop uniform. Cultivation 


\section{for the conservation of moisture is the most important of these.}

EXERCISE.-Try to find some field crops affected with disease. Bring specimens to school and be prepared to tell your teacher the diseases and how to prevent them.

\section{REFERENCES FOR COLLATERAL READING.}

Plant Diseases:

Yearbooks of the U. S. Dept. of Agriculture:

I $900-$ Fungus diseases of forest trees.

Igo8-The development of farm crops resistant to disease.

Farmers' Bulletins, Nos. :

9I-Potato diseases and treatment.

23I-Spraying for cucumber and melon diseases.

243-Fungicides and their uses in preventing diseases of fruits.

244-Fumigation for nursery stock.

250-The prevention of wheat smut and loose smut of oats. 267-Apple bitter rot.

284-Insect and fungus diseases of the grape east of the Rocky Mountains.

3I6-Potato scab.

333 - Cotton wilt.

Experiment Station Bulletins, Nos. :

54-Illinois-Spraying apple trees with special reference to apple scab fungus.

69-Illinois-Apple rots in Illinois.

9I-Florida-Tomato diseases.

I2I-Ohio-Diseases of cultivated plants.

239-N. Y.-Cornell-Some diseases of beans.

252-N. Y.-Cornell-Insect pests and plant diseases.

Books : I903-Connecticut-Annual report of the botanist.

Fungus Diseases of Plants-Duggar-Ginn \& Co., Boston.

The Spraying of Plants-Lodeman-Macmillan Co., New York City.

Minnesota Plant Diseases-Freeman.

Diseases of Plants-Tubeuf \& Smith-Longmans, Green \& Co., New York City. 


\section{CHAPTER VII.}

\section{INSECTS AND BIRDS.}

\section{Séction XL.-What an Insect Is.}

By Prof. Glenn W. Herrick.

Department of Entomology, Cornell University.

What an Insect Is.-Many people call any small, active animal a bug. This is wrong. An insect is an animal that has six legs, three distinct divisions of the body, head, thorax and abdomen, and usually one or two pairs of wings. A spider has eight legs, and is,

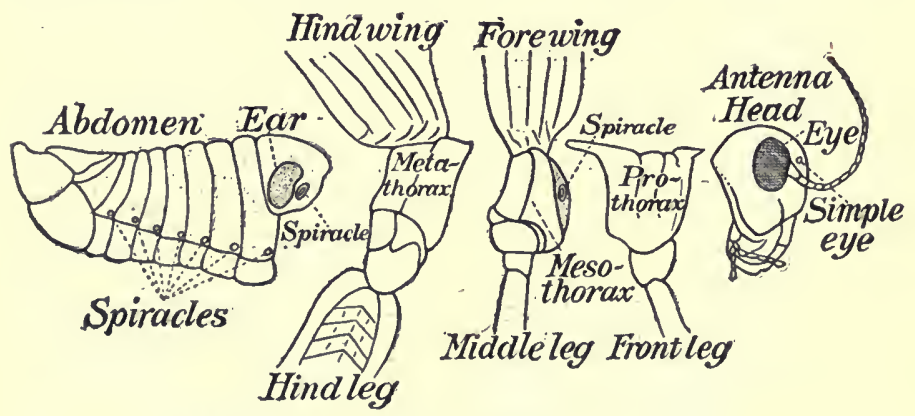

PARTS OF AN INSECT (HERRICK'S ZOÖLOGY).

therefore, not an insect. Worms have no legs at all and cannot be called insects. Familiar examples of insects are grasshoppers, butterflies, moths, mosquitoes, etc. Moreover, not all insects should be called bugs. It is not right to call butterflies, bees, mosquitoes and grasshoppers, bugs. There is a large group of insects that have sucking mouth parts which have unpleasant odors that we may rightly call bugs. The stink-bugs, 
squash-bugs and harlequin cabbage-bugs are good examples.

How Insects Move.-The grasshopper has three ways of moving. It has four strong wings attached to the thorax with which it can fly. On the other hand a house-fly has only two wings. But whether an insect has two or four wings they are always attached to the thorax. The grasshopper also has six long' legs with which it can walk, only slowly, however. House-flies can walk quite fast. Many beetles, cockroaches, and some other insects can run very fast with their six legs. Finally the grasshopper, with its very large, long and strong hind legs can leap, or hop considerable distances. Fleas, some beetles, and certain other insects, can also hop. The majority of insects, however, have only two methods of movement, flying and walking.

It must be noted that not all insects have wings. Many ants, a few moths, bedbugs, fleas, some beetles, and certain other insects have no wings and can only move by means of their legs.

How Insects See.-Insects have two, large, compound eyes, one on each side of the head, like the grass-
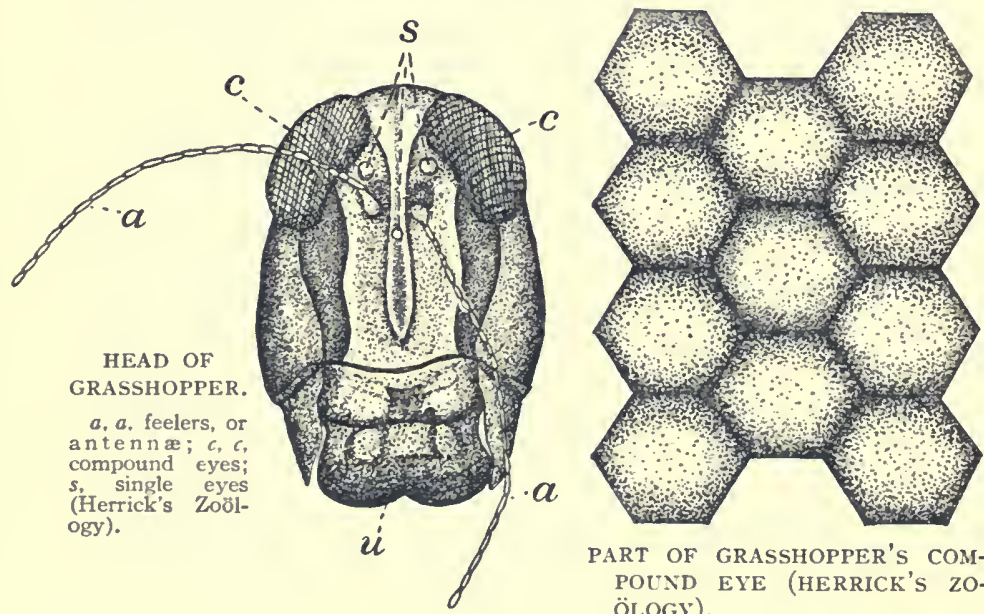

PART OF GRASSHOPPER'S COMPOUND EYE (HERRICK'S ZOÖLOGY). 
hopper. If we could examine these eyes with a strong magnifying glass we would find them made up of many, perhaps 200 or 300 , six-sided divisions much like a honey-comb. These compound eyes in a dragonfly are so large that they nearly cover the front of the head. In addition to the compound eyes, many insects have one or perhaps three or four single eyes. The grasshopper has three.

How Insects Feel.-An insect can feel the touch of a pencil point, for example, anywhere on the body, for its body is well supplied with nerves. But on the head

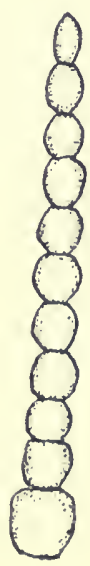

1

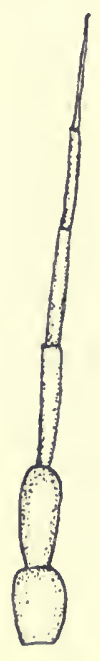

2

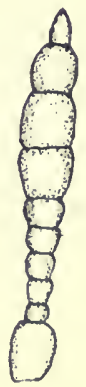

3

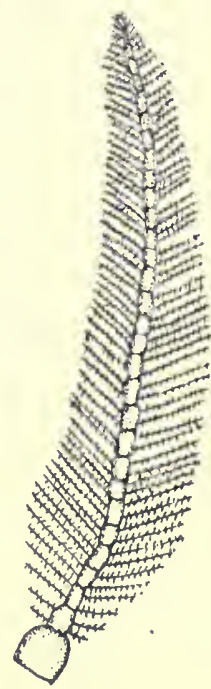

4

DIFFERENT KINDS OF ANTENNA.

I, bead-like; 2, bristle-like; 3, club-shaped; 4, feather-like.

of a grasshopper are two long, slender feelers, or antennx. 'These are' the special organs of feeling. They are made up of short ring-like divisions called segments. Every insect has two of these antennæ. The antennæ of some insects are short and club-shaped, 
others are long and threadlike, others are like a feather, others are like a string of beads, while others are of various shapes.

How Insects Breathe.- Strange to say an insect has no nose, and does not breathe through its mouth at

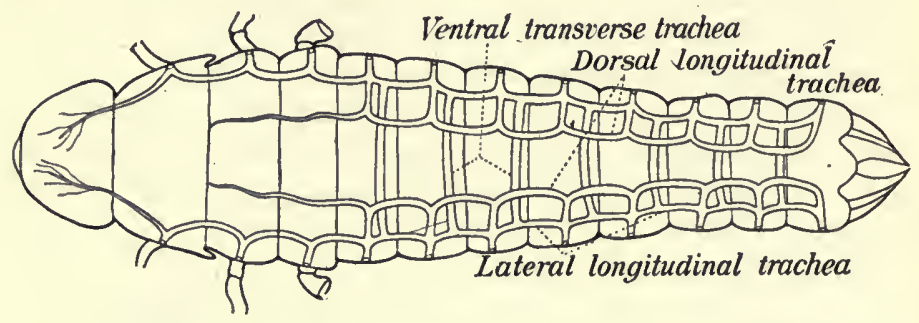

BREATHING TUBES OF GRASSHOPPER (HERRICK'S ZOÖLOGY).

all. The air enters an insect's body through holes along the sides of the abdomen and thorax, and passes into a system of tiny tubes that run all through the body, similar to the blood vessels of a higher animal. These tubes divide and subdivide into smaller and smaller branches that reach every part of the body, even entering the legs and wings to some extent.

How Insects Grow.-The mother grasshopper, in the fall, makes a hole, with the end of her abdomen, in the ground, and in this lays her eggs, several dozen, in a sort of capsule or pod, where they remain until the following spring, when they hatch and the young grasshoppers appear. The young as soon as they come from the egg may be recognized as grasshoppers. They are called nymphs. They eat greedily and grow very fast, becoming full-grown in about two months. During this time they molt or shed their skins several times. The skin of a young grasshopper gets hard and soon becomes too small, because it will not stretch, and has to be shed for a new and larger skin. Every shedding of the skin represents a step in the growth and size of the young grasshopper. After the first molt or two the wings appear as small backward-pro- 


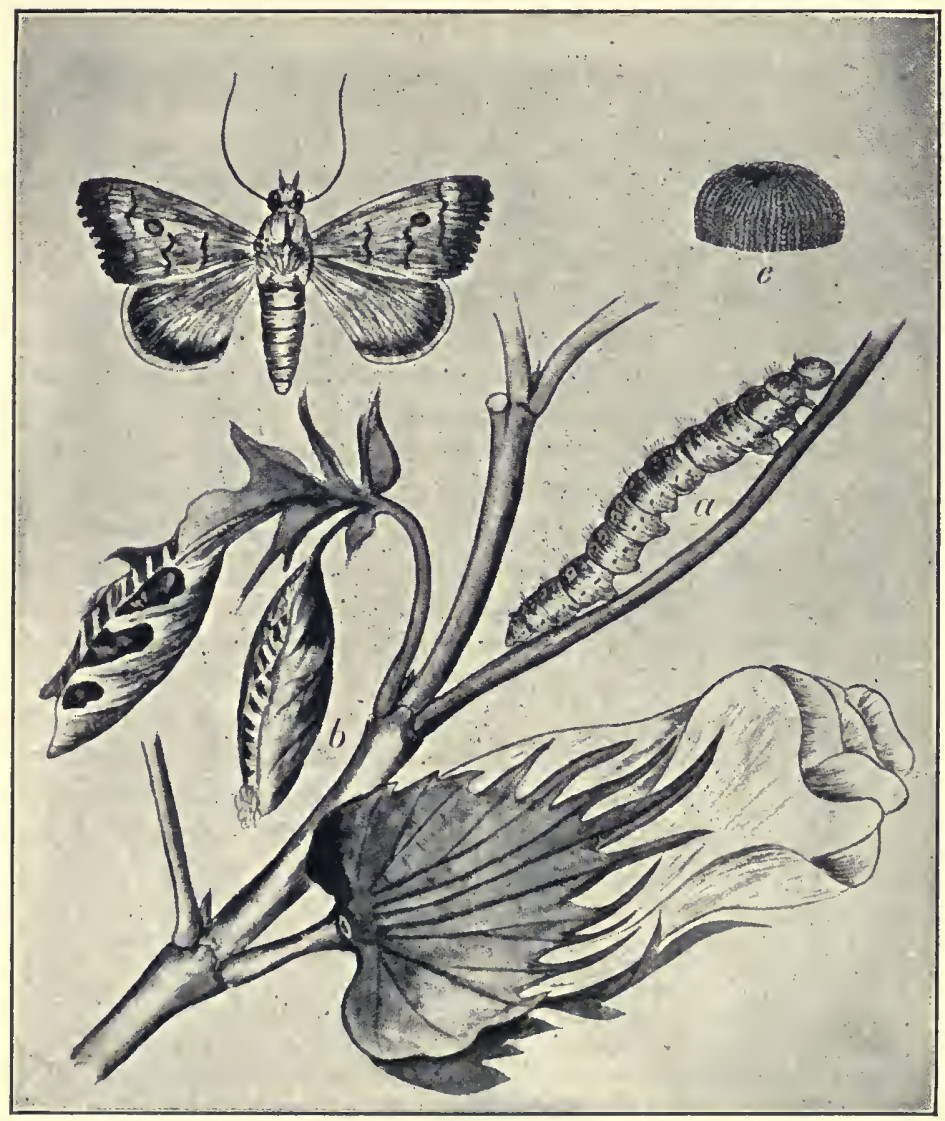

STALK OF COTTON.

Showing the egg (e), larva (a), pupa $(b)$, and adult of the cotton-leaf worm moth (Herrick's Zoölogy).

jecting pads. With each successive molt the wing-pads become larger and larger until after the last molt they appear fully developed. This is the way in which a grasshopper and many other insects like cockroaches, dragon-flies, bedbugs, etc., grow. A moth, butterfly, mosquito, house-fly, beetle, honey-bee, ant, and many other insects grow very differently from this. 
The moth of the cotton-leaf worm, for example, lays her tiny, light green eggs on the leaves of the cotton plant, where they remain for four or five days. At the end of this time each egg hatches into a tiny caterpillar, or larva, as it is more properly called. The larva lives, at first, on the under sides of the leaves and eats only the under side of the leaf. It grows rapidly, however, and, like the young grasshopper, sheds its skin several times, getting larger and larger with every new skin. Finally, after fifteen to twenty days, the larvæ become full grown, and then each one rolls the edge of a leaf, and inside of this spins a thin covering of silken threads. The covering of silk and leaf is called a cocoon. The larva, inside of the cocoon, soon changes to an object known as a pupa. The pupa lies quiet within its cocoon, eats nothing, and, after some days, its skin splits open along the back of the thorax, and the full-grown moth crawls out, dries her wings, and flies away. This moth does not grow any more. Neither do little flies, beetles, bees, or butterflies grow into large flies, beetles, bees, or butterflies. After an insect once gets fully developed wings it does not grow any more.

Exercise.-Catch a grasshopper, house-fly, and squash-bug, and count their legs. Find a common house spider and see if it has six or more legs. Observe the body of a grasshopper carefully, and see how many parts to the body. What are these parts called?

Find out how many wings a grasshopper and a fly have. Catch some ants and see how many wings they have. Examine the eyes and antennæ of a grasshopper with a hand lens. Catch a dragon-fly and look at its large eyes. Notice the black jaws of the grasshopper. Put it in a glass jar or a lantern globe with thin muslin tied over the top and watch its movements. Perhaps the grasshopper could be induced to eat some fresh grass blades.

Bring in some harlequin cabbage-bugs and put them on a small mustard plant in a pot. Put a lantern globe, with thin muslin tied over the top, over the plant and watch the bugs lay their eggs and when the eggs hatch watch the young bugs grow from day to day. Try to watch the life history of some potato beetles in the same way, using potato plants instead of mustard. 
Section XLI.-Insect Friends of the Farmer.

Fortunately, not all insects are pests of the farm. Many of these small animals are among our best friends. The honey-bee is of great and direct use to us, because it furnishes us with honey, a delicious and important article of food. The bodies of certain scale insects are dried and then pulverized to form the coloring matter, cochineal. Certain other scale insects secrete a kind of wax from which sheblac is made, and which is used so much in finishing furniture. We should not forget, either, that bees are especially useful in cross-fertilizing many of our fruits and certain of our forage plants, notably red clover. Perhaps the most notable example of the value of insects in the cross-fertilization of fruits is shown in connection with the fig in California. A tiny fly brought over from Europe now cross-fertilizes the wild and cultivated figs in California. As a result, the cultivated figs have become so much better in quality that they are pronounced by experts as good as the fig we get from Europe, if not better.

Insect Cannibals.-There is a group of small handsome, roundish beetles with red bodies specked with
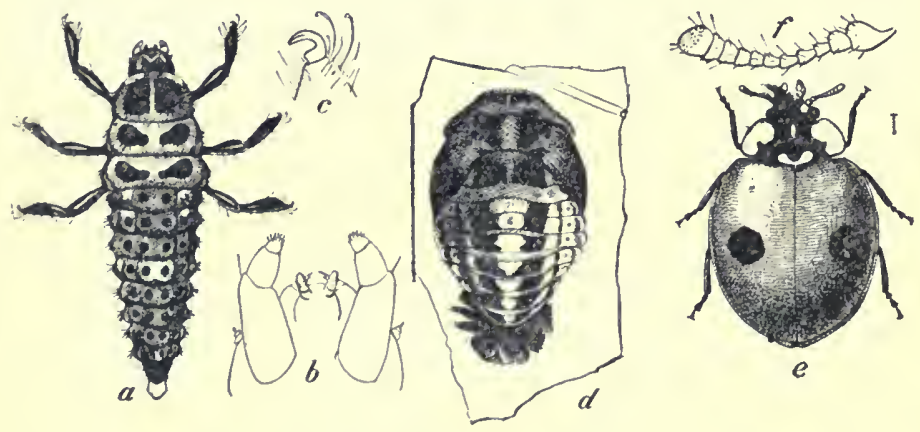

TWO-SPOTTED LADY-BIRD.

a. larva; d, pupa; e, adult. (From Bureau of Entomology, U. S. Department of Agriculture.) 
black or black bodies specked with red, known as ladybirds, lady-beetles, or lady-bugs, that belie in every

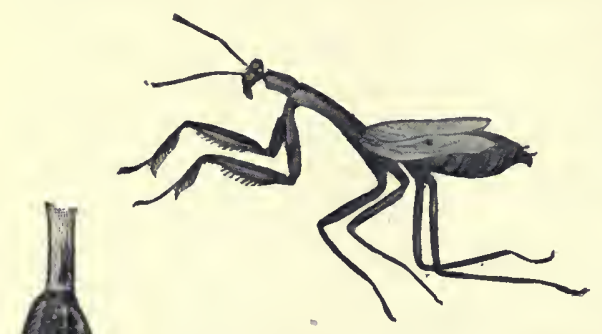

THE MANTIS, OR DEVIL'S HORSE, AND CLUSTER OF EGGS (HERRICK's ZOÖLOGY).

particular their appearance a $\mathrm{d}$ name, for they are truly nothing but cannibals. Yet, since they eat only insects, and especially those that do us the most harm, we should learn to know them and protect them. Both the lady-birds and their young, the larvæ, eat plant lice and scale insects, and are of the greatest aid to us in keeping these pests in check.

The mantis, or devil's horse, also lives upon other insects, and is one of our best friends. The gray egg

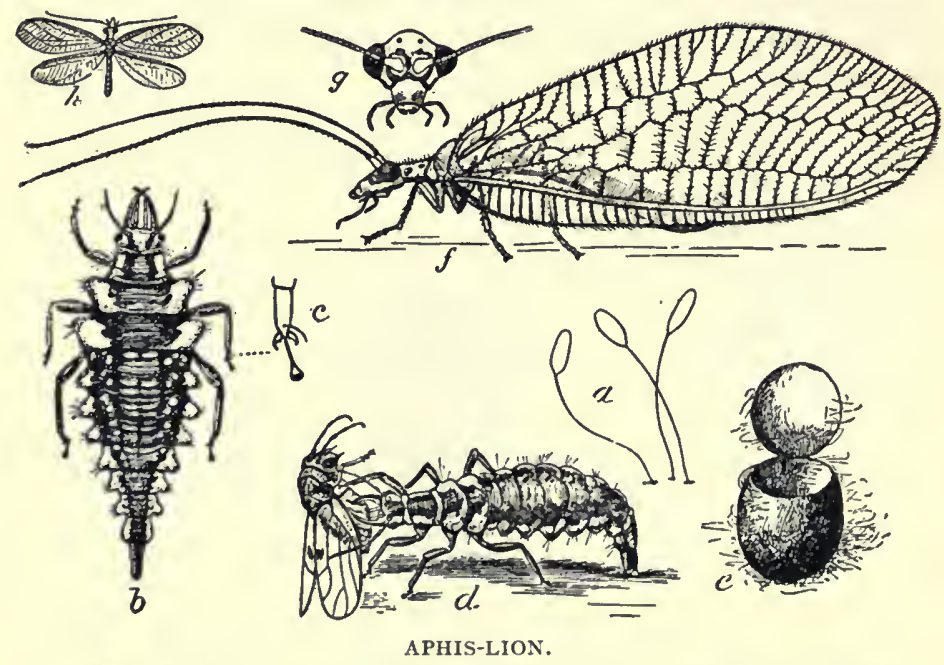

$a$, eggs; $b$, larva; $d$, larva eating a plant louse; $f$, adult enlarged; $h$, adult natural size. (From Bureau of Entomology, U. S. Department of Agriculture.) 
masses of the mantis which are often seen on bushes, fences, etc., should not be destroyed, nor the mantis itself. Those delicate insects known as lace-winged flies also aid greatly, for the larvæ of these insects live upon plant lice whenever these pests can be found.

There are many other cannibal insects that devour hordes of pests that would cause great damage if left alive.

Insect Parasites.-There is another class of insects

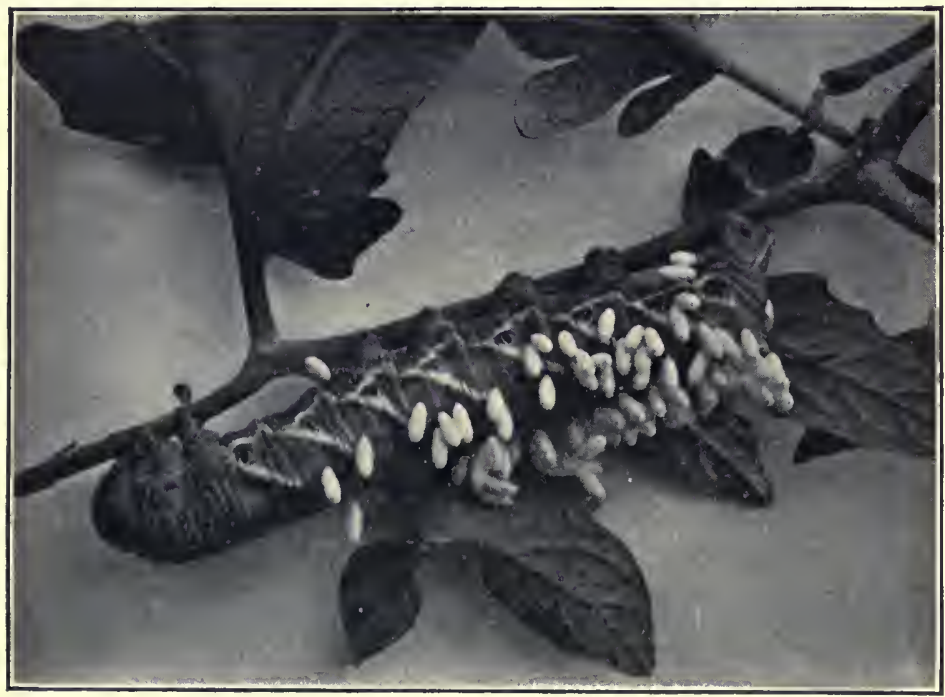

A tomato CATERPILlar, COVERED WITH THE COCOONS OF A PARASITE THAT HAS KILLED IT.

(Pholograph by $M$. V. Slingerland.)

that can be considered the greatest friends of all. These are the ones that actually lay their eggs, either in or upon the bodies of other insects, where they hatch and the young larvæ feed upon the bodies of their hosts finally causing the death of the latter. These are known as parasites.

Caterpillars are sometimes found upon grape or tomato vines with their backs covered all over with tiny 
white objects which many people think are the eggs of the caterpillars themselves. Really, these are the cocoons of a parasitic insect, the larvæ of which have

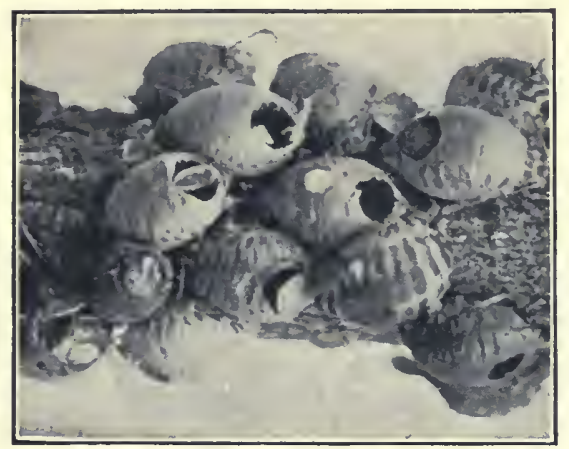

PLANT LICE, SHOWING HOLES CUT IN THEIR BACKS BY PARASITES THAT HAVE KILLED THEM.

(Pholograph by M. V. Slingerland.) actually lived within the body of the caterpillar and weakened it so that it finally dies. It is easy to see how such parasites help the grape and tomato grower.

Again, where green plant lice become abundant on cabbage or on grain they may be found sooner or later, a large part of them dead with their bodies greatly swollen and with a circular hole cut in their backs. These lice have been killed by a tiny wasp-like insect that laid its eggs within the body of the plant louse. When the egg hatched, the small larva lived within the body of its host, and finally when the parasite became full grown it cut a hole in the back of the louse, and came out ready to attack other lice. The so-called green-bug that injures the wheat in Texas in some years is subject to tremendous attacks by just such a parasite. In fact, during seasons when the green-bug is not numerous enough to cause trouble it is certain that these little bugs have been at work killing it.

These are only a few instances of the manner in which the farmer is helped by his friends, the insect parasites. If it were not for these various kinds of parasites working all the time, and in places that we know nothing about, our farm and garden crops and fruits would be destroyed much more than they are.

EXERCISE-Look on peach and plum trees and various weeds, 
wherever plant lice are present, and see if some lady-birds cannot be found. The little red, two-spotted lady-bird has a red body with a black spot on each side of the back. She is not as large as the head of a lead pencil. Other lady-birds with red bodies and black spots will also be found. The young larvæ of these lady-birds, which have long, spindle-shaped bodies, will also be found near, feeding upon the plant lice. Watch them and see how they kill the plant lice.

Search cabbage leaves or leaves of oat plants or other plants for green lice and see if any can be found with round holes in their backs. Such lice can nearly always be found on cabbage leaves. Not all of them will have the holes in their backs, but many of them will be found with their bodies round and apparently greatly swollen. These will probably have the little parasites still inside of their bodies. If such lice are brought into the room on a piece of leai and placed under a lamp chimney with a piece of muslin over the top, the tiny, dark-colored, flylike parasites will soon cut holes through the backs of the lice and come out in the chimney. This would be very interesting to watch.

\section{Section XliI.-Insect Enemies of the Farmer.}

"A tremendous shower of grasshoppers came from the South completely filling the air as high as one could see, and looking like a driving snow-storm." "They almost darken the sun in their flight, and eat everything green in their path." "Imagine every green thing on the face of the earth eaten entirely up, the meadows and bluegrass pastures as bare of vegetation as the center of a state road that is traveled a great deal, and you can probably form some idea of our conditions at this time." These are extracts from letters that the farmers of western Missouri wrote in 1874 about the hordes of grasshoppers that overran some of the western states in that year. It is said that these locusts caused a loss to Kansas, Missouri, Nebraska and Iowa in 1874 of $\$ 40,000,000$. In some portions of these states the people faced a famine.

The cotton boll weevil destroys millions of dollars' worth of cotton every year. The chinch-bug on wheat and corn, the boll worm on cotton and corn, and the weevils in stored corn, wheat and other grains cause a loss to the farmers of this country of many millions of dollars annually. It is estimated that insects cause 
more loss to the farmers of the United States every year than it costs to maintain all the public and private schools, colleges and universities of this whole country.

The Two Great Groups of Insect Pests.-There are many kinds of insects that pester the farmer and fruit grower. All of them taken together, may be divided into two great groups dependent upon the kind of mouth parts they have, and the manner in which they attack plants. The insects of one group have jaws, and bite off bits of plants and swallow them. These are known as the biting insects. The members of the other group have a beak or sucking tube which they insert into the tissues of plants and suck out the juices. These are called the sucking insects.

Insects that Bite.-The grasshopper is a familiar example of the biting insects. It has biting mouth
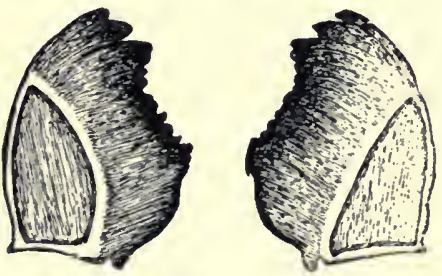

THE JAWS OF A GRASSHOPPER. parts composed of two pairs of jaws, one of which is hard and black and easily seen with the unaided eye. With these jaws the grasshopper bites off pieces of leaves, stems, etc., and swallows them much as a cow or horse does. Many insects have biting mouth parts and eat parts of plants; for example, the caterpillar, or "worms" on cotton, tomatoes, cabbage, etc., June-bugs, fig-eaters, potatobugs, and many others. All such insects are known as biting insects.

How to Fight the Biting Insects.-It is plain that an insect that bites pieces of leaves and swallows them stands a fair chance of being killed if some poisonous substance is placed upon the leaves before they are eaten. After one determines that the pest causing the trouble is a biting insect, it is necessary to decide what poison is best to use and how and when to apply it.

Pure Paris green at the rate of one pound to about 
two hundred gallons of water sprayed on plants in the form of a fine mist is a standard remedy for biting insects. Two to five pounds of arsenate of lead to fifty gallons of water applied in the same way is an even better poison.

Insects that Suck the Plant.-The squash-bug and the harelquin cabbage-bug are examples of the sucking insects. If a large squashbug is examined, there is found projecting from the under side of its head, a long, slender beak or bill. 'The same kind of a beak may be found on the head of the cabbage-bug, or a stink-bug. This little beak forms a tube which is forced into the leaf or stem and serves as a pipe through which to draw the sap into the mouth.

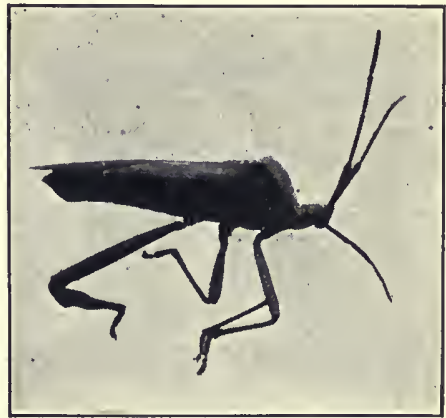

A SUCKING BUG, SHOWING BEAK. (Photograph by Glenn W. Herrick.)

How to Fight the Sucking Insects.-Since these insects draw their food from the inside of the plant it it is evident that no amount of poison placed on the leaves would kill them. The insects would get none of the poison. Such insects must be killed by putting something like oil, tobacco water, soap, or sulphur on their bodies. This is called the contact method.

A favorite way of killing these insects is to dissolve I pound of laundry soap in 2 gallons of hot water, and add 4 gallons of kerosene oil. The mixture is then churned or agitated until it forms a creamy white emulsion which is then diluted with about forty gallons of water. This is known as kerosene emulsion, and is sprayed upon the insects to be killed wherever they may be found upon the plants. Another method is to spray the insects with tobacco water made by boiling tobacco stems in water and diluting the infusion to 2 gallons of water for every pound of stems used. 
Importance of Knowing the Kind of Insect Causing the Trouble.- It is absolutely necessary to know what kind of insect is causing the trouble, whether it is a biting or a sucking one. So this is the first point to determine. If the pest is a biting one, then some kind of poison sprayed upon the plant will usually be the best remedy. If the pest is a sucking one, then something must be used that will kill by contact.

EXERCISE.-Catch some grasshoppers and kill them by putting a little chloroform along the sides of the body. Examine the mouth of a grasshopper and find the two, hard, black jaws. Catch some June-bugs and some potato beetles and see if these insects do not have similar jaws.

Find a squash-bug or harlequin cabbage-bug, and look on the under side of the head and thorax for the long, slender beak. Examine other bugs for this beak.

\section{Section XliII.-The Boll Weevil.}

By Prof. Wilmon Newell,

Texas State Entomologist.

The boll weevil is the greatest enemy of the cotton crop, for it rarely destroys less than one-third of the cotton crop in fields where it occurs. Frequently the damage amounts to one-half or three-fourths of the crop, and sometimes all is destroyed.

History of the Insect.- - Like many other of our most injurious insects the boll weevil has come to us from another country, for it is a native of Central America and Cuba, where its ancestors have lived for centuries, subsisting upon the wild "tree cotton" which grows in the tropics. Cotton culture in Mexico and Central America was not important until after the perfection of the cotton gin, but gradually large areas were devoted with profit to the production of the staple. When cultivated cotton was first grown in localities where the boll weevils existed, these insects found that the tender squares were far preferable to those of the wild cotton, and they quickly adapted themselves to the cultivated 
plants. Gradually the pest spread from its native territory to various parts of Mexico.

Invasion of the Cotton Belt.-By the year I 892 the boll weevil had reached the mouth of the Rio Grande River, and commenced its invasion of Texas. From Brownsville, Texas, it spread to the northward in Texas, and in I 895 occurred as far north as San An-

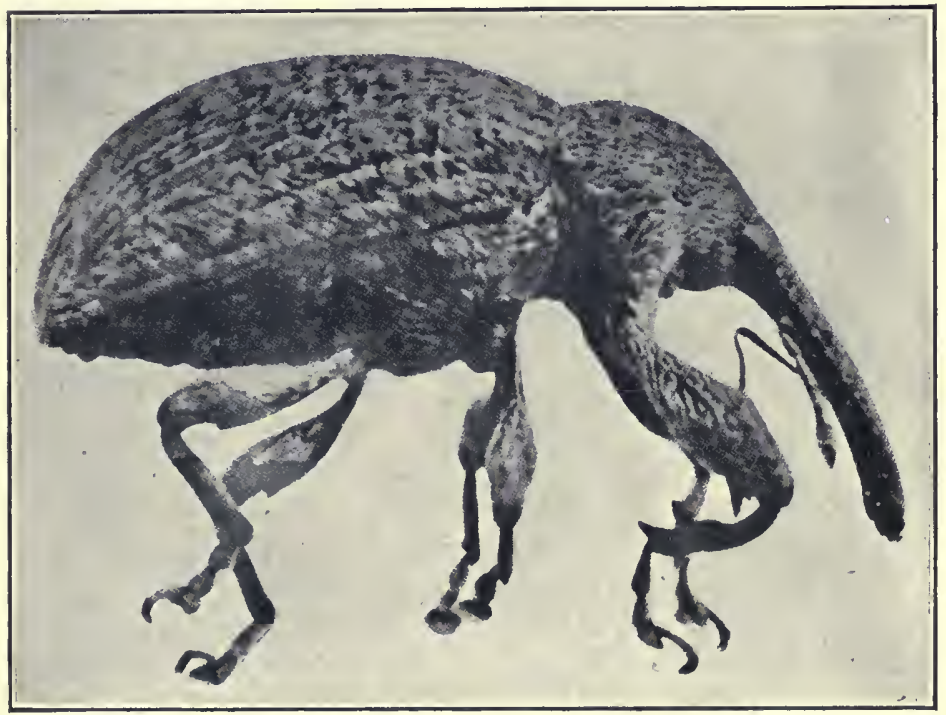

ADULT BOLL WEEVIL.

tonio. Since then it has been spreading in every direction until, at the present writing, practically all of the states of $\cdot$ Texas, Louisiana, Oklahoma, Mississippi and Arkansas are infested. There is every probability that it will spread to all parts of the Cotton Belt.

Description.-The boll weevil is a beetle, with a hard body-covering. The adult is from one-eighth to three-eighths of an inch in length, and is about one-third as broad as it is long. The mouth-parts are extended into a beak or "snout," which is about one-half as long 


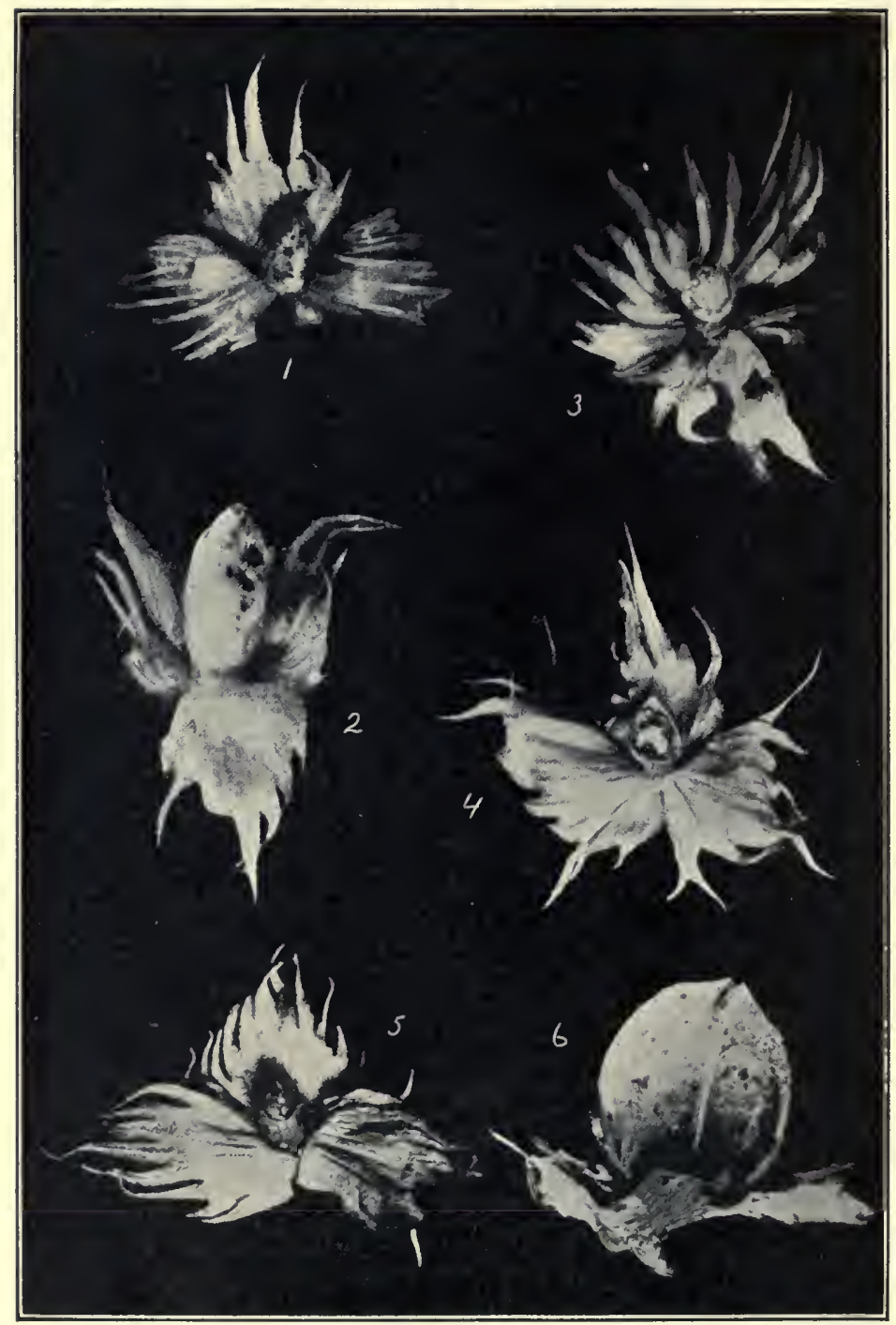

WORK OF BOLL WEEVIL.

I, Half-grown square destroyed by many feeding punctures by young weevils; 2, square ready to form bloom, very largely fed upon; 3, egg deposited at base of petal inside square; 4, large weevil larva being destroyed by smaller larva of Bracon mellitor; 5, weevil in act of escaping from fallen square; 6 , large boll severely injured by many weevil punctures. 
as the remainder of the body. The color of the adult weevil is somewhat variable, the usual color being a dark grayish brown.

How the Cotton is Injured.-The boll weevil injures the cotton in two ways : by feeding in the squares and small bolls, and by depositing eggs in them. The weevil does not chew up the leaves or buds, for it is not a "biting insect." When the weevil wishes food, it thrusts its long beak into a fresh square until it reaches the soft, juicy pollen on the inside. On this it feeds, eating all it can reach. The square which is injured in this way cannot become a blossom, for a few days after the weevil has fed in it, it wilts and falls to the ground.

How the Egg is Laid.-The boll weevil picks out a green square, and with the beak makes a deep hole in it. Then she deposits the small white egg in the opening, pushes it down into the square with her beak, and then plasters over the opening with a sticky substance. The cotton plant tries to repair the damage by causing a scar, or "wart," to grow over the opening. Instead of healing the wound, however, this wart merely serves to protect the egg, for it keeps out other insects that might get into the square and destroy the egg.

Number of Eggs Laid.-Each mother boll weevil

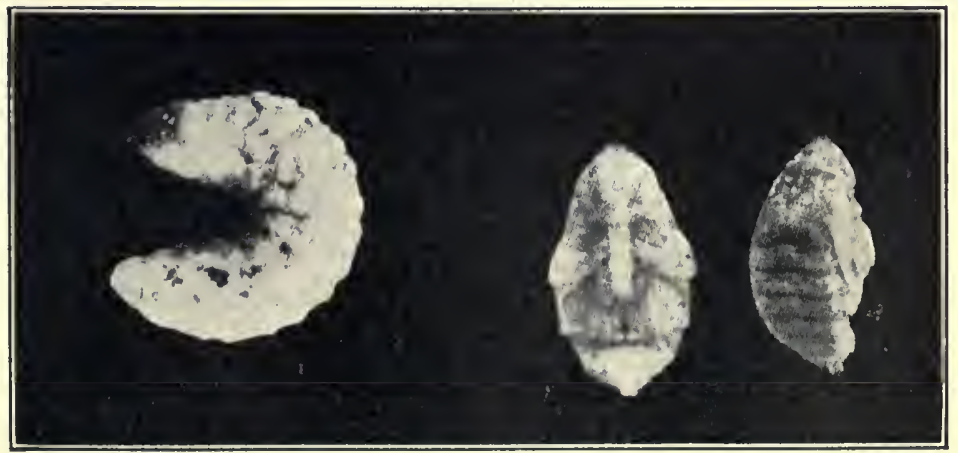

BOLL WEEVIL LARVA AND PUPA. 
lays from 75 to 150 eggs, and she places each egg in a square where no egg has been laid by another boll weevil. Every square which receives an egg is destroyed, so that one mother weevil, during the course of her egg laying, will destroy from 75 to 150 squares.

The Larva.-In 3 or 4 days after the egg is laid, it hatches into a small, white, footless "worm," called the larva. At first the larva is not much larger than

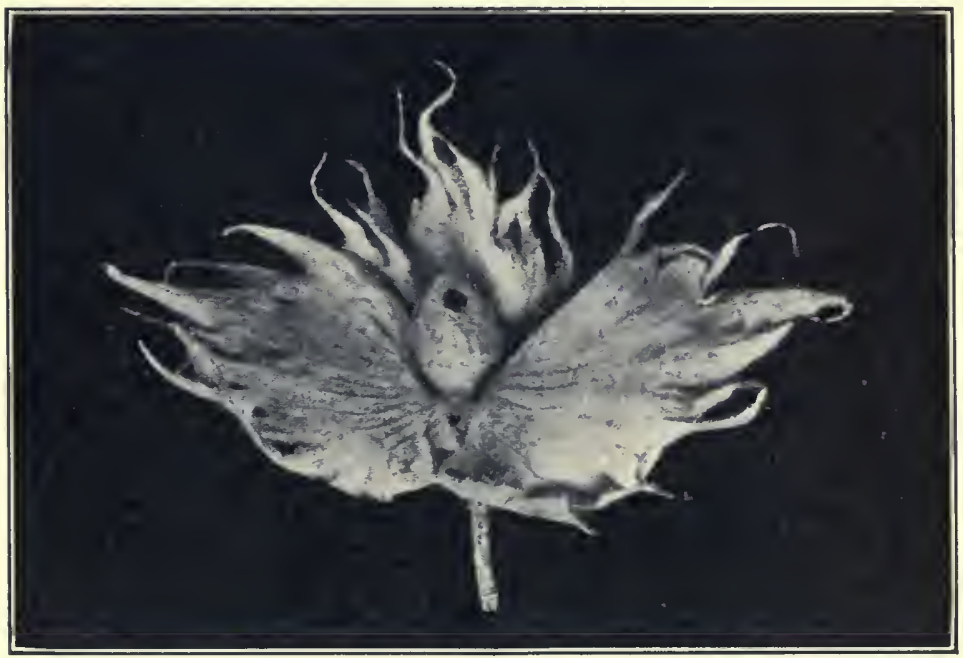

SQUARE OF COTTON, SHOWING EXIT OF ADULT BOLL WEEVIL.

the egg from which it is hatched, but it begins at once to feed on the pollen around it and grows very rapidly. At about this time the infested square drops to the ground. In about eight or ten days the larva eats up all the pollen in the square and becomes so large that it occupies all the inside of its little home, being now about one-fourth of an inch long. Its period of growth is now complete and it changes into the "pupa."

The Pupa.-The pupal stage is the third period in the young boll weevil's development. In this stage it 
begins to look more like a boll weevil. The beak appears and the small wings can be seen just commencing to grow. The pupa does not feed, for it lies helpless within the square for about a week. At the end of its pupal existence it changes into a perfect, full-grown boll weevil, still within the square. Next it eats a hole in the side of its "square house," large enough to get through, and comes out ready to destroy more squares and bolls.

Effect of Temperature on Growth.- Heat has a remarkable effect upon the development of the young insects. When the weather is warm the eggs hatches more quickly, and the larva grows much faster than in cool weather. Thus in July the complete development of the weevil, from egg stage to adult, may take place in I 2 or I 3 days. Early in the summer, during May and June, nearly a month is required for the development of a generation. In October and November, when the weather is cooler, the young boll weevil may not reach maturity until 35 or 40 days after the egg is laid.

Migration.-Early in summer the boll weevils are not usually abundant, for the rigors of winter destroy many of them. As soon as the squares appear on the young cotton plants eggs are laid, and in a few weeks the first brood of weevils reach maturity. Generation after generation of weevils follow, until by the first or middle of August there are thousands of them in the cotton field, and the plants can no longer produce squares enough to supply their wants. At this time the weevils become possessed with a desire to find new fields of cotton where there is more food for them. Accordingly many of them fly up into the air and go in every direction. This migration takes place during August and September. Many of the weevils succeed in getting to localities where there were no weevils before, and in this way the infested territory is increased 40 to 50 miles northward and eastward each summer. It should not be understoood that all the weevils leave a cotton field or locality when the migration takes 
place. On the contrary, it is only the surplus that leaves for a new locality. There are always enough weevils left behind to continue destroying the crop.

Hibernation.-At the approach of cold weather the adult weevils seek a sheltered place in which to pass the winter. Some crawl into grass and leaves right in the cotton field, others fly away to the woods and crawl into leaves on the ground, while still others push their way into bunches of Spanish moss hanging on the trees. In these protected situations they remain in a dormant condition during the winter, going without food and enjoying their winter sleep until the warm sun of springtime again makes them active.

The boll weevil eggs, larvæ and pupæ that are in the field when cold weather comes on are destroyed by the cold and never get to be grown weevils.

Many Weevils do not Survive the Winter.-Many of the weevils that hide away for the winter do not live until the following spring. Some of them die of old age, some are eaten by birds, some are destroyed by cold, wet weather, and still others are found and eaten by "pre-dac-eous" insects. Enough always live through the winter, however, to infest liberaily the cotton fields the next spring. In warm winters, in the southern part of the Cotton Belt, from io to 20 per cent. survive the winter, but in more unfavorable seasons not more than 2 or 3 per cent. live until spring.

Economic Changes.- The invasion of the South by the boll weevil has caused many important changes to be made in business methods in the country districts. Formerly, the average farmer planted nothing but cotton, and in order to provide food for his family and tenants, while he was making the crop, he secured advances from his merchant. In other words, the farmer went in debt for his supply of potatoes, bread, hay and corn, and sometimes even for the milk and eggs used on his table. In the fall when his cotton was marketed it took most of the proceeds of his crop to pay his debt to the merchant. 
Diversification.-With the boll weevil present the farmer can never count on a large cotton crop, and if he follows the old plan of buying corn, hay, meat, butter, eggs, vegetables and other things that he could raise himself, he finds that at the end of the season he owes the merchant more than his small cotton crop will bring. This state of affairs has compelled the farmer to "diversify," that is, to raise crops of many kinds so that he will not have to buy, at high prices, the food and supplies which he can produce at home. When the farmer thus makes his farm "self-supporting" he is not in debt at the end of the year, and his cotton crop is clear profit on the year's farming operations, no matter whether the crop is large or small. It is only by thus adapting sound business principles and common sense to his profession of farming that the planter can continue to grow cotton when he has the boll weevil to contend with.

Preventing Damage by the Boll Weevil.-Ever since the boll weevil first entered Texas, many different plans have been tried for his destruction. Poisons have been tested extensively. Both Paris green and London purple will kill quite a number of the weevils in early spring, but as these poisons injure the cotton plants as well as the weevils, their use in this connection is unprofitable. Recently made experiments indicate that a new poison, known as "powdered arsenate of lead," when properly used, will prove of value in fighting the weevil.

Burn the Cotton Stalks.-There is but one practical way of destroying the boll weevils. That is by picking the cotton as fast as it opens, and then destroying the cotton plants by cutting them down and burning them. Where the boll weevil occurs, no "top crop," or late crop, is ever secured, hence all the cotton actually made opens before October I $5^{\text {th, }}$ and can be picked by that date. The plants should be cut down before October I $5^{\text {th }}$, and burned before November Ist. As will be readily seen, this destruction of the cotton plants- 
which constitute the only food the weevil has-causes millions of them to starve to death before the weather gets cool enough for them to hibernate. It destroys the young weevils in the squares and grown bolls, and leaves no place for the mother weevils to lay the eggs which would produce a late autumn generation.

The Cultural Method.- The fall destruction of the cotton plants must be supplemented the following spring by what is known as the "cultural method" of fighting the weevil. By cultural method is meant the best care that can be given the growing cotton crop. The soil must be well plowed and thoroughly pulverized before the seed is planted, an early-maturing variety must be used and the seed must be planted early. On poor soils, fertilizer containing plenty of phosphoric acid must be liberally used. From the time the cotton comes up until the first bolls are opening it must receive frequent shallow cultivations. The more it is cultivated the faster will the plants grow, and the sooner will they produce bolls. It is a race with the boll weevil from the beginning, for each week sees an increased number of weevils in the field, and when there are weevils enough to destroy all squares as fast as they can grow no more bolls can be "made." Many successful farmers in the weevil-infested section cultivate their crops as many as ten or twelve times during the growing season.

Steady, persistent work, guided by an intelligent knowledge of the boll weevil's habits, will win the battle against this foe.

EXERCISE.-If the school is located in a section where boll weevils occur, have the students visit a cotton field and bring infested squares and bolls to the school. Notice the difference between feeding punctures and egg punctures. Open infested squares and find the young in different stages of development, egg, larva, and pupa. Place infested squares in a glass jar containing a little damp sand and see how long it requires for the larva to reach maturity. The mouth of the jar should be covered with thin cloth to prevent escape of the insects. Examine infested bolls and see how the injury differs from that done to the squares. In winter, examine Spanish moss for boll weevils in hibernation. 


\section{Section XliV.-The Cattle Tick.}

By Prof. Wilmon Newell,

Texas State Entomologist.

The cattle tick ("Margaropus annulatus") is one of the greatest pests to live-stock. Where the ticks are prevalent there will be hundreds, or maybe thousands, of ticks sticking here and there among the hairs. Each tick has a long beak which it inserts into the animal's skin, and through which it is constantly sucking up her blood.

Texas Cattle Fever.Then, too, the ticks often give to cattle the deadly disease known as "Texas

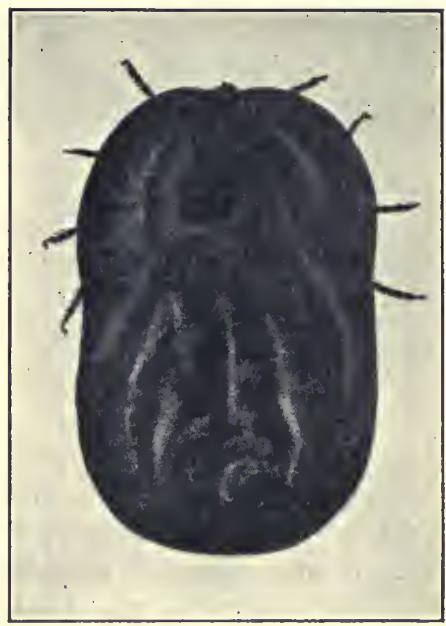

FEMALE CATTLE TICK. cattle fever," which kills thousands of cattle in the South every year. So much loss is caused by these ticks that the United States Department of Agriculture is spending nearly a half million dollars a year in trying to destroy them.

Description.-The female ticks are quite large when full grown, measuring as much as three-eights of an inch in length. The color is dark gray, and the eight legs are so small that they are not noticed without looking closely for them. These are the ticks that are so easily found on the cow.

The male ticks are much smaller and are very active. They, too, suck blood through the skin of the animal, but they do not stay in one place long at a time.

Life History. - The female tick stays upon the 
animal until fully engorged with blood. Then she lets go and drops to the ground, where she slowly and clumsily crawls under a bunch of grass or leaves.

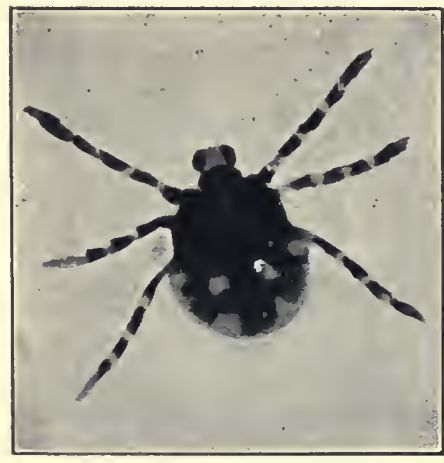

CATTLE SEED TICK.

Here she commences laying eggs, very small, brown and shiny, and during the next eight or ten days she may lay as many as 1,500 or 2,000 . Her mission in life is then completed and she dies.

Seed Ticks.-In from I 8 to 25 days the eggs hatch into seed ticks which are very tiny. They have six legs and these they make use of at once. They crawl up the nearest blade of grass, clear to the top. Here they stay, holding on by their hind legs and waving their front legs frantically in the air. When an animal brushes against the blade of grass the little ticks let go their hold and attach themselves to the animal. Then they crawl over its body, find a place that suits them and insert their beaks to get their first meal of warm blood.

Molting.-The little ticks now grow so fast that their skins become too small, so the skins are shed, or molted, from time to time. At the first molt the tick comes out with eight legs, insead of six.

Remedies.-There are two ways to free the cattle of the ticks. One way is to rub the animal thoroughly with some greasy substance, such as crude petroleum, the other is known as the "pasture rotation method."

Pasture Rotation Method.-In summer time the baby ticks cannot live more than three months after they hatch from the eggs, and unless they succeed in getting on a cow or similar animal before the three months are up they starve to death. Therefore, if all cattle are kept out of a field for more than three 
months in summer, all ticks in the field will die. Before cattle are again placed in this "tick-free" field they a re also cleaned of ticks, usually by greasing them with crude oil. When both the cattle and the pasture have been made tick-free no more ticks will get on the cattle unless a tick-infested animal is brought to the pasture. There are many modifications of the pasture rotation method. Full descriptions of them can be found in the bulletins published by the State Experiment Stations.

EXERCise- - Have one of the pupils secure several engorged ticks from a gentle cow and bring them to the school. Place them in an open-mouthed bottle or small dish until eggs are laid. Note the small size of the eggs and their abundance. Place some of the eggs in a clean glass bottle and close the mouth of the bottle with cotton. Keep in a warm room until the eggs hatch. How many days are required? Through the sides of the bottle examine the baby ticks. How many legs have they? Do not open the bottle of seed ticks in the schoolroom.

\section{Section XLV.-The Cotton Worm or Cotton CATERPILlar.}

By Prof. Wilmon Newell,

Texas State Entomologist.

The cotton worn, or cotton leaf-worm, is well known to every cotton planter. The bluish-green caterpillars, or "worms," appear in the cotton fields in middle or late summer, and feed upon the leaves and squares. When numerous they quickly strip the plants of all foliage, and the cotton crop is severely curtailed. In the southern part of the Cotton Belt five or six generations of the caterpillar are produced each summer; in the northern part only two or three broods appear.

Life History. - The adult insect is an olive-gray moth measuring about one and one-quarter inches across the wings when in flight. The moth is active only at night, and during her lifetime lays from 300 to 5 oo eggs. These eggs hatch, in from 3 to 8 days, into small greenish larvæ marked with small black dots. 

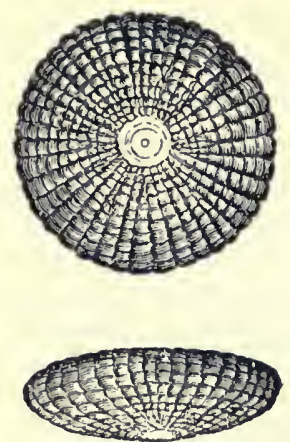

EGG OF COTTONWORM MOTH.

The larva grows rapidly, shedding its skin five times before reaching maturity. Only about two weeks are required for the growth of the larva. It then selects a convenient place on the limb of the cotton plant, sometimes within a folded leaf which its appetite has overlooked, or on an adjacent weed, and spins about itself a thin web. In this pupal, or chrysalis, stage, the insect remains quietly for from one to three weeks. Then the thin cocoon is burst asunder and the adult moth issues, to take up her task of laying the eggs, which are to produce the following generation of caterpillars.

The Moths.-The winter is passed in the adult stage only, the moths hibernating in trash, leaves, grass, etc., in the warmer parts of the South. Moths of each generation during the summer fly further and further northward, so that by autumn the caterpillars are sometimes found as far north as Arkansas and Virginia.

Its Importance. - Shortly after the Civil War, at which time the crop was almost totally destroyed by its ravages, this insect was considered the most dangerous enemy of the cotton crop. In later years, however, it has been of relatively less importance, for its natural enemies have increased to such an extent that
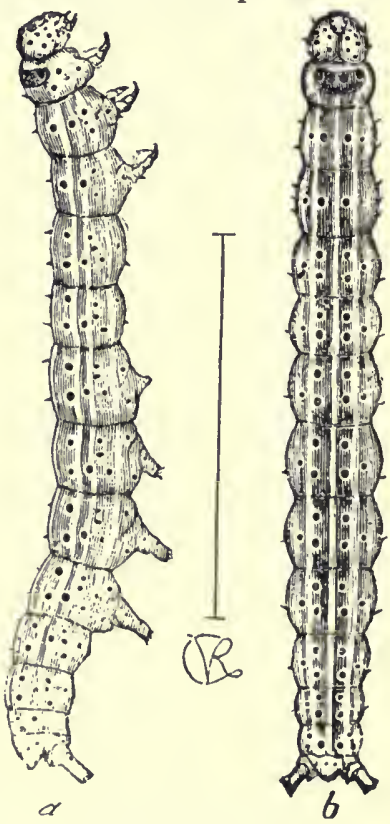

COTTON CATERPILLAR. $a$, side view; $b$, top view. 
they prevent the caterpillars from reaching injurious numbers in the average season. Indeed, in Texas and Louisiana, where the boll weevil occurs, the caterpillar is welcomed, if it does not appear in large numbers until in September or October. By destroying the squares and leaves of the cotton plant in the fall, the caterpillar destroys the breeding places and food of the boll weevil, with the result that there are less of
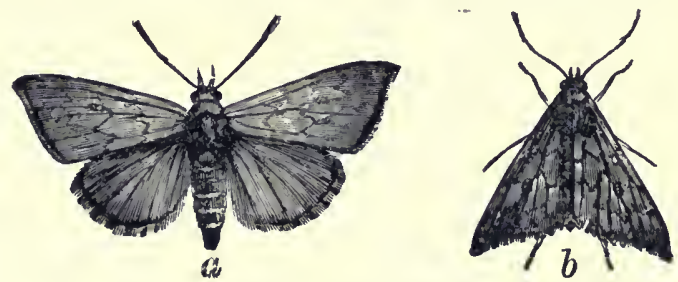

COTTON-WORM MOTH.

$a$, with wings expanded in flight; $b$, wings closed. After Riley, U.S. Dept. of Agriculture.

the latter insects to pass through the winter and attack the following season's crop.

Methods of Control.-The cotton caterpillar is easily killed with arsenical poisons, and when they appear as early as July or August, measures must be taken against them. Paris green has been extensively used for this purpose, at the rate of about one pound per acre, the "green" being applied by dusting it from cloth sacks attached to a pole which is carried through the fields on horseback. The more modern treatment is to use powdered arsenate of lead, applied in the same way. The latter substance does not cut short the cotton fruitage as does Paris green, and can be safely used at the rate of from three to five pounds per acre. One application is usually sufficient to hold the insect in check.

EXERCISE.-During the latter part of summer have the pupils search for the caterpillars in adjoining cotton fields and bring to the school living larva. Feed these on green cotton leaves until they reach maturity and transform. Note the manner in which the pupa is formed. Keep the pupx in a glass jar and note the time required for transition through this stage. What changes take place in the adult moth just after it leaves the pupal skin? 
Section XLVI.-ORchard and Garden Insects.

By Prof. A. L. Quaintance,

Bureau of Entomology, U. S. Dept. of Agriculture.

A large number of insects feed directly or indirectly upon the wood, foliage or fruit of orchard and vineyard plants, and an equally large number depredate upon various garden crops. Comparatively few species, however, are of first importance, but these are present almost every year, and are so destructive that control measures are necessary for profitable crop production.

\section{OrChaRd INSECTS.}

San José Scale.-The San José or Chinese scale infests practically all orchard trees, as apple, pear, plum, etc., and also many shade trees and ornamental plants.

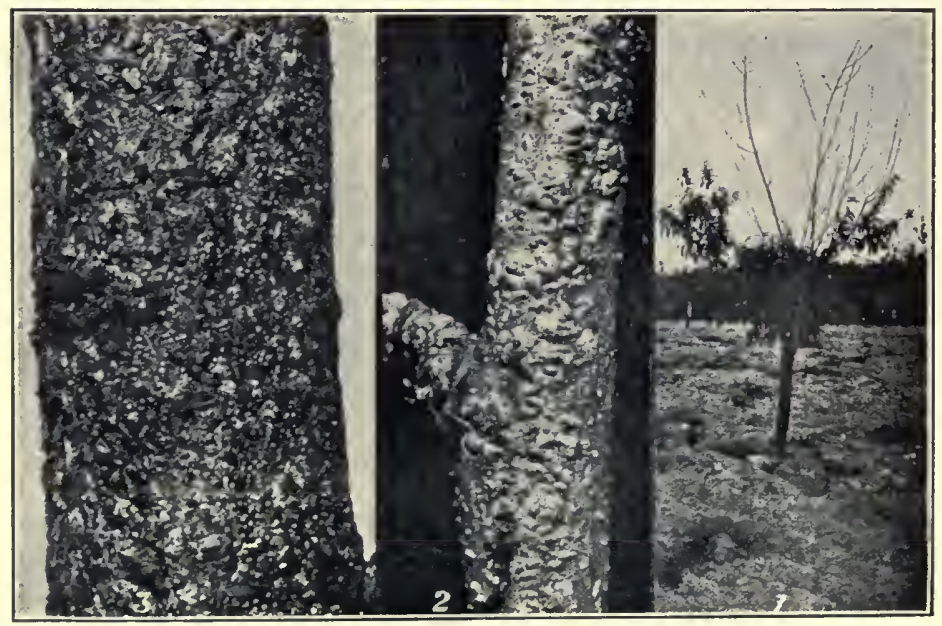

THE SAN JOSÉ SCALE, AND ITS WORK.

I. Peach tree, with top killed by the scale; 2 , peach twig, showing male and female scale; 3 , peach tree badly infested. 


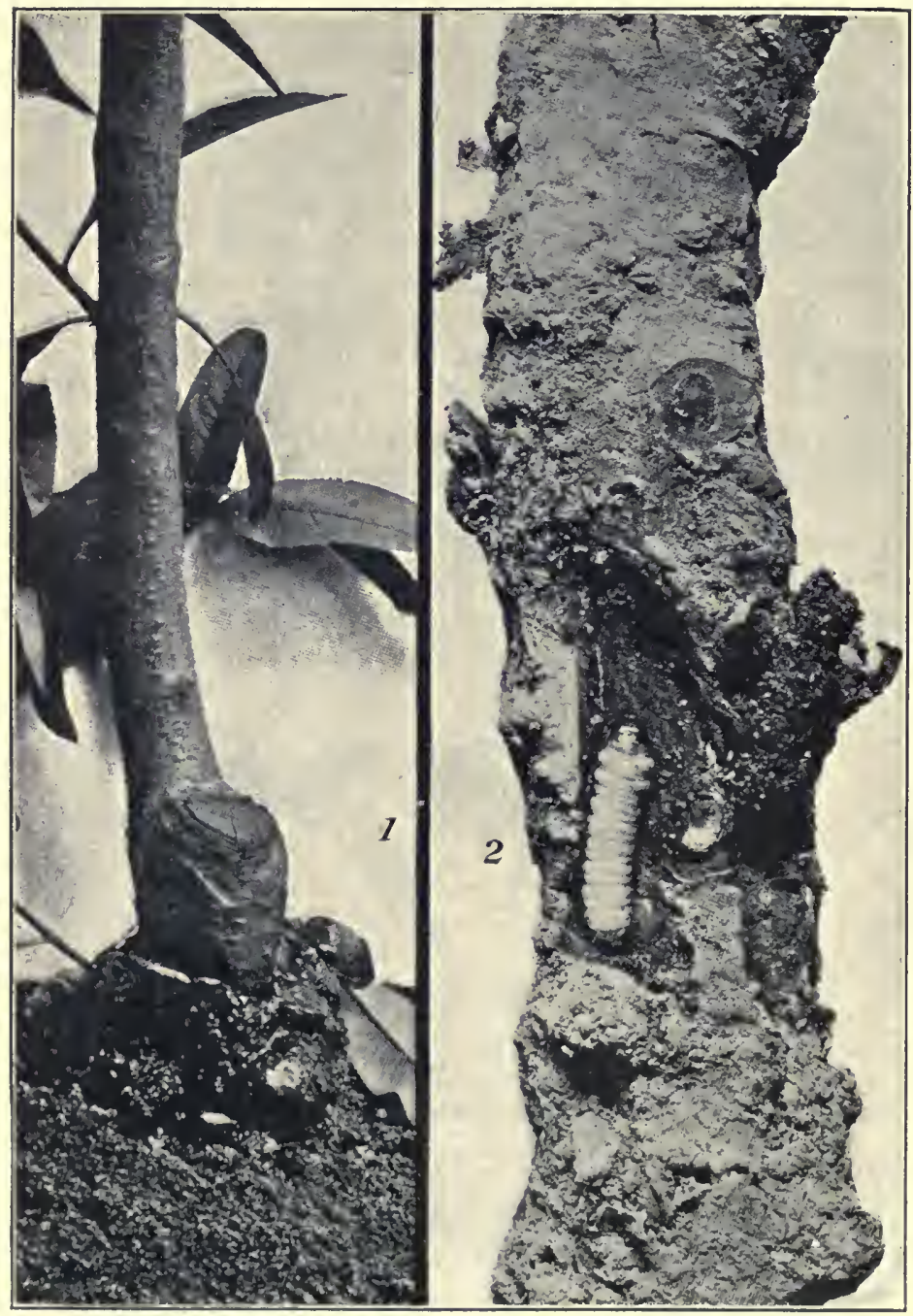

THE PEACH BORER, AND ITS WORK.

I, Exudation of gum of infected tree; 2 , the borer and its cocoon. 
This insect is very prolific, and when once established increases rapidly, soon incrusting the limbs and branches giving them a gray appearance as if dusted with ashes. The scale insects feed by sucking out the sap from the inner bark, and if unchecked quickly destroy the infested plants. This pest is readily controlled by a single thorough spraying each year during the dormant season with lime-sulphur wash, made by boiling together for an hour, 20 pounds of lime, I 5 pounds of sulphur, in about i 5 gallons of water, to be finally diluted to make 50 gallons of the wash. Other sprays may be used as 20 per cent. kerosene emulsion, strong whale oil soap solution, etc.

Peach Borer.-East of the Rocky Mountains the peach borer usually occurs wherever peaches are grown. The larvæ feed under the bark at the crown of the tree or on the roots. Young trees are greatly injured and often killed by girdling, and the vitality of

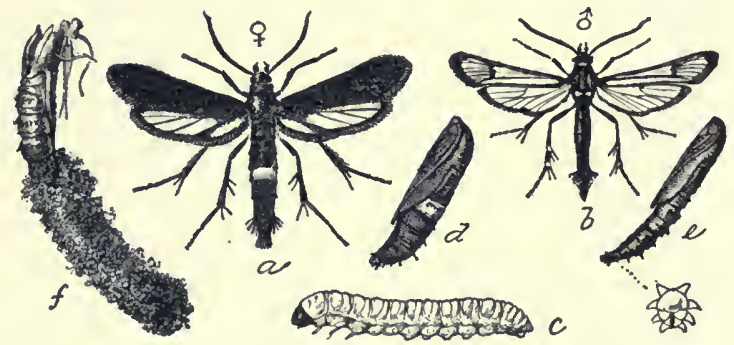

PEACH BORER.

$a$, Adult female; $b$, adult male; $c$, full grown larva; $d$, female pupa; $e$, male pupa; $f$, pupa skin partially extended from cocoon.

the older ones considerably impaired. Trees should be gone over in the spring and fall, and the borers removed with a knife, or killed in their burrows with a stiff wire.

Plum Curculio.-The plum curculio punctures in the spring peaches, plums, cherries and apples, causing them to fall or become knotty and misshapen as they grow. The egg is deposited by the parent beetle 
under the skin of the fruit. The resulting grub feeds in the flesh, usually at the pit in stone fruits, where it completes it growth, and is the cause of worminess in peaches, plums and cherries. Beginning in the spring, shortly after the fruit is set, and continuing for four or five weeks the beetles should be jarred from the

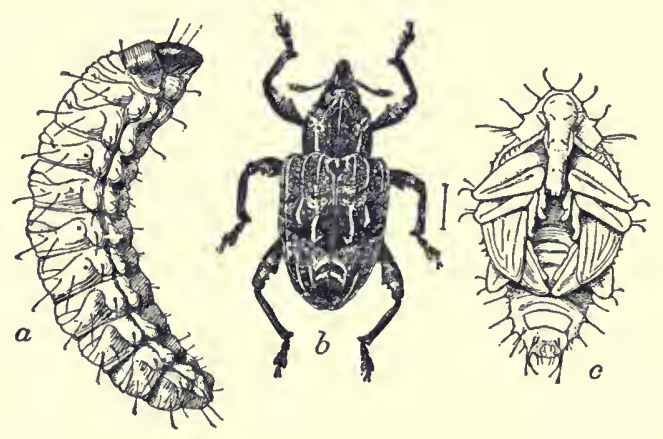

PLUM CURCULIO.

$a$, Larva; $b$, adult; $c$, pupa.

trees every day or so on sheets held or placed on the ground under the trees. A forcible stroke with a padded mallet causes most of them to fall. The beetles may also be poisoned by spraying the trees with arsenate of lead at the rate of 2 pounds to 50 gallons of water, making the first application as soon as the blossoms have fallen, and repeating twice at intervals of about ten days. This treatment, however, sometimes causes injury to the foliage, especially of the peach.

Codling Moth.-Wormy apples, the work of the codling moth, are familiar to all lovers of this fruit. Although this insect is successfully controlled, it still imposes upon the apple growers of the United States a tax of about twelve million dollars annually. Two or three weeks after blooming of trees the moths are depositing eggs in numbers here and there on the foliage and fruit. Young larvæ, upon hatching, mostly 
enter the apples at the blossom end. There are from one to three generations each year according to locality. The insect is controlled by spraying the trees with Paris green, arsenate of lead or other arsenical just after the petals fall, thus placing a dose of poison in each calyx cup to be later eaten by the larva as it seeks to enter the fruit. Additional sprayings should also be given in four weeks after the blossoms fall, and in ten weeks, this latter for the second brood of larvæ where it is troublesome. The poison is now al-

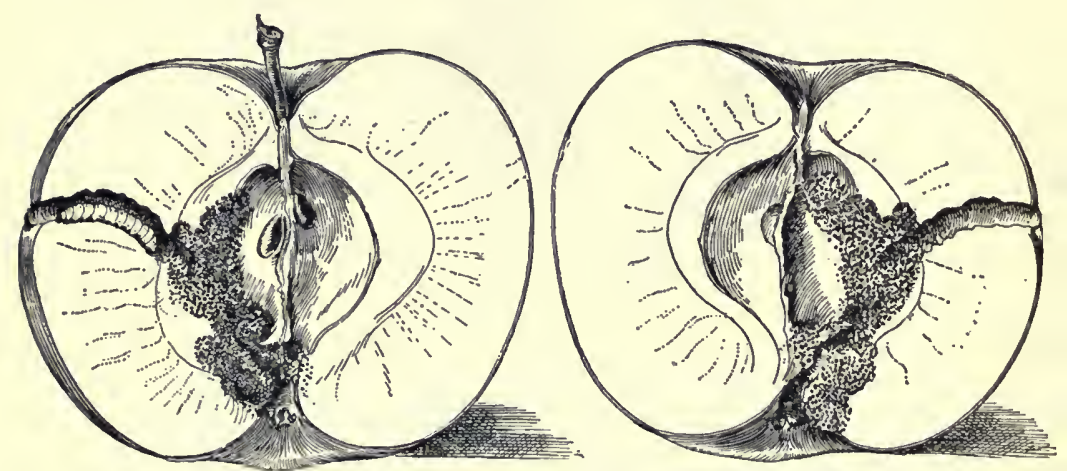

CODLING MOTH LARVA.

most always applied in Bordeaux mixture, a fungicide, thus controlling both the codling moth and fungus diseases.

\section{The Orange White Fly.}

By Dr. A. W. Morrill,

Bureau of Entomology, U. S. Dept. of Agriculture.

The Orange White Fly. - There are several species of white flies in this country, but the orange white fly easily ranks as the most injurious member of the group as well as one of the most destructive orange enemies. This insect injures the leaves of the orange tree. The adult insect, which appears like a minute white gnat, 
lays its eggs to the number of about one hundred, on the under surfaces of the leaves. The larval stages are scale like, and except for the first few hours, remain fixed in one position on the leaf until it becomes fully developed and the adult emerges. The entire period from the laying of the egg to the appearance of the adult is rarely less than seven weeks and usually much longer. The insect breeds on several plants besides those of the orange group. In order to control the insect satisfactorily, chinaberry and umbrella trees, cape jessamines and privets must not be allowed to grow near orange groves. Parasitic fungi attack the young scale-like stages of the fly and produce bright red, yellow or brown growths. These friendly fungi reduce the white fly damage about one-third. For entirely satisfactory results it is necessary to fumigate orange trees with a poisonous gas, called hydrocyanic acid gas, after covering the trees with canvas tents, or else to carefully spray the trees with a soap solution.

\section{GaRden InsEcts.}

\section{By Prof. A. L. Quaintance,}

Bureau of Entomology, U. S. Dept. of Agriculture.

Cutworms.-Cutworms are of almost universal occurrence in gardens, feeding upon all classes of crops. They attract attention mainly in the spring, as at this time they are hungry from their winter's fast, and the scarcity of green vegetation forces them to the garden crops. Cutworms are best controlled by use of poisoned baits, which should be in place some days before the garden plants are set out, or as soon as first injury is noticed. An excellent bait is fresh clover, alfalfa or other succulent vegetation sprayed with or dipped in Paris green in water, or a poisoned bran mash may be used. The poisoned bait should be placed in numerous small heaps over the infested ground or by the plants. Fresh bait should be added from time to time as necessary to keep it fresh. 
Imported Cabbage Worm.-The imported cabbage worm is very destructive to cabbage and other cruciferous (mustard family) plants, riddling the leaves as shown in the figure. Young plants should be sprayed with an arsenical, as arsenate of lead, just before being taken from the seed bed, and after they are set out additional sprayings should be given until the

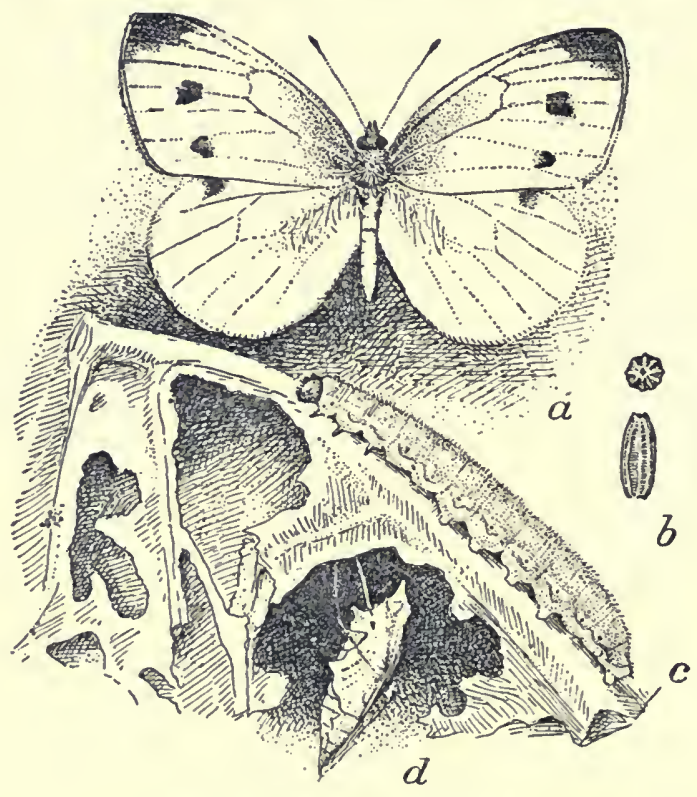

IMPORTED CABBAGE WORM.

$a$. Female butterfly; $b$, above, egg as seen from above; below, egg as seen from side; $c$, larva on cabbage leaf; $d$, suspended chrysalis.

heads are about half grown or even later. The poison washes off in three or four weeks. All plant remnants should be destroyed as soon as the crop is harvested, as otherwise the insects continue to breed on the food thus furnished.

Colorado Potato Beetle.-The Colorado potato beetle is now much less a pest than in former years. It is readily controlled by spraying or dusting the 


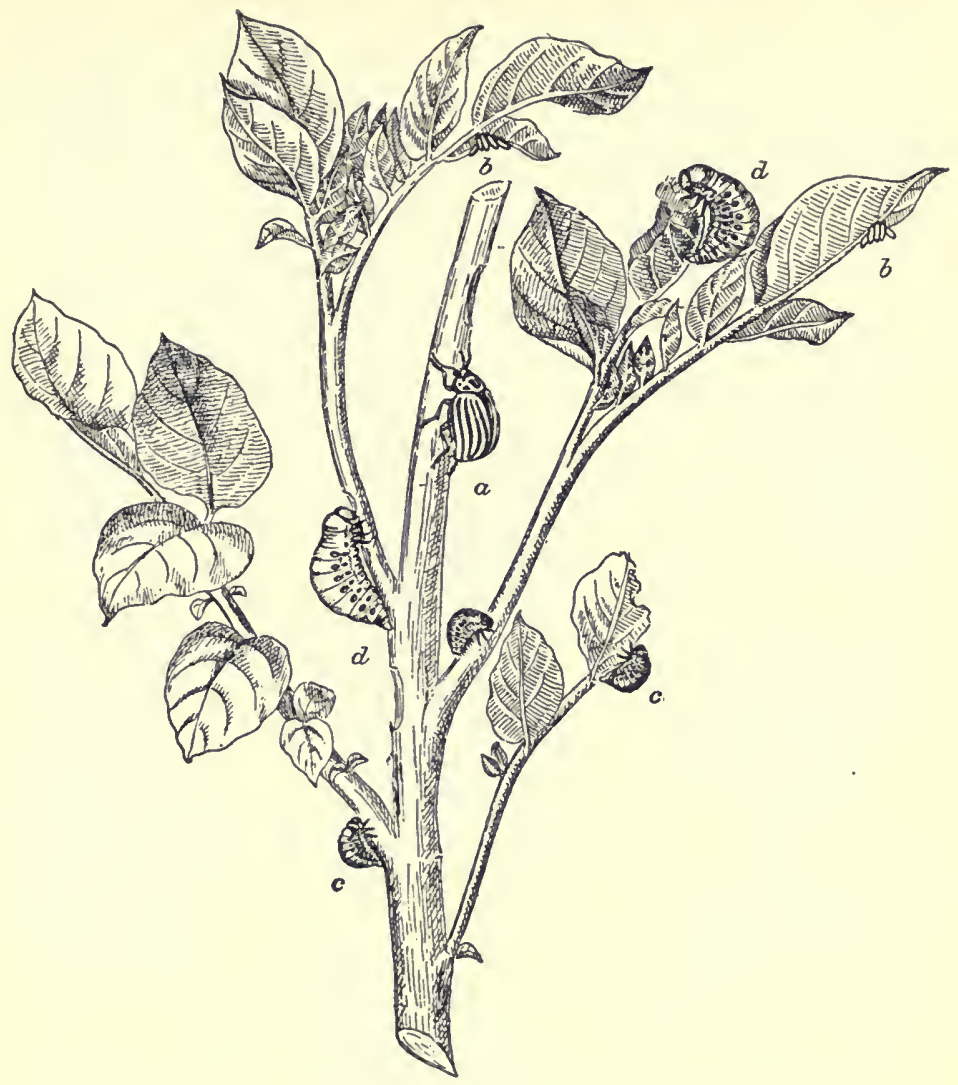

SECTION OF POTATO PLANT, SHOWING COLORADO POTATO BEETLE AT WORK.

$a$, Beetle; $b, b$, egg masses; $c, c$, half-grown larvæ; $d, d$, mature larvæ.
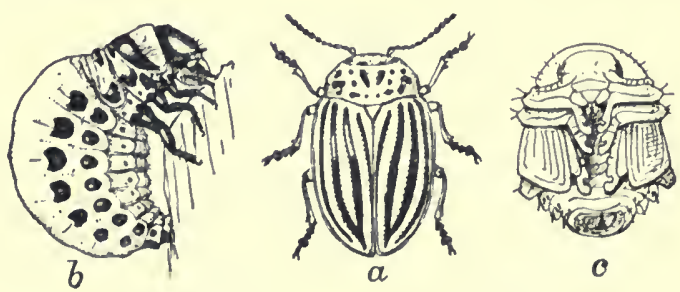

COLORADO POTATO BEETLE.

$a$, Beetle; b, larva; $c$, pupa. 
plants with an arsenical, as Paris green or arsenate of lead. A close lookout should be kept for the appearance of the beetles on the plants in the spring, and the poison applied promptly, which will largely prevent further trouble.

Harlequin Bug.- The harlequin bug infests all cruciferous plants, as cabbage, turnips, etc. The bugs
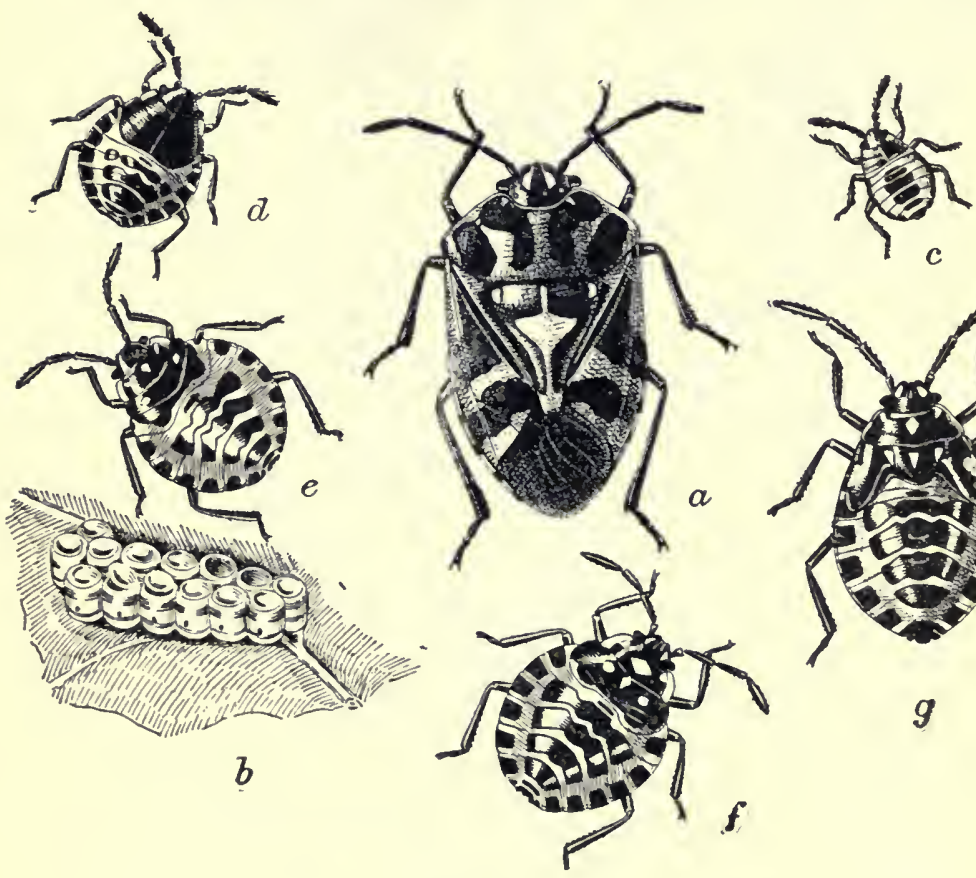

HARLEQUIN BUG.

$a$, Adult; $b$, egg masses; $c$, first stage of nymph; $d$, second stage; $e$, third stage; $f$, fourth stage; $g$, fifth stage.

hibernate in trash around gardens, and come out in early spring, feeding on wild mustard. They obtain their food by means of a beak and slender bristles inserted into the plant, thus sucking up the juices, causing the plant to wilt. Arsenicals are not effective against this insect, and a strong spray must be used 
which will corrode the body or stop the breathing pores, as kerosene emulsion, whale-oil soap solution, or strong tobacco decoction. As the bugs often congregate on wild mustard in early spring it is practicable to pick them off and destroy them by burning or submerging in a can of kerosene.

ExERCISE.-Bring specimens of wormy apples, plums and peaches to the classroom and see if the injuries are not due to one of the insects mentioned in this text.

Take the class out to an orchard and find San José scale and other insects or insect injuries.

If any farmer owns a spraying outfit, arrange to take the class to his place, preferably when he is operating it.

\section{Section XLVII.-House-flies and Mosquitoes.}

By Dr. A. W. Morrill,

Bureau of Entomology, U. S. Dept. of Agriculture.

House Fly.-Scientists are now using "typhoid fly" as the common name of the house fly in order that everyone may bear in mind the dangerous nature of this insect as a carrier of typhoid fever germs. The adult fly lays her eggs to the number of about one hundred and twenty in manure and filth of various kinds. Horse manure is the principal breeding place. The young stages are completed in from ten to fourteen days depending on the temperature. Scientists have proven that flies carry on their feet and in their bodies germs of typhoid fever, cholera, dysentery and other diseases. While these disease germs are carried by other means, flies are believed to be among the most important agents in transmitting these diseases. The typhoid fly can be controlled to a large extent in both the city and the country by screening the storage places for horse manure, and by the proper disposal of waste material and human excrement when necessary. 
Mosquitoes.-These insects rank among our most injurious ones, owing to their being the only means for the transmission of malaria and yellow fever. In the case of the former disease it has been estimated that

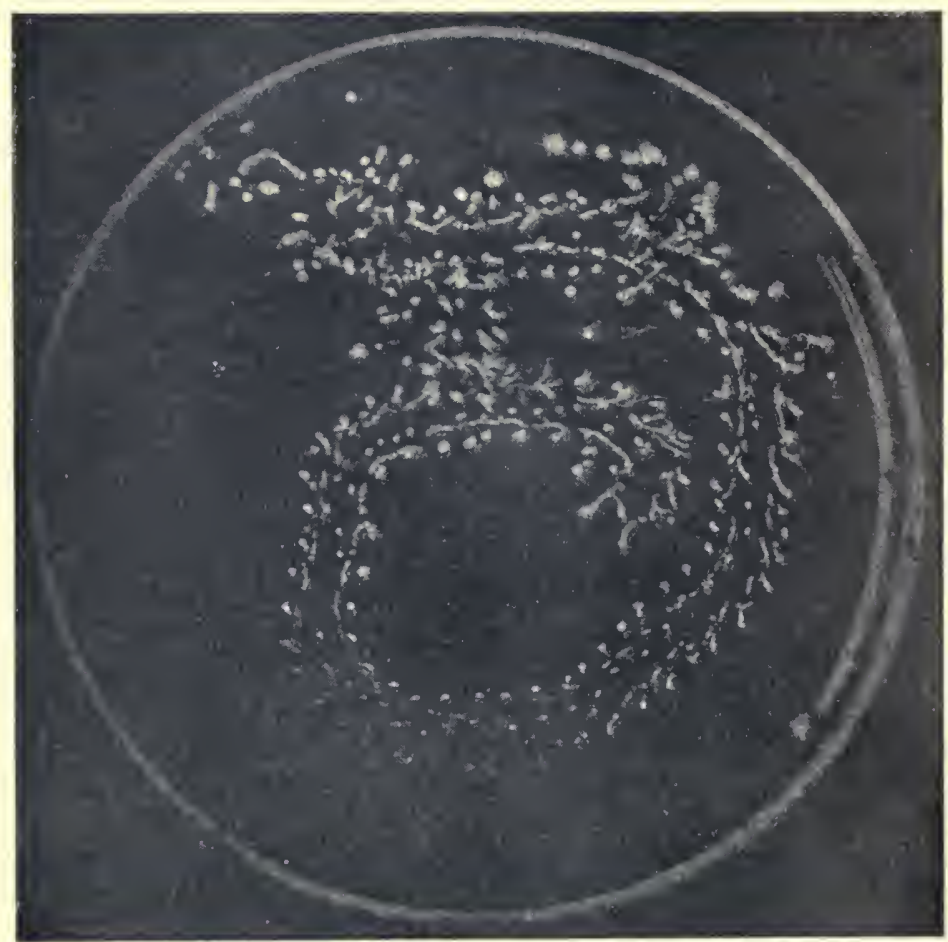

BACTERIA LEFT BY FLY PASSING OVER GELATINE PLATE.

(Permission of Doubleday, Page \& Co.)

the losses which the malarial mosquitoes cause, in the United States, amounts to not less than one hundred million dollars a year. The mosquitoes which carry malaria usually can be distinguished from the nondisease carrying forms by their spotted wings, and by their standing with their bodies at an angle to the surface upon which they may rest, rather than nearly par- 
allel with it. Malaria has been proven in many sections of the world to be entirely avoidable by preventing the breeding of malarial mosquitoes, and by the careful screening of windows and doors in dwell. ing houses.

There is only one kind of mosquito which can carry yellow fever. This is a small mosquito with banded legs and silvery stripes on the back between the wings. It breeds almost entirely in cisterns, when these are not properly screened; and in horse troughs, rain barrels, tin cans and other receptacles in which water is allowed to collect.

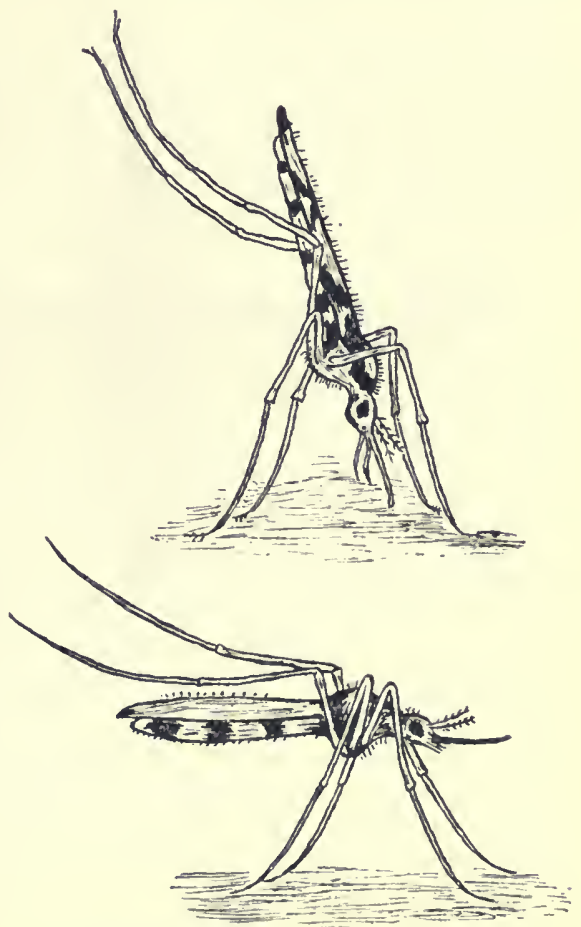

DISEASE-CARRYING MOSQUITO ABOVE. COMMON MOSQUITO BELOW.

The young stages

of all kinds of mosquitoes live in water and are familiarly known as "wigglers." They develop very rapidly in warm weather, and may reach the adult or winged stage in a week or ten days. In order to prevent the breeding of mosquitoes all receptacles that hold water, such as tin cans, should be removed or buried. Horse troughs should be emptied every few days. Wells and cisterns should be thoroughly screened with some fine wire screening or cheese 


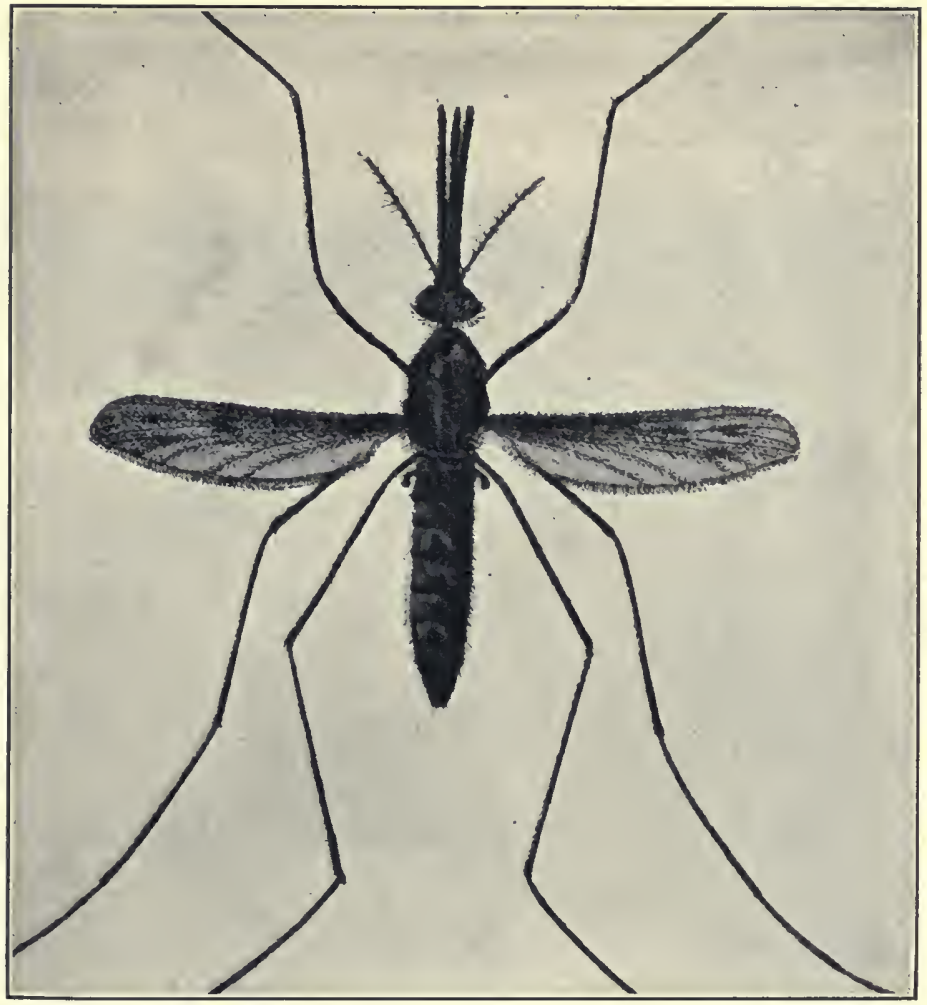

A MALARIAL MOSQUITO.

cloth. Ditches should be kept free from water as much as possible. To prevent being bitten by mosquitoes, dwellings should be well screened.

Exercise.-What enables a house-fly to stand on the ceiling? How do you explain the ease which house-flies spread infection with their feet?

Require the pupils to bring some mosquito wigglers to school. Fill two tumblers three-quarters full of water and place half the wigglers in one tumbler and half in the other. Place a lantern globe (the top of which has muslin tied on it) over one tumbler and watch the development of the mosquitoes. Add enough coal oil to the other tumbler to cover the surface of water and note the effect. 


\section{Section XLVIII.-Bee Keeping.}

\section{By Prof. Wilmon Newell,}

Texas State Entomologist.

The honey-bee is one of the few insects which have been domesticated by man and made to serve him, and they have been kept for their honey since the earliest times. The keeping of bees is a pleasant and profitable occupation.

Bees and Fruits.-Not only are bees useful for the honey they produce, but they render a valuable service to the fruit grower by carrying the pollen from one blossom to another, so that the flowers are "pollinated." Where bees are scarce and the flowers not well pollinated the fruit crop is poor. Bees do not injure ripening fruits, for the bee's mouth-parts a re not strong enough to pierce the skin of sound fruit.

The Colony.-Honey-bees are "social insects," that is, they live in large colonies, and all the bees in the colony work for the common good. In each colony there is a queen, a few drones, or males, and from 3,000 to 10,000 workers.

The queen is the mother of the colony, for she lays the eggs that are to produce the young bees.
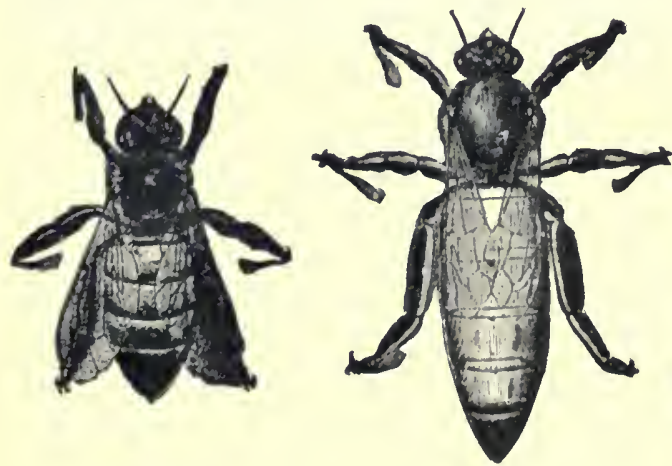

WORKER.

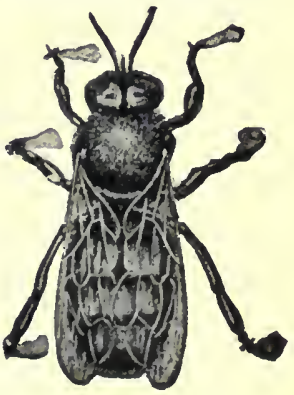

DRONE. 
The workers do all the work for the community. Certain ones go forth each day in search of honey and pollen, others act as nurses and feed the baby bees, others build new cells of wax and still others stand guard at the door of the hive.

The Life of a Worker.-About three days after the tiny white egg is laid in a cell of the honey-comb it hatches into a very small larva. The nurse bees im-

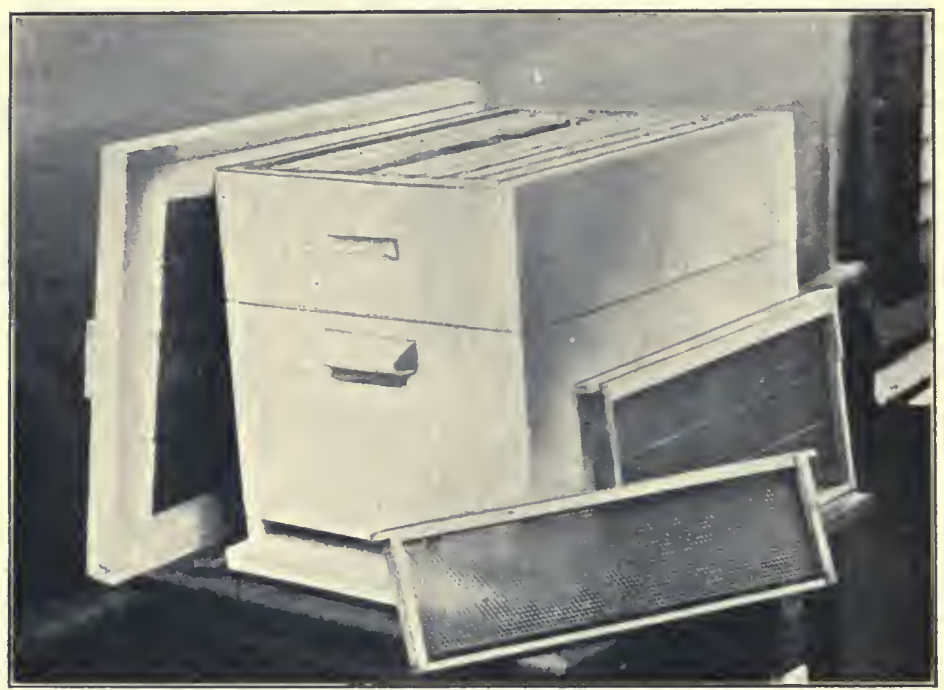

A MODERN TEN-FRAME HIVE.

mediately surround it with a white, milk-like food and it grows rapidly, sometimes doubling in size in twentyfour hours. In six days more, or in about ten days after the egg is laid, the larva is so large that it fills the entire cell. It needs no more food, for it is now ready to enter the pupal stage. The nurse bees cover the cell with a waxen cap and the little bee is left undisturbed. Within the sealed cell a wonderful change is taking place. The larva spins a thin cocoon about itself and gradually changes to a pupa, with its head, 
wings and legs just beginning to grow. In eleven or twelve days after it is shut up in its little house, or twenty-one days after the egg is laid, it becomes a fullgrown bee. It eats away the covering of the cell and in a few hours it looks like any other bee and takes up its part of the work. The queens are developed in cells much larger than those which are occupied by the young workers, and only sixteen days are required for

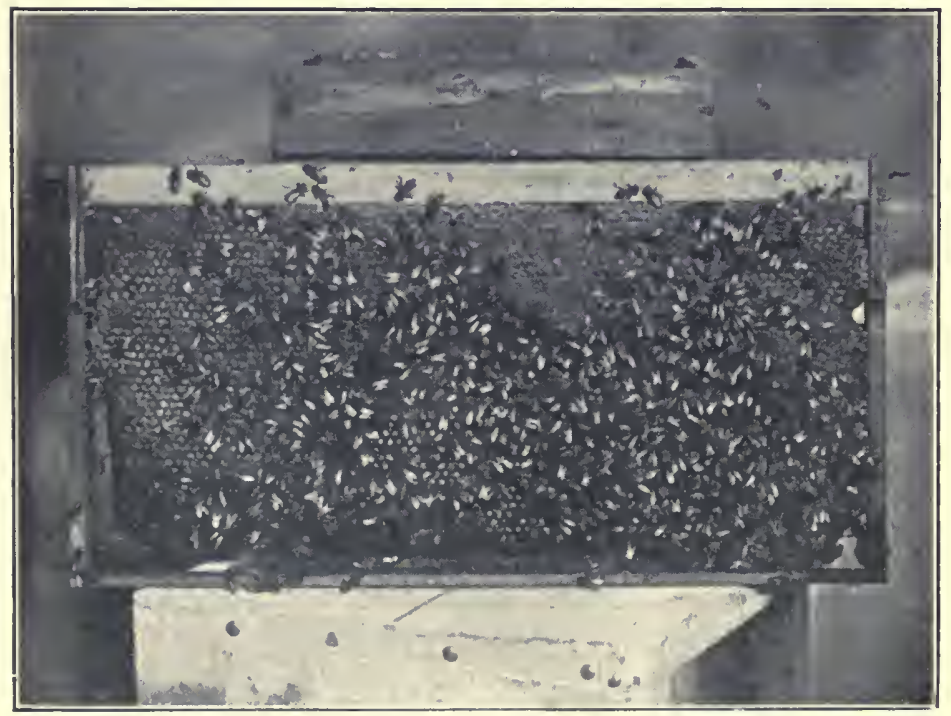

A FRAME OF BEES.

their growth. The drones require about twenty-three or twenty-four days for their development.

Swarming.-In spring and early summer, when there is plenty of honey and there are many young workers in the hive, the bees make preparations for swarming. One or more young queens a re raised, and on a bright morning the bees swarm. Thousands of them rush out of the doorway of the hive and take wing. Round and round they circle in the air, humming a merry tune. The old mother queen joins them 
and away goes the swarm, leaving the young queen and the young bees in full possession of the old home. The swarm may fly a few feet, or several miles away. Finally it settles on a limb. When the bees are thus settled on a limb they are easily captured and placed in a new hive. If the bee-keeper fails to catch them they usually find their way to a hollow tree, or into the wall of a building, and there set up their housekeeping.

Products of the Bee.-The best-known product of the bee is honey. The flavor of honey, as well as its color, is determined mainly by the kinds of flowers from which the bees obtain nectar, for honey is merely the nectar of flowers brought to the hive, stored in the cells of the comb and allowed to evaporate until it is thick enough to "keep."

Beeswax is not gathered from flowers, but is secreted by glands located on the under side of the workers' abdomens. From the wax the comb is built, the bees using their jaws to mold and plaster the particles of wax into cells. Propolis, or " bee-glue," is a sticky substance gathered from certain flowers and used by the workers to stop up cracks in the hive.

EXERCISE.-Visit open flowers and notice bees at work. Observe how the long tongue is thrust deeply into the flower to sip up the nectar. If the bee is gathering pollen see where it is placed. Does the bee carry the pollen away on the outside of its body? Where?

Get an experienced bee-keeper in the community to give the class a talk on bees, illustrating it with implements used in bee-keeping, such as smoker, veil, honey-knife, etc. On a warm, bright day take the class to visit a bee-yard or "apiary," if any is near at hand.

\section{Section XLIX.-Wild Birds.}

By Prof. E. H. Forbush,

State Ornithologist of Massachusetts.

The relations of birds to agriculture are not yet fully understood. Nevertheless it is safe to say that the great majority of birds that frequent farm lands, as well as most of the species living in inhabited regions, are either beneficial to man or neutral rather than in- 
jurious. Even those that the farmer considers as among his chief enemies are often found to be far more useful than harmful when their food habits are studied with scientific care. Whenever a bird attacks poultry, fruit or grain its ravages are conspicuous. But many birds may feed on the enemies of fruit, grain or poultry without attracting our attention in the least. Therefore the harm that birds do is often exaggerated, while the good offices they perform are either unnoticed or underestimated.

Beneficial Species.-It sometimes happens that the investigator finds so many factors entering into the food relations of a bird that it is difficult to determine whether or not the species is beneficial. But no family of birds can be regarded as wholly inimical to the farmer, and only a few species in any country can be regarded as injurious. Species vary greatly in importance and usefulness when looked at from the standpoint of the agriculturist. Some appear to be of little or no economic worth, while the services of others seem absolutely essential to successful Husbandry, Horticulture or Forestry.

The Good that Birds Do.-They are well fitted by nature for their peculiar office. Their flight is remarkably swift and well sustained. Their sight is keen and telescopic, and they are endowed with a tremendous capacity for devouring, digesting and assimilating food. The muscular exertion put forth by birds in their everyday occupations is extreme. They are so energetic and active that they need far more food than is required by mammals. It is not unusual for the growing young of certain species of birds to consume daily an amount of food fully equal to their own weight, and the quantity eaten by many small land birds is so large that when they forage in flocks on the crops of the farmer they cause excessive loss; but the severity of such losses only serves as an indication of the amount of good that birds do in devouring the destructive insect enemies of the same crops. 
Necessity for Birds.-Huxley tells us that were the increase of a species of aphis (a small insect) to go on unchecked the progeny of a single female in one year would equal in bulk the population of the Chinese Empire. Birds operate to prevent this increase. Many instances are on record where birds, gathering from far and near, have saved trees or crops from destruction by insects or other pests. If the birds were all destroyed and their repressive influence on the increase of insect life thus removed, an unparalleled in-
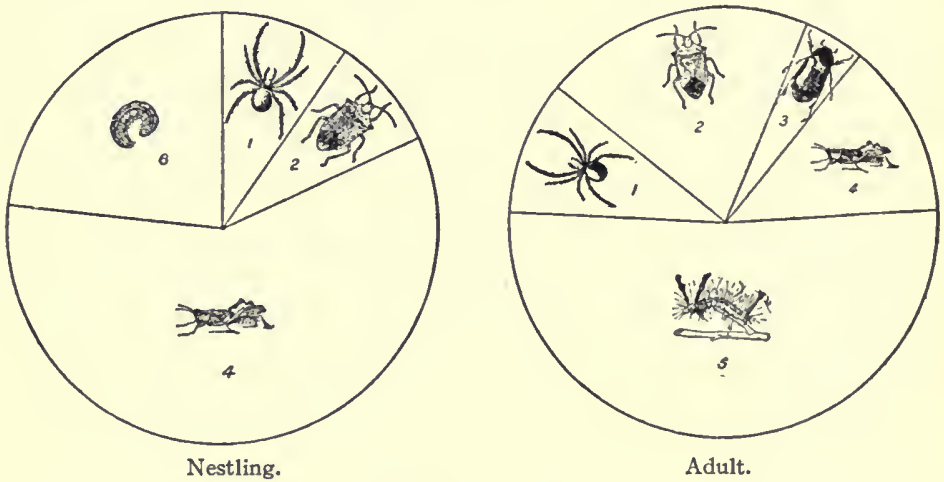

FOOD OF CUCKOO.

I, Spider; 2, stink-bug; 3. May-beetle; 4, grasshopper; 5, caterpillar; 6, cut-worm.

crease of insects might be expected to follow. The local destruction and extirpation of birds has been followed in all recorded cases by an increase of pests, a consequent serious injury to vegetation, and even at times by famine among the inhabitants.

The Food of Birds.-The investigations regarding the food of birds made by the Bureau of Biological Survey of the United States Department of Agriculture have proved conclusively that birds feed very largely on many of the most destructive insects of farm, field and forest, as well as on the seeds of pernicious weeds. The capacity birds show for such food 
is indicated by the following records of the contents of a few birds' stomachs:

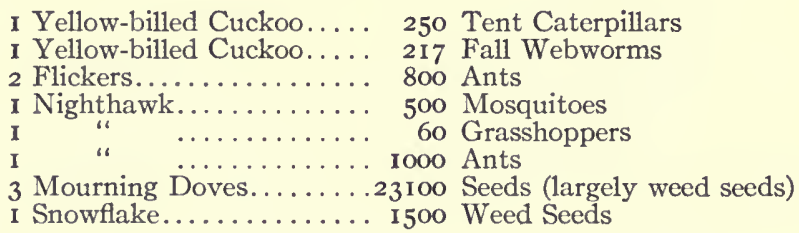

When it is considered that the contents of a stomach represents but a single meal, that the stomach of a bird is ordinarily filled many times daily, and that large
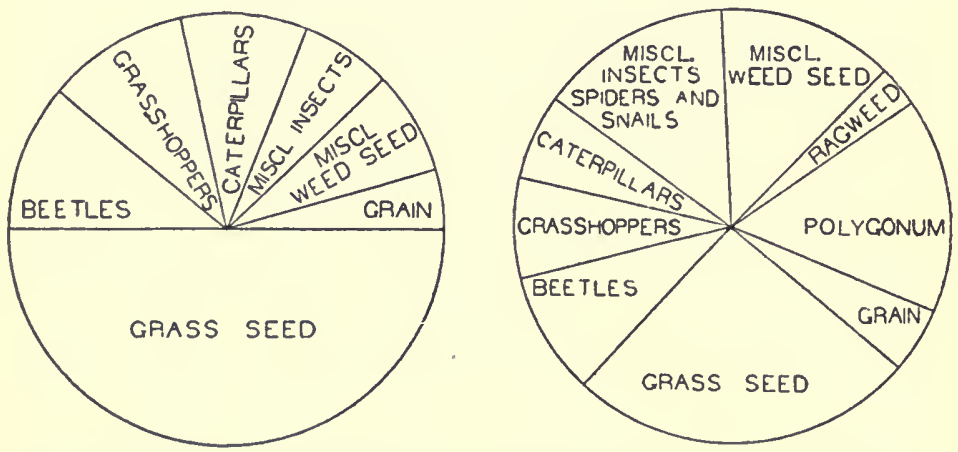

THE DIAGRAM ON THE LEFT REPRESENTS THE FOOD OF A CHIPPING SPARROW; THAT ON THE RIGHT, THE FOOD OF A SONG SPARROW.

numbers of birds can be assembled quickly where they are most needed, the capacity of the bird for good becomes evident.

Every farmer should know what families of birds are of most service to him, for then he will be able to do something intelligently to protect and increase such birds upon his own land.

EXerCise- - Name the wild birds you are familiar with. Make a list of the wild birds that stay all the year. 


\section{Section L.-Birds of Orchard and WoOdLand.}

Those birds that live largely upon the enemies of trees are indispensable to man, for it is impracticable if not impossible for him by artificial means to preserve and protect the trees from their enemies. Something he may do within the narrow limits of the orchard, but he is practically powerless to conserve the forests without the aid of birds and other natural enemies of insects and rodents.

Birds Regulate Plant Growth.-Many birds that feed on seeds vie with the squirrels in distributing seeds, and so rank high as forest planters. Others prune the trees by nipping off buds. Still others regulate the increase of certain insects that otherwise would prune the trees too closely, but that when controlled by birds exert only a moderate beneficent, restraining influence on the exuberance of plant growth.

Woodpecker Family.-First among the birds that feed on wood-eating insects is the woodpecker family. This family comprises a highly specialized group of birds, the more typical of which are especially fitted for digging into the trunks and limbs of trees and extracting ants and other wood-boring insects from their hiding places. The utility of the woodpeckers is now quite generally recognized by orchardists and foresters, both here and abroad. The common Downy Woodpecker of the Eastern United States is one of the chief enemies of timber ants, wood-boring beetles and moths, codling moths and certain plant lice and scale insects.

Nuthatches and Chickadees.-The nuthatches and the titmice or chickadees are nearly, if not quite, as important as the woodpeckers, for they feed very largely on destructive insects that hide in crevices in the bark, in holes or cavities or burrow within the buds, twigs or fruit. The common chickadee is one of the most serviceable of all. The woodpeckers, nuthatches and 


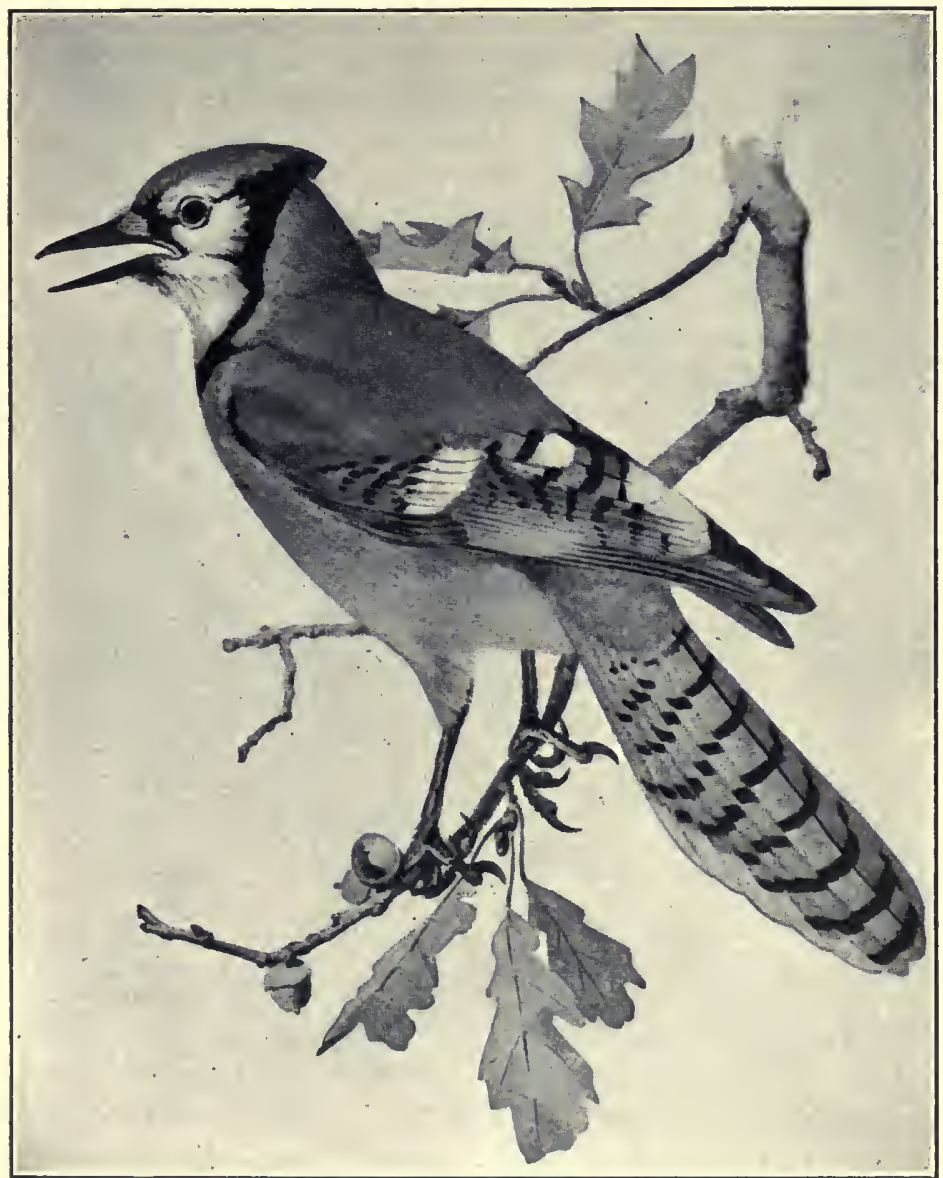

BLUE JAY, A VALUABLE BIRD FOR THE FARMER.

chickadees are doubly useful, because they guard the trees during the entire year. When, in winter, most other birds are absent these busy gleaners are searching every crevice and cranny for the hibernating larvæ, pupæ, or eggs of insects that have escaped the summer birds. The chickadee ranks among the greatest enemies 
of such fruit tree pests as the codling moth, the tent caterpillar, the gypsy moth and the cankerworm, and it is also destructive to bark borers and scale insects.

The Tree Guardians.-Among the birds that are essential to the trees are the creepers and the kinglets, the warblers, vireos, tanagers, orioles and the jays, all of which excel in guarding the limbs and foliage of trees against the attacks of many of the greatest insect pests known. When the developing insects escape all these and, assuming wings, launch out into the air they are met by the flycatchers that, sitting on some van-
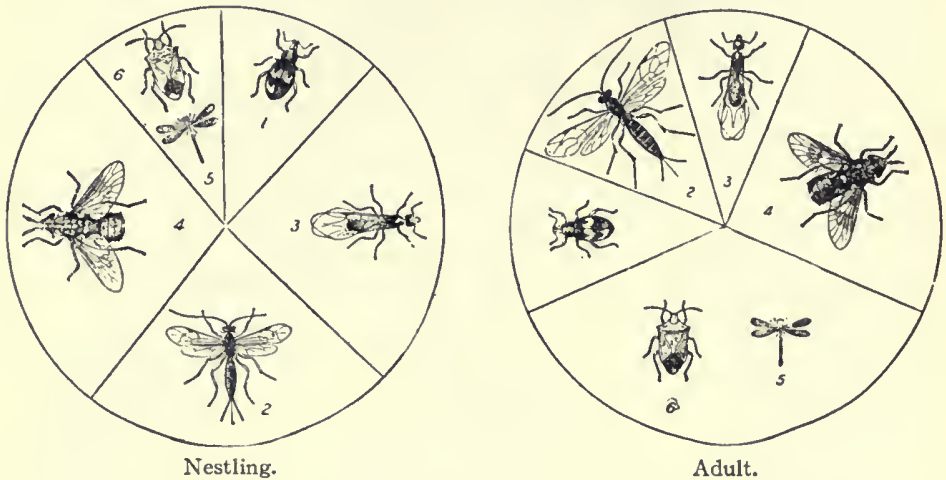

FOOD OF BANK SWALLOW.

I. Weevil; 2, ichneumon-fly; 3, winged ant; 4, fly; 5, dragon-fly; 6, stink-bug.

tage point, pursue and catch them in the air, while above and around all, sweep the swift swallows and nighthawks that pursue their prey even into the upper regions of the air. On the ground below, the thrushes, sparrows, blackbirds and towhees pick up the insects that fall to the ground, or they scratch for insects among the dead leaves on the forest floor. All these families of birds together form the inner and outer circles that guard the tree, and all should be protected by the farmer.

Exercise.-Make as complete a list as possible of the orchard and woodland birds and their food. If one bird eats 150 insects a day, how many insects will four birds eat in seven months? 


\section{Section Li.-Birds of the Field and Garden.}

Birds Protect the Grass Crop.-The services of birds in the field are quite as essential as in the forest. The task of protecting the grass in the field from the attacks of insects is quite as impossible for the farmer as that of protecting the forest trees. Birds must al-

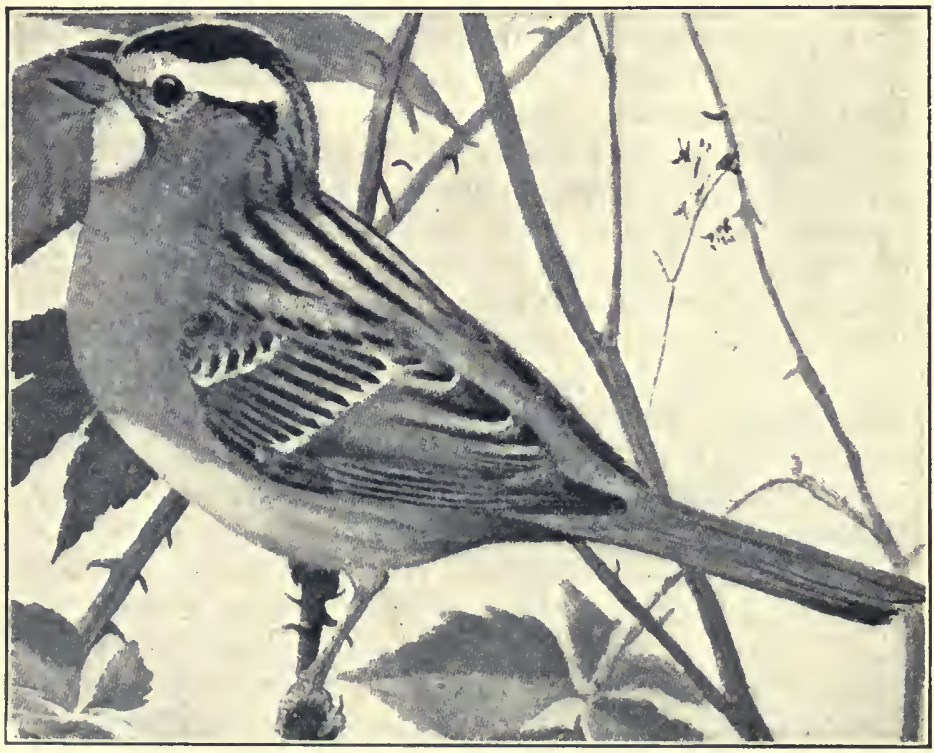

A TYPICAL SEED EATER-WHITE-THROATED SPARROW.

ways be relied upon as protectors of the grass crop from locusts, grasshoppers, leafhoppers, cutworms, grubs and most of the injurious insects of the fields. Professor Herbert Osborn has shown that on an acre of pasture land there are often a million leafhoppers, which consume unnoticed as much grass as a cow. Were these not held in check by the birds which eat them, they might increase so in numbers as to consume all the grass. Instances are on record where the ab- 
solute failure of the grass crop has followed the destruction of birds by the farmers. Wherever the numbers of field birds are greatly reduced, insects increase and the grass crop suffers in proportion.

Nesting Places.- - In the field, as in the forest, birds find hidden nesting places, and an opportunity to rear their young in safety; but the young suffer from the effects of early grass-cutting, which exposes them to the burning sun and to the attacks of their enemies, even if they are not killed by the operations of haymaking. Nevertheless the first broods of the earlynesting birds usually are on the wing by haying time.

$V$ alue of Garden Birds.-In the garden, on the contrary, birds find little chance to breed, for the operations of tillage tend to destroy their nests. Now and then a sparrow may safely rear her young in a potato hill; but few birds can nest in the garden or cultivated field, except where small fruits, trees, or vines are planted. For this reason birds are less serviceable in the garden than in field or forest. Birds which breed in orchard or woodland are nevertheless of great utility in gardens or cultivated fields nearby, and the birds of the air, including the swallows, martins, swifts and nighthawks perform some of their most beneficent services unnoticed, while skimming over garden and field. Doves, sparrows, blackbirds, larks, quail and other ground-feeding birds destroy enormous quantities of weed seeds during all seasons when these seeds are to be found. Prof. F. E. L. Beal estimates that the tree sparrows of Iowa eat 875 tons of weed seeds annually, and the experts of the Biological Survey have computed that native sparrows save the farmers of the United States $\$ 35,000$, 000 each year in this manner.

Useful Species for the Farm.-The thrushes are valuable birds from the standpoint of the husbandman. Chief among them is the American robin. This bird, although noted for its fruit eating propensities, is nevertheless one of the most useful species on the farm. It feeds mainly on fields and cultivated land 
where it finds destructive grubs and cutworms and many injurious beetles, in addition to the common earthworms, which is only one item in its bill of fare. The favorite bluebird eats very little fruit and, like the robin, feeds on field insects as well as on caterpillars.

$W$ rens are among the best helpers in both orchard and garden. The great sparrow family is valuable not only in keeping down weeds, but also in destroying insects. The native sparrows are absolutely indispensable to the man who cultivates the soil as they hold in check some of the worst pests of field and garden. Blackbirds of all species are pre-eminent as destroyers of grubs, grasshoppers and caterpillars, and even the crow, though often a nuisance to the farmer, and a destroyer of small birds, is a very necessary evil in grasshopper time.

The Bobolink, although a pest to the rice farmer of the South, is a blessing in the fields of the North. Mourning doves are among the most voracious of weed destroyers. Bobwhites and meadow larks are now generally believed to rank higher than all the other birds of the farm as destroy-

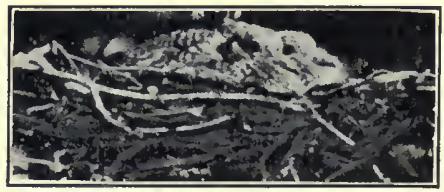

NESTING MOURNING DOVES. ers of insect and weed pests of the garden and field. It will pay the farmer to protect all the above mentioned birds, with the possible exception of the crow.

Birds are Valuable to the Farmer.-There are many birds beside the bobwhite on the game list that are worth far more to the farmer alive in his fields than the small sum he can get for them in the market. One farmer who has observed carefully the habits of the bobwhite says that he considers every one in his fields worth five dollars a year to him as an insect destroyer. While this may be an exaggeration it is easy to compute the annual value to the farmer of a family of bobwhites or meadow larks at somewhere near that figure. 
Sandpipers, plover, grouse, wild ducks, herons, and even some of the gulls and other water birds have been recorded as among the chief friends of the farmer during great insect eruptions in the western states. The history of the invasions of the Rocky Mountain locust and the western cricket is replete with instances where crops were saved by gulls, plover, sandpipers and other birds of the open.

ExERCISE.-Make a rough estimate of the value of bobwhites to the farmers of your community, when one bobwhite is worth $\$ 5$ a year.

\section{Section LiI.-OTther Birds.}

Birds Keep Down Disease.-The services of the swallows, martins, swifts, nighthawks and whippoorwills are not generally understood; but among the insects destroyed by these birds are vast numbers of flies and mosquitoes. Five hundred mosquitoes have been found in the stomach of a single nighthawk. Whippoorwills and swifts destroy millions of them. Swallows not only rank high among fly-catching insects, but they also sweep the grass tops and eat countless myriads of field and garden pests. Martins are particularly useful about the garden. Two quarts of the wingcases of the striped cucumber beetle were found in a martin box at the close of the season.

Utility of the Birds of Prey.-The eagles, hawks and owls have been regarded from time immemorial as among the chief bird enemies of the farmer. Notwithstanding the position which has been assigned them by time-honored prejudice, most of the birds of prey are beneficial to agriculture, and some of the owls are among the most useful of birds. A few species of hawks and owls are very destructive to poultry and game, but among the others only an occasional individual is the culprit, while the many seldom or never attack poultry. Most hawks and owls feed on perni- 
cious rodents, such as house rats and mice, field mice, wood mice and gophers.

Many hawks and owls feed largely on injurious insects. It has been estimated that a single species of hawk saves the western farmers more than $\$ 57,600$ annually during the grasshopper season. It is historical that certain species of field mice increase enormously wherever their natural enemies are not sufficiently numerous to check them. These irruptions of

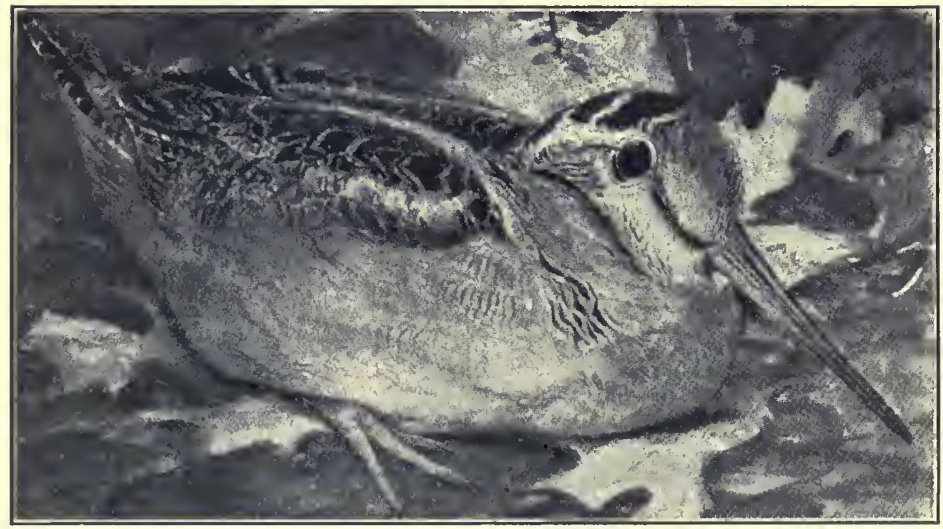

WOODCOCK.

field mice always prove destructive to vegetation, but they are usually checked by the migration of hawks, owls and other birds that feed on them, and that assemble in flocks for that purpose. Even the eagles, though in many cases destructive to farm stock, are often valuable in destroying vermin.

The Protection of Useful Birds.-The farmer is usually so situated that he can readily protect many species of birds upon his farm. He can also attract the birds by feeding them, putting up bird houses and nesting boxes, or by planting or preserving wild plants which furnish birds' food. The study of friendly 
birds and their protection is certainly of as much value to the farmer as the studv of his insect foes.
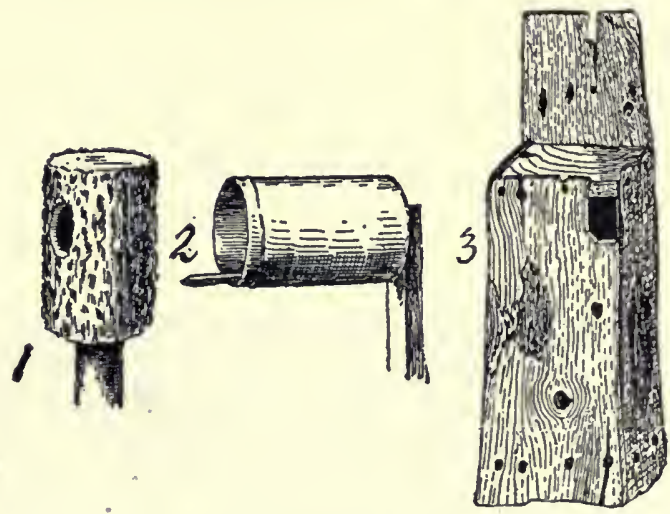

IMPROVISED BIRD BOXES.

(Courtesy National Association of Audubon Societies.)

EXERCISE.-Are there any people that you know who are protecting the birds? State their methods. Has your state a game law?

Note for the Teacher.-Take the class out to the fields and point out the beneficial species of birds. Encourage the pupils to build bird houses in their dooryards. Tin cans, old boxes, etc., will make excellent nesting places. If one class becomes imbued with the importance of bird protection a great deal of good will be accomplished for the farmers of your community. This subject can be made very interesting by the proper presentation.

\section{REFERENCES FOR COLLATERAL READING.}

INSECTS :

Yearbooks of the U. S. Dept. of Agriculture:

I895-The principal insect enemies of the grape.

I908-Information about spraying for orchard insects.

Farmers' Bulletins, Nos. :

47-Insects affecting the cotton plant.

99-296-Insect enemies of shade trees.

I 20 -Insects affecting tobacco.

I27-Important insecticides.

I32-Insect enemies of growing wheat.

133-Clearing houses of flies.

I55- How insects affect health in rural districts.

I72-Scale insects and mites on citrus trees.

244-26I-309-The cattle tick.

264 -The brown-tail moth and how to control it. 
275-The gipsy moth and how to control it.

283-Spraying for apple diseases and the codling moth in the Ozarks.

284 -Insect and fungus diseases of the grape east of the Rocky Mountains.

290-The cotton boll worm.

344-The boll weevil problem.

Bureau of Entomology, U. S. Dept. of Agriculture, Bulletins, Nos.:

13-Circular on Mosquitoes.

$7 \mathrm{I}$-Circular on House-flies.

72-The North American fever tick.

Experiment Station Bulletins, Nos.:

38-New Hampshire-Forest tent caterpillar.

39-New Hampshire-The army worm.

44-New Hampshire-The cankerworm.

5I-Missouri-The chinch-bug.

I8I-Virginia-Wormy apples and how to prevent them.

252-New York-Cornell-Insect pests and plant diseases.

For other literature on insects, address the Bureau of Entomology, U. S. Dept. of Agriculture, Washington, D. C., and the State Experiment Stations and Crop Pest Commissions.

BEEs :

Farmers' Bulletin, No.:

59-Beekeeping.

Bureau of Entomology, Bulletins, Nos.:

$70-$ Report of the meeting of inspectors of apiaries.

BIRDS :

75-Beekeeping in Massachusetts.

Yearbooks of the U. S. Dept. of Agriculture:

I895-Four common birds of the farm.

I896-The blue jay and its food.

1897-Useful birds and harmful birds.

1900-How birds affect the orchard.

I908-The relation between birds and insects.

Farmers' Bulletins, Nos. :

54-Some common birds.

366 -The crow.

376 -Game laws for I909.

383- How to destroy English sparrows.

Bureau of Entomology, Bulletins, Nos.:

6-The common crow.

15-The relation of sparrows to agriculture.

The publications of the Biological Survey, U. S. Dept. of Agriculture and the pamphlets issued by the National Association of Audubon Societies, I4I Broadway, N. Y. City, contain interesting literature on birds.

Books :

How to Keep Bees-Comstock-Doubleday, Page \& Co., New York City.

A B C and X Y Z of Bee Culture-A. I. Root Pub. Co., Medina, Ohio.

Useful Birds and Their Protection-Forbush-Mass. Board of Agriculture, Boston. 


\title{
CHAPTER VIII.
}

\section{LIVE-STOCK AND DAIRYING.}

\section{Section LiII.-Principles of Animal Breeding AND GRADING.}

\author{
By Prof. E. S. Good,
}

Department of Animal Husbandry, Kentucky State University.

All domestic animals were at one time wild, and only those survived which were fitted by nature to endure climatic, food, and other conditions of the country in which they lived. This process of the survival of the fittest is known as "natural selection."

Variation and Artificial Selection.-As man progressed these wild animals were domesticated, and finding that they did not fully meet his wants, he took advantage of the law of "variation," which is, brieflythat the offspring will present certain characteristics of size, color, quality, etc., not possessed by either parent. By selecting those animals that varied to suit his needs and taste, he has developed our present types of domestic animals. This process is known as "artificial sclection."

Heredity. - While there is a tendency for the offspring to vary from the parents in some particular or particulars, yet in the main they will resemble them, or near relatives, and this is known as the "law of heredity." Reversion.-If an animal is born with some characteristic common to its distant ancestors, it is known as a case of "reversion," which is illustrated, for instance, by a Devon cow (a breed red in color) giving birth to a white calf resembling its ancestors, the "Wild White Cattle of the Park." It must not be understood that variation and selection alone have 
given us our different types of animals, for climate, food and care have played an important rôle. There are other terms used in live-stock operations, such as pure-breeds, scrubs, cross-breeds and grades, which the student should understand. A pure-bred animal is one whose sire and dam belong to the same breed. A scrub is an animal whose ancestors belonged to no distinct breed. A cross-breed is one having for its parents animals belonging to two distinct breeds. A grade is an animal having a pure-bred animal for one parent and a scrub for the other. There. are more scrubs in this country than there are pure-breeds, crossbreeds and grades combined.

Grading up Live-stock.-Millions of dollars could be added to the profits of farming in the United States, if the people would pay more attention to the breeding, care and feeding of their live-stock. For example, the average milk cow of the United States produces but I 50 pounds of butter a year, scarcely enough to pay for the feed she eats. It is well known that the pure-bred parent has more influence in determining the form, color and useful qualities of the offspring than a scrub parent, or in other words, the pure-bred parent is called "prepotent." By taking advantage of this fact the farmer can, by continued use of purebred sires of a certain breed, soon build up a herd of grades that for all practical purposes are nearly as good as pure-breeds. The young of a pure-bred male and a scrub female is a half-blood; the offspring of a half-blood female and a pure-bred male is threequarters pure; the next generation of this system of breeding would be seven-eighths pure, or a high grade. This cannot be done, however, by using a sire of one breed at one time, and a sire of another breed at another time. It is unwise to use anything but pure-bred sires, as the characteristics of grades or cross-breeds are unstable and improvement is uncertain.

EXERCISE.-A re any of the farmers of your vicinity making an effort to build up their stock with a pure-bred sire? What is the aver- 
age butter production of the dairy cow in your section in pounds per year? If you had a herd of scrubs, how would you improve the herd? If you live in the South, would you purchase live-stock from the North or from the South? Why?

\section{Section LIV.-Types and Breeds of Horses.}

\section{By Prof. E. S. Goop,}

Department of Animal Husbandry, Kentucky State University.

Horses like cattle are not native to America. There are four principal classes of horses to meet the demands of man, namely: The Draft, Coach or Carriage, Light Driving and Saddle Horse.

I. Draft Horse.-This type of horse is large and powerful, weighing from $\mathrm{I}, 500$ to 2,200 pounds. The

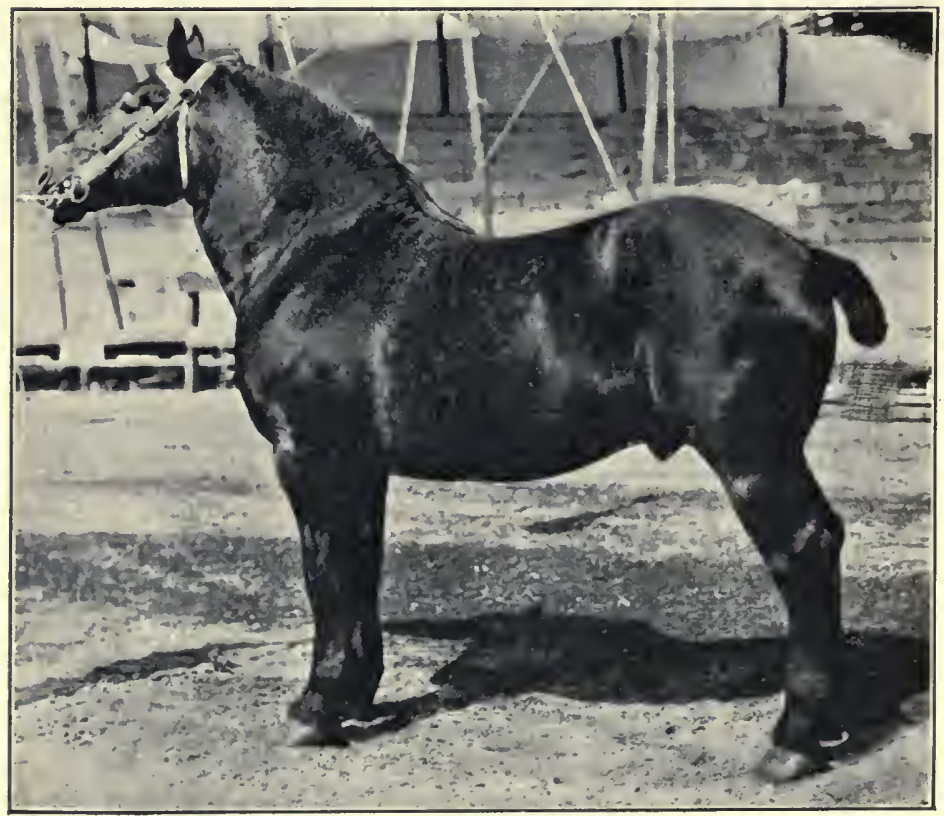

DRAFT TYPE-PERCHERON. 


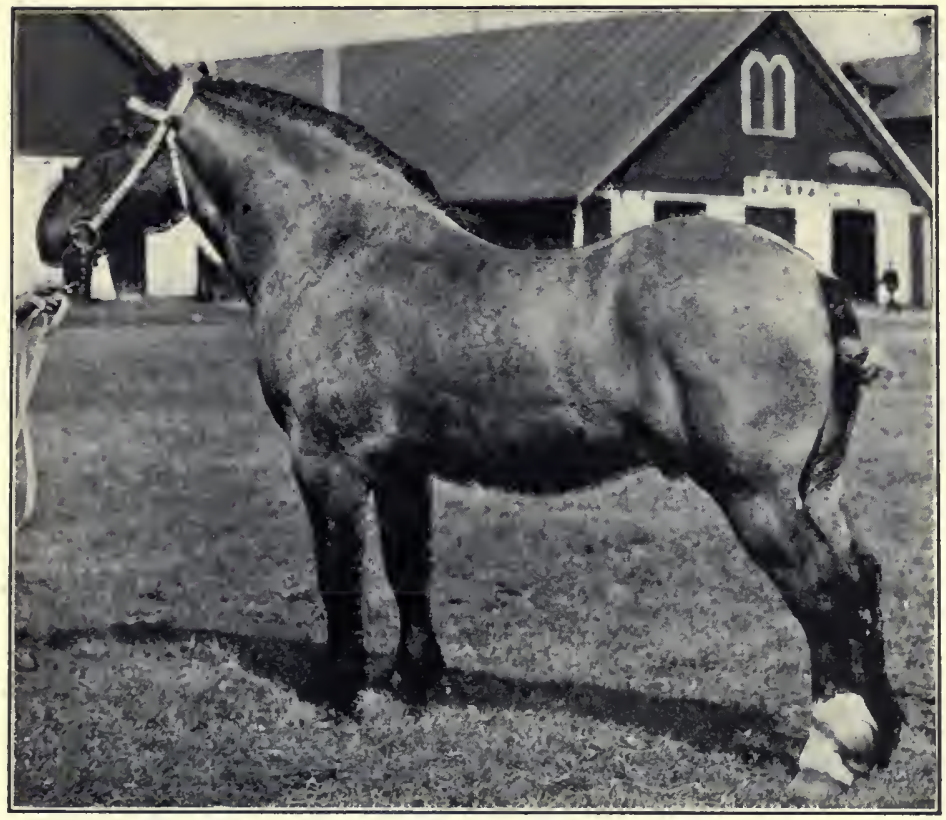

DRAFT TYPE-BELGIAN.

weighty draft horse is used largely in the cities to haul heavy loads, while the lighter ones are used to a large extent on the farms. The following are the four principal breeds of draft horses seen in America :

$$
\text { Breeds of Draft Horses. }\left\{\begin{array}{l}
\text { Percheron..... Developed in France. } \\
\text { Belgian....... Developed in Belgium. } \\
\text { Clydesdale.... Developed in Scotland. } \\
\text { Shire......... Developed in England. }
\end{array}\right.
$$

Percheron.-The Percheron is a deep-bodied, shortlegged, massive type of draft horse. Usually the colors are light or dark gray, although black is common, and brown sometimes occurs. The Percheron is a popular draft breed in the Western States.

Belgian.- This breed of draft horse resembles the Percheron, though the Belgians are more blocky of body, and the legs are shorter. The colors are roan, 


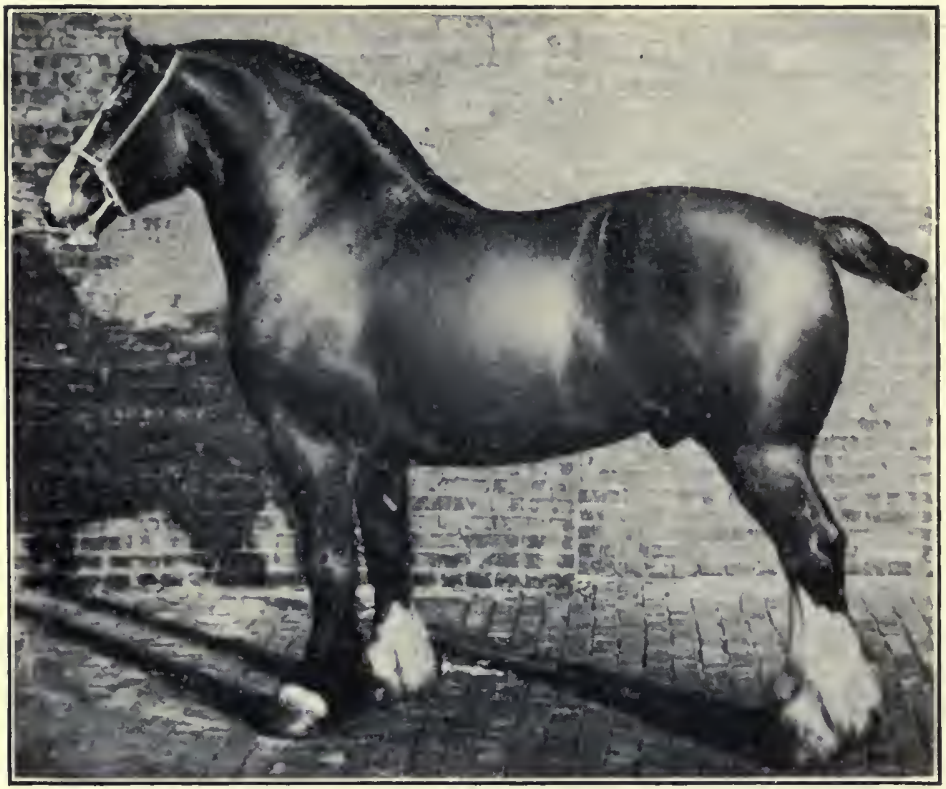

DRAFT TYPE-CLYDESDALE.

chestnut, bay and gray, although gray is not a popular color in this breed.

Clydesdale.-The horses of this draft breed are a little longer of leg, and not quite so deep in body as the Percherons and Belgians. The principal colors are bay or brown, though blacks are sometimes seen. Many horses of this breed have white markings usually confined to the lower parts of the legs and a stripe in the face. White feet are very common. From the back of the cannon grows an abundance of long silky hair called "the feather."

Shire.-The Shire looks so much like the Clydesdale that at times it is difficult to tell them apart. However, the Shire is a little heavier than the Clydesdale, and has not quite as good action.

The Score Card is a great help to a beginner in making a study of a horse in detail after he has learned 
the names of the different parts of that animal as are shown on page 324 . The description after each part of a horse teaches one how it should look when correctly formed and of the right quality. The number placed after each part or quality represents the relative importance of one part as compared with another, as determined by expert judges. If a horse were perfect he would score a hundred points, but no horse good enough for that has ever existed. It takes an exceptionally good horse to score ninety points. After a student has scored a number of horses he should lay aside the score card and learn to scan the entire animal quickly, noting in his mind the good and poor points of the animal.

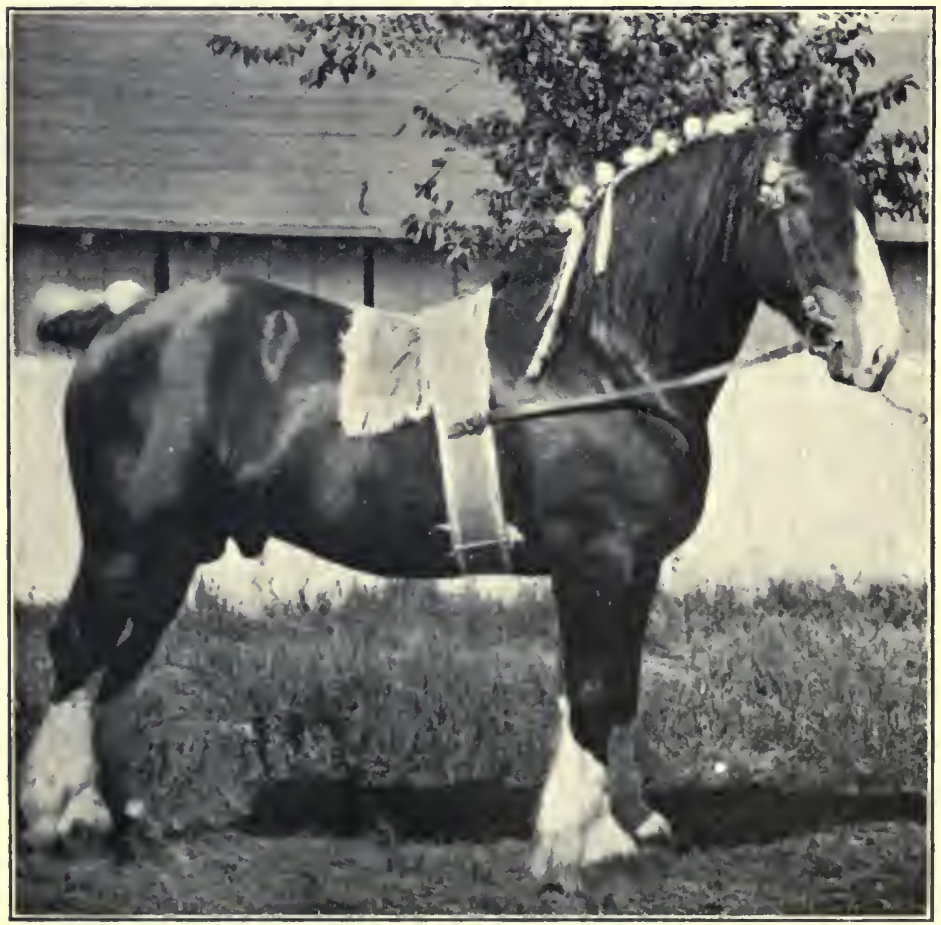

DRAFT TYPE-SHIRE. 


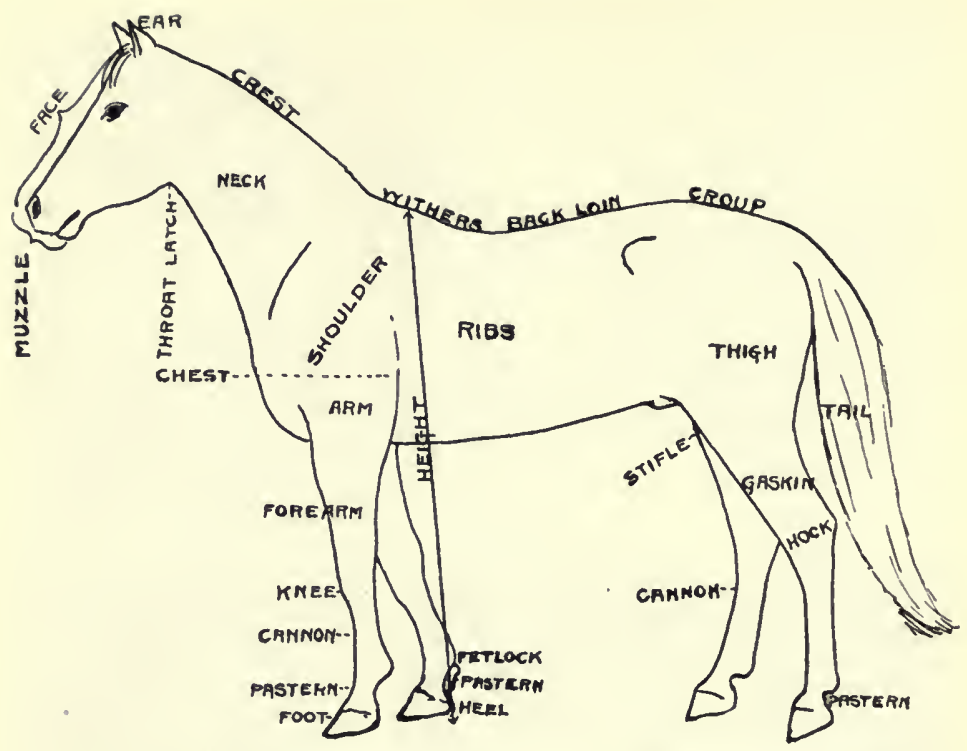

LOCATION AND NAMES OF THE DIFFERENT PARTS OF THE HORSE.

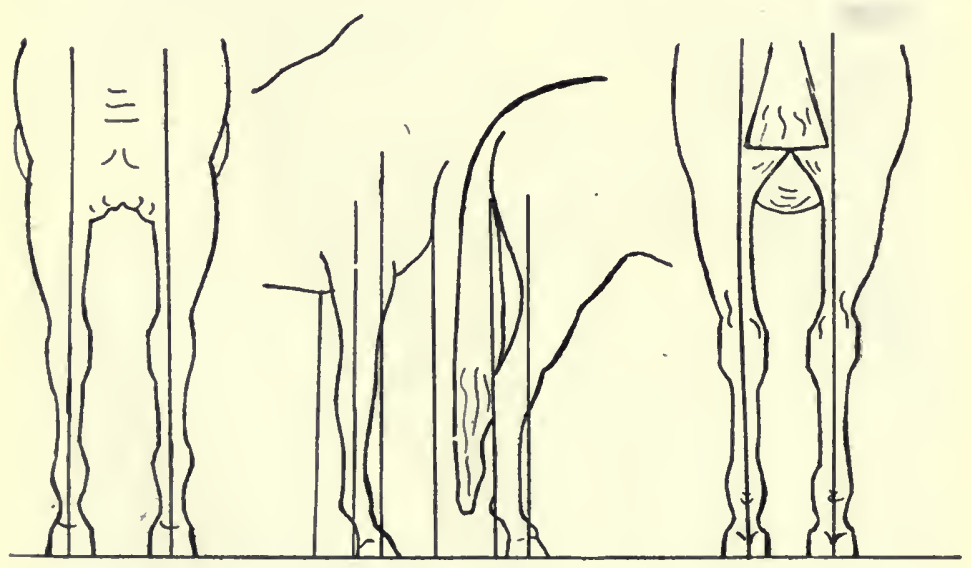

DIAGRAM SHOWING THE PROPER SHAPE OF FORE AND HIND LEGS OF A HORSE. 


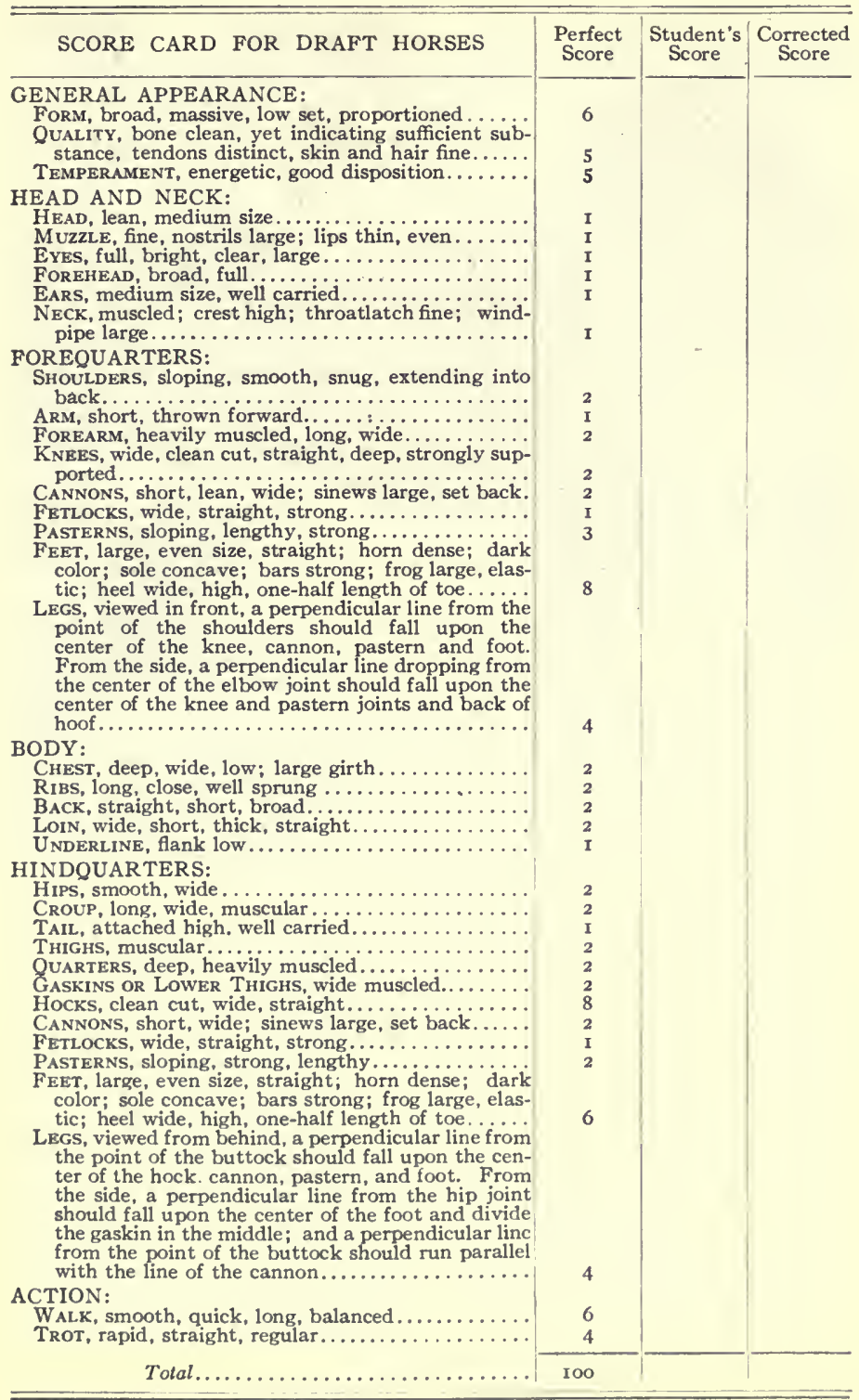




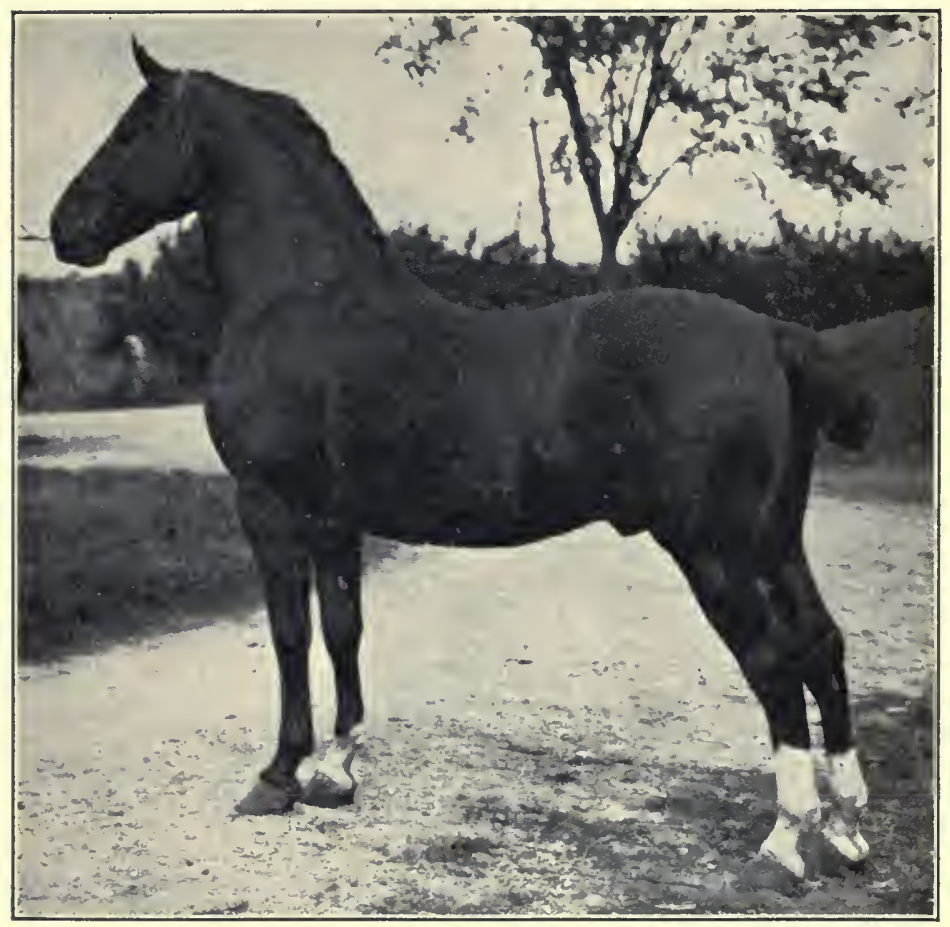

A COACH HORSE.

2. The Carriage or Coach Type.-Horses of this type are smaller than the draft type, and have smooth, graceful body lines, arched necks and neat heads. When a coach horse walks and trots he must be a stylish high stepper. The coach horse stands about I 6 hands * high and weighs from I, IOO to I,250 pounds. The stallions of the distinct coach breeds, however, usually weigh more than this. Horses of this class are used to draw coaches or heavy carriages. There are several distinct coach breeds, although some of the larger horses of the breed, called the "Ameri-

* One hand $=$ four inches. 
can Trotter," make splendid carriage and coach horses. The following are the breeds of coach horses:

Breeds of Coach Horses. $\left\{\begin{array}{l}\text { German Coach. Developed in Germany. } \\ \text { French Coach.. Developed in France. } \\ \text { Hackney ..... Developed in England. } \\ \text { Cleveland Bay. Developed in England. }\end{array}\right.$

German Coach.-This breed is a large type of the coach horse, standing I 6 to I $61 / 2$ hands high. The colors are bay, black and brown.

French Coach.- This breed is not quite as large, but has a little higher action than the German Coach. The colors are bay, chestnut and black, but bays are most often seen.

Hackney.-The Hackney is smaller and more

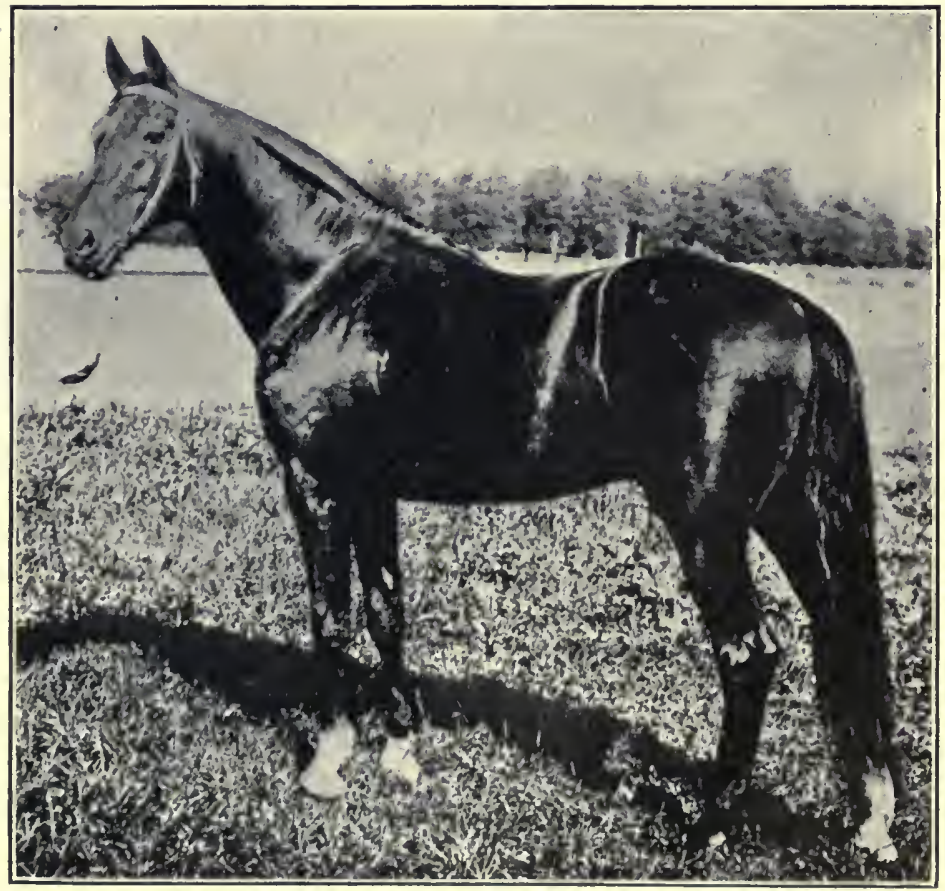

A TYPICAL ROADSTER. 
blocky in build than are the German and French coach horses. The height ranges from I $51 / 2$ to I $53 / 4$ hands. This breed has splendid constitution and endurance, combined with good action. Brown and chestnut colors are the most common; black, roan and sorrel are sometimes seen.

Cleveland Bay.-This is the largest but least stylish breed of coach horse. Horses of this breed are, however, very strong. The color is always bay with black legs, mane and tail.

3. The Roadster or Light Harness Type.-Horses of this type have been bred for speed and stamina; that is, they can cover distances quickly without becoming unduly fatigued. They average 14.3 to 16 hands in height, and weigh from 900 to I, I 50 pounds. They are more slender in body and have longer legs than the coach horse.

The following are the breeds of Light Horses:

Breeds of Light
Horses. $\left\{\begin{array}{l}\text { Thoroughbred......... Developed in England. } \\ \text { American Trotter...... Developed in United States. } \\ \text { American Saddle Horse. Developed in United States. }\end{array}\right.$

Thoroughbred or Running Horse.-A long time ago race horses from Arabia, Turkey and Barbary were imported by the English, and crossed with their light type of English horse to produce a running horse which they called the "Thoroughbred." This breed of horse with his lithe form, long nicely arched neck and small shapely head, together with long well defined legs looks every inch a speedy horse. The colors are various, although bay, sorrel and chestnut with white markings are most often seen. A Thoroughbred named Salvator, owned at Lexington, Kentucky, holds the world record in running a mile in one minute, thirty-five and one-half seconds.

American Trotter. - The foundation stock of the American Trotter was the Thoroughbred, and like that horse has great speed and endurance. The colors vary as they do with the Thoroughbred. A mare 


$$
\frac{\pi}{\pi}
$$


by the name of Lou Dillon trotted a mile in less than two minutes, the time being $1.581 / 2$.

The Pacer.-The breeding of the Pacer is the same as that of the American Trotter, the difference being in the gait, for when a horse paces, the two legs on one side are moved at the same time, while in trotting a front leg and the opposite hind leg move together.

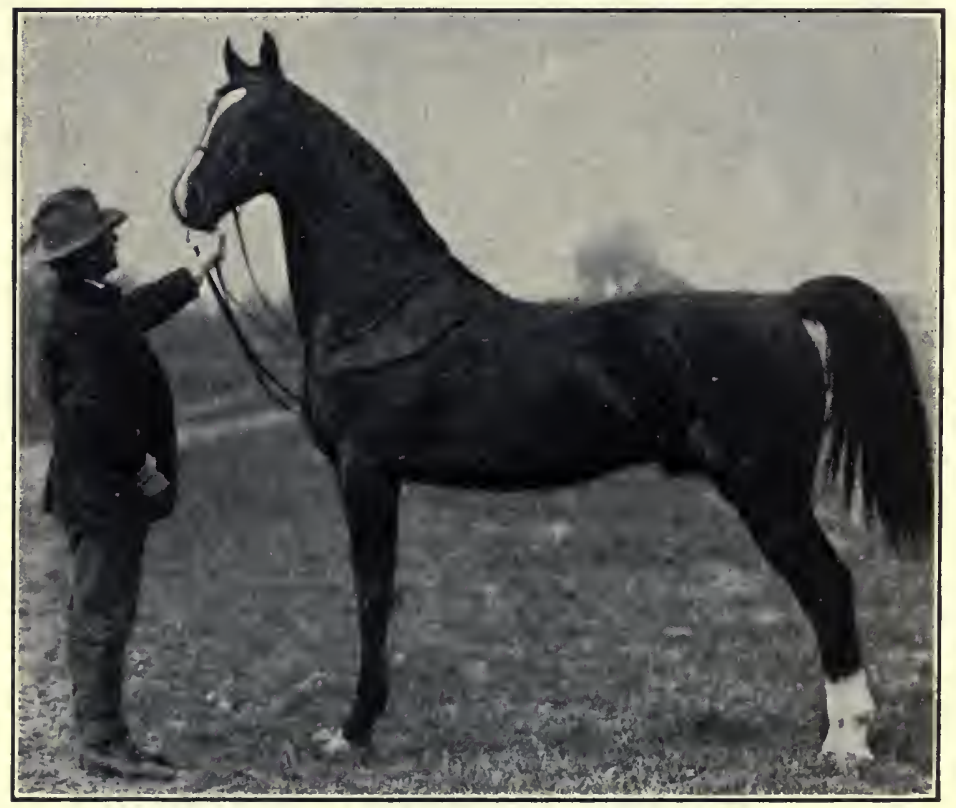

A TYPICAL SADDLE HORSE.

4. The American Saddle Horse.-In the early history of Kentucky, Virginia, Tennessee and Missouri the roads were poor, making travel in carriages very difficult. As a result, horseback riding was a favorite method of travel, and easy gaited horses were selected as saddle horses. A good many of these horses were Thoroughbreds. By careful selection of horses with shapely necks and heads, splendid bodies and legs, com- 


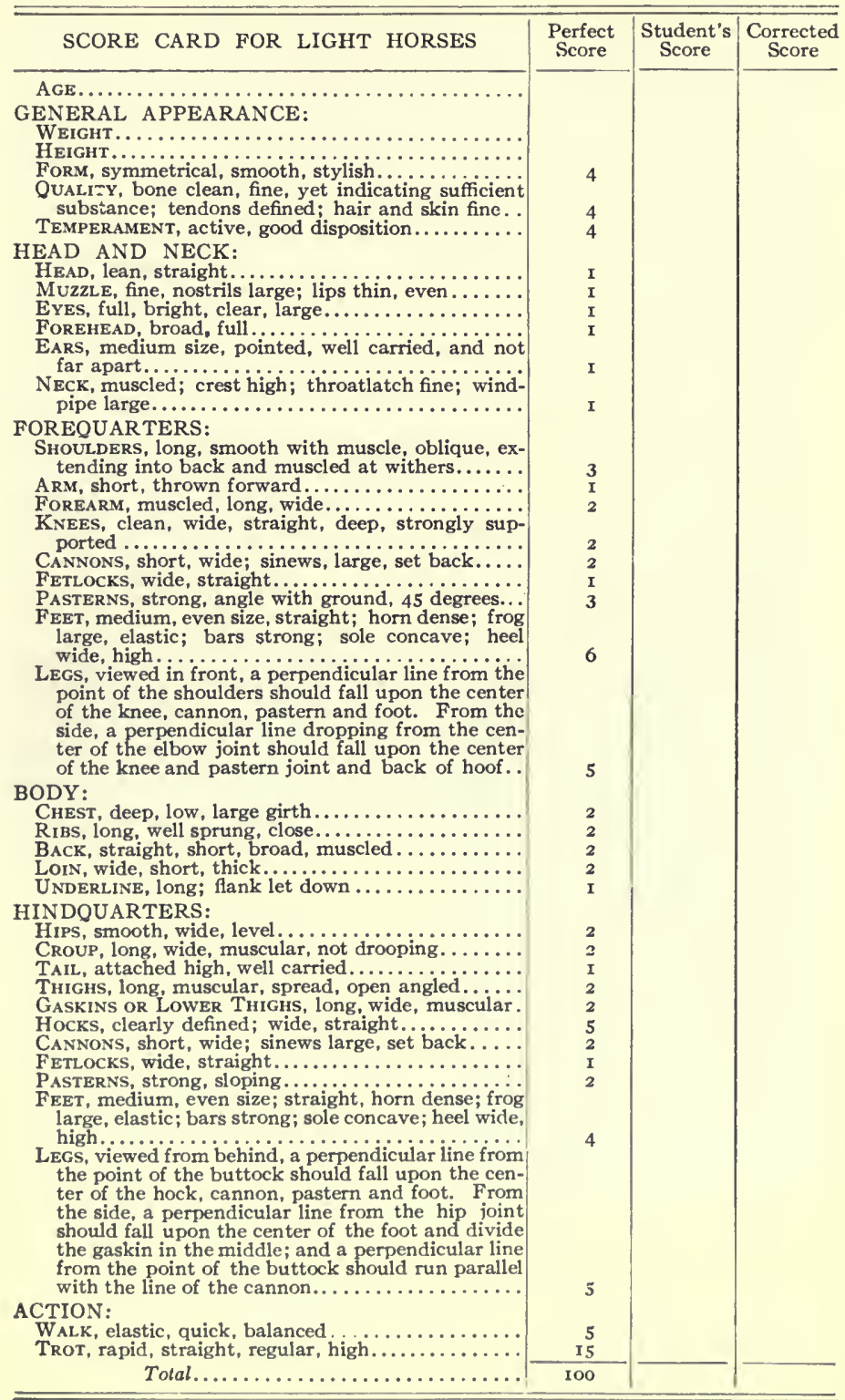


bined with ease of movement, there has been evolved the present breed of saddle horse which is beautiful to look at and a pleasure to ride. As Kentucky has been most prominent in the development of this type of horse we often hear the name "Kentucky Saddle Horse." A plain gaited saddle horse walks, trots and canters, while a gaited saddle horse must go five gaits, namely: walk, trot, canter, rack (sometimes called single foot), and either the running walk, slow pace or fox trot.

Shetland Ponies. - The Shetland Islands north of England are the home of the Shetland Pony. The scant vegetation and cold climate of these islands are responsible for the small size of the ponies raised there.

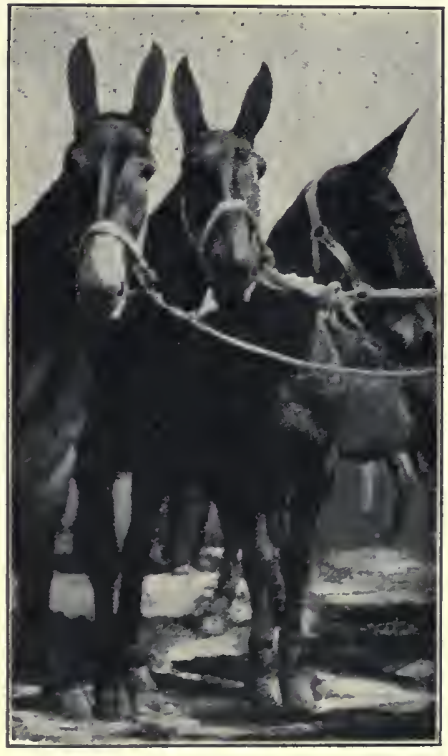

TYPICAL VIRGINIA MULES. Some of these native ponies are not more than nine hands high. In America, where food is plentiful and the climate not so severe, they grow larger from generation to generation. The colors are bay, black, chestnut, gray, brown, roan and spotted. The Shetland Pony has a gentle disposition, and is, therefore, popular as a children's pet.

Mules.-The mule is the offspring of a jackass, called a jack, and a mare. In other words, the mule is a hybrid. Mules do not breed because they are sterile. This animal is a hardy, easy keeping, steady beast of burden. It is preferred to the horse for draft purposes in some sections of the country, especially in the South. 
EXERCISE.-Name the classes of horses prevalent at your home. What breeds are they? Is there any reason why these breeds predominate? Which can stand the hot southern summers better, the mule or the horse? Do horses ever sleep standing? What position does a horse assume when lying down? How does he arise? Which goes to sleep earlier, horses or cattle?

The teacher should require the pupils to score draft and light horses.

\section{Section LV.-Types and Breeds of Cattle.}

By Prof. E. S. Good,

Department of Animal Husbandry, Kentucky State University.

To Great Britain belongs the credit of originating most of our breeds of cattle. To a large degree these breeds have been developed from the aboriginal cattle of that country. In the large parks and forests of a few of the estates of England and Scotland can be

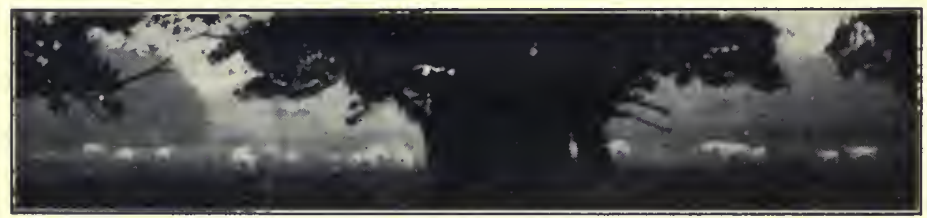

WILD WHITE CATTLE OF THE PARK.

seen the direct descendants of these aboriginal cattle, which are called the "Wild White Cattle of the Park." These have been left to run wild for centuries, but have not been allowed to cross with any other cattle. They are kept simply as objects of curiosity, as they are of little value for beef, and of no value for milk.

I. Beef Cattle.-As the word "beef" implies, this type of cattle is bred principally for the production of meat. The beef animal should have a straight, broad top line; a straight bottom line; deep, wide body, and short legs.

The Score Card.-To judge beef cattle one must know what the different parts of the animal are called, 


\section{and the comparative value of these parts as shown by the score card.}

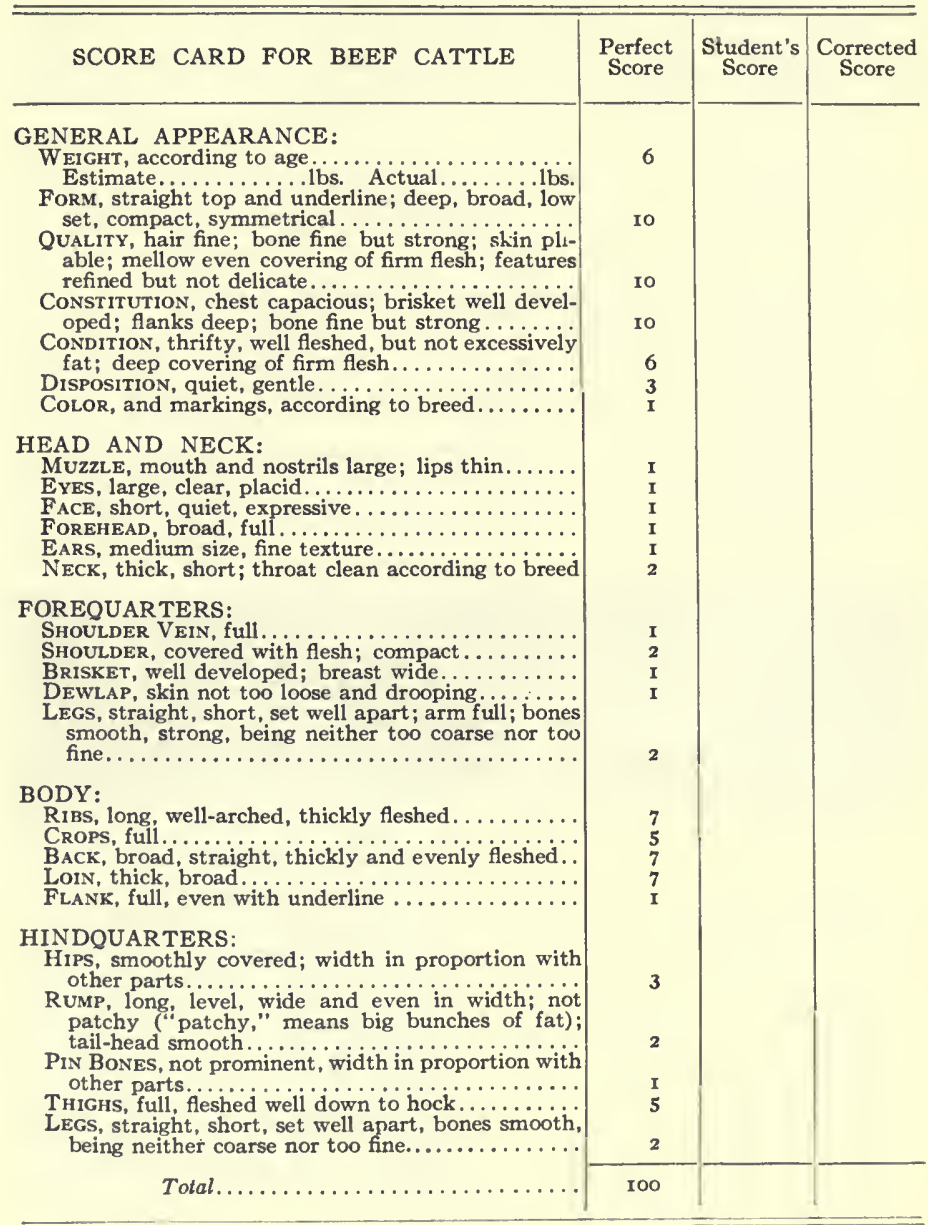

With exception of form, quality and constitution those parts of the beef animal receiving the highest counts on the score card are the regions of the best 


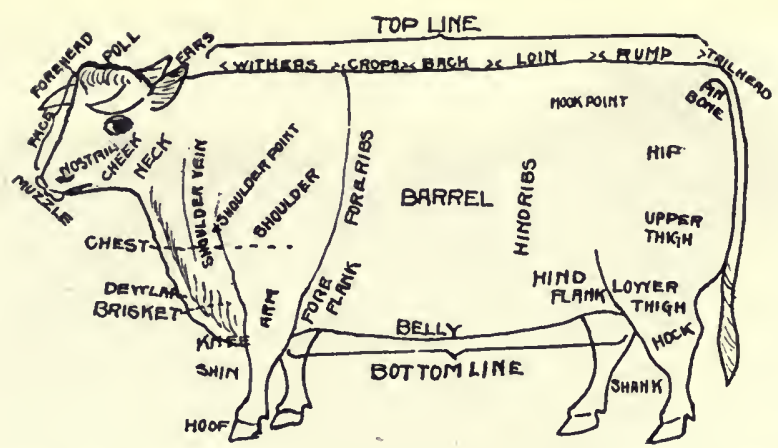

SHOWING THE BEEF FORM AND THE NAMES OF THE DIFFERENT PARTS OF THE BEEF ANIMAL.

cuts of meat. Compare score card with figures above and below.

The accompanying figure shows the different cuts of meat as well as the number of pounds of each cut that can be obtained from a choice, well fattened beef animal weighing I,400 pounds; also the price per pound for which they would retail in Chicago. The reason that some cuts of meat are more valuable than others is because they are more tender and juicy.

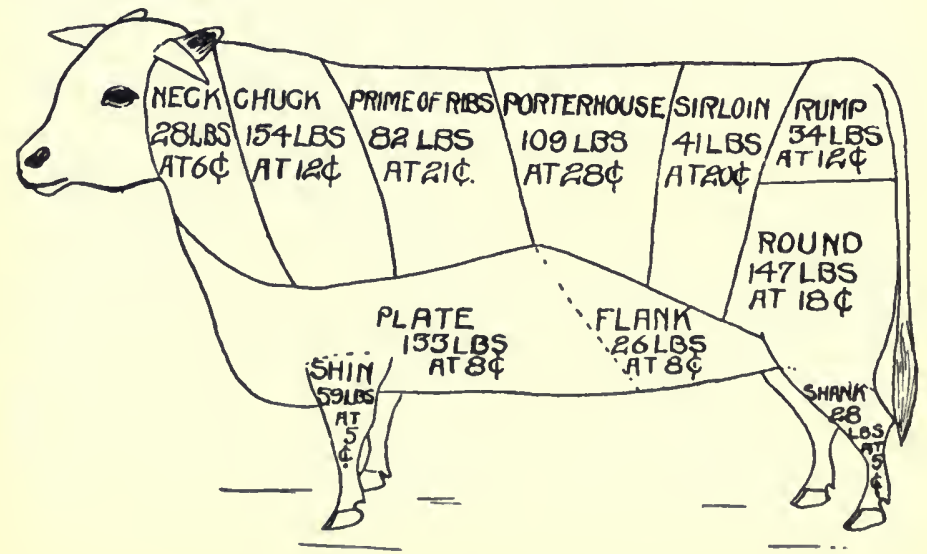

CUTS OF MEAT AND WEIGHTS OF CUTS. 


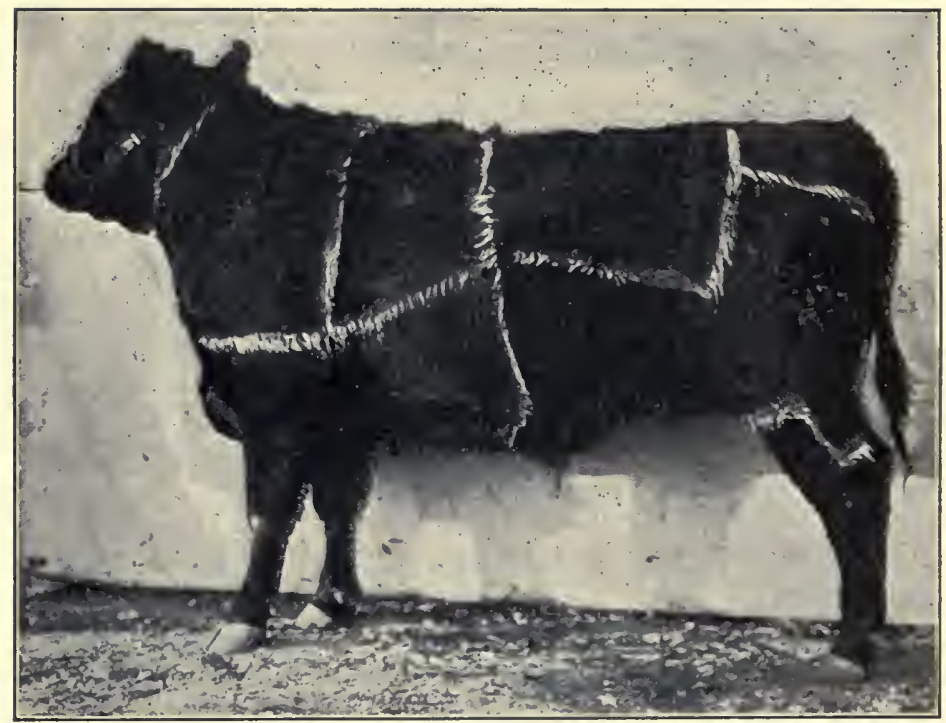

DIAGRAM SHOWING MEAT CUTS ON LIVE ANIMAL.

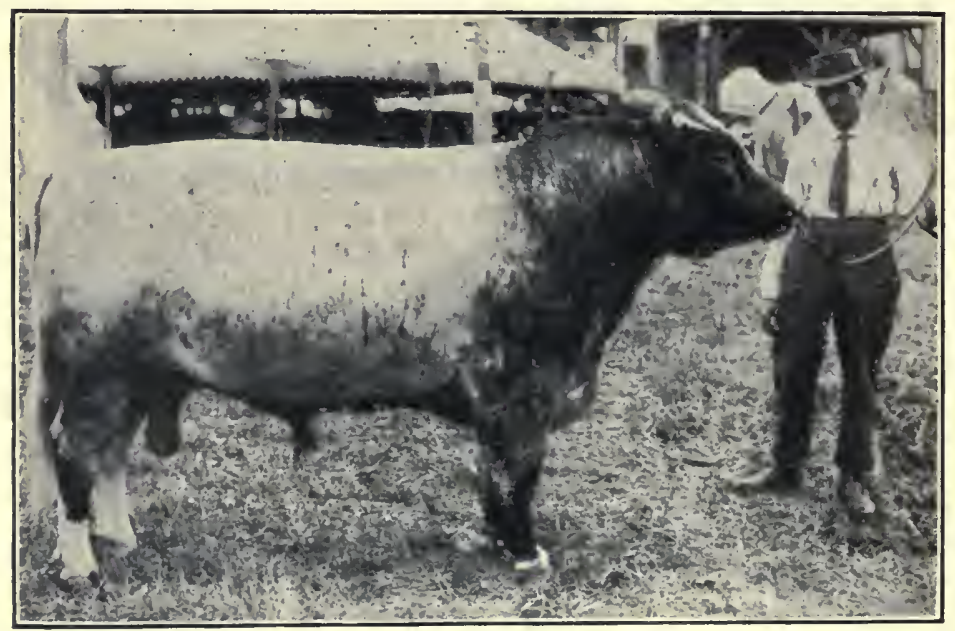

A TWO-YEAR-OLD SHORTHORN BULL. 
The breeds of beef cattle are as follows :

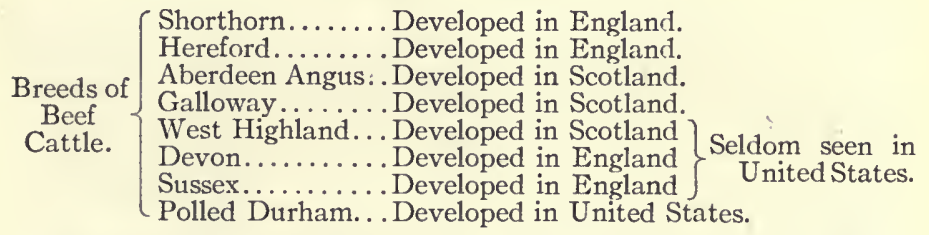

Shorthorn.-This breed is sometimes called "Durham." The Shorthorn is the largest of any of the

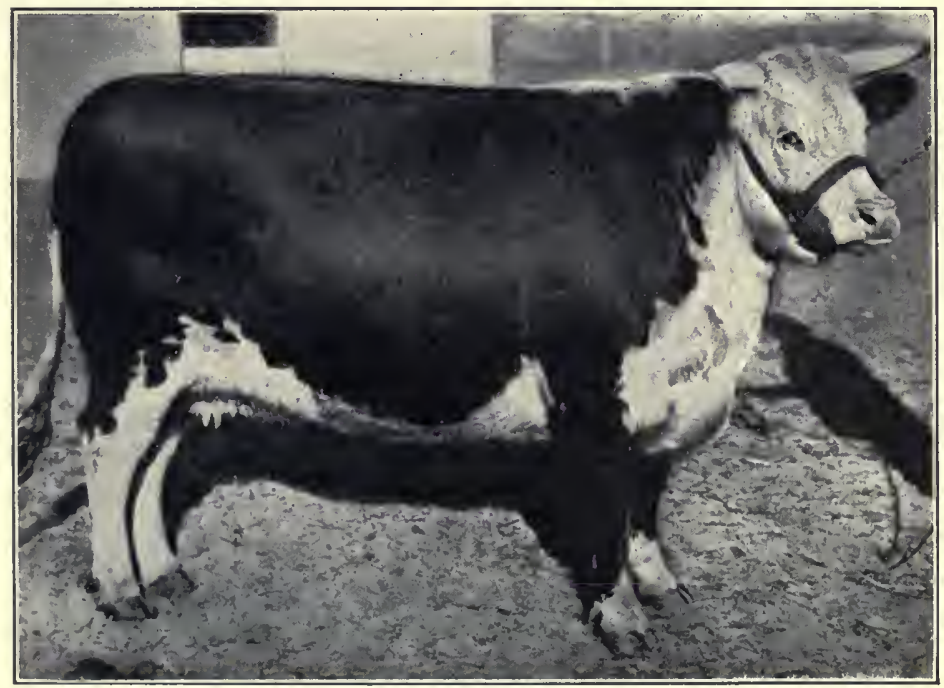

A HEREFORD COW.

beef breeds. The horns are short. The colors are red or white, or those two colors combined. Some families of this breed give large quantities of milk.

Hereford.-Herefords are sometimes called "White Faces," as they have red bodies, with the face, a part of the neck, and the underline white. The Hereford fattens more readily on grass than any other breed of cattle, hence it has been a popular breed in our Western States. 


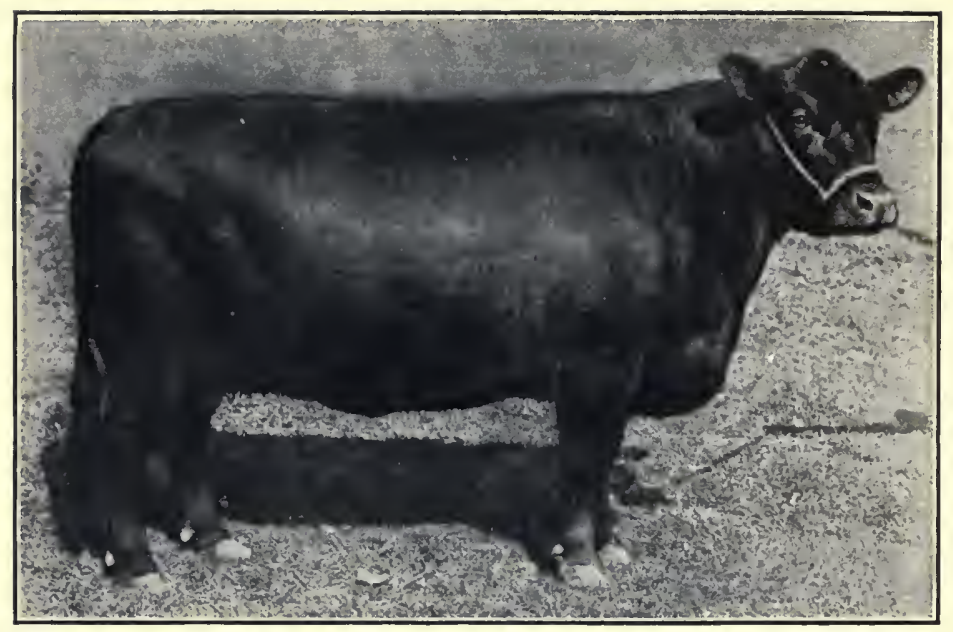

AN ABERDEEN ANGUS COW.

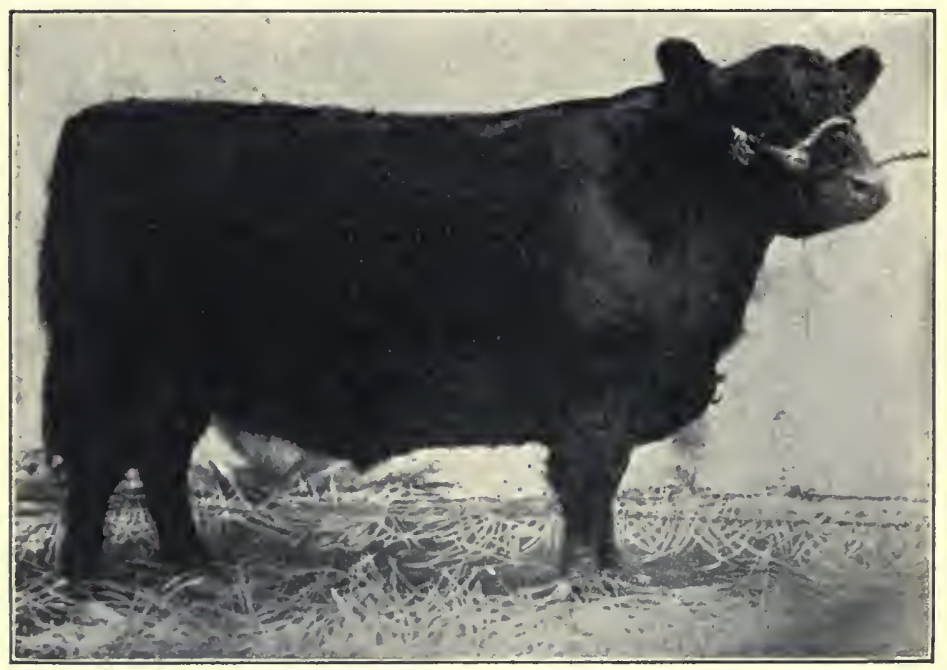

A GALLOWAY. 
Aberdeen Angus.-This is a very popular breed of beef cattle, sometimes called "Polled Angus." They are more rounding in form than other breeds of beef cattle. They are black in color and have no horns.

Galloway.-The Galloway is another breed of beef cattle without horns. The hair is most often of a brownish-black color. In the winter time the Galloway has two coats of hair, the outer coat being long and wavy, while the inner coat is short, abundant, and soft to the touch. The hides of some Galloways make good robes.

Polled Durham.-These cattle are either pure or nearly pure-bred Shorthorns without horns, the horns having been bred off through the laws of variation and heredity.

2. Dairy Cattle.-Instead of the deep, broad, smooth rounded outlines of the beef cow, the dairy

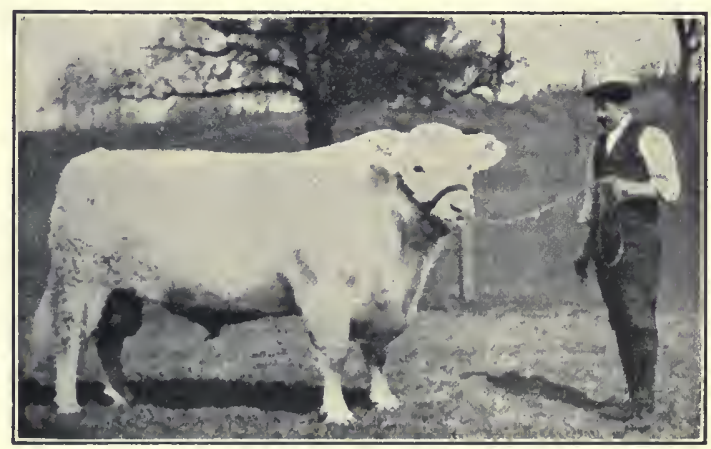

CHAMPION BULL-SHENSTONE ALBINO.

type presents one of curves and angles, and a body devoid of natural flesh, for the dairy cow uses her food to produce milk instead of beef. The form of the dairy cow is usually spoken of as being a triple wedge shape, that is, in viewing the cow from the top there is an increasing width from the withers downward, making the first wedge; viewing the cow from the front, 


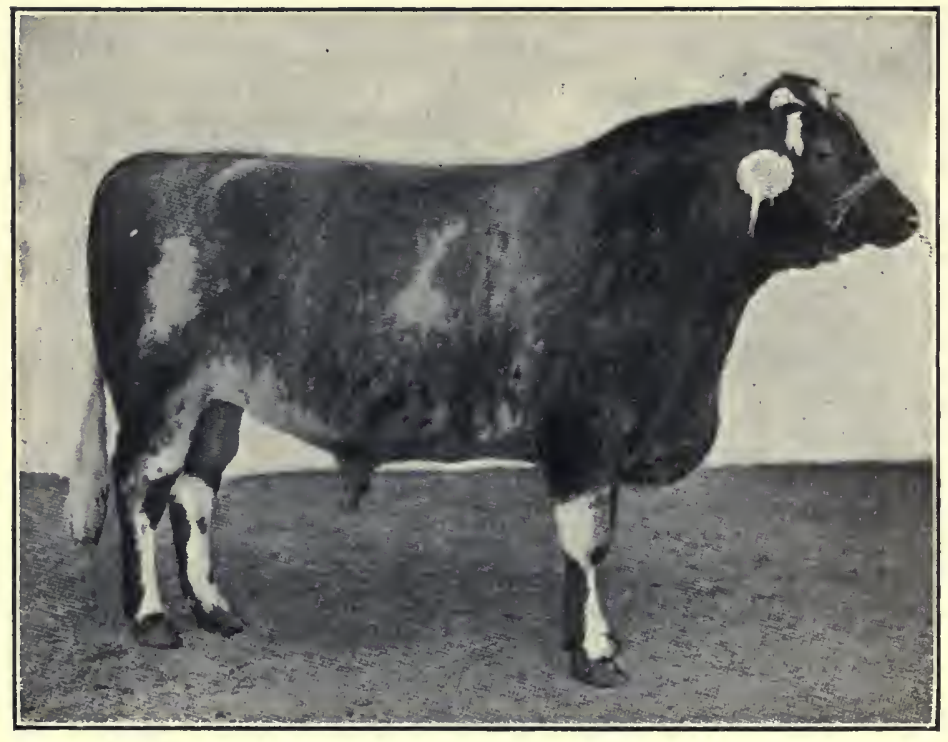

DURHAM BULL, TWO YEARS OF AGE.

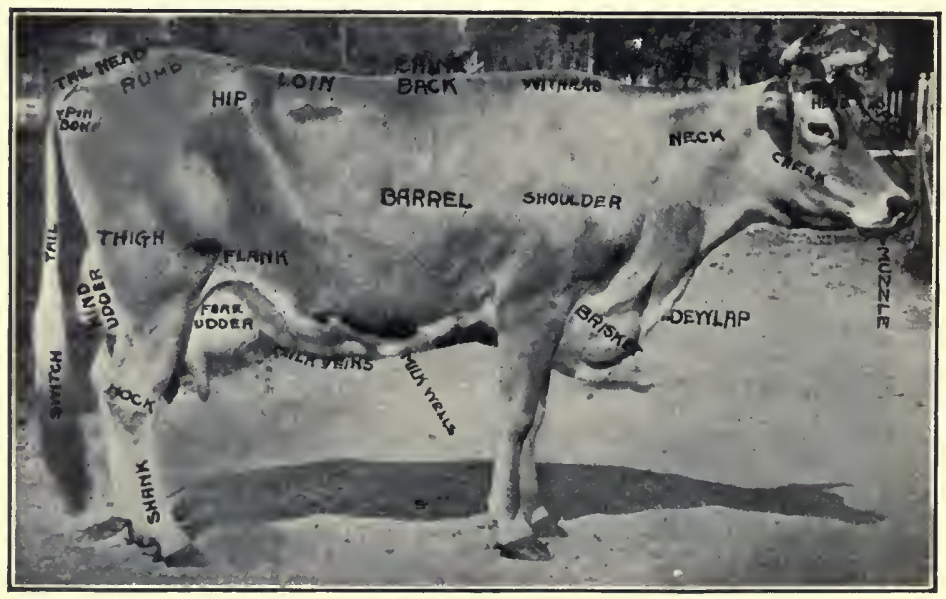

DAIRY TYPE-ALSO SHOWING THE PARTS OF THE DAIRY COW. 
there is an increasing width of body toward the rear parts, making the second wedge; viewing the cow from the side there is an increase in distance between the top and bottom lines as they go towards the rear of the animal, forming the third wedge. The withers of the dairy cow should be sharp, and the back straight and lean. The barrel of the dairy cow should be large, so that she may hold large quantities of feed and convert it into milk. The thighs should be curved in as viewed from the side, and they should also be flat. The udder is not, as many suppose, a reservoir to hold milk until it is milked out, but is made up of tissue
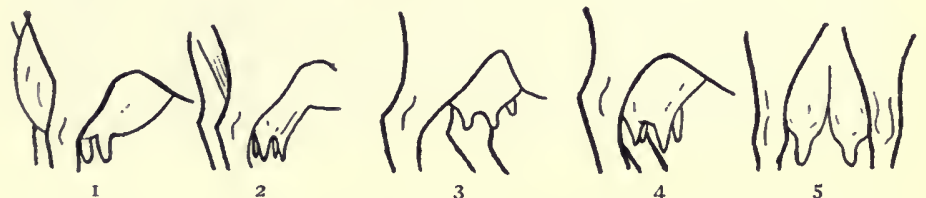

TYPES OF UDDERS.

I, A perfect udder; 2, as a perfect udder looks when milked dry; 3 , udder too small; 4 , undesirable shape; 5 , an udder too much cut up.

having a great many tiny cells which take from the blood the different substances, such as casein, water, sugar and fat, that go to make milk. Some of the milk is produced and stored in the udder between milking times, but more of it is made from these substances found in the blood, at the time the cow is being milked. If an udder is made up of the best kind of tissue to produce milk, it will be limp when milked out, instead of looking nearly as full as it did when the milking began.

The milk veins should be large, for that indicates that a large amount of blood, from which the milk is obtained, goes through the udder.

Breeds of Dairy Cattle:

Jersey....... Developed in Jersey Island ? Located between Eng. Guernsey.... Developed in Guernsey Island $\}$ land and France.

Holstein..... Developed in Holland.

Ayrshire..... Developed in Scotland.

Dutch Belted.Developed in Holland. 


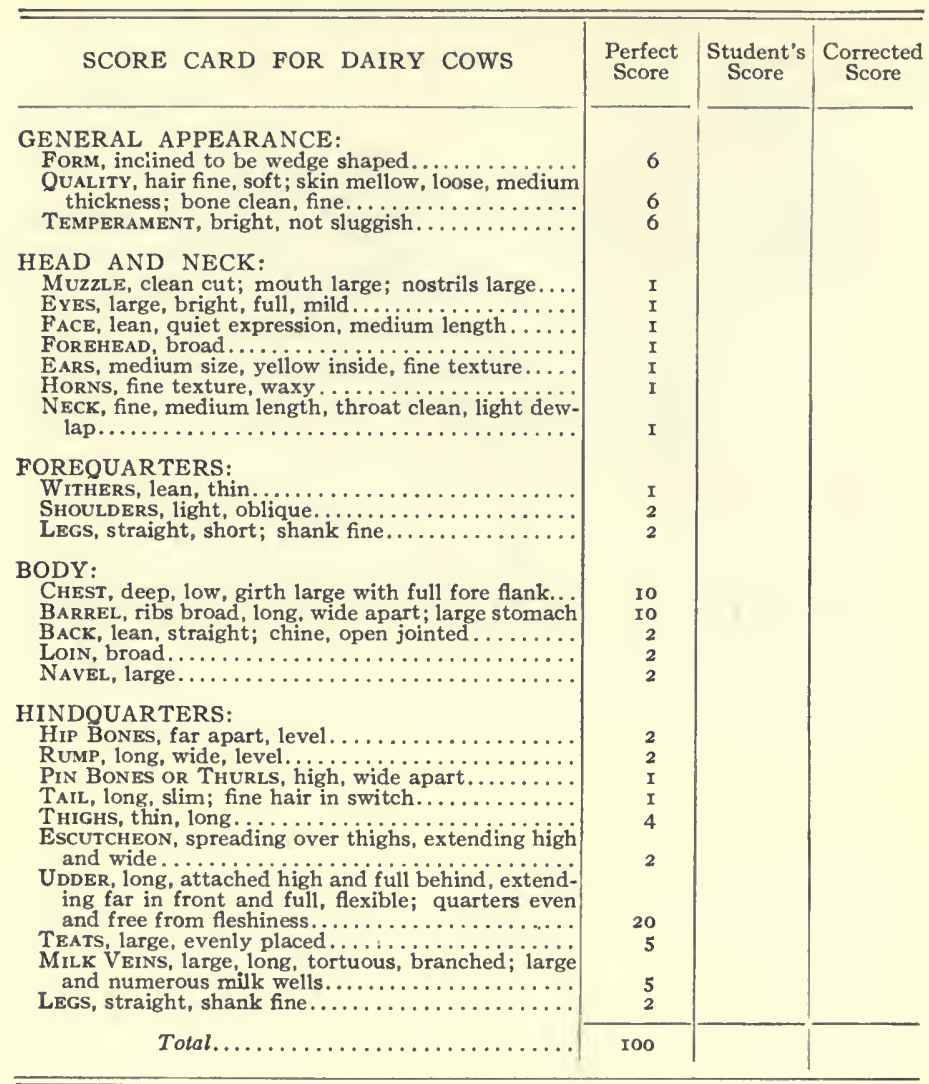

Jersey.-The Jersey cow with her refinement of form, short, crumpled horn, dished face, and large eyes is the most beautiful of any of the dairy breeds. The Jersey is noted for the richness of her milk. The colors most commonly seen are shades of gray and fawn, with occasional white markings. All Jerseys, and most grade Jerseys, have a black muzzle with a light colored band of hair around it. A Jersey cow named Jacoba Irene gave 17,253 pounds of milk in a year, from which were made I, I 2 I pounds of butter. 


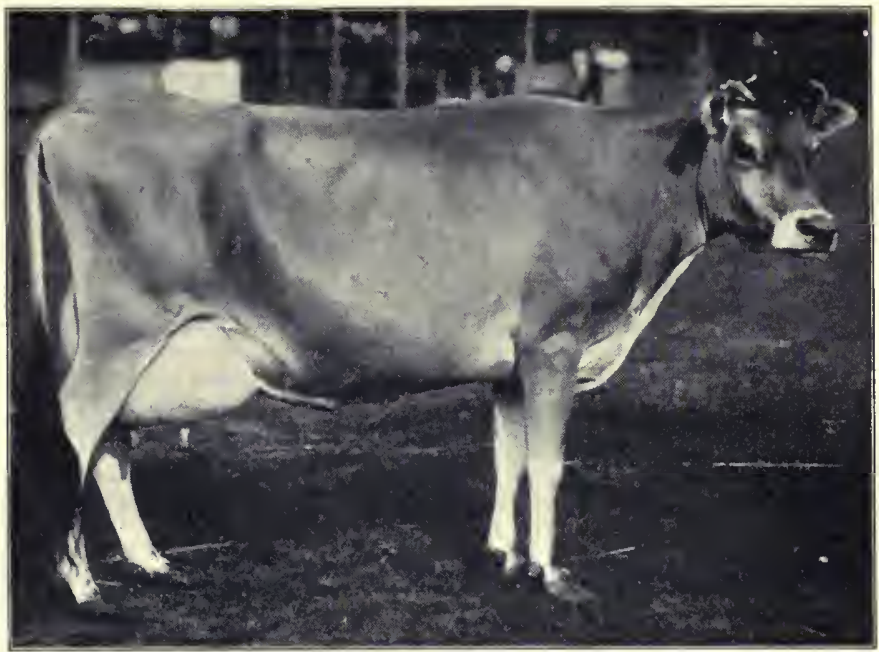

A TYPICAL JERSEY.

Guernsey.-Guernseys look very much like Jerseys, although they are a little larger. The colors are orange-fawn, lemon-fawn, and reddish yellow. White

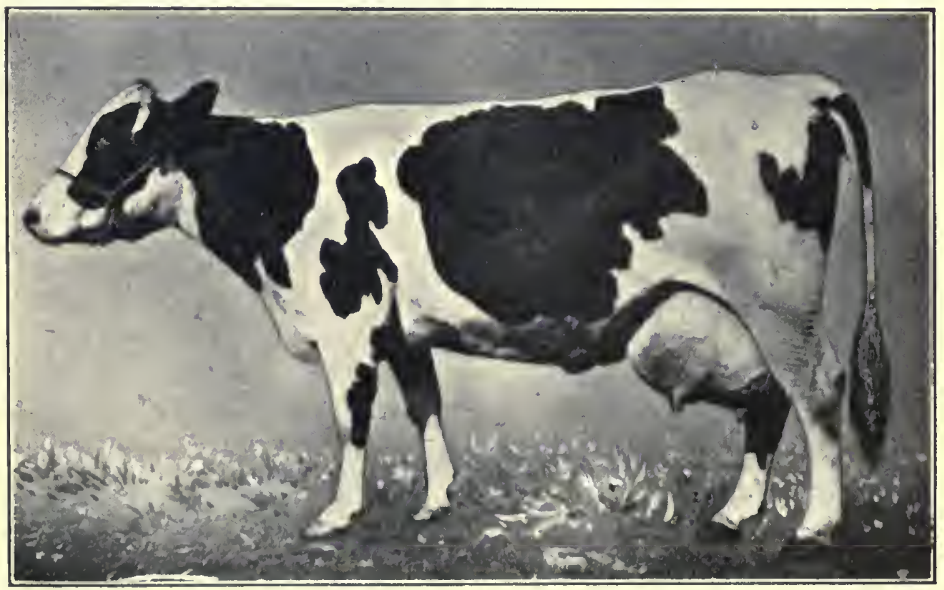

HOLSTEIN-FRIESIAN COW. COLANTHA 4TH'S JOHANNA. 
markings with these colors are common. Guernseys also give large quantities of milk, rich in butter fat.

Holstein-Friesian-Cattle of this breed are considerably larger than the Jerseys and Guernseys. They are black and white in color. These cattle are noted for giving large quantities of milk, but it is not as rich in butter fat as is that of the Jerseys and Guernseys. They also eat larger amounts of feed than the two breeds mentioned. A Holstein cow by the name of

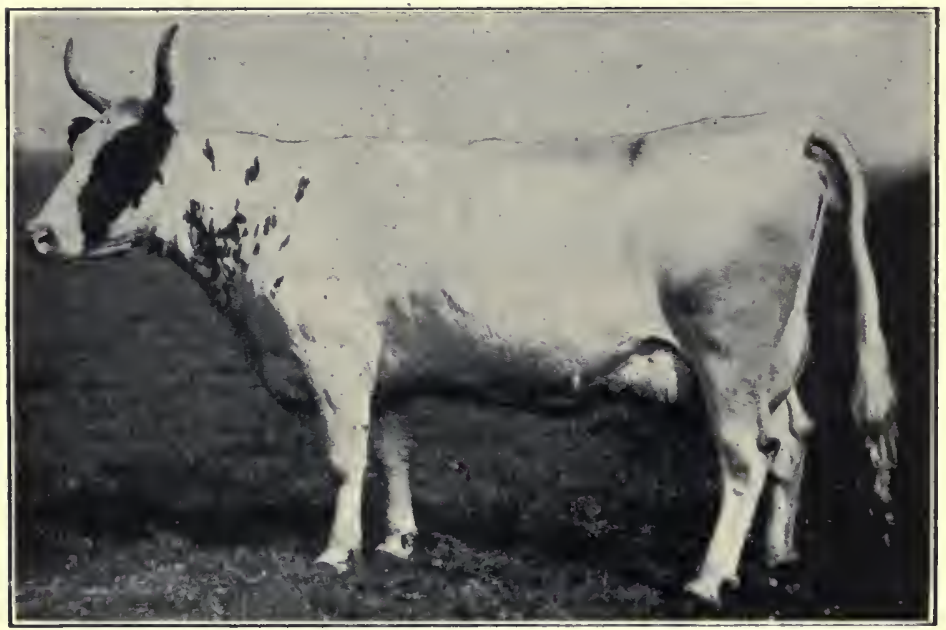

AYRSHIRE COW.

Colantha 4 th's Johanna gave 27,432 pounds of milk in a year, which produced I, I 64 pounds of butter.

Ayrshire.-This is a very hardy breed of dairy cattle, giving large quantities of milk which is especially good for cheese-making. The colors are red of any shade, brown or white. A good many cows of this breed are more or less spotted. The horns usually incline upward.

Dutch Belted.-This is a black breed of cattle with a white band around the body.

3. Dual-Purpose Cattle.-Cattle of this class are 
used both for milk and beef, and their form should be judged from both the dairy and beef cattle standpoints.

Breeds of Dual-Purpose $\{$ Red Polls....... Developed in England.

Cattle. $\quad$ Brown Swiss.... Developed in Switzerland.

Red Polls.-This breed is red in color and has no horns.

Brown Swiss.-The colors of this breed are mostly shades of brown, although gray colors are sometimes seen. They usually have a light-colored stripe along the back. Some families of the Shorthorns and Polled Durhams have the qualities of dual-purpose cattle.

Sell Unprofitable Cows.-Any dairy cow to be profitable should produce at least 250 pounds of butter in a year. The only way to weed out inferior cows from a herd of dairy cows is to keep a record of the milk each cow gives, as well as the butter fat which it contains, selling unprofitable cows to the butcher.

EXERCISE.-Name the breeds of cattle with which you are familiar. Which type of cattle is the more common in your neighborhood? Why is this type popular? What breed of cattle predominates in your state? Why? What season of the year do the people at your home market cattle? Are they grass fed entirely? What price do beef cattle sell for? Are they marketed at home or are they shipped away? Do you live in a dairy state? Are there any farmers in your section who keep a strict account of the milk and butter fat production of their cows?

The pupil should be required to know the name and location of each part of the beef and dairy animal; also the name and location of each cut of beef. How do the prices of the different cuts of beef on the Chicago retail market compare with those of your local butcher? Should the dairy cow be handled gently? Why? The pupil should score beef and dairy animals.

\section{Section LVI.-Types and Breeds of Sheep.}

By Mr. Joseph E. Wing, Staff Correspondent Breeders' Gazette.

History of Sheep.-For more centuries than written history goes back sheep have been the companions of men. No domestic animal has been more changed by 
man's care and selection than the sheep. Doubtless the first wild sheep had very little wool, and were much stronger and more active animals than any sheep known to-day. At present the wild, ancestral type has entirely disappeared from the earth, and were man to

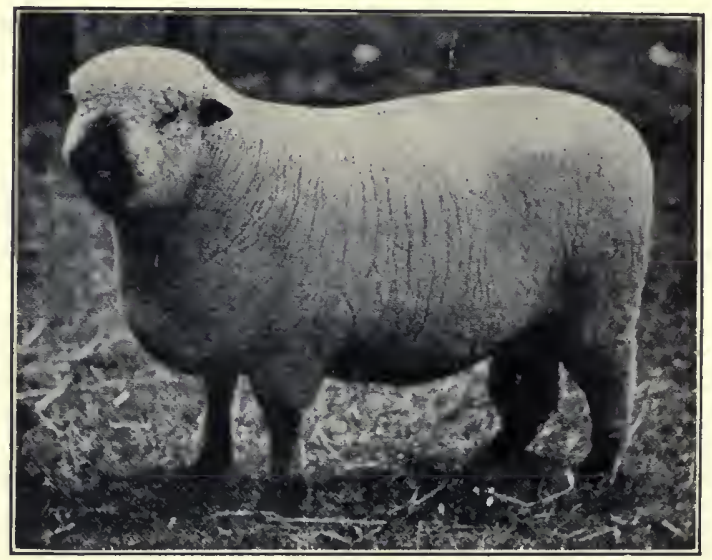

SHROPSHIRE RAM.

withdraw his fostering care, in a few years not a single survivor would remain of all the flocks now in existence. The earliest books tell of sheep and their shepherds, showing that the dependent nature of the animal was then much as it is now. As was said, the sheep to-day is a much changed animal from his prototype. It is clothed with a vast amount of wool, far more than is necessary for the purpose of keeping it warm; it is generally almost defenseless, and timid to a greater degree than any other domestic animal; it is gregarious, loving to keep in flocks. This also is a habit induced by long familiarity with the requirements of men.

Types of Sheep.-There are two general types of sheep, namely: the fine wool and the mutton. The mutton type consists of the middle (or medium) wool and long wool breeds. The fine wool type may be 
likened to the dairy cow, and the mutton type resembles beef cattle in general make up.

The following are the common breeds of sheep:

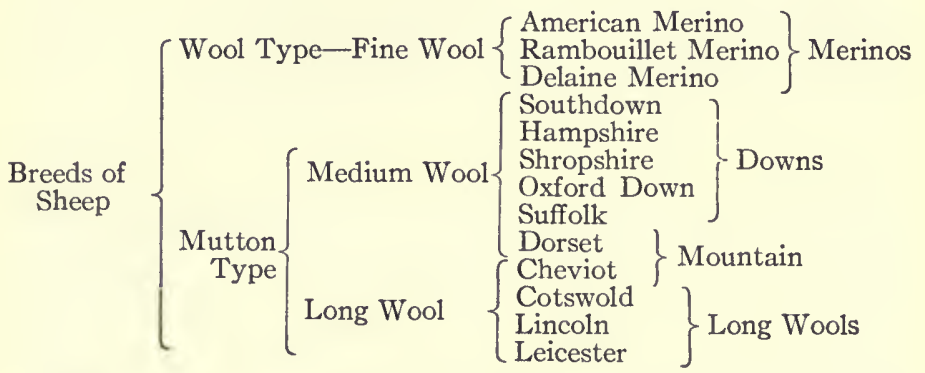

Merinos.-These breeds are the most important in the world to-day in point of numbers and yield of wool.

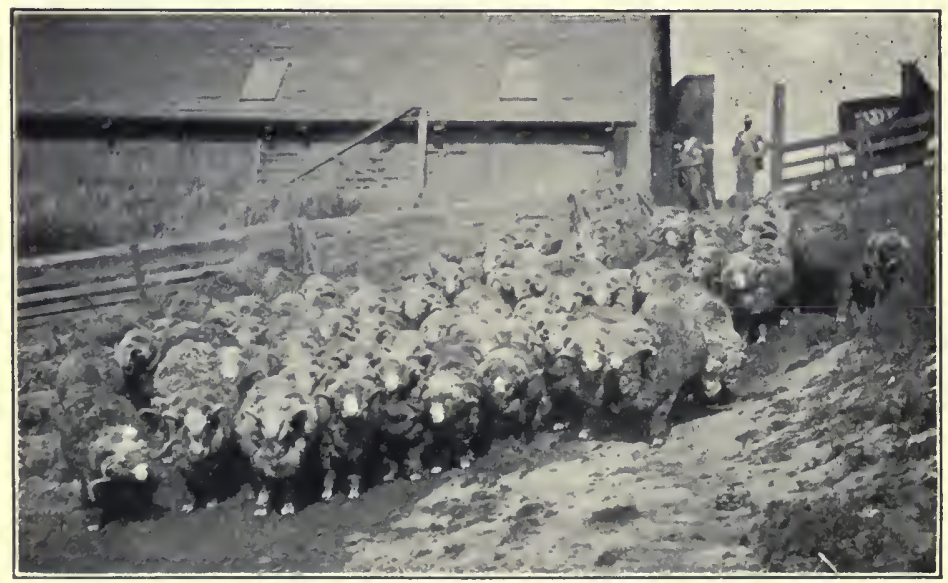

A FLOCK OF MERINO RAMS.

They were first developed, so far as we know, in Spain. Merinos form the greater proportion of the flocks of our own Western States. The Merino has not the smooth, plump, round form of the breeds of the mutton type, being more angular, thin and ungainly. On 
the other hand Merinos are covered with wool of exceeding fineness, and shear very heavy fleeces. From Merino wools are made all the finest fabrics in use, especially for ladies and children. While Merinos do not look so plump as other sheep, yet on the other hand they are really hardier and of longer life than any of the mutton breeds.

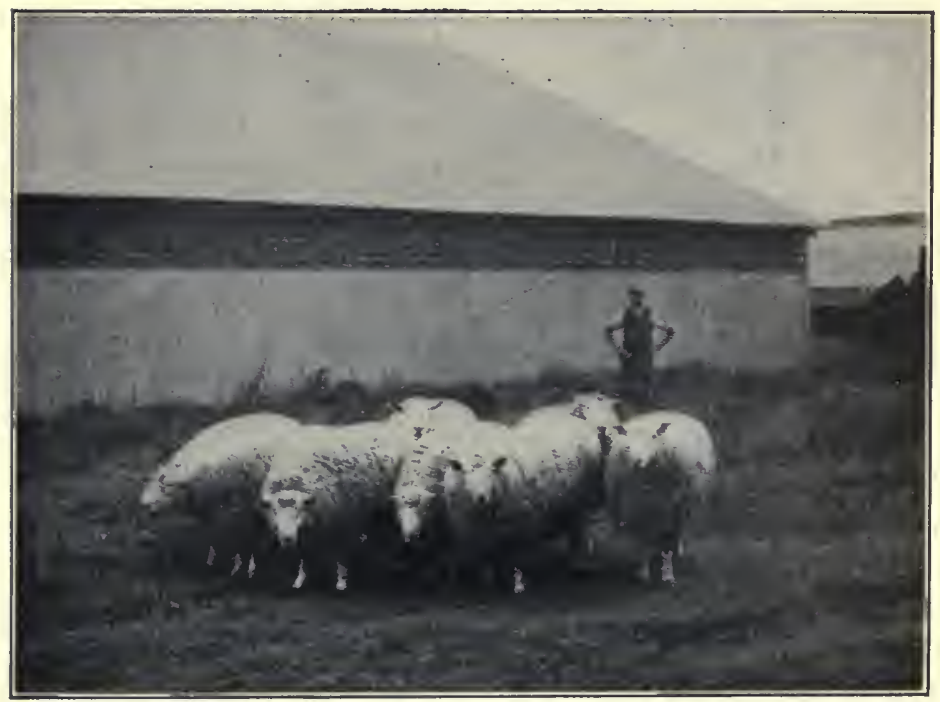

LINCOLN RAMS.

English Breeds.-Of the English breeds there are the "Downs," with their brown or black faces and legs; the Mountain breeds; and the Long Wools with white faces and legs, large bodies and long fleeces, each one adapted to its own particular purpose and living in its particular region. Of the Downs we present illustration of a flock of Southdown ewes on pasture. Back of the Hampshire lambs will be seen a peculiar fence of small round saplings, the so-called "hurdles" of England. This is a portable system of fence, and is used to inclose Hampshire lambs upon small bits of 


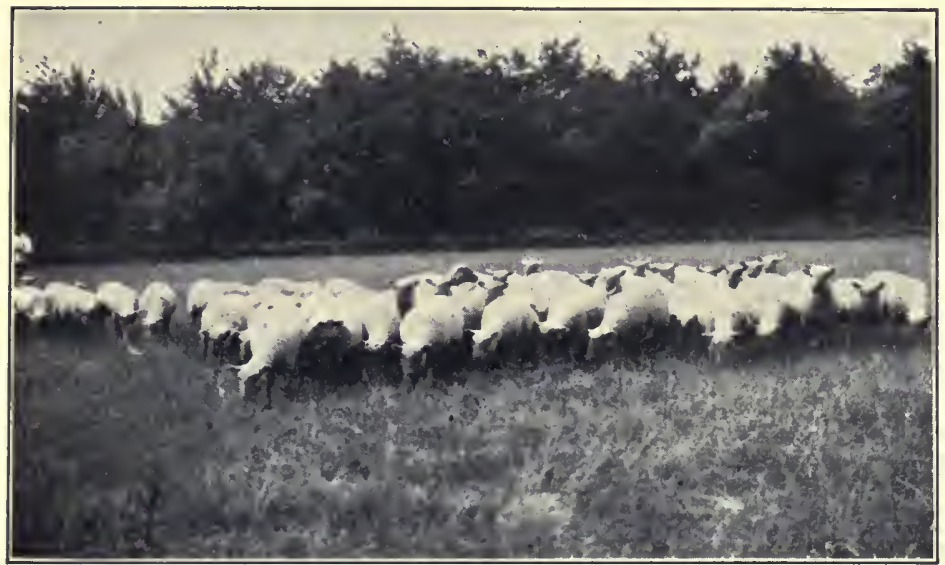

SOUTHDOWN EWES ON PASTURE.

choice herbage, perhaps of clover or of vetches, or of peas and oats, or of turnips. The hurdles being moved daily give the lambs always fresh, rich food, and thus they fatten rapidly, and often at the age of six months will weigh as much as IOO to I 50 pounds.

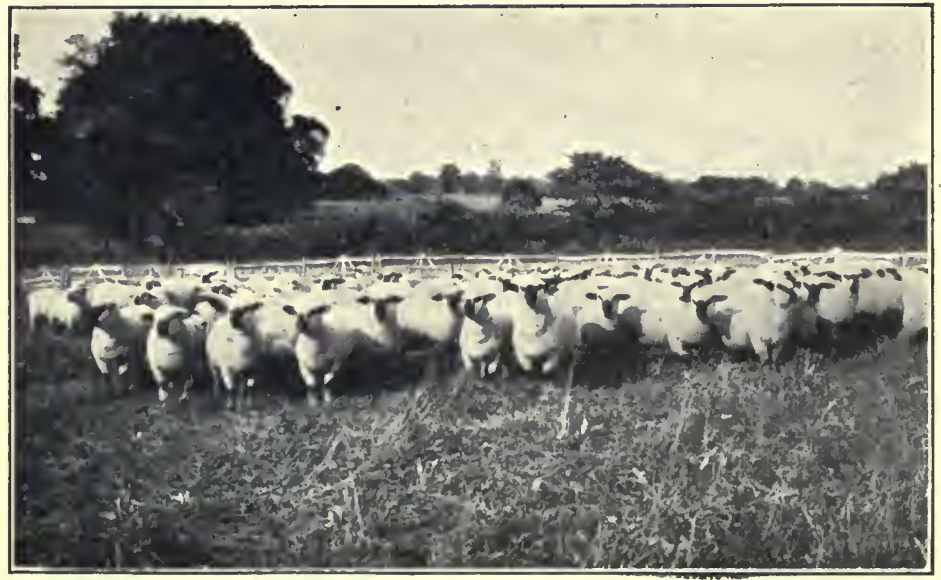

HAMPSHIRE LAMBS IN HURDLES. 
Southdown.-The Southdown, well illustrated by the group of ewes at pasture, is an older breed than the Hampshire. The illustration shows the ewes freshly shorn, and it is easy to see how plump and round are their bodies. Southdowns have brown faces and legs, are of comparatively small size, very active, hardy and easily fattened sheep; their wool is short but of high quality, making good clothing. It is customary among

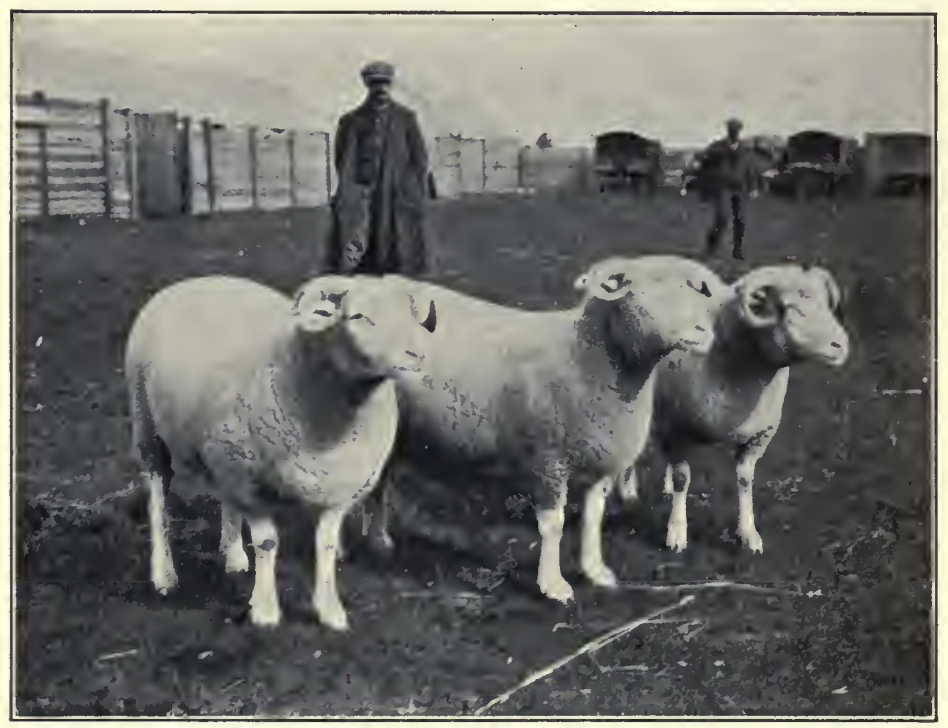

PRIZE PEN OF DORSET EWES.

all sheep men to say, of their favorites, "As good as a Southdown "; few venture to claim anything better in form or fattening powers.

Dorsets.- These are white-faced sheep belonging possibly to the mountain breeds, being more strikingly white-faced and white-fleeced than almost any other breed, even their noses are pink, and there seems to be no dark pigment about them whatever. Their native home is in the south of England, where centuries ago 
they were kept for their milk. Dorsets, unlike most sheep, have horns, both ewes and rams, the rams especially having magnificent curling horns. It is probable that at one time all sheep were horned, since it must have been necessary for the wild sheep to be able to defend their lambs from foxes and wolves. Dorsets to-day are esteemed probably for the production of early lambs, since their hereditary tendency toward milk-giving

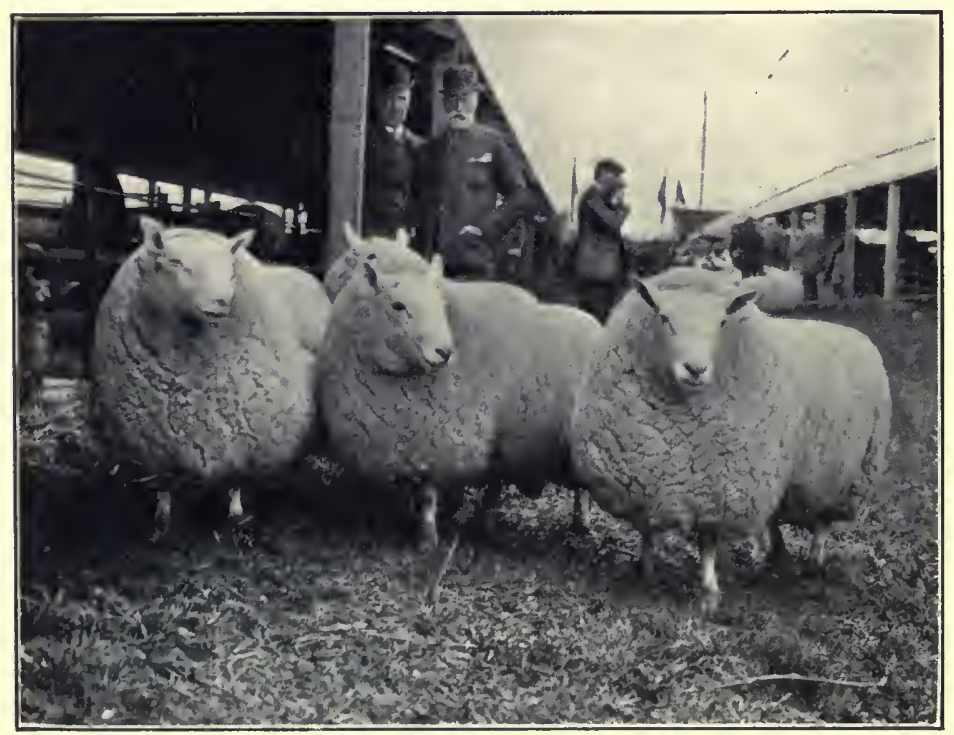

CHEVIOT EWES.

makes them nourish their lambs well, so that they fatten at a very early age. The wool of the Dorset is moderately short, close, fine and very white. It makes exceedingly good cloth and stocking yarn.

Cheviot.-Among the mountain breeds one must certainly place the Cheviot in front rank for beauty and use. These sheep, well illustrated by the photograph, have their homes in the hills and mountains. They are most active, eliergetic and enterprising sheep; their 
fleeces long and fairly fine, being made into the class of goods we term sheviots. Their mutton also is first rate and is prized in British markets.

Long Wools.-Among the long-wooled breeds are the Lincolns, great majestic sheep, as large as some Southern cows, and the Cotswolds, also of great size with beautiful long curling fleeces of coarse fiber; and the Leicesters. These three breeds are not as good for mutton as the medium wools.

$V$ alue of Sheep.-Sheep, besides being valuable for their mutton and their wool, make the land always rich and better. Sheep destroy weeds, brush, briers, and cover the hills with grass and smooth herbage.

AVERAGE WEIGHTS OF FLEECES FROM EWES

American Merino................... 12-15 lbs.

Rambouillet Merino................. I

Delaine Merino...................... 10-15

Southdown .................... 3-7

Hampshire..................... 7

Shropshire................... . 7

Oxford Down...................... 7

Suffolk....................... 9

Dorset........................6 6

Cheviot......................... 5

Cotswold........................ 10

Lincoln......................... 15

Leicester..................... 9-I I

ExERCise.-If there are any sheep in your section, find out the names of the breeds. Are they wool breeds or mutton breeds? If you have ever seen sheep sheared, prepare yourself to explain the process to the rest of the class.

\section{Section LVII.-Types and Breeds of Swine.}

\section{By Prof. C. S. Plumb,}

Department of Animal Husbandry, Ohio State University.

Types.-Swine may be divided into two great classes, the lard type and bacon type.

Lard Type.-Our American breeds of swine are mostly of the lard type. Hogs of this class, in good condition or fat, have very broad, level backs; smooth, 
thick shoulders; the hind quarter of the body thick and the hams broad, deep and thick. The lard type of hog has a great depth of body and the legs are rather short. The best specimens have rather short heads. This lard hog when fat has a thick layer of external fat over his back, hams, sides and shoulders. From his carcass the packer obtains a large amount of lard.

Bacon Type.-The bacon type of swine is narrower of back than the lard type; has thinner, leaner hams; is not so deep in his body; has a smoother, leaner shoulder and stands on longer legs than does the other kind. The side of his body from the ham to the shoulder is long and smooth. The fat bacon type is never so thickly covered with fat over his body as the lard type, but his carcass contains a greater proportion of lean meat. The bacon of the hog comes from strips of meat taken from the sides, and the best bacon has a nice mixture of fat and lean. Large, heavy, very fat bacon comes from the lard type. Bacon, in preference to lard hogs, are generally produced in Europe. In America the bacon type is more common in the South than the North. In Chicago stock yards, the greatest hog market in the world, the lard type of hogs weigh from 225 to 350 pounds, while the bacon hogs weigh nearer I 50 to I 75 pounds live weight.

Breeds.-About a dozen breeds of swine are known in America, but only five of them are important. All other breeds in this country are kept in but small numbers.

The Poland-China is one of our most noted breeds. It originated in the United States in Southwestern Ohio, from the crossing of a number of breeds on the native stock, in the first half of the last century. This breed is now largely black, usually with a little white about the face, on the legs below the knees, and on the tail. The head has what is called a straight face. The ears should break or lop over in front for about two-thirds of their length, and should be fine and small to medium size. The Poland-China fattens very 
readily and has a wide back and thick, full hams. It is a breed that is well suited to the corn-growing sections and will mature rapidly. It does not produce as large litters as most other breeds, which in recent years has caused it to become unpopular with some people. The Poland-China belongs to the lard type and easily fattens in eight months to 250 pounds.

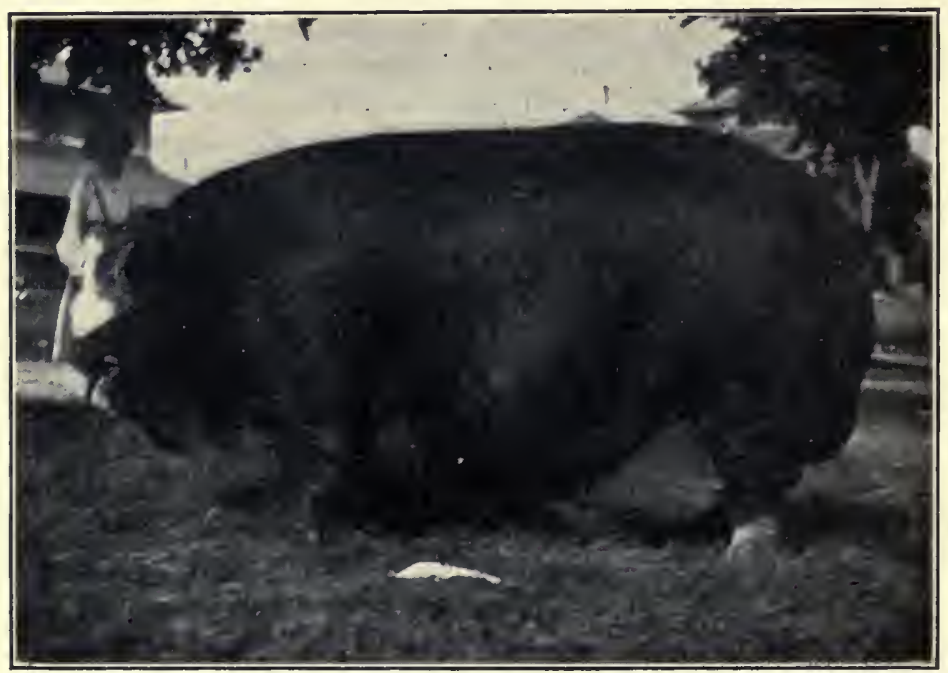

A FINE POLAND-CHINA BOAR, BRED IN OHIO. THE LARD TXPE, VERY FAT. (Pholograph by C. S. Plumb.)

Boars of this breed frequently weigh up to 600 pounds and more, and sows 400 .

The Duroc-Jersey is another American breed which originated in New York State. This is a red or sandy colored breed, with a straight face and lopped ear. The Duroc-Jersey in recent years has become popular and is attracting much attention. Pigs of this breed have broad backs, well-developed hams, and are good feeders, and weigh a little heavier than the PolandChina. The sows are quite productive of young, which has added to the popularity of the Duroc-Jersey. The 


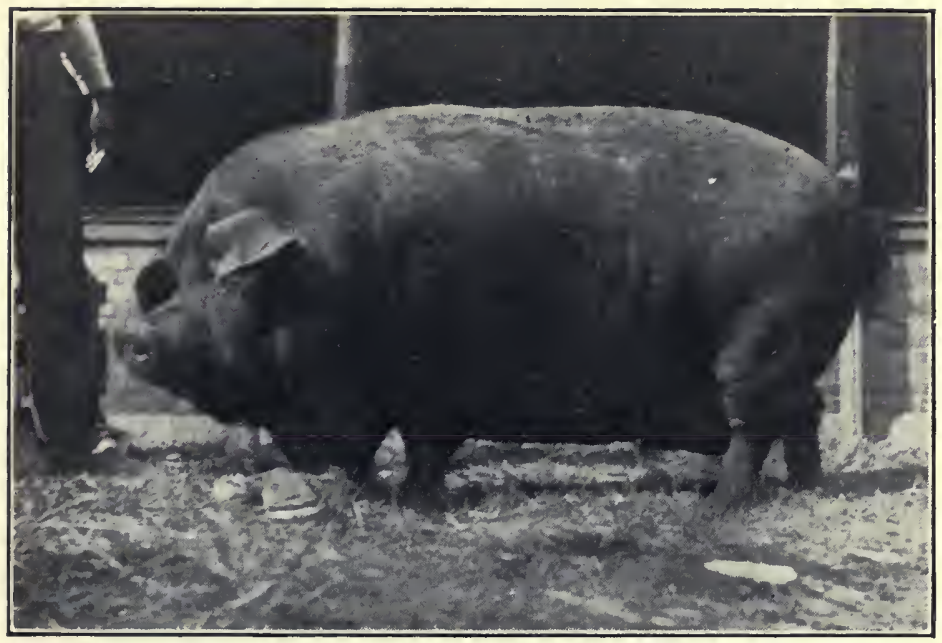

CEDAR VAlE QUEEN VII-A PRIZE-WINNING DUROC-JERSEY SOW. THE LARD TYPE.

(Photograph by C. S. Plumb.)

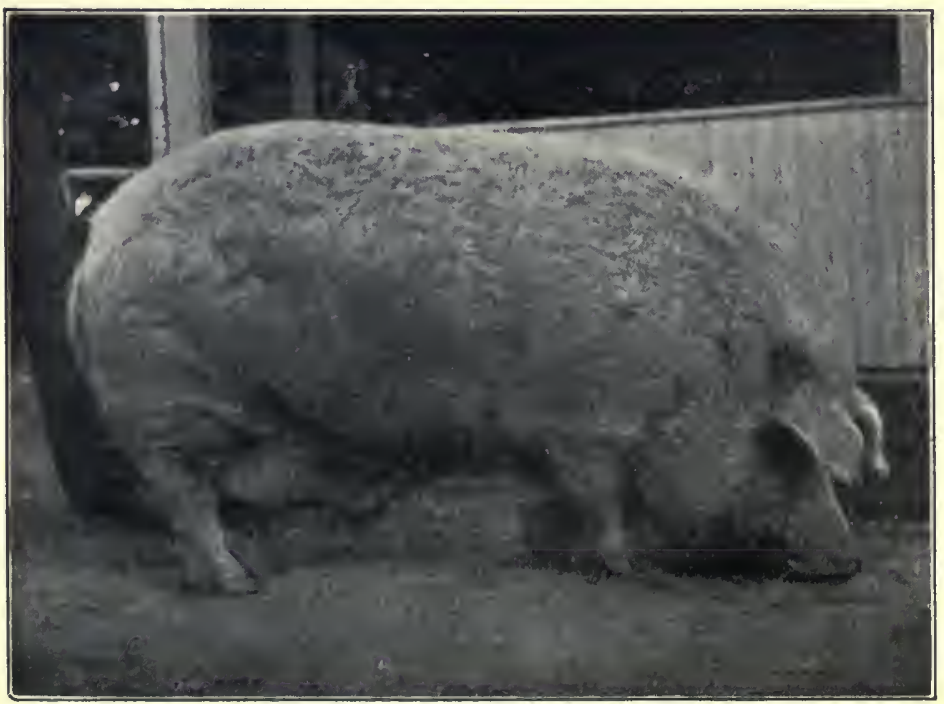


breed is getting common in Ohio, Indiana, Illinois, Iowa, Nebraska and Missouri.

The Chester White is still another American breed, originating in Pennsylvania and Ohio. It is white in color of skin and hair, and small black spots sometimes occur ' in the skin. The head is straight and the ear lopped over much like the Poland-China. The back and hams are well developed, for this breed belongs to the lard type. The Chester White fattens easily, and the sows produce good-sized litters. The weight of the boars is about 600 pounds, and sows 450 pounds. In warm, dry summer climates, hogs of this breed tend to sun scald, so that for this reason it lacks the popularity of the black breeds. Chester Whites are fairly common in the Northern United States east of the Mississippi River.

The Berkshire is a breed that originated long ago in Berkshire county, Southern England. It is black in

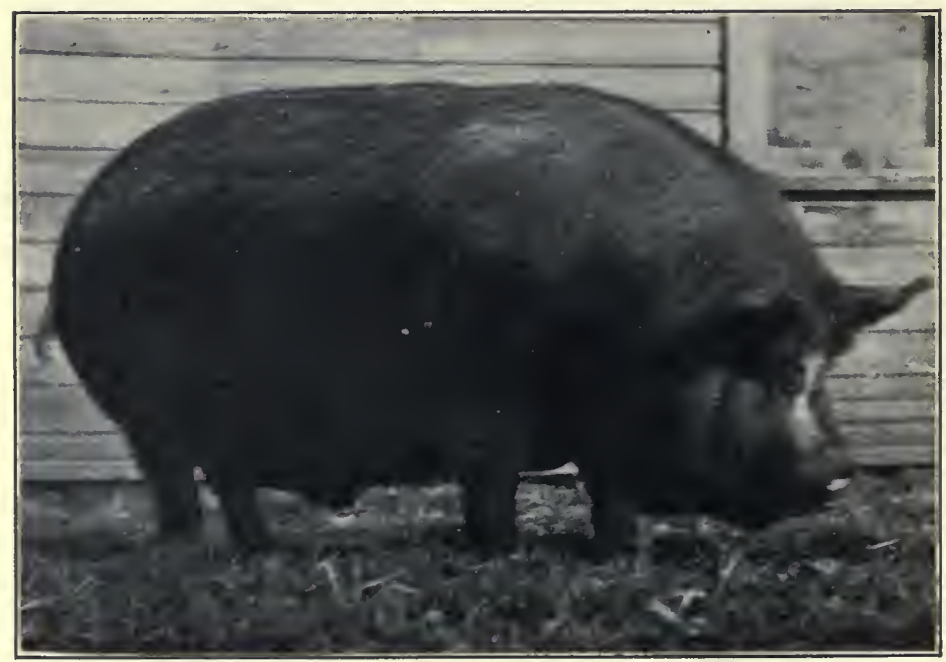

FIRST PRIZE YEARLING BERKSHIRE.

Bred and owned by Ohio State University.

(Photograph by C. S. Plumb.) 


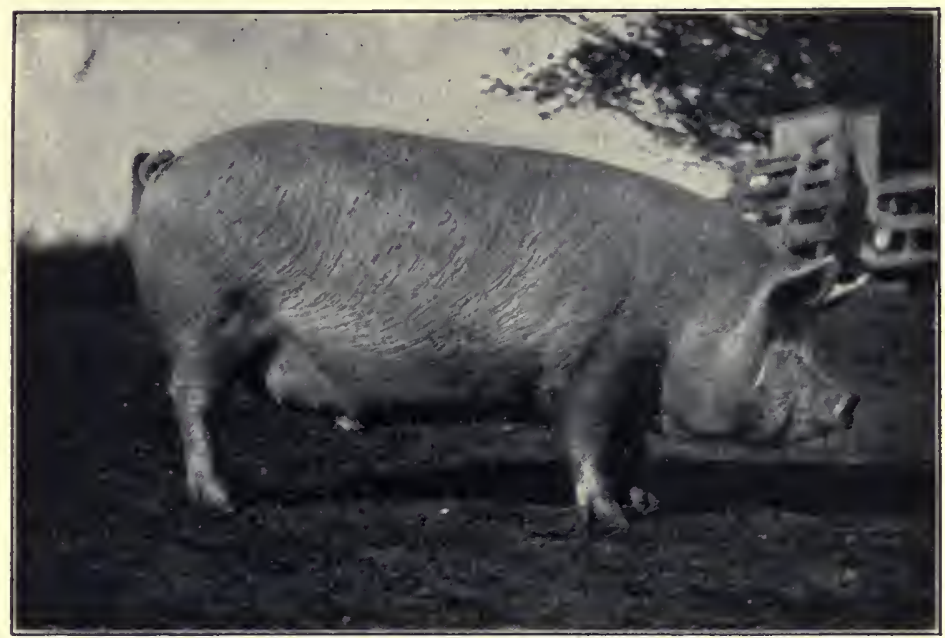

A LARGE YORKSHIRE.

Owned by Ohio State University.

color, but with six white markings, viz.: on the face, on the four feet below the knees, and the tail. Sometimes a bit of white occurs elsewhere, especially about the jaw or forearm. The head should be short, and the face curved upward or " dished," and the ears erect, although with age the ears tend to lean forward. The Berkshire does not usually get quite so thick and fat as the breeds above described, but it produces the finest pork. Berkshires mature medium well and produce good litters. This breed is kept all over the United States, and is better known in the South than any other breed, where it is quite popular. This is either a lard or bacon type, as it may be fed.

The Large Yorkshire is a strictly bacon type of swine that has been bred for centuries in England, where it is known as the "Large White." It is pure white in color, and has a rather long head and slightly curved face, with the ears carried more or less upright. This breed has a narrow back, not very thick hams, and a long body and side of meat. The legs seem long to 
Americans, in fact, the breed is more upstanding than the other breeds described. Large Yorkshires do not mature as rapidly as our native breeds, but they attain great size, the boars reaching $\mathrm{I}, \mathrm{OOO}$ pounds or more. The sows are productive and raise large litters. This is the one great bacon breed of Great Britain and Denmark, and is popular with farmers in Canada and some other sections, who want to cross with the lard type or who want more of a bacon hog than the natives.

The Thin Rind, also called Hampshire, is a black breed with a white band around the body. It is somewhat of the bacon type, and originated in the United States. It has had a special development in Kentucky, Indiana and Illinois. It is quite well suited to the Southern States. Boars sometimes weigh up to 500 pounds and sows 300 pounds.

The Tamworth is a large reddish or sandy breed from England. It is a long-nosed, long-bodied, longheaded breed, and is especially valued for bacon. Boars may reach $\mathrm{I}, \mathrm{OOO}$ pounds in weight. It has not met with much favor in America, is not the type of feeder Americans want, and matures too slowly.

Other Breeds.-The Essex, Small Yorkshire, Cheshire, Victoria and The Mule Footed, are other breeds of swine that are raised. These breeds are not popular, and are not generally grown.

Exercise.-Name the breeds of swine that you have seen. State their types. What breeds of swine are bred and grown in your community? What price do hogs bring on your market? Ask your folks if they make any money in raising hogs.

If there is a large hog farm in your section, take the class out to it and make them name the types and breeds. Write to your Experiment Station for a score card and have the pupils score a hog. 


\section{Section LVIII (A).-Poultry.}

By Prof. D. J. I.AMBBert,

Department of Poultry Husbandry, Rhode Island State College.

Importance of Poultry.-The poultry industry is much more important than is generally supposed. According to the Secretary of the United States Department of Agriculture, eggs and poultry produced on the farms of the United States for the year I908, were worth as much as the cotton crop, seed included, or the hay crop, or the wheat crop.

Breeds, Classes and Varieties.-There are fifty-five different breeds of poultry recognized by the American Poultry Association as worthy of a place in the Standard of Perfection. This book contains a complete description of all of these breeds, and is revised every five years to make changes and admit worthy newcomers. The fifty-five breeds are divided into fourteen classes. Each class has individual characteristics peculiar to the family to which they belong. Some classes contain but one breed, while others have several. Of some breeds there is only one variety, while others have from two to eight. There are one hundred and and twenty-eight standard varieties, including fowls, ducks, geese and turkeys.

Classes.-The following are the classes. I. American. 2. Asiatic. 3. Mediterranean. 4. English. 5. Polish. 6. Hamburg (Dutch). 7. French. 8. Games and Game Bantams. 9. Oriental Game and Bantam Class. Io. Ornamental Bantam Class. II. Miscellaneous. I2. Turkey Class. I3. Duck Class. I4. Goose Class.

Types of Chickens.-The first eleven classes may be further divided into four types, namely: The General Purpose Type, The Meat Type, The Egg Type and The Ornamental Type.

The General Purpose Type is the medium size, business-like hen, originally a cross between the egg and 
the meat type. In this class we have as good layers as is possible to obtain, and retain the meat-producing qualities. This type finds favor with the farmer and suburban poultry keeper, as well as the fancier on account of their popularity. The American Class, Orpingtons and Houdans are of this type.

The Meat Type includes the large size, full-breasted and yellow fleshed birds, such as are of quiet dispositions, easily confined in yards. They fatten at an early age for broilers, and being tame and inactive they remain soft, tender, fine-grained and palatable until one year old for large roasters. The largest meat type have short feathered shanks and roam around but little. The Asiatics, Dorkings and Indian Games belong to this type.

The Egg Type includes the medium size breeds with active dispositions, usually high flyers, non-sitters, and not prone to take on fat or flesh easily. An over size bird is invariably a poor layer. All egg type fowls have smooth shanks, free from feathers, a bright eye, red comb and a medium long, wedge-shaped body. Mediterraneans, Hamburgs and Red Caps are of this type.

The Ornamental Type are birds bred for show purposes, pets or hobbies. They possess brilliant markings, attractive appearance, gorgeous crests or fine feathers. Their value is assessed on account of their beauty, rather than the number of eggs they will lay, or pounds of flesh they produce. In this class is included those prized for their oddity or smallness, such as Polish, Bantam and remaining classes.

The American Class includes the Plymouth Rocks, Wyandottes, Javas, Dominiques, Rhode Island Reds and Buckeyes. All of these breeds are of American origin. The Plymouth Rocks, Wyandottes and Rhode Island Reds are the most important breeds of this class. The Plymouth Rock breed is the most popular, being the first of American origin. Males over one year old are termed cocks, and should weigh $9 \frac{1}{2}$ pounds. Fe- 


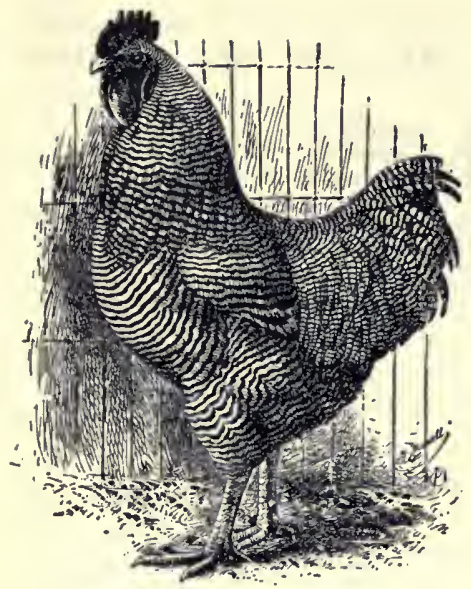

BARRED PLYMOUTH ROCK.

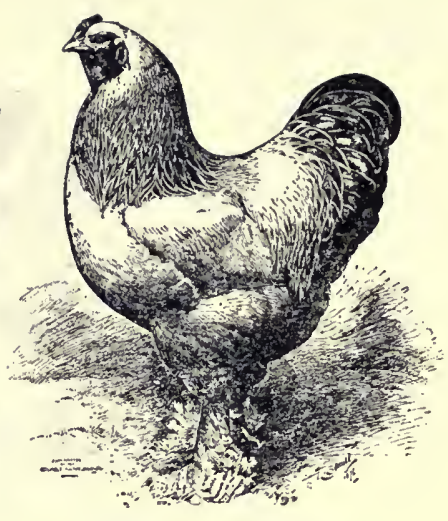

LIGHT BRAHMA, A MEAT TYPE.

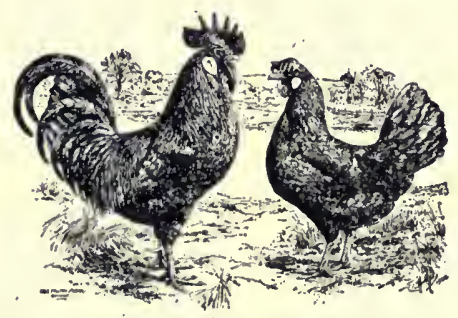

BUFF LEGHORNS, EGG TYPE.

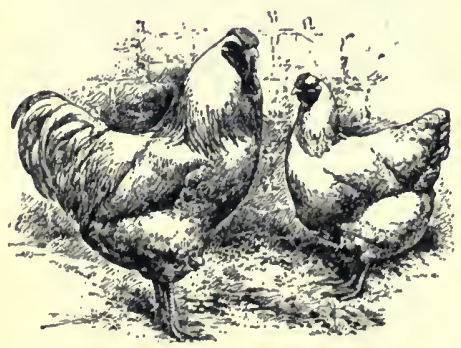

A PAIR OF WHITE WYANDOTTES.

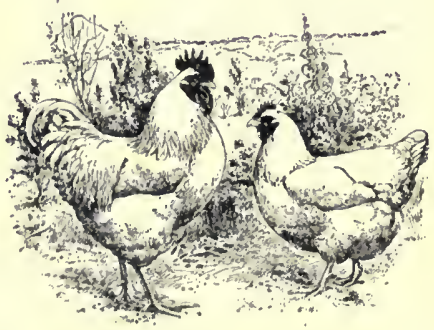

WHITE PLYMOUTH ROCKS. 
males more than one year old are termed hens, and should weigh $71 / 2$ pounds. Males less than one year

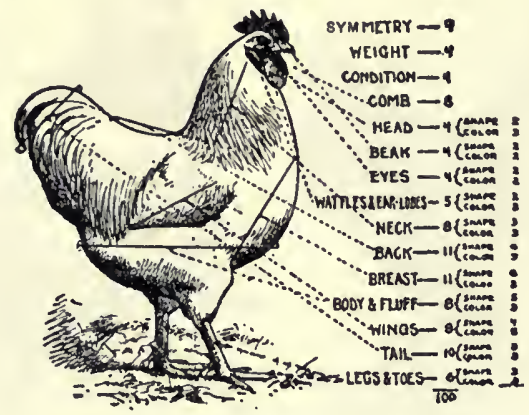

DIAGRAM SHOWING SCORE CARD FOR POULTRY.

old are termed cockerels, and should weigh 8 pounds. Females less than one year old are termed pullets, and should weigh 6 pounds at six months of age, and begin to lay when $6 \frac{1}{2}$ months old. The weights in the American class are : cocks $81 / 2-91 / 2$ pounds, hens $6-71 / 2$, cockerels 7-8, pullets 5-6.

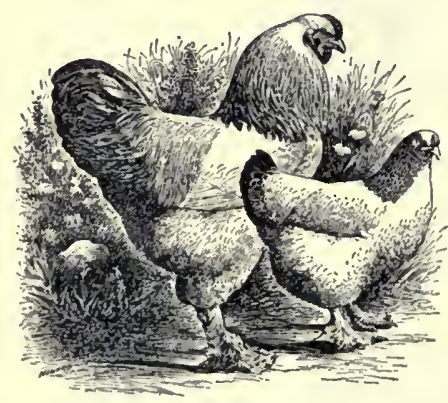

PAIR OF LIGHT BRAHMAS.

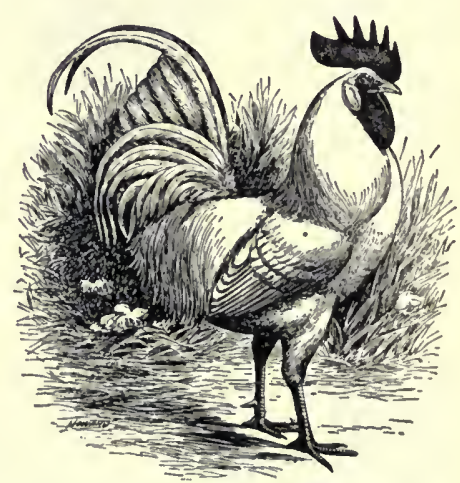

SINGLE-COMB WHITE LEGHORN COCK.

The Asiatic Class comprises the Light and Dark Brahmas, Cochins and Langshans. All breeds of this class have feathers on shanks and feet. They are of 
the meat type, and make excellent sitters and mothers. Weights : cocks I I-I 2 pounds, hens $81 / 2-91 / 2$, cockerels 9-10, pullets 7-8.

The Mediterranean Class consists of the Leghorns, Minorcas, White-faced Black Spanish, Andalusians and Anconas. The breeds of this class lay chalk white eggs, while other classes usually lay tinted-shelled eggs. The Leghorns are great layers, and are often called egg machines, but are too small to be of value for meat. The breeds of this class are non-sitters.

The English Class contains the Dorkings, Red Caps, and Orpingtons. The Dorkings are the oldest breed

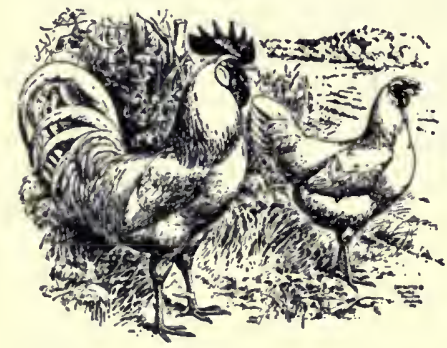

A PAIR OF SINGLE-COMB WHITE LEGHORNS.

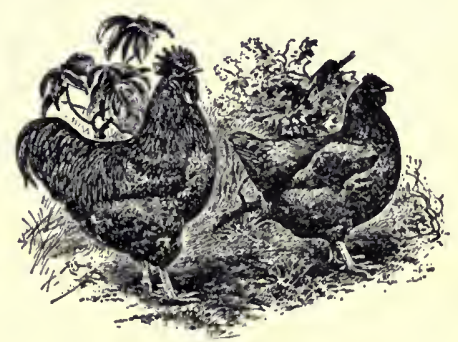

PAIR OF BUFF ORPINGTONS.

in this class, and they have five toes on each foot, long bodies and abundant white breast meat. The Orpingtons are the most popular English breed. Weights: cocks $71 / 2-10$ pounds, hens $6-8$, cockerels $6-81 / 2$, pullets 5-7.

The Polish Class includes one breed of which there are eight varieties. The Polish are strictly ornamental fowls, of little value for meat and only fair layers. Much value is placed on the development of their crests.

The Hamburgs or Dutch are an old breed, and the pencilled varieties of this family are among the finest plumed birds in the Standard. They are good layers.

The French Class consists of the Houdans, Creve- 
cœurs, La Fleche and Faverolles. The Houdans and Crevecœurs have crests and small V-shaped combs.

Games and Game Bantams are the aristocrats of the poultry yard. There are eight varieties, and they are prized as pets and for exhibition.

Oriental Game and Bantam Class.--Some of the varieties of this class are good meat-producing breeds.

The Ornamental Bantam Class are prized for their smallness, and disqualified if they weigh four ounces or more over standard weight. There are many varieties.

The Miscellaneous Class contains the White Silkies; their feathers being webless and of a silky nature. The White Sultans, with abundant stiff leg and toe feathering. The Frizzles, whose feathers have a tendency to turn backwards and curl upwards.

The Turkey Class is made up by the Mammoth Bronze, Narragansett, Buff, Slate, White and Black. Weights: cocks 27-36 pounds, cockerels i 8-25, hens I 8-20, pullets I 2-I 6 .

The Duck Class is comprised of ten breeds: Pekins, Aylesburys, Rouens, Cayugas, Gray and White Calls, East Indias, White Crested Colored and White Muscovys, Indian Runners and Blue Swedish. The Aylesburys and Rouens are the largest and should weigh: drake 9 pounds, young drake 8, adult duck 8, young duck 7. The Gray and White Calls are prized for small size, the smaller the better.

The Goose Class contains six breeds and seven varieties: Toulouse, Embden, African, Chinese, Wild or Canadian and Egyptian. Weights: adult gander IO20 pounds, young gander 8-I 8, adult goose 8-I 8, young goose 6-I6. The Toulouse, Embden and African make up the heaviest breeds, and the other three breeds weigh only about half as much.

Artificial Incubation.-Incubators are used a great deal by poultrymen because it is cheaper to hatch eggs in this way. Chickens can be better cared for in brooders, and the hens begin laying sooner. 


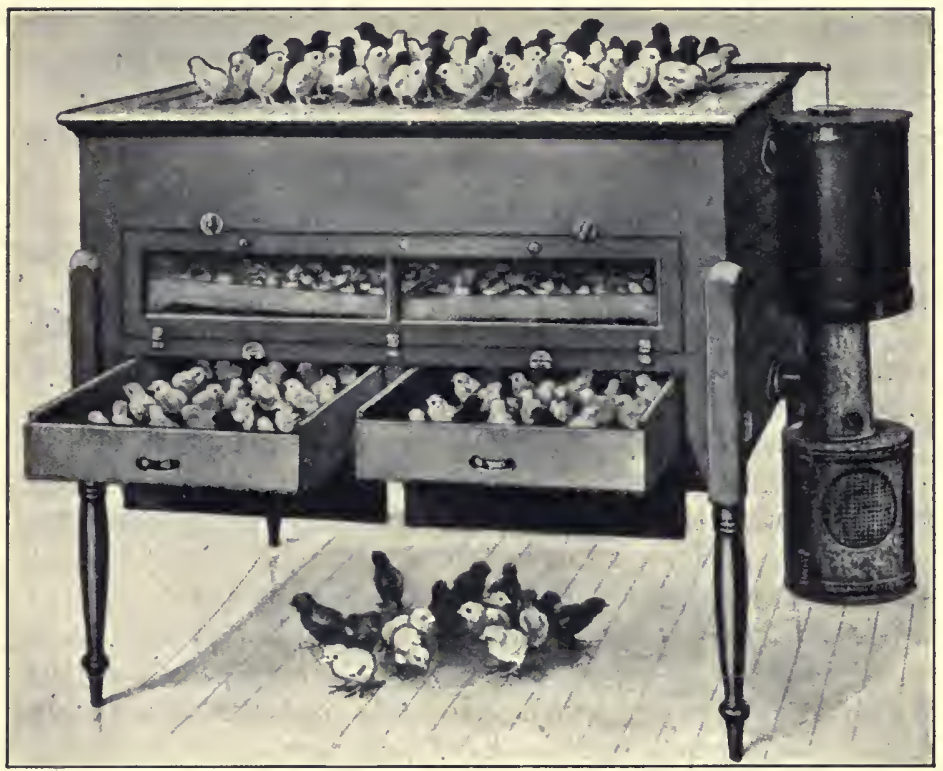

A MODEL INCUBATOR.

EXERCISE.-Make a list of the varieties of poultry in your section. Arrange them as to breeds, classes and types. What type is most prevalent? Why? What is an egg type? What is a meat type? What is a general-purpose type? What is an ornamental type? Name the breeds and varieties in the American class, the Asiatic class, the English class, the Mediterranean class.

Section LVIII (b).-Poultry Houses and Care
of Poultry. By J. E. Halligan, Louisiana State Experiment Station.

Methods of Housing.-There are two methods of housing poultry, namely: the colony system and the apartment or continuous house system.

The colony system consists of housing a few fowls in small, usually portable, houses, where they have free 
range, and far enough apart so that there is no mingling of the flocks. The advantages of the colony system are:

r. There is less danger from outbreaks of disease.

2. No fencing is required.

3. Fowls get more exercise than in yards.

4. By moving the houses once in a while, clean ground may be provided.

5. Less feed is required to be furnished during the summer months.

6. Many injurious insects are eaten up.

7. Fowls may be put on harvested fields and fit into crop rotations.

The chief disadvantages of the colony system are:

I. It is difficult to care for and feed fowls in colony houses during the winter or severe weather.

2. More land is required; under this system it is only possible to allow roo birds per acre, while in the apartment system, with properly constructed yards, 400 to 500 birds may be kept per acre.

3. The cost of colony houses is greater than the continuous house of equal capacity, because this latter house only requires wooden partitions at the ends, and the interior partitions may be made of wire netting.

The colony houses are usually built to accommodate ten to thirty birds.

The apartment or continuous house consists of a series of separate pens in one building, generally with a passage way through the entire building which has openings into every pen.

Where to Build and Why.-In building a poultry house a suitable location should be selected. A welldrained sandy loam soil is preferable to a clay or sandy soil. The soil should be rich enough to grow the necessary green crops desired for summer feeding. If possible the location should be such as to afford protection from winds and storms. Such a spot is offered behind farm buildings or on a slope of a hill.

The buildings should have a southern or southeast- 
ern exposure, as the birds prefer the morning sun, and to keep the house warm and dry.

The fowls are housed principally to protect them from the cold winds and storms, so as to keep up the egg production. Exceedingly warm houses are not necessary for poultry as has been proved by experiments. The house should be built to maintain as even a temperature as possible during night and day. The double walled houses are hard to keep dry or warm without the aid of artificial heat, which is not always satisfactory. The temperature in houses built mostly of glass is difficult to regulate, because it is so much colder during the night than in the day.

Requirements.-The building should be large enough to accommodate the number of fowls on the farm. It is generally conceded that not more than forty fowls should be kept together, and $4 \frac{\mathrm{T} / 2}{2}$ to 5 square feet of floor space should be allowed per bird. For smaller flocks more floor space per bird will be required. In sections where severe weather is encountered only occasionally, and the birds are not continually housed, about two to three square feet of floor space may be assigneu per bird. Birds should not be crowded, for it will interfere with their exercise. The building should be high enough to permit the entrance of attendants.

Windows.-The windows should be placed high so that the winter sunlight will reach every part of the house. Wide buildings or low windows prevent the sunlight from reaching the rear parts, and often cause dampness which is very objectionable in a poultry house. For sixteen feet of floor space one square foot of glass should be allowed.

Floor.-It should be the aim of every poultryman to keep the floor perfectly dry. Wood, earth or cement are used for floors. Cement makes the best floor. Every farmer can afford such a floor, as it can be made with farm labor and at little cost. Cement floors have many advantages. They are readily 
cleaned, they are durable, and they are easily constructed. A floor 2 to 3 inches thick is strong enough for a poultry house.

Wooden floors are apt to rot quickly unless a free circulation of air is allowed under them. This can be provided by making openings on the outside walls of the house. Rats are liable to prove troublesome when wooden floors are used unless extra precautions are taken. A layer of $1 / 2$ an inch of fine dry sand cov-

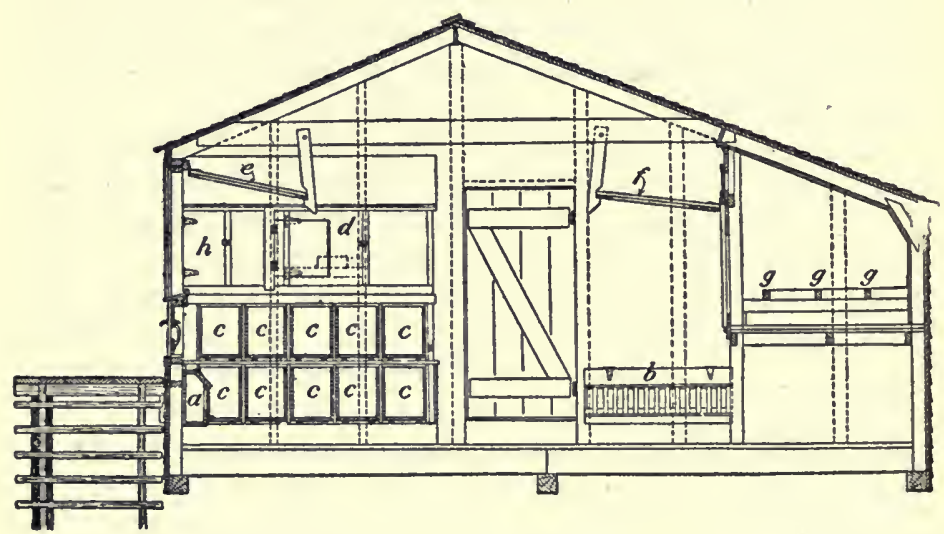

END ELEVATION (INSIDE) OF LATEST CURTAIN-FRONT POULTRY HOUSE.

ered with a litter of straw makes a good surface for a wooden floor.

Earth floors are excellent when the building is first occupied, but they soon become damp and uncleanly. Earth floors should be a few inches higher than the outside surface of the ground. In cleaning earth floors it is necessary to shave off the upper surface and replace it with fresh dry earth. At best it is difficult to keep an earth floor dry and clean.

$V$ entilation. - Good ventilation is one of the main requirements of a poultry house. Fowls require more fresh air than other farm animals because of their great activity. The house should be built tight enough 
to prevent direct drafts from blowing on the birds, but openings should be left at intervals along the top of the south side of the wall of the house between the windows, to permit of an abundant supply of fresh air.
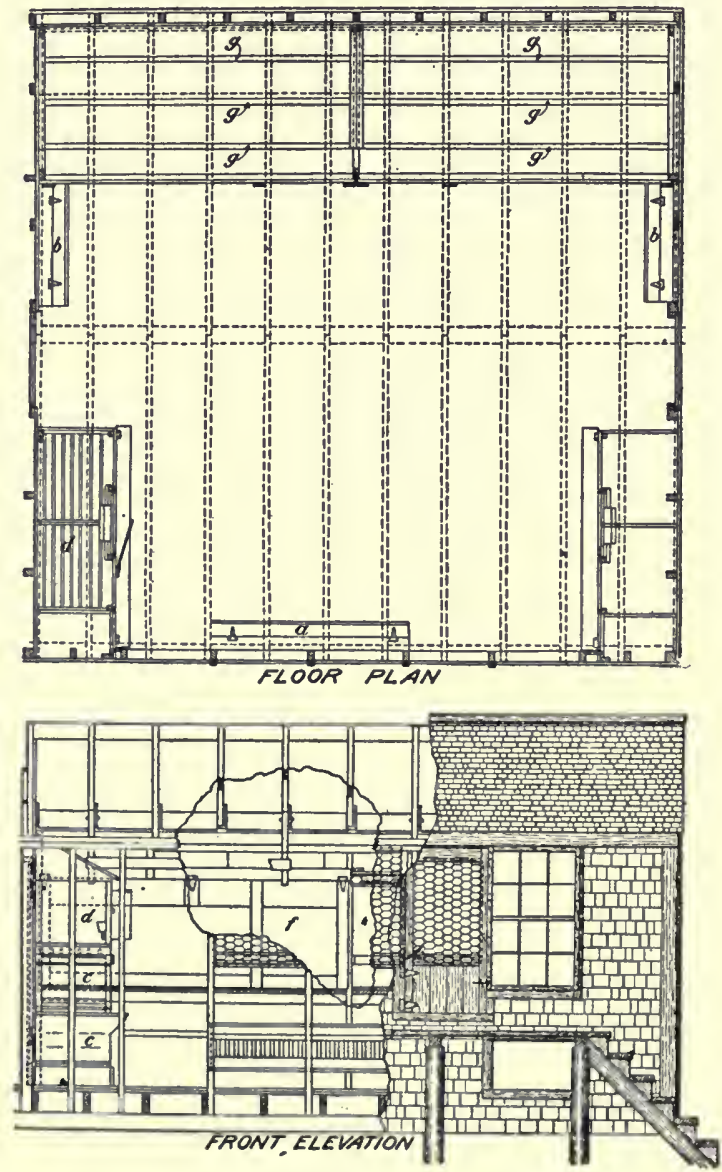

FLOOR PLAN AND FRONT ELEVATION OF SECTION OF LATEST CURTAINFRONT POULTRY HOUSE.

$a$. Feed trough for dry mash; $b$, feed trough for grit, bone, etc.; $c$, trap nest; $d$. coop for broody hens; $e$, front curtain; $f$, roosting closet curtain; $g$, roost bars; $h$, small closet in which eggs taken from nest are placed 
On severe cold or stormy nights these openings may be partially closed with curtains of duck, muslin, burlap or other suitable material.

Roosts.-A tight roost platform, made of smooth boards, should be built about 3 feet from the floor to catch the droppings, to allow an attendant to get under it to catch the birds when necessary and to retain the floor area. The roosts should be from 8 to 12 inches above the platform, I foot from the wall, and hinged to the wall so that they may be swung out of the way when the platform is being cleaned. If more than one roost is desired, a distance of I $_{5}$ inches should be allowed between the roosts. Three or four roosts may be conveniently joined together and fastened, the same as mentioned for one roost.

The roosts may be made of 2 by 3 inch lumber placed edgewise and rounded off at the top. A space of 8 to ro inches should be allowed for each bird.

The roosting place should be furnished with a curtain of duck or muslin, to provide a warm sheltered closet for the fowls at night. This curtain should be hinged at the top and hung to the ceiling during the day.

Nests.-The nests should be placed with the entrance towards the wall so as to keep it dark. Hens are not so apt to eat eggs in a dark nest. The nests should be about I foot wide, I foot high and I foot long, with partitions high enough between them to prevent the eggs from rolling out, and low enough so that the hens may go from nest to nest. Hinged covers in front of the nests a re convenient for removing the eggs. The nests should be so constructed that they may be removed easily when it is necessary to clean them. Straw makes excellent nest material.

Feed Trough.- In building a feed trough it is necessary to construct it so that the birds cannot get into it with their feet and spoil the feed. The Maine Experiment Station* uses a trough with slatted sides, and a * Farmers' Bul. 357. 
broad removable roof which gives satisfaction. The troughs are from 6 to Io feet long with sides 5 inches $\mathrm{h}$ igh. The lath slats are put 2 inches apart, and the trough is 16 inches high from the floor to the roof. The roof projects 2 inches on

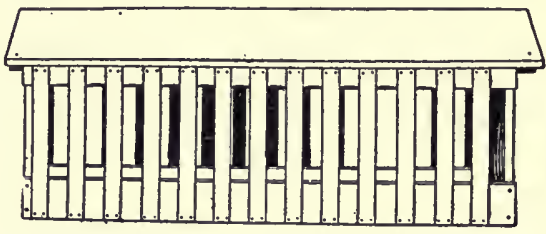

CHICKEN FEEDING TROUGH, ACCESSIBLE FROM BOTH SIDES, WITH COVER ON.

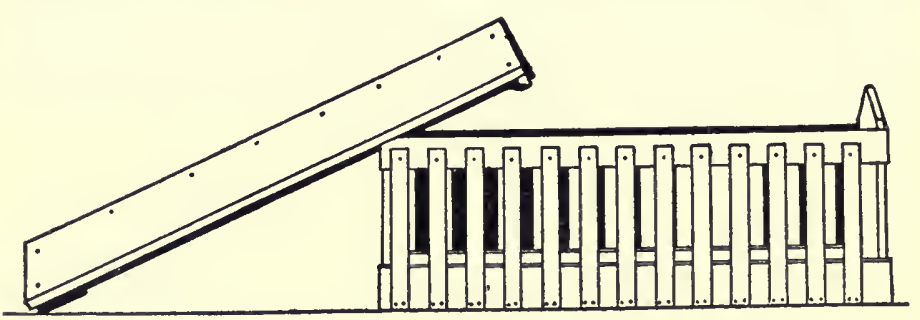

CHICKEN FEEDING TROUGH WITH COVER REMOVED.

either side, and protects the food from rain except during very windy weather.

Water Supply.-Poultry should be supplied with fresh water every day. The drinking vessels should be thoroughly cleansed whenever necessary, and placed in some protected place a few inches about the floor to keep out the dirt.

Yards.-Most poultry yards are on the south side of the building, because protection is offered from the cold winds of the fall and early spring, and the south side is always dry earlier in the spring. Sometimes yards are built on the north and south sides. It is well to have more than one yard, because green feed can be continually supplied by changing the fowls from one yard to another. Clover, grasses, rye, oats, etc., may be sown in the poultry yards to furnish the green feed. It requires about 75 square feet of green sod per bird, and if the yard area is inadequate green feed should 
be supplied to make up for the deficiency. Sometimes yards are used simply for exercising the birds, in which case the yard area may be reduced one-half.

Fences of wire netting of about 2 inch mesh are desirable. A foot or base board about 2 to 3 feet high should be placed at the bottom of the fences to prevent the male birds from fighting. The fences should be

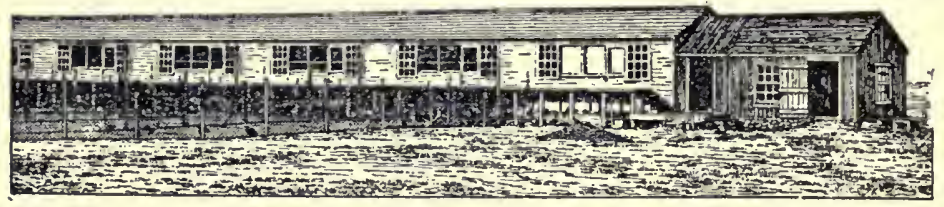

THE LATEST CURTAIN-FRONT POULTRY HOUSE.

high enough to prevent the birds from flying over. The light breeds, as Leghorn, require a fence Io to I 2 feet high, and 4 to 6 feet is high enough for heavy breeds like the Brahmas. Gates should be built so as to allow access to all the yards.

The yards should be well drained and kept clean. Fresh drinking water and a sand pile are beneficial in the yards. During the summer it often becomes very warm in poultry yards, and comfort can be provided the birds by planting shade trees in the yards. If fruit trees are planted they will serve a double purpose by providing shade and bearing fruit.

Exercise.-One of the most important features in successful poultry management is to make the birds exercise. Some breeds are apt to be lazy, and hard to keep in good laying condition unless they are forced to exercise, while other breeds are naturally very active and easily kept in good condition. Laying hens and breeding cocks especially require a great deal of exercise for best results. This may be accomplished when the birds are confined by providing a heavy loose litter of short-cut straw 3 to 6 inches in depth and scattering the grain food over it, thus forcing the birds to exer- 
cise to obtain their food. In summer the use of yards or the range will give the birds the needed exercise.

Grit.- It is not sufficient to furnish poultry with grain, animal and green food, but grit must also be supplied. Poultry have no teeth and grit performs the function of grinding the food. Broken glass and ground oyster shells should always be before the birds. Oyster shells are rich in lime, which constituent is necessary for the formation of firm shells. Grit may be purchased from any of the leading poultry supply houses.

Dusting Boxes.- The use of dusting boxes proves beneficial as a preventive against lice. Poultry must be supplied with dusting boxes for their good health. Fine road dust is excellent, and enough of it should be secured in the summer or early fall to last through the winter and early spring. The dusting box should be kept clean and new dust added from time to time. The use of loam or clay soil is not satisfactory as it tends to pack or cake. Coal ashes finely ground are sometimes employed. Wood ashes should not be used as they tend to bleach the legs and dry up the skin and feathers. A dusting box $2 \frac{1}{2}$ to 3 feet square and 7 to 8 inches high is ample for 20 to 25 birds. The dusting box should be situated so that the sun will shine on it part of the day.

Marking Poultry.-In order to keep a record of what each hen is doing and her age, the marking of poultry is important. This may be accomplished by the use of numbered legbands. The legbands should be placed on the pullets as they mature. Sometimes the poultryman punches a hole in one of the four webs of the feet each year. Legbands and punches may be purchased from any of the leading poultry supply houses. By marking poultry a complete record can be kept of every bird and those that are not profitable may be killed. All the older birds can be disposed of when their usefulness is passed.

Care of the Setting Hen.-In selecting hens for sitting, the irritable, nervous and weak hens should be 
avoided. The nests should be placed in a secluded and quiet part of the poultry house, and kept just for this purpose. A good nest may be made by putting in 3 to 4 inches of earth, and hollowing it out in the middle and covering with fine cut straw. The hens should be dusted with insect powder before they go on the nest, and again at the end of Io to I 2 days to keep them free from vermin. If the hens become infested with lice they become nervous and a poor hatch will result. If it is cold when the hens begin to sit fewer eggs should be used than in warm weather. The smaller breeds cannot sit on as many eggs as the larger fowls. The range of eggs varies from I I to I 7 per nest with an average of I3. Food, water and a dusting box should be placed near the sitting hens.

How to Preserve Eggs.- The most satisfactory method of preserving eggs is by means of waterglass. This may be purchased at most any drug store. One part of waterglass should be mixed with eight to ten parts of water, and placed in a receptacle of wood, iron or earthenware. The water should be boiled before it is mixed with the waterglass. One gallon of waterglass is ample for about fifty dozen eggs. The eggs should be kept in a cool place where the temperature remains fairly constant. Every day when the eggs are collected they should be put in the waterglass, and none other than fresh eggs should ever be preserved.

\section{SEction LIX.-Dairying.}

By Dr. F. W. Woll,

Department of Agricultural Chemistry, University of Wisconsin.

Dairying is the industry that deals with the production of milk and the manufacture of butter and cheese. This industry is of special importance in New York, Pennsylvania, Illinois, Iowa and Wisconsin. There were only seventeen million dairy cows in this country in the year I900, and the products of these 
cows represented in the aggregate a value of nearly half a billion dollars per year. In this country the cow is practically the only animal kept for the production of milk and other dairy products, but other animals, such as goats, ewes, asses, mares, buffaloes or camels, are used for this purpose in different parts of the world.

Milk Breeds. - The cow secretes the white nutritious fluid known as milk during a period of six to ten months

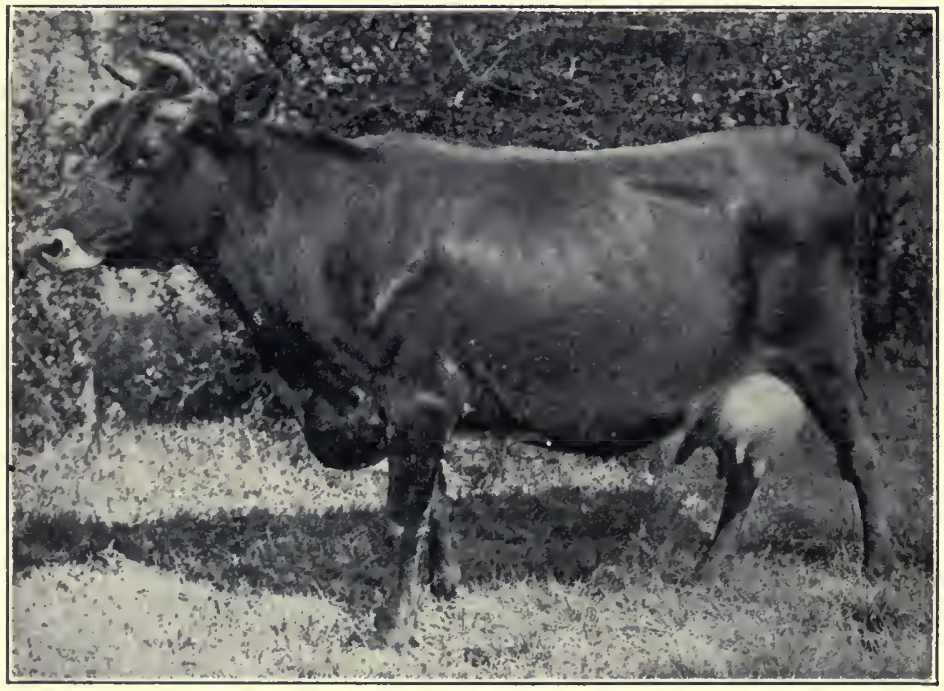

DAIRY COW, WITH GOOD UDDER.

from the time of calving. The yield of milk is largest directly after calving, and gradually decreases after a few months until it entirely ceases toward the time of the next calving. A good dairy cow will give milk at least nine months during the year; in many cases the faculty of milk secretion is so highly developed that it requires especial effort to have the cows go dry. The most important breeds of dairy cows in this country are the Jersey, Holstein, Guernsey, Shorthorn and Ayrshire cattle. All these breeds originated in northern Europe. The large majority of dairy cows in our 
country do not, however, belong to any special breed of cattle, but are of mixed breeding, and known as native cows or scrubs.

Milk.-Milk is a complete food intended by nature for the nourishment of the young calf. Man has taken advantage of the faculty of milk secretion by cows, and through careful feeding, breeding and selection he has gradually developed this faculty, so that cows now yield far more milk than is needed for their offspring. Some cows have produced ten to fifteen times their own weight of milk during a year, or over 20,000 pounds of milk in all, but most cows give less than onefourth this quantity annually.

Composition of Milk.- Milk is composed of the following substances: water, fat, casein and albumen, milk sugar, and ash. The composition of the milk varies considerably with the breed of the cow and other factors. One hundred pounds of American milk contains, on the average, the following quantities of different components :

Water.............. 87.4 pounds

Butter fat......... 3.7

Casein and albumen... 3.2

Milk sugar........ 5.0

Ash............... 0.7

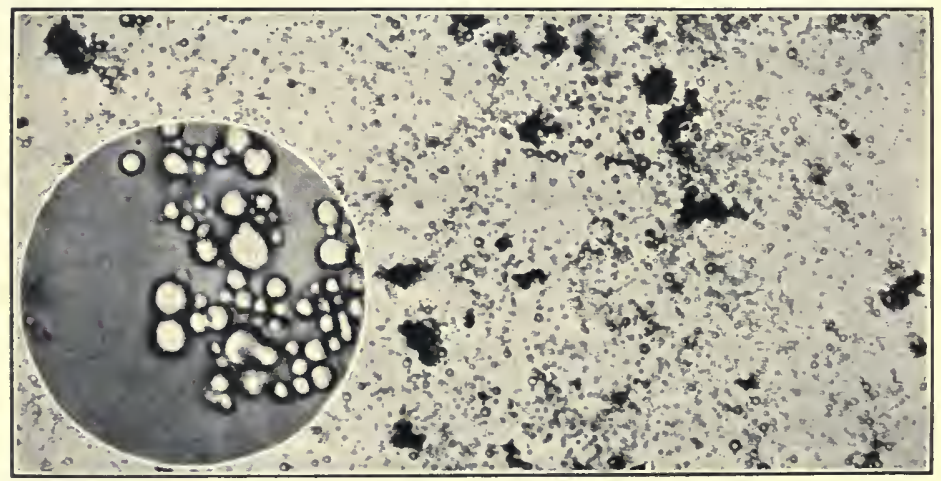

FAT GLOBULES IN MILK, AS SEEN WITH THE AID OF A MICROSCOPE:

THE GLOBULES IN THE CIRCLE ARE THE MORE HIGHLY MAGNIFIED. 
Fat.-The fat is found in the milk in the form of round globules. These are of such minute size that it takes about 6,000 of them placed side by side to make a line an inch long. The fat is the most valuable constituent of the milk from a commercial point of view; hence milk is, as a rule, paid for at creameries or cheese factories according to the amount of butter fat it contains; this has been rendered possible by the invention of the Babcock test for fat in milk.

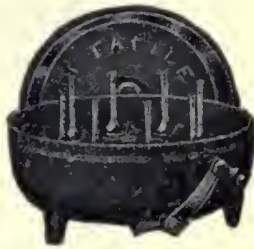

HAND BABCOCK MILK TESTER.

Cream.-When milk is left standing for some time a thick yellowish layer is formed on top. This is cream and contains most of the butter fat in the milk. The thin portion under the cream is skim milk. On account

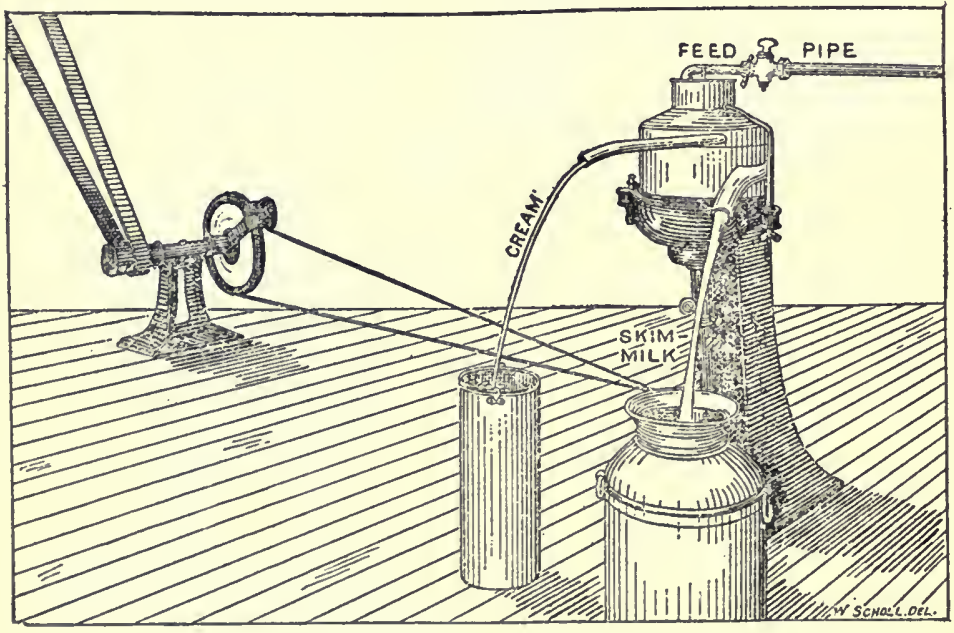

CENTRIFUGAL, CREAM SEPARATOR.

of the difference in the specific gravities of cream and skim milk (i. e., the weight of either compared with that of an equal quantity of water) the separation can also be effected by centrifugal force; the machine 
in which this is done is called a cream separator or centrifuge. These are either hand or power ma.

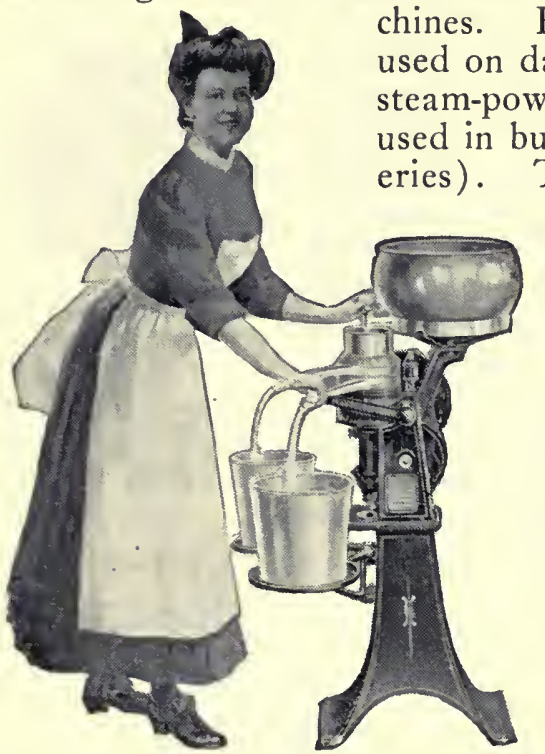

Hand separators are used on dairy farms, while only steam-power centrifuges are used in butter factories (creameries). The largest of these machines separate the cream from the skim milk at the ratc of 5,000 pounds, or about 2,500 quarts, of milk per hour. Cream is used for table or culinary purposes, and for the manufacture of butter.

Butter.-In the manufacture of but-

A HAND CREAM SEPARATOR.

ter the cream is either allowed to sour (ripen) before being placed in the churn, or is churned directly without ripening. The former method gives us the ordinary market butter (sour-cream butter), the latter method sweet-cream butter. When cream of a temperature of 50 to 60 degrees Fahrenheit is stirred or agitated in a

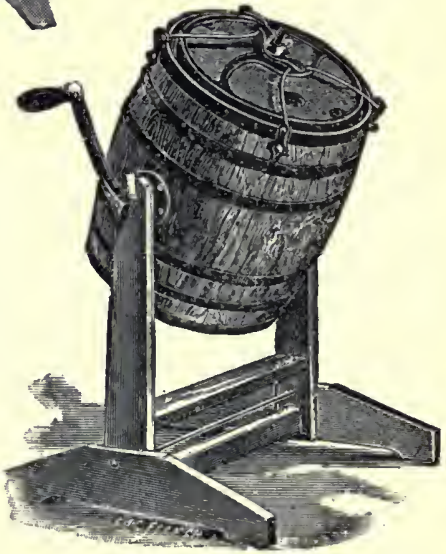

A BARREL CHURN.

churn for twenty minutes or more, the butter fat will gather into granules or small lumps which also contain 
other components of butter, viz., water, casein, and a little milk sugar or acid. The buttermilk is allowed to drain off and the butter is washed with cold water, salted to suit the taste of the consumer and worked on a butter worker, or in a combined churn and worker; it is then ready to be packed into tubs or made into packages weighing a pound each ("point butter"). Ordinary market butter has the following average composition:

Water 12.0 per cent., fat 84.2 per cent., casein and milk sugar I.3 per cent., and ash (salt) 2.5 per cent.

Butter made from sweet cream is usually not salted, and contains somewhat more water, fat and casein than sour-cream butter, and only about one-tenth of a per cent. of ash. Under the Federal pure-food law butter must contain at least 82.5 per cent. of fat and not more than 16 per cent. of water. A small amount of butter color is added to the cream in order to secure butter of a uniform color through the entire year.

Cheese.-Numerous kinds of cheese are made from milk. We shall here only mention two types commonly made in this country, viz., Cheddar cheese and cottage cheese.

Cheddar or American Cheese is made by adding a small amount of rennet extract to the milk. The rennet contains a ferment which causes the milk to curdle. The curd is cut into small cubes and carefully heated in the cheese vat so that it contracts and hardens. The whey is then strained off, and the curd salted, put into forms and pressed. The cheese is placed in a curing cellar where it is kept at an even temperature for a period ranging from a few weeks to half a year or more. American cheese is often sold only a couple of weeks old when it has not yet ripened into a nutritious, easily digested food; it takes several months for cheese to ripen properly.

Cottage Cheese.-Instead of adding rennet to curdle the milk, this may be allowed to sour spontaneously at ordinary room temperature, which will occur within 
two or three days. The curd thus obtained is strained from the whey and, after being salted, makes sour-milk or cottage cheese. This kind of cheese does not have to undergo any ripening process, but is consumed within a few days after it is made.

Composition of Cheese.-Cured Cheddar cheese is composed of about 32 per cent. of water, 34 per cent. of butter fat, 28 per cent. of casein and albumen, 3 per cent. of organic acids (mainly lactic acid, the acid of sour milk), and 3 per cent. of salt. "Full-cream cheese" means cheese made from milk containing all the cream it ordinarily had. Milk is sometimes partly skimmed before being coagulated with rennet, and the product thus obtained is called part-skim, half-skim cheese, etc. Full-skim cheese is also manufactured at times from pure skim milk, but this does not make a palatable food, being hard, horny and flavorless, even when cured for months. In many states the manufacture of part or full-skim milk cheese is prohibited by law.

Other Dairy Products.-Condensed Milk is manufactured from whole milk or partly skimmed milk by evaporating a certain portion of the water contained therein. The volume of the milk is reduced to onethird or more in the process of evaporation, which takes place in large vacuum pans. Condensed milk should contain at least 8 per cent. of butter fat, and be free from any foreign substance, except cane sugar, which is added in the manufacture of sweetened condensed milk. Condensed milk makes a good substitute for whole milk or cream, and is used in cases where whole milk cannot be obtained, e. g., on long voyages, in mining camps, etc.

Milk Sugar is obtained by evaporating the whey and allowing the crystals of milk sugar to form. It is used extensively in the manufacture of infant foods and medicinal preparations.

Buttermilk and Whey are, as we have seen, by-products in the manufacture of butter and cheese. Both of 
these materials, as well as skim milk, are used for feeding farm animals, especially calves, pigs or poultry.

Care of Milk.-Milk is a very unstable product, and unless special precautions are taken it will turn sour within twenty-four hours, if kept at ordinary temperature. This is due to the presence therein of bacteria. These are microscopic plants which get into the milk through dust in the barn and from other sources, and begin to multiply in the milk shortly after it is drawn; through their life-processes they break down the sugar of the milk into lactic acid. When a certain acidity has been reached (over 0.3 of one per cent.) the milk will taste and smell sour, and if the acidity exceeds 0.75

PROGENY DF $\mathrm{A}$ SINGLE GERM IN TWELVE HDURS

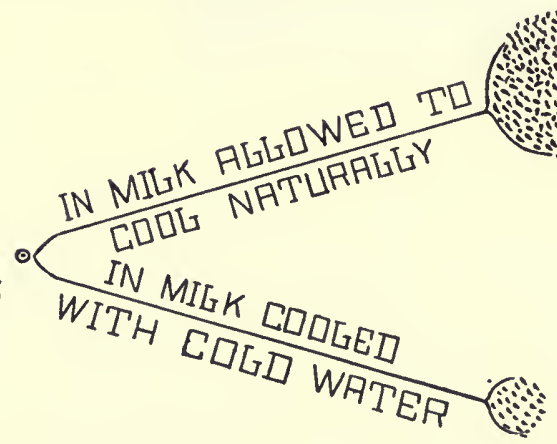

COOLING MILK PREVENTS THE RAPID GROWTH OF BACTERIA.

of one per cent., it will curdle (coagulate). Any means of precaution that will prevent the infection of the milk or check the growth of bacteria therein will tend to increase the keeping quality of the milk. As bacteria are abundantly present in all kinds of dirt, cleanliness is a most important factor in preventing the souring of milk. Milk pails, glass bottles, and other utensils in which milk is kept must be scrupulously clean. Another factor is cooling the milk to a low temperature (below $40^{\circ} \mathrm{F}$. if practicable), and keeping it at this temperature until consumed. Bacteria grow very slowly or not at all at low temperatures. 
Sterilization and Pasteurization.--Since the souring of milk depends on the growth of the bacteria found therein it follows that if these are destroyed, e. g., by heating the milk to the

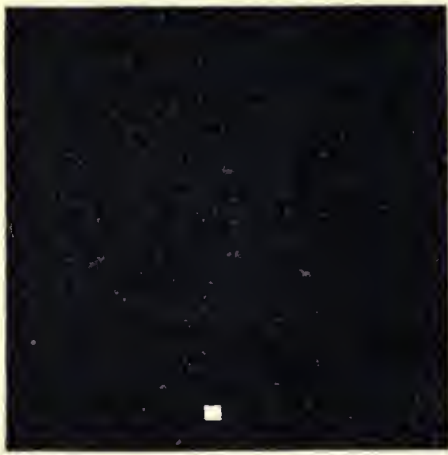

THE BLACK SPACE SHOWS NUMBER OF BACTERIA IN NORMAL FRESH MILK; THE WHITE SQUARE THE NUMBER AFTER PASTEURIZATION. boiling point, it will keep for a long period, perhaps indefinitely, provided all the bacteria have been destroyed in the heating process. The milk has then been sterilized. As the process of sterilization changes the properties of the milk and may decrease somewhat its value as a food for infants or invalids, the heating is now not generally carried so far, but only to the point of pasteurization. By"pasteurization "is meant the application of sufficient heat to destroy all bacteria in the milk, but not their spores. This is accomplished by heating the milk for twenty minutes at $14 \mathrm{O}^{\circ} \mathrm{F}$., or for shorter periods at higher temperatures. If the milk is cooled promptly after being heated, it will not have a cooked taste, and will have similar properties as fresh, so-called raw milk. Owing to its freedom from bacteria pasteurized milk will remain sweet for several days if kept at a low temperature.

Preservation of the milk by heat and subsequent cooling is the only legitimate method of improving the keeping qualities of milk. The laws of most states in the Union prohibit the use of chemicals for preserving milk. The reason for this is that chemicals decrease the digestibility of the milk, and may seriously affect the health of infants and sick persons who depend largely on milk for their nourishment. 


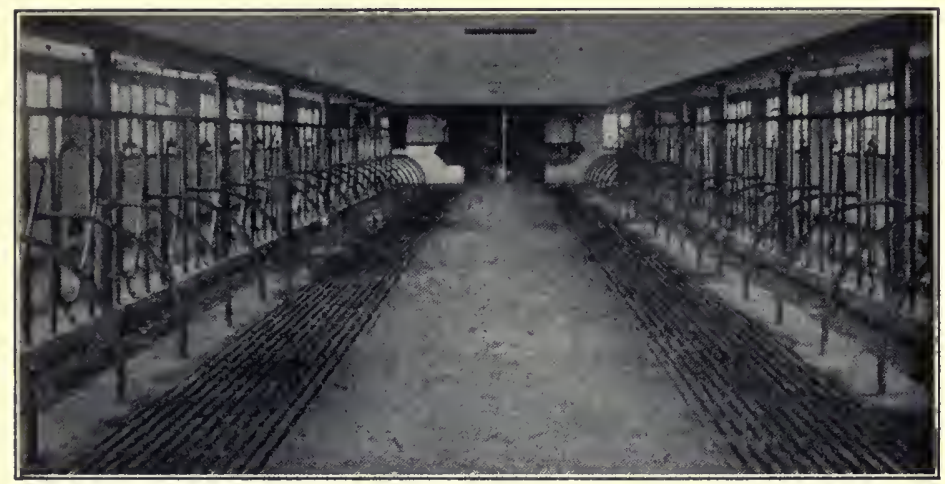

A WELL-KEPT DAIRY BARN WITH A DOUBLE ROW OF STALLS.

Necessity for the Caring of Milk.-Milk from diseased cows should never be used as a food for man or beast, unless it has been sterilized. Since milk is the most important and often the sole diet of infants and

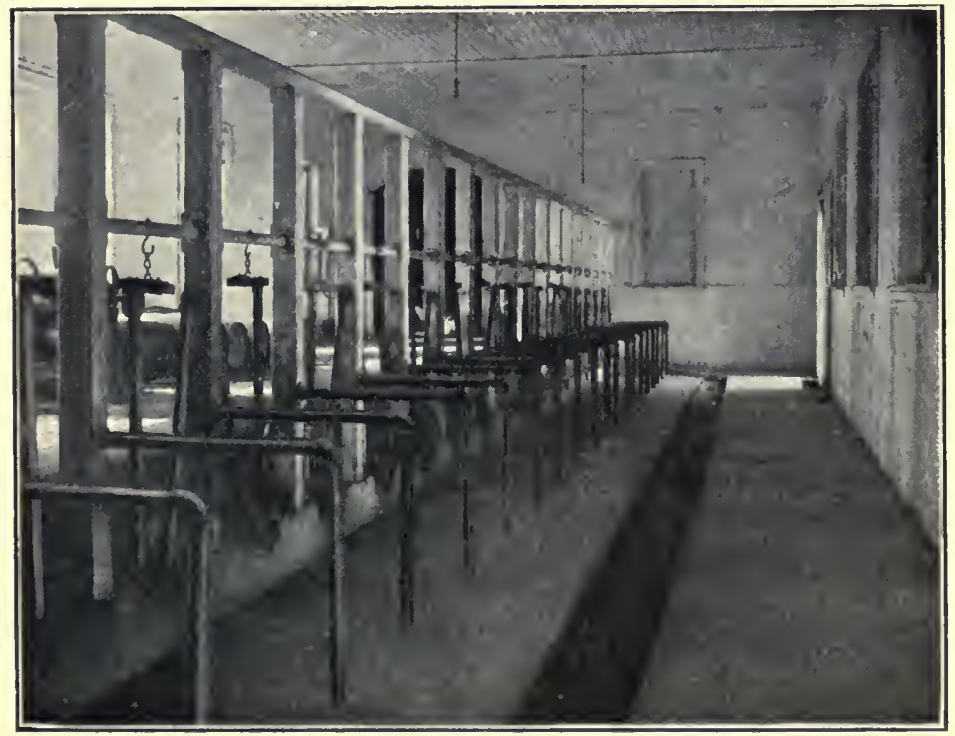

A MODEL BARN FOR DAIRY PURPOSES. 
young children, the purity of the milk supply should be safeguarded by all means known to modern dairy science. Milk has at times been the means of spreading contagious diseases, like scarlet fever, typhoid fever, etc. The greatest stress must, therefore, be laid on the importance of cleanliness in the barn and the dairy, as well as in the handling of the milk in the household.

Dairying is a special branch of agriculture, which makes great demands on those that follow it, with regard to industry, order, care and cleanliness; on the other hand, when conducted right, it is more remunerative than most other branches of farming; dairy farmers are able to maintain and even increase the fertility of their farms by purchasing commercial feeding stuffs for their cows and taking good care of the stable manure produced on the farm. Dairying is, therefore, not an exhaustive system of farming, like the production of field crops, truck gardening, etc.

EXERCISE.-Have you ever seen a Babcock test worked? If so, be prepared to describe it to the rest of the class. When engaged in butter-making, which is the more economical to keep, a cow giving 6,000 pounds of milk a year testing 5 per cent. butter fat, or one giving 7,000 pounds of milk testing 3.5 per cent. butter fat? Having two cows, one producing 25 pounds of milk per day and the other producing 16 pounds of milk per day, and both cows receiving the same amount of feed, what would be the saving per day and per month, when milk is selling at 30 cents a gallon (weight 8.6 pounds) retail, by feeding according to milk production?

\section{REFERENCES FOR COLLATERAL READING.}

Horses :

\section{LIVE-STOCK AND DAIRYING.}

Bureau of Animal Industry, Circular Nos.

37-Market classes of horses.

I37-The preservation of our native types of horses.

Experiment Station Bulletin, No.: 122-Illinois-Market classes and grades of horses and
mules.

CATTLE:

Yearbook of the U. S. Dept. of Agriculture:

I908-Some facts about tuberculous cattle.

Farmers' Bulletins, Nos. :

55-The dairy herd.

$7 \mathrm{I}-$ Essentials of beef production. 
I06-Breeds of dairy cattle.

I83-Meat on the farm; butchering, curing and keeping.

I84-Marketing live-stock.

206-Milk fever.

233-Beef vs. dairy types for beef.

350 - The dehorning of cattle.

$35 \mathrm{I}$ - The tuberculin test of cattle for tuberculosis.

378 -Methods of exterminating the Texas fever tick.

Experiment Station Bulletin, No.:

84-Louisiana-Texas fever.

\section{SHEEP :}

Farmers' Bulletins, Nos.:

96-Raising sheep for mutton.

I I9-Establishing a flock of mutton sheep.

$360-$ Market classes and grades of sheep.

Experiment Station Bulletin, No.:

I29-Illinois-Market classes and grades of sheep.

SWINE :

Yearbook of the U. S. Dept. of Agriculture:

I908-Recent work of the Bureau of Animal Industry concerning the cause and prevention of hog cholera.

Farmers' Bulletins, Nos. :

22-92-97-I33-I 44-210-25I-305-Feeding.

56-84-97-1 24-305-331-334-Forage crops for hogs.

Ioo-Hog-raising in the South.

I33-Profitable crops for pigs.

205-Pig management.

222-Market classes and grades of swine.

272-A successful hog and seed corn farm.

329-Hogging off corn.

379-Hog cholera.

Poultry :

Farmers' Bulletins, Nos. :

5I-Standard varieties of chickens.

64 -Ducks and geese.

I03-273-296-Preserving eggs.

II 4 -Floor space necessary per hen.

200-225-Turkeys.

225-227-Poultry-house construction.

236-28I-309-Incubation and incubators.

244-316-3I7-Poultry appliances.

287-Poultry management.

355-A successful poultry and dairy farm.

357 -Methods of poultry management at the Maine Experiment Station.

DAIRYING :

Yearbooks of the U. S. Dept. of Agriculture:

1896-Care of dairy utensils.

I 897-Utilization of by-products of the dairy.

I902-Dairying at home and abroad.

Farmers' Bulletins, Nos. :

29 -Souring of milk and other changes in milk products.

42-Facts about milk. 
55-The dairy herd.

63 - Care of milk on the farm.

74-363-Milk as a food.

I 4-I62-I90-Profitable and unprofitable cows.

I49-Effect of exposure on milk production.

I5I-349-Dairying in the South.

I66-Cheese-making on the farm.

24I-Butter-making on the farm.

348 - Bacteria in milk.

355-A successful poultry and dairy farm.

366 -Milk supply of cities.

Books :

366-Effect of machine-milking on cows.

Types and Breeds of Live Stock-Plumb-Ginn \& Co., Boston.

Principles of Breeding-Davenport-Ginn \& Co., Boston.

Farm Animals-Wilcox-Doubleday, Page \& Co., New York City.

The Horse-Roberts-The Macmillan Co., New York City.

Farm Poultry-Watson-The Macmillan Co., New York City.

Testing Milk and Its Products-Farrington \& Woll-Mendota Pub. Co., Madison, Wis.

Milk and Its Products-Wing-Macmillan Co., New York City. Bacteria in Milk and Its Products-Conn-P. Blakiston's Son \& Co., Philadelphia.

Elements of Dairying-Decker-Published by the author.

Principles and Practice of Butter-Making-McKay \& LarsenWiley \& Sons, New York City.

Modern Methods of Testing Milk and Milk Products-Van Slyke-Orange Judd Co., New York City.

Dairy Chemistry-Snyder-The Macmillan Co., New York City. 


\title{
C HAPTER IX.
}

\section{FEEDS AND FEEDING.}

\section{Section LX.-The Composition of Plants.}

\author{
By Prof. J. E. Halligan,
}

Chemist in Charge, Louisiana State Experiment Station.

Animals live on entirely different substances from plants. The latter require mineral substances and air for existence, while animals use the substances which are stored up by the plants for their food. The substances which the plant stores up in its period of growth are termed dry matter and water. When the water is driven off from plants the dry matter is what remains. If we burn this dry matter a large proportion of it passes off in the form of invisible gases. This material which so disappears is known as organic matter. That which is left is the ash or mineral matter. The amounts of organic matter and ash vary in different kinds of plants and grains. The organic matter is composed of protein, fats, nitrogen free extract, and fiber. The ash is made up of soda, phosphorus, sulphur, potash, lime, sand and other mineral substances.

Protein.-This includes all the nitrogenous compounds present in plants. It is represented in the animal by the lean meat, muscles and ligaments which connect the bones, the organic parts of bone, the nerves, the brain and the internal organs. The white of egg, the curd of milk, glue, gelatin, and the gluten of flour approach pure protein in composition. The other constituents, namely, fats, carbohydrates, water and ash, do not contain any protein. 
Fats.-The substances called fats are also termed ether extract because they include those parts of feed stuffs which are dissolved out by ether. Oils, fats, waxes, and coloring matters (such as chlorophyll) come under this group. Cotton-seed oil, olive oil, linseed oil, butter, hog lard, fish oil, and tallow are examples of fats.

Nitrogen Free Extract.-This is made up principally of the sugars, starches, dextrins and gums. As the name implies, it is free from nitrogen.

Fiber.-The woody parts of plants are called fiber. Cotton lint is almost pure fiber.

Carbohydrates.-This is the name given to the nitrogen free extract and the fiber, when taken together. These substances are called carbohydrates, because they are compounds of carbon, hydrogen and oxygen. When they are digested by the animal they have the same value, and they satisfy equal demands.

$W$ ater.-All feed stuffs, no matter how dry they may appear to be, contain water. The average per cent. of water in feeds such as oats, corn (grain), cottonseed meal, etc., is about Io per cent. The green grasses contain about 80 per cent. of water, and root crops carry about 90 per cent. of water.

Classification.-The following statement gives the parts of plants (feed stuffs) in a condensed form:

Feed Stuff $\left\{\begin{array}{l}\text { Water } \\ \text { Dry Matter }\end{array}\left\{\begin{array}{l}\text { Ash } \\ \text { Organic } \\ \text { Matter }\end{array}\left\{\begin{array}{l}\text { Protein } \\ \text { Fats } \\ \text { Carbohydrates }\end{array}\left\{\begin{array}{l}\text { Nitrogen Free } \\ \text { Extract } \\ \text { Fiber }\end{array}\right.\right.\right.\right.$

Composition of Feed Stuffs.-The composition of feed stuffs (plants and grains) may be expressed as follows :

Protein

Fats (Ether Extract)

Nitrogen Free Extract
Fiber

Water

Ash

Exercise.-Take one pound of green grass and dry it in the sun. What is the loss in weight? What is this loss in weight due to?

Have some pupils bring grains of corn and Irish potatoes to the classroom. Purchase five cents' worth of tincture of iodine at any 
drug store. Dilute this with water. Cut the corn and potatoes into small pieces and place a drop of the diluted iodine solution on a few of these pieces. Note the blue color, due to the presence of starch which is stored up by the plants during the growing process. It is well to have the iodine dilute in order to get a delicate reaction.

Take a small quantity of hay and have the pupils approximate the weight of it. Burn this hay in a dish and show the scholars the ash. Ask them the loss in weight. Let them rub the ash between their fingers.

\section{Section LXI.-The Composition of Farm Animals and the Nutritive Elements.}

Animal Substances.-The constituents of animals are similar to those of plants, although they are somewhat different in actual composition.

The substances in an animal may be divided into water and dry matter. The dry matter is composed of the ash and the organic matter. The organic matter is made up of protein and fats.

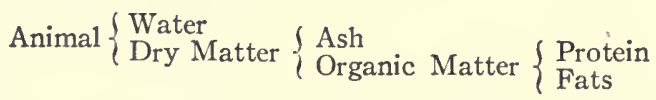

$W$ ater.-The bodies of all animals are made of 50 per cent. water. The water is present in the animal in a free state in the tissues and the blood. Young animals contain a greater per cent. of water than the old animals.

Dry Matter.-This is what is left after the water is driven off, and represents about 50 per cent. of the weight of the animal. It is made up of fats, protein and ash.

Fats.-Mutton suet, hog lard and beef tallow are examples of animal fats. Animal fats are entirely different from the fats of plants.

Protein.-This is represented in the animal in the form of lean meat, organic part of bones, muscles, ligaments, nerves, internal organs and the brain.

Ash.-This includes all the mineral substances, and is made up of the same ingredients as mentioned under the composition of plants. 
Carbohydrates.-This group of substances is not included in the above classification, because the animal changes the carbohydrates into fats and glycogen in the processes of digestion and assimilation.

COMPOSITION OF ANIMALS.

\begin{tabular}{|c|c|c|c|c|}
\hline Steer, 17 months old. & $\begin{array}{l}\text { Water } \\
59.4 \%\end{array}$ & $\begin{array}{l}\text { Ash } \\
4.4 \%\end{array}$ & $\begin{array}{l}\text { Protein } \\
17.4 \%\end{array}$ & $\begin{array}{l}\text { Fat } \\
\text { I } 8.8 \%\end{array}$ \\
\hline Steer, 24 months old. & 53.1 & 5.1 & 16.6 & 25.2 \\
\hline Swine, well fed....... & 57.9 & 2.9 & 15.0 & 24.2 \\
\hline Swine, fat..... & 43.9 & 1.9 & I I. 9 & $42 \cdot 3$ \\
\hline Sheep, lean................ & 67.5 & 4.0 & I 8.3 & 10.2 \\
\hline Sheep, very fat. . . . . . . . . & $43 \cdot 3$ & 3.1 & 12.2 & $41 \cdot 4$ \\
\hline
\end{tabular}

The data in the above table was worked out by Lawes and Gilbert and the Maine Experiment Station. It shows that lean animals contain a great deal more water than fat animals.

Lean and Fat Animals.-The following table gives the proportion of dressed carcass of lean and fat animals, according to Lawes and Gilbert:

$\begin{array}{llll}\text { Ox } & \text { Sheep } & \text { Swine } \\ \text { Lean animal.......... } 47 \% & 45 \% & 73 \% \\ \text { Fat animal........ } 60 & 53 & 82\end{array}$

A fat animal contains less water than a lean animal, because the increase in fat is made up largely of dry matter. The fatty substances do not replace the water, but an increase in fat in the animal body means a greater increase in dry matter.

The Nutritive Elements.-Protein, fats, carbohydrates, water and ash serve to supply the needs of animals. Protein, fats and carbohydrates are usually called the nutritive elements. Water and ash are not included. The water can be supplied in a cheaper form than in a feed stuff, and there is generally sufficient ash present in feed stuffs to enable us not to consider this ingredient.

Purpose of the Nutritive Elements.-Animals use food in two ways: I. To build up the body and repair broken down tissue. 2. To produce energy, to keep warm, and to supply that power which gives locomotion or movement to the animal body. 
Function of Ash or Mineral Matter.-All the bones and framework of the animal body contain ash or mineral compounds. The blood, tissues and the digestive fluids require mineral compounds for their existence. It is fortunate that nature has supplied sufficient mineral matter in most of the feeds that animals live on. It is only necessary to furnish mineral compounds when a diet consisting chiefly of grain is fed. Animals could not live without mineral matter. Such substances as

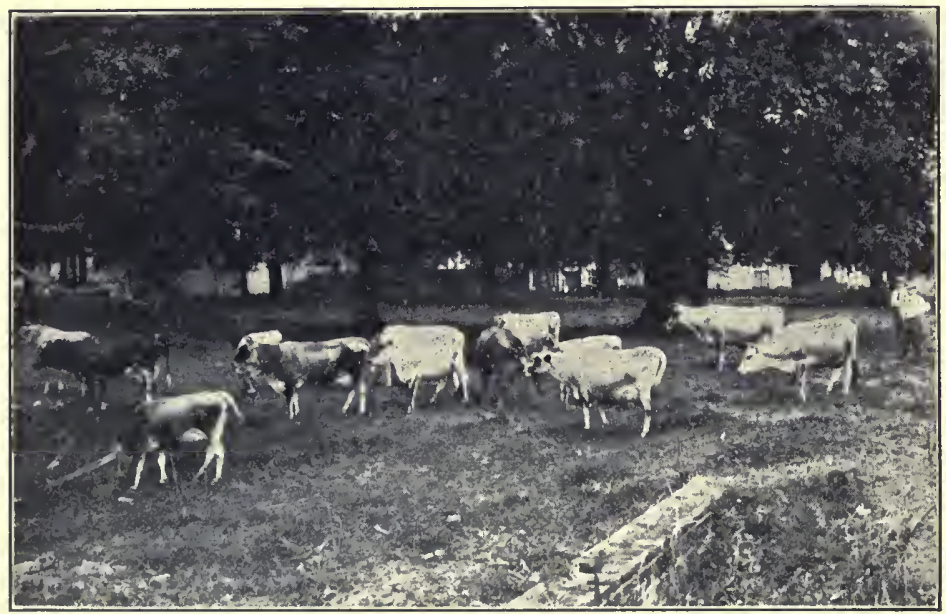

DAIRY CATTLE CONTAIN MORE WATER THAN FAT BEEF CATTLE.

common salt, wood ashes and precipitated chalk, are sometimes fed in conjunction with other feeds to supply the needs of growing animals.

Function of Protein.-Protein is the main constituent of muscles, horn, hoof, hair, ligaments and working parts of the animal body. The protein substances are in reality the flesh formers. Protein bodies repair the broken down tissues, help form blood, and milk. When animals are fed protein in the right proportions they possess great vigor, and without protein the animal would die. Sometimes protein can be made to take the 
place of fats and carbohydrates, but such substitution is not practicable, as protein generally costs more than fats and carbohydrates. Protein hardly ever performs the functions of fats and carbohydrates unless these latter compounds are lacking in the animal's food.

Functions of Fats and Carbohydrates.-These nutrients supply the fuel for the animal body. They furnish the materials that keep the animal warm. The fats and the carbohydrates also produce fat in the animal body. The fats are not always changed in forming fatty tissue, but the carbohydrates are transformed into fats before being stored as such. As an energy and heat producer fats have a greater value than carbohydrates. Fats are considered as being 2.25 times more valuable than carbohydrates in this respect. In other words, one pound of fat is worth 2.25 times as much as one pound of carbohydrates for animal fuel. * Classification of the functions of the nutritive elements :

Ash........ $\left\{\begin{array}{l}\text { Supplies materials for the bones and framework of the } \\ \text { body. Helps build up the blood, tissues, digestive } \\ \text { fluids and secretions. }\end{array}\right.$

Protein..... $\left\{\begin{array}{l}\text { Theflesh formers. Substances for the making of the lean } \\ \text { meat, muscles, skin, ligaments, horn, hair and milk. } \\ \text { Sometimes used as fuel to give warmth and energy. }\end{array}\right.$

Fats....... $\begin{aligned} & \text { Furnish fuel to keep the a nimal warm. Help to pro- } \\ & \text { duce energy. Aid in the production of fatty tissue. } \\ & \text { As a heat producer fats are } 2.25 \text { times as valuable as } \\ & \text { carbohydrates. }\end{aligned}$

Carbohydrates $\left\{\begin{array}{l}\text { Supply the fuel to keep the animal warm and to pro- } \\ \text { duce energy. Are transformed into fats for the } \\ \text { production of fatty tissue. }\end{array}\right.$

Do not make the pupils memorize the tables in this section, but require them to understand the fundamental principles involved. Take the class to some pasture or stable and have them look over some animals. Make them feel the body warmth. Show them to which parts of the animal the protein, fats, carbohydrates, water and ash are distributed.

* The idea and some of the data in this classification came from Bulletin 106 of the North Carolina Experiment Station. 


\section{Section LXII.-Physiology of Digestion AND Food Economics.}

By Dr. W. H. Dalrymple,

Department of Veterinary Science, Louisiana State University.

That which an animal eats and drinks for the purpose of nourishing its body, constitutes its food. Digestion is the physiological process, or act, of changing the food into soluble materials that may be absorbed, or taken into the circulation and assimilated, or made use of by the cells of the different tissues of which the body is composed.

The different steps in this physiological process are:

I. Prehension, or seizing the food. This is accomplished in the horse by the lips and front teeth; in the $o x$ by the tongue, lower front teeth and dental-pad. The $d o g$ prehends fluids by the tongue-laps water, for example.

2. Mastication, or chewing, and insalivation, or mixing the food in the mouth with saliva, from the different salivary glands, which enters the mouth through small ducts or tubes.

Mastication is performed by the large back teeth, molars, or grinders, which break up the grains and hard particles; exposes them to the chemical action of a ferment (ptyalin) of the saliva (which changes insoluble starch into soluble sugar); and otherwise prepares them for later steps in the digestive process, viz., in the stomach, intestines, etc.

3. Deglutition or swallowing. This step is accomplished by the aid of the tongue, certain muscles of the throat, and the wave-like contractions of the osophagus or gullet, which carries the food into the stomach.

In the ruminating animal, such as the ox, sheep and goat, which " chew the cud," the food, in a somewhat imperfectly-masticated condition, passes into the large first compartment of the stomach (the rumen or paunch), and then into the second (honeycomb or retic- 
ulum). Then, by a special arrangement of the parts, it is forced back into the æsophagus and into the mouth for final preparation by the teeth and the saliva. When swallowed a second time, the mouthful of food passes into the third compartment (omasum or manyplies), and on to the fourth (abomasum or true digestive compartment) for final stomachal digestion.

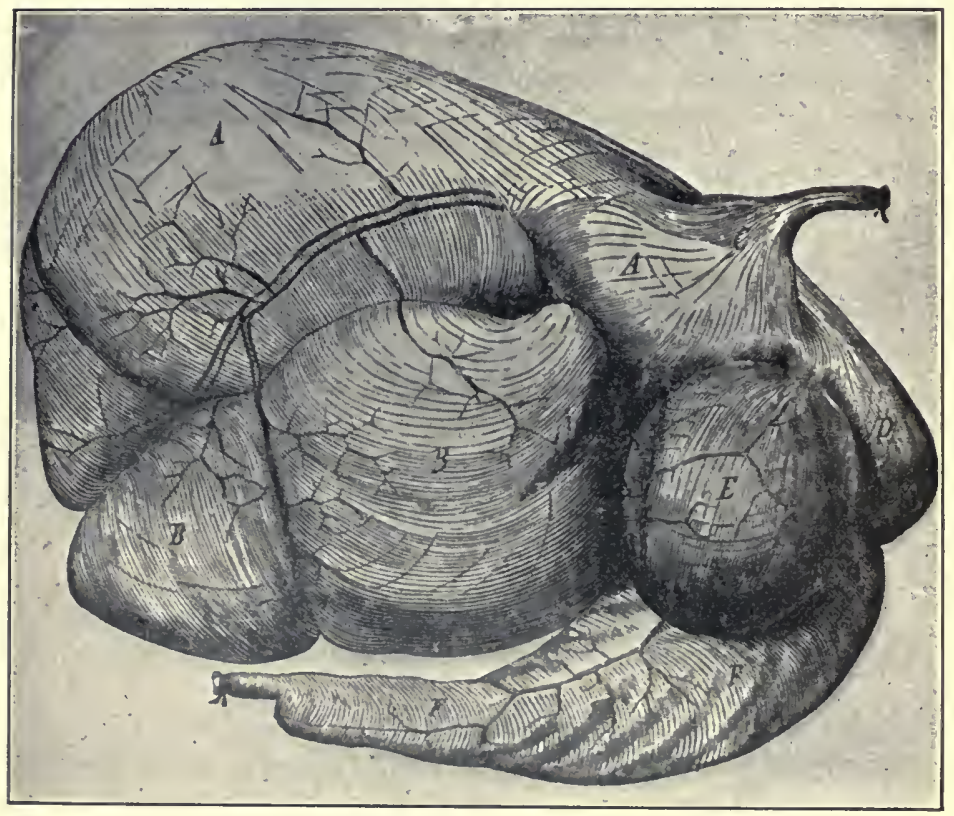

STOMACH OF THE OX.

$A$, rumen, left hemisphere; $B$, rumen, right hemisphere; $C$, termination of œsophagus; $D$, reticulum; $E$, omasum; $F$, abomasum. After Fleming.

4. Chymification or stomachal digestion. This step refers to the food materials being converted into chyme, which is the liquid, or semi-liquid, mass into which the food in the stomach is changed by the action of the gastric juice, aided by the churning motion produced by the muscular wall of that organ. When in the stomach the food is not only rendered more liquid or 
poultaceous by the gastric juice as a whole, but, by the chemical ferment, pepsin, the insoluble protein is changed into soluble peptone.

5. Chylification or intestinal digestion. This step has reference to the food in the small intestine being converted into chyle, which is the nutritive materials, in liquid form, ready for absorption into the circulation. After reaching the small intestine, the food materials are again acted upon by ferments which have a somewhat similar action to those already spoken of in connection with the saliva and the gastric juice. These ferments are chiefly from the pancreas, or "sweetbread," and are conveyed to the intestine, as a part of the pancreatic juice, through the pancreatic duct or tube.

These ferments alluded to are:

(a) Amylopsin, which changes the insoluble starch into soluble sugar.

(b) Trypsin, which converts insoluble protein into soluble peptone.

(c) Steapsin, which emulsifies the fats and oils in the food, and renders them more easy of absorption into the circulation.

6. Absorption.-This is the step by which the nutrient materials of the food, in liquid form, are taken from the alimentary canal into the circulation to be carried by the blood to all parts of the body to nourish the different tissues. And no food is capable of being absorbed until it has first been rendered soluble by the action of the different ferments.

The sugar (carbohydrate) and the peptone are absorbed by the small veins in the walls of the stomach and intestines, while the emulsified fats are absorbed, mainly, by the lacteals-small beginnings of the lymphatic system distributed to the small intestine.

7. Circulation.-This step is accomplished by the blood in the arteries carrying the nutritive materials, absorbed from the food, to all parts of the body.

8. Assimilation.-This step is undertaken by the 
tissue-cells themselves, selecting from the blood or lymph, the nutritive elements required for their maintenance and development.

9. Defecation.-This final step refers to the casting off from the body, in the form of excrementitious matter, the inert indigestible parts of the food.

Food Economics.-Waste of food materials may be lessened in various ways, viz.:

By having the required digestible nutrients properly balanced.

By maintaining the proper function of the skin through careful cleansing, grooming, etc.

By proper shelter in cold weather, thereby preventing loss of heat from the body through radiation from the skin.

By preventing, when possible, too high a temperature of the surroundings, stables, exposure to the hot sun, etc.

By kind and gentle handling or treatment, as all forms of rough usage tend to cause nervousness and excitement, which are incompatible with a normal healthy bodily condition.

By a sufficiency of pure wholesome water, and a moderate supply of common salt; both of which are aids to digestion, etc.

EXercise.-Trace the food from the time the ruminant first prehends it until it reaches the fourth or true compartment of the stomach. What ferments act on starch and on protein? What could be done to economize an animal's food during cold weather?

\section{Section LXIII.-Natural and Commercial Stock FEEDS.}

By Prof. J. E. Halligan,

Chemist in Charge, Louisiana State Experiment Station.

The natural feeds used for feeding stock include forage crops, root and tuber crops, and grains and seeds. Forage Crops.-Under this head come the leguminous plants, the grasses and the grain plants. 
I. Leguminous Plants. These plants differ from the grasses, and the grain plants in that they contain more nitrogenous substances, namely, protein ; alfalfa, clovers, vetches, cowpeas, soya bean Japan clover (lespedeza), are some of our leguminous plants.

2. Grasses. The principal grasses used for feeding are timothy, Bermuda, orchard, crab, Johnson, Kentucky blue (June), and red top.

3. Grain Plants. Corn, oats, barley, rye, rice and wheat are some examples of this class.

Husbanding of Forage Crops.-Forage crops are not always fed in their natural green state, but are sometimes husbanded in other ways. For instance, our leguminous plants, grasses and grain plants are often dried in the field before harvesting. This field curing is done to permit the farmer to save these crops and feed at his pleasure. Oftentimes these forage crops are put into an air-tight box, called a silo, in their green state. The crops are chopped into small pieces about one inch long. This method of preserving crops enables the feeder to furnish succulent feed at any time of the year. Because of unfavorable weather

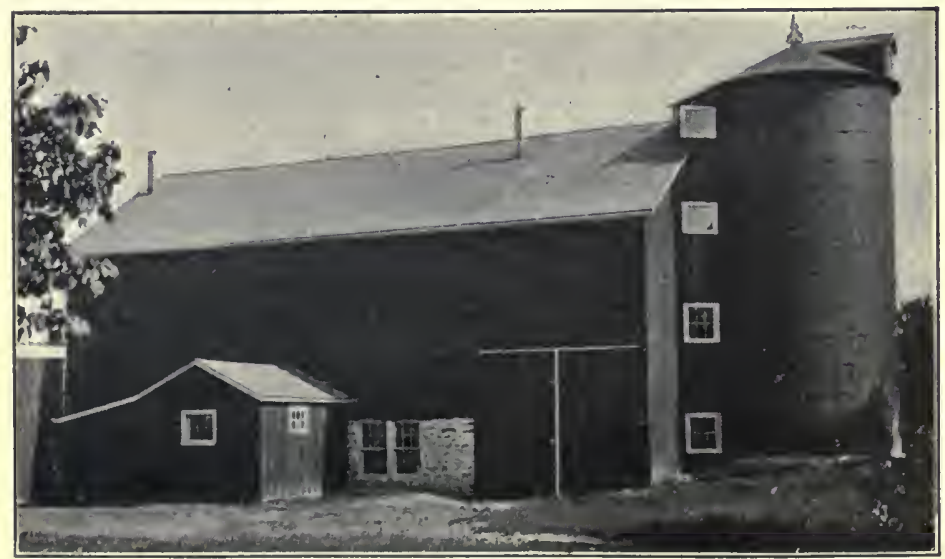

A MODERN BARN WITH SILO. 
there are sometimes losses in the field curing of crops. On the whole the preserving of forage crops in a silo is more profitable.

Root Crops.-Turnips, carrots, rutabagas, mangelwurzels (a kind of beet), and beets are the principal root crops used for feeding. Potatoes are sometimes fed, but they are generally grown for human consumption. For making milk or producing beef the feeding of root crops is satisfactory. On account of the

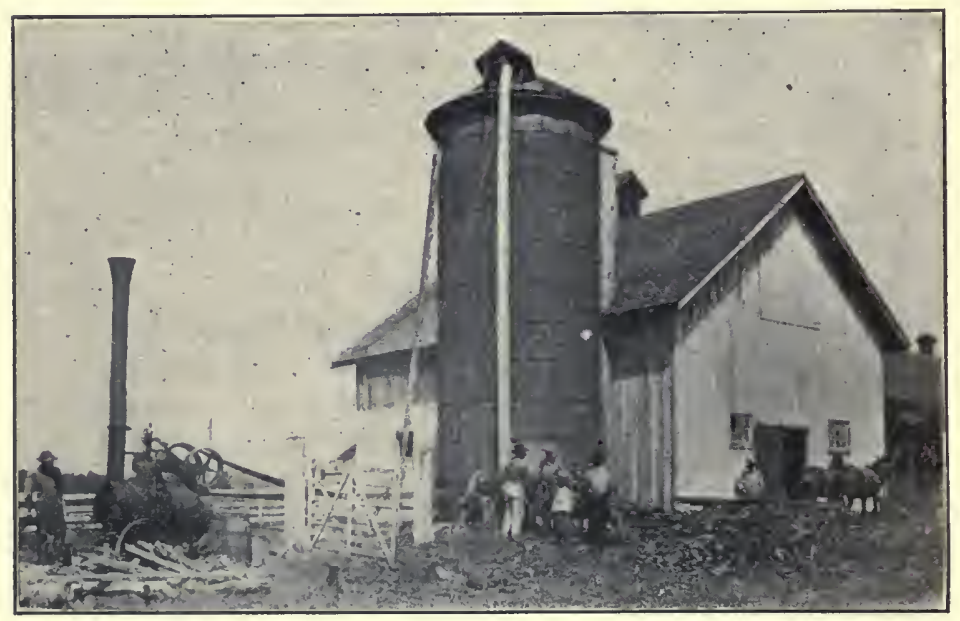

FILLING A WOODEN SILO.

tonic effect, roots give results far above what the chemical value would indicate.

Grains and Seeds.- Some of our principal grains and seeds used for feeding farm animals are corn, cottonseed, rice, oats, barley, flaxseed, rye, wheat, beans and peas. Most of our grains and seeds must be thoroughly dried before they are stored away. If they are not completely dried they are liable to ferment and decompose. Such deterioration spoils them for feeding purposes.

Commercial Feeds. - These can be defined as those 


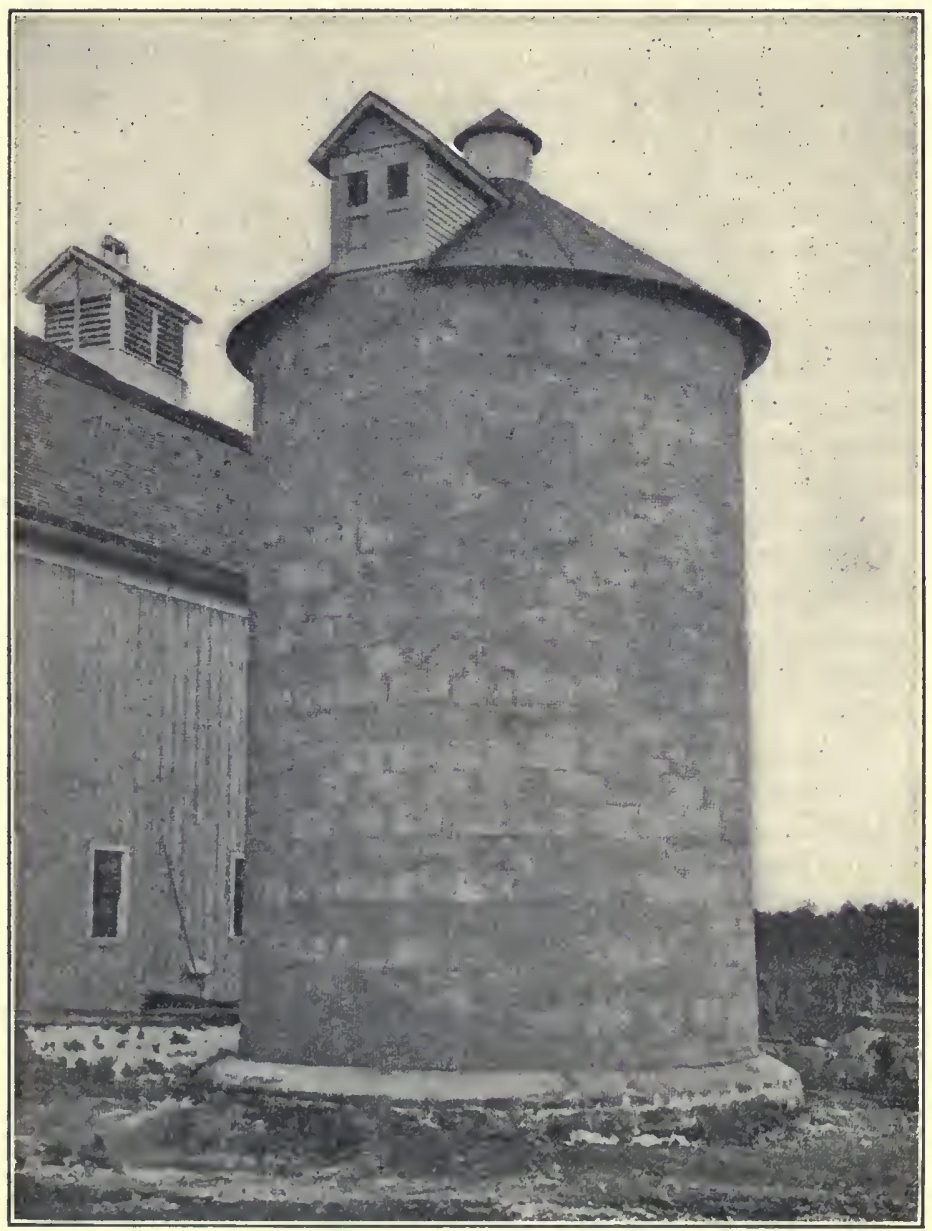

A CONCRETE BLOCK SILO (CONCRETE REVIEW).

feeds made from the grains, seeds, their by-products, all products left after the preparation of human foods and beverages, and the by-products left after oil extraction.

Where Derived.-In the manufacture of cereals, 
for human food, there are many parts of the grain and seed which are of no further value in such manufacture. In most cases these by-products are saved and utilized for feeds for our stock.

$V$ alue of By-Products.-Many of these by-products are valuable for feeding. Cotton-seed meal, wheat bran, linseed meal, gluten feed, dried brewers' grains, distillers' grains, rice polish and hominy feeds are a few of the valuable by-products found on our markets. Others of these waste products, such as inferior corn, oat hulls, rice hulls, flax bran, and dust from grain possess little feeding value and are sometimes injurious.

Nerv By-Products.-On account of the high prices of grain and seeds and keen competition, almost all the by-products are being saved and disposed of in our commercial feeds. New by-products are continually being put on our market, either mixed with other materials, or sold unmixed.

Sources of Commercial Feeds.-The following statement summarizes the sources of the by-products. These by-products are derived from-

I. The manufacture of cotton-seed oil, linseed oil, and other vegetable oils.

2. The manufacture of whisky, beer, alcohol, spirits, etc.

3. The manufacture of human cereals (breakfast foods).

4. The manufacture of glucose and starch.

5. The manufacture of products from grains such as flour and rice.

6. The manufacture of cane sugar, beet sugar and sorghum cuite.

7. The manufacture of animal and fish products.

EXERCise.-Why do we call forage crops natural feeds? What are the names of the natural feeds used at your home? Does the corn at your home ever get moldy? What are the names of the commercial feeds used at your home?

If any of the pupils have a silo at home or have ever seen one, have one of them explain to the class the construction of it, the 
way the crop is prepared before storing, and the appearance of the crop after it has been in the silo for some time. Let one pupil bring a sample of ensilage to school. Taste it and show it to all the pupils.

Section LXiV.-Vegetable Oil, Alcoholic and BREAKFAST FoOd By-Products.

Vegetable Oil By-Products.-The by-products from the manufacture of vegetable oils are cotton-seed meal, cotton-seed hulls, linseed meal and flax feed.

Cotton-seed Meal and Hulls.-Attached to the seed of cotton are long white fibers known to us as cotton. When the cotton is ginned all of these fibers or lint are removed except a few short fibers which adhere to the seeds. The seeds are then taken to a cotton-seed oil mill and treated. First the lint is removed leaving nothing but the seed. The seed is composed of the hull, or hard outer covering, and the kernel or meat. The seeds are then put through a machine called the huller. This machine separates the hulls from the meats. This process is called decorticating the cotton seed. The hulls obtained in this process are known as cotton-seed hulls. The meats are then cooked in special kettles and made up into cakes or forms. These hot forms are subjected to great pressure and the oil is extracted. The remaining product is ground and sold as cotton-seed meal.

\section{ANALYSES OF COTTON SEED, COTTON-SEED MEAL AND HULIS *}

\begin{tabular}{|c|c|c|c|c|c|c|}
\hline Cotton seed...... & $\begin{array}{l}\text { Protein } \\
\mathrm{I} 8.4 \%\end{array}$ & $\begin{array}{l}\text { Fat } \\
19.9 \%\end{array}$ & $\begin{array}{c}\text { Nitrogen } \\
\text { Free Ext. } \\
24.7 \%\end{array}$ & $\begin{array}{c}\text { Fiber } \\
23.2 \%\end{array}$ & $\begin{array}{l}\text { Water } \\
10.3 \%\end{array}$ & $\begin{array}{l}\text { Ash } \\
3.5 \%\end{array}$ \\
\hline Cotton-seed meal. & 43.0 & 8.5 & 25.7 & 7.8 & 8.2 & 6.8 \\
\hline Hulls........... & 4.2 & 2.2 & $33 \cdot 4$ & 46.3 & I I. I & 2.8 \\
\hline
\end{tabular}

The composition of cotton-seed meal is apt to vary *Henry, "Feeds and Feeding." 
a great deal depending upon the season, the nature of the land it was raised on, and the climatic conditions.

Cotton Seed Nitrogen

Meal from Protein Fat Free Ext. Fiber Water Ash

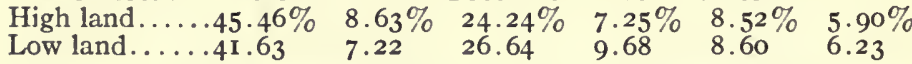

Linseed Meal and Flax Feeds.-These materials are common in certain sections of the Middle West. They are derived from the flax plant which is grown for its valuable fiber. I. Linseed meal. There are two classes of linseed meal found on the American market, namely, old process and new process meal. The old process meal is obtained by pressing out the oil from the cold or warmed crushed flax seeds. The new process consists of extracting the oil from the warmed crushed flax seeds by the use of naphtha. This new process is employed because it permits of a greater extraction of oil. The naphtha is driven off by steam before the product is placed upon the market.

\section{ANALYSES OF OLD AND NEW PROCESS LINSEED} MEAL AND FLAX SEED *

\begin{tabular}{|c|c|c|c|c|c|c|}
\hline meal.. & $\begin{array}{l}\text { Protein } \\
32.9 \%\end{array}$ & $\begin{array}{l}\text { Fat } \\
7.9 \%\end{array}$ & $\begin{array}{c}\text { Nitrogen } \\
\text { Free Ext. } \\
35.4 \%\end{array}$ & $\begin{array}{l}\text { Fiber } \\
8.9 \%\end{array}$ & $\begin{array}{l}\text { Water } \\
9.2 \%\end{array}$ & $\begin{array}{l}\text { Ash } \\
5.7 \%\end{array}$ \\
\hline New process meal. & 33.2 & 3.0 & 38.4 & 9.5 & I0. I & 58 \\
\hline Flax seed........ & 22.6 & $33 \cdot 7$ & 23.2 & 7. I & 9.2 & $4 \cdot 3$ \\
\hline
\end{tabular}

Flax Feed.-This by-product is composed of the screenings from the flax seed as well as part of the shell and fiber of the flax. It is used to some extent in mixed feeds.

Alcoholic By-products.-Brewers' grains, malt sprouts and distillers' grains are examples of these byproducts. They are rich in nitrogenous substances containing about $1 / 2$ to $3 / 4$ as much protein as good cotton-seed meal. I. Dried brewers' grains. These are the kiln-dried by-product from the manufacture of beer. They consist principally of barley grains * Henry, "Feeds and Feeding." 
from which the starch and other soluble matter have been extracted. 2. Malt sprouts. In the fermenting of barley for the manufacture of beer the barley begins to grow or sprout. When these barley sprouts have attained the height of about $1 / 4$ inch they are removed from the grain by machinery. They are then artificially dried and sold as malt sprouts. 3. Distillers' grains. In the manufacture of whisky and alcohol the starch and other soluble matter are removed from the grain. The remaining product is kiln dried and sold as dried distillers' grains.

Breakfast Food By-products. - In the manufacture of cereal foods only the sound grains are used. Oats,

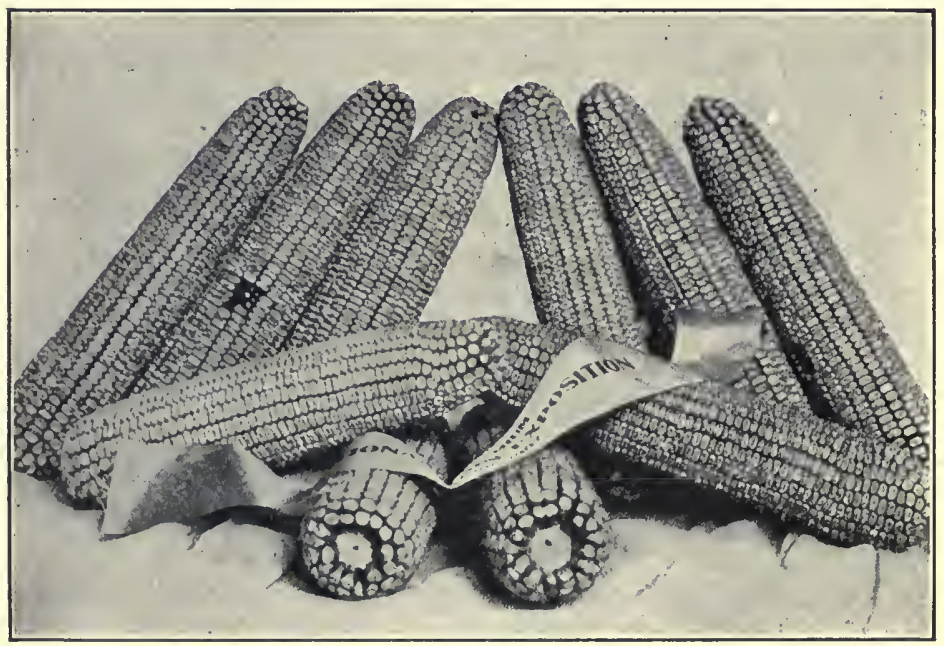

PRIZE EARS OF CORN. CORN IS THE SOURCE OF MANY BREAKFAST FOODS.

wheat, corn and barley are the principal grains from which breakfast foods are made. The hulls of the grains are removed, and these hulls together with the inferior grains, go to make up commercial stock feeds. Oat feeds and corn and oat feeds are stock feeds which are made up almost entirely of breakfast food by- 
products. These feeds sometimes cost almost as much as the original grains from which they are derived.

ExERCise.-I. If possible, get samples of cotton seed, cotton-seed meal, cotton-seed hulls, linseed meal and flaxseed. Write in your note-book a description of them. Cut the cotton seed or the flax seed open and make a note of the quantity of oil and its odor. No matter what section you live in, you can no doubt get some of the above materials at a feed store. 2. Name all the different kinds of breakfast foods you have ever seen or eaten.

Have as many different kinds of breakfast foods brought by the pupils as possible. As far as possible let the pupils state the grains from which they were made. Send one or two pupils to a feed store to get samples of alcoholic by-products.

\section{Section LXV.-OTher By-Products.}

Glucose and Starch By-products.-There are many by-products left from the manufacture of glucose and starch. These by-products usually come from the grain of corn. Gluten meal, gluten feed, corn bran, hominy feed, feed meal, and corn germ meal are corn by-products. I. Gluten meal is derived from the nitrogenous portion of the corn grain, known as the gluten layer. 2. Gluten feed is ground corn grain minus the starch. 3. Corn bran is made up of the outer husks or coverings of the corn grain. 4. Corn germ meal is generally the ground corn germs with more or less of the oil extracted. 5. Hominy feed and feed meal are the by-products from the manufacture of hominy grits and starch. They vary in composition. They usually consist of the softer parts of the corn kernel, and sometimes they contain corn bran.

Milling By-products.-These consist principally of wheat by-products and rice by-products.

Wheat By-products. - Wheat bran, wheat middlings and flour are products derived from the wheat kernel. I. Wheat bran. This consists mostly of the outer portions of the wheat kernel. 2. Wheat middlings. This material is sometimes called shorts, and is made up of the inner layers of the outer cov- 


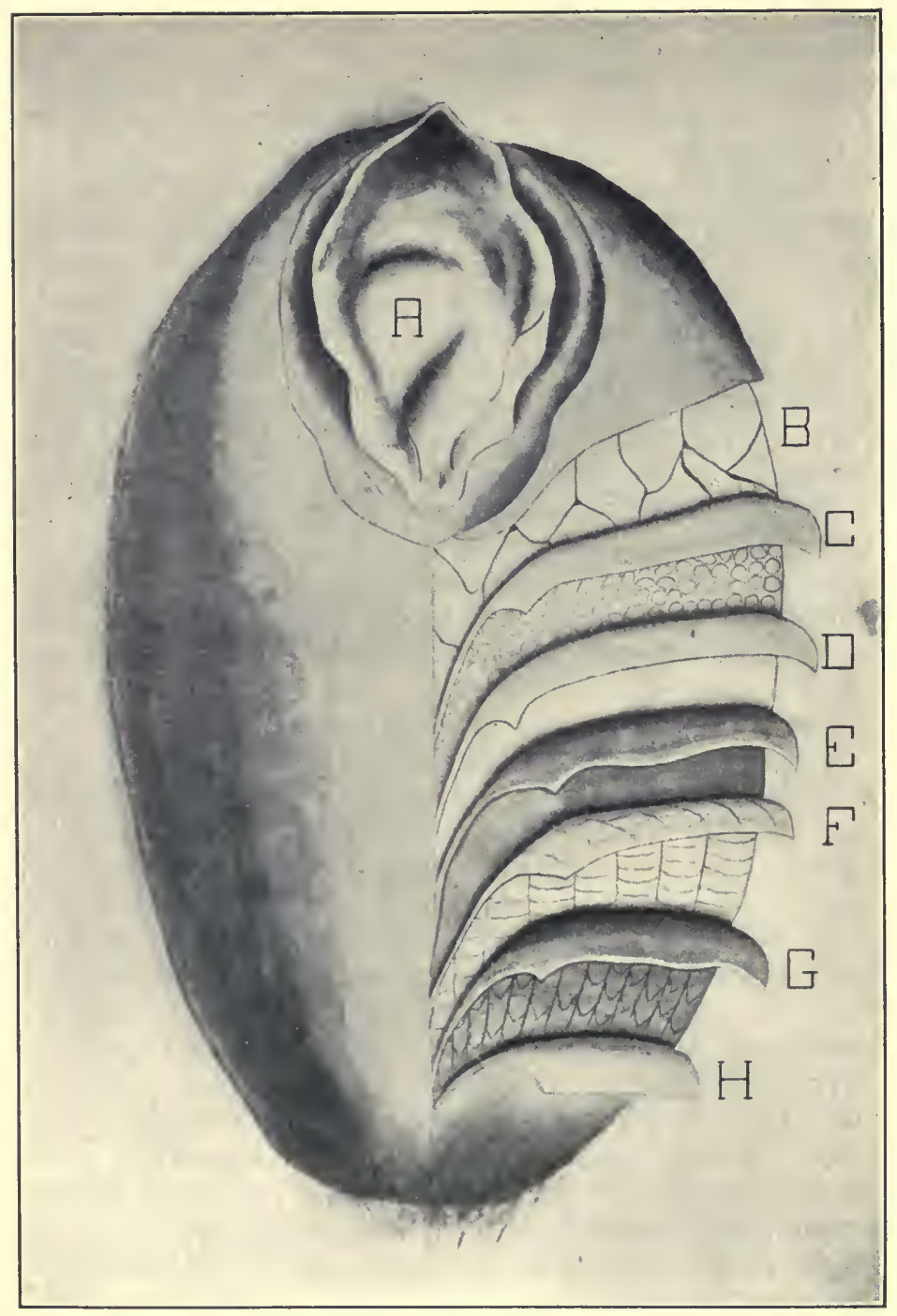

A DISSECTED WHEAT KERNEL MAGNIFIED.

A, Germ containing gluten. starch, and particularly rich in oil and mineral matter; B, starch cells, comprising the larger portion of the inner parts of the kernel; c, gluten cells, which lie directly beneath the husk, especially rich in gluten; D, inner coat of the bran; E, coloring matter of the bran; F, G, outer coats of bran; H, epidermis, or exterior covering of the kernel. 
ering of the wheat kernel. 3. Flour. This is made from the starchy part of the wheat kernel, or the soft white interior portion.

Rice By-products.-Rice hulls, rice bran, rice meal, rice grits and rice polish are the by-products obtained in the milling of rice. I. Rice hulls. These are the outer protecting parts or hulls of the rice kernel. They are sometimes injurious when fed in large quantities, on account of their silicious or sandy structure. 2. Rice bran. This material is made up of the outer layer of the rice kernel together with some of the germ. Most of the rice brans contain some rice hulls. The rice hulls cannot always be entirely eliminated in manufacture. 3. Rice meal. This material is usually sold under the name of rice bran. It is similar to rice bran except that it is practically free from hulls. 4. Rice polish. This consists of the flour which is removed from the rice kernel. The rice kernel is corrugated or rough, and in giving to it the smooth appearance and pearly luster, that the trade demands, the rough parts are smoothed down and brushed off with special machinery.

Sugar By-products. - The sugar by-products used for stock feeds are cane molasses, beet molasses, dried beet pulp and sorghum cuite. r. Cane molasses. The cane molasses sold for stock feed is usually the final product from the manufacture of cane sugar. It is called blackstrap, and it is noted for its high content of digestible carbohydrates. 2. Beet molasses. This is a product derived from the manufacture of sugar from the sugar beet. Beet molasses contains less carbohydrates than cane molasses and more ash. It has a bitter taste due to the large amount of potash present. It is used a great deal for feeding purposes. 3. Dried beet pulp. This is the refuse, or what is left, of the sugar beet after the sugar has been extracted. This refuse is kiln dried and sold as dried beet pulp. 4. Sorghum cuite. This is a product obtained from sorghum, and is used to a limited extent. 
Animal and Fish By-Products.-Skim milk, refuse from packing houses and fish refuse are often sold as feeds for hogs and poultry. From the packing houses come tankage and dried blood. Tankage is composed entirely of animal matter. It consists of meat and bone (from which the fat has been extracted), and more or less dried blood. It is variable in composition, but it usually contains a high content of protein. Dried blood is simply what the name signifies. It has a black-brown color and is ground very fine. Fish refuse is the dried product from canneries, whalebone factories, and establishments where glue is manufactured. The oil is generally extracted and the fish refuse dried and sold as fish scraps or dry ground fish.

ANALYSES OF ANIMAL AND FISH BY-PRODUCTS.

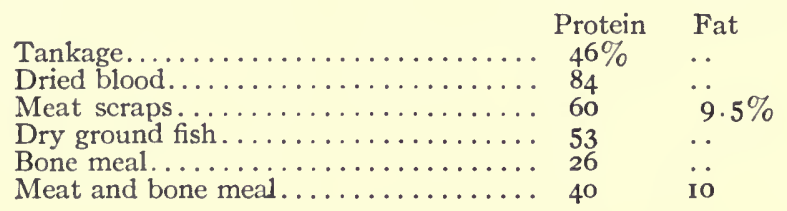

EXERCISE.-What milling by-products are used at your home? Describe them.

Choose four pupils to bring to school all the products mentioned in this section, that are used at the table. Flour, rice, molasses, starch, grits, hominy are some of these products. Send two pupils to the feed store for samples of wheat bran, wheat middlings, rice bran, bone meal, etc. Require the pupils to become familiar with the appearance of these materials and the sources from which they are manufactured.

Section LXVI.-Composition, Digestibility and
Nutritive Ratio.

Composition of Feeds.-The previous sections explained the meaning and function of the nutritive elements contained in plants and animals. The next thing is to become familiar with the composition and 
digestibility of feeds. The chemist has already worked out these for us, and he expresses the composition as follows:

COMPOSITION OF CORN (GRAIN) IN PER CENT.

$\begin{array}{cccccc}\text { Protein } & \text { Fat } & \text { Nitrogen Free Extract } & \text { Fiber } & \text { Water } & \text { Ash } \\ \text { 10.3 } & 5.0 & 70.4 & 2.2 & 10.6 & 1.5\end{array}$

The above analysis is very simply translated. It means that in every I oo lbs. of corn grain, there are $10.3 \mathrm{lbs}$. of protein, $5.0 \mathrm{lbs}$. of fat, $70.4 \mathrm{lbs}$. of nitrogen free extract, $2.2 \mathrm{lbs}$. of fiber, I0.6 lbs. of water and I. 5 lbs. of ash. Or there are I0.6 lbs. of water and 89.4 lbs. of dry matter.

Digestibility of Feeds.-Knowing the composition of feeds, it is now necessary to become acquainted with the actual amounts of the nutrients (protein, fat, nitrogen free extract and fiber) that the animal can assimilate or digest. When food is eaten by the animal it is not all digested. Part of it is excreted as manure. This latter part, or that which is excreted, is indigestible. We can mention the digestibility of the above sample of corn grain, which composition is given, for an example.

\section{DIGESTIBILITY OF CORN IN PER CENT. \\ Protein Fat Nitrogen Free Extract Fiber $\begin{array}{llll}76 & 85 & 93 & 5^{8}\end{array}$}

That is, in Ioo lbs. of the grain of corn, 76 per cent. of the I0. 3 lbs. of protein is digestible, 86 per cent. of the 5 lbs. of fat is digestible, 93 per cent. of the 70.4 lbs, of nitrogen free extract is digestible, and 58 per' cent. of the 2.2 lbs. of fiber is digestible. We can represent this in another way by stating the total pounds of digestible ingredients in IOO lbs. of corn grain.

TOTAL POUNDS DIGESTIBLE NUTRIENTS IN 100 POUNDS OF CORN GRAIN

Protein Fat Nitrogen Free Extract Fiber $\begin{array}{llll}7.8 & 4.3 & 65.5 & 1.3\end{array}$ 
The digestible fiber is generally added to the digestible nitrogen free extract and called digestible carbohydrates. In this case, then, the total digestible carbohydrates would be $65.5+\mathrm{I} .3=66.8 \mathrm{lbs}$. As mentioned previously the water is not considered a nutrient as it can be supplied so much cheaper by itself. The ash is also omitted because most of our feeds contain enough of this substance for the needs of the animal.

Necessity of Composition and Digestibility.-There are several feeds which have practically the same chemical composition but different percentages of digestibility. Then in order to ascertain the real value of any feed it is necessary to know the chemical composition and the digestibility.

Nutritive Ratio.-The ratio between the digestible protein and the digestible carbohydrates + the digestible fats is called the nutritive ratio. This ratio is obtained in the following manner. The per cent. of digestible fat is multiplied by 2.25 , to reduce it to terms of carbohydrates. (It was previously stated in Section LXI, that the fuel value of fat is 2.25 times that of carbohydrates.) This product is then added to the per cent. of digestible carbohydrates. This sum is divided by the per cent. of digestible protein. To explain this more clearly let us take the digestibility of corn, as just cited in the article under digestibility of feeds.

Digestible fat (4.3) $\times$ fuel value (2.25) = carbohydrate equivalent (9.7). Digestible carbohydrates $(66.8)+9 \cdot 7=$ Total digestible carbohydrates (76.5).

Total digestible carbohydrates $(76.5) \div$ digestible protein $(7.8)=9.8$. Nutritive ratio is then $1: 9.8$

EXERCISE.-What is the per cent. digestibility of the ingredients of wheat bran? The composition and the digestibility of this feed are given in table No. I. What is the nutritive ratio of a feed containing I2.6 per cent. digestible protein, 20 per cent. digestible carbohydrates and 5.2 per cent. digestible fat? If a horse is fed 7 pounds of corn and cob meal a day, how many pounds of protein, fat and carbohydrates does it digest? 
TABLE NO. I

AVERAGE COMPOSITION AND AVERAGE DIGESTIBLE MATTER OF FEEDING STUFFS

\begin{tabular}{|c|c|c|c|c|c|c|c|c|c|c|}
\hline \multirow[b]{2}{*}{$\begin{array}{l}\text { FEEDING } \\
\text { STUFF }\end{array}$} & \multicolumn{6}{|c|}{ Composition of yoo LBS. } & \multirow[b]{2}{*}{ 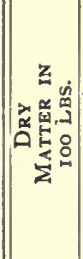 } & \multicolumn{3}{|c|}{$\begin{array}{l}\text { DIGESTIBLE } \\
\text { MATTER IN } \\
\text { IOO LBS. }\end{array}$} \\
\hline & 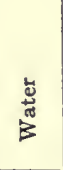 & 要 & 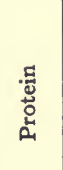 & 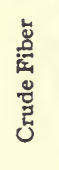 & 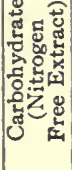 & 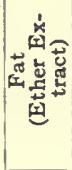 & & 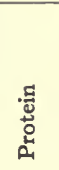 & 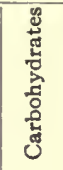 & 若 \\
\hline $\begin{array}{c}\text { Corn (grain) or corn } \\
\text { meal................. }\end{array}$ & I0.6 & I. 5 & I0, 3 & & & 5.0 & & 78 & 667 & \\
\hline Corn and cob meal. & 15.1 & 1.5 & 8.5 & $\begin{array}{l}2.2 \\
6.6\end{array}$ & $\begin{array}{l}70.4 \\
64.8\end{array}$ & $\begin{array}{l}5.0 \\
3.5\end{array}$ & $\begin{array}{l}89.4 \\
84.9\end{array}$ & $\begin{array}{l}7.8 \\
4.4\end{array}$ & $\begin{array}{l}00.7 \\
60.0\end{array}$ & $\begin{array}{l}4.3 \\
2.9\end{array}$ \\
\hline Oats (gra & II.0 & 3.0 & $\begin{array}{l}11.8 \\
11.9\end{array}$ & 9.5 & 59.7 & 5.0 & 89.0 & 9.2 & $\begin{array}{l}47 \cdot 3 \\
69.2\end{array}$ & 4.2 \\
\hline $\begin{array}{l}\text { Wheat (grain)..... } \\
\text { Wheat bran } \\
\text { Wheat midding.... }\end{array}$ & $\begin{array}{l}\text { I0.5 } \\
\text { II.9 }\end{array}$ & $\begin{array}{l}1.8 \\
5.8\end{array}$ & $\begin{array}{l}\text { I } 1.9 \\
\text { I } 5.4\end{array}$ & $\begin{array}{l}1.8 \\
9.0\end{array}$ & $\begin{array}{l}71.9 \\
53.9\end{array}$ & $\begin{array}{l}2.1 \\
4.0\end{array}$ & $\begin{array}{l}89.5 \\
88.1\end{array}$ & $\begin{array}{l}\text { I0.2 } \\
12.2\end{array}$ & $\begin{array}{l}69.2 \\
39.2\end{array}$ & $\begin{array}{l}1.7 \\
2.7\end{array}$ \\
\hline (shorts). & 12.1 & 3.3 & I5.6 & 4.6 & 60.4 & 4.0 & 87.9 & I 2.8 & 53.0 & 3.4 \\
\hline Cotton seed ......... & 10.3 & 3.5 & 18.4 & 23.2 & 24.7 & 19.9 & 89.7 & 12.5 & 30.0 & 17.3 \\
\hline $\begin{array}{l}\text { Cotton-seed meal .. } \\
\text { Linseed meal (new) }\end{array}$ & 8.2 & 7.2 & 42.3 & 5.6 & 23.6 & I3.I & 91.8 & 37.2 & 16.9 & 12.2 \\
\hline process)...$\ldots \ldots$ & I0. I & 5.8 & 33.2 & 9.5 & 38.4 & 3.0 & 89.9 & 28.2 & 40.1 & 2.8 \\
\hline Peanut me & 10.7 & & 47.6 & 5.1 & 23.7 & 8.0 & 89.3 & 42.9 & 22.8 & 6.9 \\
\hline Dried brewers' gr'ns & 8.2 & 3. & 19.9 & II.0 & 51.7 & 5.6 & 91.8 & 15.7 & 36.3 & 5.1 \\
\hline $\begin{array}{l}\text { Cowpeas (seed) } \\
\text { Rice bran (15\% }\end{array}$ & 14.8 & 3.2 & 20.8 & 4. I & 55.7 & I.4 & 85.2 & 18.3 & 54.2 & I. I \\
\hline hulls) $\ldots \ldots \ldots$ & 9.9 & II.3 & 9.9 & 14.5 & 44.5 & 9.9 & 90.1 & 6.4 & 36.7 & 5.4 \\
\hline Rice polish ${ }_{\text {Rice }}$ meal (pure & II.5 & 3.5 & II.I & 3.8 & 64.3 & 5.8 & 88.5 & 7.3 & 60.4 & 4.3 \\
\hline $\begin{array}{l}\text { bran)................ } \\
\text { Cane molasses }\end{array}$ & 8.6 & 8.9 & 13.3 & 8.7 & 49.8 & 10.7 & 91.4 & 8.6 & 40.0 & 5.9 \\
\hline & 22.4 & 9.3 & 2.4 & $\cdots$ & 65.9 & $\cdots$ & 77.6 & $\ldots$ & 65.9 & $\cdots$ \\
\hline $\begin{array}{l}\text { Beet molasses...... } \\
\text { Skimmed milk }\end{array}$ & 20.8 & 10.6 & 9.1 & $\cdots$ & 59.5 & .. & 79.2 & $\cdots$ & 59.5 & $\cdots$ \\
\hline (gravity).... & 90.4 & 0.7 & $3 \cdot 3$ & & 4.7 & 0.9 & 9.6 & 3. I & 4.7 & 0.8 \\
\hline $\begin{array}{l}\text { Corn silage... } \\
\text { Corn stover (whole }\end{array}$ & 79.1 & I.4 & 1.7 & 6.0 & II.0 & 0.8 & 20.9 & 0.9 & $\begin{array}{l}4 \cdot 1 \\
11.3\end{array}$ & 0.7 \\
\hline plant except ears) & 22.8 & 4.9 & 5.5 & 25.6 & 39.9 & I.3 & 77.2 & 2.8 & 42.3 & 0.7 \\
\hline Cotton-seed hulls .. & II.I & & 4.2 & 46.3 & 33.4 & 2.2 & & 0.3 & 33.1 & 1.7 \\
\hline & I3.2 & & 5.9 & 29.0 & & 2.5 & 86.8 & 2.8 & 43.4 & I.4 \\
\hline & 15.3 & & 12.3 & 24.8 & & 3.3 & 84.7 & 6.8 & 35.8 & I.7 \\
\hline Crimson clover hay. & 9.6 & 8.6 & I5.2 & 27.2 & 36.6 & 2.8 & 90.4 & 10.5 & 34.9 & 1.2 \\
\hline & 8.4 & 7. & 14.3 & 25.0 & 42.7 & 2.2 & 91.6 & II.0 & 39.6 & I. 2 \\
\hline & I 1.9 & 8 & 14.4 & 21.5 & & 2.5 & & 9.3 & 38.3 & I.2 \\
\hline & II.3 & 7.2 & 15.4 & 22.3 & 38.6 & 5.2 & & 10.8 & 38.7 & I.5 \\
\hline & 10.3 & 7. & 6.9 & 32.9 & 41.0 & 1.6 & 89.7 & 2.2 & 42.8 & 0.6 \\
\hline $\begin{array}{l}\text { Oat hay (cut in milk) } \\
\text { Kentucky blue grass }\end{array}$ & 15.0 & 5.2 & 9.3 & 29.2 & 39.0 & 2.3 & 85.0 & 5.0 & 33.0 & 1.4 \\
\hline hay............. & 21.2 & 6.3 & 7.8 & 23.0 & 37.8 & 3.9 & 78.8 & 4.8 & 37.3 & 2.0 \\
\hline Turnip..... & 90.5 & & I.I & I. 2 & 6.2 & 0.2 & 9.5 & I.o & 7.2 & 0.2 \\
\hline $\begin{array}{l}\text { Carrot (M..... } \\
\text { Beet }\end{array}$ & 88.6 & I.0 & I.I & 1.3 & 7.6 & 0.4 & II.4 & 0.8 & 7.8 & 0.2 \\
\hline zel).... & 90.9 & I.I & & 0.9 & 5.5 & 0.2 & 9.I & I.I & 5.4 & 0.1 \\
\hline Kaffir corn ......... & 9.3 & I. 5 & 9.9 & I. 4 & 74.9 & 3.0 & 90.7 & 7.8 & 57.1 & 2.7 \\
\hline
\end{tabular}

A great deal of the data in the above table was taken from Henry, "Feeds and Feeding." The results in the table are the work of many investigators. 


\section{Section LXVII.-Feeding Standards.}

\section{Explanation of the Table.-The table on feeding} standards is divided into two parts A and B. Table A gives the amounts of dry matter, and digestible nutri-

TABLE NO. II

FEEDING STANDARDS *

A.-Per Day and i,ooo Pounds Live Weight

Oxen at rest in stall.........

Wool sheep, coarser breeds....

Wool sheep, finer breeds.......

Oxen moderately worked......

Oxen heavily worked.........

Horses lightly worked.........

Horses moderately worked....

Horses heavily worked........

Milk cows................

Fattening oxen, preliminary

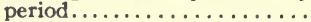

Fattening oxen, main period...

Fattening oxen, finishing period

Fattening sheep, preliminary

period....................

Fattening sheep, main period. .

Fattening swine, preliminary

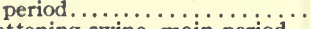

Fattening swine, main period..

Fattening swine, finishing period

\begin{tabular}{|c|c|c|c|c|}
\hline \multirow{2}{*}{$\underset{\text { Matter }}{\text { Dry }}$} & \multicolumn{3}{|c|}{ Digestible } & \multirow[b]{2}{*}{$\begin{array}{l}\text { Nutri- } \\
\text { tive } \\
\text { Ratio }\end{array}$} \\
\hline & Protein & $\begin{array}{c}\text { Carbohy- } \\
\text { drates } \\
\text { and Fat }\end{array}$ & Total & \\
\hline Lbs. & Lbs. & Lbs. & Lbs. & \\
\hline I 7.5 & 0.7 & 8.3 & 9.0 & I : 1 1.9 \\
\hline 20.0 & I. 2 & I0.8 & I 2.0 & I :9.0 \\
\hline 22.5 & I. 5 & I 2.0 & 13.5 & $1: 8.0$ \\
\hline 24.0 & 1.6 & I 2.0 & 13.0 & $1: 7.5$ \\
\hline 26.0 & 2.4 & 14.3 & 16.7 & I :6.0 \\
\hline 20.0 & I. 5 & I 0.4 & I 1.9 & I :6.9 \\
\hline 21.0 & 1.7 & I 1.8 & 13.5 & $1: 6.9$ \\
\hline 23.0 & 2.3 & I 4.3 & 16.6 & I :6.2 \\
\hline 24.0 & 2.5 & 13.4 & I5.9 & I :5.4 \\
\hline 27.0 & 2.5 & I6. I & I 8.6 & $I: 6.4$ \\
\hline 26.0 & 3.0 & I6.4 & I9. 4 & $I: 5.5$ \\
\hline 25.0 & 2.7 & I6.2 & I8.9 & $1: 6.0$ \\
\hline 26.0 & 3.0 & I6. 3 & I9.3 & I :5.4 \\
\hline 25.0 & 3.5 & I 5.8 & I9.3 & $I: 4.5$ \\
\hline 36.0 & 5.0 & 27.5 & 32.5 & $I: 5.5$ \\
\hline 31.0 & 4.0 & 24.0 & 28.0 & I :6.0 \\
\hline 23.5 & 2.7 & 17.5 & 20.2 & $I: 6.5$ \\
\hline
\end{tabular}

B.-Per Day and Per Head

\begin{tabular}{|c|c|c|c|c|c|c|}
\hline \\
\hline \multicolumn{7}{|l|}{ Growing cattle: } \\
\hline $3-6 \ldots \ldots \ldots \ldots 300 . \ldots 30$ & 10 & 7.0 & $\begin{array}{l}0.0 \\
1.0\end{array}$ & 4.9 & $\begin{array}{l}3.4 \\
5.9\end{array}$ & $\begin{array}{l}1: 4.0 \\
1: 4.9\end{array}$ \\
\hline $6-12 \ldots \ldots \ldots .500$ & 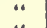 & 12.0 & 1.3 & $7 \cdot 5$ & 8.8 & $1: 6.0$ \\
\hline I 2-I8 ........700 & “ & 16.8 & I. 4 & 9.7 & I I. I & $1: 7.0$ \\
\hline$\quad 18-24 \ldots \ldots \ldots .850$ & “• & 20.4 & I. 4 & I I. I & 12.5 & I :8.0 \\
\hline \multicolumn{7}{|l|}{ Growing sheep: } \\
\hline $5-6 \ldots \ldots \ldots \ldots$ & “ & 1.6 & 0.18 & 0.974 & I. I54 & I:5.4 \\
\hline $6-8 \ldots \ldots \ldots 67$ & " & I.7 & 0.18 & $0.98 \mathrm{I}$ & $1.16 \mathrm{I}$ & $1: 5.4$ \\
\hline $8-11 \ldots \ldots \ldots \ldots 75$ & " & 1.7 & 0.16 & 0.953 & I. I I3 & $1: 6.0$ \\
\hline $11-15 \ldots \ldots \ldots 82$ & “ & 1.8 & 0.14 & 0.975 & I.I I 5 & I:7.0 \\
\hline$\quad 15-20 \ldots \ldots \ldots \ldots 85$ & “ & I.9 & 0.12 & 0.955 & I.075 & I $: 8.0$ \\
\hline \multicolumn{7}{|l|}{ Growing fat swine: } \\
\hline $2-3 \ldots \ldots \ldots \ldots 50$ & 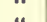 & 2.I & $0.3^{8}$ & I.50 & I. 88 & $I: 4.0$ \\
\hline $3-5 \ldots \ldots \ldots \ldots 100$ & ". & 3.4 & 0.50 & 2.50 & 3.00 & $I: 5.0$ \\
\hline $5-6 \ldots \ldots \ldots \ldots$ I25 & " & 3.9 & 0.54 & 2.96 & 3.50 & $I: 5.5$ \\
\hline $6-8 \ldots \ldots \ldots 170$ & $"$ & 4.6 & 0.58 & 3.47 & 4.05 & I :6.0 \\
\hline $8-12 \ldots \ldots \ldots 250$ & 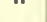 & 5.2 & 0.62 & 4.05 & 4.67 & $x: 6.5$ \\
\hline
\end{tabular}

* La. Exp. Station, Bul. No. I I5. 
ents required per day for farm animals under all conditions of work and rest. This table is based on $\mathrm{I}, \mathrm{ooo}$ lbs. live weight. Table $\mathrm{B}$ is similar to Table A, except that the standards are based on the weights of the animals as mentioned. To make this clearer the first standard in Table A is for "oxen at rest in stall." The standard reads 17.5 lbs. dry matter, 0.7 lbs. protein, 8.3 lbs. carbohydrates and fat, 9.o lbs. total, with a nutritive ratio of I :II.9. This standard is for oxen weighing $\mathrm{I}, 000 \mathrm{lbs}$. at rest in the stall. The first standard in Table B is for "growing cattle 2-3 months old weighing I 50 lbs." The standard reads $3.3 \mathrm{lbs}$. dry matter, $0.6 \mathrm{lbs}$. protein, $2.8 \mathrm{lbs}$. carbohydrates and fat, $3.4 \mathrm{lbs}$. total, with a nutritive ratio of $\mathrm{I}: 4.6$. This standard is figured on growing cattle weighing I 50 lbs.

Practical Use of Feeding Standards.-It must be remembered that the dry matter is given in this table to regulate the bulk of a ration. In compounding rations it is not necessary to have the dry matter exact, and a variation of a few pounds does not affect the value of a ration. In feeding farm animals no other food should be allowed them except what is included in the ration. Animals will eat a great deal

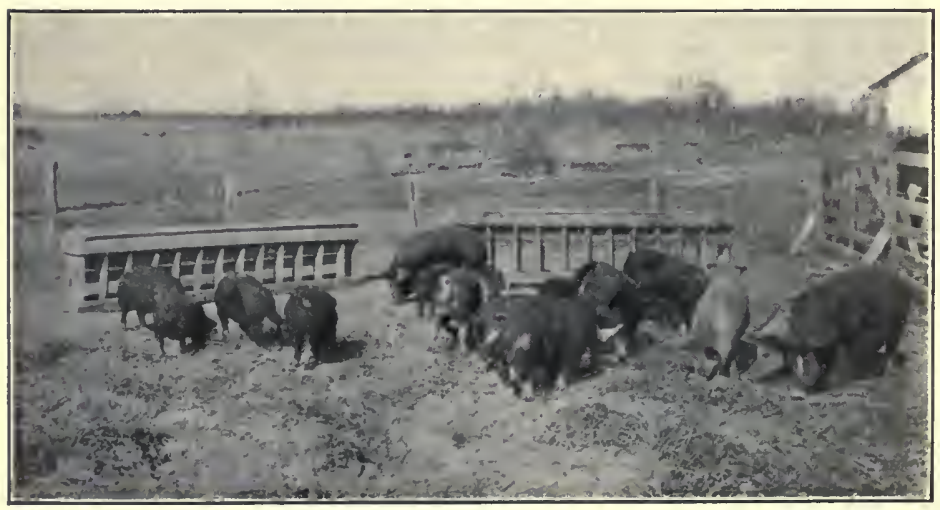

HOGS IN A FEED LOT. 
more than is good for them if they are allowed to eat all the feed they wish. Most of our feeders permit farm animals to eat all the hay they want. This is bad practice. These feeding standards are not always absolutely correct for every individual animal. These standards are the results of many experiments and practical experience. By compounding rations according to these standards, as laid down in this table, the results are bound to meet with satisfaction. There are many people who feed farm animals in an off-hand way, and there is a great chance for improvement in this phase of agriculture.

Selection of the Feed.-In selecting a ration for farm stock it is important to consider palatability and adaptability. The ration should meet the requirements of the particular animal or animals. The market prices of feeds should also be taken into account.

Palatability.-No matter what the composition of a feed is, it must be sweet, clean and possess an agreeable flavor. Animals, like people, do not get along well on food that is not palatable.

Adaptability.-Poultry and hogs are fond of cottonseed meal. This feed often makes them sick. Horses and hogs are so constructed that they cannot do well on a large amount of roughage. Roughage includes materials such as hays, corn stover and cotton-seed hulls. Certain feeds cannot be allowed to milch cows, because they produce a bad flavor in the milk.

Market Prices.-In making up a ration it is necessary to not only consider the nutritive ratio, palatability and adaptability, but the available feeds and their prices must be investigated. In other words the cost of a ration should be figured. Oftentimes the same amounts of digestible nutrients can be supplied from other feeds and at a cheaper price. Oats, for example, is an expensive feed. It is an easy matter to substitute other feeds that will furnish the same amounts of digestible ingredients as oats at a less cost. Tim- 
othy hay, in the South, is generally an expensive feed. It is sometimes a better financial proposition to sell some of the feed stuffs raised on the farm and purchase other feeds for consumption.

Weights and Measures.-This table is given to enable the feeder to compound rations easily. In making rations for animals large amounts of the grain portion can be mixed at one time. This saves the trouble of mixing and calculating at every feeding. The measure of roots, molasses, hay, fodder and ensilage can be determined once and fed accordingly without any inconvenience.

WEIGHT AND MEASURE OF FEED STUFFS

Feed

Cotton-seed meal.

Brewers' grains (dried)

Wheat middlings (flour) .........

Wheat middlings (standard)...

Wheat mixed feed..............

Wheat bran

Whole oats.

Ground oats.

Whole wheat.

Ground wheat.

Whole corn

Corn meal.

Corn and cob meal

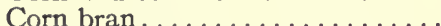

Hominy meal.

Corn and oat feed (Victor) .......

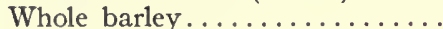

Whole rye....

Rye meal

Rice bran

Rice polish

Cotton-seed hulls.

Alfalfa meal

Molasses (blackstrap)
One quart One pound weighs measures

I. 5 lbs.

0.6

I. 2

0.8

0.6

0.5

I.O

0.7

I.9

I.7

I.7

I. 5

I. 4

0.5

I.I

0.7

I.5

I.I

I.7

I.5

0.8

I. 2

0.26

I.O

3.0
0.7 qts.

I.7

0.8

I.3

I.7

2.0

I.O

I. 4

0.5

0.6

0.6

0.7

0.7

2.0

0.9

I. 4

0.7

0.9

0.6

0.7

I. 3

0.8

3.8

I.O

0.3

Much of the data in the above table was compiled by the Massachusetts Experiment Station.

EXERCISE.-Weigh pint measures of flour, corn meal, corn, rice, and any other feeds that you may have at home. Put the weights obtained in your note book. What are the market prices of five common feeds used in your town? 


\section{Section LXVIII.-Rations.}

Trial Ration.-Referring to Tables I and 2, and knowing the meaning of the terms as set forth in the preceding pages under Feeds and Feeding, it will now be a simple matter of arithmetic and judgment to compute or balance any ration. Let us suppose, for example, that we have a horse or a mule at home plowing. Plowing all day is hard or heavy work. Now if we turn to Table No. 2 we find that the standard for a horse weighing $\mathrm{I}, 000$ lbs. heavily worked is as follows :

$\begin{array}{cccc} & & \text { Digestible } & \text { Nutritive } \\ \text { Dry Matter } & \text { Digestible Protein } & \text { Carbohydrates and Fat } & \text { Ratio } \\ \text { 23 lbs. } & 2.3 \mathrm{lbs} . & \text { I } 4.3 \mathrm{lbs} . & \mathbf{1}: 6.2\end{array}$

This means that if our horse at home doing heavy work weighs $\mathrm{I}, 000 \mathrm{lbs}$. he will require $23 \mathrm{lbs}$. of dry matter, 2.3 lbs. of digestible protein, and $14.3 \mathrm{lbs}$. of digestible carbohydrates to satisfy his needs for a day of twenty-four hours. The digestible carbohydrates includes the digestible nitrogen free extract, digestible fats and digestible fiber.

Let us suppose we have the following feed stuffs at home: cotton-seed meal, corn (shelled), wheat bran and timothy hay. To figure our ration let us try 2 lbs. of cotton-seed meal, 6 lbs. of shelled corn, 6 lbs. of wheat bran and Io lbs. of timothy hay. We must now find the total dry matter, digestible protein, digestible carbohydrates and fat, in each of the above feeds that make up our ration. Referring to Table I we find that roo lbs. of cotton-seed meal contain 9r.8 lbs. dry matter, 37.2 lbs. of digestible protein, i 6.9 lbs. of digestible carbohydrates and $\mathrm{I} 2.2 \mathrm{lbs}$. of digestible fat. Then as 2 lbs. of cotton-seed meal are included in our trial ration we get the amounts of digestible nutrients as stated.

$2 \mathrm{lbs} . \times .918=\mathrm{r} .836 \mathrm{lbs}$. of dry matter.

2 lbs. $\times .372=0.744$ lbs. of digestible protein.

2 lbs. $\times .169=0.338$ lbs. of digestible carbohydrates.

2 lbs. $\times .122=0.244$ lbs. of digestible fat. 
In the same way we arrive at the digestible amounts contained in $6 \mathrm{lbs}$. of shelled corn, $6 \mathrm{lbs}$. of wheat bran and ro lbs. of timothy hay. Then we add together the dry matter and digestible ingredients in the cotton-seed meal, shelled corn, wheat bran and timothy hay and compare it with the standard.

2 lbs. cotton-seed meal

6 lbs. shelled corn ....

6 lbs. wheat bran....

Io lbs. timothy hay...

24 lbs. Total...... 2 I. I66
Digestible Dry Matter Protein

\begin{tabular}{ll}
1.836 & .744 \\
5.364 & .468 \\
5.286 & .732 \\
8.680 & .280 \\
\hline 21.166 & 2.224
\end{tabular}

Digestible Digestible Carbohydrates Fat

\begin{tabular}{cc}
.338 & .244 \\
4.002 & .258 \\
2.352 & .162 \\
4.340 & .140 \\
\hline 11.032 & .804
\end{tabular}

To reduce our fat to terms of carbohydrates we must multiply by $2.25 . .804 \times 2.25=\mathrm{I} .809 . \quad \mathrm{II} .032$ $+\mathrm{r} .809=\mathrm{r} 2.84 \mathrm{I}$ lbs. total digestible carbohydrates. I 2.84 I (total digestible carbohydrates) $\div \mathbf{2 . 2 2 4}$ (digestible protein) $=5.8$. That is, the nutritive ratio is $\mathrm{I}: 5.8$. This trial ration is stated as follows:

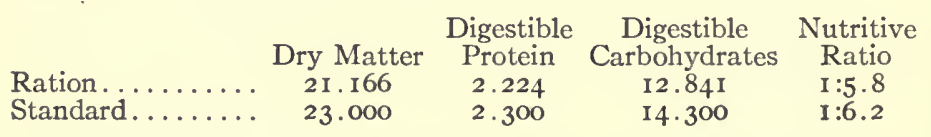

Balancing the Ration.-This trial ration is not entirely satisfactory. It is almost correct for dry matter

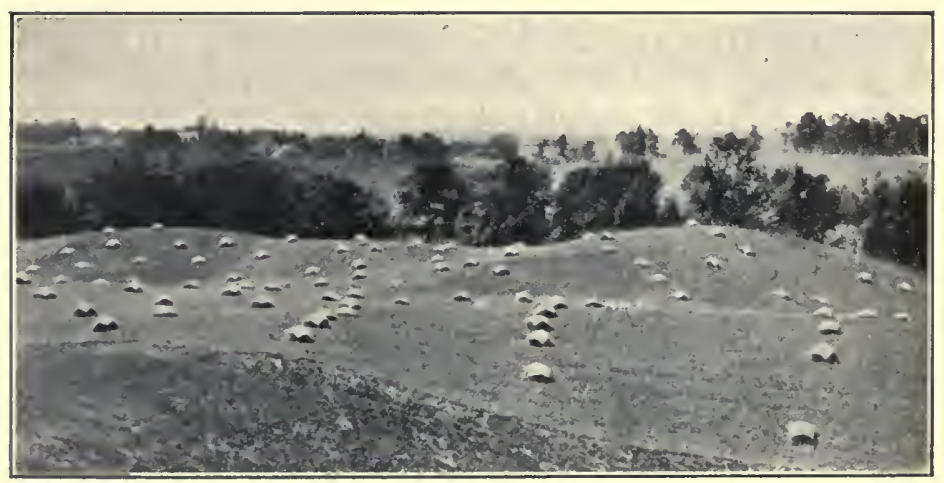

ALFALFA FIELD WITH HAY CAPS. 
and near enough to the standard in protein. It is too low in carbohydrates. We must correct the ration to make it more nearly approximate the standard. Let us add 3 lbs. of timothy hay and see what effect it has on balancing the ration.

2 lbs. cotton-seed meal...........

6 lbs. shelled corn. .

6 lbs. wheat bran. .

I3 lbs. timothy hay

27 lbs. Total....

\section{Digestible Digestible Digestible Dry Matter Protein Carbohydrates Fat}

The ration as it now stands:

\begin{tabular}{rrrr}
1.836 & .744 & .338 & .244 \\
5.364 & .468 & 4.002 & .258 \\
5.286 & .732 & 2.352 & .162 \\
11.284 & .364 & 5.642 & .182 \\
\hline 23.770 & 2.308 & 12.334 & .846
\end{tabular}

\begin{tabular}{|c|c|c|c|c|}
\hline & & Digestible & Digestible & Nutritive \\
\hline & Dry Matter & Protein & Carbohydrates & Ratio \\
\hline & $23 \cdot 77$ & $2.3 I$ & 14.24 & I :6. 2 \\
\hline Standard......... & 23 & 2.3 & $14 \cdot 3$ & I :6. 2 \\
\hline
\end{tabular}

It is practically impossible to get the exact amounts as laid down in the standard. The above ration is perhaps nearer the standard than one will ordinarily approximate.

Rations for Animals Weighing More or Less than a $I, 000 \mathrm{lbs}$. - If animals weigh more or less than a $\mathrm{r}, \mathrm{OoO}$ lbs. it is necessary to increase or decrease the amounts of the feed proportionately. The nutritive ratio, however, should remain the same. In the above example suppose the horse weighs $\mathrm{r}, 200 \mathrm{lbs}$., then we would increase the amounts of feed one-fifth. That is, instead of feeding 2 lbs. of cotton-seed meal, 6 lbs. of shelled corn, $6 \mathrm{lbs}$. of wheat bran and $\mathrm{r} 3 \mathrm{lbs}$. of timothy hay, we would feed $2.4 \mathrm{lbs}$. of cotton-seed meal, 7.2 lbs. of shelled corn, 7.2 lbs. of wheat bran and $15.6 \mathrm{lbs}$. of timothy hay. If the animal weighed less than $\mathrm{I}, 000$ lbs. the ration should be proportionately reduced. Sometimes the individuality of the animal must be considered. Dairy cattle weighing $700 \mathrm{lbs}$., giving $25 \mathrm{lbs}$. of milk need more feed than 
dairy cattle weighing the same, but only giving 20 lbs. of milk.

Exercise.-How many pounds of timothy hay are required to balance a ration for a horse weighing $I, 100$ pounds, doing moderate work, when the following are the feeds already included: 2 lbs. cotton-seed meal, $8 \mathrm{lbs}$. oats, and $5 \mathrm{lbs}$. shelled corn?

\section{Section LXIX.-Terms of a Nutritive Ratio.}

Narrow, wide and medium are the terms applied to nutritive ratios.

Narrow Ration.-A narrow ration is one in which the proportion of protein is large as compared to the carbohydrates. A ration having a nutritive ratio less than $I: 5.5$ is considered narrow.

\section{A NARROW RATION}

3 lbs. cotton-seed meal...........

Io lbs. wheat bran. 15 lbs. crimson clover hay.........

28 lbs. Total..... Dry Matter Digestible Digestible Digestible
Protein Carbohydrates

$2.754 \quad$ I. I I 6

8.810

$$
\text { I. } 220
$$

$13 \cdot 560$

25.124
I. 575

3.911

$\begin{array}{rr}.507 & .366 \\ 3.920 & .270\end{array}$

$\mathbf{5 . 2 3 5}$

9.662

The protein in the above ration is high as compared to the carbohydrates. Nitrogenous ration is another

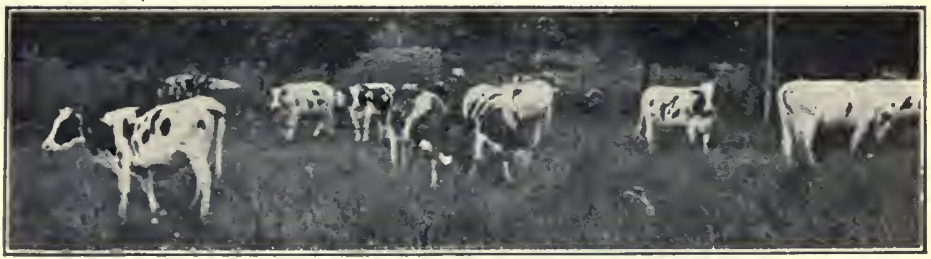

HERD OF PURE-BRED HOLSTEINS, WHICH REQUIRE A NARROW RATION.

name sometimes applied to a narrow ration, because of the predominance of nitrogenous substances (protein). Wide Ration.-A wide nutritive ratio is one where 
the proportion of carbohydrates is large as compared to the protein. Such a ration has a nutritive ratio of more than I :8.o.

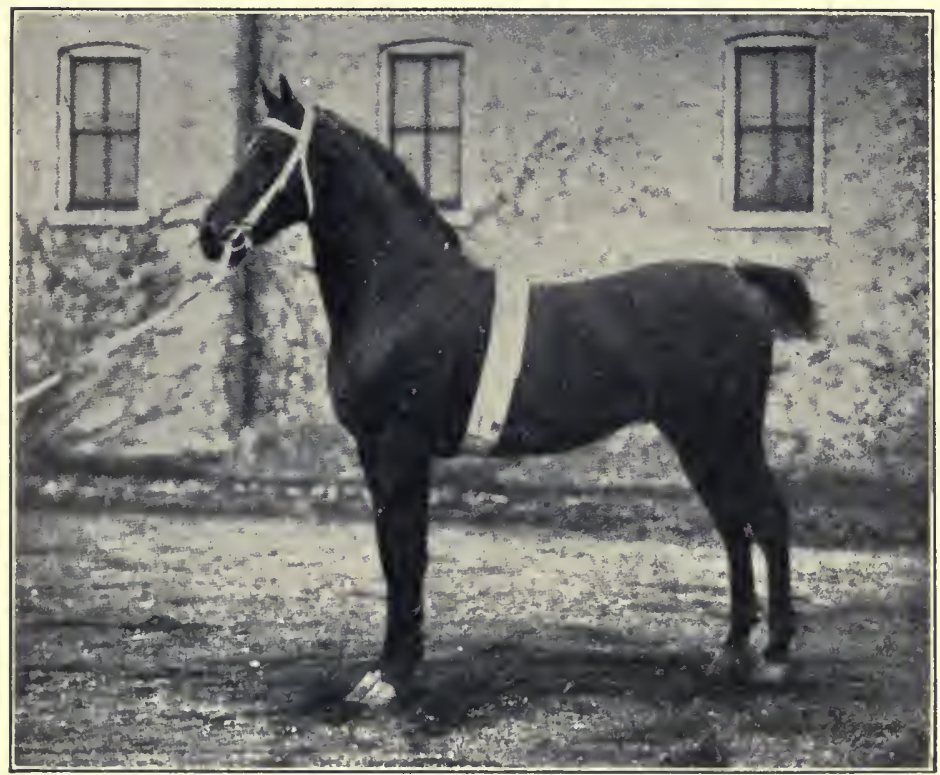

SADDLE HORSF, A MODERATE WORKED ANIMAL, REQUIRES A WIDE RATION.

A WIDE RATION

Digestible Digestiblc Digestible

5lbs. oats........

Io lbs. corn and cob meal...........

I 5 lbs. timothy hay

Dry Matter Protein

Carbohydrates Fat

$$
4 \cdot 45^{\circ}
$$
.460

2.365

.210

\begin{tabular}{|c|c|c|c|}
\hline 8.490 & $.44^{\circ}$ & 6.000 & .290 \\
\hline 13.020 & .420 & 6.510 & .210 \\
\hline $25.96 c$ & 1.320 & 14.875 & .7 \\
\hline
\end{tabular}

30 lbs. Total....

Nutritive ratio, I:125.

This style of ration is sometimes called a carbonaceous ration on account of the high proportion of carbohydrates. Protein contains carbonaceous substances; therefore this term is incorrectly used in wide rations. 
Medium Ration.-A ration with a nutritive ratio between $\mathrm{I}: 5.5$ and $\mathrm{I}: 8.0$ is called a medium ration.

\section{A MEDIUM RATION}

3 lbs. dried brewers' grains......

6 lbs. wheat middlings......... I 5 lbs. corn stover. 5 lbs. alfalfa hay..

29 lbs. Total.... Dry Matter $\begin{gathered}\text { Digestible } \\ \text { Protein Carbohydrates }\end{gathered} \begin{gathered}\text { Digestible } \\ \text { Fat }\end{gathered}$ (1)

\begin{tabular}{|c|c|c|c|}
\hline 2.754 & .471 & 1.089 & . I 53 \\
\hline 5.274 & .768 & 3.180 & .204 \\
\hline II. 580 & .420 & 6.345 & .105 \\
\hline 4.580 & .550 & I. 980 & .060 \\
\hline 24.188 & 2.209 & $\begin{array}{l}\text { 12. } 594 \\
\text { Nutriti }\end{array}$ & $\begin{array}{c}-522 \\
\text { tio, I :6. }\end{array}$ \\
\hline
\end{tabular}

Amounts of Protein and Carbohydrates for Feeding.-I. Young animals and dairy cows. In feeding young stock it is necessary to supply a ration that will build up and enable them to put on flesh. In the production of milk from the dairy cow it is also important that the ration be such as to produce a good flow of milk. In other words a narrow ration is necessary for young growing animals and dairy cows. 2. Fattening animals. Rations containing relatively large amounts of carbohydrates are required for laying on fat. As previously stated the carbohydrates are changed into fat in the process of digestion. Therefore a wide ration is the proper one to feed for fattening animals. Animals doing little or no work should also receive fairly wide rations. They do not expend much energy, and must simply be kept in condition. 3. Hardworking mature animals. A medium ration has been found to be the best for this class of stock.

EXERCISE.-Choose some feeds common to your section and compute narrow, wide and medium rations.

\section{Section LXX.-How to Improve a Ration.}

A Common Ration.-A herd of dairy cows is receiving the following ration per day of twenty-four hours, per I,000 lbs. live weight: 5 lbs. cotton-seed 
meal, 3 lbs. wheat bran, Io lbs. red clover hay and I 5 lbs. corn stover. Let us figure this ration and find out if it is properly balanced for the herd of dairy cows. Turn to Table $I$ and find that the following amounts of digestible ingredients are present in 100 lbs. of each feed stuff.

Cotton-seed meal. .

$\begin{array}{cccr}\begin{array}{c}\text { Dry Matter } \\ \text { lbs }\end{array} & \begin{array}{c}\text { Protein } \\ \text { lbs. }\end{array} & \begin{array}{c}\text { Carbohydrates } \\ \text { lbs. }\end{array} & \begin{array}{c}\text { Fat } \\ \text { lbs. }\end{array} \\ 91.8 & 37.2 & 16.9 & 12.2 \\ 88.1 & \text { I2.2 } & 39.2 & 2.7 \\ 84.7 & 6.8 & 35.8 & 1.7 \\ 77.2 & 2.8 & 42.3 & 0.7\end{array}$

Then as 5 lbs. of cotton-seed meal are in the ration, we multiply the amounts of dry matter, digestible protein, digestible carbohydrates, and digestible fat as given above for cotton-seed meal, by 5 . Or $5 \times$.9 I 8 $=4.590 \mathrm{lbs}$. of dry matter in $5 \mathrm{lbs}$. cotton-seed meal. $5 \times 372=1.860$ lbs. digestible protein in 5 lbs. cottonseed meal. $5 \times$ x. $69=.845$ lbs. digestible carbohydrates in 5 lbs. cotton-seed meal. 5 x.1 $22=.610$ lbs. of digestible fat in 5 lbs. of cotton-seed meal. In the same way we compute the digestible ingredients in the wheat bran, red clover hay and corn stover.

5 lbs. cotton - seed meal..........

3 lbs. wheat bran.

Io lbs. red clover

hay...........

15 lbs. corn stover.

$3 . \mathrm{lbs}$. Total.... Dry Matter $\begin{gathered}\text { Digestible } \\ \text { Protein }\end{gathered} \begin{gathered}\text { Digestible Digestible } \\ \text { Carbohydrates }\end{gathered}$

\begin{tabular}{rrrr}
4.590 & 1.860 & .845 & .610 \\
2.643 & 0.366 & 1.176 & .081 \\
8.470 & 0.680 & 3.580 & .170 \\
11.580 & 0.420 & $\frac{6.345}{.105}$ \\
\hline 27.283 & $\frac{.3 .326}{11.946}$ & $\frac{.966}{}$
\end{tabular}

With the fat reduced to carbohydrates the ration reads :

Rtandard......... 27.283

$3 \cdot 326$

2.5

14. I 195

Nutritive Ratio

I : 4.2

I $: 5 \cdot 4$

The ration is too high in dry matter, digestible protein and digestible carbohydrates. The ration is also too narrow. 
Improving the Ration.-Let us try to improve this ration by supplying less of the ingredients and particularly less protein. By consulting Table $\mathrm{I}$ we can see that cotton-seed meal has more digestible protein then we reduce our amount of cotton-seed meal to 3 then we reduce our amount of cotton seed meal to 3 lbs. Then our ration will be as follows:

\begin{tabular}{|c|c|c|c|c|}
\hline & Dry Matter & Digestible & $\begin{array}{c}\text { Digestible } \\
\text { Carbohydrates }\end{array}$ & $\underset{\text { Fat }}{\text { Digestible }}$ \\
\hline $\begin{array}{l}3 \mathrm{lbs} \text {. cotton }- \text { seed } \\
\text { meal. . . . . }\end{array}$ & & & & \\
\hline $\begin{array}{l}3 \text { lbs. wheat bran. } \\
\text { Io lbs. red clover }\end{array}$ & $\begin{array}{l}2.754 \\
2.643\end{array}$ & .366 & $\begin{array}{l}0.507 \\
1.176\end{array}$ & $\begin{array}{l}.300 \\
.081\end{array}$ \\
\hline $\begin{array}{l}\text { hay.............. } \\
\text { I } 5 \text { lbs. corn stover. }\end{array}$ & $\begin{array}{r}8.470 \\
\text { II. } 580\end{array}$ & $\begin{array}{l}.680 \\
.420\end{array}$ & $\begin{array}{l}3.580 \\
6.345\end{array}$ & $\begin{array}{l}.170 \\
.105\end{array}$ \\
\hline 3 I lbs. Total..... & $25 \cdot 447$ & $2.5^{82}$ & I I. 608 & $\begin{array}{c}.722 \\
\text { Nutritive } \\
\text { Ratio }\end{array}$ \\
\hline $\begin{array}{l}\text { Improved ration... } \\
\text { Standard }\end{array}$ & $25 \cdot 447$ & $2 \cdot 5^{82}$ & 13.232 & I :5. I \\
\hline
\end{tabular}

The ration as it now stands approximates the standard. It is close enough to the standard for all practical purposes.

EXERCISE.-Find out from your parents, or some of your neighbors, the rations they are feeding. Choose one of them and improve it. Of course the kind of animal must be considered in the calculation of the ration.

\section{Section LXXI.-How to Reduce the Cost of a RATION.}

John Smith has a large farm, and he is feeding his fifteen horses, who are doing hard work, the following ration:

\begin{tabular}{|c|c|c|c|c|}
\hline $\begin{array}{l}8 \text { lbs. oats......... } \\
4 \text { lbs. shelled corn. } \\
6 \text { lbs. wheat bran. } \\
\text { Io lbs. timothy hay }\end{array}$ & $\begin{array}{c}\text { Dry Matter } \\
7.120 \\
3.576 \\
5.286 \\
8.680\end{array}$ & $\begin{array}{c}\text { Digestible } \\
\text { Protein } \\
.736 \\
.312 \\
.732 \\
.280\end{array}$ & $\begin{array}{c}\text { Digestible } \\
\text { Carbohydrates } \\
3.784 \\
2.668 \\
2.352 \\
4.340\end{array}$ & $\begin{array}{c}\text { Digestible } \\
\text { Fat } \\
0.336 \\
0.172 \\
0.162 \\
0.140\end{array}$ \\
\hline Total..... & 24.662 & 2.060 & I 3.144 & $\begin{array}{c}0.810 \\
\text { Nutritive } \\
\text { Ratio }\end{array}$ \\
\hline $\begin{array}{l}\text { Ration............ } \\
\text { Standard........ }\end{array}$ & $\begin{array}{l}24.662 \\
23\end{array}$ & $\begin{array}{l}2.060 \\
2.3\end{array}$ & $\begin{array}{l}14.97 \\
14 \cdot 3\end{array}$ & $\begin{array}{l}\text { I }: 7.2 \\
I: 6.2\end{array}$ \\
\hline
\end{tabular}


Cost of the Ration.-Let us learn what it is costing John Smith to feed his horses. The following are the market prices of some of the feeds which are available to John Smith:

Per Ton of $2,000 \mathrm{lbs}$.

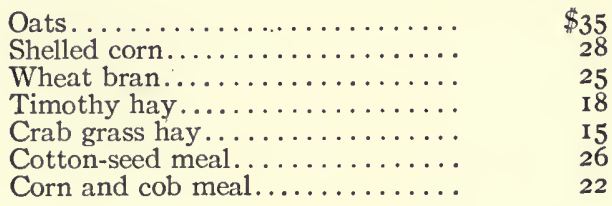

Oats cost $\$ 35$ per ton of 2,00o lbs. One pound of oats costs $\$$ O.OI 75 . Then $8 \mathrm{lbs}$. will cost $8 \times$.OI $75=$ $\$$ O.I4. In a similar way the prices of the shelled corn, wheat bran and timothy hay are calculated.

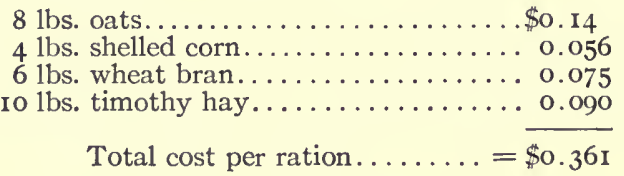

It is costing John Smith \$0.36 I per day per horse. Or it is costing him I $5 \times \$ 0.36 \mathrm{I}=\$ 5.4 \mathrm{I} 5$ for his fifteen horses per day. We will now substitute some other feeds and see if we cannot reduce John Smith's feed bill.

A Cheaper Ration.-Oats, shelled corn and timothy hay are the expensive feeds in this ration, considering the nutrients they furnish. By perusing Table I we find that cotton-seed meal contains a high percentage of digestible protein. We can substitute this feed for oats. Shelled corn and corn and cob meal contain about the same amounts of dry matter and carbohydrates, so we will substitute corn and cob meal for the shelled corn. The shelled corn is richer in protein than the corn and cob meal, but we can get this ingredient cheaper from our wheat bran. The crab grass hay is of about the same nutritive value as timothy 


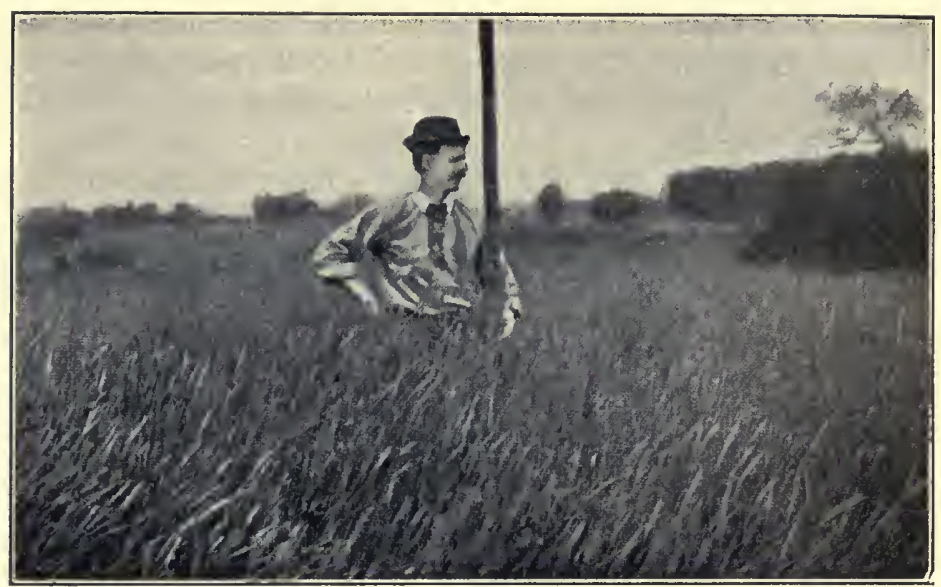

A MEADOW OF TIMOTHY, AN EXPENSIVE ROUGHAGE TO PURCHASE.

hay. It is also cheaper, so we will use crab grass hay. A balanced ration from these feeds would be as stated.

2 lbs. cotton - seed meal...........

7 lbs. corn and cob meal..........

8 lbs. wheat bran.

12 lbs. crab grass Dry Matter $\begin{gathered}\text { Digestible } \\ \text { Protein }\end{gathered} \begin{gathered}\text { Digestible Digestible } \\ \text { Carbohydrates }\end{gathered}$ Fat hay..........

$\begin{array}{llll}1.836 & .744 & 0.338 & .244 \\ 5.943 & .308 & .200 & .203 \\ 7.048 & .976 & 3.136 & .216\end{array}$

29 lbs. Total.....

10.764

$\frac{.264}{2.292}$

5.136

.072

$25 \cdot 591$

12.810

.735

Nutritive Ratio

Ration........ 25.59I $2.292 \quad$ I $4.464 \quad 1: 6.3$

$\begin{array}{llll}\text { Standard....... } 23 & 23 & \mathbf{2} .3 & \mathbf{1 4} .3\end{array}$

Compared to the Standard.-This ration is better than the one John Smith is feeding. It comes nearer the standard. The dry matter and carbohydrates in John Smith's ration approximate the standard, but the protein is too low. His ration is too wide. The dry matter in this second ration is a little high, but animals can take care of an excess of dry matter. The protein and carbohydrates in the balanced ration are very 
close to the standard. The nutritive ratio very closely approximates the standard nutritive ratio.

At the market prices the new ration will cost:

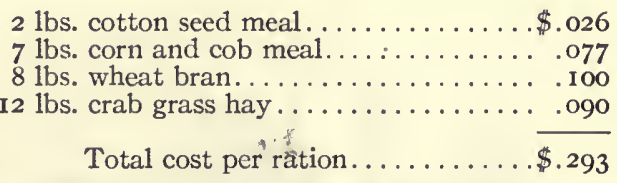

In other words this ration will cost John Smith $\$ 0.293$ per day per horse. The ration of John Smith's costs \$0:36r "per day per horse. This new ration will save John Smith $\$ 0.36 \mathrm{I}-\$ 0.293=\$ 0.068$ per day per horse. On fifteen horses the saving will be $\mathrm{r} 5 \mathrm{x} \$ .068=\$ 1.02$ per day. In a year the saving will amount to $365 \times \$ 1.02=\$ 372.30$. This example just cited is not exceptional. There are many farmers, livery men and others who are throwing away money every day on their feed bills, and still they are not always getting the best returns. This second ration, as it more closely approximates the standard, is indeed a better one, besides being cheaper.

EXERCISE.-Learn from your people or some acquaintance the rations used. Select one of these rations; find out the cost of the feeds that are used and try to substitute some other feeds to reduce the cost of the ration. Is the ration you figured out better than the original one? What is the saving in your ration?

\section{Section LXXII.-FeEds For Farm Animals.}

Feeds for the Horse.-Most horses and mules are working animals. They need materials to produce energy, and repair the wastes of the broken down tissues. Oats, wheat products, corn, dried brewers' grains, barley, rice meal, rice polish, and cotton-seed meal are some of the more concentrated feed stuffs which are fed to horses and mules. The roughage used generally consist of hays, roots and silage. It is advisable not to include more than 2 lbs. of cotton 
seed meal in any ration for the horse or mule. Hays should not constitute more than I 2 to 15 pounds of the ration. Most horses are allowed too much hay.

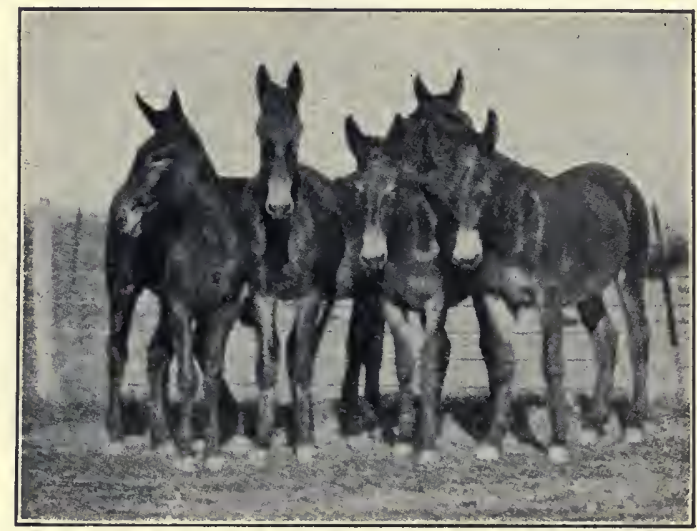

MULES-A TYPE OF HARD-WORKING ANIMAL.

The stomach of a horse or mule is small, and the practice of permitting a horse to eat all the hay he wishes is entirely wrong. We should aim to feed Io to I 2 pounds of roughage, and supply the balance of the ration with concentrates.

Feeds for Cattle.-In feeding cattle we must consider rations for milch cows and for fattening cattle.

I. Nilch cows. Rations for cows giving milk should predominate in protein substances. The ration should be narrow. It should supply substances for milk production, and for the general repair and energy needed in the maintenance of the animal body. Some of the feeding stuffs fed with success to dairy cows are cotton-seed meal, linseed meal, dried brewers' grains, malt sprouts, distillers' grains, gluten feed and gluten meal. These feeds are highly nitrogenous. Corn and wheat products are often fed. For roughage, cotton-seed hulls, roots, silage and hays are good. Cattle can take care of a larger amount of roughage than 
horses. Molasses is sometimes used with good results for furnishing some of the carbohydrates. A ration for the dairy cow should contain at least three kinds of feeds. A variety of materials in a ration, gives better results than a ration made up of two feeds, provided the ration is properly balanced. Most grains and their by-products can be used in feeding dairy cows. It is important to use only those feeds

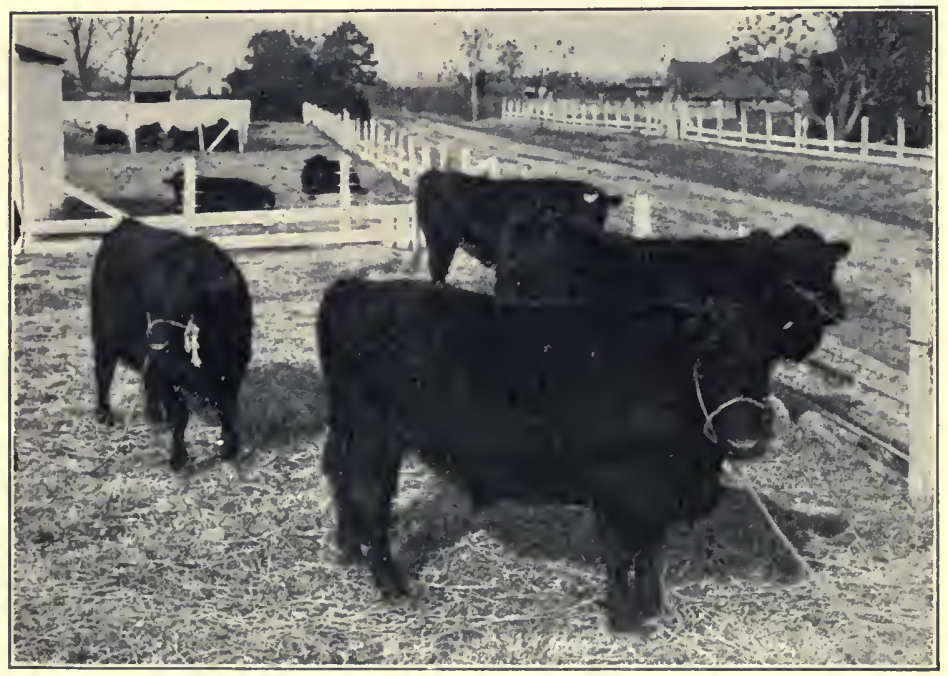

FATTENING CATTLE REQUiRE LITTLE PROTEIN.

which meet the requirements of the dairy cow and which can be fed at a profit.

2. Fattening cattle. This class of animals requires food that will help to form fat. They must have rations containing a large proportion of carbohydrates. They need only enough protein substances to keep the animal body in good condition. The amount of protein required is very small. Easily digestible feeds should compose the ration. Cotton-seed meal, cotton-seed hulls, roots, hays, wheat by-products, rice bran, rice polish, corn and its by-products are accepta- 
ble feeds for fattening cattle. Large amounts of rough fodders should be avoided. Jordan in his book, "The Feeding of

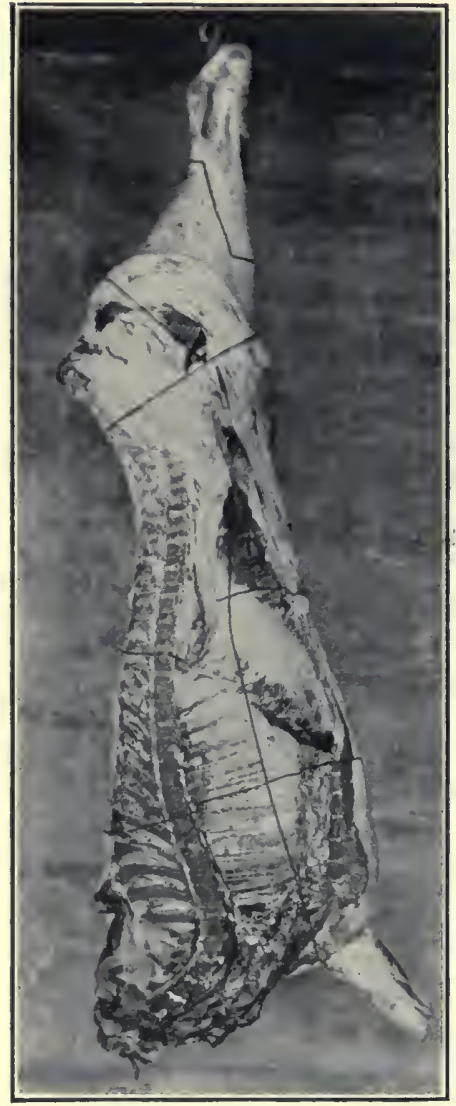

INNER VIEW BEEF SIDE. PRODUCED BY A WIDE RATION. Animals," says, "that under proper conditions 8 to Io pounds of dry, coarse food and I 5 to I 8 pounds of grain is all that can generally be fed with greatest profit to a steer weighing $\mathrm{I}, \mathrm{OOO}$ pounds, and may be even more than is utilized by the animal to the best advantage."

Fattening Sheep:Sheep which are being prepared for the market require a ration rich in ca rbohydrates. They need a wide ration. Most of our feed stuffs are suitable. Corn, oats, wheat bran, cotton-seed meal, silage, roots, and the leguminous hays (alfalfa, lespedeza, cowpea, vetches, soya bean, etc.) are very acceptable. A ration made up of two or three grains is better than one containing a single grain. The rations for sheep vary according to the age of the animal.

Fattening Swine.-Swine are generally fed the waste food of the farm. This usually includes the wastes from the dairy and the kitchen. A ration composed of skim milk and grain is a good combination for pigs. 
For young pigs the ration should be made up mostly of milk with a little grain. For older animals the grain part of the ration can be increased. Skim milk, corn meal and wheat shorts is a good milk and grain combination. Cotton-seed meal should not be fed, as it makes pigs sick. Corn, wheat middlings, rice polish, dried brewers' grains, oats, molasses, peanuts, rape, sorghum, clover, tankage and alfalfa are all good feeds for hogs. Hogs which are kept in pens should receive wood ashes, or ground bone to furnish the mineral constituents necessary to build up the bones.

Feeding Young Animals.-Young animals should be allowed their mothers' milk and gradually permitted the access of a little grain and roughage. The mothers should in all cases be fed rations that will tend to produce milk. When the young stock have been on their mothers' milk for about a week a little grain should be given them. Grain should be fed in very small quantities at first. When the young animals are kept in the barn they should receive only very small quantities of roughage, until their digestive organs become developed. If too much roughage is permitted, the animals get sick. When they are in good pasture it is not necessary to supply roughage. The roughage should include pasturage or a small amount of good hay such as leguminous hay. Wheat middlings, linseed meal, oats, corn meal, wheat bran are some of the grains that are fed.

Feeding Poultry.-Most of our poultry are fed the wastes from the table. This food is usually lacking in protein. In purchasing feed for poultry the farmer should endeavor to secure materials rich in protein. In the making of eggs, protein is one of the essentials needed, as the egg contains a great deal of proteın. Meat scraps, fresh bone, ground alfalfa, and wheat products are satisfactory poultry feeds. Never feed cotton-seed meal alone, as this feed is apt to make poultry sick.

Laying hens require narrow rations and large 
amounts of lime. Ground oyster shells are often used. Fattening hens should receive wide rations.

EXERCISE.-Compute a ration for fattening a steer weighing I,200 pounds. What would be the amounts of corn, wheat middlings and skim milk to feed fattening swine 6 to 8 months old? How much hay is the horse at home receiving per day? Wouldn't it be better to cut down the quantity of hay fed?

\section{Section LXXIII.-A Few Remarks About Feed Stuffs.}

Importance of State Feed Laws.-On account of the adulteration of commercial feed stuffs many of our states have passed feed laws. These laws require the manufacturers and dealers in these commodities to "state what they sell and sell what they state." In other words they are forced to guarantee their products. Example-John Doe is manufacturing and selling cotton-seed meal. Before he is allowed to sell his cotton-seed meal he must have printed on the sacks, or on tags attached to the sacks, the composition of the cotton-seed meal. Let us suppose that John Doe has printed on his sacks the following:

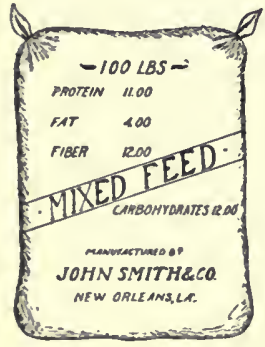

A SPECIMEN BAG OF COMMERCIAL FEED. protein 40 per cent., fat 9 per cent., carbohydrates 24 per cent., and fiber Io per cent. Weight roo lbs. Such a statement is the guarantee. The weight of the package is required because some feeds, such as cracked corn, are put up in 90 and $100 \mathrm{lb}$. sacks. The $90 \mathrm{lb}$. sacks are used instead of the roo lb. sacks, because most purchasers take it for granted that all feeds are sold in lots of Ioo lbs. or more. Feeds put up in $90 \mathrm{lb}$. sacks are generally sold per sack and not by weight. The guarantee, then, protects the purchaser. Many of our State Feed Laws provide for a fine on all goods below the guarantee. 
Adulteration of Feeds.-If it were not for the protection our feed laws give us, we would find it hard to purchase good standard products. In the above case, John Doe could easily introduce ground cotton-seed hulls with his cotton-seed meal, and sell the product with any guarantee he pleased. $\mathrm{He}$ could sell this mixed product under the name of cotton-seed meal, when in reality it is cotton-seed meal and ground cottonseed hulls. Of course John Doe could afford to sell the mixed product at a lower figure, but for the ingredients received the purchaser would pay a higher price. Most states permit manufacturers to sell low grade products, but they are required to place another name on the product. Perhaps John Doe would not care to put out a mixture of cotton-seed meal and cottonseed hulls under the true name, and he no doubt would give it a brand name such as Cracker Feed. The purchasers of low grade mixtures should know their values. The Experiment Stations and the State Boards of Agriculture are continually sending out bulletins which comment and set forth the values of commercial feeds. In all feeds the principles as cited in the foregoing are true. It is unfortunate, but possible for manufacturers to put out feeds that resemble standard products, which are badly adulterated. These adulterated feeds are generally ground so fine that the casual observer cannot detect the adulteration with the naked eye.

How to Buy a Feed.-Do not buy cotton-seed meal, linseed meal, wheat bran, etc., just because they are so named. In purchasing feed stuffs send for a bulletin from your State Experiment Station or from the State Board of Agriculture. Read it thoroughly and find out the composition of the standard products and purchase accordingly. When you learn the composition of the standard product or products which you intend to purchase, ask your feed dealer the guarantee on his feeds. That is, the composition and weight of the package. If the feed or feeds you want to purchase are below 
the standard do not buy. Tell your dealer his feed or feeds are below the standard. Tell your neighbors about it and force the feed dealer to handle standard feeds. There are many dealers and merchants who purchase the cheapest feeds possible. They sell these inferior feeds to their customers for as nearly as high a price as high class feeds bring. They do this to make greater profits.

Raise Your Feed at Home.-It is really unfortunate that our farmers do not raise more of their feed at home. No matter what section of the country you live in, you should aim to have some feed to sell, and not be forced to buy continually. Raise forage crops, grow root crops and harvest grain. Sometimes one is forced to purchase protein concentrates, such as cottonseed meal, linseed meal, etc.; but the roughage or carbohydrates feeds can generally all be raised on the farm. In purchasing commercial feeds, especially mixed feeds, one is forced to pay for the cost of manufacture, business losses, manufacturers' profit, expenses of the traveling men who sell the feed, and the cost of freight. The most successful farmers in this country to-day are those who raise most of their feed at home.

Condimental Feeds.-There are a great many of these feeds sold upon the American market. They are made up of mixtures of sulphur, salt, saltpeter, epsom salts, Glauber's salts, sodium bicarbonate, fenugreek seeds, fennel seeds, charcoal, red and black peppers, ground bone, venetian red, anise and similar products, together with some feed as a basis, in varying proportions. These feeds generally carry attractive names, and the manufacturers make great claims regarding their curative properties. Some of them exert a tonic effect; but tonics and condition powders are not needed by animals in good health. If animals are sick it is cheaper to consult a veterinarian.

Experiments have been conducted by experiment stations on this class of feed, and the results of these 


\section{investigations have shown that the economical feeder cannot afford to purchase them.}

ExERCise.-Go to a feed store and copy the guarantees of the feeds the dealer has on hand. Note the weight of the packages. Compare the guarantees with the standards given in Table I. Classify these feeds as standard or inferior. Visit your drug stores and feed dealers and make a list of the various condimental feeds sold for hogs, cattle, poultry and horses. Ascertain the selling prices. Figure the cost of these feeds per ton. Do your folks use any of these feeds? Secure a few of these feeds and try to distinguish some of their ingredients. Shelled corn is worth $\$ 30$ a ton and cane molasses can be purchased for $\$ 18$ a ton. If you had considerable corn on hand, would it be cheaper to sell your corn and purchase molasses for feeding purposes? What is your reason for your decision? Which is the more economical to feed: cotton-seed meal carrying 40 per cent. protein at $\$ 25$ a ton, or cotton-seed meal containing 36 per cent, protein at $\$ 23$ a ton?

\section{REFERENCES FOR COLLATERAL READING.}

Feeds and Feeding:

Farmers' Bulletins, Nos. :

$32-$ Silos and silage.

36 - Cotton seed and its products.

84-97-I22-225-305-Feeding poultry.

I70-Principles of horse feeding.

I86-Rations for laying hens.

202-Home-grown protein for dairy cows.

222-Silage for cows.

249-Cereal breakfast foods.

25I-Indoor $v s$. outdoor feeding of steers.

25I-Cheap dairy rations.

305-Roots and cabbages for stock food.

346 -Computation of rations by energy values.

Experiment Station Bulletins, Nos.:

58-Missouri-Feeding the dairy cow.

ro6-North Carolina-Rational stock feeding.

I I4-Louisiana ; I3I-Indiana ; 220-New Jersey ; I20-Massachusetts-Commercial feeds.

I I -Louisiana-Feeding.

Books :

I82-Virginia-Silo construction.

Feeds and Feeding-Henry-W. A. Henry, Madison, Wisconsin. The Feeding of Animals-Jordan-The Macmillan Co., New York City.

Chemistry of Plant and Animal Life-Snyder-The Macmillan Co., New York City.

Human Foods-Snyder-The Macmillan Co., New York City. 


\title{
CHAPTER X.
}

\section{MISCELLANEOUS.}

\section{Section LXXIV.-Farm Management.}

\author{
By Prof. Fred. W. CARd,
}

Late of Department of Horticulture, Rhode Island College of Agriculture and Mechanic Arts.

Choice of the Farm.- Many things enter into the problem of successful farm management. First among these is the choice of the farm itself. If one is free to choose many things should be considered.

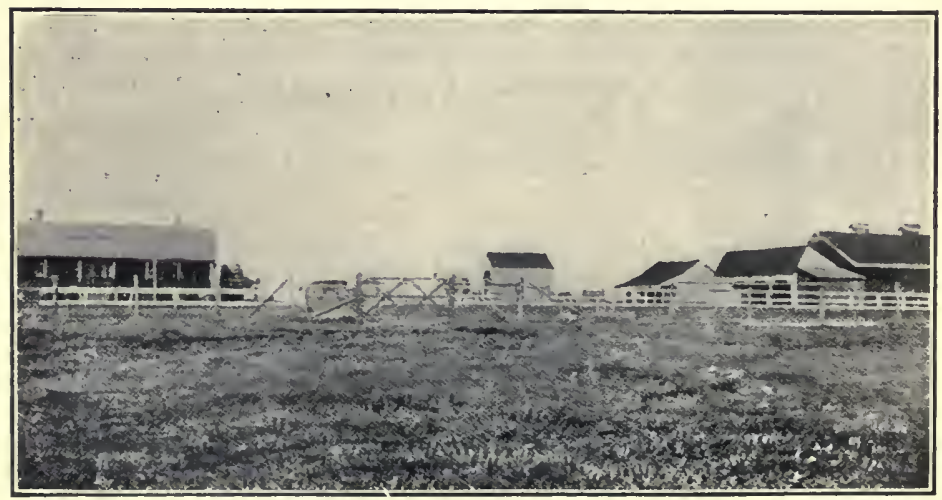

A MODEL SET OF FARM BUILDINGS.

These include the fertility and general character of the land, its contour, its freedom from stones or otherwise, its need of drainage, etc.; its distance from market and the character of the roads, whether hilly or level, and good or bad in other respects. The adaptability 
of the farm and the buildings to the type of farming intended, the condition of these buildings, the water supply, etc., all have an important financial bearing. Since the farm is to be a home as well as a business, the character of the neighborhood, convenience to church and schools, and beauty of location all demand attention.

Adaptation of the Farm.-The problem of adaptation of the farm, the market, the climate, and the general conditions to the type of farming followed is one of the most important things to be kept in mind. If one is not free to get a farm suited to the kind of farming he likes best, the next best thing is to adapt the farming to the farm in hand. Failure to do this is the cause of much unprofitable farming.

Types of Farming.- - In deciding upon the type to be pursued the comparative advantages of special and mixed, extensive and intensive methods should be carefully weighed.

I. Extensive farming demands a heavier investment in land, with relatively less in equipment and labor.

2. Intensive methods are adapted to fertile and high-priced land convenient to markets, but are wholly unsuited to many locations where land is poor and markets remote. Yet intensive methods are generally relatively more profitable than extensive methods with the same crop. It seldom pays to neglect a crop. Certain charges are about the same in either case; an additional outlay in labor and fertilizer will often double the return.

3. Mixed farming has the advantage of a more continuous income, less risk from crop failure and low prices, with less difficulty in maintaining fertility and employing a continuous labor supply than most specialties.

4. Special farming, with two or three well-chosen lines which fit well together, permits greater economy of capital and of labor, develops greater skill in the farmer, and gives better marketing facilities. 


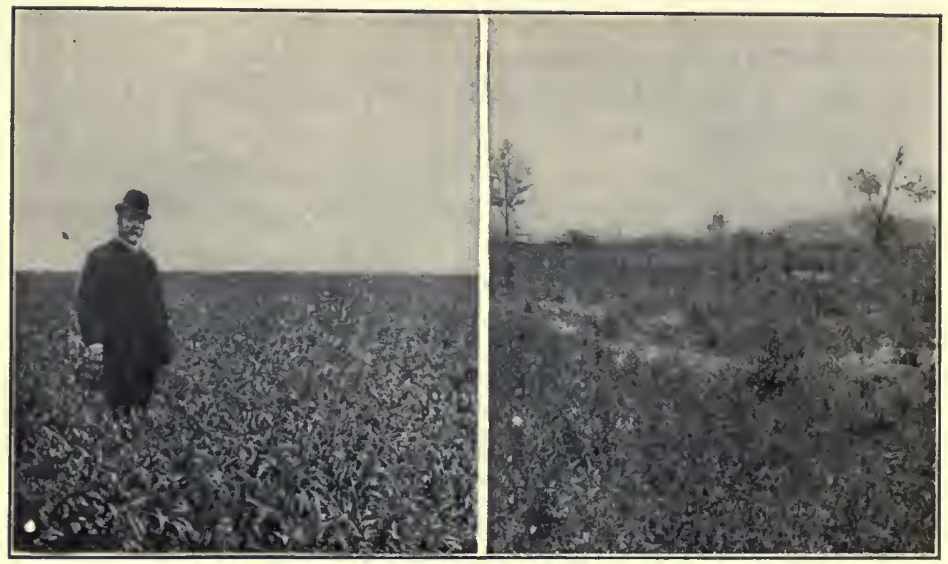

'FIELD OF RYE ON MODEL, FARM. FIELD OF RYE, ON ADJACENT FARM. FERTILITY MAINTAINED. FERTILITY RUN DOWN.

Balancing Capital and Labor.-Closely connected with the choice of the farm and the type of farming should go a careful study of the problem of balancing the capital to be invested in the various ways in which it will be needed, together with the proper balance between capital and labor employed. What proportion of the money invested ought to be put into the land itself, into the buildings and their equipment, into livestock and implements, and how much should be reserved with which to pay for feed, fertilizer, labor and other expenses of management? No rule can be laid down, for the proportion will vary with many things; but in general the more intensive the type and the methods employed, the larger will be the relative amount needed for equipment and running expenses.

A Farm Should Run at Its Full Capacity.-Enough labor should be employed to run the farm at its full capacity and to do things at the right time. Much loss results from not being able to reach things just when they need attention. It often happens that a few days' delay will double the cost of a piece of work. No factory owner feels that he can allow part of his 
factory to stand idle for lack of men to keep it running, and no farmer should feel that he is doing his best unless his farm factory is fully employed. This is often the most difficult problem in farming, for good labor, at prices which the returns will warrant, is hard to get. Furnishing steady employment to men throughout the year, and if possible providing a neat and comfortable tenant house in which they may live are aids in solving the problem.

Team Labor is on a different basis; its cost is in the expense of feed, bedding, care, shoeing, depreciation in value, etc. These items do not vary greatly whether the team is working or idle. It should be the aim to bring the cost of keeping to the lowest point consistent with efficiency, by a wise choice of the foods used, but this is not the most improtant phase of the problem. If it costs $\$ 25$ per month to keep a team of horses, and the team works 250 hours during the month, the average cost per hour is ten cents. If instead, the team works only I 25 hours, the average cost is twenty cents per hour. To so plan the operations of the farm that no more horses are kept than are needed, and then to keep them at work as much as possible, should be the aim.

Records and Accounts.-A simple system of records and accounts is needed on every farm. These should enable the farmer to determine the profit or loss at the end of the year, and to find out where the gains and losses occur. It should also furnish a record for future reference. A careful inventory of all property at the end of each year is the first essential. From the total assets should be deducted all liabilities, to obtain the "net worth." A comparison of this net amount at the beginning and end of the year is the only thing which will show the actual gain or loss.

A Cash-Book, showing all money taken in and paid out, is the next essential, and this should be full enough to furnish a record of transactions for future reference. By adhering strictly to a cash business the cash-book 
and the check-book are the only records necessary for this purpose so far as business transactions are concerned.

Cost of Each Crop.-To find where gains and losses occur it is necessary to know the cost of each crop. The labor cost is most difficult to obtain unless a time record is kept. This is a simple thing to do, and should show the amount of manual and team labor expended on each crop and each line of work. The printed timebooks which contractors use serve the purpose well. By the aid of this and by adding the cost of seed, fertilizer, rent of land, etc., the cost of a crop is readily determined. Then by knowing its yield and value it is easy to see the profit or loss. Feeding records, milk weights and butter fat tests are also necessary in livestock and dairy lines.

A careful study of such business phases of the enterprise will do much to put the farm on a paying basis.

ExERCISE-Make a list of farms following the four types of farming and tell why the different types are followed on these farms. State what crops are raised, live-stock and equipment on hand, buildings, and the number of hands employed. On how many of these farms are the hands and horses always employed? What is the average price paid to farm hands? How many hours constitute a working day? Are records and accounts kept on any of these farms? Do the dairy farms weigh their milk and test it for butter fat? Write your ideas on how you would improve conditions on some of these farms.

\section{Section LXXV.-Farm Machinery.}

By Prof. L. W. Chase,

Department of Farm Mechanics, University of Nebraska.

I. Tillage Machinery.-The action of the atmospheric forces and the weight of the soil itself, together with the trampling of beasts and human beings, causes it to settle and become hard and compact. The hardest soil is that which has stood for ages undisturbed by either man or nature. The earliest farmers learned that to procure good crops the soil must be loosened or 
stirred, and the better the soil was stirred, or as is generally known, pulverized, the larger the crop. Different devices have been used for pulverizing the ground, but the most common and probably the best one is the plow.

Plows.-There are two general classes of plow, the moldboard and disk plows.

Moldboard Plows.-If plows are all equally sharp and equally well adjusted there will not be any difference in their draft unless the moldboard of one has a more abrupt curve than that of another. Plows with

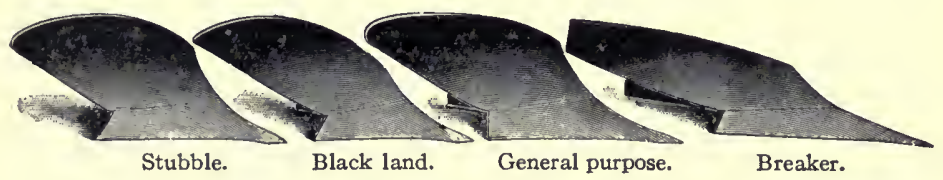

TYPES OF MOLDBOARDS.

nearly straight moldboards are used for breaking wild grass sod. The share, which is the cutting edge of the plow cuts the roots of the grass about three and onehalf inches beneath the surface of the ground, then the moldboard carefully and smoothly turns the sod upside down. Such a plow is known as a breaker. Plows

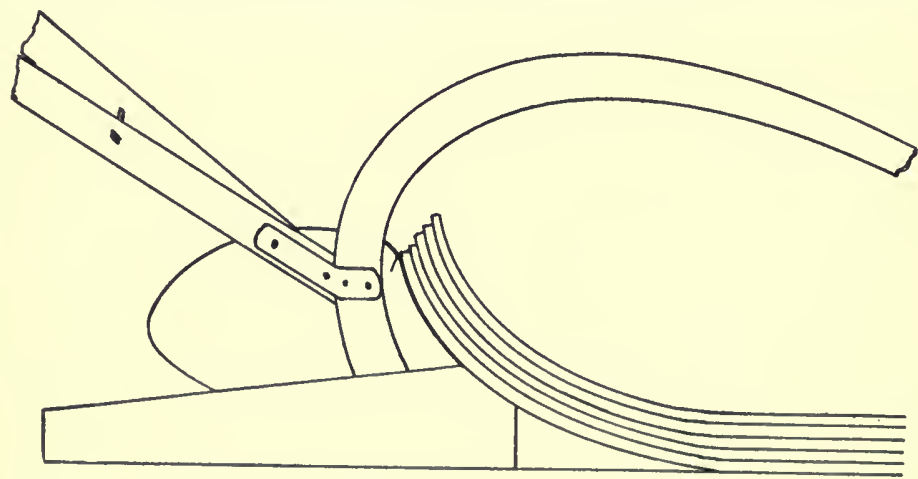

DIAGRAM SHOWING HOW ONE LAYER OF SOIL TENDS TO SLIDE PAST ANOTHER WHILE BEING TURNED BY THE PLOW. 
used for plowing tame grass sods have a shorter curved moldboard than those used for plowing wild grass sods; and plows used for plowing old ground and stubble have a very short, abrupt moldboard.

Disk Plows handle the soil much as do moldboard plows, but with a rolling instead of a sliding motion. Generally they will work in ground which is too dry and hard or too sticky for moldboard plows; but, as

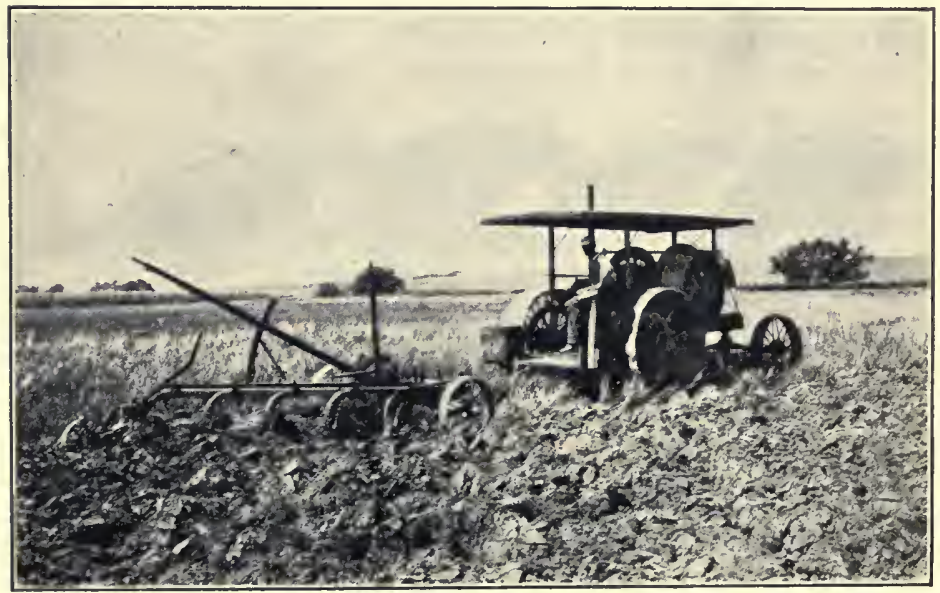

TWENTY-HORSE-POWER TRACTION GASOLINE ENGINE DRAWING FIVE FOURTEEN-INCH PLOWS.

has been determined, the draft of the two classes of plows is about the same.

Riding Plows. - If the fields are not too small, riding plows if properly adjusted pull as easily as walking plows, do better work, and the operator has the advantage of riding.

Harrows.-After the ground has been plowed its surface must be smoothed, so that the seeders will do better work and evaporation will be diminished by causing less surface to be exposed to the sun's rays. Harrows are the tools utilized to smooth the surface of the plowed fields, and are classified as follows: the 
disk, the spring tooth, and the spike tooth harrows. The disk harrow pulverizes the ground exceedingly well, firms the plowed field and makes a uniform seed bed. The spring tooth harrow and spike tooth harrow pull much easier than the disk harrow, but they will not penetrate hard soils. Generally after the ground has been plowed or cultivated they are used to smooth the surface or make a soil mulch.

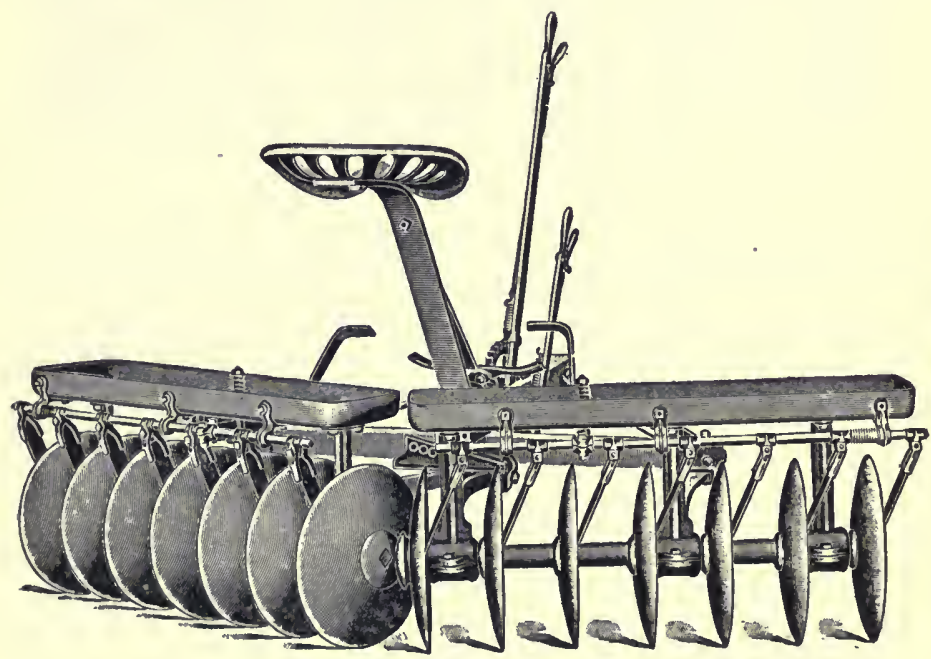

DISK HARROW.

Cultivators.-After the crops have been sowed or planted the ground must be tilled to prevent the growth of weeds, and also to keep the surface friable. Cultivators are used for this purpose. In the early days, the single shovel cultivator was used almost entirely, and later the double shovel came into use. Now, in nearly all extensive farming operations, the two-horse walking or riding cultivator with four or six shovels, and sometimes eight are used. In the prairie sections two-row cultivators with eight or twelve shovels are becoming popular. 


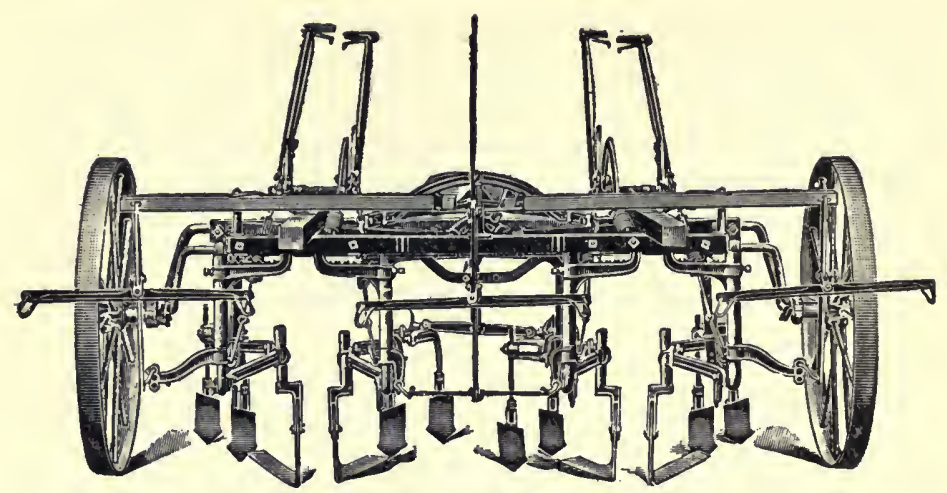

TWO-ROW CULTIVATOR WITH THREE-HORSE HITCH.

The essentials for a good cultivator are that the axles have dustproof bearings, that the levers be accessible and easily worked, that there be a device to equalize the weight of the man and the tongue, that the rigs which hold the shovels be as long as possible, and yet be not too far behind the team, and that all the parts be made of the best kind of material.

2. Seeding Machinery.-Machines used for seeding are generally known as seeders, drills, and plantcrs. Seeders are used for sowing the grains broadcast, drills for putting it in rows, and planters for both drilling it in rows and planting it in hills.

Seeders.-Handseeders are either carried on the

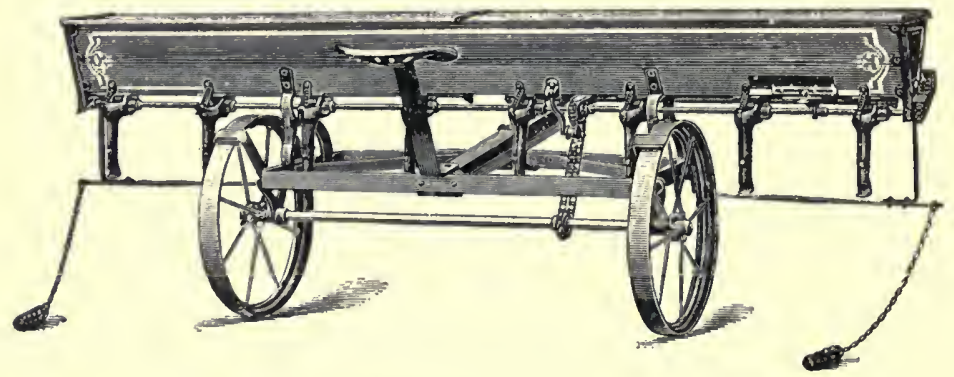

BROADCAST SEEDER, DRAWN BY HORSES. 
shoulder and worked by means of a crank or bow, or are attached to a wheel and pushed in the form of a wheelbarrow. Endgate seeders are attached to the rear end of the wagon and driven by means of a chainwheel on the rear wheel of the wagon. With the broadcast type of seeder more grain can be carried and the operator rides. It also distributes the grain more uniformly, especially in a wind, than the endgate seeder.

Drills generally have a force feed in the bottom of the seed box. By this means the seed is constantly being measured so that a uniform amount is dropped through the spouts into the ground. In order that the seed from a drill may be dropped into the ground, a furrow must be opened which will permit the seed to fall into it. To make this furrow there are four different types of openers in use:- the hoe, the shoe, the single disk opener, and the double disk opener.

The hoe is the least expensive design, but gathers trash badly, is likely to break and seems to clog more than the other designs. The shoe is a very satisfactory style of opener, but will not penetrate hard ground. Disk openers seem to be in the greatest demand at present. They are not very troublesome about clogging, will enter nearly all kinds of soil, and if properly designed do not require many repairs. The single disk penetrates the ground better than the double, but is harder to pull. In some localities where fall seeding is carried on very extensively the single disk is preferred to the double because it leaves the ground rougher, and thus it catches the snow and breaks the wind. The double disk leaves the ground smoother and is often desired for this reason.

Planters are generally spoken of as machines for planting cotton, corn and potatoes.

The Potato Planter is a new machine and is only being developed; however, it is already being successfully used in many localities.

Cotton Planters are either of the one-row or the two-row type. The earlier planters simply drilled 
the seed in a row and covered it with a roller, but during recent years two-row types have been made which in certain localities are very successful. For the farmer who raises cotton in small fields the one-horse drill is better adapted than the two-row drill. For a farmer who raises corn as well as cotton, the combined corn and cotton planter answers very well.

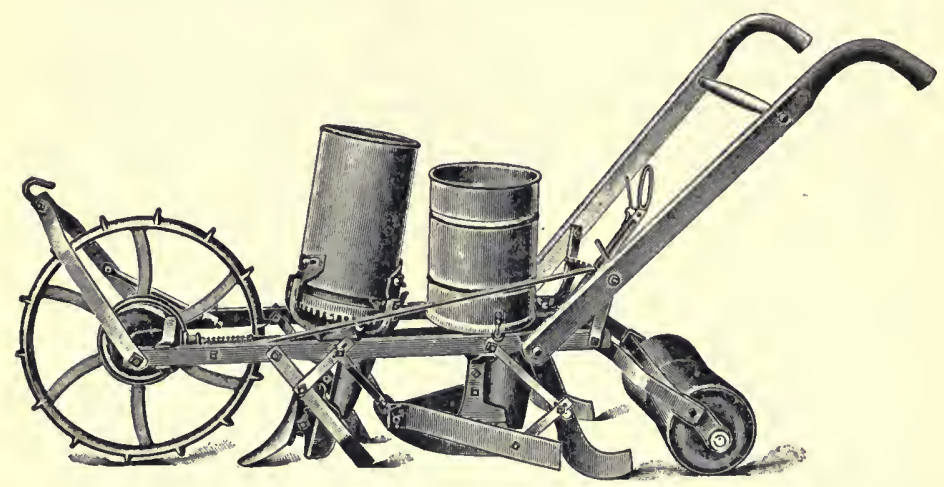

COMBINED COTTON AND CORN PLANTER WITH FERTILIZER DISTRIBUTER ATTACHMENT.

A Corn Planter which does good work is an implement which is important to the farmer. There are two classes: the lister and drill combined, and the planter and drill combined. The former type is a machine which plows the ground and plants the corn at the same time; and the latter drills the corn in rows; or, by a simple adjustment, plants it in hills. The place for the lister is in semi-arid countries, and where there is a great deal of wind. Listers plant the corn so that the stalks are well down in the ground where the moisture is, and at the same time furnish a brace for the stalks, thus preventing them from drying out so quickly or being blown down badly.

The different operations of the present day corn planter are to mark the field by means of a marker, which furnishes a guide by which to drive the team, 


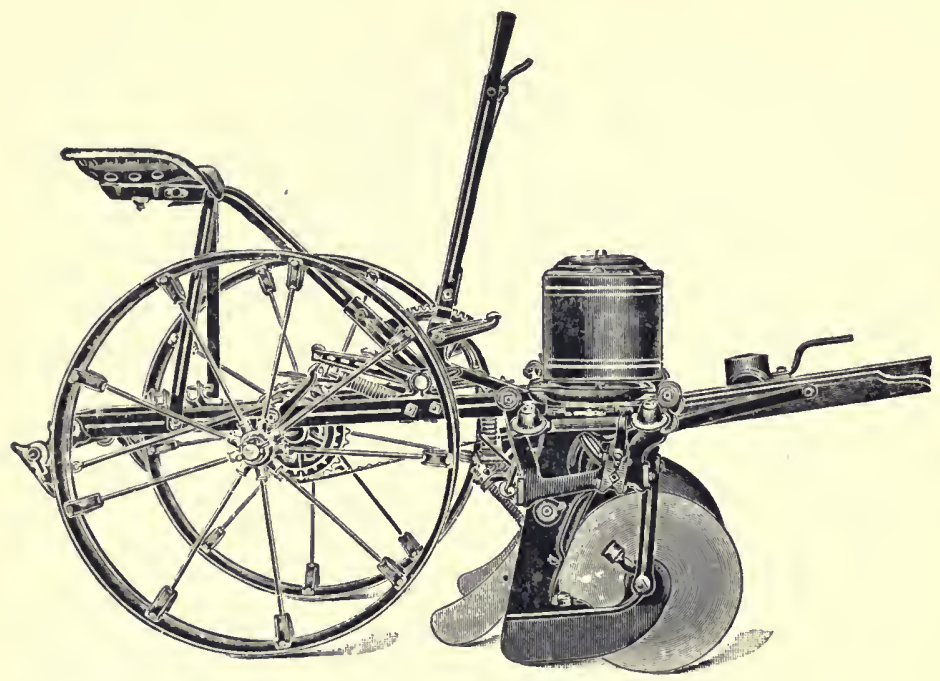

CORN PLANTER WITH DISK FURROW OPENERS.

to open a small furrow in which the corn is dropped, to select the proper number of kernels from the seed box, gather them into a hill, drop them into the furrow and cover them.

3. Harvesting Machinery.-If the crops have been grown and ripened they must be harvested. In the early days all harvesting was done by hand, and as the age of farm implements approached various ma-

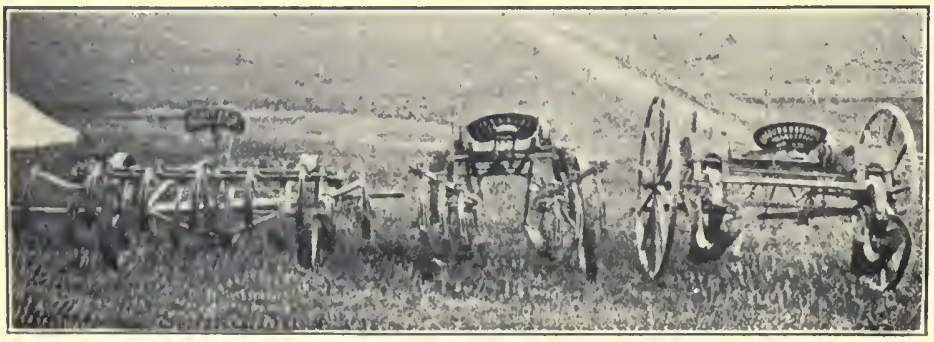

IMPLEMENTS USED IN PRODUCING IOO BUSHELS OF CORN PER ACRE. 
chines were devised to harvest the different kinds of crops. Such crops as wheat, rice, oats, barley, rye, etc., need a machine which will gather all the heads of the grains and keep them separated from the straw. Machinery for harvesting the grasses wherein it is immaterial whether the blades are kept perfectly straight or from mingling together, are more simple than for harvesting grains; while machinery for harvesting root crops are yet a new feature.

Sickles, or reaper hooks, were the first implements used for gathering the grains.

Cradles.-The cradle has taken the place of the sickle in nearly all countries where hand machines are yet used. This machine is simply a heavy scythe with several fingers extending above the blade in such a way that they gather the stalks of grain as they are cut, and hold them together so that they may be deposited in a uniform pile on the stubble. The bundles are then gathered together and tied in sheaths by hand. Although this was a great improvement over the sickle, it was not satisfactory, and inventors kept working on new machinery until the self-rake came into use. The self-rake cuts the grain, drops it on a platform, and when a sufficient amount has been cut to make a bundle, large arms or rakes come around and rake the bundle off the platform and leave it on the ground. At one time the dropping of the bundles from the platform to the ground was accomplished by a man walking behind and raking the bundles off with a hand rake. It was a tiresome piece of work to follow a self-rake, stoop over and gather the bundles and tie them up; hence, a machine was devised wherein two men could ride and tie the bundles as fast as they were gathered. Such a machine did not satisfy the wishes of the inventors, so after more studying and experimenting, the self-binder was produced.

Self-Binder.-The self-binder now in use cuts the grain, gathers it, ties it in bundles and deposits the bundles on the ground. 
Binders-The self-binder cuts the grain, drops it uniformly upon a canvas, by means of a reel, the canvas carries the grain to an entrance between two elevating canvasses, they elevate the grain to the upper part of the machine, it is then dropped upon a deck where it is allowed to slide down into the clutches of the packers. These packers, assisted by the butter which makes the ends of the bundles uniform, pack the grain into a bundle of the size desired by the operator. A string is then drawn around this bundle by means of

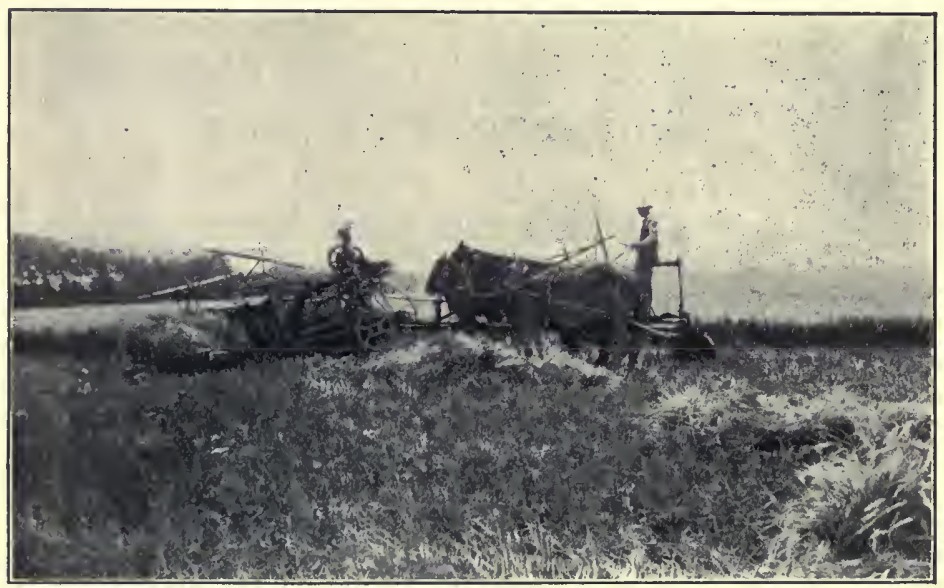

BINDER RUN BY GASOLINE ENGINE OR HORSES.

a needle. After the string has been thrown around it is tied and severed from the main ball of twine, the bundle is then kicked from the binder to the carrier. This carrier carries the bundles untit the proper number have been gathered when it drops them adjacent to the bundles which have been dropped by a previous round of the machine. In operating a grain binder care should be exercised in the manipulation of the reel. If the reel is held too high it does not cause the grain to fall properly on the platform canvas. If too low it hits the grain a blow which knocks it to 
the back side of the platform and sometimes upon the ground. If too far back it does not grapple the grain sufficiently to be of service, and if too far ahead it does not give the grain sufficient momentum to cause it to drop upon the canvas uniformly. The canvas should be kept as tight as possible while in operation, but should always be loosened when the machine is to stand a few hours without working. The canvas rollers should be parallel, and with their ends at rightangles to each other. All the parts of the knotter should be kept polished perfectly smooth and free from rust. There should be no lost motion in these parts no matter how slight it may be. If the knotter pinion becomes worn it must be replaced by a new one. The twine disk should be adjusted so that it takes a force of about forty pounds to pull the twine from it. If an untied band has a knot on one end it is generally because the disk does not move far enough, and the knotter-hook grasps only one cord. Sometimes, however, this same trouble will occur when the needle does not carry the twine far enough. In that case the needle which is of malleable iron can be bent. Always keep the knife perfectly smooth and sharp. It is best to sharpen it with a fine whetstone during every thirty or forty acres of cutting.

Headers.-In countries where there are large fields and they are not too heavy, harvesters are used which are known as headers or push machines. These headers generally cut a swath about twelve feet wide, and unless the machine has the binder attachment it elevates the grain into a rack known as a header-box. This header-box is on a wagon and is driven along beside the header by means of an extra team. Four or six horses are generally used upon push machines, and they travel behind it pushing the machine before them.

4. Mowers.-Such machinery as is used for gathering the grasses can be called hay machinery. The first of these is the mower which cuts the grass. The cut- 
ting is accomplished in the same manner as though having several pairs of shears moving through the grass side by side. On the mower, however, one blade of the shears is fixed, and is known as a guard while the other blade moves back and forth and is known as a section. There is a section for each guard, and all the sections are riveted to one bar making a device known as the sickle. This sickle is driven by means of a pitman, one end of which is attached to a crank-wheel. This crank-wheel in turn is driven by a system of gears which are propelled by the mower wheels. The guards are attached to one long bar, and they go together and comprise what is known as the cutter-bar. In the earlier machines this cutterbar was drawn directly behind the horses, but because of the horses trampling the grass it was soon moved out to one side so that the horses could travel on the mown grass while the machine cut a new swath. The essentials of a good mower are that there be very little weight on the horses' necks, that the cutter-bar does not tend to pull the machine around to one side, making side draft, that the sections bear perfectly on the guard plates, that the cutter-bar be in perfect line with the pitman. There should be no lost motion whatever in the gears, the cutter-bar should be so designed that it will conform to uniform ground, and yet be raised very easily, and a good feature is to have the machine thrown out of gear as soon as the cutterbar is raised a certain height.

Rakes.-After the grass has been cut and allowed to dry it is raked into windrows. There are two kinds of horse rakes for this purpose. One which is the older is the sulky rake, and the other is the side delivery rake. This rake is used by traveling in the same direction in which the mower has traveled gathering the hay into one large bunch, and as soon as the rake is full it is dumped. Every round one bunch is dumped adjacent to the bunch of the previous round, making windrows. This dumping action can be ac- 
complished either by hand or automatically as the machine is designed to operate. The side delivery rake is one in which the rake very much resembles a cylinder

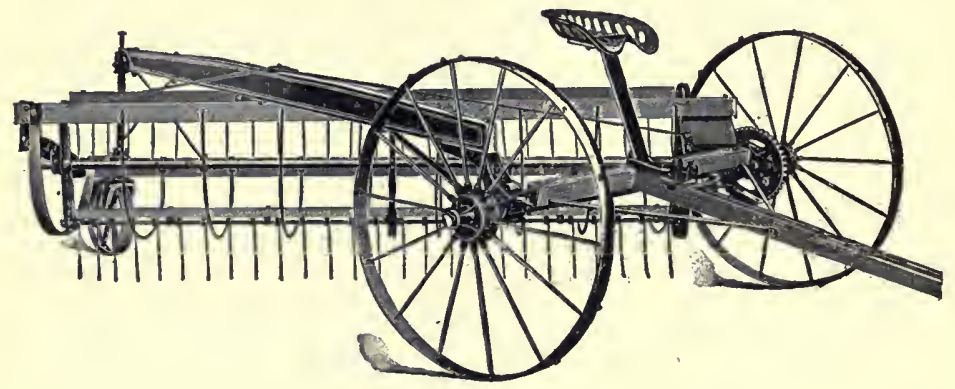

SIDE DELIVERY RAKE.

with teeth sticking out on it moving along at an angle with the swath. This rake or cylinder in revolving picks up the grass and keeps a continual stream of it moving off to the side which forms the windrow. It does not pack the hay as tight in the windrow as the sulky rake, but if properly operated lifts all the grass from the ground. As large a windrow as desired can be gathered by pulling several swaths together. The strong features of this rake are its ability to rake very green grass, and its action in leaving the grass in a loose windrow. It is exceedingly well adapted for the clover crops, especially for alfalfa.

Hayloaders.-After the grass has been cured it is then ready to be stacked or be put in the mow. If taken from a field and put in a mow a hayloader is a very convenient device. This machine is intended to be coupled on the rear end of the hayrack. It gathers the grass or hay by means of a cylinder, elevates it into the air by means of rope-webs or rakes, and deposits it in the racks where it is placed about by the men. The loaders which load the hay by means of rakes crowd it upon the load in very good shape, but in handling clover hays is apt to shake a great many 
leaves off, while the loaders which load the hay by means of a cylinder and rope-web do not leave the hay in quite as good shape on the load, but preserve nearly all the leaves.

When the hay is to be stacked in the field it is more economically gathered together by means of a sweep. This sweep is operated by means of two horses, one hitched at each end, and driven on each side of the windrow, the sweep often gathering as much hay as can be carried on a small hayrack. The hay is then taken to the stack where it is deposited on the fork of the stacker. Here there is another team which by means of ropes and derricks raises it and drops it on the stack. There are two general kinds of stackers now in use. One is where the load of hay is raised up similar to raising a board flat on the ground up on its end. In this case the load of hay is carried completely over the machine, and the machine itself is known as an over-shot stacker. The other style is known as a swing stacker. It simply lifts a load of hay straight up, swings it around and drops it on the stack.

5. Care of Farm Machines.-The elements cause the rapid deterioration of machinery, and a sheltered

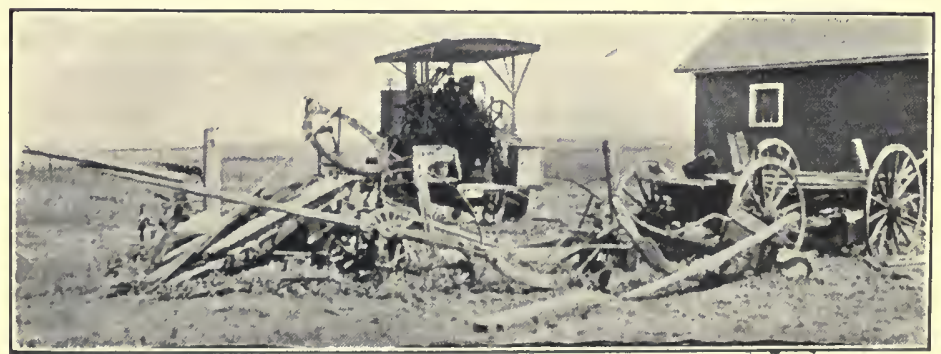

CARELESS HANDLING OF FARM MACHINERY.

place should be set aside on every farm for the storage of farm machinery. A farmer of to-day must necessarily be somewhat of a mechanic in order to 
keep farm machines in good working order. All breakages should be repaired at once, and duplicate parts should be kept on hand to save delay. The failure to repair farm machines promptly, often causes a loss of much time and sometimes the discarding of valuable machinery.

EXERCISE.-Make a list of the farm machines you are familiar with. Classify them under the heads as given in this article. How much more labor did it take to raise an acre of corn in the year 1800 than at the present time? What do you attribute this saving of labor to? Do you know any farmers who do not keep their farm machines in a sheltered place? State how these farmers lose money from year to year by such practice.

The teacher should take the class out to a large farm and examine the machinery.

Section LXXVI.-The Disposal of Sewage on THE FARM.

By Prof. J. B. Davidson,

Department of Agricultural Engineering, Iowa State College.

The Requirements of Sewage Disposal.-Modern ideals of sanitation demand that new methods be utilized to dispose of the sewage from the farm house and the outbuildings. Methods in use a few years ago a re not acceptable now, largely on account of the installation of plumbing fixtures in the farm houses. A good sewage disposal system should prevent an accumulation of material to harbor disease, should not endanger, by contamination, the water supply, and should provide for the saving of fertilizer material which would otherwise be wasted. The sewage from a farmstead may be emptied into a large stream of flowing water if available, similar to the method pursued by the larger river cities. It is not often, however, that this method can be made use of.

The Cess-Pool.-. The sewage may be discharged into a cess-pool, which is a reservoir with an open wall through which the liquids seep away into the soil. This method is the cheapest, but has little to commend it. A cess-pool for average requirements can be con- 
structed for from $\$ 15$ to $\$ 20$. The great danger from the cess-pool lies in the contamination of the water supply if secured from wells in the vicinity. Grease is also apt to collect upon the wall and prevent the liquids from seeping through. Often lye is used for dissolving this grease and overcomes the difficulty. The solids settle in the cess-pool, and must be removed at stated intervals, perhaps once in two years.

The Septic Tank.-If the sewage is carried into a large reservoir where it may be allowed to remain for

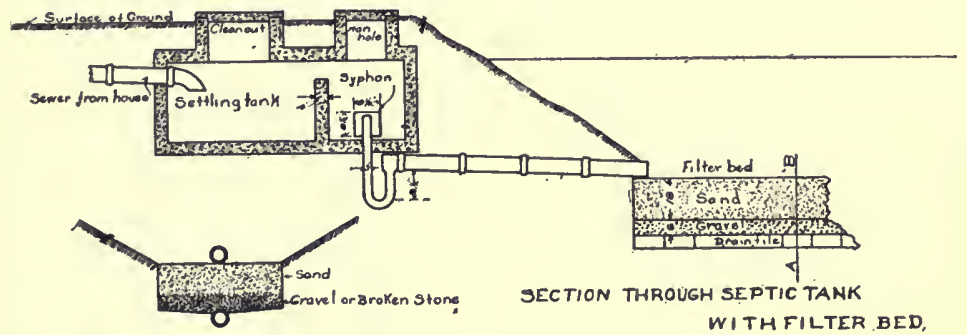

some time, it is purified by bacterial action. There is one kind of bacteria which attacks the solids of the sewage and causes them to decay if the sewage is allowed to remain in a quiet dark reservoir for a short time. This action causes the sewage to clarify and the insoluble parts to settle to the bottom of the tank. The purified sewage may be led anywhere to water a garden or a field without any danger of contamination. The flow of the sewage into the septic tank, the name given to the reservoir, should be as quiet as possible so as not to disturb the bacterial action. For this reason, low partitions are placed across the tank, over which the sewage must pass in a thin stream.

The Filter Bed System.-The bacterial action may be accomplished in another way by allowing the sewage after settling in a tank to be discharged at inter- 
vals on a filter bed of gravel. In this case, a variety of bacteria requiring air purifies the sewage by oxidation. The settling tank for the aver-

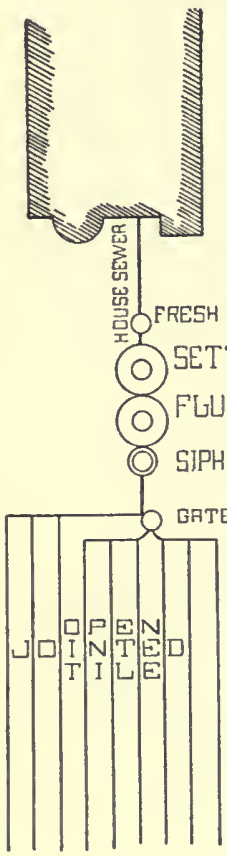

HOW THE SEWAGE MAY BE TAKEN CARE OF AFTER PASSING TH ROUGH A SEPTIC TANK. age family should hold I 25 to 200 gallons. Due provision should be made for removing the solids which settle in the tank at least once in two years. The filter bed should be about three feet wide and twenty feet long. It is made up of sand and gravel of a depth of about two feet. At the bottom of the bed is a drain tile to care for the purified sewage. With this system, a syphon is necessary to discharge the sewage on the bed at intervals, otherwise the bacteria would be drowned. A sewage disposal plant can best be made of concrete in which case an average cost at this time would be about $\$ 60$. The settling tank may be made of three barrels placed end to end, in which case the cost may be reduced to $\$ 25$.

The latter system on account of the syphon is more complicated, and has not in all cases proven satisfactory for private systems, although it has been eminently successful for towns and small cities. In any case it should be remembered that a sewage disposal plant must have some care and attention if it is to give the best results.

Note: Typhoid fever is often caused by drinking water, which is contaminated by seepage from the outbuildings. In every community where typhoid fever prevails an investigation of the sewage disposal should be made. 


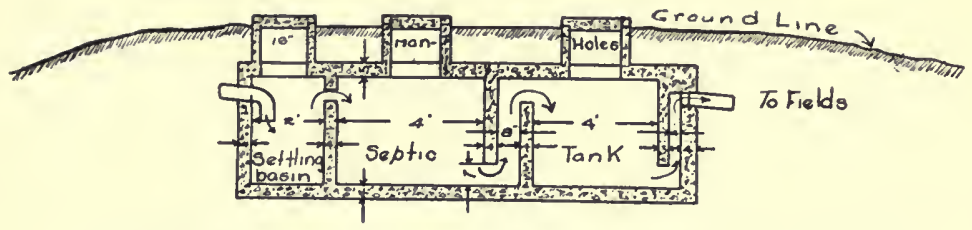

\title{
SEWAGE DISPOSAL PLANT FOR FARM HOME
}

Exercise.-Write a description of the methods of sewage disposal in use in the community. Give your views on how these systems of sewage disposal can be improved. How many farmers use the sewage as fertilizer? How far is the well at your home from the outbuildings? Does the land slope from the outbuildings towards the well? Is there any chance of contaminating the well water by seepage from the outbuildings?

\section{Section LXXVII.-Earth Roads.}

\author{
By Prof. J. B. Davidson,
}

Department of Agricultural Engineering, Iowa State College.

\section{INTRODUCTION.}

It is doubtful if there is another factor which has as great an influence upon the betterment of rural life as good roads. Good roads have two important functions; first, to facilitate travel and make it a pleasure, and second, to reduce the cost of the transportation of farm and manufactured products over them. The cost of the transportation of one ton one mile over a railroad, which represents the highest type of a road, is from one-tenth to one-twenty-fifth of what it costs over an average country road. The total cost of transporting twelve of the principal farm products to market in 1905 has been estimated at $\$ 73,000$,ooo, about 5.2 per cent. of the value of these crops.* Better roads which would reduce the cost of

* Bu1. 49-Bureau of Statistics-Cost of Hauling Crops from Farms to Shipping Points. 
transportation, even but a small per cent., would result in a large saving to the country.

By far the largest portion of the roads of the United States are earth roads aggregating about 2,000,00o miles.* It is thought that it will be many years before even a small proportion of these roads can be improved by surfacing with some other material suitable for road building. For this reason, the subject of earth road construction and maintenance is of great importance to all interested in rural development.

\section{Earth Road Construction.}

The subject of earth roads readily divides itself into two main divisions: first, earth road construction - the building or making of the roads, and second, earth road maintenance - the care of the road after it is made. The ideal road of any material is constructed and maintained so as to be as hard, level and smooth as possible. An earth road is best when it is made to comply with these requirements. Water, either directly or indirectly, is the most destructive agent of earth roads, and their construction consists primarily in excluding the water from the road or, in other words, providing drainage.

The Crown.-If water is allowed to remain on the surface of an earth road, it softens the surface and destroys that fundamental characteristic of a good road, its hardness or firmness. If the surface of a road is earth, it will absorb the water that comes to it in the form of rain or snow, and will be converted into mud unless the water is shed to each side as soon as possible. The slope or oval shape given to a road for this purpose is called the crown. The slope of the crown must not be too steep to make it dangerous for vehicles to pass, but it should be steep enough to shed the water as quickly as possible. The usual

* Farmers' Bul. 32I-U. S. Department of Agriculture. 
Crownefporfon

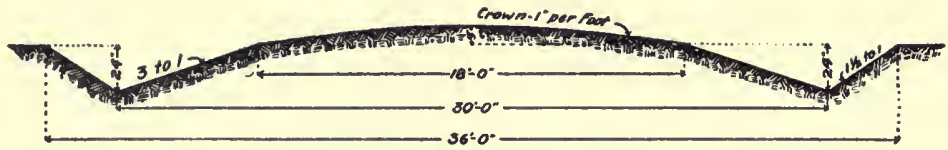

FIDST CLASB

Section in Cur

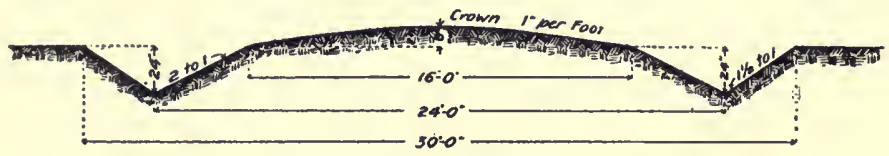

SECOMO CLASS

Section in Cut

STANDARD CROSS-SECTIONS FOR EARTH ROADS. IOWA HIGHWAX COMMISSION.

amount of the slope amounts to about one inch raise to one foot of width of the roadway. The accompanying figure shows standard cross-sections for earth roads in Iowa, and the lower figure shows a recently constructed road with a standard cross-section. This cross-section is such that it can be readily built with a

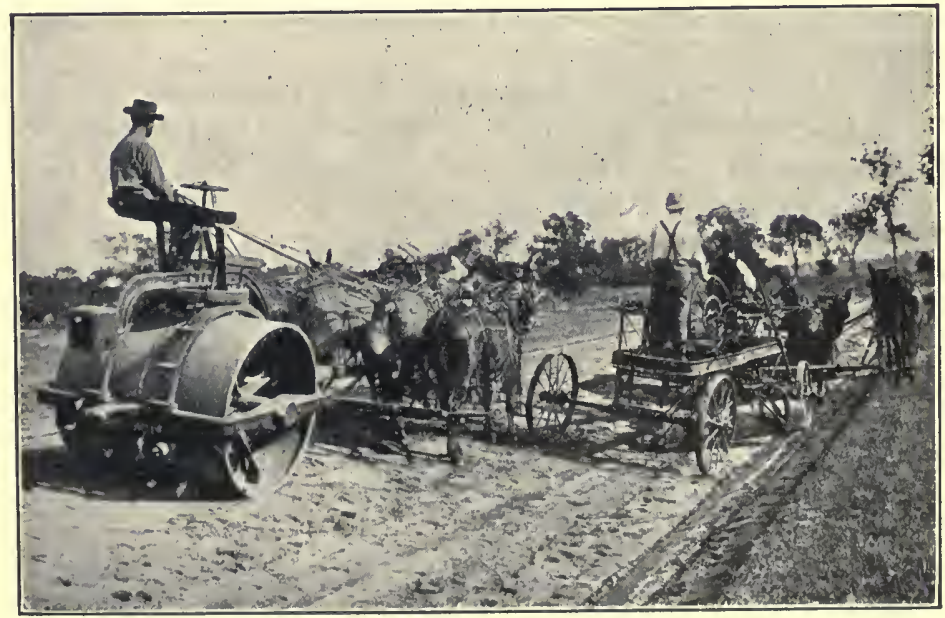

A ROAD BUILT TO STANDARD, THE ROAD ROLLER AND SCRAPING GRADER AT WORK. 
scraping grader as shown in the figure, which makes the cost of construction low. To make a road more nearly level, hills must be cut down and hollows filled by means of machines designed to carry earth for some distance. After a road has been formed, it is desirable that the crown be made as firm as possible with a heavy roller, but the travel may be depended upon to do this work.

Side Ditches.-After the water is shed from off the crown, it is necessary to have side ditches to carry the water along the road to points where it may be turned into natural water courses. These ditches should be of a form which may be easily constructed at a low cost, and they should be ample in size to carry away the water after a heavy rainfall. They should not be so deep as to be dangerous should a vehicle be driven into them, and their form should be such as to permit them to be easily cleaned. The side ditches will fulfil in a large measure all of these requirements. The side ditches should be provided with a uniform slope to a good outlet. It is rarely possible for a good road to exist where water stands in ponds in the side ditches.

Underdrainage.-Ground water must not stand within three or four feet of the road surface, or it will pass to the surface by capillary action, and not only soften the foundation, but the road proper. No road material will sustain a heavy load unless the foundation on which it rests is firm and solid. Earth will not make a good foundation if saturated with water. Not only will the water soften the road and its foundation, but in climates where the ground is frozen during the winter seasons the action of frost is very destructive where water is present, due to its heaving action or expansion upon freezing.

Most earth roads are provided with natural underdrainage; that is, the ground water does not lie within three or four feet of the surface. But where natural underdrainage does not exist, artificial underdrainage 
must be provided. This consists in placing one or more lines of drain tile under the road. Opinions differ in regard to the exact location of the tile, but that is more or less immaterial so long as the ground water is removed. In laying tile the principal points to be considered are, that sufficient fall be allowed to provide good drainage and prevent filling with silt, and to have the outlet above standing water.

\section{Road Maintenance.}

The Road Drag.-After the earth road is properly constructed, it should then be maintained so as to retain as far as possible

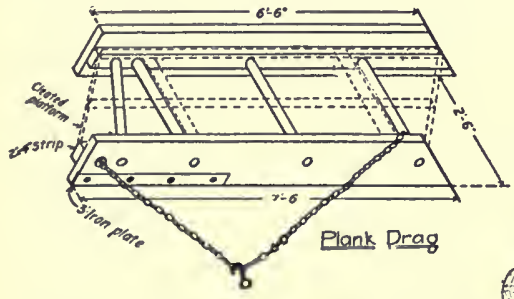
its original form. To do this work the best implement now known is the road drag, two forms of which are shown. These road

drags consist of two planks or the two halves of a $\log$ made into a drag, as shown, and which is drawn along the road so that the planks make an angle with the direc-

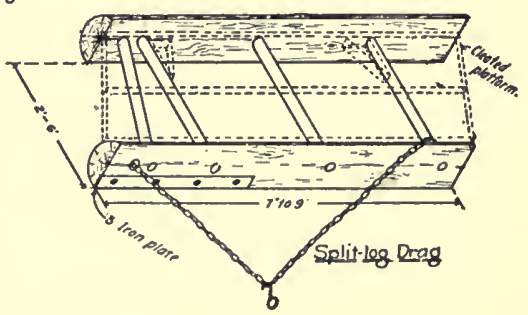

TWO COMMON FORMS OF ROAD DRAG. tion of motion, and tends to draw the earth toward the center, maintaining the original cross-section which is worn away by travel. The action of the drag is to keep the surface of the road oval and smooth that water cannot remain on the surface and soften it. The best time to use the drag is following a rain after the surface has dried until the earth can be moved in front of the drag. The continued use of the drag 


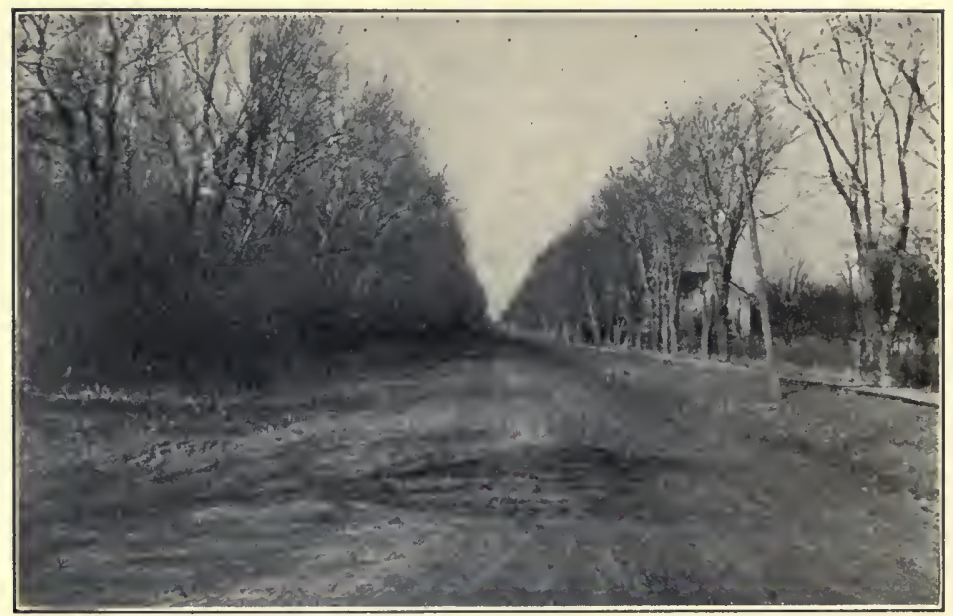

AN EARTH ROAD MAINTAINED WITH A ROAD DRAG.

and the action of travel distributed over the crown in time make a very satisfactory road. The figure shows a road maintained by the road drag and shows the road at a time of the year when roads are generally bad.

EXERCISE.- State the annual appropriation made in your county the past year for the maintenance of good roads. How do poor roads affect agriculture?

\section{Section LXXVIII.-The Country Home.}

By J. E. Halligan,

Chemist in Charge, Lotisiana State Experiment Station.

The House.-A well natural-drained spot should be selected for the site of the house, somewhat above the level of the surrounding ground so that rain water will not accumulate about the premises.

The house should be substantially built. It is not necessary to have an expensive house, but it should be large enough to furnish ample room for the needs 
of the family. Covered galleries or porches are very attractive and convenient for the comfort of the home. A country house should not always be patterned after a city house. In the city, land is high-priced and scarce, and often a house must be constructed to occupy a limited space. Such a house in the country

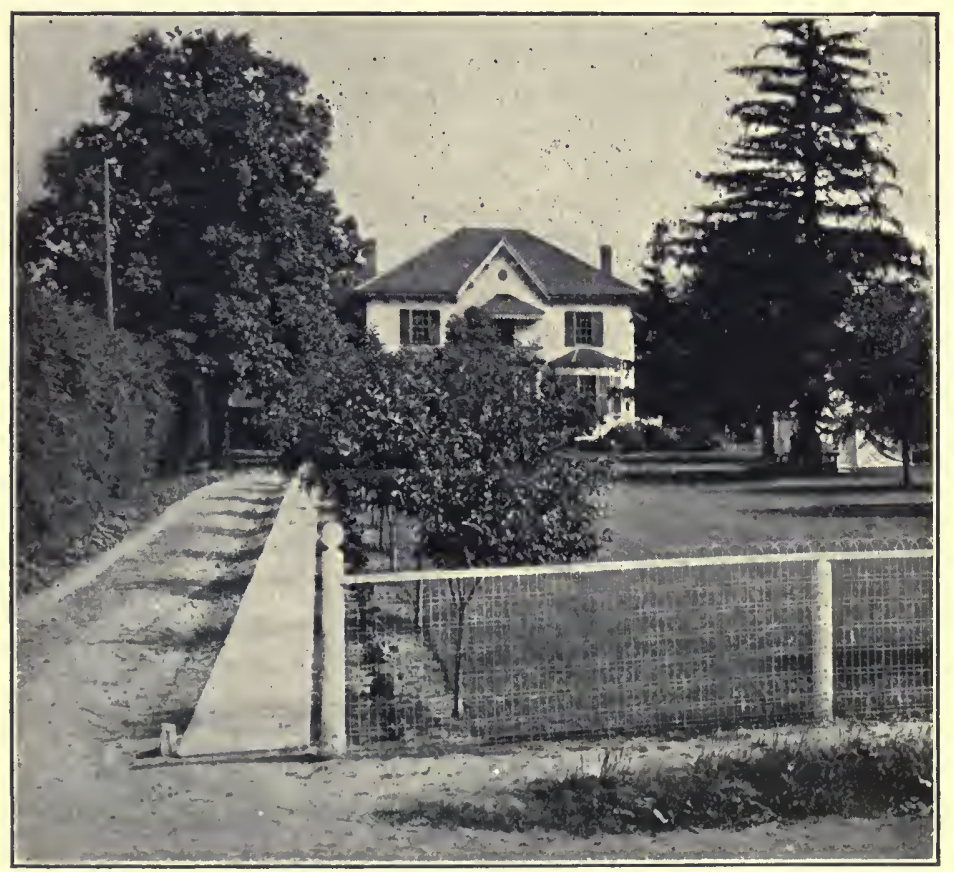

A WELL-KEPT COUNTRY HOME.

would be entirely out of place and unattractive, but it looks very well in the city, for it is bordered on both sides by other houses. Tall narrow houses are unsuitable for the country. A country house should be built along simple and strong lines, and be free from fancy trimmings and odd shapes. It should be kept well painted in moderate colors. 
Ventilation.-It seems almost needless to say that the house should be well aired, yet there are many farm homes where the air and sunshine scarcely ever reach all of the rooms. Fresh air and sunshine are two things every farmer can enjoy in his home, and every room in the house should be thoroughly aired and penetrated by sunlight every day. In sleeping rooms the windows should be left open day and night. During severe cold or stormy weather at least one window should be left open for every two occupants.

Water Supply. - An abundant supply of pure water is essential in every farm house. In many sections the drinking water is not fit for use. Many country people become troubled with stomach disorders and other sickness because of impure water. If well water is used, the well should be placed far enough from the house and outbuildings to prevent any seepage into it. It should be covered with cement to prevent contamination. The water may be pumped from the well or spring into a large elevated storage tank by the aid of a windmill for use in the house.

As soon as the farmer is able, a sink in the kitchen, a bathroom, wash bowl and sanitary closets should be installed. The farm labor may be used to do this work, and if the services of a plumber a re needed only a little of the inside work will be necessary to hire done. A good waterworks system for a country home may be installed for $\$ 200$ to $\$ 300$.

Conveniences. - The house should be substantially furnished with good, strong, plain, comfortable furniture. Expensive furniture is not necessary in a country home. An acetylene lighting system is a great comfort. The principal cost of this system of lighting is in the installation. It costs about $\$ 200$ to put in an acetylene plant. The cost of maintenance is about equal to that of coal oil lamps.

If the farmer can afford it, a furnace will be found very convenient to heat the house. The cost of putting in a furnace varies from $\$ 300$ to $\$ 400$. If the work is 
done by farm labor the expense is much less. In a large house the cost of maintaining a furnace is less than for stoves or fireplaces. A hot water system may be installed by connecting coils with the furnace or kitchen stove so that hot water can easily be obtained and supplied to the kitchen and bathroom.

There is no reason why a farmer should not supply his home with the leading farm papers, magazines, a good daily paper, rural books and a few instructive books for the children, as nowadays the rural free delivery reaches most farm homes every day.

The telephone is another convenience many farmers can afford. It enables the family to communicate with the neighbors and keep in touch with the outside world.

The house should be well screened to keep out flies and mosquitoes.

Comforts for the Children.-The children's comfort should be considered. Hammocks and swings placed in shady convenient places will afford much amusement for the children. A good shepherd or collie dog and a cat are excellent companions for the younger folks, and they generally earn their keep. A properly trained dog is a valuable asset on every farm. Bird houses are a means of attracting valuable birds to the farm, and serve as ornaments and help to keep down injurious insects.

The mother should have a knowledge of food, and the functions of the nutrients so as to nourish properly the growing children. Many children do not get the proper start in life, because of inferior or unbalanced food, and they are permanently injured for future development.

The Dooryard should be simple and kept clean. Rubbish of all kinds should be dispensed with. A plain lawn with shrubbery in the corners, screens of vines to hide the unsightly places, and flower beds in nooks near the house or against the fence are desirable in the dooryard. A grass lawn should predominate 
and the trees, shrubs, vines and flower beds should be used to fill in. Many people make the mistake of overcrowding their dooryards with flowers and shrubbery, and cause the place to appear unattractive. It is easier to keep a grass lawn in good condition than an earth yard, and it is indeed much more attractive. On the porches or galleries of the house some vines may be grown to furnish shade, and thus serve to make a sitting room during summer afternoons.

The Home Garden.-There is no excuse for any farmer buying vegetables and fruits that he can raise at home. A small garden planted with vegetables, fruits and vines that will grow in the locality should be well cared for to supply the home table. Enough should be raised so that they may be preserved for winter consumption.

Organization.-The farmers, their wives and grown-up children in every community should meet for their individual and community improvement. In other words, they should form organizations which should consider amusements, improvements of schools, churches, roads, marketing of farm products, and the many other problems that confront the farmer and his family. These organizations may often obtain some lecturer to discuss some particular phase of farming they are interested in, from the State Agricultural College.

\section{Section LXXIX.-Truck Gardening.}

By Prof. G. L. Tiebout,

Department of Horticulture, Louisiana State University.

There is no branch of horticulture, or even of agriculture, that has received more attention, especially in the South, during the last few years, than truck gardening. As the great railway systems are extending their North and South Trunk Lines, vast areas with soils and climate well adapted to this industry, are be- 
ing opened up. Very often where general farming was only possible before the advent of good transportation facilities, truck gardening is now receiving attention. There was a time when the large cities of the North, East and West had to do without the fresh, tender vegetables during the cold winters. To-day the fast freight and express trains bring vegetables from the far South to these cities in good condition.

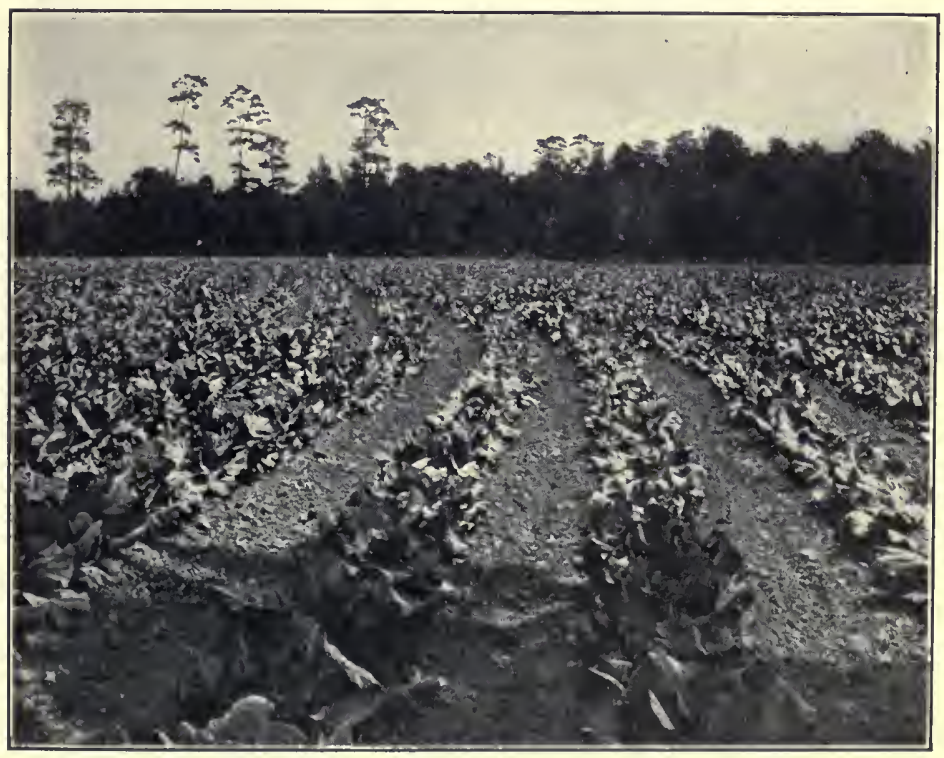

A WELL-CULTIVATED TRUCK PATCH.

Classes of Truck Crops.-Truck gardening is the most intensive form of farming. The crops produced are, as a rule, quite perishable. Truck crops may be divided into two classes: the more staple or less perishable, such as onions, cabbage and Irish potatoes, and the perishable as lettuce, tomatoes, snap beans, cucumbers, eggplants, cauliflower, radishes, beets, etc.

Staple Crops.-The staple truck crops do not re- 


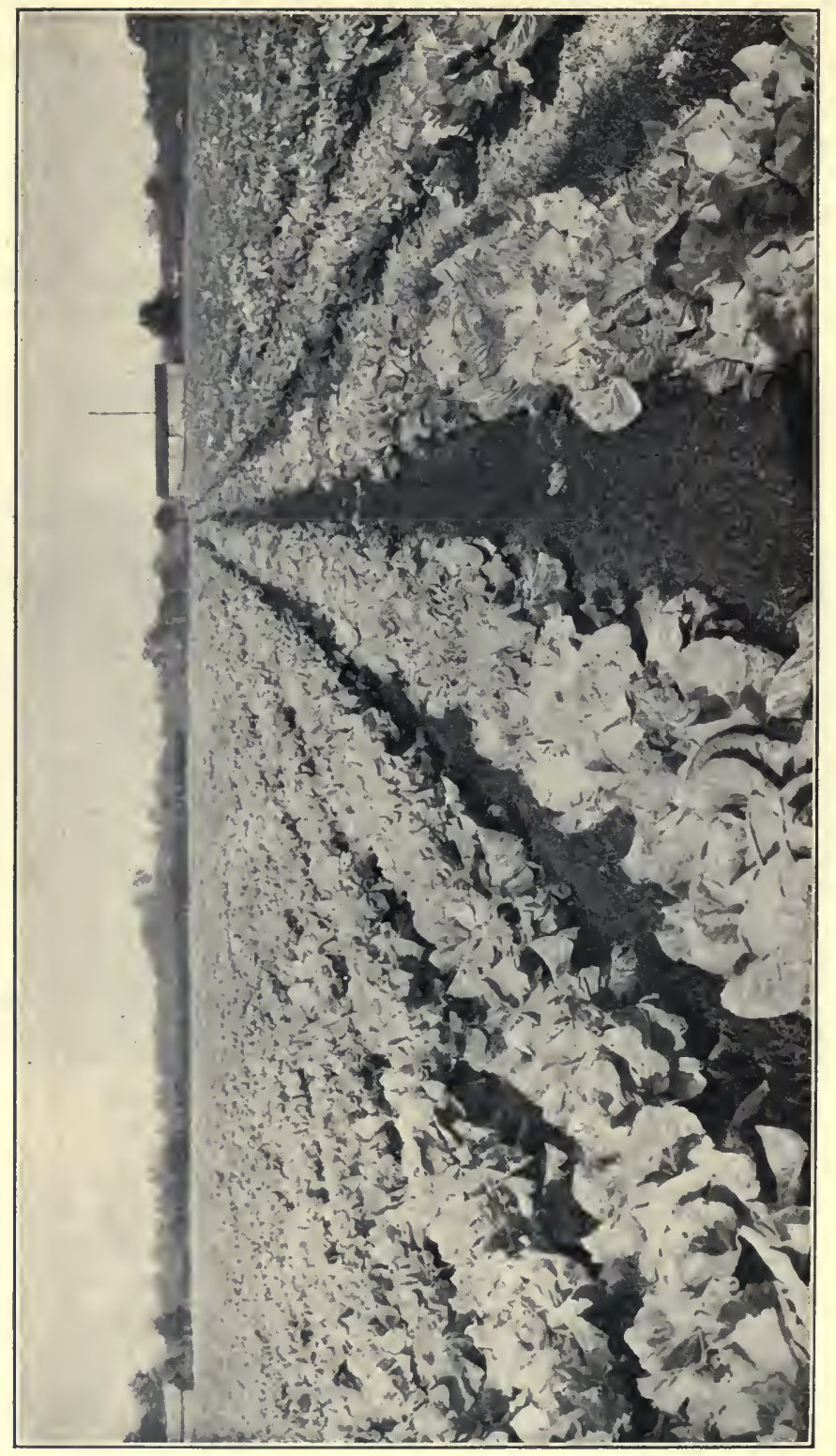

留 
quire much equipment. They are easier grown, shipped in open ventilated cars, and are not so liable to sudden market fluctuations.

Perishable Crops.-These generally demand expensive equipment, such as coldframes and hotbeds, and special care must be exercised until they are disposed of. They have to be packed in small packages, shipped in refrigerator cars, and are more subject to market fluctuations.

Kind of Soil.-Vegetables will grow on almost any type of soil, but when one wishes to make a business of raising very early vegetables in large quantities for shipment to distant markets, a favorable soil and climate must be obtained. A well-drained, sandy loam, which warms up early in the spring, is desirable. Such a soil should be in a good mechanical condition to permit of feeding the plants to the best advantage.

Fertilizers.-Humus or decayed animal or vegetable matter, and quickly available commercial fertilizers are favorable for these crops.

Climate.-The climate determines the season in which the particular truck crops can be grown. The mild winters of southern Florida will permit the growing of tender crops, such as tomatoes, eggplants, etc., which could not be planted in the far North until late spring.

Natural Protection is Favorabie.-As the season advances, each truck zone, so to speak, furnishes the sections north of it, until these in turn receive their supply from home-grown products. Certain localities have natural advantages which enable the truckers to market their crops earlier than their competitors in the same latitude. Protection is offered by large bodies of water, rivers, heavy forests and swamps.

Rapid Transportation Necessary.-Rapid transportation must be at hand before truck gardening can possibly exist. Fast freights, express trains, and rapid steamboats are instruments that determine 
where truck shall be grown, the nature of the crops and the profitableness of the undertaking.

Irrigation is playing an important part in the development of the truck industry. The majority of truck crops are not able to withstand any prolonged drought, and when they do, their quality is so impaired as to render them practically worthless. Irrigation, therefore, often results in the saving of the crop, and in many instances appreciably increases the profits. If the drought is general, the supply is greatly reduced and prices correspondingly increased.

Systems of Irrigation.-The two principal systems of irrigation employed are the furrow and overhead. In the furrow system the water is applied in the furrows between the rows of vegetables. In the overhead system, the plants are sprinkled from a system of perforated pipes which are supported on posts high enough to permit horse or man to pass under them with ease when cultivating. This latter system approaches nature's method of watering plants and is becoming popular where very intensive culture is practiced.

Begin on a Small Scale.-When the trucker has chosen a favorable spot he must study the culture of the various crops he wishes to raise. If he has been a general farmer he will naturally look to the more staple truck crops in beginning. For these he will have most of the necessary equipment, and he should begin on a small scale until he masters the details in the management of a certain crop or crops, when he will be in a position to enlarge operations.

Diversification should be practiced in truck farming as well as in general farming. By raising several crops which mature at different seasons, the trucker will be able to give his hired hands continuous labor. $\mathrm{He}$ will be in a position to devote more attention to each crop, and, as a rule, under such management all of his crops will not fail, or bring poor returns, no matter how bad the season may be. Suppose the 
trucker raises only one crop, invests heavily and some natural calamity, such as an unexpected freeze or hail comes and destroys it; or still worse, after the crop has been raised, packed and shipped it arrives on a glutted market, and does not sell for freight charges.

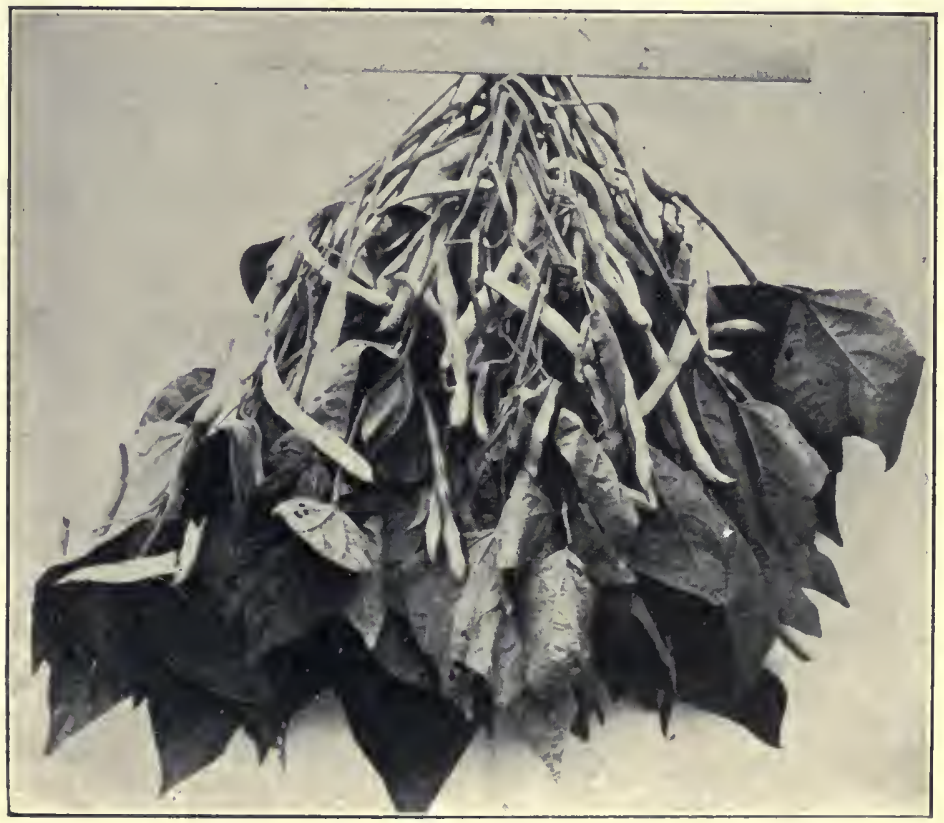

WAX BEANS.

Southern Conditions.-In the far South the truck farmer does not need so much equipment in the way of hotbeds, coldframes and greenhouses as the northern growers. Neither is it necessary to make his operations so intensive. After the truck crops are off in the early spring or summer, some of the staple crops, such as corn, cowpeas, sweet potatoes, etc., can be grown as feed for the live-stock.

What Crops to Raise.-Years ago when competition was not great the problem that confronted the 


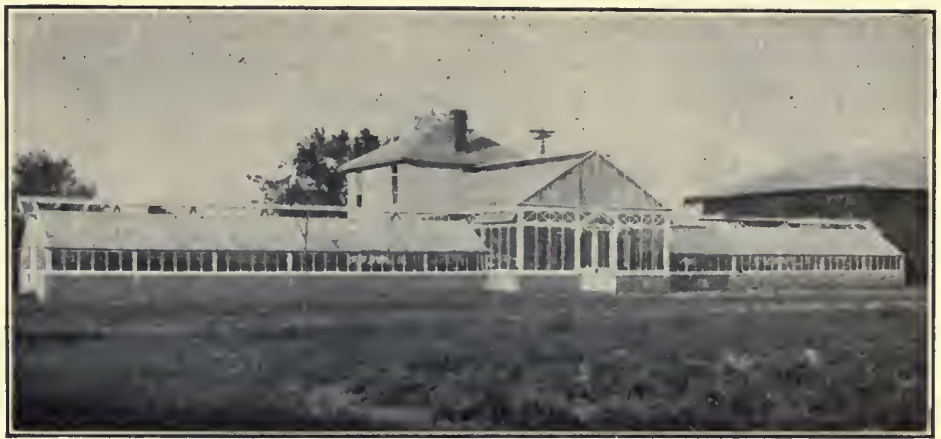

A MODERN GREENHOUSE.

grower was how to raise a particular vegetable. Today the question is, how to grade, pack, ship, and sell the product. Of course the grower who has mastered the art of raising vegetables can often rise above his competitors, especially so with novelties. The cultural methods of the more staple crops are so generally understood and literature is so abundant, that the expert grower does not have the opportunity he formerly had. To-day the expert seller holds the important position.

Associations. - It would be hard for each individual grower to attend to both the growing and the marketing of his crops. Where truck growing is most successful, the truckers organize and form associations. Each association employs a competent sales manager to properly attend to the shipping and selling of the members' products.

Shipping and Selling.-Grades, on the different crops, are established and not more than one grade is loaded in the same car. This is necessary in order to demand a good price for shipments. In season, buyers from the large cities come to the shipping points and purchase the produce, the cars generally being sold at auction to the highest bidder. In order that the association manager may be reliably informed as 
to market conditions, the associations generally have representatives located in all the large markets, whose duty it is to telegraph daily or oftener as to the supply, the prevailing prices and other conditions of importance. In this way the association manager is in a position to receive bids to the best advantage of the growers.

Crops are not Always Sold at Shipping Point.-An association is not always able to sell its produce at the

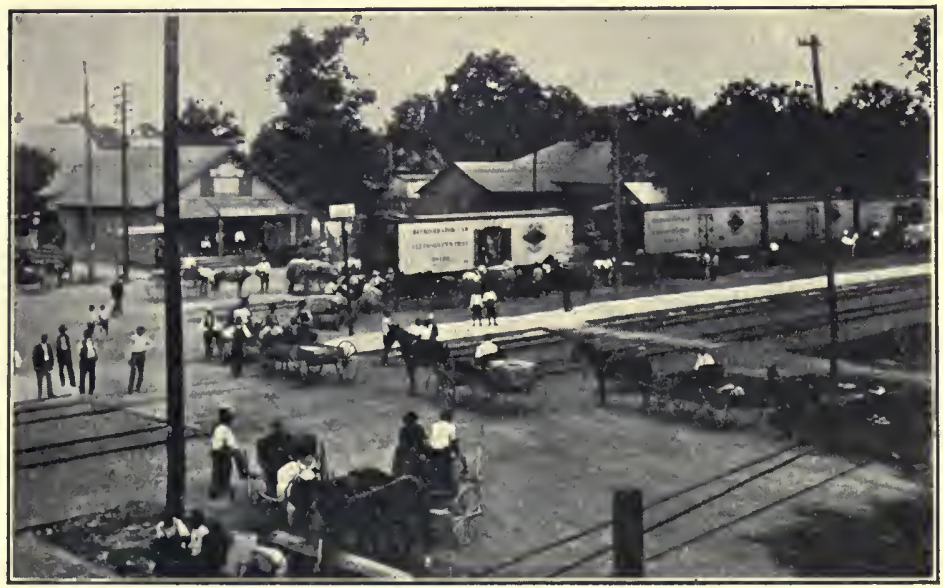

A SHipping scene.

shipping point; especially is this true when there is overproduction, or the crops are very perishable. Under these conditions it is necessary to consign the shipments to a reliable commission house, or sell the output through a representative of the association at the marketing point. Even if these less desirable methods of disposition are necessary, the association through its sales manager will be in a position to distribute its products intelligently and avoid glutted markets.

Other Advantages of Organization.-There are many other advantages of truck organizations, such 
as co-operative buying of shipping packages, fertilizers, seeds, implements, etc.; better recognition by the railroads, express companies, and other corporations with which the trucker deals; more power in the courts and in legislation for the control of rates, time schedules and car service.

Kind of Packages.-Incident with the development of modern truck growing has arisen the demand for vegetables packed in small packages, the size being in proportion to the bulkiness of the crop or the demand of an average family. This is the day of small, gift packages, and the trend of the times is certainly being felt in the truck business. Each shipping section usually has its own particular styles of packages. This gives rise to an innumerable variety. The time will come, however, when a uniform standard package will be demanded by the consuming public.

EXERCISE.-Make a list of the truck crops that may be grown in your section. Classify them as to perishability. State when the truck crops are grown and the length of the growing season. Are the soils, climate and transportation facilities favorable? Is irrigation practiced? Are the growers organized; if so what is the membership of the association?

REFERENCES FOR COLLATERAL READING.

\section{Miscellaneous.}

Farm Management:

Yearbooks of the U. S. Dept. of Agriculture: I908-Types of farming in the United States. 1908-Wastes of the farm.

1908-Causes of Southern rural conditions and the small farm as an important remedy.

Forest Service, U. S. Dept. of Agriculture, Circular, No. :

I59-The future use of land in the United States.

Farmers' Bulletins, Nos. :

62-Marketing farm produce.

I26-Practical suggestions for farm buildings.

242-An example of modern farming.

272-A successful hog and seed corn farm.

280-A profitable tenant dairy farm.

3ro-A successful Alabama diversified farm.

312-A successful Southern hay farm.

325-Small farms in the corn belt.

326 - Building up a run-down cotton plantation.

327 -The conservation of natural resources. 
337-Cropping systems for New England dairy farms.

340-Declaration of governors for conservation of natural resources.

$357-$ Methods of poultry management.

362 -Conditions affecting the value of market hay.

364 -A profitable cotton farm.

FARM MACHINERY :

$370-$ Replanning a farm for profit.

Farmers' Bulletins, Nos. :

277-The use of alcohol and gasoline in farm engines.

303-Corn harvesting machinery.

347-Repair of farm equipment.

The Disposal of Sewage on the Farm:

Farmers' Bulletin, No.:

ROADS :

270-Modern conveniences for the farm home.

Yearbooks of the U. S. Dept. of Agriculture :

I897-Object lesson roads.

I90I-Road building with convict labor in the Southern

States.

1904-Practical road building in Tennessee.

Farmers' Bulletins, Nos. :

79 - Testing of road materials.

95-Goods roads for farmers.

I36-Earth roads.

$32 \mathrm{I}$ - The use of split-log drag on earth roads.

338-Macadam roads.

Office of Public Roads, U. S. Dept. of Agriculture, Bulletins Nos. :

24-Proceedings of the North Carolina good roads convention.

29-The construction of macadam roads.

Missouri State Board of Agriculture, Columbia, Mo., Bulletins, Nos.:

I-Vol. 3-Road dragging.

Io-Vol. I-Road Improvement.

The Country Home:

Yearbook of the U. S. Dept. of Agriculture:

I902-Plants as a factor in home adornment.

Farmers' Bulletins, Nos. :

185-Beautifying the home grounds.

248-The lawn.

270-Modern conveniences for the farm home.

342-A model kitchen.

375-Care of food in the home.

Office of Experiment Stations, U. S. Dept. of Agriculture, Circular No. :

84-Education for country life.

Truck Gardening:

Farmers' Bulletins, Nos. :

35-1 49-244-365-Potato.

$6 \mathrm{I}-84-23,3-259-$ Asparagus.

62-Marketing farm produce. 
I05-289-Beans.

133-169-282-Celery.

176-178-221-Cranberries.

I8I-Pruning.

I86-220-225-296-Tomatoes.

198-2 ro-Strawberries.

203-Canned fruits, preserves and jellies.

208 -Varieties of fruits recommended for planting.

2 ro-Effect of shading vegetables.

231-Spraying for cucumber and melon diseases.

232 -Okra; its culture and uses.

233-354-Onion culture.

254-Cucumbers.

295-Potatoes and other root crops.

324-Sweet potatoes.

359 - Canning vegetables at home.

Books :

Farm Management-Card-Doubleday, Page \& Co., New York City.

The Farmstead-Roberts-The Macmillan Co., New York City. How to Choose a Farm-Hunt-The Macmillan Co., New York City.

The Farmers' Business Hand Book-Roberts-The Macmillan Co., New York City.

The State and The Farmer-Bailey-The Macmillan Co., New York City.

Farm Machinery and Farm Motors-Davidson \& Chase-Orange Judd Co., New York City.

Chapters in Rural Progress-Butterfield-Univ. of Chicago Press, Chicago.

One Woman's Work for Farm Women-Buell-Whitcomb \& Barrows, Boston.

Principles of Vegetable Gardening-Bailey-The Macmillan Co., New York City. 


\section{APPENDIX,}

\section{SUGGESTIONS FOR AN AGRICULTURAL SCHOOL LIBRARY.}

\section{Table I.}

Every school should endeavor to build up a good library so that the students may have reference to the literature on the several agricultural subjects. A great deal of valuable literature may be secured, free of charge, from the United States Department of Agriculture, State Experiment Stations and State Boards of Agriculture.

A complete list of Farmers' Bulletins should be obtained. These may be had by writing to the Secretary of Agriculture, Washington, D. C., or through your congressman. Ask for Farmers' Bulletin, Circular No. 670, which gives a complete list of the available bulletins, and for Circular No. 4, which contains an index of the subjects. Have your name entered on the mailing list to receive the future publications.

Write to the State Experiment Stations of your section for their available bulletins, and ask to have your name placed on their mailing lists.

For publications of your State Board of Agriculture address your communication to the state capital.

A complete set of the Yearbooks of the United States Department of Agriculture should be in your library. For these publications write to the Secretary of Agriculture, or apply for them through your congressman. 
The Cornell University, and the Ohio State University, Nature Study Leaflets are valuable.

All of the above institutions will be glad to serve you. When you are teaching a subject which is of especial interest in your section you should try to obtain bulletins on these subjects for the pupils' use. Copies of Farmers' Bulletins and Experiment Station Bulletins may readily be obtained provided they are not out of print.

The United States Department of Agriculture is made up of many bureaus, all of which publish interesting and valuable farm literature. These publications may be had through your congressman or from the Secretary of Agriculture, Washington, D. C. A few of these bureaus are:

$\begin{array}{ll}\text { Bureau of Animal Industry } & \text { Bureau of Plant Industry } \\ \text { Bureau of Chemistry } & \text { Bureau of Statistics } \\ \text { Bureau of Entomology } & \text { Bureau of Soils } \\ \text { Bureau of Biological Survey } & \text { Weather Bureau } \\ \text { Forest Service } & \text { Division of Publications } \\ \text { Office of Experiment Stations } & \text { Office of Public Road Inquiries }\end{array}$

A few of the leading farm papers should be received regularly.

The following list is recommended. A few papers should be selected which are best suited for the section.

For the New England States and the Middle East:

Rural New Yorker-New York City-Weekly-\$I.00 per year.

Country Gentleman-Albany, N. Y.-Weekly-\$I.50 per year.

American Agriculturist-New York City-Weekly - \$I.oo per year.

New England Homestead-Springfield, Mass.-Weekly-\$I.oo per yr.

For the South Atlantic States:

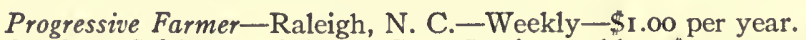

Southern Cultivator-Atlanta, Ga.-Semi-monthly - \$1.0o per year.

\section{For the Gulf States:}

Southern Cultivator-Atlanta, Ga.-Semi-monthly-\$1.oo per year.

Progressive Farmer and Southern Farm Gazette-Starkville, Miss.Weekly-\$1.0o per year.

Rice Journal and Southern Farmer-Crowley. La.-Monthly-\$1.oo per year.

For Texas and the Southwest:

Farm and Ranch-Dallas, Tex.-Weekly-\$1.00 per year. 


\section{For Upper Mississippi Valley:}

Homestead-Des Moines, Iowa -Weekly $-\$ 1.00$ per year.

Wallace's Farmer-Des Moines, Iowa-Weekly-\$1.oo per year.

For the Northwest:

Northwest Pacific Farmer-Portland, Oregon-Weekly- \$1.oo per yr.

Field and Farm-Denver, Colo.-Weekly- $\$ 2.00$ per year.

For Breeders and Dairymen in any Section:

Breeder's Gazette-Chicago, Ill.-Weekly - \$1.75 per year.

Hoard's Dairyman - Fort Atkinson, Wis. -Weekly- $\$$ I.0o per year.

For Poultrymen:

Reliable Poultry Journal-Quincy, Ill.-Monthly-\$0.50 per year.

The following list of books should be in every school library. If the funds will not permit of the purchase of all these books, those books which cover the subjects of most importance in your community should be given preference:

Published by the Macmillan Co., New York City:

Bailey-Cyclopedia of American Agriculture............\$20.00

Vol. 1 -Farms, Climates and Soils.

Vol. 2-Farm Crops.

Vol. 3-Farm Animals.

Vol. 4-The Farm and the Community.

Bailey-Plant Breeding.................... $\quad$.00

Bailey-The Principles of Vegetable Gardening ......... I.25

Bailey - The Principles of Fruit Growing............ 1.50

Hunt-How to Choose a Farm................. 1.75

Jordan-The Feeding of Animals (difficult) ........... I.50

King - The Soil (difficult) .................... 1.50

Lipman-Bacteria in Relation to Country Life.......... 1.50

Roberts-The Farmstead.................... I.50

Roberts-The Farmers' Business Hand Book........... 1.25

Roberts-The Horse....................... I.25

Snyder-Chemistry of Plant and Animal Life........... I.25

Snyder-Human Foods.................... I.25

Snyder-Soils and Fertilizers.................... I.25

Voorhees-Fertilizers...................... I.25

Watson-Farm Poultry..................... 1.25

Wing-Milk and Its Products......................

Published by Doubleday, Page \& Co., New York City:

Card-Farm Management....................... 2.00

Comstock-How to Keep Bees...................

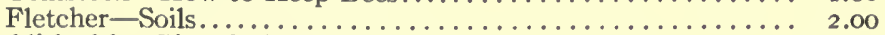

Published by Ginn \& Co., Boston, Mass.:

Conn-Bacteria, Yeasts and Molds in the Home......... I.20

Davenport-The Principles of Breeding (difficult)......... 2.50

Duggar-Fungus Diseases of Plants............... 2.00

Plumb-Types and Breeds of Farm Animals........... 2.00 
Published by Orange Judd Co., New York City.:

Davidson \& Chase-Farm Machinery and Farm Motors.... 2. 2.00

Fraser-The Potato......................... .75

Hunt-Cereals in America..................... I.75

Hunt-Forage and Fiber Crops in America........... 1.75

Waugh-The American Apple Orchard.............. I.oo

Published by W. A. Henry, Madison, Wis.:

Henry-Feeds and Feeding.................. 2.00

Published by Houghton, Mifflin \& Co., New York City:

Sargent-Corn Plants........................... ${ }_{.75}$

Published by Mendota Pub. Co., Madison, Wis.:

Farrington and Woll-Testing Milk and Its Products....... I.oo

Published by Longmans, Green \& Co., New York City:

Weathers-School, Cottage and Allotment Gardening....... I.00 Published by A. I. Root Pub. Co., Medina, Ohio:

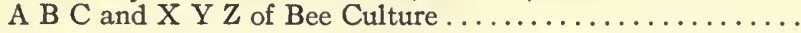

\section{Table 2.}

\section{THE STATE AGRICULTURAL EXPERIMENT STATIONS.}

Alabama-

College Station: Auburn

Canebrake Station: Uniontown

Tuskegee: Tuskegee

Arizona-Tucson

Arkansas-Fayetteville

California-Berkeley

Colorado-Fort Collins

Connecticut-

State Station: New Haven

Storrs Station: Storrs

Delaware-Newark

Florida-Gainesville

Georgia-Experiment

Idaho-Moscow

Illinois-Urbana

Indiana-Lafayette

Iowa-Ames

Kansas-Manhattan

Kentucky-Lexington

Louisiana-

State Station: Baton Rouge

Sugar Station: Audubon Park, N. $O$.

North La. Station: Calhoun

Rice Station: Crowley

Maine-Orono

Maryland-College Park

Massachusetts-A mherst

Michigan-East Lansing

Minnesota-St. Anthony Park, St. Paul

Mississippi-Agricultural College
Missouri-

College Station: Columbia

Fruit Station: Mountain Grove

Montana-Bozeman

Nebraska-Lincoln

Nevada-Reno

New Hampshire-Durham

New Jersey-New Brunswick

New Mexico-Agricultural College

New York-

State Station: Geneva

Cornell Station: Ithaca

North Carolina-

College Station: West Raleigh

State Station: Raleigh

North Dakota-Agricultural Col.

Ohio-Wooster

Oklahoma-Stillwater

Oregon-Corvallis

Pennsylvania-State College

Rhode Island-Kingston

South Carolina-Clemson College

South Dakota-Brookings

Tennessee-Knoxville

Texas-College Station

Utah-Logan

Vermont-Burlington

Virginia-Blacksburg

Washington-Pullman

West Virginia-Morgantown

Wisconsin-Madison

Wyoming-Laramie 


\section{Table 3.}

\section{STATISTICS ON LIVE-STOCK AND CROPS *}

I. LIVE-STOCK

\begin{tabular}{|c|c|c|c|}
\hline Kind of Live-STock & $\begin{array}{l}\text { Number on } \\
\text { Farms in the } \\
\text { United States } \\
\text { Jan. I, I } 909\end{array}$ & $\begin{array}{c}\text { Average Price } \\
\text { Per Head } \\
\text { Jan. I, I } 909\end{array}$ & $\begin{array}{l}\text { Farm Value } \\
\text { Jan. I, I } 909\end{array}$ \\
\hline Horses. & $20,640,000$ & $\$ 95.64$ & $\$ I, 974$ \\
\hline & & & 2,000 \\
\hline Mil & $2 \mathrm{I}, 7$ & & 45,000 \\
\hline & & 17. & $863,754,00$ \\
\hline & $56,084,0$ & & $192,632,000$ \\
\hline & $54,147,000$ & 6.55 & $354,794,000$ \\
\hline
\end{tabular}

II. Crops

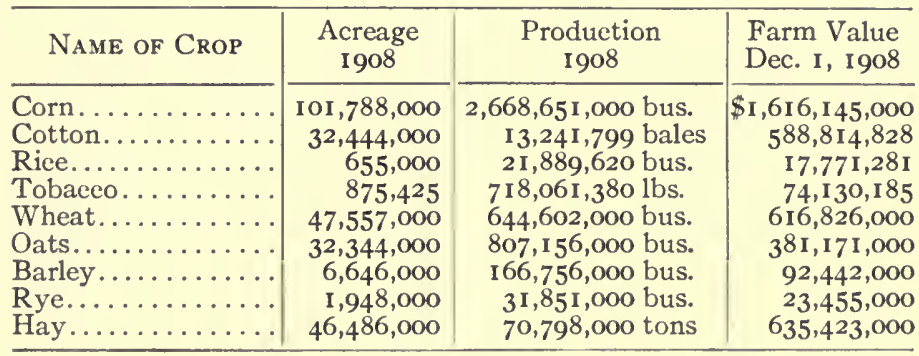

* 1908 Yearbook, U. S. Dept. of Agriculture.

\section{Table 4 .}

AVERAGE LEGAL WEIGHTS PER BUSHEL OF SOME FARM PRODUCTS *

\begin{tabular}{|c|c|c|c|}
\hline $\begin{array}{l}\text { Name of } \\
\text { MATERIAL }\end{array}$ & $\begin{array}{l}\text { Weight in } \\
\text { Pounds }\end{array}$ & Name of Material & $\begin{array}{c}\text { Weight in } \\
\text { Pounds }\end{array}$ \\
\hline Apples .... & 48 & Kentucky blue grass (sced) & I4 \\
\hline Apples (dried) ... & 24 & Millet.............. & $5^{\circ}$ \\
\hline Barley........... & 48 & Oats....... & 32 \\
\hline Beans .......... & 60 & Onions..... & 57 \\
\hline Buckwheat....... & 52 & Peas........... & 60 \\
\hline Carrots........... & 50 & Potatoes (Irish) ... & 60 \\
\hline Clover Seed ...... & 60 & Potatoes (sweet)........ & 55 \\
\hline Corn (ear) ......... & 70 & 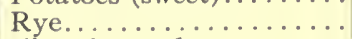 & 56 \\
\hline Corn (shelled) & 56 & Timothy seed........... & 45 \\
\hline Cotton seed ... & 32 & 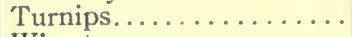 & 55 \\
\hline Flax seed .... & 56 & 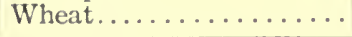 & 60 \\
\hline
\end{tabular}

* Yearbook of the U. S. Dept. of Agriculture. 


\section{Table 5 .}

FERTILIZER CONSTITUENTS IN I,000 POUNDS OF FEED STUFFS *

\begin{tabular}{|c|c|c|c|}
\hline NAME OF FEED & $\begin{array}{l}\text { Nitrogen } \\
\text { in } \\
\text { pounds }\end{array}$ & $\begin{array}{c}\text { Phosphoric } \\
\text { Acid in } \\
\text { pounds }\end{array}$ & $\begin{array}{l}\text { Potash } \\
\text { in } \\
\text { pounds }\end{array}$ \\
\hline 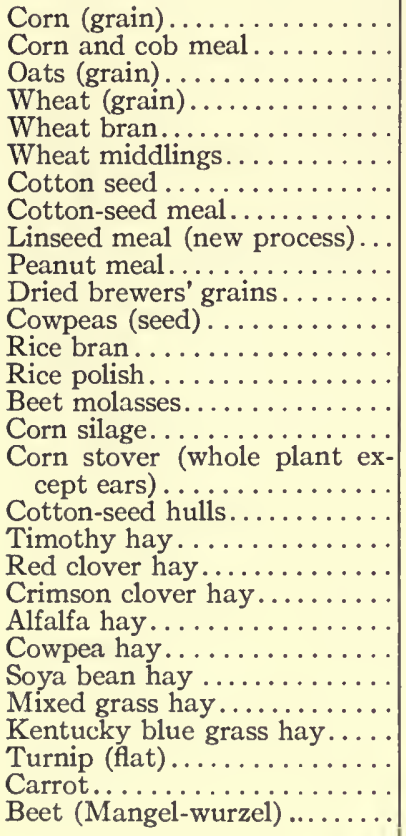 & $\begin{array}{r}18.2 \\
14.1 \\
20.6 \\
23.6 \\
26.7 \\
26.3 \\
31.3 \\
67.9 \\
57.8 \\
75.6 \\
36.2 \\
33.0 \\
7.1 \\
19.7 \\
14.6 \\
2.8 \\
10.4 \\
6.9 \\
12.6 \\
20.7 \\
20.5 \\
21.9 \\
19.5 \\
17.5 \\
14.1 \\
11.9 \\
1.8 \\
1.5 \\
1.9\end{array}$ & $\begin{array}{r}7.0 \\
5.7 \\
8.2 \\
7.9 \\
28.9 \\
9.5 \\
12.7 \\
28.8 \\
18.3 \\
13.1 \\
10.3 \\
3 . \\
2.9 \\
26.7 \\
0.5 \\
1.1 \\
\\
2.9 \\
2.5 \\
5.3 \\
3.8 \\
4.0 \\
5.1 \\
5.2 \\
4.0 \\
2.7 \\
4.0 \\
1.0 \\
0.9 \\
0.9\end{array}$ & $\begin{array}{r}4.0 \\
4.7 \\
6.2 \\
5.0 \\
16.1 \\
6.3 \\
11.7 \\
8.7 \\
13.9 \\
15.0 \\
0.9 \\
13 \\
2.4 \\
7.1 \\
56.3 \\
3.7 \\
14.0 \\
10.2 \\
9.0 \\
22.0 \\
13.1 \\
16.8 \\
14.7 \\
13.2 \\
15.5 \\
15.7 \\
3.9 \\
5.1 \\
3.8\end{array}$ \\
\hline
\end{tabular}

* Henry, "Feeds and Feeding." 


\section{Table 6.}

\section{AVERAGE COMPOSITION OF FERTILIZERS}

\section{Nitrogenous Fertilizers}

\begin{tabular}{|c|c|c|c|c|}
\hline \multirow[b]{2}{*}{ NAME of Fertilizer } & \multicolumn{4}{|c|}{ Pounds Per Hundred } \\
\hline & Nitrogen & $\begin{array}{c}\text { Total } \\
\text { Phosphoric } \\
\text { Acid }\end{array}$ & Potash & Lime \\
\hline 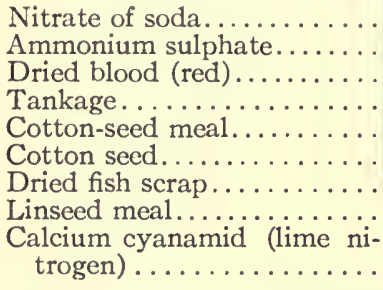 & $\begin{array}{c}\text { I } 5^{-\mathrm{I} 6} \\
2 \mathrm{O} \\
\mathrm{I} 3^{-\mathrm{I} 4} \\
4 \cdot 5^{-\mathrm{I} 2} \\
5-7 \cdot 5 \\
3 \\
6.5^{-\mathrm{IO}} .5 \\
5 \cdot 5 \\
9.5-\mathrm{I} 8.4\end{array}$ & $\begin{array}{c}\ldots \\
\ldots \\
\cdots \\
3^{-14} \\
\mathrm{I} \cdot 5^{-3} \\
\mathrm{I}^{2}{ }^{2} \\
5-\mathrm{I} 6 \\
\ldots\end{array}$ & $\begin{array}{c}\ldots \\
\ldots \\
\ldots \\
\ldots \\
\mathrm{I} .3-2 \\
\mathrm{I}-\mathrm{I} \cdot 5 \\
\ldots \\
\ldots\end{array}$ & $\begin{array}{l}\cdots \\
\cdots \\
\cdots \\
\cdots \\
\cdots \\
\cdots \\
\cdots \\
\cdots \\
\text { IO-II }\end{array}$ \\
\hline
\end{tabular}

2. Phosphoric Acid Fertilizers

Tennessee phosphate rock..... Florida phosphate rock........ South Carolina phosphate rock Ground raw bone............ Ground steamcd bone........ Boneblack................ Pounds Per Hundred

NAME of Fertilizer Basic slag (iron phosphate)....

\begin{tabular}{|c|c|c|}
\hline Nitrogen & $\begin{array}{l}\text { Total } \\
\text { Phosphoric } \\
\text { Acid }\end{array}$ & $\begin{array}{c}\text { Available } \\
\text { Phosphoric } \\
\text { Acid }\end{array}$ \\
\hline$\ldots$ & $30-32$ & $\ldots$ \\
\hline 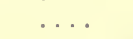 & $18-40$ & $\ldots$ \\
\hline & $26-28$ & \\
\hline $3-4$ & 22 & $4^{-8}$ \\
\hline $2-4$ & $18-32$ & $5-10$ \\
\hline$\ldots$ & $32-36$ & $\ldots$ \\
\hline$\ldots$ & $15^{-20}$ & $\ldots$ \\
\hline
\end{tabular}


3. Potash Fertilizers

\begin{tabular}{|c|c|c|c|}
\hline \multirow[b]{2}{*}{ Name of Fertilizer } & \multicolumn{3}{|c|}{ Pounds Per HundRed } \\
\hline & Potash & $\begin{array}{c}\text { Total } \\
\text { Phosphoric } \\
\text { Acid }\end{array}$ & Lime \\
\hline 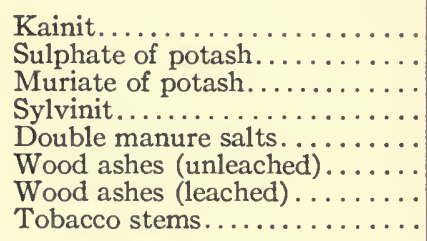 & $\begin{array}{l}\text { I2 } \\
50-52 \\
49-59 \\
14-16 \\
26 \\
4-7 \\
1-2 \\
5-10\end{array}$ & $\begin{array}{l}\cdots \\
\cdots \\
\cdots \\
\cdots \\
\cdots \\
I \cdot 5^{-2} \\
I-I \cdot 5 \\
\cdots \cdots\end{array}$ & $\begin{array}{l}\cdots \\
\cdots \\
\cdots \\
\cdots \\
30 \\
30-33 \\
27-29 \\
3\end{array}$ \\
\hline
\end{tabular}

Table 7.

AVERAGE COMPOSITION OF FARM MANURES

\begin{tabular}{|c|c|c|c|c|c|}
\hline \multirow{2}{*}{ Kind of MANURE } & \multicolumn{5}{|c|}{ Pounds Per Hundred } \\
\hline & Water & $\begin{array}{l}\text { Nitro- } \\
\text { gen }\end{array}$ & $\begin{array}{l}\text { Phos- } \\
\text { phoric } \\
\text { Acid }\end{array}$ & Potash & Lime \\
\hline Cow manure (fresh)... & $85 \cdot 3$ & 0.38 & 0.16 & 0.40 & $0.3 \mathrm{I}$ \\
\hline Horse manure (fresh) & 71.3 & 0.58 & 0.28 & 0.53 & $0.2 \mathrm{I}$ \\
\hline Sheep manure (fresh). & 64.6 & 0.83 & 0.23 & 0.67 & 0.33 \\
\hline Hog manure (fresh)... & 72.4 & 0.45 & 0.19 & 0.60 & 0.08 \\
\hline Hen manure (fresh). & 56.0 & I. 63 & I. 54 & 0.85 & 0.24 \\
\hline Mixed stable man & 75.0 & 0.50 & 0.26 & 0.63 & 0.70 \\
\hline
\end{tabular}


Table 8.

DIGESTIBLE NUTRIENTS IN ONE TON OF FEED STUFFS *

\begin{tabular}{|c|c|c|}
\hline & $\begin{array}{l}\text { Protein } \\
\text { lbs. }\end{array}$ & $\begin{array}{c}\text { Carbohydrates } \\
\text { lbs. }\end{array}$ \\
\hline Alfalfa hay $\ldots \ldots \ldots \ldots \ldots \ldots \ldots$ & 220 & 792 \\
\hline 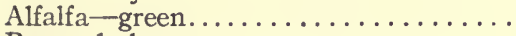 & 78 & 254 \\
\hline 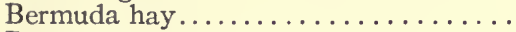 & I I5 & 760 \\
\hline 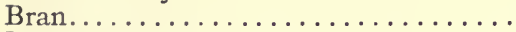 & 244 & 772 \\
\hline Beet pulp-wet............... & I2 & 146 \\
\hline 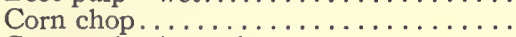 & I 58 & $\mathbf{I}, 334$ \\
\hline 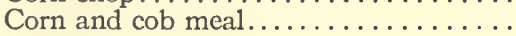 & 98 & 1,260 \\
\hline Corn stover. $\ldots \ldots \ldots \ldots \ldots \ldots \ldots$ & 36 & 648 \\
\hline Corn silage $\ldots \ldots \ldots \ldots \ldots \ldots \ldots \ldots$ & I8 & 226 \\
\hline Cotton-seed meal. ................ & 744 & $33^{8}$ \\
\hline Dried brewers' grains.............. & 314 & 627 \\
\hline 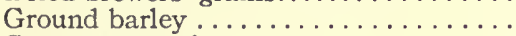 & I 74 & $\mathbf{I}, 3 \mathbf{I 2}$ \\
\hline 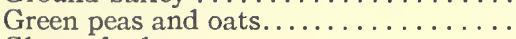 & 36 & 142 \\
\hline 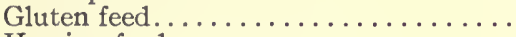 & 446 & 962 \\
\hline 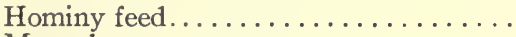 & I 50 & $\mathrm{I}, \mathrm{IO} 4$ \\
\hline 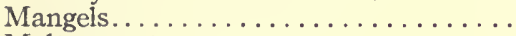 & 22 & 108 \\
\hline 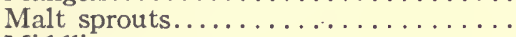 & 372 & 742 \\
\hline Middlings.................. & 256 & 1,060 \\
\hline 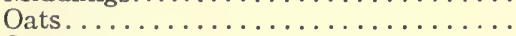 & I 80 & 946 \\
\hline 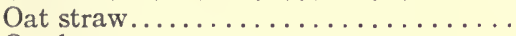 & 24 & 772 \\
\hline 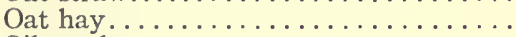 & 86 & 928 \\
\hline 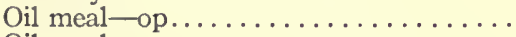 & 586 & 802 \\
\hline 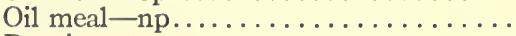 & 564 & 802 \\
\hline 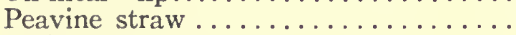 & 86 & 646 \\
\hline Red clover-green ............... & 58 & 296 \\
\hline 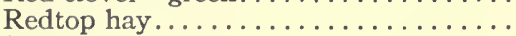 & 96 & 938 \\
\hline Stugar beets. $\ldots \ldots \ldots \ldots \ldots \ldots \ldots \ldots \ldots$ & 22 & 204 \\
\hline Timothy hay................. & 56 & 868 \\
\hline 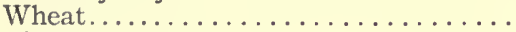 & 204 & 1,384 \\
\hline Wheat straw . . . . . . . . . . . & 8 & 726 \\
\hline
\end{tabular}

* Louisiana Experiment Station, Bul. II5. 



\section{INDEX.}

Aberdeen-Angus cattle, 339 .

Absorption, 395 .

Acid phosphate, 65.

Acidity of soils, 9.

Adaptability of feeds, 413 .

Aerating roots, 33 .

African geese, 364 .

Agricultural Experiment Stations, 478.

Agricultural life, means of promoting, Section 1, Introduction.

Agricultural school library, 475, 476, 477,478 .

Air, dry, 18.

Air in soil, I5.

Alfalfa, 30, 191; amount to sow per acre, 197; composition of, 410 .

Algæe, 35 .

American cheese, 379.

American saddle horse, 330 .

American trotter, 328.

Amylopsin, 395.

Ancona fowls, 363 .

Andalusian fowls, 363 .

Animal, artificial selection of, 318; breeding and grading of, 318 ; byproducts of, 407; composition of, 390 ; food of, 387; lean and fat carcasses of, 390 ; natural selection of, 318; substances, 389 .

Annual defined, 187 .

Annual rings, $4 \mathrm{I}$.

Antennze of insects, 263.

Anther, 44.

Anthracnose of bean, 252.

Apple, 209; blight of, 250; scab of, 248; weight per bushel, 479.

Arsenate of lead, 273, 281, 287, 291, 292, 294, 296.

Ash, functions of, 391, 392; of animals, 389 ; of plants, 387 .

Assimilation, 395 .

Association for truckers, 470 .

Atmospheric nitrogen, 6, 9.

Auricle, 130.

Available phosphoric acid, 66 .

Awn, 130, 133.

Aylesbury ducks, 364 .

Ayrshire cattle, 344 .

Babcock milk tester, 377 .

Bacteria, 10, 30, 34, 382 .

Bacterial wilt, 254 .

Bantam chickens, 364 .

Bark, 42.

Barley, I47; classification of, I48; description of, 147; enemies of, 149; plant food removed by, 3; position of, 149; seeding of, 149; weight and measure of, 414; weight per bushel, 479.

Bean, 30; pod spot of, 252.

Beard, definition of, 133 .

Beef cattle, 333; parts of, 335 .

Bees, section on, 301 ; aid in fertilization, 267; bees and fruits, 301; life of a worker, 302; products of, 304; swarming, 303; the colony, 301.

Beeswax, definition of, 304 .

Beggarweed, 30 .

Belgian horse, 321 .

Berkshire hog, 356 .

Bermuda grass, 40, 192 ; amount to sow per acre, I97.

Birds, section on, 304; beneficial species, 305; food of, 306 ; houses for, 316; keep down disease, 314; necessity for, 306; nesting places, 312 ; of field and garden, 311; of orchard and woodland, 308; protection of, 315; regulate plant growth, 308; tree guardians, 310; useful species, 312 ; utility of birds of prey, 314; value of garden birds, 3 I2.

Black Spanish chickens, 363 .

Blackberry, 217.

Blackstrap molasses, 406; composition and digestibility of, 410; weight and measure of, 4I4.

Blade, 39.

Blight, 35, 249, 250.

Blue Su edish" ducks, 364 .

Bobolink, 313 .

Boll weevil, 271; section on, 274; de. scription of, 275; effect of temperature on 279; economic changes, 280; hibernation, 280; history of, 274; invasion of, 275 ; life history of, 277; migration, 279; preventing damage by, 281 .

Boll worm, 271 .

Bones, 65, 66; composition of bone meal, 407.

Books, 23, 57, 74, 203, 239, 260, 317, $386,433,474$; list of publishers and prices of, 477,478 .

Bordeaux mixture, how made, 247.

Brackett fungi, 37.

Brahma chickens, 362 .

Brewers' grains, definition of, 402; composition and digestibility of, 410; weight and measure of, 414.

Brown rot, $33,250$.

Brown Swiss cattle, 345 . 
Buckeye chickens, 360 .

Buckwheat, weight per bushel, 479.

Bud, 40.

Budding, 46, 50 .

Bug, definition of, $26 \mathrm{r}$.

Bulb, 50.

Butter, how made and composition of, 378,379 .

Buttermilk, 380 .

By-products, alcoholic, 402; animal and fish, 407; breakfast food, 403; glucose and starch, 404; milling, 404; sugar, 406; vegetable oil, 401.

Cabbage, club root of, 253; cultivation and storing of, 175 ; resetting, 175; seeding, 175; soil and fertilizer for, I75.

Call ducks, 364.

Calyx, 44.

Cambian, $4 \mathrm{I}$.

Canada pea, 196.

Canadian geese, 364 .

Capillary moisture, 18

Carbohydrates, absorption of, 395; amounts for feeding, 420; definition of, 388; function of, 392.

Carbon dioxide, 4, 12, 25, 27.

Carpet grass, 187 , 190.

Carrot, 174; composition and digestibility of, 410; weight per bushel, 479 .

Cassava, 39.

Cattle, section on, 333; breeds of beef cattle, 337; breeds of dairy cattle, 34í dairy cattle, 339; dual purpose cattle, 344; milk breeds, 375; score card for beef cattle, 334; score card for dairy cattle, 342 .

Cattle tick, section on, 283; description of, 283 ; eradication of, 284 ; remedies, 284; seed ticks, 284; Texas fever, 283 .

Cayuga ducks, 364 .

Cells, 24.

Cheat, 144.

Cheese, kinds of and composition of, 379,380 .

Cherry, 212.

Cheshire hog, 358.

Chester white hog, 356 .

Cheviot sheep, 35I.

Chickadees, 308 .

Chickens, classes of, $360,362,363$, 364; how to prevent lice and mite of, 373; types of, 359 .

Chinch bug, 136, 145, 149, 271.

Chinese geese, 364 .

Chlorophyll, I99, 388 .

Chyle, 395.

Chylification, 395 .

Chyme, 394.

Chymification, 394.

Cion, 50.

Circulation, 395.

Citron, 55 .

Clay, 13.

Cleveland Bay horse, 328 .

Close fertilization, 45 .

Clover, amount of water required, 4 ; elements removed by hay of, 3; alsike, 187; bur, I88; crimson,
188, 195: amount per acre, 197; composition of, 410 ; red, 187, I90; amount per acre, 197; composition of, 410; white, 187; weight per bushel, 479 .

Clydesdale horse, 322 .

Coach horse, 326 .

Cochin chicken, 362 .

Cock, definition of, 360 .

Cockerel, definition of, 362 .

Cockle, I44.

Cocoon, definition of, 266 .

Codling moth, 29I.

Collateral reading, 22, 57, 74, 200, $201,202,203,237,238,239,260,316$, $317,384,385,386,433,472,473,474$.

Colorado potato beetle, 294 .

Combine, I44.

Combustion, 25.

Commercial feeds, definition of, 398 ; sources of, 400; value of by-products, 400; where derived, 399.

Commercial fertilizers, 62 .

Composition of feeds, $388,410$.

Compost, 6r.

Condensed milk, 380 .

Condimental feeds, 432.

Contact method for killing insects, 273.

Corn, section on, 83; amount of water required, 4 ; brace roots, 38 ; bran, 404; breeding, 102; classification, 87; composition of, 410 ; cultivation, 96; description of plant of, 9I; digestibility of, 410 ; elements removed by, 3; germ meal, 404; harvesting, 98; judging, 99; methods of culture, 93; prepara. tion of seed bed, 95; planter for, 444; planting, 96 ; present distribution, 83 ; production in United States, 86; rotation, 103; seed corn testing, ror; selection of seed, 99; silage composition and digestibility of, 410; smut, 256, 257; stover, composition and digestibility of, 410 ; varieties, 98; weight and measure of, 414; weight per bushel, 479; yield of leading corn producing states, 85 .

Corn and cob meal, composition and digestibility of, $4 \mathrm{ro}$; weight and measure of, 414 .

Corn and oat feed, how made, 403; weight and measure of, 414 .

Corolla, 44.

Corrosive sublimate solution, 247 , $249,253$.

Cortex, 40.

Cotswold sheep, 352 .

Cotton, section on, I04; black rust of, 259; boll weevil injury, 277; botanical characters and habit of growth, 106; burn stalks to prevent boll weevil damage, 281; credit system of raising, II7; cultivation, 114; culture of, III; cultural method, 282; fertilizers for, I13; gin invented, 105; ginning, 115; harvesting, 115; history of, 104; importance of, 104; length of fiber improved by selection, 52; 
long staple, IIo; nature of fiber, 109; planters for, 443; planting, I12; region of cultivation, 105; seed of, 116; selecting and breeding, 107; shedding of bolls and squares, 259 ; short staple, III; thinning, II3; wilt of, 33, 257; worm of, 286.

Cotton seed, 116; composition of, 401, 410; digestibility of, 410; elements removed by, 113 ; products from, 116; weight per bushel, 479 .

Cotton-seed hulls, 401; analysis of, 401; composition and digestibility of, 410; weight and measure of, 414 .

Cotton-seed meal, 63, 401; analysis of, 401, 402; composition and digestibility of, 410; weight and measure of, 414 .

Cotton-seed meats, $40 \mathrm{r}$.

Cotton-seed oil, 388, 401 .

Cotton worm or cotton caterpillar, section on, 285.

Country home, section on, 460 .

Cowpea, 6, 30, 193; amount to sow per acre, I97; seed and hay, composition and digestibility of, 410.

Crab grass, 196; composition and digestibility of, 410.

Cradle, 446.

Cream, definition of, 377 .

Crevecour chickens, 363 .

Crops, rotation of, 75,77 ; water requirements of, 17; statistics on, 479 .

Cross-breed, 319.

Cross-pollination, 53 .

Culm, 129.

Cultivation, 20.

Cultivators, 21, 441 .

Currant, 218.

Cutting, 50.

Cutworm, 293.

Dairy cattle, 339.

Dairying, section on, 374, 384.

Deciduous, 39, 229.

Defecation, 396.

Deglutition, 393 .

Devil's horse, 268.

Devon cattle, 337

Dewberry, 217.

Digestibility of feeds, 410 ; necessity of, 409 .

Digestion, physiology of, 393 .

Distillers' grains, definition of, 403 .

Diversification, 75,281 .

Dodder, 33, 199.

Dominique chickens, 360 .

Dorking chickens, 360,363 .

Dorset sheep, 350.

Drainage, 18.

Dried beet pulp, 406.

Dried blood, 407 .

Drills, 443 .

Dry farming, 22

Dry ground fish, analysis of, 407 .

Dry matter, 388,389 .

Ducks, breeds of, 364 .

Duroc-Jersey hog, 354 .

Dutch belted cattle, 344 .

Earth roads, section on, 455 .

East India ducks, 364.
Eggs, how to preserve, 374 .

Egyptian geese, 364 .

Electrical injuries to trees, 224.

Elements removed by crops, 3 .

Embden geese, 364 .

Embryo, 48.

Endosperm, 48.

Erosion, loss by, 6.

Essential elements, 2, 62.

Essex swine, 358 .

Evaporation, 18.

Evergreen, 39.

Farm, adaption of, 435; choice of, 434; records and accounts for, 437; should run at full capacity, 436; team labor for, 437 .

Farm animals, composition of, 390.

Farm crops, chapter on, 75 .

Farm management, section on, 434 .

Farm manures, 58; composition of, 482.

Farm machinery, section on, 438 ; care of, 451; for cotton and corn, 117.

Farm papers, list of, 476,477 .

Farm products, legal weights per bushel, 479 .

Farming, types of, 435 .

Fats, function of, 392; of animals, 389 ; of milk, 377 ; of plants, 388 .

Faverolle chickens, 364 .

Feeds and feeding, chapter on, 387 ; adulteration of feeds, $43 \mathrm{I}$; by-products of feeds, 400 ; classification of feeds, 388; composition of feeds, $387,388,410$; digestibility of feeds, 410; digestible nutrients in one ton of feeds, 483 ; feeds for cattle, 426; feeds for fattening cattle, 427; feeds for fattening sheep and swine, 428; feeds for horses, 425; feeds for young animals and poultry, 429; fertilizer constituents in feeds, 480; food of animal and plant, 387; grains and seeds, 398; how to buy feeds, 431; market prices of feeds, 413; natural and commercial stock feeds, 396; nutritive elements, 390; raise feed at home, 432; Table of composition and digestibility of feeds, 410; weights and measures of feeds, 414.

Feed laws, importance of, 430 .

Feed meal, 404.

Feed selection, 413 .

Feeding standards, 411 ; use of, 412 .

Ferments, 395.

Ferns, 37 .

Fertilization of plants, 45 .

Fertilizers, amounts per acre, 72; application of, 72 ; composition of 481,482 ; constituents in feed stuffs, 480; cost of, 71 ; effect of, 73: fillers, 71; for the crop and soil, 73; for truck crops, 72, 467; guarantee, 67; home mixing, 69; kinds for the crop, 72 ; mixing of, 69 ; nitrogenous, 63; phosphoric acid, 64; potasli, 66; valuation of, 67.

Fiber, definition of, 388 . 
Filament, 43.

Fish scraps, 64 .

Flax, elements removed by, 3; seed, composition of, 402; feed, 402; weight per bushel, 479 .

Flour, 406.

Flower garden, 234; flowers to plant, 227; location of, 234.

Flowering plants, kinds of, 48,230 . Flowers, 44; parts of, 42.

Fodder, 186.

Food economics, 396.

Forage crops, section on, 185; amounts of seed to sow per acre, 197; annual grasses and legumes, 187, 188; characteristics of, 187; classes of, 186; hay, 186; husbanding of, 397; meadows, 186; meadow mixtures, 188; origin of legumes and grasses, 188; pasturage, 185; pasture mixtures, 188; perennial grasses and legumes, 187; soiling crops, 185; some important forage plants, section on, 190 .

Formalin, 247, 253, 256.

Forestry, section on, 219; destructive section, the South, 220; government control and study of, 220; how to manage, 220; how trees are injured, 221; pine barrens, 220 .

French coach horse, 327.

Frizzle chickens, 364 .

Fruits, 47, 209; garden for, 232; see PoMology.

Fungi, 35; definition of, 240; food of, $24 \mathrm{I}$; reproduction of, 242 ; structure of, 240.

Fungicide, definition of, 246; examples of, 247; preparation of, 247.

$F$ ungus diseases, 33, 248, 252, 255; of rice, 125; means of control, 243 .

Galloway cattle, 339.

Game chickens, 364 .

Garden, section, 232; home, 236; how to plan, 233; flower garden, 232; fruit garden, 232; meaning of, 232: vegetable garden, 233 .

Gas, injury to trees by, 222, 223, 224.

Geese, breeds of, 364 .

German coach horse, 327.

Germination, $48,49$.

Glucose and starch by-products, 404.

Glume, 130.

Gluten, 14 I.

Gluten feed and meal, 404.

Goose, weights of, 364

Gooseberry, 218.

Grades and grading of live-stock, 319.

Grafting, 50 .

Grain plants for feeding, 398; rusts of, 136, 145, 257; smuts of, 255, 256.

Grape, 213; black rot of, 251 .

Grass, annual and perennial, 187; for feeding, 397; origin of, 188 ; soils for, 20; water requirements of; 20.

Grasshopper, 262, 264, 271.

Gravel, 13.

Gravitational water, 18.

Green manuring, 8 .
Ground water table, 20.

Guernsey cattle, 343 .

Gymnosperms, 47.

Gypsum, 6I.

Hackney horse, 327.

Half-blood, definition of, 319.

Half-sugar mangel wurzels, 167.

Hamburg chickens, 360,363 .

Hampshire sheep, 350 .

Hampshire swine, 358 .

Hard pan, 17.

Harlequin bug, 262, 296.

Harrows, 440.

Harvesting machinery, 445.

Hay, composition and digestibility of, 410; definition of, 186; red clover and meadow, elements removed by, 3 .

Haying machinery, 448.

Hayloaders, 450.

Headers, 448.

Hen, definition of, 362 .

Heredity, law of, 318 .

Hereford cattle, 337 .

High-grade, definition of, 319.

Hog, see SWINE.

Holstein-Fresian cattle, 344 .

Home, building of house, 460 ; comforts for children, 463 ; conven. iences, 462; dooryard, 463; garden, 464; organization, 464; ventilation, 462 ; water supply, 462 .

Home garden, 236 .

Hominy feed, 404 .

Honey, 45; definition of, 304 .

Horses, section on, 320 ; breeds of coach horses, 327; breeds of draft horses, 321; location and names of different parts of, 324; proper shape of fore and hind legs, 324; roadster or light harness type, 328; score card for draft horses, 325; score card for light horses, 331 .

Host, definition of, 240 .

Houdan chickens, 363 .

House-fly, 262, 297.

Humus, 8; sources of, 8.

Hybrid, 47, 332 .

Hybrid turnips, 173.

Hybridization, 46; methods of, 55 .

Hydrogen, 2 .

Hygroscopic moisture, 18.

Imported cabbage worm, 294.

Incubation, 364 .

Indian runner ducks, 364 .

Inoculation of soil, 30 .

Insalivation, 393 .

Insects, chapter on, 26r; biting insccts, 272; cannibals, 267 ; crossfertilization by, 267; enemies of farmer, 271; friends of farmer, 267; how insects breathe, 264; how insects feel, 263; how insects grow. 264: how insects move, 262; how insects see, 262; how to fight biting insects, 272; how to fight sucking insects, 273; insects of orchard and garden, 288; parasites, 269; sucking insects, 273; two great groups of insect pests, 272; what 
an insect is, 261 .

Irish potato, see Potato.

Iron sulphate as a weed destroyer, 199.

Irrigation of truck crops, 468; systems of, 468 .

Italian rye grass. I96; amount to sow per acre, 197.

Jack, 332.

Japan clover, see LESPEDEZA.

Java chickens, 360 .

Jersey cattle, 342.

Johnson grass, 193, 198; amount to sow per acre, 197.

Kaffir corn, composition and digestibility of, 4 IO.

Kainit, 66; composition of, 482 .

Kelps, 35.

Kentucky blue grass, I92; amount to sow per acre, 197; composition and digestibility of, 4 IO; weight per bushel, 479 .

Kentucky saddle horse, 332.

Kerosene emulsion, 273, 290, 297.

Kohlrabi, 174.

Lacteals, 395.

Lady-bird, 267.

La Fleche chickens, 364.

Langshan chickens, 362 ,

Large Yorkshire swine, 357.

Larva, definition of, 266 .

Lawn, 234; amount of seed for, 235; grass for, 235; privacy of, 236 .

Layering, definition of, 50 .

Leaching, loss by, 6 .

Leaf, parts of, 39 .

Leaflets, 39 .

Leaves, 39; function of, 39 .

Leghorn chickens, 363 .

Legumes, annual and perennial, 187 , I88; maintaining fertility with, 9; origin of, 188; plants, 10, 30, 79; SEe ForAGE CROPS.

Leicester sheep, 352 .

Lespedeza, 30, I95; amount to sow per acre, 197.

Lightning, effect on trees, 255.

Ligule, 130.

Lime, 28 .

Lime sulphur wash, 247, 290.

Liming, 9.

Lincoln sheep, 348,352 .

Linseed meal and flax seed, 402; composition and digestibility of, $402,410$.

Live-stock, chapter on, 318; statistics on, 479 .

Loaders, $45^{\circ}$.

Magnesium, 2.

Malt sprouts, definition of, 403 .

Mammoth bronze turkeys, 364 .

Mangels, climate and soil for, 167; composition and digestibility of, 410; cultivation of, 168; elements removed by, 3; fertilizers for, 168; harvesting, 169; seeding and plant- ing, 168; varieties of, 167 ; yields of, 169 .

Manures and fertilizing materials, chapter on, 58 ; barnyard, 58,482 ; conditions affecting value of, 58 ; effects of, 59; farm, lasting qualities of, 6o; loss by leaching, 6; natural, 58 ; stable, 58,482 .

Marl, 6o.

Mastication, 393.

Maturity, 48.

Meadow, definition of, 186 .

Meadow fescue, 187; amount to sow per acre, 197.

Meadow mixtures, 188.

Meat and bone meal, 407.

Meat scraps, analysis of, 407.

Mediterranean chickens, 360 .

Merino sheep, 347.

Mill, care of, 381; composition of, 376; definition of, 376 ; necessity of caring for, 383 ; sterilization and pasteurization, 382 .

Milk sugar, 380 .

Millet, I96; amount to sow per acre, 197; weight per bushel, 479 .

Milling by-products, 404 .

Minorca chickens, 363 .

Molasses, I56; cane and beet, 406; composition and digestibility of cane and beet, 410; weight and measure of, 414 .

Molt, definition of, 264 .

Mosquitoes, 298.

Mosses, 37.

Moth, definition of, 266 .

Mowers, 448.

Mule, defined, 332 .

Mule footed swine, 358 .

Muriate of potash, 66; composition of, 482.

Muscovy ducks, 364 .

Mushroom, 36 .

Mycelium, 240.

Narragansett turkeys, 364 .

Nectar, 45.

Nematodes, 30 .

Nitrate of soda, 63 .

Nitroge11, 2, 30; function of, 73 .

Nitrogen free extract, definition of, 388.

Nitrogen gathering plants, see LEGUMES.

Nitrogenous fertilizers, 63,481 .

Nitrogenous ration, 418 .

Nuthatches, 308 .

Nutritive elements, 390 ; function of, 390.

Nutritive ration, definition of, 409; terms of, $4 \mathrm{I} 8$.

Nymph, definition of, 264 .

Oat feeds, how made, 403.

Oats, aniount of hull, 131; classification of, 131; composition and digestibility of, 410 ; clements removed by, 3; enemies of, 136; improvement of, 133; position of as a crop, 131; seeding of, 134; smut of, 33, 255; the head, 130; the leaves, 129; the plant, 127; the 
stalk, 129; the roots, 128; weight and measure of, 414 ; weight per bushel, 479; yield of, 135 .

Onion, weight per bushel, 479.

Orange, 53, 212; white fly of, 292.

Orchard, planting and care of, sec. tion on, 204; age to plant trees, 205; cover crops, 207; cultivation, 206; distance between trees, 205; how to plant a tree, 205; insects that injure, 288; pruning, 206; selection of site, 204; spraying, 207.

Orchard grass, 187; amount to sow per acre, 197.

Organic matter, 9 .

Orpington chickens, 360,363 .

Ovary, 43.

Ovule, 44.

Oxford sheep, 347 .

Oxidation, 25.

Oxygen, 1, 2.

Pacer, 330.

Packages for vegetables, 472.

Paddy, 124.

Palatability of feeds, 413 .

Panicle, 130.

Parasites, 33, 240.

Paris green, 272, 281, 287, 292, 293 , 294.

Pasteurization of milk, 382 .

Pasture defined, I85; mixtures, 188.

Pea, 30.

Peach, 210; leaf curl, 250; varieties of, 211.

Peach borer, 290.

Peach yellows, 211 .

Peanut meal, composition and digestibility of, 410 .

Peanuts, I82; as a pasture crop, I84, cultivating and harvesting of, 183 ; how to plant, 182; preparation of land for, 182 ; rotation crop, 182.

Pear, 209; varieties of, 2 Io.

Pear blight, 249.

Peas, elements removed by, 3; weight per bushel, 479.

Pedicel, 130.

Pekin ducks, 364

Pepsin, 395.

Peptone, 395

Percheron horse, 320, 321.

Perennial, definition of, 187.

Petal, 44.

Petiole, 39.

Phosphate rock, 12, 65; composition of, $48 \mathrm{I}$.

Phosphoric acid, 28; forms of, 66; function of, 73 .

Phosphorus, 2; amount in soils, I1; amount to apply, 12; supplying the soil, II.

Pistil, 42.

Pith, 41.

Plant diseases, chapter on, 240; causes of, 240; field crop diseases, 255; fruit crop diseases, 248; garden crop diseases, 252.

Plant life, chapter on, 24.

Planters, 443.

Plants, breeding of, 51; changes in appearance of, 228; composition of,
387; energy requirements of, 25; food manufacturers, 25; food of, 387; growth of, 48; length of life of, 49; light requirements of, 27 ; list of woody plants, 229; number of. 34 ; power requirements, 27 ; propagation of, 50, 56; reproduction of, 49; stages of development of, 48 ; substances of, 387 .

Plows, 439, 440 .

Plum, 211 .

Plum curculio, 290.

Plummule, 49.

Plymouth Rock chickens, 360.

Pod, 47.

Poland China swine, 353.

Polish chickens, 363 .

Polled Durham cattle, 339.

Pollen, 44, 45, 48.

Pollination, 45,46 .

Pomology, section on, 209; definition of, 209; citrus fruits, 212; pome fruits, 209; small fruits, 215; stone fruits, 210; tree fruits, 209; vine fruits, 213 .

Potash, 28; amount in soil, 12; amount to apply, 12; function of, 73.

Potassium, 2.

Potatoes, amount of water required by, 4; beetle, 294; cultivation of, I79; elements removed by, 3 ; fertilizers, 179; harvesting and storing, 180; importance, 176; planter for, 443; planting, 179; scab of, 253; soil for, 177; weight per bushel, 479 .

Poultry, section on, 359; classes, breeds, and varieties, 359 ; feeds for, 429; importance of, 359.

Poultry houses and care of poultry, section on, 365; care of setting hen, 373; dusting boxes, 373; exercise, 373; feed trough, 370; floors, 366; grit, 373; marking poultry, 373; methods of housing, 365; nests, 370; requirements of houses, 366 ; roosts, 370 ; ventilation, 367 ; water supply, 371; where to build and why, 366; windows, 366; yards, 371.

Praying mantis, 268.

Prehension, 393.

Prepotent, definition of, 319.

Propagation, 50.

Protein, 387, 389, 392, 395; amounts for feeding, 420; function of, 391, 392.

Protoplasm, 24; activities of, 24.

Puddling of soil, 16.

Puff ball, 36.

Pullet, definition of, 362 .

Pupa, definition of, 266.

Pure-breed, 319.

Quince, 2 ro.

Rachis, 140 .

Radicle, 49.

Rakes, 449.

Rape, I76.

Raspberry, 217. 
Rations, sections on, 415; balancing, 416; for dairy cows, 417, 426; for fattening animals, 427; for working animals, 425; for young animals, 429; how to improve, 420; how to reduce cost of, 422; narrow, wide and medium, 418, 419, 420 ; trial, 415 .

Recurring stem, 50.

Red cap chickens, 363 .

Red polled cattle, 345 .

Red top, 186, 187; amount to sow per acre, 197.

Rescue grass, 196; amount to sow per acr, 197.

Reversion of animals, 318 .

Revolving fund of soil fertility, 5 .

Rhode Island red chickens, 360 .

Rice, section on, 118; canals, 121; diseases of, 125; fertilizers for, 124; flooding, 120; gravity and syphoning of water for, 121; harvesting, 122 ; importance of, 118 ; insect enemies, 125; kinds of water used, 121; planting, 120; rotation of crops, 124; threshing and yields, 123; types of, I18; weeds, 124; wells, 122 .

Rice products; bran, grits, hulls, meal, polish, 406; composition and digestibility of, 410; weight and measure of, 414 .

Road drag, 459.

Roads, section on, 455; construction of, 456 ; maintenance of, 457 .

Rockweed, 35

Rogueing, 52 .

Root crops, section on, 164; for feeding, 398; roots versus cereals, 167 ; weight per bushel, 479; yields of, 166.

Root hair, 3t.

Root knot, 30 .

Root stalk, 49.

Roots, composition of, 388 , 410 ; coro$\mathrm{nal}$ and seminal, 128; function of, 38.

Rotation, section on, 75 .

Rouen duck, 364.

Rough rice, 124.

Roughage, definition of, 413 .

Runners, 40

Rutabagas, 173.

Rye, 145; cnemies of, 146; position of, 146; the culm, 145; the head, 146; the roots, 145; varieties, 146; weight and measure of, 414 ; weight per bushel, 479; yield of, 146 .

Salad vegetables, 233.

Salts of the soil, 2, I7.

San José scale, 288.

Sand, 13.

Sandy loam, 20.

Saprophytes, 33, 34, 36 .

Scion, see Cion.

Score card for cattle, 334, 342; for liorses, 325, 331.

Scrub, 319 .

Sea Island cotton, ro6; length of fiber, 110

Seed, 37; parts of, 48 .
Seed leaves, 49 .

Seed plants, 38; kinds of, 47; parts of, 38.

Seed selection, methods of, 5I.

Seeders, 442 .

Seeding machinery, 442.

Seeds for feeding, 398.

Self-binder, 446 .

Self-pollination, 46 .

Sepal, 44.

Separator, $377,378$.

Seven-eights pure, definition of, 3 rg.

Sewage disposal, section on, 452; cesspool, 452; disposal requirements, 452; filter bed system, 453; septic tank, 453.

Sheep, types and breeds of, section on, 345 ; average weights of fleeces, 352; English breeds, 348; history of, 345 ; long wools, 352 ; value of, 352.

Shetland pony, 332.

Shire horse, 322, 323.

Shorthorn cattle, 337.

Shropshire sheep, 346 .

Shrubs, section on, 226; see Trees.

Sickle, 446.

Side delivery rake, 449.

Silage, 397; composition and digestibility of, 4 IO.

Silkies chickens, 364 .

Silo, 397.

Silt, 13.

Silt loam, 20.

Skim milk, 377, 407; composition and digestibility of, 410 .

Small Yorkshire swine, $35^{8}$.

Smut, 33, 145, 255; how to avoid, 256; how to control, 256.

Soil, chapter on, I; air in, 15; causes of shrinkage of, 15 ; chemical reaction of, 8; classes of soil particles, 13; cracks, 15; limiting factors of soil fertility, 7 ; mechanical composition, 14; mulch, 20; puddling, 16 ; relation of soil to plant growth, 1; silt, I3; silt loam, 20; soil fertility, 4; soil physics, 12; texture, 14; water holding capacity, 19.

Soiling crops, 185 .

Sorghum, 187; cuite of, 406.

Southdown sheep, 350 .

Soy bean, 30, I94: composition and digestibility of hay of, 410 .

Spores, 37; kinds of, 242.

Spraying, 207, 246.

Stackers, 45I.

Stamen, 42; parts of, 44.

Steapsin, 395 .

Stems, kinds of, 40 ; parts of, 42 ; structure of, 40 .

Sterilization of milk, 382 .

Stigma, 44.

Stipule, 39.

Stock, 5o.

Stolon, 40.

Storing roots, 39.

Straw, elements removed by, 3 .

Strawberry, 47, 215.

Style, 44.

Sucker, 49. 
Suffolk sheep, 347 .

Sugar, 156.

Sugar beet, 169; harvesting. 173; irrigation of, 172; time to plant, 172; varieties, 172 .

Sugar cane, section on, 150 ; bud or eye and seed of, 151 ; cultivation of, 154; drainage, 154; fertilizers for, 156; harvesting and planting, 155; leaves, I5I; manufacture of sugar, 156; other cane countries, I57; products from, I56; roots, I50; soil analysis, 154; soil for, 153; stalk, I50; territory in United

States, I53; tissues, 152; yield, 157.

Sulphate of ammonia, 63; composition of, $48 \mathrm{r}$.

Sulphate of potash, 66; composition of, 482 .

Sulphur mixtures used as fungicides, 247.

Sultan chickens, 364 .

Sussex cattle, 337 .

Sweeps, 45I.

Sweet potatoes, 39, 180; harvesting, I8I; how to plant, I8I; preparation of land, 180; storage house, I8I; storing and preservation, 181 ; varieties, I82; weight per bushel, 479 .

Swine, types and breeds of, section on, $35^{2}$; bacon and lard types, 352 , 353.

Syrup, 157.

Tall meadow oat grass, 186, 187; amount to sow per acre, 197 .

Tamworth swine, 358 .

Tankage, $63,407,481$.

Teosinte, 185, 187; amount to sow per acre, 197.

Texas cattle fever, 283 .

Thin rind swine, 358 .

Thoroughbred or running horse, 328 .

Three-quarters pure defined, 319.

Thrushes, 312.

Tillage machinery, 438 .

Tilth, 16.

Timothy, 187, 190; amount to sow per acre, I97; composition and di. gestibility, 4ro; weight per bushel, 479.

Toadstool, . 36, 240.

Tobacco, section on, I58; curing, 162; harvesting, 161; importance of, 159; planting and growing, 161 ; plants from diseased and resistant strains, 244; seed selection, effect of, 53 , 54; sorting and grading, 163; types, 160.

Tobacco water, $273,297$.

Toulouse geese, 364 .

Trees, injury of gas and electricity to, section on, 222; detection of leakage, 224; effect of lightning, 225; electrical injuries, 224; gas leakage, 222; injury by attaching wires, 224; symptoms of gas poisoning, 222.

Trees and shrubs, ornamental, section on, 226; adaptability, 226; changes in appearance, 228 ; individuality, 227; list of, 229; selection and site to provide shade, 235; shrubbery border, 236 .

Truck crops, advantages of organization, 471; associations, 470 ; classes of, 465 ; climate, 467 ; crops to raise, 469 ; diversification, 468 ; fertilizers, 467; irrigation, 468; kind of soil, 467 ; kinds of packages, 472; rapid transportation, 467 ; shipping and selling, 470 ; systems of irrigation, 468 .

Truck gardening, section on, 464 .

Trypsin, 395.

Tuber, $40,50$.

Tubercles, I0, 30.

Turkeys, breeds of, 364 .

Turnip, 173; composition and digestibility of, 410; weight per bushel, 479.

Underground stems, 49.

United States Department of Agri. culture, bureaus of, 476 .

Variation of animals, 318.

Vegetable garden, 233 .

Velvet bean, 30, 195; amount to sow per acre, 197.

Vetches, 193; amount to sow per acre, 197 .

Victoria swine, 358 .

Water, absorption of, I; kinds of, I7; uses of to plant and amounts required, 4,30 ; in animals, 389 , 390 ; in feed stuffs, 388 .

Water-logged, I8, 33 .

Watermelon, cultivation of, I84; how to grow large melons, 184; preparation of land, 184; wilt of, 254.

Weeds, section on, 197; chemicals as weed destroyers, 199; cultivation keeps down weeds, 199; eradication, 199; loss from, I98; preventive measures, 199.

Weight and measure of feeds, $4 \mathrm{I} 4$.

Whale oil soap, 290, 297.

Wheat, classification of, I42; composition of, 141; elements removed by, 3 ; enemies of, 144; harvesting, 144; position of, 14I; scab, 145; seeding of, 143; smut, 33,256 ; the grain, I4r; the head, 139; the leaves, 139; the plant, 136; the roots, 138; the stalk. 138 ; weight per bushel, 479; yield of, I44.

Wheat products; bran and middlings, 404; composition and digestibility of, 410; weight and measure of, 414 .

Whey, 380 .

White fly, 292.

Whorl, I28.

Wild white cattle, 13, 33 .

Wood ashes, 61 .

Woodpecker, 308.

Woody plants, list of, 229 .

Wren, 313.

Wyandotte chickens, 360 .

Yorkshire swine, 357,358 . 





This book is DUE on the last date stamped below

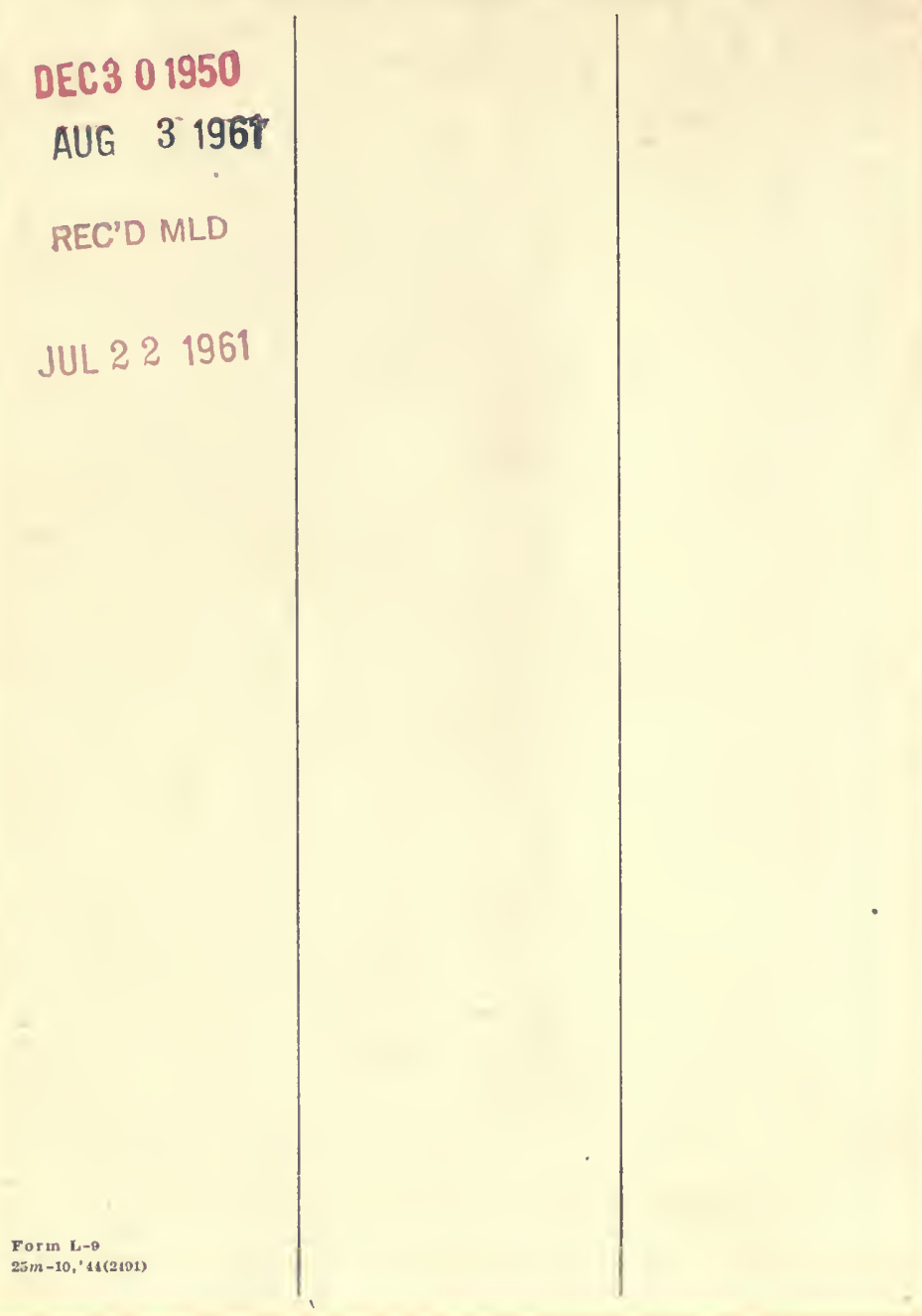


5493

H15f Halligan -

Fundamentals of agriculture.

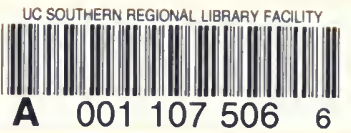

5493

H工I $5 f$

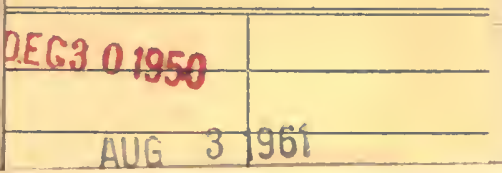


3.

$\frac{1}{11}$

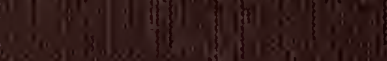

(4) is is

(3)

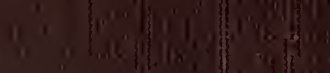

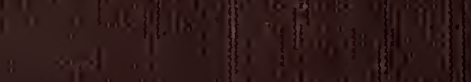

ti

|

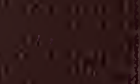

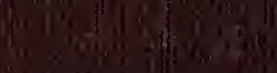

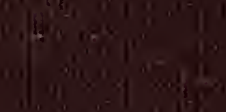

1,35

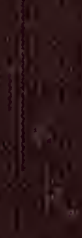

(1)

I.

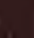

$(1+2)=1$

간.

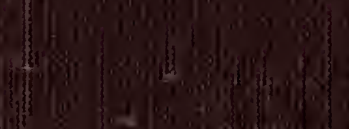

+

I.

(4)

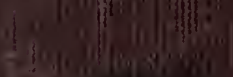

and

1.

(6) [1. abs. 